\title{
Derivational Syntax: A Minimalist approach to affixation in Bahasa Indonesia predicates
}

\author{
Wahyono Sukarno
}

\author{
A Thesis \\ submitted to the Victoria University of Wellington \\ in fulfilment of the requirements for the degree of \\ Doctor of Philosophy \\ in Linguisties
}

Victoria University of Wellington

2003 
VICTORIA UNIVERSITY OF WELLINGTON 


\section{Abstract}

This thesis focuses on verbal phrase aspect ( $v \mathrm{P}$-aspect) in Bahasa Indonesia (BI). In BI, $\nu \mathrm{P}$-aspect is morphologically marked on the predicate. I claim that the suffix $-k a n$ marks an aspect, which I refer to as kan-aspect, indicating that the object undergoes change. This is in a stark contrast with $i$-aspect, where the object is stationary and unchanged. The analysis is based on the notion that the semantics and syntax of a predicate should be analysed within the $v \mathrm{P}$ (for instance, Tenny 1987, 1994, Chomsky 1995, Arad 1998, Croft 1998, among others), with the core argument determining the aspectual property of an event structure (Tenny 1987, Arad 1998, Ritter and Rosen 1998).

Since this thesis proposes to take into account the $-k a n$ and $-i$ distinction as an important aspect in the analysis, the structural location of the two suffixes will take centre stage. This has not been done in the literature on BI that looks at these derivational suffixes. This thesis further develops the analysis beyond verb phrases: it takes into account the syntax of Voice Phrase of sentence structures that include (temporal) Aspect Phrase, Wh-extractions, and Relative Clauses. 


\section{Acknowledgements}

I wish to acknowledge my profound indebtedness to all those who have made the writing of this thesis possible.

First, and foremost, my deepest gratitude is to my first supervisor, teammate and friend, Liz Pearce. Without Liz's detailed and critical reading of my argumentation and her insistence on precision and clarity, this thesis would have been far less comprehensible than it is. However, I did not always follow her suggestions. Thus, for all errors that might be found in this thesis I accept full responsibility.

I would like to thank my second supervisor, Laurie Bauer, for all his clear-headed and unstinting encouragement.

I am grateful to the Postgraduate Scholarship Committee for its generous financial assistance that sustained my life as a student. I also wish to thank all the staff of the School of Linguistics and Language Studies for their support, in particular, Janet Holmes (whom I first met at a party one hazy afternoon) for introducing me to, and getting me hooked on, Linguistics.

A quickly snatched thirty-minute discussion with Kate Kearns, chatting in the lowest audible voices, had a profound impact on my thinking about my topic. This thirtyminute was beyond price! And of course, I have to thank Heidi Quinn of the Linguistics 
Department, University of Canterbury, for introducing me to Kate, as well as for her own encouraging comments on the plans of this work.

I would like to thank Tim Stowell for his generous welcome during my stay at the UCLA as a guest student for a quarter. It was a privilege to be accepted into his syntax lectures, where I was made to feel so welcome.

I would also like to acknowledge the useful feedback from the audience at the presentation of one part of this thesis at the $9^{\text {th }}$ International Conference of Austronesian Linguistics in Canberra, January 2002. A special thanks to Andrew Pawley for his encouraging comments.

I would like to thank two others who also made special contributions: Catherine Adams of the Linguistics Department, University of Canterbury, for her support and thoughtful communication throughout my research; Tom Mylne of the Department of English, University of Queensland, Australia for sharing his research with me.

And last but not least, many thanks to my life-mate Jack who remains patient as ever, and knows who he is and what he has to be thanked for. 


\section{Table of Contents}

\section{Introduction}

1.1. Motivation for the inquiry 1

1.2. Summary of the relevant literature on the BI suffixes $-k a n$ and $-i \quad 1$

1.3. Scope of discussion 6

1.4. Organisation of the thesis

\section{2 vP-aspect}

$\begin{array}{lr}\text { 2.1. Overview } & 10\end{array}$

2.2. vP-aspect 11

2.3. BI $v$ P-aspect 16

2.3.1. $-k a n$ and $-i$ as morphological realisations of $v \mathrm{P}$-aspect $\quad 16$

2.3.2. Significance of $v \mathrm{P}$-aspect analysis for $\mathrm{BI}$ syntax 22

2.3.2.1. Temporal aspect and $v \mathrm{P}$-aspect interactions 23

$\begin{array}{ll}\text { 2.3.2.2. Surface subject and } v \mathrm{P} \text {-aspect } & 30\end{array}$

2.4. The notion of change 36

2.5. Summary 41 
page

\section{3 kan-aspect and change}

3.1. Overview

3. 2. Change of Type 1: kan-aspect with derived predicates

3.2.1. The Kan-aspect expresses LOCATION as the FINAL DESTINATION of move/shift

3.2.2. The Kan-predicate expresses the final form of the THEME

3.2.3. The Kan-predicate expresses reclassification of the THEME

3.2.4. The Kan-predicate with a MANNER component

3.2.4.1. Instruments expressed in/by the kan-predicate

3.2.4.2. Body parts as instruments of motion

3.2.5. Directional Prepositions expressed in/by the kan-predicate

3.2.6. De-adjectivals and FINAL STATE

3.2.6.1. Change of state with common Adjectives

3.2.6.2. Change of state with Psych-Predicates

3.3.1.1. Bangun as a bare unaccusative, and with the prefix ter- 107

3.3.1.2. Kan-aspect with the unaccusative bangun 111

$\begin{array}{ll}\text { 3.3.1.3. Basic structures } & 116\end{array}$

$\begin{array}{ll}\text { 3.3.2.The verb bangun as an unergative } & 117\end{array}$

3.3.2.1. Bangun as a bare unergative, and with the prefix ter- 118

$\begin{array}{ll}\text { 3.3.2.2. Kan-aspect with the unergative bangun } & 127\end{array}$

3.3.3. The verb bangun as a transitive 132

3.3.3.1. Bangun without kan-aspect 132

3.3.3.2. Kan-aspect when used with the transitive bangun 133 
3.3.3.3.Kan-aspect and benefactivity: transit path of change

page

3.3.4. Summary

3.4. Derivations: Syntactic analysis of kan-predicates

3.4.1. The $v$ P-shell

3.4.2. Derivations with the kan-aspect

3.5. Summary and remarks

3.5.1. Summary

3.5.2. Remarks

\section{$4 i$-aspect}

4.0. Overview

4.1. The BI $i$-aspect and the lack of change

4.1.1. The suffix $-i$ is not in free variation with $-\varnothing$

4.1.2. Kan- and $i$-predicates are not synonymous

4.1.3. The $i$-aspect and the lack of change

4.2. Kan-aspect and $i$-aspect: an alternation of paths of derivation

4.2.1. Aspect alternation, with minimal pairs

4.2.2. The $v \mathrm{P}$-aspect that does not alternate: unavailable arguments

4.2.2.1. Psych-predicates: frighten and fear verbs

4.2.2.2. Common adjective kan-predicates

4.2.2.3. Transit path of change

4.2.3. Prepositions for the secondary internal arguments

4.2.3.1. The ke-dengan frames with spray/load verbs 208

4.2.3.2. The kepada - $\varnothing$ frames with give/send/lend verbs 210

4.2.3.3. Covert preposition untuk 'for' at PF: an illusory DOC 214

4.3. Derivations: the status of PATIENT as the primary internal argument 218

$\begin{array}{ll}\text { 4.3.1. The BI } i \text {-DOC } & 218\end{array}$

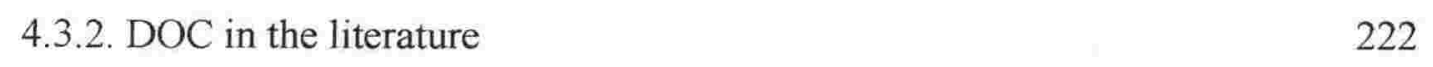


4.3.3. The basic structures of the BI $i$-aspect $\quad 230$

4.3.4. Alternative analyses of DAC-DOC 231

4.4. Summary and remarks 239

4.4.1. Summary 239

$\begin{array}{ll}\text { 4.4.2. Remarks } & 241\end{array}$

\section{Higher layers of derivation, above $v \mathrm{P}$}

5.0. Overview 243

$\begin{array}{ll}\text { 5.1. BI VOICE } & 244\end{array}$

5.1.1. The Voice Phrase 244

5.1.2. The BI Voice Phrase 252

5.1.3. BI VOICE $+v \mathrm{P}$ transitive 260

5.1.4. Two ACTIVEs, two PASSIVEs: DAC-DOC revisited 263

5.2. The distribution of BI VOICE morphology: meN-, ber-, and ter- 270

5.2.1. meN-unergative and ber-unergative 270

5.2.2. The BI impersonal transitive, di-versus ter- 280

5.2.3. Predicates with-kan: ber-V-kan and ter-V-kan 285

5.2.3.1. ber-V-kan 286

5.2.3.2. ter- $\sqrt{-k a n} \quad 288$

5.2.4. Frighten versus fear verbs 290

$\begin{array}{ll}\text { 5.2.5. Summary } & 294\end{array}$

5.3. Derivations above VoiceP: Aspect merge and edges 296

5.3.1. Aspect merge 296

5.3.1.1. The progressive with canonical state predicates 298

5.3.1.2. The progressive with agentive and causative events 300

$\begin{array}{ll}\text { 5.3.1.3. State versus process predicates } & 301\end{array}$ 
5.3.1.4. The future Aspect with the psych-predicates 302

5.3.1.5. The [+perfective] sudah and baru 303

5.3.1.6. Combinations of two Aspect MODALS 305

5.3.1.7. The derivation of BI Aspect Phrase 307

5.3.2. Wh-extractions: The move of edge to edge continues 314

5.3.2.1. Direct imperatives $\quad 314$

$\begin{array}{ll}\text { 5.3.2.2. Invitations } & 319\end{array}$

$\begin{array}{ll}5.3 .2 .3 . \text { Expectations } & 320\end{array}$

5.3.2.4. Wh-extraction in interrogative sentences 321

$\begin{array}{ll}\text { 5.3.2.4.1. Echo questions } & 321\end{array}$

5.3.2.4.2. 'Yes/No' questions: Q-CP with the functional head - kah 323

5.3.2.4.3. Constituent questions with the complementiser yang 326

$\begin{array}{ll}\text { 5.3.3. Summary and implication } & 331\end{array}$

6 Conclusions $\quad 340$

Reference 343 


\section{List of Abbreviations}

$\begin{array}{ll}\text { A } & \text { Adjective } \\ \text { AP } & \text { Adjectival Phrase } \\ \text { AspP } & \text { Aspect Phrase } \\ \text { BI } & \text { Bahasa Indonesia, the lingua franca of Indonesia } \\ \text { C } & \text { Complementiser head } \\ \text { CP } & \text { Complementiser Phrase } \\ \text { DP } & \text { Determiner Phrase } \\ \text { LSR } & \text { Lexical Semantic Representation } \\ \text { N } & \text { Noun } \\ \text { NPI } & \text { Negative Polarity Item } \\ \text { P } & \text { Preposition } \\ \text { PP } & \text { Prepositional Phrase } \\ \text { Q-CP } & \text { Question Complementiser Phrase } \\ \text { RC-CP } & \text { Relative Clause Complementiser Phrase } \\ \text { Spec } & \text { Specifier } \\ \text { TLV } & \text { True Light Verb } \\ \text { VAV } & \text { Vague Action Verb } \\ \text { VoiceP } & \text { Voice Phrase } \\ \text { pP } & \text { verb(-al) Phrase of transitive and unergative verbs } \\ \text { V } & \text { Verb } \\ \text { VP } & \text { verb(-al) Phrase of unacusative verbs } \\ \text { Wh- } & \text { represents constituent that is questioned: What, Which, Why, Who... }\end{array}$

From the GLOSSES:

a-CLASS Indefinite article ' $a$ ' with a Classifier

ACT Active VOICE

AT AGENT-Topic

CLASS Classifier

COMP Complementiser

DAT Dative

DEM Demonstrative

DET Determiner

FUT Future Aspect 


$\begin{array}{ll}\text { LOC } & \text { Locative } \\ \text { NEG IMP } & \text { Negative Imperative } \\ \text { NOUN } & \text { is used to mean 'Nominal' instead of NOM, to avoid ambiguity } \\ \text { PASS } & \text { Passive VOICE } \\ \text { PERF } & \text { Perfective Aspect } \\ \text { PERS } & \text { Person } \\ \text { PI } & \text { Polarity Item } \\ \text { PL } & \text { Plural } \\ \text { PROG } & \text { Progressive Aspect } \\ \text { PT } & \text { PATIENT-Topic } \\ 1 \mathrm{sg} & 1^{\text {st }} \text { person singular } \\ 2 \mathrm{sg} / \mathrm{pl} & 2^{\text {nd }} \text { person singular/plural, and so on }\end{array}$

\section{A note on the use of parentheses in the data:}

(a) $\quad \alpha$ is optional

$\left({ }^{*} \alpha\right) \quad \alpha$ cannot be used because it creates ungrammaticality

$*(\alpha) \quad \alpha$ is obligatory, i.e., the parentheses are unacceptable

\section{A note on the enclitic-nya:}

For simplicity, throughout the present work -nya is glossed as ' $3 \mathrm{sg}$ '. This enclitic bears a default Case, either genitive or accusative Case. Depending on the context, in the English translation - nya may be 'borrowed' as the English definite article 'the'. A complete gloss for-nya would be '3sg Genitive/Accusative/Definite Article'. 


\section{Chapter 1}

\section{Introduction}

\subsection{Motivation for the inquiry}

The initial inquiry is based on an apparently simple question as to why sometimes in $\mathrm{BI}$ we add the suffix $-k a n$ and not $-i$ to the predicate, or vice versa, and why sometimes we use neither, e.g., mengirimkan, mengirimi, mengirim, all of which mean 'to send'. The analyses previously done in the literature are good as far as the data provided are concerned. However, I am going to disagree with them. And rather than assigning many functions to these suffixes, as has been done in the literature, I argue that they have an individual function, namely, as particular $v \mathrm{P}$-aspect markers. And analysing the suffixes in terms of aspect, as it turns out, gives us a simple picture: the affixation is not as complicated as some might have us believe.

\subsection{Summary of the relevant literature on the BI suffixes $-k a n$ and $-i$}

Most research that looks at the derivational verbal suffixes $-k a n$ and $-i$ in BI discusses these suffixes as part of the study within a single component of the grammar of a language, Morphology. Both suffixes are discussed in the context of word formation. The discussion outlined below takes on two different approaches: either the suffixes are treated as part of lexicon, or as part of syntax.

Chung (1976) treats the suffix - kan as part of transformational syntax. She argues that -kan suffixation, by changing indirect object/benefactive to direct object structure, 
has syntactic effects which can also be seen in the loss of the preposition which marks canonical indirect object/benefactives. The other suffix,$-i$, is mentioned only very briefly as one of the two alternatives to - kan (the other being just $\emptyset$ (=empty)), which, like -kan, is added to the verb "after Dative", that is, the affix is added after object1 and object2 swap positions (Chung 1976:55,56).

Chung's assumption that the related prepositions kepada 'to' and untuk 'for' are in a complementary distribution with the suffix - kan is included by Baker (1988) as a piece of empirical evidence that there is "preposition-incorporation" within the verbal complex. Den Dikken (1995) follows this line of inquiry, and adds the suffix - kan to his list of "particles" that indicate triadicity, thus giving the suffix the same status as the English particles to, for, off, up and so on. A minor work by Poser (1983) also uses Chung's (1976) data to present evidence to counter Williams (1981), showing that it is possible to "exchange internal arguments" by the addition of the suffix -kan to predicates. In Williams' terms, the positions of internal arguments cannot be exchanged by lexical rules. Fokker (1972) views BI affixation in general as being inseparable from syntax. His analysis contributes considerably to the understanding of the syntactic correlates of affixation in BI. Unfortunately, the work does not mention the affixation of $-k a n$ and $-i$ in particular.

Other work discusses the suffixes from the morphological point of view, with ample data provided: lists of words either with $-k a n$ or with $-i$. In this type of study, examples of sentences are presented to show where each of the affixed words can occur. The focal point of the approach is usually the determination of the base (State, Action, Process, etc.) and the meanings produced by the affixation. A major work of this type, Voskuil (1996) makes good comparison between the Dutch be-, the BI $-k a n$ and $-i$, and the Tagalog $i-$ and $-a n$. Voskuil's study is thus of a comparative nature, namely, a comparison of verb classes. Detailed syntactic analyses are not adequately provided. It is important to note that in Voskuil's terms, because affixes do not have meanings, the resulting words and the properties of the stem define the function of an affix. 
A different approach, but still morphologically based, is Tampubolon (1983), who discusses affixations that involve verb and adjective formation. Tampubolon approaches affixation on a semantic basis, considering the semantics of the base and the semantics of the complex predicate after the affixation. In Tampubolon's analysis, $-i$ is treated like -kan as a CAUSATIVE marker, 'make'. BI affixation is divided into three types: "derivation" (Causatives, Resultatives, and Comparisons), "incorporation" for verbs which have bi-clausal alternants, and "inflection" (Iterative, Excessive, Reciprocal, Passive). In Tampubolon's theory, meN- (ACTIVE VOICE) affixation involves "incorporation", while $d i$ - (PASSIVE VOICE) is an inflection. The suffixes $-k a n$ and $-i$ appear in both "derivation" and "incorporation".

Two descriptive approaches should be included here: Tarigan (1985), morphology for primary school teachers' training, and Sneddon (1996), a reference grammar. In Tarigan's description, $-i$ appears where - kan can. Tarigan analyses the affixation in terms of (grammatical) categories. Examples of sentences are provided for each occurrence of $-k a n$ and $-i$, side by side. However, there is no syntactic explanation of the occurrences, especially when, in some cases, only one of the suffixes can appear. Sneddon (1996) sees $-i$ in his comparison with $-k a n$ as a problem for analytical description, and therefore, no conclusive analysis is provided. Nevertheless, one begins to recognise that $-i$ is not like $-k a n$.

In summary, except for Chung (1976) the research outlined above fails to see that there are syntactic correlates in the derivations involving the suffixes. Voskuil's leading idea of taxonomy is that "verbs can be classified in terms of the environment they occur in" (Voskuil 1996:30). Tampubolon (1983) recognises that the affixation has regular syntactic correlates. Despite the statements made, however, both Voskuil (1996) and Tampubolon (1983) put the emphasis strongly on the words, affixed or unaffixed. The roles of the participants in the syntactic structure, for instance of the direct internal argument, are not discussed. Neither Voskuil nor Tampubolon contrasts $-k a n$ with $-i$. Given that in most cases, as exemplified in the above studies (Tampubolon 1983, Tarigan 1985, Sneddon 1996, Voskuil 1996), the same root takes both affixes - not at the same 
time: $-k a n$ and $-i$ are in complementary distribution - it is rather pointless to describe, and to taxonomise without comparing the types of sentences the affixed verbs may occur in. In these studies, the meaning of the complex predicate is thus taken out of context.

What is needed is an analysis with two focal points. The first focus is to contrast predicates bearing $-k a n$ with those that bear $-i$, and the second, an analysis that views three components of grammar, namely, Morphology, Semantics and Syntax not only as being somehow dependent on each other, but also as having an interface.

As for the first focus, the lack of contrast between the two suffixes has led to analyses with strong statements. For intance, Chung (1976) postulates that: (a) "Passive applies to direct objects, but it does not apply to indirect objects or oblique NPs" (Chung 1976:43), and (b) "a DO [Direct Object, WS] affected by Dative is inaccessible to other syntactic rules" (Chung 1976:79). Some of Chung's examples of ungrammatical sentences in Passives can be 'rescued' merely by putting the appropriate suffix, either $-k a n$ or $-i$ to the verb. On the other hand, Voskuil's $(1996: 64,65)$ statement that "some types of derived verbs with $-i$ or $-k a n$ prefer or even require the passive voice" can be countered, with a question as to which of the underlying objects occupies the nominative (surface subject) position in the Passive so described. In Voskuil's theory, the two systems - the voice system and the - kan/ $i$ derivation system - correlate. In my opinion, the two systems may indirectly correlate, if forced to.

For the second focus, a predicate-based analysis of clause structures will place $-k a n$ and $-i$ within the contexts, i.e., within the sentence in which an affixed verb occurs. The immediate environment for the predicate should be the verb phrase $(v \mathrm{P})$, because this is the lexical or "thematic layer" of verb projections (Haegeman 1997:24-26). While lexical information pertaining to the base/root is relevant, as Arad (1998) argues, "the syntax of verbs cannot be fully determined by their semantics... the syntax itself has some part in determining the meaning of the verb". Similarly, Chomsky (1995) takes projections of lexical items to be "relational properties of categories" rather than inherent properties. Their presence is determined by the structure or context in which the lexical item is 
placed. That is, instead of viewing an item as Noun, Verb, etc., it is either Subject, Predicate, Object, etc. in terms of structural relations.

Since the present work proposes to take into account the $-k a n$ and $-i$ distinction as an important aspect in the analysis, the structural location of the two suffixes will take centre stage. This has not been done in the literature outlined above. Analyses that put strong emphasis on word-formation (Tampubolon 1983, Sneddon 1996, Voskuil 1996) fail to see the distinction, for instance, between the occurrence of $-k a n$ in (a) and of $-i$ in (b) in the following example (1), from Voskuil (1996).

(1) base/root: kagum 'to be amazed', 'to be awed'
a. kagum-kan
b. kagum-i

Either because the suffixes carry no meaning (Voskuil 1996), because both $-k a n$ and $-i$ mean 'to make', 'to cause' (Tampubolon 1983), or, because the suffixes have a function as a "CAUSATIVE marker" (Sneddon 1996), the resulting analysis is the same: kagumkan and kagumi are considered synonymous, that is, both mean 'to cause someone to admire'. This is misleading, because, by putting them in sentences, one can see that they are not synonymous, as shown in the following examples, (2).

(2)a. Saya meN-kagum-kan kamu

$1 \mathrm{sg}$ ACT-admire-KAN 2sg

'I am admirable/awesome to you' / 'I make you awed/admire (me)'
b. Saya meN-kagum-i kamu
$1 \mathrm{sg}$ ACT-admire-I $2 \mathrm{sg}$ 'I admire you'

What examples (2) show is that within their 'environment', $-k a n$ and $-i$ give exactly the opposite effects in terms of thematic relations of the complex predicate. 
In summary, the contrast between the two suffixes should be discussed to ensure a proper place for these suffixes within syntax, which is within the thematic layer that involves aspectual-thematic properties. To use Chomsky's (1995) Minimalist Program (MP) terms, the derivation of this thematic layer - what Chomsky calls "the base property" - the suffixes reflect the (semantic) relation between the predicate and its internal argument(s). In addition, instead of grouping the affixation into three different types - "derivation", "incorporation", and "inflection" - as argued in Tampubolon (1983), the present thesis will seek to analyse the affixation in terms of derivation. And instead of compiling a list of classified words in the way Voskuil (1996) does, it will focus on when and why, for instance, the suffix $-i$ cannot appear where - kan can - and vice versa. Where irregularities occur, the present work aims to provide adequate explanation.

Since the present thesis will adopt the MP, the most current framework, it must, then, keep the analysis within the spirit of the MP, with a belief that the language system built in the speaker's mind is not as complicated as some might have us believe (following for instance, Lasnik 1999, Chametzky 2000, Ura 2000). The present thesis will further develop the analysis beyond verb phrases. The derivation will take into account the structure of BI Voice Phrase, (temporal) Aspect Phrase, Relative Clause, and interrogative sentences.

\subsection{Scope of discussion}

For simplicity, the discussion presented in this thesis is limited to BI aspects that are morphologically marked by the suffixes $-k a n$ and $-i$. There are others, like for instance, those marked with the nominal suffix - an that require combination with the prefix ber- or $k e$-, indicating, for instance, aimlessness or adversarial experiences, and so on. Those and the aspects that are marked with nominal affixes are worth a separate paper.

For simplicity also, I avoid comparing the BI suffixes $-k a n$ and $-i$ with their analogues in other languages such as the Javanese (-ake and $-i$ respectively) and the 
Madurese ( $-a g i$ and $-e$ respectively). Some examples in this thesis would be very strange, if not outright unacceptable, if applied to Javanese or Madurese.

\subsection{Organisation of the thesis}

This thesis is organised as follows (references will be included in the relevant section).

Chapter 2 introduces detailed analysis of the $\mathrm{BI} v \mathrm{P}$-aspect. In this chapter I discuss briefly two main categories of aspect: "tense aspect" includes for instance, [+perfective] and [-perfective], subjunctive, etc., and, quite separate from "tense aspect", the second category, $v \mathrm{P}$-aspect, concerns some aspectual properties encoded in the event structure. Some discuss this second category in terms of telicity, delimitedness/boundedness of the event, affectedness on the object and so on. Although the two categories are interdependent, each can be discussed separately. This chapter focuses on the second category, which I refer to as $v \mathrm{P}$-aspect. I argue that the $\mathrm{BI}$ suffixes $-k a n$ and $-i$ encode a $v \mathrm{P}$-aspect. In this chapter, I introduce change as a notion.

In Chapter $3 \mathrm{I}$ demonstrate in detail how the suffix -kan encodes a $v$ P-aspect, which I call 'kan-aspect', and show that with kan-aspect the direct internal argument undergoes change. Following Dowty (1991), I call the argument that undergoes change THEME as a convenient term. Included in the change are, for instance, change of location (or 'shift through location', 'translocation', 'move'), change of state (mood, size, form, condition and so on), change of perception, change hands/possessors, and so on. I make it clear, however, that change is also notional, not just physical. I also include in the discussion a change involving a transit path in the shift before the THEME reaches its final destination. I demonstrate in this chapter that the path of change can be either direct or having a transit point. I argue that some verbs (such as buy, make) contain a change component even without the kan-aspect, and adding the kan-aspect to the verbs makes the path of change a transit path.

Chapter 4 is concerned with the contrasts between the kan-aspect and the $i$-aspect. I demonstrate in this chapter that the primary contrast between the two is dependent on the 
interpretation of the direct internal argument. With the kan-aspect the argument at [SpecVP] has the interpretation of a THEME (by definition, this argument undergoes change) whereas with the $i$-aspect it has the interpretation of a PATIENT (an argument that does not undergo change, and is stationary). The dative/double object constructions are discussed in this chapter in terms of $v \mathrm{P}$-aspect alternation. The dative construction belongs to the kan-aspect, and the double object construction to the $i$-aspect. There is no dative construction with the $i$-aspect, and conversely, there is no double object construction with the kan-aspect. Because each $v \mathrm{P}$-aspect is derived independently of the other, dative/double object constructions are thus not 'transformationally related' to each other. As part of the $v \mathrm{P}$-aspect alternation this chapter also gives indications of how to account for Hale and Keyser's (1993) LOCATION versus LOCATUM predicates, and Pesetsky"s (1995) “Object-Experiencer" versus "Subject-Experiencer" psych-predicates, all in terms of $v \mathrm{P}$-aspect, namely which argument undergoes change in a given event.

Chapter 5 is concerned with the BI VOICE and transitivity. This chapter proposes the use of VoiceP, an intermediate layer between the Asp-P and the $v \mathrm{P}$. I discuss in particular the morphological realisation of the Voice head in BI. I argue that BI VOICE system is not as simple as ACTIVE (realised by the head meN-) versus PASSIVE (realised by the head di-). Other morphological realisations of Voice heads, ber-and ter-are also included in the discussion related to the unaccusative, unergative and impersonal transitive structures. I demonstrate that in BI we have two different unergatives, one that takes the Voice head meN- as a True Light Verb (TLV) and the other that takes ber-as a Vague Action Verb (VAV). Thus, the ACTIVE Voice head meN- occurs not just with the transitive structure, but also with the unergative one, the TLV, which is potentially transitive. On the other hand, the Voice head ter- occurs also with the impersonal transitive, not just with the unaccusative structure.

A very important part of the discussion in this chapter is the notion that once the Spec-head relation is established, namely, the relation between the argument at [SpecVoiceP] and the related Voice head ( $m e N-$, di-, ber-, ter-, or $\varnothing)$, the argument structure of the predicate is no longer accessible for further syntactic operation. I adopt Chomsky's 
(1999) notion of "edge", to demonstrate that further derivation only involves local head movement and successive-cyclic edge-to-edge movement. Any element left behind that does not undergo further movement is spelled out in its base position. I also demonstrate that in $\mathrm{BI}$ the derivation involving the $\nu \mathrm{P}$-external aspect (Asp-P), the Relative Clause $\mathrm{CP}$ (RC-CP) and the Question CP (Q-CP) all strictly follow the local head movement and successive-cyclic edge-to-edge movement. The theory of $W h$-extractions in BI CP thus must be understood in these terms.

In Chapter 6 I conclude that a simple notion of change answers the simple question as to why in BI sentences the predicate sometimes bears the suffix $-k a n$, sometimes $-i$ or $-\emptyset$. The present work also gives indications of how to account for Larson's (1988) "dative/double object constructions", Hale and Keyser's $(1993,1998)$ "LOCATION" verbs (e.g., 'to jail the thieves') versus "LOCATUM" verbs (e.g., 'to salt the stew'), Pesetsky's (1995) "Object-Experiencer" versus "Subject-Experiencer" psych-predicates, and Arad's (1998) THEME at [Spec-VP] versus PATIENT at [Spec-VP]. All are included in the change versus non-change distinctions encoded by the $v \mathrm{P}$-aspect. 


\section{Chapter 2}

\section{$v \mathrm{P}$-aspect}

\subsection{Overview}

This chapter introduces $\mathrm{BI}$ verbal phrase aspect, $v \mathrm{P}$-aspect. ${ }^{1)}$ In $\mathrm{BI}, v \mathrm{P}$-aspect is morphologically marked on the predicate. Two kinds of $v \mathrm{P}$-aspect, marked by the verbal suffixes $-k a n$ and $-i$, will be exemplified using some simple data. The first kind, indicated by the verbal suffix -kan (kan-aspect henceforth), implies that, in general, there is a sense of change affecting the internal argument (this will be discussed in detail in Chapter 3). This change includes change of location (displacement, shift, translocation), change hands, change of state, movements, and so on.

The second kind of $v \mathrm{P}$-aspect is indicated by the verbal suffix $-i$ ( $i$-aspect henceforth). This aspect does not imply any change affecting the internal argument. I will demonstrate that $i$-aspect is in a stark contrast with kan-aspect. Consequently, I will argue against previous analyses: firstly, against the belief that the suffix $-i$ is just like $-k a n$, to the extent that they are synonymous, namely, in that they are both causative (e.g., Tampubolon 1983, Sneddon 1996, Voskuil 1996); and secondly, against the lack of analysis itself, which is due to the belief that the suffix $-i$ is either just an option of $-k a n$ or of $-\varnothing$ (e.g., Chung 1976, Musgrave 2000). In short, both of the previous types of analysis involve synonymy and optionality. In the present analysis, both $-i$ and $-k a n$ apply to predicates with an internal argument.

1) Or Aktionsart(-en), inner-aspect, as against tense aspect: the distinction between the two types of aspect is discussed briefly by Comrie (1976), and elaborately, by Tobin (1993). Tense aspect, which I refer to as $\nu \mathrm{P}$-external aspect, will be discussed in the later chapters. 
I will further argue, following the discussion put forward in Chapter 1, that BI predicate suffixes $-k a n$ and $-i$ are markers of an abstract entity found in the domain of verbal phrases. Because it is an abstract entity, it must be looked for beyond that which meets the eye: a fine-grained analysis captures fine-grained effects.

I shall demonstrate that analysing BI predicate suffixes $-k a n$ and $-i$ in terms of their aspectual properties is more tenable than what has been done so far in the literature, as outlined in Chapter 1 . The most obvious advantage of the theory advocated here, I will conclude, is that both suffixes can be seen as having a single function, rather than many. The sole function is to encode, whether or not there is a change affecting the internal argument.

The analysis is based on the notion that the semantics and syntax of a predicate should be analysed within the environment in which it occurs, namely, within the $v \mathrm{P}$ (for instance, Tenny 1987, 1994, Chomsky 1995, Croft 1998, Arad 1998, among others), with the internal argument determining the aspectual property of an event structure (Tenny 1987, 1994, Arad 1998, Ritter and Rosen 1998). However, we have a different motivation for including the internal argument. The inclusion of the internal argument is obligatory in the present analysis of $\mathrm{BI}$, because each $v \mathrm{P}$-aspect selects a distinct direct internal argument. The notion that the internal argument "measures out", namely, that it can affect the aspectual interpretation of the verb phrase is set aside. The focus in the present chapter will be on introducing the notion of change, which I argue to be encoded morphologically in BI verbal phrases.

\section{2. vP-aspect}

The term "aspect" can be used to describe two distinct - yet interdependent - temporal properties of a linguistic expression. The first one refers to a moment in time determined by the context in which the expression is used. The temporal property described in this manner is dependent on time reference (Tenny 1987: 14, 15). It is also convenient to refer to this temporal aspect as "tense", or, "tense aspect". Tense aspect includes, for instance, [+perfective] and [-perfective], subjunctive, and so on. Tense aspect has been discussed 
elaborately in, for instance, Reichenbach (1947), Comrie (1976), Stowell (1995), Smith (1997), Giorgi and Pianesi (1997), Cinque (1999), among others. Smith (1997) calls this first type of aspect "viewpoint types".

The second use of the term "aspect" refers to the structure of an event ${ }^{2)}$, for instance, whether or not the event can be understood to involve change over time, whether it has a definite endpoint (or endpoints) or is ongoing in time, whether or not it is repetitive and so on.

It is not my intention to disclaim what has been proposed in the literature regarding $v \mathrm{P}$-aspect. Neither is it my claim that the notion of change proposed in the present work is the only aspectual property (or "event characteristic" in Kearns" 2000: 201 terms) of the verbal phrase. But rather, to demonstrate what characteristics the two suffixes encode in a given event. Also, no attempt is being made to modify, for instance, Vendler's (1967: $100 \mathrm{ff}$ ) four "event classes" 3) - states, activities, accomplishments and achievements - as has been done by for instance, Tenny $(1987,1994)$ who claims that the four event classes are reducible into two distinct aspectual properties, namely, delimited versus nondelimited events (see also Arad 1998, Croft 1998, Ritter and Rosen 1998, among others). According to Tenny (1987), an event is interpreted as delimited if it has a definite endpoint. ${ }^{4)}$ In the present work, event classes such as states, activities, accomplishments and achievements are still considered relevant, especially for discussion with respect to predicates without the kan-aspect. Thus, on occasions, the terminology will come up where relevant.

However, it is useful for the present work to show the properties of states, activities, accomplishments and achievements in terms of "event characteristics", namely, of the durative/change/boundedness properties as set out in Kearns (2000: 200 - 227), because

\footnotetext{
2) The term "event", which will be adopted here, is used "loosely" (as in Tenny 1987), as a non-technical term, which is distinct from "episodes", "scenes", or "happenings in the real world" (Ritter and Rosen 1998).

3) This is Kearns" (2000: 201) terms what Smith (1997) calls "situation types" of aspect.

4) The terms delimited, bounded, culminated and telic all more or less refer to the same thing.
} 
the present work focuses on the notion of change (kan-aspect) and non-change ( $i$-aspect). As a reminder, this work is about $\mathrm{BI}$ two suffixes, $-k a n$ and $-i$, and the terms durative and boundedness will follow, because they are also related to change. What is not relevant in the present discussion is the notion of "affectedness" - that includes (physical) "contact" between the agent and the internal argument - as proposed by, for instance, Croft (1998); this matter will become clear as we proceed.

As a convenient term, I shall call the first category of "aspect" $v$ P-external aspect, and the second category $v \mathrm{P}$-internal aspect, or $v \mathrm{P}$-aspect for short, an early indication that the phenomena we are going to look at are internal to $v \mathrm{P}$. ${ }^{5)}$ Although the two categories of aspect are interdependent, each can be discussed separately. We shall focus on the second category, the $v \mathrm{P}$-aspect.

To see the difference between the two categories of aspect, consider the following example, (1). The descriptions in (1a) and (1b) are not intended to be as a formal notation of aspect, but rather, they are used for expository reasons.

(1). A friend sent this article to me from London:

a. $\quad v$ P-external aspect: $[+$ perfective $]$ indicated by PAST-TENSE marker on the verb sent;

b. $v \mathrm{P}$-aspect: this article MOVE: [path [Pploc GOAL to me] [Pploc SOURCEfrom London]] i.e., this article undergoes translocation (from London to me).

\footnotetext{
5) Alternatively, one may call it "inner-aspect", as in Travis (2000), except that we do not want it to be misconstrued as "within-the-verb"-aspect (cf. Tobin 1993), which belongs to word-based analyses; $v \mathrm{P}$ aspect, on the other hand, as the name indicates, is more compositional/syntactic than morphological. In addition, one may have a different view regarding what can be considered inside or outside of $\mathrm{vP}$ (cf. Kayne 1984). Regardless of what all those various aspects are, the ones we are looking at here are vPinternal, an assumption based on the work dealing with the topic (along the lines with, for instance, Tenny 1987, Arad 1995, Ritter and Rosen 1998, Croft 1998, Larson 1988, Hale and Keyser 1993, Pesetsky 1995, Chomsky 1995). Therefore, I shall not be concerned with defending the assumption.
} 
The main concern for this chapter, and throughout this work, is the second aspect, (1b), vP-aspect. To start with it must be mentioned that sometimes it is difficult to see $v \mathrm{P}-$ aspect by using English examples. For instance, an expression that is interpreted as delimited (defined in Tenny 1987: 17, 41, as an event having "a distinct temporal endpoint") such as the following example, (2), can become ambiguous when it is stripped of the $v$ P-external aspect, shown as example (3). Both examples, including the delimited/non-delimited interpretation of (2) and the ambiguity of (3), are taken from Tenny (1987) and (1994) respectively.

\section{(2)a. Patricia climbed the tree [delimited]}

e.g., It took Patricia an hour to climb the tree

\section{b. Patricia was climbing the tree [non-delimited] \\ e.g., *It took Patricia an hour to be climbing the tree}

Clearly, from (2a) and ( $2 b$ ) we can see only one difference: (2b) contains the progressive form BE-ing. This raises questions, firstly, as to whether the non-delimitedness interpretation is actually forced by the progressive form, secondly, whether this progressive form is part of $v \mathrm{P}$-aspect, or, otherwise, is part of $v \mathrm{P}$-external aspect. Note also that both (2a) and (2b) contain past tense, and only (2a) gives the delimitedness interpretation, presumably because of the [+perfective] aspect. If that is the case, then the so-called "distinct endpoint" interpretation as Tenny (1987) sees it through example (2a), belongs to the $\nu \mathrm{P}$-external aspect, namely, the [+perfective] interpretation.

To see the $v \mathrm{P}$-internal aspect - i.e., without the interference from the $v \mathrm{P}$-external Tenny (1994: 32) strips off the tense inflection from the verb, and as a result, the phrase climb the bridge is ambiguous in terms of delimitedness, shown in (3a) and (3b). ${ }^{6}$

(3)a. climb the bridge (in an hour)

b. climb the bridge (for an hour)

6) In the literature dealing with the topic, temporal/durative adverbials such as "in/for+TIME" are used as a standard test for delimitedness/telic versus non-delimitedness/atelic interpretations. 
The phrase climb the bridge is considered ambiguous because it can be modified with both types of durative adverbial, time adverbial with in and time adverbial with for.

In summary, it is difficult to see the "distinct end-point", as argued for by Tenny (1987) and (1994), without the $v$ P-external aspect. In other words, we still gain the interpretation of an expression through the $v \mathrm{P}$-external aspect, because the two types of aspect are interdependent, and without this aspect, neither example (2a) nor example (2b) indicates delimitedness, or the lack of it - and without the $v$ P-external aspect, they do not give distinct aspectual interpretations. According to Comrie (1976), Smith (1997), Giorgi and Pianesi (1997), among others, the aspects [+perfective] and/or progressive such as in examples (2) are both "tense aspect", that is, both are $v$ P-external ${ }^{7}$.

As Tenny (1994:32) notes, "English is particularly messy in this respect, since delimitedness or measuring out is not morphologically marked in the language". Tobin (1993:3-4), who approaches English verb Aktionsart - i.e., not of the $v$ P-aspect, just of the verb - in terms of markedness (of "PROCESS" versus "RESULT"), also notes the notoriety of English aspectuality:

"English is notorious, however, for expressing aspectuality in very many diverse ways which break the barriers between the rigid traditional categories of tense and aspect, lexicon and grammar, syntax and semantics, and aspect and Aktionsart, thus making 'aspect in English' a particularly challenging area of research as well as fertile ground for comparing and contrasting alternative linguistic theories."

And:

"More often than not, the distinction between aspect and Aktionsart is ignored or overlooked and different scholars have often argued either for against the maintaining of the distinction between these two categories of aspectuality."

\footnotetext{
7) Tenny (1987: 16) proposes to view "aspect" independently of "tense" although they are "interdependent in certain ways".
} 


\subsection{Bahasa Indonesia $v \mathrm{P}$-aspect}

\subsubsection{BI $v \mathrm{P}$-aspect is morphologically realised on the predicate}

English is "notorious", "particularly messy", for expressing aspectuality, as noted by Tenny (1994:32) and Tobin (1993:3-4) above, because its $\nu \mathrm{P}$-aspect is "not morphologically marked in the language". ${ }^{8)} \mathrm{BI} v \mathrm{P}$-aspect, as I claim, is morphologically realised on the predicate. It does not mean, however, that BI is not - or is less "notorious" or "particularly messy". So far, analysis of BI aspects has been rare, if not non-existent. Not only is the distinction between $v \mathrm{P}$-external aspect and $v \mathrm{P}$-aspect ignored or overlooked, the existence of BI $v$ P-aspect itself has not been recognised in the literature. What is needed for both languages is a closer examination, to determine how or to what extent both BI and English have something in common, although in one $v \mathrm{P}$ aspect is morphologically realised and in the other it is not. As we will see immediately, what is marked morphologically in BI in fact exists in English, although it is not marked morphologically, and thus, there is no reason that we should parameterise $\mathrm{BI} v \mathrm{P}$-aspect.

My main aim is to discuss what is often ignored or overlooked, that is, the aspectual properties of verbal phrases. I shall also remind the reader that I treat the suffixes $-k a n$ and $-i$ differently from those treatments, as outlined in Chapter 1: Chapter 1 discusses surface treatments in the literature. This work suggests a closer analysis, that is, an analysis that includes what is beyond the surface forms of sentences, because it's what is needed to capture the essence. In order to do so, the present work assumes that something abstract is involved in expressing "notional categories" (Hale \& Keyser 1993: 66) such as event, instance or entity, state, and relation in linguistic form.

8) This statement is not absolutely accurate, since some English particles force telicity/delimited interpretation, given the right environment. Also, some English affixes (e.g., -en, en-, -ise etc.) encode vPaspect. See for instance, Hale and Keyser's (1998: 81-90) discussion of the English conflation involving -en and en-, Lieber (1998) for the CAUSE interpretation of English predicates bearing the suffix -ise, and Farrell's (1998) discussion of conversions such as $\mathrm{A} \rightarrow \mathrm{V}, \mathrm{N} \rightarrow \mathrm{V}$, and so on. 
I shall show what the markers are encoding, by comparing the two languages in terms of $v \mathrm{P}$-aspect. As a reminder, we will also be investigating in detail the phenomena within $\mathrm{BI}$. Consider again, example (1b) above, repeated here as (4).

\section{(4). A friend sent this article to me from London}

vP-aspect: this article MOVE: [path [Pploc GOAL to me] [Pploc SOURCEfrom London]].

For now, we shall ignore the argument $a$ friend, but assume that this argument is outside the path of change that is yet to be introduced in the present chapter (after, for instance, Tenny 1987: 162-170, 1994: 83, where it is argued that "external arguments", such as $a$ friend in our example, are not able to participate in aspectual structure in the same way as internal arguments, this article and me above; and Dowty 1991, who argues that the change phenomenon, such as to be discussed here, belongs to the THEME this article, but not to the AGENT a friend; and also Arad 1998: 9, who terms an argument such as $a$ friend above "external", because it is excluded from the temporal path denoted by the event).

From the above example, (4), there may be several phenomena related to the $v \mathrm{P}$ aspect that can be discussed. However, for simple comparison between English and BI $v \mathrm{P}$-aspect, let us consider two things to account for from (4):

(i) the arguments this article and me;

(ii) the consistent contrasts of (i) from some other BI examples of translocation.

(i). The argument this article is "implicated" (Hale \& Keyser's 1993 term) as undergoing translocation, namely, moving from London to me. This translocation is not morphologically marked on the verb send. One way to represent the translocation interpretation in (4) is by using a standard template of lexical semantic representation such as (5) (for instance, Lieber 1998, Rappaport Hovav \& Levin 1998: 125-126, among others). 


\section{(5) $(\alpha$ ACT $\quad($ CAUSE $(x<\mathrm{GO}>)))$}

Here $\alpha$ represents $a$ friend, and $x$ represents this article. In what is represented, namely, the event of sending this article, the act of sending causes the article to undergo a translocation. For convenience, I shall adopt Dowty's (1991) terminology in distinguishing between the two arguments: in his terms, $x$, or this article in (4), is the primary internal argument, meaning, in the expression such as (4) above, the argument this article receives a primary importance in comparison with the peripheral arguments (me and/or London). In short, the primary internal argument in (4) undergoes translocation. The BI counterpart of (4) would be (6b).

(6)a. A friend sent this article to me from London

b. Se-orang teman meN-kirim-kan artikel ini ke-pada-(a-)ku dariLondon "A friend sent this article (to me) (from London)"
b'. *Se-orang a-CLASS
teman meN-kirim
artikel ini
ke-pada- $(a-) k u$
friend ACT-send article this
to-DAT-1sg
dari London
'A friend sent this article (to me) (from London)'
from London

The morphological realisation of the translocation of artikel ini 'this article', is shown in (6b) in the form of the suffix -kan. Whether morphologically marked like in (6b), or not, as in (6a), the essence is there: there is a translocation concept in both examples, as well as the causal relation between the transitive verb and its complement. When the translocation interpretation is intended, but the suffix is not included, the BI sentence is bad, (6b'). To capture the essence, let's assume the following tree diagram, (7). Diagram (7) is adopted from Hale \& Keyser (1993: 70) with a slight modification: here their upper $\mathrm{V}$ is represented as $v$. Of interest here is that in $\mathrm{BI}$, the causal relation of $v$-VP is morphologically realised, represented in the diagram as - kan in BI, and - $\emptyset$ in English. 


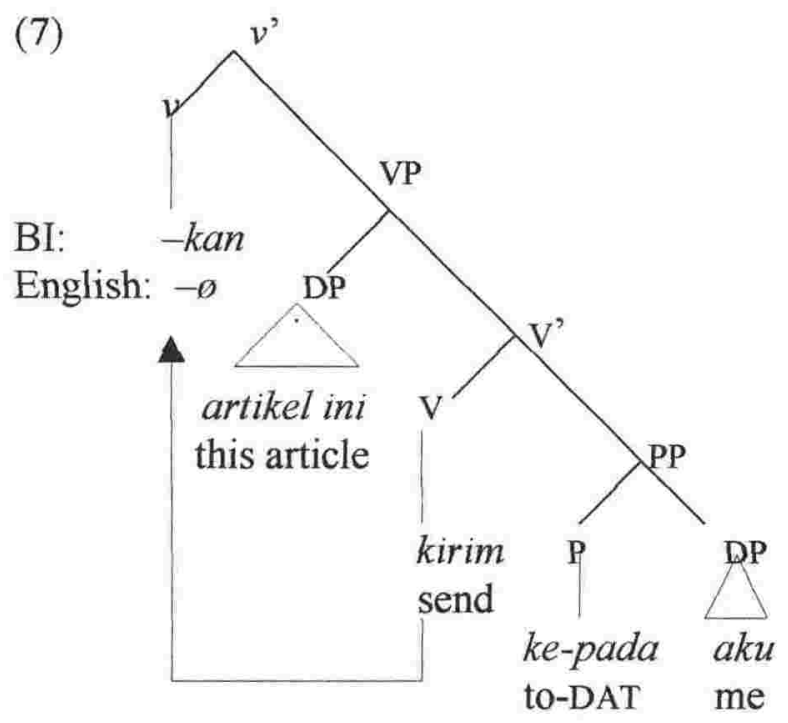

The THEME artikel ini 'this article' must be present, shown at [Spec-VP]. The dynamic event (e) of sending the letter to me would be represented as (8), from Hale \& Keyser (1993: 71).

(8) $e \rightarrow r$

Where $r$ represents the interrelation - between this article and me - encoded by the preposition ke-pada 'to-DATIVE'. In Hale \& Keyser's (1993) terms, (8) simply means change. The representation in (8) is thus strictly VP-internal, as shown in (7). As a reminder, at this stage the inclusion of the external argument $a$ friend is still irrelevant.

This assumption, however, is good only for the kan-aspect. If we select the argument me, instead of this article, as the primary internal argument, then we have (9) for both English and BI examples.

(9)a. A friend sent me this article (from London)

$\begin{array}{lll}\text { b. Se-orang teman meN-kirim- } \boldsymbol{i} \text {-(a-)ku artikel ini } & \text { (dari London) } \\ \text { a-CLASS friend ACT-send-Isg article this } & \text { (from London) } \\ \text { 'A friend sent me this article (from London)' }\end{array}$


And again, whether it is morphologically marked or not, the translocation concept does not apply to the primary internal argument, $m e / k u$, ' $1 \mathrm{sg}$ ', neither in English nor in BI, (9). The predicate in BI example, (9b), bears the $i$-aspect, and the interrelation - between this article and $m e$ - as encoded by the preposition ke-pada 'to-DATIVE' cannot be represented as a dynamic event such as (8) (The status of the arguments aku '1sg' and artikel ini 'this article' will be discussed in Chapter 4).

We have seen a tree diagram (7) that shows the argument this article as the primary internal argument, with the kan-aspect assumed to be involved in the $v \mathrm{P}-\mathrm{VP}$ relations. The tree diagram (10) below shows a contrast, that is, when the $i$-aspect is used, and the argument $a k u$ ' $1 \mathrm{sg}$ ' poses as the primary internal argument (After, for instance, Larson 1988, Pesetsky 1995, Arad 1998, Bowers 2002, amongst others).

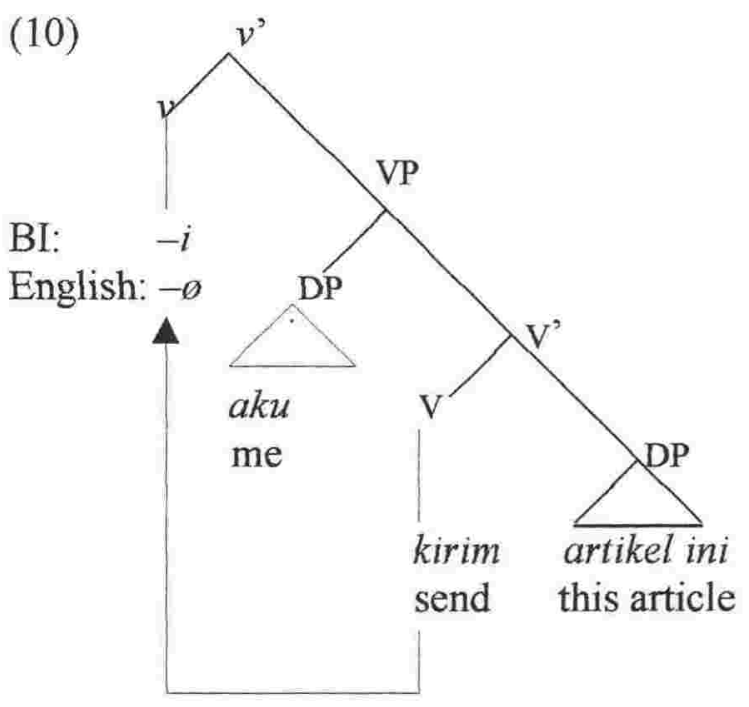

In summary, in (6) the primary internal argument artikel ini 'this article' is sent (to me from London), and hence undergoes a translocation: the kan-aspect is involved. In contrast, (9), the primary internal argument $a k u$ ' $1 \mathrm{sg}^{\prime}$ that receives the article is stationary, and the $i$-aspect is involved. To use Dowty's (1991) terms, with the $i$-aspect, (9), the article is of a "secondary importance in terms of information that is expressed in the sentence" (As previously noted, I have set aside the argument a friend in this 
discussion because this argument does not appear to play part in distinguishing the aspectual properties of the event, namely, as to whether or not the primary argument artikel ini 'this article', (6), or aku '1sg', (9) - undergoes a translocation.) The distinction between the "primary" and "secondary" internal arguments will be immensely crucial for understanding the ACTIVE-PASSIVE derivations (This will be introduced in Section 2.3.2.2, and discussed further in Chapter 4, where the role of AGENT such as a friend above, a CAUSER, and a THEME in the derivations will also be included).

We have discussed point (i) regarding the arguments this article and me of the example (4) and showed the contrast between the two types of argument in terms of translocation sense. We have argued that in BI the translocation sense pertaining to the primary internal argument is encoded by the kan-aspect, and the non-translocation sense (of the argument with the same status) by the $i$-aspect. Thus, we analyse the contrast in terms of $v \mathrm{P}$-aspects. The second point, (ii), to argue for is that the contrast as discussed in point $(i)$ is consistent in $\mathrm{BI}$.

(ii) Other examples of contrasting BI vP-aspect can be seen in (11) and (12). In the (a) examples the predicate bears the kan-aspect, in the (b) examples it bears the $i$-aspect.

(11) Ini dokumen saya,
DEM document 1sg
'This is my document,

a. tolong Bapak meN-tanda-tangan-kan-nya (delegation sense) help sir ACT-sign-hand-KAN-3sg please (you) have it signed' (i.e., please give it to someone else to sign)

b. tolong Bapak meN-tanda-tangan-i-nya help sir ACT-sign-hand-I-3sg please (you) sign it'

(12)a. Minggu depan PakParto akan meN-kawin-kan anak-tiri-nya week front $\mathrm{Mr} P$ FUT ACT-marry-KAN child-step-3sg 'Next week Mr Parto will marry his stepdaughter off' 


\section{b. Minggu depan PakParto akan meN-kawin-i anak-tiri-nya week front $\mathrm{Mr} P$ FUT ACT-marry-I child-step-3sg \\ 'Next week Mr Parto will marry his stepdaughter'}

In both the (a) examples the agents do not do the ACT of signing the document or marrying the stepdaughter. In (11a) the second person is not asked to sign the document, and in (12a) Mr Parto does not marry his stepdaughter himself. However, both predicates imply the translocation concept (such as a change of hand), and both bear a CAUSE interpretation. In contrast, in both the (b) examples the agents do the ACT of signing the document or marrying the stepdaughter, and there is no CAUSE interpretation implicated.

In summary, the claim that is made in this section is that the BI predicate suffix -kan marks a vP-aspect, which I refer to as kan-aspect, indicating that the primary internal argument undergoes change, which is exemplified by the translocation (change of location) of the argument. This is in contrast with $i$-aspect, where the primary internal argument is stationary and/or unchanged. Comparing English with BI vP-aspects, we discovered - albeit from small number of examples - that, despite the lack of a morphological $v \mathrm{P}$-aspect marker in English, the similarity with $\mathrm{BI}$ is very striking. vPaspect, we shall propose, is not a language specific parameter.

\subsubsection{Significance of $v \mathbf{P}$-aspect analysis for BI syntax}

It is known in the literature that there are some sorts of interactions between the $v \mathrm{P}$-aspect and $v$ P-external aspect (for instance, Vendler 1967, Tenny 1987, 1994, Tobin 1993, Smith 1997, Kearns 2000, among others). The phenomenon that the English progressive, for instance, cannot occur with certain predicates has been discussed successfully in the afore-mentioned references. The present work takes the same position with what others have proposed in this regard. However, to see how the two categories of aspect interact with each other one needs to see first the characteristics of each. In order to do so, it is thus necessary for us to discuss them separately. The two chapters that follow, Chapter 3 and 4 discuss the $v \mathrm{P}$-aspect (kan-aspect and $i$-aspect, respectively), and the $v \mathrm{P}$-external 
aspect will be discussed in terms of selection of $\mathrm{BI}$ temporal aspect MODALs in the derivation (which will be included in Chapter 5 in the context of Aspect merge in $\mathrm{BI}$ ).

The examples to be provided in the two sub-sections that follow will show that BI temporal aspect, $v \mathrm{P}$-external aspect, is sensitive to $v \mathrm{P}$-aspect (2.3.2.1), and that in $\mathrm{BI}$ the mechanism of raising an argument to its surface subject position (which for now I assume to be the [Spec-AspP]) is dependent on the $v \mathrm{P}$-aspect (2.3.2.2). Other phenomena, such as PASSIVE and ACTIVE derivations, the so-called "dative-double object alternation", and so on, will be included in the body of discussion as syntactic effects of $v \mathrm{P}$-aspect.

\subsubsection{The interactions between temporal aspect and $v \mathrm{P}$-aspect}

BI sentences without overt $v$ P-external aspect are not uncommon. Furthermore, BI predicates are not inflected with tense aspect markers such as the English -ed, -en, -ing, and so on. In isolation, often it is difficult to relate a BI sentence to temporal aspect, and often one has to rely on the interpretation of the discourse, or on the occurrence of time reference. $^{12)}$

Of interest here is when the $v \mathrm{P}$-external aspect is overt, which can be represented by (i) a MODAL, (ii) a combination of two MODALs, (iii) time references. The following (13) lists such representations.

12) The distinction between definite ( $i$ ) versus indefinite (ii) articles, or the bare NP object (iii) sometimes helps the $v \mathrm{P}$-external aspect interpretations:

(i) Kue-nya saya makan Cake-3sg 1sg eat

'I ate the cake'

(ii) Mira meN-baca se-buah artikel M ACT-read a-CLASS article

'Mira is/was reading an article'

(iii) Mira meN-baca article

M ACT-read artikel

'Mira reads articles'

However, these interpretations are based on intuition. A thorough investigation on the matter is required, which is beyond the scope of the present work. What we have here are the most likely interpretations. 
(13) BI $v$ P-external aspect

(i) MODALs (those indicated by [ \pm expected] are not interchangeable):

[-perfective]: akan 'will' (but not 'will BE'), 'BE going to'(but not 'going to $\mathrm{BE}$ '); hampir 'very near future'

sedang 'progressive, $\mathrm{BE}+\mathrm{ing}$ ', [+expected]

masih 'progressive', 'have not finished' [-expected]

tengah 'in the midst of doing', 'half-way';

[+perfective] sudah '[+expected] have'

telah '[-expected] have'

habis ' $[+$ expected $]$ very near past'

baru, '[-expected $]$ very near past'

baru saja, 'have just, just now', and so on.

(ii) Combinations of two MODALs are possible, for instance,

sedang akan 'progressive + future' (but not akan sedang, i.e., 'will BE+ing')

baru saja akan 'just about to' (but not akan baru saja, i.e., 'will have just')

sudah akan 'have will' (but not akan sudah 'will have')

sudah sedang 'have started to' (but not sedang sudah, i.e., 'have been + ing'),

and so on, similar to the English combinations of will have, should have been, and so on, except in different linear order.

(iii)Time references help relate the event to the time of utterance, such as, kemarin 'yesterday' (beyond 12 hours)

tadi 'very near past' (within a 12 hour frame-time)

tadi pagi 'this morning'

nanti 'very near future' (within a 12 hour frame-time)

nanti malam 'tonight'

besok 'tomorrow' (beyond 12 hours),

and so on.

I will demonstrate that to use these aspect MODALs, one must take into consideration the $v \mathrm{P}$-aspect of event classes such as state/process, activity, achievement, and accomplishment. In this instance, I will show that in $\mathrm{BI}$ mati ' $\mathrm{BE}$ dead' and hidup 'BE alive' are state predicates. The first examples show a contrast between an event that happens only temporarily, (14a,b), and event that happens once only (cannot be repeated) $(15 \mathrm{a}, \mathrm{b})$. In both cases the predicate mati 'dead' contains both the initial and end-state, but only the former is durative (14b) contrasts with (15b). 
(14)a. Kemarin listrik-nya ${ }^{13)} \quad$ mati

yesterday electricity-3sg dead

'Yesterday the electricity was dead' i.e., it was not on then but it is now

b. Listrik-nya sedang mati

electricity-3sg PROG dead

'The electricity is dead' i.e., it is not on, for the time being

$\begin{array}{lll}\text { c. Listrik-nya } & \text { mati } & \text { kemarin } \\ \text { electricity-3sg } & \text { dead } & \text { yesterday }\end{array}$

'The electricity has been dead since yesterday' i.e., it is still dead now

(15)a. ?Kemarin ikan-nya mati

yesterday fish-3sg dead

'Yesterday the fish was dead' (Is it alive now? i.e., not 'Yesterday, the fish died')

b. *Ikan-nya sedang mati

fish-3sg PROG dead

'The fish is (being) dead' (Is it coming back to life soon?)

c. Ikan-nya mati kemarin

fish-3sg dead yesterday

'The fish has been dead since yesterday' i.e., it is still dead now

Sentences $(14 a, b)$ can take all time/reference markers, shown in the following, (16a); sentences $(15 \mathrm{a}, \mathrm{b})$ only those that refer to time before and time after the event, (16b). Intuitively, the simplest reason is that once a fish dies, it stays dead. ${ }^{14)}$

\section{(16)a. Listrik-nya akan/sudah/sedang ... mati electricity-3sg FUT/PERF/PROG dead \\ b. Ikan-nya akan/sudah/*sedang mati fish-3sg FUT/PERF/PROG dead} 'The electricity will be/has been/is dead' i.e., not it will die/has died/is dying 'The fish will be dead/has been dead' i.e., not it will die/has died

We can thus conclude, that a temporary event such as (14a), contains a single entity that is made up of three parts: initial point, shaft/tempo, and final point. Because of the

13) Refer back to the note on -nya, page vii. In this case the definite article the is the most likely translation, rather than his/her.

14) I am indebted to a reader who pointed out that (15a) is anomalous for pragmatic reasons, but possibly not ungrammatical'. However, the sentence is acceptable only if it is possible to say that the fish was not dead after the end of yesterday. 
shaft/tempo, the event takes the progressive modal sedang. This phenomenon is what Tenny (1987) calls "delimited event", except here the concept is extended to cover the two endpoints with the tempo in the middle connecting the two (in Tenny's 1987 terms, the event can be "measured out" or "scaled"). Without the shaft, the two points meet and become a single endpoint, just like that is represented in (15a). Hence, the notion that an event is delimited because it contains "a definite endpoint" (Tenny 1987) needs to be redefined, because having a single endpoint does not necessary mean that the event can be measured out.

It is tempting to analyse the contrast in terms of [ \pm living]. Like the state of being dead for fish, the state of being dead in plants too, cannot be temporary (i.e., bearing a tempo). The predicate mati 'dead' in BI is a state (i.e., an adjective, in terms of grammatical category). But the first kind of state, (16a), is only temporary, and the second, (16b), is permanent. Other objects that can be involved in temporary change of state (of being dead and alive) include engines, television sets, radio, all electronic equipment; things that can be "turned on or off". Human beings and (other) animals are included in the second kind of change of state. The former can be started and stopped "at will", as in the following examples, $(17 \mathrm{a}, \mathrm{b})$, but not the latter, $(18 \mathrm{a}, \mathrm{b})$. The predicate hidup ' $\mathrm{BE}$ alive' is like mati 'BE dead' in that it also has the dichotomy of temporal versus permanent states. Both predicates can be involved in "causativization" (Lieber 1998, Farrell 1998), or "causal relation" (Hale \& Keyser 1993), - i.e., with the kan-aspect - only when the state is temporary, $(17 \mathrm{a}, \mathrm{b})$, but not when it permanent, $(18 \mathrm{a}, \mathrm{b})$.

(17)a. Udin (akan/sedang/sudah...) meN-mati-kan listrik-nya U FUT/PROG/PERF ACT-dead-KAN electricity-3sg

'Udin will turn/is turning/has turned the electricity dead', i.e., to turn it off

b. Udin (akan/sedang/sudah...) meN-hidup-kan listrik-nya U FUT/PROG/PERF ACT-alive-KAN electricity-3sg

'Udin will turn/is turning/has turned the electricity alive, i.e., to turn it on

(18)a. *Udin (akan/sudah/sedang...) meN-mati-kan ikan-nya/tanaman-nya U FUT/PERF/PROG ACT-dead-KAN fish-3sg/plant-3sg

'Udin will make/is making/has made the fish/the plants dead', i.e., to kill them 


\section{b. *Udin (akan/sudah/sedang...) meN-hidup-kan ikan-nya/tanaman-nya U FUT/PERF/PROG ACT-alive-KAN fish-3sg/plant-3sg} 'Udin will make/is making/has made the fish/the plants alive', i.e., to revive them

For arguments that cannot be involved in temporary events like in $(17 \mathrm{a}, \mathrm{b})$, such as fish or plants, (18a,b), the change of state (of being dead or alive) cannot be represented morphologically, namely, by involving them in the kan-aspect (as a reminder, included in the notion of change are the change of location, change of state, movement, and so on, refer back the beginning of this chapter). The change of state can be represented either syntactically/analytically, as the following, (19a), or lexically with the verb meN-bunuh 'to kill' (19b).

\section{(19)a. Air kotor akan/sedang/sudah meN-sebab-kan ikan-nya mati water dirty FUT/PROG/PERF ACT-cause-KAN fish-3sg dead 'The dirty water will cause/is causing/has caused the fish to die'}

\section{b. Udin akan/sedang/sudah meN-bunuh ikan-nya U FUT/PROG/PERF ACT-kill fish-3sg 'Udin will kill/is killing/has killed the fish'}

The relevant predicate for the $v \mathrm{P}$-external aspects in (19a) is meN-sebab-kan 'to cause', and not mati 'dead', and thus all the $v \mathrm{P}$-external aspects can co-occur with the predicate.

We have seen in (15b) and (16b) that mati 'BE dead' of the second kind of state, namely, of the permanent state, cannot co-occur with the progressive sedang. It is not impossible, however, to express the concept of His father is dying. A different predicate is available for similar expression, such as sekarat that describes a physical state just before a person's death, i.e., in a death-agony, and it takes the progressive MODAL sedang, shown in the following example, (20a). Another strategy for similar expression is by using the future MODAL hampir 'almost, just about to', that precedes the state predicate mati 'BE dead', but this is just a "very near" future aspect, which may give a different interpretation, that is, there is a possibility that in the end, the person may not be dead after all, (20b). The $v$ P-external aspect in (20b) indicates that the initial end-point of 
the event - which may or may not happen - is coming. As mentioned at the beginning of this section, a combination of two MODALs is possible, such as in (20c), where the progressive sedang procedes hampir 'almost, just about to'.

(20)a. Ayah-nya sedang sekarat
father-3sg PROG death-agony
'His father is/was (being) in death-agony'
b. Ayah-nya hampir mati father-3sg FUT dead 'His father is/was almost dead'
c. Ayah-nya sedang hampir mati father-3sg PROG FUT dead 'His father is/was (being) almost dead'

One way of describing the occurrence of the progressive sedang in (20c) is that it actually modifies the future hampir 'almost, just about to', or, strictly speaking, hampir mati 'almost dead'. A different order is not allowed, (21).
(21) *Ayah-nya father-3sg
hampir sedang mati FUT PROG dead 'His father almost being dead'

We shall set the complexity of tense aspect aside; apart from the fact that it is beyond the scope of the present work, the literature on the topic is voluminous (although not for BI, for instance, Reichenbach 1947, Comrie 1976, Stowell 1995, Giorgi and Pianesi 1997, Smith 1997, Cinque 1999, among others).

The "causativization" (Lieber 1998, Farrell 1998), or "causal relation" (Hale \& Keyser 1993), as exemplified in the examples above, from (14) to (21), - either it is shown as morphological, analytical or lexical - all implicates change. When there is no change implicated (or because change is impossible, for instance, a dead fish or plant cannot be changed into alive), the sentence cannot include some or all of $v \mathrm{P}$-aspect. Because change takes time, albeit short (such as a bomb explosion, Tenny 1987), then a 
process of change exists, and therefore, the sentence can take the progressive sedang. The main point under discussion is that some of our examples show that for the permanent state of being dead, the two points, namely, the initial and the final points become one, and the process of change cannot be inferred. Thus, the sentence can only take the future akan or the perfective sudah.

Unlike the state of being dead or alive, being sad in the examples in (22) and (23) is rather complicated: in (22a) the progressive sedang can co-occur with the predicate sedih 'sad'. It follows from the previous claims that the state of being sad in example (22a) is understood to be as temporary. But with the kan-predicate meN-sedih-kan 'to cause someone sad', (22b), the progressive is not allowed: here we see that the predicate has been "modified" by a $v \mathrm{P}$-aspect, which in this case is by the kan-aspect. There is change that can be interpreted, and yet the progressive cannot occur (here the distinction between AGENT and CAUSER is relevant, but I set this aside for the coming chapters). The future akan is allowed in (22b), and so is the [-expected] perfective telah, (22c). In (23a) none of the vP-external aspects is allowed, and only time adverbials that mean 'often', 'always', 'sometimes' and so on can co-occur with the predicate, shown in (23b).

(22)a. Ibu sedang/baru/*akan/*sudah sedih
mother PROG/PERFjust/FUT/PERFhave sad
'Mother is/has just been/will be/has been sad'
b. Berita itu *sedang/ ${ }^{*}$ barw/akan'*sudah meN-sedih-kan ibu
news that PROG/PERFjust/FUT/PERFhave ACT-sad-KAN mother
'The news will/is saddening/has just saddened/has saddened mother'
c Berita itu telah meN-sedih-kan ibu ${ }^{\text {15) }}$
news that PERF ACT-sad-KAN mother
'The news has saddened mother'

(23)a. Toni *akan $/{ }^{*}$ sedang $/{ }^{*}$ barw ${ }^{*}$ sudah/*telah meN-sedih-kan ibu-nya T FUT/PROG/PERFjust/PERFhave/perfPERF ACT-sad-KAN mother- $3^{\text {rd }}$ 'Toni will/is saddening/has just saddened/has saddened his mother'

b. Toni sering/selalukadang-kadang... meN-sedih-kan ibu-nya $\mathrm{T}$ often/always/sometimes... ACT-sad-KAN mother-3sg 'Tony often/always/sometimes... saddens his mother'

15) This is a case where telah ([-expected] perfective) and sudah ([+expected] perfective) are not interchangeable. 
What it is that allows certain vP-external aspects but not the others, for instance, with the psychological predicate like sedih 'sad' in (22) and (23), will feature in the chapters that follow (Chapter 3 to 5). In general, to include a vP-external aspect the internal aspect must be left open for consideration, perhaps for matching/compatibility reasons.

To pre-empt our discussion in the next chapters, I shall emphasise again the existence of (time) frame within some event structures, like those bearing the tempo. It could be that psych-predicates are not (tightly) framed; for instance, some may only have the initial end-point with tempo, but no final end-point (or vice versa - another term for this is "durative", see for instance, Kearns 2000). Whether or not an event is framed plays a part in determining the compatibility of the two aspects. Because a frame is made of three entities: an initial end-point, the body/shaft (tempo), and the final end-point, missing one or two of them may result in some restrictions for the occurrence of the $v \mathrm{P}$ external aspect.

\subsubsection{Surface subject and $v \mathrm{P}$-aspect}

The second group of examples shows that in BI the mechanism of raising an argument to the surface subject position is heavily constrained by the $v \mathrm{P}$-aspect. For reasons that will be apparent in the later chapters, I assume this subject position in BI to be the specifier of "(Temporal) Aspect Phrase" ("AspP" henceforth). An immediate instance is the derivation of BI PASSIVE. Although the notion that a PASSIVE structure is derived from the ACTIVE counterpart is rather out of date, there is a tendency that "old habits die hard". My aim is to show that different surface PASSIVE sentences are the result of different derivations involving different $v \mathrm{P}$-aspects. Consider the usual examples of dative (24) and locative (25) constructions below to start with. The (a) examples of (24) and (25) show their ACTIVE form, and the (b)/(c) examples show their PASSIVE forms.

(24)a. Ibu meN-kirim-kan se-pucuksurat ke-pada abang mother ACT-send-KAN a-CLASS letter to-DAT older brother/sister 'Mother sent a letter to (our) elder brother/sister' 
b. Se-pucuk surat di-kirim-kan (oleh) ibu ke-pada abang a-CLASS letter PASS-send-KAN (by) mother to-DAT older brother/sister 'A letter was sent (by mother) to elder brother/sister' or,

c. Se-pucuk surat di-kirim-kan ke-pada abang oleh ibu a-CLASS letter PASS-send-KAN to-DAT older brother/sister by mother 'A letter was sent to elder brother/sister by mother'

(25)a. Helen Clark meN-kirim-kan tentara yang kuat ke TimTim HC ACT-send-KAN soldier COMPstrong to(LOC) East Timor 'Helen Clark sent strong troops to East Timor'

b. Tentara yang kuat di-kirim-kan (oleh) Helen Clark ke TimTim soldier COMP strong PASS-send-KAN (by) HC to(LOC) ET 'Strong troops were sent (by Helen Clark) to East Timor' or,

c. Tentara yang kuat di-kirim-kan ke TimTim olehHelen Clark soldier COMP strong PASS-send-KAN to(LOC) East Timor by HC 'Strong troops were sent to East Timor by Helen Clark'

In $(24 b, c)$ and $(25 b, c)$ the argument sepucuk surat 'a letter', and tentara yang kuat 'strong troops', is raised to occupy the [Spec-AspP] position, and the appropriate $v \mathrm{P}$ aspect is involved in the derivation of the passive. The $v \mathrm{P}$-aspect is appropriate because it encodes the translocation of the THEME sepucuk surat or tentara yang kuat. But when the noun abang 'elder brother/sister' (24a), or TimTim 'East Timor' (25a), the argument of the dative kepada or locative $k e$ respectively, is raised, the same $v \mathrm{P}$-aspect cannot be involved in the derivation, (26) and (27).

(26)a. Ibu meN-kirim-kan se-pucuk surat ke-pada abang mother ACT-send-KAN a-CLASS letter to-DAT older brother/sister

'Mother sent a letter to (our) elder brother/sister'
b. *Abang di-kirim-kan (oleh) ibu se-pucuk surat elder brother PASS-send-KAN (by) mother a-CLASS letter 'Elder brother was sent (by mother) a letter'
c. *Abang di-kirim-kan se-pucuk surat oleh ibu elder brother PASS-send-KAN a-CLASS letter by mother 'Elder brother was sent a letter by mother'




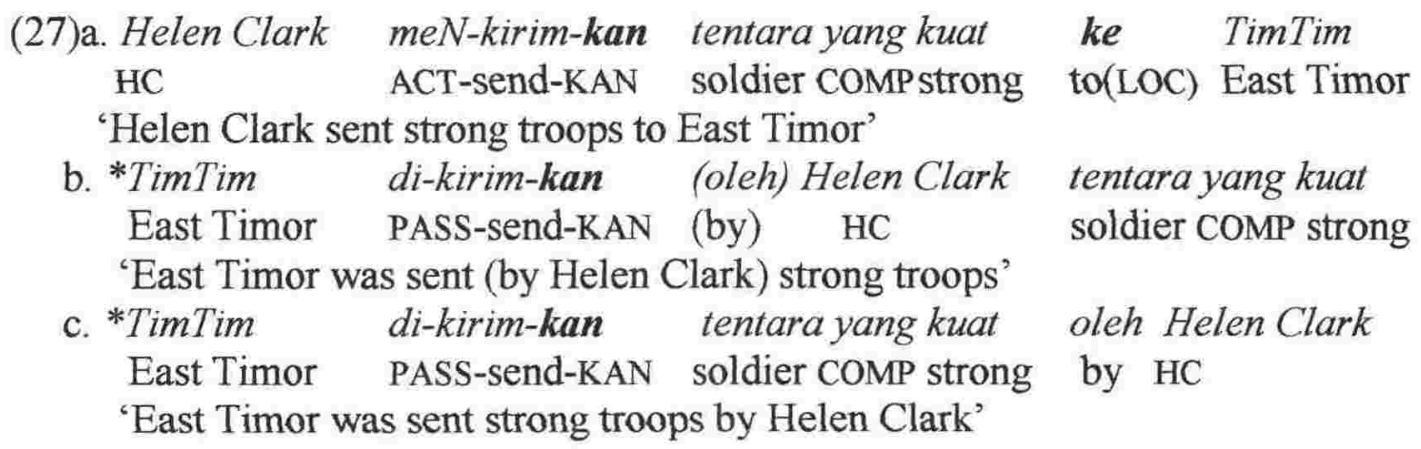

Each derivation of the sentences $(26 \mathrm{~b}, \mathrm{c})$ and $(27 \mathrm{~b}, \mathrm{c})$ above crashes because abang 'elder brother', or TimTim East Timor', which is actually a PATIENT (see Section 2.4) does not undergo change in the event structure, which in this case is a translocation, while the kanaspect realised on each predicate tells us that it does. For the derivation to converge, the $i$ aspect is then required, $(28 b, c)$ and $(29 b, c)$. As a warning, the ACTIVE forms (26a)/(27a) above and $(28 a) /(29 a)$ below are entirely separate beasts, and the PASSIVE forms with the $i$-aspect, $(28 \mathrm{~b}, \mathrm{c})$ and $(29 \mathrm{~b}, \mathrm{c})$, are not derived from the ACTIVE forms with the kan-aspect. I will come back to this matter in Chapter 4 .

\section{(28)a. Ibu meN-kirim-i abang} mother ACT-send-I older brother/sister 'Mother sent (our) elder brother/sister a letter'
b. Abang di-kirim-i (oleh) ibu elder brother PASS-send-I (by) mother a-CLASS letter 'Elder brother was sent (by mother) a letter' se-pucuk surat a-CLASS letter or,
c. Abang
di-kirim- $\boldsymbol{i}$
se-pucuk surat
elder brother PASS-send-I
a-CLASS letter by mother
'Elder brother was sent a letter by mother'
(29)a. Helen Clark meN-kirim-i TimTim tentara yang kuat $\mathrm{HC} \quad$ ACT-send-I East Timor soldier COMP strong 'Helen Clark sent East Timor a strong troop'
b. TimTim di-kirim-i (oleh) Helen Clark tentara yang kuat East Timor PASS-send-I (by) HC soldier COMP strong 'East Timor was sent (by Helen Clark) a strong troop' c. TimTim di-kirim-i tentara yang kuat oleh Helen Clark East Timor PASS-send-I soldier COMP strong by $\mathrm{HC}$ 'East Timor was sent a strong troop by Helen Clark'


Which of the arguments undergoes change, which is stationary, and which aspect shows change, which does not, must be considered, or the derivation will crash. This simple rule accounts for the convergence of derivations that result as $(28 \mathrm{~b}, \mathrm{c})$ and $(29 \mathrm{~b}, \mathrm{c})$. The bad examples in $(26 \mathrm{~b}, \mathrm{c})$ and $(27 \mathrm{~b}, \mathrm{c})$ are the result of mixing the raised argument with the wrong aspect. The inverse of $(26 \mathrm{~b}, \mathrm{c})$ and $(27 \mathrm{~b}, \mathrm{c})$ are just as bad, (30) and (31) below.

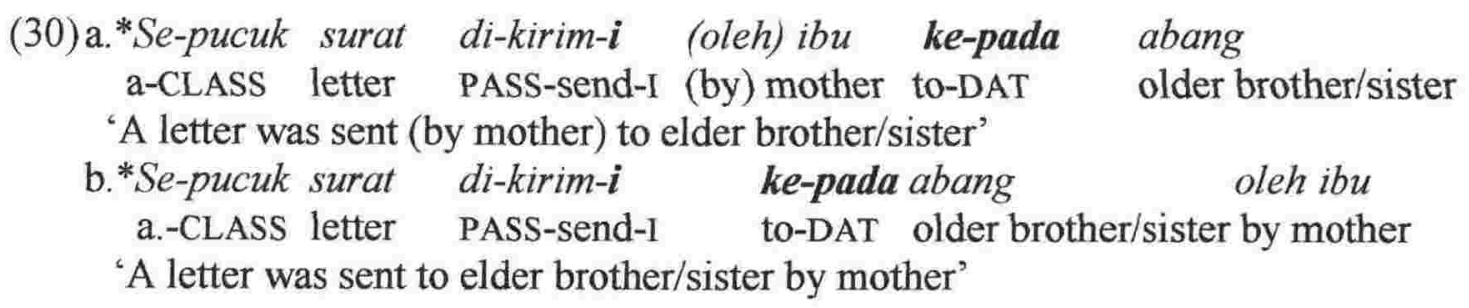
(31)a. *Tentara yang kuat di-kirim-i (oleh) Helen Clark ke TimTim soldier COMP strong PASS-send-I (by) HC to(LOC) East Timor 'A strong troop was sent (by Helen Clark) to East Timor'
b. * Tentara yang kuat di-kirim-i ke TimTim soldier COMP strong PASS-send-I to(LOC) East Timor by $\mathrm{HC}$
'A strong troop was sent to East Timor by Helen Clark'

Another important reason for the impossibility of raising a certain argument in syntax is because in BI, sometimes the causal relation of $v$-VP does not involve a volitional AGENT, although it is well formed in the English counterparts, as seen in the English translation of (32b) below. Assume for now for simplicity reasons that both the AGENT and the CAUSER (i.e., non-volitional) occupy the same position, [Spec-vP] (Hale \& Keyser 1993, Arad 1998 among others), because the two cannot occur at the same time. If $v-v \mathrm{P}$ includes a CAUSER in its configuration, a personal PASSIVE cannot derive, (32b), and in (33c) the PASSIVE is impersonal.
(32)a. Kelakuan-nya meN-sedih-kan hati ibu behaviour-3sg ACT-sad-KAN liver mother 'His behaviour saddened/saddens mother's heart'
b. *Hati ibu di-sedih-kan oleh kelakuan-nya liver mother PASS-sad-KAN by behaviour-3sg 'Mother's heart is/was saddened by his behaviour'


c. Hati ibu sedih karena kelakuan-nya

liver mother sad because behaviour-3sg

'Mother's heart is/was sad because of his behaviour'

(33)a. Awan gelap meN-tutup-i bumi

cloud dark ACT-cover-I earth

'Dark clouds cover the earth'

$\begin{array}{lll}\text { b. }{ }^{* B u m i} \text { di-tutup-i } i & \text { oleh awan gelap } \\ \text { earth PASS-cover-I } & \text { by cloud dark }\end{array}$

'The earth is covered by dark clouds'

c. Bumi ter-tutup (oleh/dengan) awan gelap

Earth TER-cover (by/with) clouds dark

'The earth is covered by/with dark clouds'

Often the surface subject has a THEME interpretation, (34a) below, but the passive form (of the same interpretation) cannot derive, one reason is because this moving object cannot be the argument of the PP by-phrase, (34b), because it is not an AGENT. The good structure with the PP with-phrase, (34c), cannot be derived from the same $v \mathrm{P}$ because it contains an implicit AGENT, and the (instrument) THEME sebutir kelapa 'a coconut', is derived from somewhere else but not from the [Spec- $v$ P]. The ACTIVE counterpart of $(34 c)$ is not (34a) but (34c'). The sentence (34d) provides the closest equal interpretation to (34a), as a counterpart of some sort, perhaps as a passive, or perhaps as an "adversarial construction". The example (34d) is included here because this expression, rather than (34c), is the "passive" counterpart of (34a), in that, they have the same intended meaning. Sie (1988: 47-48) calls construction such as (34d) "passive-like construction", quite correctly, because the construction does not take an oleh by-phrase.

(34)a. Se-butir kelapa meN-jatuh-i atap rumah a-CLASS coconut ACT-fall-I roof house

?'A coconut fell the roof'(but see (28a) below)

b. *Atap rumah di-jatuh-i oleh se-butir kelapa roof house PASS-fall-I by a-CLASS coconut 'The roof was fallen upon by a coconut'

c. Atap rumah di-jatuh-i *(dengan) se-butir kelapa (*(oleh) se-ekor kera) roof house PASS-fall-I with a-CLASS coconut (by a-CLASS monkey) 'The roof was fallen upon with a coconut (by a monkey)' 
c'. Se-ekor kera meN-jatuh-i atap rumah *(dengan) se-butir kelapa a-CLASS monkey ACT-fall-I roof house with a-CLASS coconut 'A monkey dropped a coconut on the roof'

d. Atap rumah ke-jatuh-an (*oleh*dengan) se-butir kelapa 'roof house KE-fall-AN (by / with) a-CLASS coconut 'The roof "experienced" being fallen upon by a coconut' (i.e., $\neq$ was fallen upon,

The structure (34a) looks like an unaccusative construction, where sebutir kelapa 'a coconut' is the THEME argument of jatuh 'fall', raised from the [Spec-VP]. However, compare the following unaccusative construction, (35a), with the transitive construction, (34a), repeated below as (35b). In both constructions, the coconut undergoes translocation. In the transitive construction, (35b), however, the roof is a PATIENT, which sounds bizarre in the English translation.

$\begin{array}{cccc}\text { (35)a. Se-butir kelapa jatuh } & \text { (ke/diatas } & \text { atap rumah) } \\ \text { a-CLASS coconut fall } & \text { to/on } & \text { roof house } \\ \text { 'A coconut fell (on the roof)' } & & \end{array}$

$\begin{array}{llll}\text { b. Se-butir kelapa meN-jatuh-i } & \left({ }^{*} k e /{ }^{*} \text { di atas }\right) & \text { atap rumah } \\ \text { a-CLASS coconut ACT-fall-I } & \text { to/on } & \text { roof house } \\ \text { ?'A coconut fell the roof" } & & \end{array}$

When the argument at the [Spec-vP] is a volitional AGENT, the passive derivation involving PATIENT-focus is acceptable, although it sounds odd in the English translation, with the THEME relegated as the object of the PP with-phrase as a moving instrument, $(36 b, c)$. Note again that sentence $\left(34 c^{2}\right)$, repeated here as $(36 a)$, is the active form of (34c). Note also that in all cases the preposition dengan 'with' is obligatorily present to introduce the THEME sebutir kelapa 'a coconut' as an instrument that moves.

(36)a. Se-ekor kera meN-jatuh-i atap rumah *(dengan) se-butir kelapa a-CLASS monkey ACT-fall-I roof house with a-CLASS coconut 'A monkey dropped the roof with a coconut'

b. Atap rumah di-jatuh-i *(dengan) sebutir kelapa oleh se-ekor kera roof house PASS-fall-I (with) a.CLASS coconut by a-CLASS monkey 'The roof was dropped upon with a coconut by a monkey' 
or,

c. Atap rumah di-jatuh-i (oleh) se-ekor kera *(dengan) se-butir kelapa roof house PASS-fall-I (by) a-CLASS monkey with a-CLASS coconut 'The roof was dropped upon by a monkey with a coconut'

The difference between CAUSER and AGENT can be explained, for instance, by determining whether or not the event is a result of an intention (volitional ACT), or just of some triggering cause ('real cause'), i.e., between the intent to bring about the event (by an AGENT), versus something ('real cause', CAUSER) that happens to trigger the event. The personal/agentive passive alternant cannot be derived - unless there is at least an understood agent, (34b) versus (34c) - because it is impossible, in aspectual terms, to have an event that is done intentionally by an argument that cannot have intention.

I have often mentioned change that affects the argument when the kan-aspect is present. In Section 2.4 I attempt to provide a clear picture of the idea of change, using examples of simple sentences with the kan-aspect.

\subsection{Change}

In the literature it is commonly known that an object may undergo a change caused by the action in the event, although the notion of change itself is not of primary importance. Change is mentioned in passing in Tenny (1987: 39) as part of the term "motion-throughlocation", which I translate for the present analysis as change of location. Dowty (1991) includes change in his lists of entailments pertaining to "proto-Patient" or "PATIENTtype" arguments, where, in his theory, change is primarily an entailment of THEME (also Hale \& Keyser 1993: 72, 73); it can be a property of AGENT only if there is no CAUSE involved. ${ }^{16)}$ Dowty argues that among other things, change - that also includes movement - typifies an Object as THEME, as against PATIENT that is "almost always" stationary and does not undergo change. Change is also used in Voskuil (1996) and Levin (1993), based on the interpretation of the verb to give or verbs in other languages that

\footnotetext{
16) To pre-empt our discussion, it is important to note here that change as an entailment distinguishes THEME from PATIENT: a THEME is a special PATIENT (Dowty 1991).
} 
mean to give. Based on Levin's classification of English verbs, Voskuil argues that to give involves changing hands until the object reaches the other hand. In their analysis of transitivity alternations and asymmetries in distribution, Hale \& Keyser (1993:70-71, 8586) are concerned with two large classes of verbs; one class is represented with the verb get, and the other with put. Both classes, they argue, "depict events in which some entity or material 'undergoes a change of location, so that it comes to be located' at a place corresponding to the nominal expression in the prepositional phrase..." In Hale \& Keyser's (1993) view, in an inner structure of VP, where V-PP constitutes a headcomplement relation, $\mathrm{P}$ is subordinate to $\mathrm{V}$; they assume that the notional type of $\mathrm{V}$ is dynamic event $(e)$, and the notional type of $\mathrm{P}$ is interrelation $(r)$. The semantics of the relation embodied in the $V^{\prime}$ ' is that of a dynamic event that implicates an interrelation; and "the most salient "meaning" attached to the structure is "change" (Hale \& Keyser 1993: 71). Kearns (2000: 201-204) views change as one of the three chief event characteristics (change, duration and bound) that determine the four event classes (state, achievement, activity/process and accomplishment). The fact that the notion of change is recognised as an important 'aspect' of linguistic description justifies the use of the term in the present work. The present work proposes to put the notion of change at centerstage in the discussion of the $v \mathrm{P}$-aspect of all types of BI predicates.

The notion of change is not discussed as the main topic in the afore-mentioned works (Tenny 1987, Dowty 1991, Hale \& Keyser 1993, Levin 1993, Voskuil 1996, Kearns 2000), yet it is considered important. Even when it is not mentioned (for instance in Croft 1998), the notion is - more or less - there, which can be made more visible. For instance, in proposing a "difference in degree of affectedness" that affects "objectoblique alternation", Croft (1998: 45) mentions "a movement of some sort" that is interpreted from the following example, (37b), but not from (37a).

(37)a. I shot the sheriff

b. I shot at the sheriff 
In (37a), according to Croft, the verb "includes successful contact with the target (the sheriff) as part of its meaning" and no such contact is interpreted from (37b): "Instead, its meaning more closely resembles that of fire - launch of the projectile" (my underline). This fire, according to Croft, occurs only in the construction (37b), as in (38).

(38) The troops fired *(on/at) the protesters.

According to Croft, the object the sheriff in (37a) is directly affected by the action, whereas in (37b) the sheriff receives a "lesser degree of affectedness" (Croft 1998: 44). The "launch of the projectile" is not discussed further, presumably because it is not considered important in English. The main focus of Croft's analysis of examples such as (37) and (38) is the object (the sheriff) and its alternant, the prepositional object (at the sheriff, on/at the protesters),

Two equally important points must be mentioned here.

Firstly, Croft argues that there is a movement of some sort in (37b) but not in (37a), and yet a "successful contact" with the target is interpreted for (37a). The question is, a successful contact between what? If there was something that moves in (37b) as Croft argues, then I shall point out, that there should also be one in (37a), otherwise one can further argue that it is impossible to have "a successful contact" without anything that moves, for it is understood that "something" hits the sheriff.

Expressions like in (37) also occur in BI. The BI equivalents of (37), however, do not show any change or movement, because, it is not realised morphologically, (39).

(39)a. Saya meN-tembak sheriff itu

$1 \mathrm{sg}$ ACT-shoot sheriff DEM 'I shot the sheriff'

b. SayameN-tembak ke arah sheriff itu

$1 \mathrm{sg}$ ACT-shoot to direction sheriff DEM

Lit. I shot towards/to the direction of that sheriff

'I shot at the sheriff' (cf. 'I shot a rubber bullet towards the sheriff', see (41a)) 
As mentioned before in the previous section, Section 2.3.1, in $\mathrm{BI}$, change - or other aspects - is realised morphologically on the predicate. No object that moves is mentioned, and no morphological realisation is shown in examples (39). The "conative preposition" (for instance, Levin's 1993: 42) ke arah, literally 'to direction', or, 'towards' - i.e., 'at' in the examples - only indicates the direction or orientation of the shooting.

Secondly, the notion of "successful contact" or "affectedness" may be useful for giving different interpretations between the objects of (37a) and (37b). However, the event of shooting itself is aspectually "complete", that is, having end-points, with or without any contact with the object. If "boundedness of the event" is the order of the day (cf. Tenny 1987, 1994, Arad 1998, Ritter and Rosen 1998, among others), then the "boundedness" of this particular event has nothing to do with "successful contact" or "affectedness". The following examples, examples in (40), use the adverbial tiga kali 'three times', to show that the event can be repeated regardless of contact. The intuition here is that an event can be repeated because it is bounded, i.e., it has end-points.

\section{(40)a. Saya meN-tembak sheriff itu tiga kali \\ $1 \mathrm{sg}$ ACT-shoot sheriff DEM three time \\ 'I shot the sheriff three times' \\ b. Saya meN-tembak ke arah sheriff itu tiga kali 1sg ACT-shoot to direction sheriff DEM three time \\ Lit. I shot towards/to the direction of that sheriff three times}

'I shot at the sheriff three times'

To show an aspect - or, conversely, if the information about the object that moves is of primary importance - the suffix - kan must be added to the predicate, $(41 \mathrm{a}, \mathrm{b})$.

(41)a. Saya meN-tembak-kan pelurukaret

1sg ACT-shoot-KAN bullet rubber

'I shot (with) rubber bullets three times'
a'. *Saya meN-tembak peluru karet
1sg ACT-shoot bullet rubber
'I shot the rubber bullet three times'

\section{tiga kali}

three time

tiga kali

three time 
b. Saya meN-tembak-kan pelurukaret kearah sheriffitu tiga kali

1sg ACT-shoot-KAN bullet rubber towards sheriff that three time

Lit. I shot rubber bullet towards that sheriff three times

'I shot (off/with) rubber bullets at the sheriff three times'

b'. *Saya meN-tembak-kan $\quad \underline{\text { ke arah sheriff itu tiga kali }}$
1sg ACT-shoot-KAN towards sheriff that three time
'I shot (with) (pro) at the sheriff three times'

In (41a) we have the information regarding something that moves, that undergoes change of location as part of the event of shooting, which, in this case happens to be peluru karet 'rubber bullet'. Should the notion of contact - or the lack of it - be needed, it is the contact between the rubber bullets and the sheriff, (41b). The use of kan-aspect requires that the argument that undergoes change be stated overtly, (41a') and (41b'), or, conversely, the appearance of this type of argument requires that the kan-aspect be used. The lack of change can be inferred, when kan-aspect is not used, like in expressions such as (39), and the English equivalents, (37), they are repeated here in the following, (42).

$\begin{array}{ccc}\text { (42)a. Saya } & \text { meN-tembak } & \text { sheriff itu } \\ 1 \mathrm{sg} & \text { ACT-shoot } & \text { sheriff that 'I shot the sheriff' }\end{array}$

b. SayameN-tembak ke arah sheriff itu $1 \mathrm{sg}$ ACT-shoot to direction sheriff that Lit. I shot towards/to the direction of that sheriff 'I shot at the sheriff'

In summary, when kan-aspect is present, an object, a specific type of argument is required. The specificity of this type of argument must be made clear: it undergoes change. In examples (41a) and (41b) above we have a change of location ("motionthrough-location", "translocation", and so on). Throughout this thesis, I shall use the term change to cover all types change: change of location, change of state (of psychpredicates, of common adjectives), reclassification of an argument, and so on. In addition, as a convenient term, I shall adopt Dowty's (1991) terminology: THEME will be used henceforth, instead of saying "an argument/object that undergoes change" every time we need to refer to the argument; PATIENT is for "an argument that is stationary and/or unchanged". 


\subsection{Summary}

This chapter claims that the BI predicate suffixes $-k a n$ and $-i$ realise a $v$ P-aspect, an abstract entity pertaining to a notional type category. Analysing the suffixes in terms of aspectual properties of events has the advantage of seeing them as having an individual function. The sole function is to mark, whether or not there is a change affecting the primary internal argument. The type of analysis suggested here captures the essence i.e., what the suffixes are all about - without giving the suffixes several different functions.

Not only does the $v \mathrm{P}$-analysis capture the generalisation regarding the predicate suffixes, it also gives us a very simple picture: kan-aspect selects a THEME, $i$-aspect a PATIENT. This type of analysis, however, should not be done only for BI. Comparing English with $\mathrm{BI}$ in terms of $v \mathrm{P}$-aspect, this chapter argues that what is not marked in English, and what is marked in BI, is in fact one and the same thing. In both languages $v \mathrm{P}$-aspect is best discussed notionally; v $\mathrm{P}$-aspect is notional because it is involved in determining the interpretation of notional type categories such as event, instance, state and relation.

I suggest in this chapter that the principle underlying the notion of $v \mathrm{P}$-aspect is not language specific. It is mentioned - albeit in passing - that the "causal relation" (Hale and Keyser 1993) / "causativization" (Lieber 1998, Farrell 1998), or the lack of it, by means of the suffixes is only one of the three strategies employed in the language, termed as morphological causation. The other two strategies are the syntactic/analytical and lexical causations.

An important part in the discussion is the distinction between an event that is temporally framed and one that is not: in BI, this distinction constrains the use of $v \mathrm{P}-$ external aspect MODALs, namely, when they are overt. An event is framed if it contains three parts: an initial endpoint, tempo (the length, time wise), and a final endpoint. This fact must be taken into account in explaining why certain MODALs are incompatible with the $v$ P-aspect (On the other hand, there must also be certain features of the MODALs 
themselves that constraint the co-occurrence, Chapter 5). Another important point is that the $v \mathrm{P}$-aspect also puts constraints on the process of raising an argument to the [SpecAspP] position. The "causal relation" - or the lack of it - carries along for each derivation (e.g., ACTIVE, PASSIVE etc.), for reason of convergence. Overall, the syntax as described in this chapter is sensitive to aspectual properties - or, the aspectual properties are encoded in the $(v \mathrm{P}$-internal) syntax. 


\section{Chapter 3:}

\section{Kan-aspect and Change}

\subsection{Overview}

The previous chapter, Chapter 2, claims that the BI predicate suffix -kan marks a $v$ Paspect, referred to as kan-aspect. The primary information given in an event involving kan-aspect is that the internal direct argument of the predicate undergoes change of some sort. For convenience, I have adopted the terminology used in Dowty (1991) and Hale \& Keyser (1993), namely, to call the argument that undergoes change THEME. In Chapter 2 , the notion of change is introduced, as a part of a causal relation, which means that with change, a cause is required in the event - either an AGENT or a 'real' CAUSE (CAUSER). The difference between the two is explained by determining whether or not the event is a result of an intention (volitional ACT), or just of some triggering cause (CAUSER), i.e., between the intent to bring about the event, versus something that happens to trigger the event.

The present chapter lists some types of change affecting the internal argument that is involved in the event structure with kan-aspect. The idea that the direct internal argument that participates in the event undergoes change holds through. The groupings of the similar types of argument and predicate in the following subsections are not intended to be viewed as an exhaustive list of variations, neither is the whole presentation to be viewed as a word taxonomy. In addition, one group may overlap with another. The aim is to see different kinds of possibility under the umbrella of kan-aspect. 
An interesting part of the data that follow are cases in which an expression that is included in the predicate itself may express the final destination of the object's movement, that is, if the object changes location. A different terminology that can be employed for this type of predicate is "denominal predicate" containing location.

Although the present work accepts that the suffix -kan may bear causativity, the data will show, however, that a predicate involved in change of state of the argument or, an adjective-derived predicate - in fact expresses the final state of the change imposed on the argument. This is on a par with our view that denominal predicates express the final destination of the change of location.

A denominal predicate may express final state, just like deadjectivals, although it may be only the view of the THEME argument that is changed, rather than the argument itself, such as to regard somebody or something as a god, as a father, a son, and so on, where in actual fact this person or thing is not such. The "change of view" of the THEME argument, however, occurs also in some deadjectivals, for instance, to regard somebody or something as stupid, great, small, and so on. For both, I use the term "reclassification" of argument. Thus we will conclude that there are two possible readings of final state: one that happens when the change of state of the argument itself is involved, and the other when it is only the view of the argument that is changed. The two readings are dependent on the argument that is involved.

What follows presents two major types of kan-predicate expressing change, according to whether the predicate is a derived one, i.e., a denominal, a deadjectival, or derived from some kind of functional element. I shall call this type "Change of Type1" (Section 3.2). "Change of Type2" (Section 3.3) lists variations involving verbs, of intransitive (unergative and unaccusative), transitive and ditransitive verbs. 


\subsection{Change of Type1}

This type of change occurs with derived kan-predicates: the predicate is derived from a noun (noun-based), an adjective (adjective-based), or a directional preposition. Included in the denominal groups are nouns that can occur as a location, namely, as a complement of a preposition $k e$ 'LOCATIVE to', relational nouns such as bapak 'father', pronouns, proper names. In the deadjectival groups we have kan-predicates expressing the emotion of the argument (usually human), like sedih 'sad', or emotion of/about a certain object (animate and inanimate objects) such as senang 'to like', as well as expressing the final state of the argument. By directional preposition I mean to include only those that contain modifications such as ke bawah 'to below/under' including 'downwards', ke atas 'to above', including 'upwards', ke samping 'to side', 'sidewards', and so on.

It is known in the literature, as outlined in Chapter 1, that the suffix - kan changes an item, such as a noun or an adjective, into a verb, thus - kan is a "verbaliser", or "verb converter" (for instance, Tampubolon 1983, Tarigan (1985), Sneddon 1996). Tarigan (1985) includes proper name (place names included), and numbers, in his examples of -kan affixation. As a part of my claim, I shall argue that this is not what the suffix is all about. The notion of change holds through, in fact, it can be seen more clearly with derived verbs, which I shall refer to henceforth as kan-predicates, because they must involve the suffix $-k a n$.

\subsubsection{The $k a n$-predicate expresses location as the final destination of the move/shift}

The final destination is expressed within the complex of the derived kan-predicate. These types of predicates are what Hale and Keyser (1993: 55) call "location verbs" which, they assume, are formed by incorporation (as in Baker's 1988 concept, where it is strictly a head movement process), and there is a grammatical function change in the process, namely, the change from a noun to a verb. ${ }^{1)}$

\footnotetext{
${ }^{1)}$ What Hale \& Keyser (1993) call "locatum verbs" (as against "location verbs" of this section) in BI occur with the other $v \mathrm{P}$-aspect, $i$-aspect. I return to this point in Chapter 4 .
} 
In the long form, (1), the predicate is masuk-kan 'to enter/PUT something into $x$ ' (where $x$, which in this case is buku 'book', as an enclosure) is the final destination (GOAL) of the translocation, indicated by the prepositional phrase with the preposition $k e$ 'LOCATIVE to' (as against kepada 'DATIVE to').

\section{(1) Masuk-kan pendapatan ke buku enter-KAN income to book '(To) Put/enter income in the book'}

In the concise form, as follows, (2), buku 'book', as the final destination, is expressed in the kan-predicate.

(2) Buku-kan pendapatan/pengeluaran book-KAN income/expenditure '(To) Put/enter income in the book'

Some other forms on the model of (2) such as shown in the following examples, (3), are similar to the English "location verbs".

(3)a. Penjara-kan semua pencuri/perampok/penjahat... jail-KAN all thieves/robbers/criminals... '(To) Jail all the thieves/robbers/criminals...'

b. Asrama-kan mahasiswaltentaralyatim-piatu... ashram-KAN students/soldiers/orphans... '(To) Put students/soldiers/orphans... in a dormitory (ashram)'

c. Kandang-kan kambing/ayam/babi... shed-KAN goat/chicken/pigs...

'(To) Put the goat/chicken/pigs... in the shed'

d. Makam-kan jenazah tomb-KAN corpse

'(To) Put the corpse in the tomb/cemetery', i.e., to bury the corpse

e. Sekolah-kan anak-anak school-KAN children

'(To) Send children to school' 


\section{f. Bank-kan uang \\ bank-KAN money}

'(To) Bank the money'

All the examples in (3) have an "analytical causal relation" (discussed briefly in Chapter 2), just like example (1). Namely, they all have masuk-kan 'enter', 'PUT in', alternants. ${ }^{2)}$ To see the pattern, applying to the forms in (3a-f):

\section{Long form:}
a. masuk-kan pendapatan
b. masuk-kan pencuri
c. masuk-kan mahasiswa
d. masuk-kan kambing
e. masuk-kan uang
f. masuk-kan jenazah

ke buku
ke penjara
ke asrama
ke kandang
ke bank
ke makam

Concise form:

buku-kan pendapatan

penjara-kan pencuri

asrama-kan mahasiswa

kandang-kan kambing

bank-kan uang

makam-kan jenazah

Here in (4) we have, for example, to put thieves in jail: masuk-kan pencuri ke penjara, or, jail the thieves: penjara-kan pencuri, (4b), the thieves move or are moved from outside to the inside of the jail.

We do not know where each argument in the above examples comes from, but the direction of the movement is indicated by the preposition that bears movement, $k e$ 'to' (i.e., not by the preposition $d i$ 'in/at'). The endpoint of the movement, which is indicated by the location above, is in fact the GOAL of the change of location/position. Here I use "GOAL" as a term to indicate the final location of the path of movement, i.e., as the event

\footnotetext{
2) The event characteristics of the above pairings (long versus concise forms) may differ, for instance, the event with masuk-kan 'enter', is primarily bounded, and the concise form is primarily un-bounded (although it can also be bounded). This is due, presumably, to the fact that the predicates are different: one has 'enter'/'put in', the other "contain" a location in the predicate. In addition, the concise form, but not the long form, may restrict the type of the argument that can be involved in. One can 'put in' anything that can be put in, or entered in, for instance, to put a child or a cat in an animal shed: masuk-kan anak/kucing ke kandang for whatever reasons; but we cannot shed them: *kandang-kan anak/kucing. Intuitively, the event in the first column is more specific in terms of what type of ACT is done, and the second column is more specific in terms of the argument that is usually involved in the event. However, I shall not be concerned with giving details of these semantic differences. 1 shall discuss the bounding of event in Section 3.3.3.2.
} 
terminus, as used by Tenny (1994). Perhaps this term can also be indicative of traditional "roles" of an argument, but at this stage this consideration is irrelevant here. The term is adopted from Tenny (1994), that in an event involving change of location, prepositions such as the BI ke 'LOCATIVE to', indicate the direction of change, and the prepositional object is the GOAL, which is the end-point of the aspectual path. Tenny (1994) discusses the aspectual path of English verbs such as give, pass, throw, put and so on. Since the present discussion is about the movement of an object (that undergoes change), I propose to extend her theory of aspectual path to cover a wider range of predicates, such as shown in our data.

The following expression, (5), occurs daily in the national papers of Indonesia.

(5) Jenazahtelah di-makam-kan pada tanggal (sekian) corpse PERF PASS-tomb-KAN on date (mention the date) "The corpse has been/was "tombed" (i.e., buried) on the (date)"

In keeping with the notion of change outlined in Chapter 2, we can see that in examples (3), (4) and (5) above, it is the argument of kan-predicates, such as pencuri 'thief', mahasiswa 'student', kambing 'goat', jenazah 'corpse', that undergoes translocation (from outside to inside), rather than penjara 'jail', asrama 'dormitory', makam 'cemetery', and so on.

This is different from Hale \& Keyser's (1993) analysis applying to English denominals, namely, to house the poor is to provide/give a house for/to the poor (or, to provide/give the poor with a house): the house changes hands/possessors. In $\mathrm{BI}$ one does not offer/provide/give a tomb/cemetery to a corpse, but rather, we put the corpse in the tomb, like in (5). The difference regarding which object is the moving participant in an event is crucial, especially in terms of the THEME-Object correlation in syntax. 


\subsubsection{The kan-predicate expresses the final form of the THEME}

The kan-predicate in (4a), buku-kan 'to put something in a/the book', can also occur in another type of change, namely to turn/make something into $x$, where $x$ is the final form, (6).

(6) Buku-kan cerpen/puise/artikel/essei...

book-KAN short stories/poems/articles/essays...

'(To) Make/compile short stories/poems/articles/essays... into a book'

In English this particular causal relation, as depicted in (6), is syntactic/analytical, as shown in the translation; expressions such as *to book the short stories are odd. Other cases of turning something into something else are shown in (7).

\begin{tabular}{|c|c|c|}
\hline $\begin{array}{l}\text { 7)a. Abu-kan } \\
\text { ash-KAN }\end{array}$ & $\begin{array}{l}\text { jenazah } \\
\text { corpse }\end{array}$ & '(To) Cremate the corpse' \\
\hline $\begin{array}{l}\text { b. Uang-kan } \\
\text { money-KAN }\end{array}$ & $\begin{array}{l}\text { cheque } \\
\text { cheque }\end{array}$ & '(To) Cash the/a cheque' \\
\hline $\begin{array}{l}\text { c. Materi-kan } \\
\text { material-KAN }\end{array}$ & $\begin{array}{l}\text { ide-ide } \\
\text { ideas }\end{array}$ & '(To) Materialise the ideas' \\
\hline
\end{tabular}

Beside (5), the following expression, (8), also occurs daily in the national papers of Indonesia.

(8)Jenazah akan di-abu-kan pada tanggal
corpse FUT PASS-ash-KAN on
'The corpse will be cremated on the (date)'

When a corpse is cremated, like in abu-kan jenazah 'to turn the corpse into ash', (7a) and (8), the change is not completed until the form of a dead human body completely, or almost completely, turns to ash. Here ash is the final form of change. It is a concise - and perhaps more euphemistic - turn of phrase, rather than saying 'burning the corpse until it turns into ash'. This type of kan-predicate is not solely the property of noun-based 
predicates; adjective-based predicates will be exemplified in Section 3.2 .5 as expressions of final state.

To have a change, sometimes the initial form does not exist, ada, (9), or, if it does, it is lost, or we are not aware of its existence, (10).

(9) Setiap akhir tahun mahasiswa meN-ada-kan pesta every end year student ACT-exist-KAN fiesta 'Every end of the year students organise a party'

(10) $\mathrm{Si}$ kecil meN-temu-kan mainan-nya (yanghilang)

ART small ACT-find-KAN toy-3sg (COMP missing)

'The child found his toy (that was missing)'

In (9), pesta 'fiesta, party' is turned from nothingness into existence. It is not that the party is changed from disorganised into organised as one might interpret the English translation (as in "to organise my room", "to organise my life" and so on). In some sense, what is found when it has been missing, (10), also undergoes change into existence. The inverse of (9) would be (11), where the change is from existence to non-existence, using the negative phrase tidak ada (ti.ada), 'does not exist'.

(11) MeN-ti.ada-kan

kemiskinan/dana...

ACT-NEG.exist-KAN poverty/fund...

'(To) Eliminate/cancel/get rid off poverty/funds...'

Sometimes, the change, as part of making or turning something into something else happens only in our perception, namely, we only regard, or treat something or somebody as $x$. In actual fact the person regarded as $x$ is not $x$, and thus the initial form is retained, as in the section that follows.

\subsubsection{The kan-predicate expresses reclassification of the THEME}

When something or someone as an argument is regarded, or treated as something or someone else, the implication is that this thing or person is not actually changed physically. However, there is a sense that the argument undergoes change, from the 
actual object, or, the object in reality, to the perceived one, as well as a sense of before and after the change of perception. ${ }^{3)}$ For instance, to regard a person or money or other substances as a god is to apply whatever the characteristics of god to the person, money or substances.

\section{(12)a. Long form:}

anggap seseorang regard somebody sebagai dewa
as $\operatorname{god}$

\section{Concise form:}

dewa-kan seseorang

god-KAN somebody

\section{b. The forms in a sentence:}

b'. Orang desa di Jawa sering [meN-anggap wayang sebagai dewa] person village in Java often ACT-regard puppet as god

'Villagers in Java often regard puppets as gods'
b". Orang desa diJawa sering [meN-dewa-kan wayang] person village in Java often ACT-god-KAN puppet 'Villagers in Java often regard puppets as gods'

The pattern is consistent, as shown in (13): under the A column are the long forms; column B lists the concise forms.

A

a. anggap $X$ regard $X$

sebagai dewa

as $\operatorname{god}$

b. anggap $X$ sebagai anak-emas

c. anggap $X$ sebagai anak-tiri

d. anggap $X$ sebagai nomer-satu
B

dewa-kan $X$

god-kan $X \quad$ 'to regard $X$ as (a) god'

anak-emas-kan $X$

anak-emas, 'beloved child'

anak-tiri-kan $X^{4)}$ anak-tiri, 'step

child'

nomer-satu-kan X nomer-satu, 'number

one'

3) What is suggested here is that the THEME is "perceived as" something else, hence the term "reclassification", although the change on the part of the external argument may be implicated.

4) Due to its "un-PC-ness" (i.e., not every parent is the same), the use of this predicate within families is discouraged, especially within those with step children, although a blood-child may complain as being treated as a step child:
Saya selalu di -anak-tiri-kan (oleh ayah)
1 sg always PASS-child - step-KAN (by father)
'My father always treats me like (I was) a step child' 

e. anggap $X$ sebagai nomer-dua
f. anggap $X$ sebagai Tarigan
nomer-dua-kan $X \quad$ nomer-dua, "number two'
tarigan-kan $X$
Tarigan, a person's
name
g. anggap X sebagai Saddam Hussein saddam-hussein-kan X Saddam Hussein, a person's name

Whatever is the most prominent characteristic of a god is applied to $X$; and whoever regards the object money or puppets as a god must have some degree of respect for money or puppets, in a manner resembling the way people respect gods. Anak-emas, literally 'golden child', i.e., the most loved child, may get whatever he/she wants. In a situation where $X$ is one of the many workers, such as in a factory environment, anakemas-kan $X$ can be interpreted as $X$ gaining the most favour from the person who has the power in that factory. Conversely, as an object that is perceived as anak-tiri 'step child', in anak-tiri-kan $X, X$ will have difficulties finding a favour in comparison with the other workers. Tarigan as a person may have a silly or funny personality, thus tarigan-kan $X$ implies that $X$ is regarded as silly or funny just like the person Tarigan. ${ }^{5)}$ The same explanation applies also to saddam-hussein-kan. Thus, each predicate in B column expresses likeness that can be applied to the object $X$, making $X$ god-like, Tarigan-like and so on, where the initial state of $X$ is retained. ${ }^{6}$ ) The final state, however, becomes analogous to the expression within the predicate.

This analogous expression also appears in English. For instance, in an article entitled "Izationization", Safire (1991) describes similar occurrences to those exemplified in (13) as "ugly but necessary", referring to "the creation of lengthy nouns out of shorter words by adding-ization", such as in (14).

\footnotetext{
5) Tarigan's (1983) own example and explanation.

6) This is different from de-adjectival panjang-kan $X$ 'to lengthen $X$ ', where $X$ BECOMES
long, although some de-adjectival predicates behave similarly:
}

(i). Kesan saya John tidak begitu pandai 'John strikes me as (being) not very bright'

(ii). Saya menganggap John tidak begitu pandai 'I regard John as (being) not very bright'

(iii). Saya menidakbegitupandaikan John 'I regard John as (being) not very bright'.

I return to this point in Section 3.2.6.2. 
In Safire's analysis:

(14)a. Vietnamization as in 'the Vietnamization of Lebanon'

(i.e., Israel removed its troops from Lebanon) is analogous to the process of Americans withdrawing from Vietnam;

b. Lebanonization as in 'the Lebanonization of Lebanon'

(i.e., returning Lebanon to the Lebanese) is analogous to the returning of Vietnam to the Vietnamese;

c. Saddamization as in 'Saddamization of Iraq', is different from 'Lebanonization of Iraq'. The former gives a sense 'to let all Iraq be taken under Saddam's wings', including the Kurdish and the Shiite. The latter is analogous to Vietnamization (of Vietnam or Lebanon).

The term Lebanonization does not have the same meaning as Balkanization, because the latter means 'taking a country and splitting it into parts.' Nevertheless this 'meaning' is derived from what has happened in the Balkans. Whichever the intended 'meaning' is, the characteristics of one object can be applied to another. For instance, to Balkanise X (a country) means to split $X$ into small countries, because that is what is understood to have happened in history.

Since this type of 'ization' process cannot occur without the 'ize' process being applied first (in Selkirk's 1982 terms), I shall assume that the first step, namely, the affixation of -ize to the base is acceptable. This assumption is also supported by the occurrence of the verb sodomise (from Sodom, a city in the Old Testament of the Bible), as in 'to sodomise somebody'. The result, (15), is similar to the occurrences shown in (13) above.

to Vietnamise Lebanon

to Lebanonise Lebanon

to Balkanise The USA

to sodomise somebody 
The interpretation of (15) may depend on the reader's/hearer's knowledge of the world, for instance, as to what he/she knows about Vietnam, Lebanon, the Balkans, or Sodom, in the same manner as for the interpretation of the predicates in column B in (13). The process of change as a reclassification is included in this knowledge, as to how and why $X$ comes to be perceived or treated as god-like, Vietnam-like, and so on.

To summarise, likeness of an object can represent the final state of change of what is perceived of another object. This likeness is expressed in some kan-predicates of $\mathrm{BI}$, and to some degree in the English examples in (15). What follows is likeness of a different kind, namely, of a manner, the way an object moves.

\subsubsection{The kan-predicate with a manner component}

The predicates in this group contain a manner component, namely, how a particular object moves or is moved, including how a certain instrument is used. In particular, it is the movement itself that is completely expressed in the predicate. We also have, in this sub-section, the distinction between movements involving an instrument (other than body parts) and movements involving only body parts, such as, usap-kan sapu-tangan ke dahi 'stroke (a) handkerchief against/to forehead', as against elus-kan/belai-kan tangan ke dahi 'stroke (a) hand to forehead'. While the preceeding sub-section shows examples of reclassification of an object that is derived from some characteristics of another object, this sub-section shows more specific characteristics, namely, the manner in which a certain object moves or is moved.

An example of such movement is derived from an object called tusuk, which also includes any objects that have the shape of a pin, i.e., sturdy, sharp, usually used in stabbing motion until it pierces (Kamus Lengkap 1980, 'Complete Dictionary', KL henceforth); size irrelevant, for example pin, meat skewer, knife, spear, sword... giving rise to tusuk-kan, 'to jab, to stab, to pierce'. ${ }^{7}$ )

\footnotetext{
7) I include to pierce here because the verb contains a movement similar to that of to stab, although it may have an additional characteristic, such as whether or not the instrument (the object that moves) goes right through the other object that is pierced, as described by Gruber $(1970: 11,13)$.
} 
Other examples include lambai 'movement of sweeping motions', used as in (English) waving a hand (as against waving at somebody). We can imagine how a hand moves as we are cleaning, for instance, a wall mirror or windows (wipe, sweep). What can usually be described having this type of movement are hands, trees, paddy-rice, the wilderness, handkerchiefs and so on. When we wave a hand or a handkerchief at somebody, there is no contact that can be interpreted, between the hand (or the handkerchief) and the person who is waved at. The lack of contact can be explained in the same way as to kick at the door or to shoot at the sheriff discussed in Chapter 2, Section 2.4. Recall that the so-called contact reading is in fact the contact between THEME and the prepositional object. It is the contact between my foot, the bullet, as a THEME, and the door, the sheriff, as an "oblique" (in Croft's 1998 terms). However, the notion of contact is reducible; it is only a part of the interrelation between the THEME and the Object of the PP (Chapter 2, Section 2.3.1).

English expressions like to kick (at) the door and to shoot (at) the sheriff, for example, do not include the THEME (which is understood to be a foot and the bullet, respectively). However, in the English examples below, (16) and (18), which are taken from Rappaport Hovav and Levin (1998:97-99), a THEME can be expressed overtly, although as we will see, in the BI counterparts, (17) and (19), the kan-aspect cannot be used. $^{8}$ )

(16) English:

a. ?Terry swept.

b. Terry swept the floor.

c. Terry swept the crumbs into the corner.

d. Terry swept the leaves off the sidewalk.

e. Terry swept the floor clean.

f. Terry swept the leaves into a pile.

${ }^{8)}$ Example (16a) and the BI counterpart (17a) are actually only marginally acceptable. The BI example is rescued by a progressive MODAL, (20). 
With the kan-aspect, the inclusion of THEMEs such as the crumbs (16c) and the leaves $(16 \mathrm{~d}, \mathrm{f})$ creates confusion in BI, because these arguments are then used as/treated as/regarded as sapu 'broom', or lap 'rag' $(17 \mathrm{c}, \mathrm{d})$.

(17) BI:
a. ?Terry meN-sapu
$\mathrm{T}$ ACT-broom
'Terry broomed'
b. Terry meN-sapu lantai itu
$T$ ACT-broom floor DEM
'Terry broomed that floor'

c. Terry meN-sapu(-*kan) remuk-an roti kesudut

T ACT-broom(-KAN) crumb-NOUN bread to corner

'Terry broomed the bread crumbs to the corner'
d. Terry meN-sapu(*-kan) daun-daun ke samping jalan
$\mathrm{T}$ ACT-broom(-KAN) leaf-pl to side walk-way
'Terry broomed the leaves off the sidewalk'

e. Terry meN-sapu bersih lantai itu

$\mathrm{T}$ ACT-broom clean floor DEM

'Terry broomed clean the floor'
e'. *Terry meN-sapu lantai itu bersih
$T$ ACT-broom floor DEM clean
'Terry broomed that floor clean'

$\begin{array}{cllll}\text { f. Terry } & \text { meN-sapu-(*-kan) } & \text { daun-daun } & \text { meN-jadi } & \text { tumpuk-an } \\ \text { T } & \text { ACT-broom-KAN } & \text { leaf-PL } & \text { ACT-become } & \text { pile-NOUN }\end{array}$

'Terry broomed the leaves into a pile"
f'. Terry meN-tumpuk-kan daun-daun
$T$ ACT-pile-KAN leaf-PL
'Terry piled the leaves'

(18) English:
a. ?Terry wiped.
b. Terry wiped the table.
c. Terry wiped the crumbs into the sink.
d. Terry wiped the crumbs off the table.
e. Terry wiped the slate clean.
f. Terry wiped the crumbs into a pile.

The pattern is consistent, of $(17 \mathrm{c}, \mathrm{d})$ above and $(19 \mathrm{c}, \mathrm{d})$ below: these examples have the same problem. 
(19) BI:

$\begin{array}{cc}\text { a. *Terry meN-lap } & \text { ('mengelap') } \\ \mathrm{T} & \text { ACT-rag } \\ \text { 'Terry ragged' } & \end{array}$

b. Terry meN-lap meja

$\mathrm{T} \quad$ ACT-rag table

'Terry ragged the table'

c. Terry meN-lap(*-kan) remuk-an roti kebasin

$\mathrm{T}$ ACT-rag-KAN crumb-NOUN bread to sink

'Terry ragged the bread-crumbs to the sink'

d. Terry meN-lap(*-kan) remuk-an roti dari meja

$\mathrm{T}$ ACT-rag-KAN crumb-NOUN bread from table

'Terry ragged the bread-crumbs off the table'

e. Terry meN-lap bersih lempeng-an itu

$T$ ACT-rag clean slate-NOUN DEM

'Terry ragged clean the slate'

e'. *Terry meN-lap lempeng-an itu bersih

T ACT-rag slate-NOUN DEM clean

'Terry ragged the slate clean'

f. *Terry meN-lap-(*-kan) remuk-an roti menjadi tumpuk-an

T ACT-rag-KAN crumb-NOUN bread ACT-become pile-NOUN

'Terry ragged the bread crumbs into a pile'

f'. Terry meN-tumpuk-kan remuk-an roti

$T$ ACT-pile-KAN crumb-NOUN bread

'Terry piled the bread-crumbs'

Thus, in BI, if the kan-predicate "contains" an instrument, such as meN-sapu-kan "to broom', $(17 \mathrm{c}, \mathrm{d})$ and meN-lap-kan 'to rag', $(19 \mathrm{c}, \mathrm{d})$, the movement applies to the instrument (the broom and the rag), rather than to the direct internal arguments the leaves and the crumbs.

With the kan-aspect such as in meN-sapu-kan 'to broom' (and meN-lap-kan 'to $\operatorname{rag}^{\prime}$ ), the direct internal argument lantai 'floor' (20b') below may also have a THEME interpretation. Thus, if this object - which is not supposed to undergo a translocation must appear, the kan-aspect must not be used. 
(20)
a. Terry *(sedang) meN-sapu
$T$ PROG ACT-broom
'Terry is brooming'

a'. *Terry (sedang) meN-sapu-kan

$\mathrm{T}$ (PROG) ACT-broom-KAN

'Terry is brooming'

b. Terry meN-sapu lantai

$\mathrm{T}$ ACT-broom floor

'Terry broomed the floor' i.e., 'Terry swept the floor (with a broom)'

b'. *Terry meN-sapu-kan lantai

T ACT-broom-KAN floor

'Terry broomed the floor on/against something' i.e., 'Terry used the floor as a

broom?

Although the English verbs to sweep and to wipe in the above examples, (16) and (18), are said to "'lexicalize' the manner in which the action denoted by the verb is carried out" (Rappaport Hovav and Levin 1998: 100), they are different from the predicates in the BI analysis, namely for the BI events of sweeping and wiping. In BI, activities such as sweeping and wiping, i.e., cleaning activities, require the inclusion of an instrument: sapu 'broom', for (17), and lap 'rag', 'cloth', for (19). In fact, the instrument itself is expressed in the predicate, (20). Example (20a') shows that with the kan-aspect a direct object is required, and yet, (20b') is unacceptable.

The unacceptability of the sentence (20b') above can be related to the analogy discussed in the preceding section, section 3.2.3. To treat (or to regard), and use lantai 'floor', as a broom for cleaning purposes would be unimaginable. The same reasoning goes also for the crumbs and the leaves as in (17) and (19). Consequently, in BI, the rest of the examples, examples (c)-(f) of (16) and (18), must be paraphrased using the appropriate predicates. Although I agree that the variation illustrated in (16) and (18) "is not associated with individual verbs, but rather with entire semantic classes of verbs" (Rappaport Hovav and Levin 1998:99), I shall emphasise that for BI, what Rappaport 
Hovan and Levin call "range of contexts" (referring to each group of examples included in (16) and (18)), in fact requires several different paths of derivation, which, in effect, involves different $v \mathrm{P}$-aspects. But for now, it must be noted that the objects the crumbs and the leaves in the above examples cannot appear when the kan-predicate 'contains' instruments like sapu 'broom', and lap 'rag', like in examples $(17 \mathrm{c}, \mathrm{d}, \mathrm{f})$ and $(19 \mathrm{c}, \mathrm{d}, \mathrm{f})$. Otherwise as THEME arguments they give the interpretation along the lines of to wipe the table with the crumbs $(19 \mathrm{c}, \mathrm{d}, \mathrm{f})$, and to sweep (aside) the path with the leaves $(17 \mathrm{c}, \mathrm{d}, \mathrm{f})$, which is the correct full interpretation of the arguments as instruments.

To conclude, what we see here is that the manner in which the direct internal argument moves must match the manner of instrument expressed within the predicate. In other words, the object must be able to be used as an instrument in the same MANNER as that in which the instrument which is expressed in the predicate is usually used, (21b) and (22b).

$$
\begin{aligned}
& \text { (21)a. (=20b)*Terry meN-sapu-kan lantai } \\
& \mathrm{T} \text { ACT-broom-KAN floor } \\
& \text { 'Terry broomed the floor against something' } \\
& \text { i.e., 'Terry used (the) floor as a broom' }
\end{aligned}
$$
b. Terry meN-sapu-kan sapu-ijuk ke lantai $T$ ACT-broom-KAN broom (palm-fibre) to floor 'Terry swept (a) palm-fibre broom against the floor'

(22)a. (=21b) *Terry meN-lap-kan meja

T ACT-rag-KAN table

'Terry ragged the table against something'

i.e., 'Terry used the table as a rag'
b. Terry meN-lap-kan kain basah ke meja $\mathrm{T}$ ACT-rag-KAN cloth wet to table 'Terry wiped (a piece of) wet cloth against the table'

To put it simply, sapu-ijuk 'broom made of palm-fibre', is used as a sapu 'broom', for sweeping the floor, (21b), and kain basah 'wet cloth', is used as a lap 'cleaning rag', for 
wiping the table, $(22 \mathrm{~b})^{9)}$. In summary, the THEME is an instrument, a family member of that expressed within the predicate (see also the section that immediately follows, 3.2.4.1: Instruments expressed by the predicate).

The behaviour of the English sweep and wipe of the examples in (16) and (18) above is typical of verbs of what Rappaport Hovav and Levin call "surface contact through motion" (Rappaport Hovav and Levin 1998: 99). I shall emphasise that for BI, the "motion" is expressible in the predicate itself, and the "contact" is primarily between the instrument used (sapu 'broom', and its family; lap 'rag', and its family) and the "surface". As it happens, the crumbs, the leaves, 'intervene' with this contact. However, the objects the crumbs, the leaves, may be included as part of objects that move, namely, together with the instrument used in the wiping or sweeping, or otherwise as part of the stationary object (because the crumbs are already there on the table before the event of wiping, and the leaves are already there on the path before the event of sweeping).

We now return to the topic of sweeping motions, lambai (these motions, and the rest of the examples that follow are included in paradigms (23)). In BI, when the same movement with sweeping motions is applied to a contact situation, namely between the THEME and the prepositional argument, a different lexical item is used instead: usap 'sweep/wipe, with a contact', like in English to sweep the floor, to wipe the table/windows/his forehead. The contact may be between the instrument used, and the surface. However, for belai, or elus 'stroke', a similar predicate containing manner of movement to usap 'sweep/wipe' also occurs, except with belai or elus 'stroke', an instrument used to sweep with or to wipe with cannot occur. The contact is strictly between the hand - which can also be viewed as an instrument - and the surface of an

\footnotetext{
9) Redundant expressions such as following examples are unheard of, although not unacceptable.

(i). Terry meN-sapu-kan sapu ke lantai T ACT-broom-KAN broom to floor 'Terry broomed a broom against the floor'

(ii). Terry meN-lap-kan lap ke meja T ACT-rag-KAN rag to table 'Terry ragged a rag against the table'.
} 
object (see manner movements of body parts in the sub-section that follows, Sub-section $3.2 .4 .2)$.

Different from English, in BI, the waving motion is used to describe something else that can move or is moved in a manner resembling the movements of sea waves (or, undulation). Sounds, speeches, a song, paddy rice, wilderness are amongst objects that are understood to make wave-like movements in the same manner as sea waves. The waving movement, alun, however, is understood to cover only horisontal-plane waves, thus, resulting in vertical waves. Presumably that is why expression such as the English to wave a hand does not occur in BI: *meng-alun-kan tangan (ACT-wave-KAN hand). Flags, banners, dancers, are amongst things that can be described as objects that undulate in a vertical-plane (horizontal waves); the kan-predicate used is kibar-kan: kibar-kan bendera, 'wave (a) flag'.

All those motions: stabbing, sweeping, wiping, waving and so on can be included in the following paradigms, (23), with some examples of usage within a sentence, (24). In sentence (24c) the slogans move around (and around) so that they can be 'heard afar', just like sounds that are 'resonant'.

(23) Paradigms
A. Manner
B. THEME

a. tusuk (stabbing motion is used)
tusuk-kan
jari/pensil/jarum/pisau/pedang/bayonet/tombak....
stab-KAN finger/pencil/needle/knife/sword/bayonet/spear...
b. ayun (swinging motion) ayun-kan swing-KAN

kaki/pedang/sabit/langkah...

legs/sword/sickle/foot-step...

c. kumandang (goes around in resonance, 'heard afar')
kumandang-kan
slogan-slogan/ajaran/ide-ide/caci-maki...
resonant-KAN
slogans /teaching/ideas/swear-words...

d. lambai (sweeping motion without contact)
lambai-kan
tangan/sapu-tangan...
wave-KAN
hand/handkerchief... 
e. usap (sweeping motion with contact) usap-kan jari/tangan/sapu-tangan..

wipe-KAN fingers/hand/handkerchief...

f. belai/elus (sweeping motion with contact) $\begin{array}{ll}\text { belai-kan } & \text { jari/tangan (no other instruments intervene) } \\ \text { stroke-KAN } & \text { fingers/hand }\end{array}$

g. putar (turning around, rotating motion) $\begin{array}{ll}\text { putar-kan } & \text { radio/televisi/gramaphone/cassette... } \\ \text { rotate-KAN } & \text { radio/television/gramaphone/cassette... }\end{array}$

h. balik (turning around, the opposite direction of putar) putar-balik turn around, turn back around putar-balik-kan keadaaan'fakta/bukti.. turn around-KAN reality/fact/proof...

(24)

a. Komandan pelatih meN-tusuk-kan pensil ke dada boneka commandant trainer ACT-stab-KAN pencil to chest doll 'The trainer commandant stabbed a pencil to the doll's chest'
b. Pendudukdesa bersama-sama meN-ayun-kan kaki meN-tinggal-kan inhabitant village together ACT-swing-KAN leg ACT-leave-KAN desa/village

'The villagers left the village simultaneously' (i.e., they swung their legs together)

c. Para demonstran meN-kumandang-kan slogan-slogan di depan parlemen pl. protester ACT-resonance-KAN slogan-PL in front parliament 'The protesters shouted/sang/chanted slogans in front of the parliament'

Although the physical shape of an object in all our examples above, from (17) to (24), may play a part in the combination of kan-predicate and its THEME, what is more important is the manner, how the object moves or is moved. This is apparent from additional examples that follow.

The following examples show the occurrence of kan-predicates with two types of mass noun: one type is that of liquid or semi-liquid (e.g., air 'water'), the other is of grains (e.g., padi 'rice'). The English translation is kept literal, which may sound rather unusual in some cases. 
The examples in (25a) and (26) show objects that usually have some kind of liquid form, because the movement is that of liquids. This manner of movement can be used metaphorically to describe the movement of other objects, for instance, (25b).

(25)a. Tiba-lah waktu-nya petani meN-alir-kan air kesawah arrive-EMP time-3sg farmer ACT-flow-KAN water to rice-field 'The time has arrived for farmers to flow the water into the rice-field' (i.e., to irrigate the field)

b. Di masa krisis, siapa-pun boleh meN-alir-kan lalu-lintas kota in time crisis, who-PI allow ACT-flow-KAN traffic city 'During the crisis, anyone was allowed to flow the city traffic'

(26) Paradigms

\section{A. Manner}

a. alir (flowing motion)

alir-kan

flow-KAN

\section{B. THEME}

air/minyak/air-mata/lalu-lintas/manusia... water/oil/tears/traffic/humans...

b. salur (flowing motion through a channel)

salur-kan

channel-KAN air/minyakide-ide/tenaga/dana/bantuan asing... water/oil/ideas/energy/funds/foreign aids...

c. tuang (movement of object being poured)
tuang-kan
air/kopi/cat/beras//ajaran...
pour-KAN
water/coffee/paint/rice/teachings...

d. siram (splattering, showering motion)
siram-kan
air/cat/minyak/kata penghiburan...
shower-KAN
water/paint/oil/comforting words...

e. semprot (motion of spraying objects: liquids, semi-liquids including gas) semprot-kan air/ludah/cat/obat-nyamuk/aerosol/caci-maki... spray-KAN water/spittle/paint/mosquito-repellent/airfreshener/swear-words...

f. sembur (the same as semprot, except with a strong gush/blast) 
sembur-kan

blast-KAN

g. tetes (dripping of liquid)

tetes-kan

drop-KAN air/ludah/tawa/amarah..

water/spittle/laughter/scoldings...

h. ciprat (sprinkling of liquid, not of particles like black pepper or salt)

ciprat-kan

sprinkle-KAN air/air-mata/obat-mata...

water/tears/eye-lotion...

Predicates like those grouped in (26) involve an incremental THEME. To repeat the event, a 'different load of object' is required. Thus, they are different from those of the (23) group, where the same THEME is involved in the same event. The events of group (23) are self-bounding, like 'kicking' and 'shooting' mentioned before, regardless of whether or not there is any contact that can be implied. But then, contact, or the lack of it, is context dependent for group (26). The contact between "the object" and "the oblique" (as argued for by Croft 1988) - i.e., between the THEME and the prepositional argument - is readable only when the prepositional phrase appears. Expressions involving predicates like alirkan air (ke sawah) 'to flow water (to the field)', tetes-kan obat (ke mata) 'to drop lotion (to the eyes)', are in fact complete even without the prepositional phrase that contains a goal: ke sawah 'to the field', or ke mata 'to the eyes'.

Notice that air 'water', as an object that moves, is readily available to use as a predicate to represent all the movements of liquids as exemplified in (26). Although BI has air 'water', functioning as a predicate, $i$-aspect is involved: air- $\boldsymbol{i}$, but not *air-kan. When we want to have an event of watering with kan-aspect, it is the manner in which the water moves that must be expressed within the predicate, namely, a manner that can be selected from group (26). Thus, the English expression 'to water the plants' has the BI equivalent as follows, (27).

(27) Sudah waktu-nya kita 
In (27) we have tanaman 'plants', as a stationary object, and air 'water', the THEME, is expressed in the predicate itself. We come back to this issue in Chapter 4. To have air 'water', as a THEME complement, a wide range of manner predicates is available for selection, as grouped in (26) above, depending on how we water the plants, i.e., how the water moves until it reaches the plants, (28).

meN-alir/salur/tuang/siram/semprot/tetes/ciprat...-kan air ke tanaman ACT-flow/channel/pour/spray/drop/sprinkle... -KAN water to plants 'to flow/channel/pour/spray/drop/sprinkle water to the plants'

There is yet another group that can be added, (29) and its paradigms, (30). This group requires that the object be non-liquid. The predicates express the manner of movement, similar to the predicates in (26).

(29)a. Begitu hujan turun, petani meN-tabur-kan benih padi that rain descend farmer ACT-sprinkle-KAN seed rice 'As soon as the rain falls, the farmers sow the rice (seeds)'

b. Tabur-kan sedikit gula setelah kuah-nya mulai meN-kental sprinkle-KAN a little sugar after gravy-3sg begin ACT-thick 'Sprinkle a little (of) sugar after the gravy begins to thicken'

c. Sebar-kan beritagembira ini ke desa-desa spread1-KAN news glad this to village.PL 'Spread this good news to villages?

d. Oles-kan selai ke roti bakar setelah margarine spread2-KAN jam to bread toast after butter 'Spread jam on toast after (you spread) the butter'

(30) Paradigms

For predicates tabur/sebar/oles/rontok/lempar... 'sprinkle/spread1/spread2/fall/throw...'

\section{A. Manner \\ B. THEME}

a. tabur (sprinkling motion of solid objects) 
tabur-kan

sprinkle-KAN

b. sebar (spreading motion)

sebar-kan

spread1 benih, garam, tepung, abu...

seeds, salt, flour, ash...

benih, berita, isu-isu...

seeds, news, issues...

c. oles (spreading motion of semi-solid objects)

oles-kan

spread2

margarine, selai, gincu...

butter, jam, lipstick...

d. rontok (falling motion of plural objects)

rontok-kan

fall-KAN, drop kelapa, mangga, daun, gigi, rambut ... coconuts, mangoes, leaves, teeth,

hair...

e. lempar (motion unspecified, but there is an element of speed)

lempar-kan

throw-KAN

f. luncur (smooth motion, with trajectory)

luncur-kan

launch-KAN apa saja/senyuman pandangan..

throwables/grins/look...

kapal/rudal/rocket...

ship/guided missile/rocket...

Within this group, (30), oles 'spread2', (30c), is used only for semi-solid objects, like butter, jam, oil, mud, lipstick, etc., while rontok 'fall', sebar 'spread1', tabur 'sprinkle', occur only with plural objects such as fruit, hair, teeth and so on. Lempar 'throw', (30e), requires a distance (albeit relatively), and luncur 'launch', (30f), contains smoothness of the movement. While tuang-kan 'pour', (26c), can occur with both water and grains, the rest are not interchangeable: namely, kan-predicates that normally occur with a THEME that is liquid, (26), cannot be used for grains, or grain-like objects, (30), and vice-versa. However, what is more important is the manner, how the object moves or is moved is expressed by the kan-predicate. This seems right, because the manner of flowing, for instance, can also be used metaphorically to describe what seems unlikely, such as, lalulintas 'traffic', manusia 'human', as shown in (25b) and (26a). 
In summary, two points can be noted from examples (23) - (30). The first point is that the path of change is not always straight. The THEME moves in a manner so described by the predicate; and manner varies, as exemplified. The second point is that a particular manner of movement pertaining to a certain object can be applied to another object, as exemplified in the previous section, Section 3.2.3, namely, the characteristic of a particular object is applied to another. The analogy still holds through, shown in the following two sub-sections: Section 3.2.4.1 gives us examples of instruments that are expressed by the predicate, and objects that can be considered as 'part of' the instrument (as "part-whole" relation, including "cognate objects"); Section 3.2.4.2, which is closely related to manner of movement, describes body parts that are used as instruments including "body parts" of an instrument such as a broom.

\subsubsection{Instruments ${ }^{10)}$ expressed by the predicate}

Some instruments that are expressed by/in the kan-predicate have a range. The THEME that immediately follows this type of predicate must be within the range of this 'instrument-predicate'. Two kinds of part-whole relation will be shown: class/family membership (the present section) and bodypart of AGENT (next section, 3.2.4.2). To start with, we return to Rappaport Hovav and Levin's (1998) examples. We will see that their examples are problematic for the BI kan-aspect analysis.

I mentioned in the previous section, Section 3.2.4, that in BI, activities like sweeping and wiping, i.e., cleaning activities, require the inclusion of an instrument, such as for instance, sapu 'broom', and lap 'rag', 'cloth'. In fact, the instrument itself is expressed by the predicate, (31) and (32) below. I concluded, that the THEME is "cognate" with the predicate through MANNER, meaning, the object must be able to be used as an instrument in the same manner the instrument expressed in the predicate is usually used, as in the examples (21) and (22), repeated here as (31) and (32).

\footnotetext{
10) These are instruments in the real sense, and thus not intended to be an indication of any thematic role. In addition, one may consider water, hands, feet, and so on, used in the previous sub-sections, to be instruments. No formal definition of the term is provided.
} 
(31)a. *TerrymeN-sapu-kan lantai

$T$ ACT-broom-KAN floor

'Terry used (the) floor as a broom'

b. Terry meN-sapu-kan sapu - ijuk ke lantai

T ACT-broom-KAN broom (palm-fibre) to floor

'Terry swept (a) palm-fibre broom against the floor'
(32)a. *Terry meN-lap-kan meja
$T$ ACT-rag-KAN table
'Terry used the table as a rag'

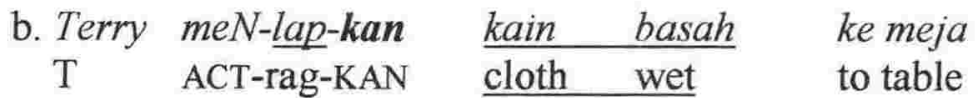
'Terry wiped (a piece of) wet cloth against the table'

It was concluded in Section 3.2.4 that the THEME in these cases is an instrument, a family member of - i.e., 'part of' - the instrument expressed in the predicate. ${ }^{11)}$ In this case, manner is relevant for the discussion: the manner in which an instrument is usually used is applied to another instrument that can be used similarly. Here we have the treatment of a certain object that is 'used as', rather than a mere 'regarded as' (recall Section 3.2.3). It must be noted, however, that most objects that can be used as instruments can be expressed in the predicate, but not many can be involved with kan-aspect, because only a few are members of the class/family. And some families have more members than others, (33). As compound words, some may indicate 'made of', while others 'made for' relations.

11) Notes on the notion:

(i) This is not the same as the term 'cognate object' as defined, for instance, by Crystal (1991), Trask (1993), (1997), Asher (ed.) (1994), Bussmann (1996), Matthews (1997) (although it may also cover cognate objects).

(ii) The definitions - with slight variations - given by those cited in (i) include primarily the semantics of the 'direct object', which is related to the verb. However, their examples use nouns bearing the same roots with the verbs, and the noun phrases contain some sort of modifier. Furthermore, the verbs are all intransitive, and the cognate objects 'cannot be passivized' (e.g., Bussmann (1996: 79), and the reference cited in there).

(iii) The term 'part-whole relation' as used in the present work explains the semantic relation between the kan-predicate and the direct internal argument (which is necessarily the THEME). The THEME in part-whole relations 'can be passivized', to use Bussmann's (1996) term, and the predicate involved, because it is a kan-predicate, is not intransitive. 
Instrument $\quad$ Class/family membership

a. sapu 'broom', ' $b$ ' the family of sapu (all types of broom):

sapu-lidi, sapu-lantai, sapu-ijuk, sapu-halaman,

$b$-ribs, $b$-floor, $\quad b$-fibre, $\quad b$-yards,

sapu-oman, sapu-rumput, sapu-jagat...

$b$-rice stalks, $b$-grass, $\quad b$-earth...

As a member of sapu 'broom', they can be used in the same/similar manner.

b. sikat 'brush' the family of sikat (all types of brush):

sikat-gigi, sikat-sepatu, sikat-lantai, sikat WC,

brush-tooth, brush-shoe, brush-floor, brush-toilet,

sikat kamar-mandi...

brush-bath-room...

As a member of sikat 'broom', they can be used in the same/similar manner.

c. lap 'rag' the family of lap (all types of rag), including kain 'cloth' and the family of kain (that includes also sapu-tangan 'hand-broom', i.e., handkerchief, handuk'towel', 'tea-towel' etc.)...

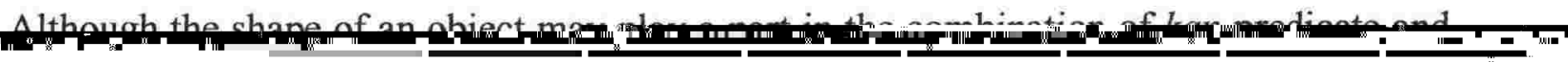

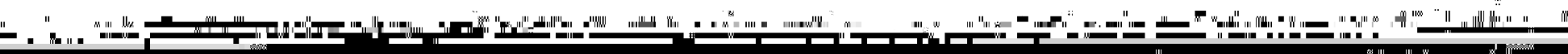

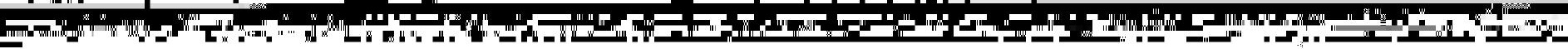

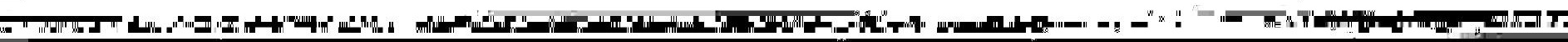

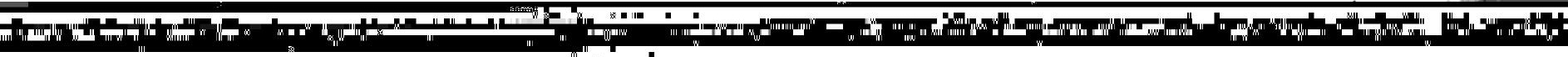

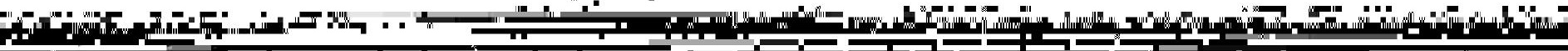

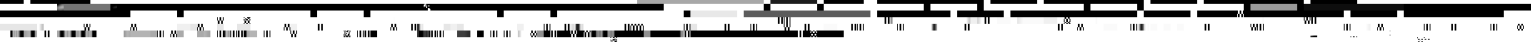
r

م

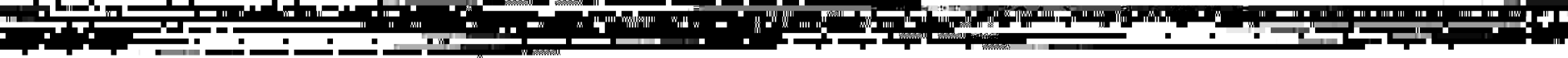

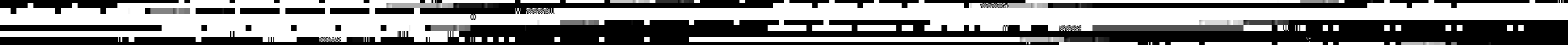

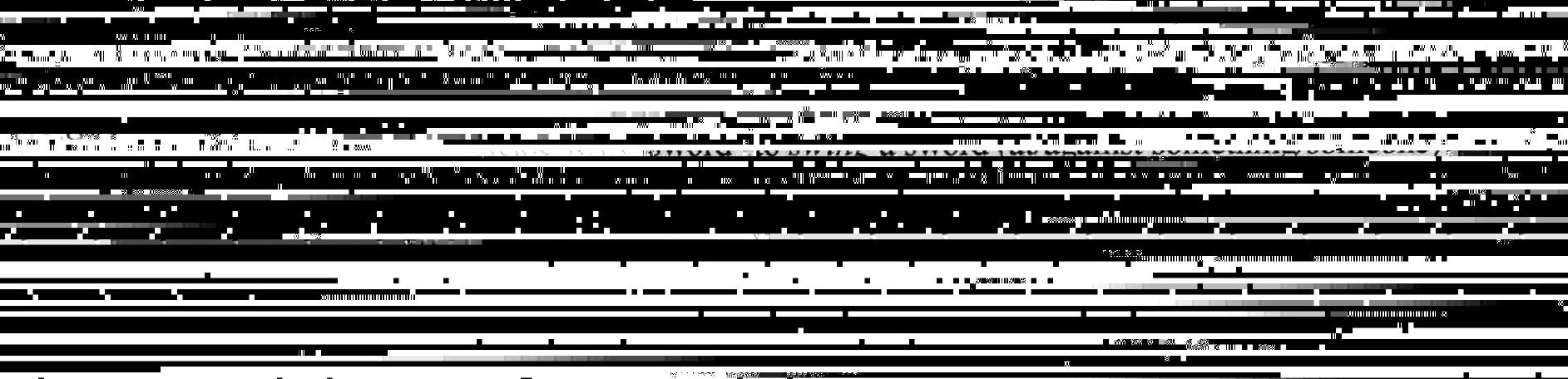


Like in the case of (34), manner expressions may also be interchangeably interpreted, for instance, between stabbing and swinging motions, (35a) against (35b).

a. bayonet-kan pedang

bayonet-KAN sword 'to stab a sword against/at something/someone)'

b. pedang-kan bayonet

sword-KAN bayonet 'to swing a bayonet on/at something/someone)'

The 'part-of' relation as exemplified in (34) and (35) can also be extended to objects which are not exactly in the same part-whole relation as, for instance, between sikat 'brush' as the domain, and sikat-gigi 'toothbrush' as a type of brush as well as which do not share the same root. Instrument wise, sword, sickle and bayonet may have different functions: for cutting human flesh, grass and for stabbing respectively. The manner, how these instruments are usually used (expressed by/in the kan-predicate) is applied to the THEME (also as an instrument). The focus is on the particular manner that is applied, (36) (in English we can say shovel the rice even if using a spoon; in BI we can also say spoon the rice using a shovel - or some other instruments having similar shape).

a. sekop 'spade': meN-sekop pasir 'to scoop sands (using a spade)' sendok 'spoon': meN-sendok nasi 'to scoop rice (using a spoon)'

b. meN-sekop-kan sendok (ke pasir, ke nasi) ACT-spade-KAN spoon (to sands, to rice) 'to scoop a spoon (on sands, on rice)' i.e., the spoon is used like a spade

c. meN-sendok-kan sekop (ke pasir, ke nasi) ACT-spoon-KAN spade (to sands, to rice) 'to scoop a spade (on sands, on rice)' i.e., the spade is used like a spoon

We can postulate that both sekop 'spade', and sendok 'spoon', in (36) have 'something in common' when kan-aspect appears: both sekop-kan, and sendok-kan are used to describe manner of scooping. The chart (38) recaptures the main point. 
(37) Class membership:

$\underline{\text { Kan-predicate }}$

[INSTRUMENT-kan]
THEME

'family/part-of' INSTRUMENT

The combination of instrument kan-predicates and the THEME expresses part-whole relation. The object is used/moved in a manner of instrument that is denoted by the predicate.

The notion of part-whole relation can also be applied to a wider range of predicate-THEME relations, for instance, to the denominal kan-predicate with kata 'word', making kata-kan 'to say something'. ${ }^{12}$ Here kata becomes instrumental, (38).

\section{(38)a. kata-kan + family of words :}

word-KAN kata-kata manis, kata-kata steren/tajam, pendapatmu,

say/convey sweet words, stern/sharp words, your opinion, persoalan-nya, apa saja

the problems, whatever (anything that can be said)...

b. Biasa, orang curang selalu meN-kata-kan kata-kata manis usual, person cheat always ACT-word-KAN word.PL sweet 'Predictably, a person who cheats always says sweet words (i.e., nice things)'

12) Often the nominal form is retained if the predicate is transliterated, for instance, in expressions such as 'to discuss the problem/the matter/the plans/anything that can be discussed', 'to combine the ideas/the colours' and so on, (i)-(ii), but not if indigenous words are used, (iii)-(iv).

(i) Mereka ber-kumpul untuk meN-diskusi-kan persoalan itu $3 \mathrm{pl}$ BER-gather for ACT-discussion-KAN problem DEM

'They gathered to discuss the problem'

(ii) Saya akan meN-kombinasi-kan dua warna ini 1 sg FUT ACT-combination-KAN two colour DEM 'I am going to combine these two colours'

(iii) Mereka ber-kumpul untuk meN-runding-kan persoalan itu $3 \mathrm{pl} \quad$ BER-gather for ACT-discuss-KAN problem DEM 'They gathered to discuss the problem'

(iv) Saya akan meN-gabung-kan dua warna ini $1 \mathrm{sg}$ FUT ACT-combine-KAN two colour DEM 'I am going to combine these two colours' 
The part-whole relation applies also to other activities, like senyum 'smile', (39).

(39)a. senyum-kan senyuman manis, senyuman lebar, ejekan, senyuman kecut... smile-KAN sweet smile, wide grin, mocking, sour smile....

b. Senyum-kan senyuman manis, meskipun hati kecut smile-KAN smile sweet, even though liver sour 'Give us a sweet smile, even though you feel sour'

Both kata-kan 'to say something', (38a,b) and senyum-kan 'to smile (something)', (39a,b), mean 'to convey the objects (of saying and smiling, respectively) to someone else. A different THEME can also occur with senyum-kan, namely, an object that is used as an instrument for smiling (Section 3.2.4.2) below.

It appears that the pattern seen in examples like in (38) and (39) above also occurs regularly for other 'self-activities' or 'intransitives', namely, what is usually done for oneself is conveyed to other people. These activities include, for instance, meN-nyanyi 'to sing', meN-tari 'to dance', and so on. For these intransitives, we can apply the notion of "cognate objects": meN-nyanyi (nyanyian) Sunda 'to sing a Sundanese song', meN-tari (tarian) Bali 'to dance a Balinese dance'. We shall come back to this matter in Section 3.3 and in Chapter 5 (BI $m e N$-unergatives).

\subsubsection{Body parts as instruments of motion}

In this section we consider cases in which the kan-predicate expresses the movement of a particular body part. Some of the following examples are related to the MANNER component of activity described in the previous sub-section, Section 3.2.4.1. Also, they can be included in the section discussing Change of Type 2 (3.3), namely, verbs of activity. In these examples, a more specific movement is used, instead of, for example, jalan 'road', deriving ber-jalan 'walk' or 'move', lari 'run', and dengklek 'hop', which are activities/movements of the whole body, we can use langkah 'step', giving rise to langkah-kan kaki 'step the feet' (as well as, like before, ayun-kan langkah 'swing the steps'), jinjit-kan kaki 'tip-toe the feet', and so on. 
A certain body part may have different kinds of manner movement that can be expressed in the predicate. For this reason, I will present the examples, (40), in the inverse order. Instead of the kan-predicate followed by the THEME, as in examples (24), (26), and (30), the following examples will be ordered as body parts (THEME) followed by the kan-predicate expressing different possible movements. Common activities like angkat 'lift', turun 'descend', taruh/letak, 'put (down)', buka 'open', etc. are not included, although they can be used to include body parts as an object, with or without kan-aspect. Not all possible combinations of kan-predicate and body part are included in (40). Examples of expressions in a sentence are provided immediately after.

\section{(40) Paradigms}

\section{THEME:}

a. kepala: head

b. mata:

eye

c. bibir:

lips

d. mulut: mouth

e. gigi: tooth

f. lidah: tongue

g. tangan: hand

h. jari: fingers

\section{movement described with kan-predicate as}

tunduk-kan, geleng-kan, angguk-kan, tengadah-kan look down, shake, nod, look up

pejam-kan, kedip-kan, lirik-kan, belalak-kan close, wink/blink, look side-ways, open wide

cibir-kan, senyum-kan

mock, smile

ringis-kan, nganga-kan, senyum-kan

grin gasp/agape, smile

(h) unjuk-kan, gerat-kan, gertak-kan show (as a challenge), grit (frustration), slam (anger)

julur-kan, goyang-kan

poke out, sway/shake

acung-kan, lambai-kan, jabat-kan,

rise, wave, shake (as in 'shake hands'),

ayun-kan, belai-kan or elus-kan, ulur-kan

swing, stroke reach out

tunjuk-kan, remas-kan, belai-kan or elus-kan, sisir-kan

point, wring, stroke, comb 


\section{i. kaki:}

leg/foot

. pinggul/pantat

hips/buttocks langkah-kan, ayun-kan, hentak-kan, jinjit-kan,

step, swing, stomp, tip-toe,

sepak-kan, lompat-kan, goyang-kan,

kick, jump, sway,

*lari-kan, *jalan-kan, *dengklek-kan

run, walk, hop

Notice that some movements in the group (40) are also used to describe different parts of the body, for instance, goyang 'sway', applies not just to lidah 'tongue', but also to pinggul 'hips', pantat 'buttocks', and kaki 'leg'. It could be that swaying is a common movement. Some body parts, like kaki 'leg', tangan 'hands, arms', have more movements assigned to them, while some others, such as, pantat 'buttocks' and lidah 'tongue', have less due to the restricted number of movements they can do. Each movement - and the corresponding body part as the moving object - is expressible in the range of expressions, (41)-(43).

(41)a. Ia meN-angguk

3 sg ACT-nod

goyang-kan

sway

b. Kepala-nya meN-angguk

head-3sg ACT-nod 'His/her head nodded' i.e., He/she nodded

(42)a. Ia meN-angguk-kan kepala(-nya)

3 sg ACT-nod-KAN head (-3sg) 'He/she nodded (his/her) head'

b. *Kepala-nya meN-angguk-kan ia

head-3sg ACT-nod-KAN 3sg 'His head nodded him'

(43) *Ia meN-angguk kepala(-nya)

3 sg ACT-nod head (-3sg) 'He/she nodded (his/her) head'

Except for the unacceptable examples, (42b) and (43), all of the expressions in (41)-(43) occur naturally in BI, although - from the English point of view - some may find the forms rather odd, especially (41b). In (42a) the THEME - in this case kepala-nya 'his/her head' - must be present because of the kan-aspect, as argued in Chapter 2. Also, it will become clearer as we proceed (see in particular, Section 3.2.6.2), that the kan-aspect can 
only occur in the presence of an AGENT or a CAUSER, such as ia 'he/she' in (42a). Note that without the kan-aspect, kepala-nya 'his head', (42a), cannot follow the predicate, as shown in the unacceptable example, (43). In general, the sentence pattern shown in (41)(43) occurs consistently with all other body parts, for example, (44)-(46). ${ }^{13)}$

(44)a. Ia meN-kedip

3sg ACT-wink 'He/she winked'

b. Mata-nya meN-kedip eye-3sg ACT-wink 'His/her eye winked' i.e., He/she winked

(45)a. Ia meN-kedip-kan mata(-nya)

3sg ACT-wink-KAN eye (-3sg) 'He/she winked (his/her) eye'

b. *Mata-nya meN-kedip-kan ia eye-3sg ACT-wink 3sg. 'He his eye winked something'

(46) *Ia meN-kedip mata(-nya)

3sg ACT-wink eye (-3sg) 'He/she winked (his/her) eye'

At this stage it is not relevant, for instance, as to whether the (a) and (b) sentences of (41) and (44) should differ syntactically. What is relevant for the present section is that the (a) sentences above express the 'whole person' in the subject position, while the (b) sentences only part of the person, and the two expressions are more or less synonymous. Looking closely, however, only the body part undergoes the movement. Namely, even if the form used is that of the (a) sentences, it is understood that the object that undergoes the movement is only the body part (i.e., one does not ask what instrument he/she uses to nod or wink with). This whole and 'part of' relation does not suggest homomorphism as postulated in the previous section (Section 3.2.4.1), because it is about a 'body part' in

13) Both (42a) and (45a) can occur in/as metaphors, (i) and (ii) respectively:
(i). Ia meN-angguk-kan persetujuan
3sg ACT-nod-KAN agreement
(ii). Ia meN-kedip-kan rahasia mereka secret $3 \mathrm{pl}$ 'He winked their secret'
3 sg ACT-wink-KAN
both (i) and (ii) the THEME is conveyed (as abstract objects). 
relation with the body, rather than a relation between a body and its family members, other bodies, (47).

The constructions (42a) and (45a) above do not occur with homomorphics such as sapu-lidi 'rib broom' in (47).

(47) *Sapu ini sapu-lidi-nya patah
broom DEM broom-rib-3sg break
'This broom its rib-broom broke'

Sapu-lidi, a type of broom made of coconut leaf-ribs, is part of the range, a family member of brooms. While it 'belongs to' the domain (i.e., the family of) sapu 'broom', it is not a 'body part' in the sense of examples in (41)-(46). We can have, however, some parts of the broom expressed as a body part, (48).

(48)a. Sapu ini tangkai-nya patah broom DEM stick-3sg break 'This broom, its handle broke'
b. Sapu ini patah
broom DEM break
'This broom broke' i.e., this broom is broken
c. Tangkai-nya patah stick-3sg break
'Its handle broke' i.e., the handle is broken

To recapture our main purpose of discussion, we shall come back to the (a) examples of (42a) and (45a) above, repeated here as (49) and (50). Examples (49b) and (50b) are without the kan-aspect.

(49)a. Ia meN-angguk-kan kepala(-nya)

3 sg ACT-nod-KAN head (-3sg) 'He/she nodded (his/her) head'

b. Ia (kepala-nya) meN-angguk

3sg head-3sg ACT-nod 'He/she (his/her head) nodded'

$\begin{array}{rll}\text { (50)a. Ia } & \text { meN-kedip-kan } & \text { mata }(-n y a) \\ \text { 3sg } & \text { ACT-wink-KAN } & \text { eye }(-3 \mathrm{sg})\end{array}$ 'He/she winked (his/her) eye' 
$\begin{array}{lll}\text { b. Ia } & \text { (mata-nya) } & \text { meN-kedip } \\ 3 \mathrm{sg} \text { eye }-3 \mathrm{sg} & \text { ACT-wink }\end{array}$

Angguk 'nod', or, kedip 'wink', as a manner of movement of body-parts is expressed by the kan-predicate, while the THEME is the body part itself, (49a) and (50a). A good point to note from these examples is that, with the kan-aspect, only the body parts undergo change, but not ia 'he/she', which is the whole body. (Here kepala 'head', or mata 'eye', is used as an instrument by the person 'attached to it'). In the (b) examples of (49) and (50) the body parts are understood to undergo movement, even though we can leave them covert. Without the kan-aspect, as shown in the ungrammatical examples of (43) and (46), it is not immediately clear which participant, ia 'he/she', or kepala-nya 'his/her head', undergoes change.

In summary, we have some facts about events involving body parts as participants, with kan and without kan-predicates:

(i) The kan-predicate expresses the manner movement of body parts, and the body parts are the THEME, (40), (42a), (45a), (49a), and (50a).

(ii) without the kan-aspect, the argument that undergoes change can be left covert, yet understood (what else do we nod or wink with?), (41a), (44a).

\subsubsection{Directional Prepositions expressed by kan-predicate}

The strongest and most apparent evidence of change is the expression of direction that exclusively describes the shift of location. It is the PATH of the shift to be travelled through by the THEME that is expressed in the predicate. This type of expression includes backwards, forwards, inwards, outwards, upwards, downwards, towards and so on, where upwards, for instance, means "along the path up"(Gruber 1970: 58 - 59).

Some kan-predicates expressing direction include the 'preposition of movement' ke 'to' (e.g., ke-samping-kan 'to sideway' 'to put aside'), while others use only arah the 'direction" or 'ward' (e.g., arah-kan). I mentioned briefly in Section 2.4 the "conative 
preposition" ke arah 'to the direction of', or 'towards' that is related to the English examples (37b) and (38) of Chapter 2, repeated here as (51), and the BI equivalents are repeated as (52).

(51)a. I shot at the sheriff

b. The troops fired on/at the protesters

(52)a. Saya meN-tembak 1sg ACT-shoot

ke arah

sheriff itu

'I shot to the direction of that sheriff'

sheriff DEM

i.e., 'I shot at that sheriff'

b. Tentara-tentara itu meN-tembak ke arah para demonstran soldier.PL DEM ACT-shoot to direction PL protester

'Those soldiers shot to the direction of the protesters'

i.e., 'The troops fired on/at the protesters'

Both (51) and (52) have the direction and the (intended) GOAL, but the kan-aspect is not present because there is no THEME. In (51) and its BI equivalents, (52), there is no information as to whether or not the moving object reaches the goal of the shooting, but at least the direction, including the intended goal are included in the expressions. The objects sheriff itu 'the sheriff and para demonstran 'the protesters' may not even be within the range of shooting distance. This is like saying that I am walking in the direction of the post office as against I am walking to the post office, where in the former I may not reach the post office at the end of my walk. In Bl, arah 'direction' must be included in expressions such as $(52 \mathrm{a}, \mathrm{b})$.

In the following examples, example (53a) has an overt THEME, and the sentence is grammatical. And again, like examples (52a,b), arah 'direction', must be included in the prepositional phrase ke arah para demonstran 'to the direction of the protesters', that is, if the prepositional phrase must appear. Example (53b) has both the direction and the goal, but the moving object, the THEME is not mentioned, and the sentence is ungrammatical, and thus different from $(52 \mathrm{a}, \mathrm{b})$ where the kan-aspect is not used. With the kan-aspect, the THEME must be included overtly (except for psych-predicates, which will be discussed in the section that immediately follows, Section 3.2.6). 
(53)a. Tentara-tentara soldier.PL itu meN-tembak-kan
DEM ACT-shoot-KAN gas air-mata ke arah gas water-eye to direction para demonstran PL protester

'Those soldiers shot tear gas to the direction of the protesters' i.e., they shot at/on the protesters using tear gas

\section{b. * Tentara-tentara itu meN-tembak-kan ø ke arah para demonstran} soldier.PL DEM ACT-shoot-KAN - to direction PL protester 'Those soldiers shot to the direction of the protesters'

c. *Tentara-tentara itu meN-tembak-kan gasair-mata ke soldier.PL DEM ACT-shoot-KAN gas water-eye to para demonstran PL protester

'Those soldiers shot tear gas to $ø$ the protesters'

In the following example, (54), it is arah 'direction', that is expressed in the kanpredicate, and the THEME tembak-an 'shot', 'fire', 'projectile', is overt.

\section{(54)Tentara-tentara itu meN-arah-kan soldier.PL DEM ACT-direction-KAN}

'The troops aim the fire at/on the protesters'

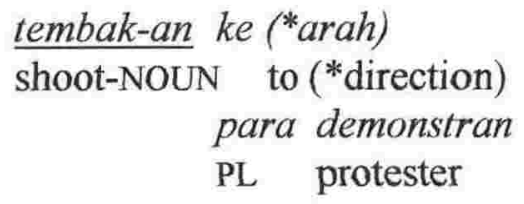

i.e., in the sense of 'to GIVE a direction' or 'to direct the firing'.

In (54), it is the direction of the fire that is expressed in the kan-predicate, and not the action of shooting, thus, different from the usual kan-predicate with the moving object, (53b), or, (52a,b) which are without the kan-aspect. From (54) above, we can see that the predicated $a r a h$, 'direction', '-wards', in itself, does actually express movement, and arah cannot be included in the prepositional phrase with the intended goal para demonstran 'the protesters'. The acceptable prepositional phrase is ke para demonstran 'to the protesters' (i.e., locative), and not ke arah para demonstran 'to the direction of the protesters' (i.e., conative) as in (53b) where arah must appear. Directions exist as a path to be travelled through by the THEME. Here we have $a r a h$ '-wards', as a path, expressed within the predicate. 
This brings us to the core of the discussion, namely, what Gruber (1970: 58) calls "expression of direction", which is "elaboration of the expression of Goal". The FINAL DESTINATION of the movement, as has been discussed in Section 3.2.1, may be omitted, as long as the direction/orientation is right. In fact, as we will see, the goal may not be stated at all. As Gruber notes: "The essence of the expression of direction is the specification of the path along which the theme is travelling, but not to indicate any necessary goal". Moreover, note that for BI, we have the direction, the path along which the theme is travelling, expressed in the kan-predicate, rather than as a preposition that introduces a goal.

It is the "specification of the path along which the theme is travelling" that is the main point of this section, regardless as to whether or not the goal is indicated (by the inclusion of a prepositional phrase). As we will see, some expressions even ban a prepositional phrase. Although, as Gruber notes, all expressions of goal may be used in the sense of expression of direction, our examples indicate that the inverse is not true, namely, expressions of direction do not necessarily include any particular goal. Note that in English, particles such as up, down, in, out (i.e., without -wards) are actually prepositions expressing directions, which can also be goals. These all take -wards, e.g., upwards, which changes the sense in the same way that towards varies from to. Thus, upwards means 'along a path up'. The point is, although to and towards, for instance, both require a DP (and up, down, in, out, can be used without - wards and also without a DP), the addition of-wards changes the sense. This 'wardness' sense is what we have in the BI kan-predicates that express directions.

This type of expression of direction in a kan-predicate in BI is as productive as there are directional prepositions available. The following, (55), is a relatively closed set of paradigms. The preposition ke 'to' may or may not be included in the predicate; when it is included, the predicate expresses both the path and the direction. 
(55) Paradigms

\section{Path and direction}

(a)

ke atas 'to above', 'up', 'upwards'

ke bawah 'to below', 'down', 'downwards' ke samping, 'to the side', 'aside', 'side-wards' ke belakang 'toward the back' ke muka 'to the front', 'forwards' ke sudut 'to the corner'

ke luar 'to outside' ke bumi '(in-)to the earth'

(c)

turun 'to descend', 'downward'

naik 'to ascend', 'upward'

arah 'direction', '-wards'

\section{as kan-predicate}

\author{
(ke-)atas-kan \\ (ke-)bawah-kan \\ (ke-)samping-kan \\ (ke-)belakang-kan \\ (ke-)muka-kan \\ (ke-)sudut-kan
}

ke-luar-kan

ke-bumi-kan

\section{turun-kan \\ naik-kan \\ arah-kan}

In group (55a) the preposition ke 'to', is optional within the kan-predicate; it is obligatorily present in ke-luar-kan 'shift something outwards', 'to expel', and ke-bumikan 'put something inside the earth, i.e., to bury', (55b); and finally, since the direction of movement itself is included in the profile of the predicate such as turun 'to descend', and naik 'to ascend', or, just arah 'direction', '-wards', the preposition is not needed, $(55 \mathrm{c})$

It is a matter of opinion, as to whether we can call atas 'above', bawah 'below', etc. of group (55a), a goal. However, for this group, a prepositional phrase with goal cannot be included, (56).

(56)a. Jangan hanya meN-(ke-)atas-kan persoalan (*ke atas) NEG.IMP only ACT-to-above-KAN problems (*to above)

'Do not just shift the problem upwards 'i.e., do not just prioritise the problem
b. Jangan
meN-(ke-)belakang-kan
mobil-nya
(*ke belakang)
NEG.IMP ACT-to-back-KAN
car-3sg
(*to the back)

'Do not shift the car backwards' also, 'Do not reverse the car (*backwards)'. 
Kan-predicates of groups (55b) and (55c) take both source and goal, introduced by the prepositions dari 'from', and ke 'to', respectively, (57).

(57)a. Ayah meN-ke-luar - kan mobil-nya dari garasi father ACT-to-outside-KAN car-3sg from garage

'Father took his car out from the garage'

b. Ayah meN-ke-luar-kan mobil-nya ke halaman (*keluar) father ACT-to-outside-KAN car-3sg to front-yard (to outside)

'Father shifted out his car to the front-yards'

c. Kuli-kuli meN-turun-kan beras dari truk coolie.PL ACT-descend-KAN rice from truck

'The coolies unloaded the rice from (the) truck'

d. Kuli-kuli meN-turun-kan beras ke truk (darikapal) coolie.PL ACT-descend-KAN rice to truck (from ship)

'The coolies unloaded the rice to the truck (from the ship)'

To conclude, a kan-predicate expression of direction may include a goal within it, as in (55a), or it may be purely a direction of the path to be travelled through, like in groups (55b) and (55c). For the latter, however, a contrast between the source and the goal may be needed, like for instance, the source must be higher or lower than the goal in terms of position: for turun 'to descend', 'to unload' in (57c), the ground is understood to be lower than the truck, and in (57d) the truck is lower than the ship, and conversely for naik 'to ascend', or, 'to load'.

The BI equivalent of Rappaport Hovav and Levin's (1998) example, (16c) above, can be paraphrased using the kan-predicate that expresses a direction, (58c) below, although the alternative expression is just as good, (58b). The English example (16c) and its $\mathrm{BI}$ equivalent are repeated here as $(58 \mathrm{a}, \mathrm{b})$.

\begin{tabular}{clll} 
(58)a. Terry & swept & the crumbs & \multicolumn{2}{c}{ into the corner } \\
b. Terry & meN-sapu & remukan roti & ke sudut \\
$\mathrm{T}$ & ACT-broom crumb bread & to corner
\end{tabular}




\section{c. Terry meN-(ke-)sudut-kan remukan roti (*ke sudut)}

$\mathrm{T}$ ACT-(to)corner-KAN crumb bread (*to corner)

(?)'Terry cornered the crumbs' i.e., Terry shift the crumbs to the corner

In summary, whether or not the goal of the move is indicated, the path along which the moving object is travelling is expressed by the kan-predicate. This expression of direction provides - if there was any need at all - the best piece of evidence that the object of kanpredicate undergoes change, in this case, a shift-through-location. After all, that is what directions are for.

\subsubsection{De-adjectivals and FINAL STATE}

The final state of change can be expressed in the kan-predicate. This is on a par with the final destination and the final form discussed in Sections 3.2.1 and 3.2.2. It seems to matter whether a kan-predicate is derived from a common adjective or a psychological one, although both indicate a change of state. For instance, expressions with a psychpredicate that include the kan-aspect do not have a PASSIVE counterpart. The simplest explanation is that the cause of change in psych-predicate with the kan-aspect is consistently non-volitional (cf. Dowty 1991, Arad 1998), meaning, that the event does not occur as a deliberate action. This is in general the case with PASSIVEs involving the kan-aspect in BI, not just with psych-predicates. Recall the discussion in Section 2.3.2.2, with examples (32)-(34), where it is shown that in BI sometimes the causal relation of $v$ VP does not involve a volitional AGENT. In such cases, the PASSIVE cannot be formed. An important point to note is that with the psych-predicates, the CAUSER of change is consistently non-volitional.

Different from the psych-predicates, kan-predicates of common adjectives (adjective-based) have a PASSIVE alternant. The reason is, unlike the kan-psych-predicate - where the cause of change is consistently non-volitional - the non-psych kan-predicate requires an AGENT (or, 'agentive'). Furthermore, unlike psych-predicates, predicates of common adjectives can also occur in a middle construction indicating a process (in a manner of the English the gravy thickened), i.e., without the kan-aspect. 
The kan-predicates in this section are divided into three groups. (i) For kanpredicates with common adjectives (de-adjectival kan-predicates), the initial state is understood to be relatively the opposite of the final state, for instance, if the final state is panjang 'long', then the initial state is understood to be 'not long', i.e., pendek 'short', (Section 3.2.6.1). (ii) With psych-predicates, however, it is not easy to pinpoint what actually the initial state is; it is not as straightforward as the opposite of the final state (Section 3.2.6.2). (iii) Another group of predicates, included as a type of psych-predicate, do not give the entailment of change on the object. The predicates of this group, which I will refer to as 'fear verbs', are used only with $i$-aspect. These three groups have something in common: they are all state-predicates, and they can occur bare (unaffixed) as an adjective. Only group (i), however, can occur in middle constructions, with the prefix meN-indicating that there is a process of change, 'BECOME'.

\subsubsection{Change of state with common adjectives}

The form is regular, as regular as the need to use adjectives of dimensional states (all sizes), forms (thick, watery etc.), colours (all colours), description (those that mean good, bad, smart) and so on. The expression formed with this type of kan-predicate regularly means 'to change the state of something or someone into the next state'.

Before we go on to the kan-aspect, I shall discuss briefly occurrences without causal relation, namely, the unaccusative/middle expressions. We start from state predicates such as kental 'thick', cair 'liquid (an adjective, as against the noun cair-an)', panjang 'long', and merah 'red, to show non-agentive (perhaps also non-causative) readings in (59). These examples are one-place predicates and they do not indicate causal relation. Each surface subject can be considered a THEME, because it undergoes change.

(59)a. Kuah-nya meN-kental(karena api terlalu panas) gravy-3sg ACT-thick (because fire too hot) 'The gravy has started to thicken/is thickening/has thickened/thickened

b. Salju-nya meN-cair (karena panas matahari) snow-3sg ACT-liquid (because heat sun) 
'The snow has started to melt/is melting/has melted/melted (because of the heat of the sun)'

c. Jenggot-nya meN-panjang (karena malas cukur)

beard-3sg ACT-long (because lazy hair-cut)

'His beard has started to grow long/is lengthening/has lengthened/lengthened

d. Pipi-nya meN-merah (karena malu) cheek-3sg ACT-red (because embarrassed)

'His/her cheeks reddened (because of embarrassment)

If the causal relation is included, that is, with the kan-aspect, an AGENT for each expression is needed, as in (60).

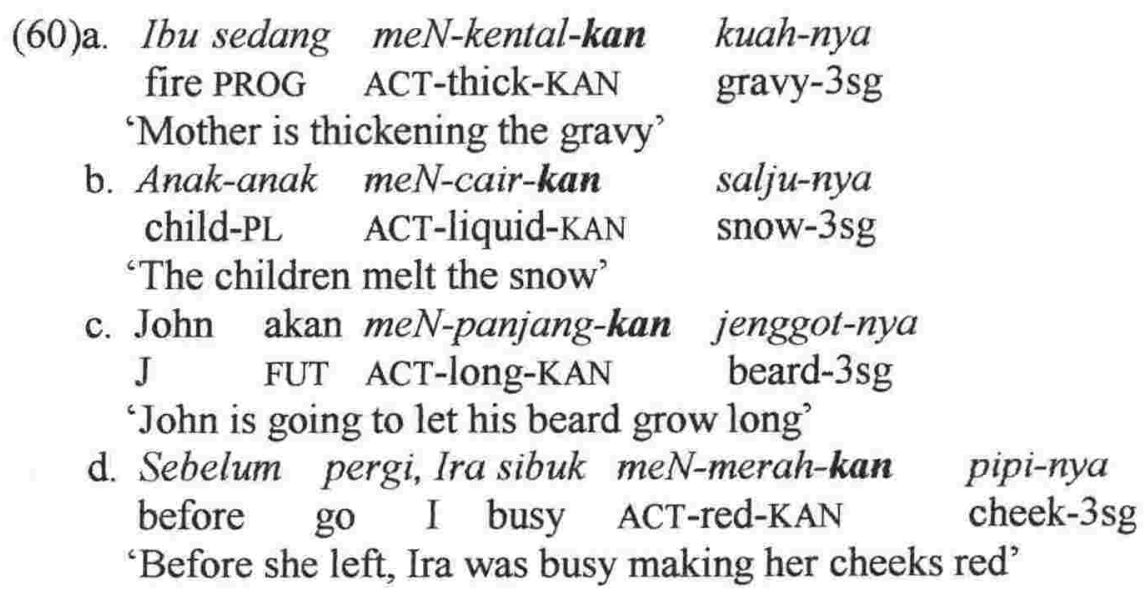

All the kan-predicates in (60) express the final state of change, as thick, liquid, long and red. The THEMEs such as used in examples (59) are the direct internal arguments of the kan-predicates in (60), and we have AGENTs such as mother, the children, John, and Ira.

The CAUSER included (parenthesised in examples (59)) cannot behave like an AGENT: they cannot intend to bring about the event - not even with kan-aspect, (61); they only happen to trigger the event. The distinction between the CAUSER/stimulus and the AGENT will be apparent as we proceed, by using some contrasting examples involving the two. For instance, if we substitute the AGENTs ibu 'mother', anak-anak 'children', John, and Ira, with the CAUSERs parenthesised in (59), each sentence becomes ungrammatical, (61). 


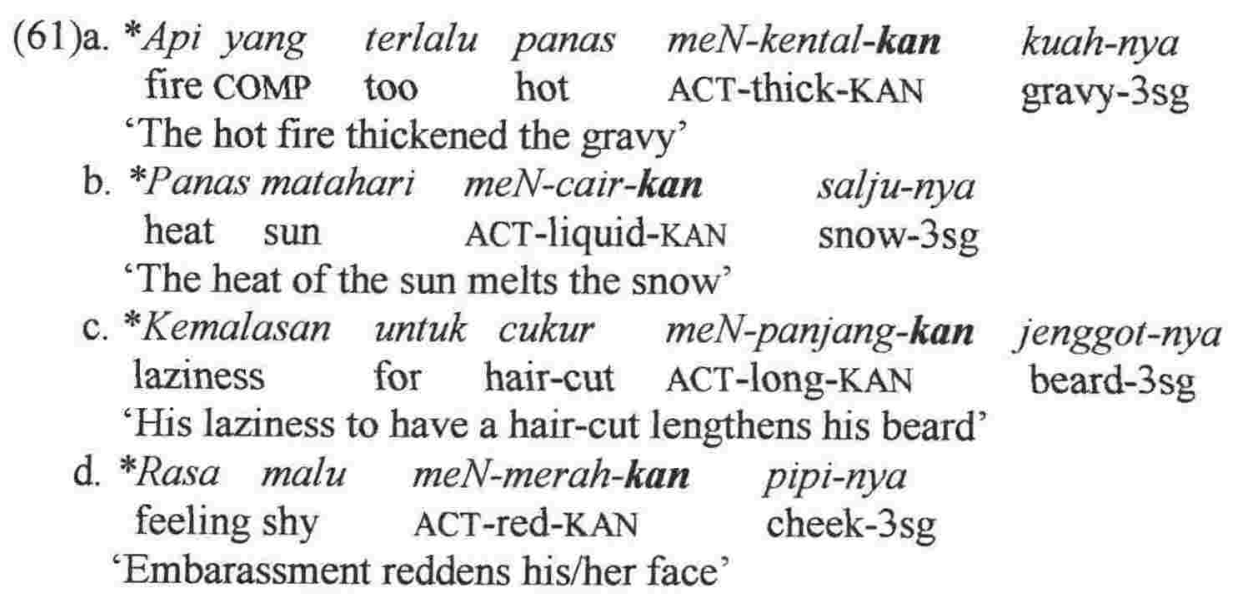

Out of all examples, (59), (60), and (61), only (60) have a PASSIVE alternant, represented as (63) below. Note that each sentence in (60) has an AGENT as the surface subject. In contrast, examples in (59) and (61) each has a CAUSER (included as a cause phrase in (59)). Examples (62) and (64) represent the unacceptable PASsIVEs of (59) and (61), respectively.

(62)
*Kuah-nya di-kental
gravy-3sg PASS-thick
'The gravy is/was thickened'

(63) Kuah-nya sedang di-kental-kan oleh ibu gravy-3sg PROG PASS-thick-KAN by mother

'The gravy is being thickened by mother'
(64) *Kuah-nya di-kental-kan oleh api yang panas gravy-3sg PASS-thick-KAN by fire COMP hot 'The gravy was thickened by the hot fire'

The three examples above, (62)-(64), are distinguished by the agentive versus nonagentive readings. The fact that a CAUSER is different from an AGENT is supported by the impossibility of interchanging them, for instance, while the CAUSER in (61) must be expressed analytically in order to have a grammatical expression, (65) below, the inverse is true, that is, examples in (60) cannot be expressed analytically, (66). 
(65) Panas matahari meN-sebab-kan salju-nya meN-cair heat sun ACT-cause-KAN snow-3sg ACT-liquid 'The heat of the sun caused the snow to melt' (66) *Ibu sedang meN-sebab-kan kuah-nya meN-kental
mother PROG ACT-cause-KAN gravy-3sg ACT-thick
'Mother is causing the gravy to thicken'

The state predicates used in our examples above, (59) to (66), such as kental 'thick', cair 'liquid', panjang 'long', and merah 'red', are taken from the paradigms in (67), which is not intended to be an exhaustive listing. Note that all the forms in (67) can occur in middle constructions, such as (59) above. Examples (59)-(60) can be included in the following paradigms, (67)-(68).

(67) Paradigms

\section{a. Dimensions}

State kan-predicate THEME

panjang 'long' panjang-kan jenggot 'to let the beard grow long'

pendek 'short' pendek-kan rambut 'to cut the hair short'

besar 'big' besar-kan anak-anak 'to nurture the children'

kecil 'small' kecil-kan baju 'to reduce the size of the shirt'

sempit 'narrow' sempit-kan fokus 'to narrow (down) the focus'

luas 'broad' luas-kan pandangan 'to broaden the view'

lebar 'wide' lebar-kan jalan 'to widen the road'

b. Colours

State

$\begin{array}{llll}\text { merah 'red' } & \text { merah-kan } & \text { bibir 'to make the lips red' } \\ \text { kuning 'yellow' } & \text { kuning-kan } & \text { telur 'to make eggs turn yellow' } \\ \text { hijau 'green' } & \text { hijau-kan } & \text { kota 'to make the city green' } \\ \text { putih 'white' } & \text { putih-kan } & \text { kain 'to bleach cloths' } \\ \text { hitam 'black' } & \text { hitam-kan } & \text { rambut 'to make the hair black' }\end{array}$

\section{c. Forms}

State kan-predicate THEME

$\begin{array}{llll}\text { cair 'liquid' } & \text { cair-kan } & \text { es } & \text { 'to turn/make the ice into liquid' } \\ \text { beku 'frozen' } & \text { beku-kan } & \text { air } & \text { 'to freeze the water' } \\ \text { lunak 'tender' } & \text { lunak-kan } & \text { daging 'to soften/tenderise the meat' }\end{array}$


keras 'hard' keras-kan semen 'to harden the cement'

The process in middle syntax with the suffix meN-above, as exemplified in (59), is not confined only to de-adjectivals. Some denominals may enter this type of predication, in which case the process has a slightly different semantic interpretation. The examples that follow in (68), are included here because they do not fit in the denominal categories of those discussed in Section 3.2.2 to 3.2.4.

(68) Process involving de-nominals
a. uap 'steam'
meN-uap
'to evaporate', 'having the characteristics of steam', 'to become like steam'
b. batu 'stone'
meN-batu 'to have the characteristics of stone, e.g., hard'
c. embun 'dew' meN-embun 'to become like dew'
d. semut 'ants' meN-semut 'to behave like ants, to look like ants'
e. rayap 'termites' meN-rayap 'to move like termites'
f. rambut 'hair' meN-rambut 'to have the characteristics of hair'

The process of 'becoming like something else', or taking different forms from the original is reminiscent of the reclassification of THEME discussed in Section 3.2.3, except here the kan-aspect does not have to be used. I shall show the difference of the semantics of the two types of process, (59) as against (68), respectively, (69) and (70). The reclassification of THEME is included in (70).

$$
\left.\begin{array}{lll}
(\mathrm{BECOME} & (x & \text { <STATE }>)
\end{array}\right) \quad \text { schematically: }\left[\begin{array}{ll}
\mathrm{DP} & m e N-\mathrm{V}
\end{array}\right]
$$

While (69) and (70) do not show a causal relation, the following, (71) and (72) are the interpretations of the non-agentive examples (i.e., non-volitional cause), such as examples in (59), and the agentive examples (i.e., volitional AGENT), such as examples in $(60)$, respectively.

(71) ( $\beta$ HAPPEN (CAUSE (BECOME $(x<$ STATE $>))$ ) [DP CAUSER $m e N-v-k a n$ DP]

(72) $(\alpha$ ACT $($ CAUSE $($ BECOME $\quad(x<$ STATE $>)))) \quad$ [DP AGENT meN-v-kan DP] 
Where in (71) $\beta$ represents a non-volitional cause (= CAUSER) that happens to trigger the event, and in (72) $\alpha$ represents a volitional AGENT that intends to bring about the event. Adopting Dowty's (1991) terminology, I shall henceforth continue to call the nonvolitional cause "CAUSER" - to replace the term "real cause' I often use so far - because it is non-volitional (as well as non-sentient).

It is worth noting that, like air 'water', that is expressed in the $i$-predicate as a denominal (i.e., a THEME within the predicate), as seen previously, repeated here as (73a), warna 'colour', as the superordinate of merah 'red', kuning 'yellow' and so on (of all colours, not just of those listed in (67b)), can also appear similarly, (73b), also as a denominal with the $i$-aspect. The point to note is that although they are denominals, they cannot be included in (69)-(72), because there is no process involved. And thus, the denominals grouped in (68) above are special, in that, they behave like state predicates of (70) type.

(73)a. Sudah waktu-nya kita meN-air-i tanaman PERF time-3sg 1pl.incl ACT-water-I plant 'It's (about) time we water the plants' i.e., PUT some water on the plants

b. Sudah waktu-nya kita meN-warna-i rambut kita PERF time-3sg 1pl.incl ACT-colour-I hair 1pl.incl 'It's (about) time we colour our hair' i.e., PUT a colour (or colours) on the hair

The two predicates in $(73 \mathrm{a}, \mathrm{b})$ simply mean to put water on the plants or to put colour on the hair. These predicates do not indicate the outcome of the process, in fact, there is no process (and they are not state predicates). Note also that the forms in (68) can also occur with $i$-aspect, with meaning similar to those in (73) (as a reminder, occurrence such as shown in (73) is what Hale \& Keyser (1993) call "locatum verbs", which will be discussed in Chapter 4). In addition, there is no MANNER expressed in (73a,b), of how we water the plants, how we colour the hair for instance, as to whether we should sprinkle, water-blast, or just pour the water on the plants. Similarly, no specific colour is mentioned for colouring the hair in (73b). 
A very important point of the present section is the distinction between a CAUSER, and an AGENT. With the kan-aspect, the passive by-phrase in BI requires an AGENT as its argument, but not a CAUSER, as shown in examples (63) and (64), respectively. The template shown in (72) is the interpretation of both ACTIVE and PASSIVE forms, or, conversely, only expressions having the (72) template can have ACTIVE-PASSIVE alternations. This distinction also carries through other events such as described in the next section, Section 3.2.6.2.

\subsubsection{Change of State: Psych-predicates}

Like psych-predicates widely discussed in the literature, BI psych-predicates are also of interest because they show peculiar syntactic effects. However, the present section will mainly discuss the relevant phenomena that relate to kan-aspect, namely those reflecting aspectual properties of the verbal phrase. For example, when we say in English that John annoys me, there is something about John that annoys me, perhaps it is his voice, his wit and so on. In English we can also say I'm annoyed (by John'by his voice). The BI counterpart, (74a,b), however, does not have the PASSIVE form, (75). Example (74c) shows that the predicate is non-agentive.

(74)a. John meN-jengkel-kan saya

$\mathrm{J} \quad$ ACT-annoy-KAN $1 \mathrm{sg}$

'John annoys me'

b. John suara-nya meN-jengkel-kan saya

$\mathrm{J}$ voice-3sg ACT-annoy-KAN $1 \mathrm{sg}$

'John, his voice annoys me'

c. *Dengan sengaja John meN-jengkel-kan saya with intention $\mathrm{J}$ ACT-annoy-KAN $1 \mathrm{sg}$

'Deliberately, John annoys me'

\begin{tabular}{|c|c|c|c|}
\hline (75)a. *Saya & di-jengkel-kan & oleh & John \\
\hline $1 \mathrm{sg}$ & PASS-annoy-KAN & by & $\mathrm{J}$ \\
\hline \multicolumn{4}{|c|}{ 'I am annoyed (by John)' } \\
\hline $\mathrm{b} *$ Saya & di-jengkel-kan & oleh & suara-nya/suara John \\
\hline $1 \mathrm{sg}$ & $\begin{array}{l}\text { PASS-annoy-KAN } \\
\text { noved by his yoice }\end{array}$ & & \\
\hline
\end{tabular}


As a strategy, an analytical/syntactic expression of causal relation, such as (76) below can be used instead of (75).

(76)a. John meN-buat saya jengkel
J ACT-make/cause 1sg annoy
'John makes/causes me (to become) annoyed'
a'. 'John meN-buat-kan
J saya jengkel
'John makes/causes me (to become) annoyed'

b. Kelakuan-nya/suara-nya meN-buat saya jengkel behaviour-3sg/voice-3sg ACT-make/cause 1sg annoy 'His behaviour/his voice makes/causes me (to become) annoyed'
b'. *Kelakuan-nya/suara-nya meN-buat-kan saya jengkel behaviour-3sg/voice-3sg ACT-make/cause-KAN 1sg annoy 'His behaviour/his voice makes/causes me (to become) annoyed'

Where the PASSIVE counterpart of $(76 \mathrm{a}, \mathrm{b})$ is $(77 \mathrm{a}, \mathrm{b})$ below.

(77)a. Saya di-buat jengkel oleh John
1sg PASS-make/cause annoy by J
'I am made (to become) annoyed by John'
b. Saya di-buat jengkel oleh kelakuan-nya/suara-nya $1 \mathrm{sg}$ PASS-make/cause annoy by behaviour-3sg/voice-3sg 'I am made (to become) annoyed by his behaviour/his voice'

Notice that the relevant verb in both (76) and (77) is buat 'to make'. Thus, the passive form in (77) is that of the MAKE clause, i.e., a non-psych-predicate, which we shall set aside. However, notice that kan-aspect cannot be used in $(76 \mathrm{a}, \mathrm{b})$. Without the kan-aspect, John (77a), or kelakuan-nya/suara-nya 'his behaviour/his voice' can be the arguments of the by-phrase. Recall the discussion in the preceding section, Section 3.2.6.1, that with the kan-aspect, a PASSIVE construction cannot be formed if the external argument is a CAUSER, because in BI a CAUSER that is involved in an event with kanaspect cannot be the argument of the by-phrase (examples (63) and (65)), and the event is not the result of an ACT (refer back template (71) as against (72)). 
Recall also the discussion in Section 3.2.4.2 with respect to 'Body Parts' where on the surface we seem to have two different subjects: one is the person or the thing as a whole, (41a) and (44a), the other is a body part of this person/object, (41b) and (44b). I propose to extend the notion of whole-part relations here for psych-predicates with the kan-aspect. In this case, kelakuan-nya 'his behaviour', or suara-nya 'his voice', (76b), is in fact an inseparable part of John (76a) (e.g., something about John, what John does, and so on). Either just John, or something about John, or, both of them, can appear in the subject position, (74a,b). Even when it is only John that appears, it implies that what causes the annoyance is in fact only part of him: kelakuan-nya 'his behaviour' or suaranya 'his voice'. The fact that the sentence cannot take an adverbial dengan sengaja 'with intention, intentionally, deliberately' supports this proposal; his behaviour or his voice cannot have an intention to annoy me: it only happens to trigger the event. John may not even be aware that some 'part-of' him annoys me.

The fact that only part(s) of the person triggers the event must be emphasised. To do so, we bring back our discussion regarding a person or a thing as a whole, and 'part-of' the person or the thing, or 'Body Parts', in Section 3.2.4.2, where, for instance, both the person and part-of him/her may appear on the surface structure simultaneously (although the English translation may sound rather odd, it occurs naturally in BI). The surface subject as shown in (74a) is in fact a Topic. For the inseparable 'part-of' the Topic, take for instance kelakuan-nya 'his behaviour', (78).

$\begin{array}{llll}\text { (78) } \mathrm{John}_{i} & \text { kelakuan-nya } & \text { meN-jengkel-kan } & \text { (saya) } \\ \mathrm{J} & \text { behaviour-3sg } & \text { ACT-annoy-KAN } & 1 \mathrm{sg} \\ \text { 'John, his behaviour annoys me' } & \end{array}$

In (78) John is neither a CAUSER that happens to trigger the change of state, nor an AGENT that intends to change the state: he is included in the causal relation through his behaviour. He is only the possessor of kelakuan 'behaviour': the $3^{\text {rd }}$ singular (possessive) pronoun nya is co-indexed with John, and John can 'replace' it, (79). 
$\begin{array}{lll}\text { (79) Kelakuan John meN-jengkel-kan } & \text { (saya) } \\ \text { behaviour J } & \text { ACT-annoy-KAN } 1 \mathrm{sg} \\ \text { 'John's behaviour annoys me/is annoying' } & \end{array}$

However, the occurrence of simultaneous whole-part subject such as in (78) is widespread and it is not just the property of psych-predicates with the kan-aspect. What is peculiar about psych-predicates is that the THEME, such as, saya, $1^{\text {st }}$ singular person, (78) and (79), does not have to be overt (parenthesised in the examples). This constitutes an exception to our 'rule' that with kan-aspect, the THEME must be overt. When the THEME is covert, the event becomes impersonal, for instance, John's behaviour may annoy anyone who knows him, like in the English John's behaviour is annoying.

In English, when we say that someone is sad, we do not necessarily include, as part of the information whether or not there is a change of state, from whatever the initial state of the person is, into being sad; that is the reason the following expression, (80), can be ambiguous of state versus individual level predicate. ${ }^{14)}$

(80) Mother is sad

Perhaps mother in (80) is sometimes or always sad, or perhaps mother was sad only during the time frame referred to by the linguistic expression, i.e., when the sentence was uttered, although one may infer that mother was not sad before or after. We shall leave this type of aspectuality to the $v \mathrm{P}$-external aspects. The $\mathrm{BI}$ equivalent of (80) is shown in the following expression, (81).

(81) Ibu sedih

mother sad

'Mother is/was sad'

14) If forced, that is, since normally the expression implies that mother's state of being sad occurs only for the particular moment; because we know mother well, we do not say that mother is 'a sad case'. In John is a sad case the change of state is not implicated. 
The BI sentence above, (81), means 'Mother is or was sad', is unambiguous for at least two reasons:

(i) if mother was a sad person (i.e., if the state of being sad was an individual level one), then another means of expression must be used, such as for instance shown in $(82 \mathrm{a})$ or $\left(82 \mathrm{a}^{\prime}\right)$, which is similar to the English example used in footnote 14; and

(ii) the best - and only - vP-external aspect that can occur with (81) is progressive aspect, implying that ibu 'mother' was not sad before, and she will be alright sooner or later, (83a). However, when the cause of the state of being sad is included, the future $a k a n$ ' will' can occur, (83b).

Another means of expressing an individual state level predicate is shown in (82b), with $\left(82 b^{\prime}\right)$ as a variation.

(82)a. John orang-nya sedih J person-3sg sad

'John is sad as a person'

$\begin{array}{lll}\text { a'. John (adalah) (se-)orang } & \text { yang sedih } \\ \text { J COPULA a-CLASS } & \text { COMP sad } \\ \text { 'John is a sad person' } & \\ \text { b. John orang-nya/tubuh-nya } & \text { jangkung } \\ \text { J person-3sg/body-3sg tall } & \\ \text { 'John is tall as a person' } & & \\ \text { b'. John (adalah) (se-)orang } & \text { yang jangkung } \\ \text { J COPULA a-CLASS } & \text { COMP tall } \\ \text { 'John is a tall person' } & \end{array}$

(83)a. Ibu sedang $/{ }^{*}$ akan ${ }^{*}$ sudah ${ }^{*}$ telah sedih mother PROG/ FUT/ PERF1/ PERF2 sad 'Mother is (being) sad'

b. Ibu *(tentunya) akan sedih kalau meN-dengar berita itu
mother certainly 'Mother will certainly be sad if she hears the news'
c. $* I b u$ akan sedih ketika meN-dengar mother FUT sad when ACT-hear
'Mother will be sad when she hears the news'

15) The word orang 'person' in se-orang 'a [+human]' is a classifier, to distinguish the noun from other [+animate] beings: se-ekor 'a [-human]' is used for animals. 
The state of being sad in (83a) is only temporary. In the hypothetical expression ( $83 \mathrm{~b})$ the future akan can appear only if preceded by the adverbial tentumya 'certainly' to make the $\nu \mathrm{P}$-external aspect subjunctive (or perhaps also because we never know exactly how a person would react to a news) and is grammatical only if combined with kalau 'if', rather than ketika 'when' (83c). In BI the time adverbial ketika 'when' is used only if the event has happened.

Unlike the state predicates of common adjectives discussed in Section 3.2.6.1, such as kental 'thick', cair 'liquid (adjective, as against the noun cair-an)', panjang 'long', and merah 'red, and so on, all of which can indicate a process in meN-kental 'thicken', meN-cair 'melt', meN-panjang 'lengthen', meN-merah 'redden', and so on, here the psych-predicates cannot occur in such a process, $(84 \mathrm{~b})$. The template as represented in (69) is thus inapplicable, ( $\left.84 b^{\prime}\right)$.

(84)a.

$<$ STATE $>\quad$ sedih, 'sad', jengkel, 'annoyed'

b. *Ibu meN-sedih

mother PROC-sad

'Mother is/was becoming sad'

b'. $\left(\left({ }^{*} \mathrm{BECOME}\right) \quad(x<\right.$ STATE $\left.>)\right)$

When we say that something makes, or causes, someone to become sad, there is a process that can be inferred from the expression, namely, the process of change from being not sad into being sad. In BI the explicit change of state can be expressed in two different ways, namely with and without the kan-aspect; example (85a) below shows that without the kan-aspect, the state predicate must be the 'focus of expression', and not hatinya 'his heart'; the latter is a very 'text-book' type of sentence that does not actually occur naturally, (85b). Example (86) shows the use of kan-aspect to express the change, as usual. 
(85)a. Sedih hati-nya meN-lihat kelakuan-nya sad liver-3sg ACT-see behaviour-3sg 'His heart is sad to see his behaviour'

b. Hati-nya sedih meN-lihat kelakuan-nya liver-3sg sad ACT-see behaviour-3sg 'His mother's heart is sad to see his behaviour'

(86) Kelakuan-nya meN-sedih-kan (hati) ibu-nya behaviour-3sg ACT-sad-KAN (liver) mother-3sg 'His behaviour saddens his mother('s heart)'

Every psych-predicate with kan-aspect, like meN-sedih-kan in (86), which I shall refer to as the concise form, has longer form (i.e., syntactic/analytical) alternants, (87a) and (87b).

(87)a. Kelakuan-nya meN-buat (hati) ibu-nya meN-jadi sedih behaviour-3sg ACT-MAKE (liver) mother-3sg PROC-become sad 'His behaviour makes his mother to become sad'

$\begin{array}{clll}\text { or, b. Kelakuan-nya meN-buat sedih } & \text { (hati) } & \text { ibu-nya } \\ \text { behaviour-3sg ACT-MAKE sad } & \text { (liver) } & \text { mother-3sg } \\ \text { 'His behaviour makes his mother sad' } & & \end{array}$

Regarding the choice between long and short forms, the Language Committee of Bahasa Indonesia (Dewan Bahasa Indonesia) suggests, in its 'Guidelines for good writing of Bahasa Indonesia' (Kamus Besar, 'Large Dictionary', 1988, KB henceforth), that we use the short form, such as (86), because it is more concise, instead of the longer forms such as $(87 \mathrm{a}, \mathrm{b})^{16}$. The meaning given by $K B$ for all de-adjectivals with the suffix - $k a n$ (not just psych-predicates) is consistently 'to MAKE something or somebody to BECOME [whatever is stated by the] Adjective' (KB, passim).

I shall point out that, firstly, while each concise form (with -kan) has longer alternants, the inverse is not true (recall the two strategies discussed in Chapter 2

\footnotetext{
16) The difference between ( $87 a)$ and ( $87 b)$ is a matter of stylistic rules.
} 
regarding the morphological and syntactic/analytical expression of causation); in addition, those psych-predicates that do not take kan-aspect take $i$-aspect. For this reason, the examples of the psych-predicates are grouped in three separate classes of psychpredicates, (88), (89) and (90) below.

Secondly, it is apparent, as argued at the beginning of this section that some PASSIVE cannot be formed due to the fact that the causer is a non-volitional AGENT: with the kan-aspect, real causers cannot be the object of a PP by-phrase.

I have discussed, and exemplified, some BI psych-predicates such as jengkel 'BE annoyed' and sedih 'sad'. Without the kan-aspect, these predicates are states, and with the kan-aspect, they bear change of state interpretation. The internal argument of the BI psych-predicates with the kan-aspect undergoes change of state (i.e., this argument is a THEME). To elaborate this discussion, I shall refer to what has been proposed in the literature regarding psych-predicates.

In the literature, it is known that there are two opposing classes of psych-predicates. They are termed as the "frighten" verbs, as against the "fear" verbs (Grimshaw 1990), or, "Object Experiencer" predicates as against "Subject Experiencer" predicates (for instance, Belleti and Rizzi 1988, Pesetsky 1995, Arad 1998). The first class includes verbs such as frighten, disgust, amuse (such as in 'This dog frightens/disgusts/amuses Nina'), whereas the second class includes fear, like, adore, love (such as in 'Nina fears/likes/adores/loves the dog'). In the first class it is the "Object" (such as Nina) that "experiences" a psychological state, whereas in the second class it is the "Subject" (such as Nina) that "experiences" a psychological state.

The two different terminologies proposed in the literature refer to the same thing, namely, the distinctions between two opposing classes of psych-predicates. As we have seen, in BI, with the kan-aspect the "Object" that undergoes change is a THEME (Perhaps 
the term "THEME Experiencer" predicates is more accurate, since here we are talking about argument roles, besides, what is subject or object on the surface can be an AGENT, a CAUSER, THEME, or a PATIENT. This matter will be made clear in Chapter 5). What matters most here is the use of the kan-aspect for the first class of psych-predicates, and of the $i$-aspect for the second class in BI. Without the kan-aspect or the $i$-aspect, in BI the psych-predicates are states (i.e., non-eventive, non-agentive). For convenience, I shall adopt Grimshaw's (1990) terminology because it is more concise: frighten verbs for the first class (with $-k a n$ ), and fear verbs for the second class (with $-i$ ).

The following paradigms show the BI psych-predicate classes: the first paradigms, (88), show a group of frighten verbs, Groupl. Amongst the characteristics of verbs in this group are that they do not have a PASSIVE form, they take only the kan-aspect, and the internal argument is a THEME. In addition, the THEME ' $X$ ' may be covert.

(88) Group1, frighten verbs take only the kan-aspect:
a. bosan, 'BE bored'
bosan-kan $(X)$
'to bore $X$ ', 'boring'
b. senang, BE glad' senang-kan $(X)$
'to please $X$ ', pleasing'
c. sedih, 'BE sad'
sedih-kan $(X)$
'to sadden $X$ ', 'saddening'
d. susah 'BE troubled'
susah-kan $(X)$
'to bother $X$ ', 'bothering', 'troublesome'
e. gembira, 'BE joyful'
f. curiga, 'BE suspicious'
gembira-kan $(X)$
'to gladden $X$ ', 'good'
curiga-kan $(X)$
'to act suspiciously'
g. jengkel, 'BE annoyed'
jengkel-kan $(X)$
'to annoy $X$ ', 'annoying'
h. takut, 'BE frightened'
takut-kan $(X)$
'to frighten $X$ ', 'frightening'

The second paradigms of the BI psych-predicates, (89) below, show a group of fear verbs, Group2. In contrast with the frighten verbs of (88) above, these verbs have a PASSIVE form, they take only the $i$-aspect, and the internal argument is a PATIENT. While the argument $X$ can be covert in Group1, it is obligatorily present in Group2, namely, with the $i$-aspect. Group2 psych-predicates thus behave like transitive verbs.

(89) Group2, fear verbs take only the $i$-aspect:
a. senang, 'to like'
senang-i $*(X)$
b. suka, 'to like'
suka-i $\quad *(X)$
'to like $X$ '
c. curiga, 'to suspect'
curiga-i $\quad *(X)$
'to like $X$ '
'to suspect $X$ ' 


$\begin{array}{lll}\text { d. cemburu, 'BE jealous' } & \text { cemburu-i } *(X) & \text { 'to BE jealous of } X \\ \text { e. tahu, 'to know' } & \text { (ke-)tahu-i } *(X) & \text { 'to know } X \text { ' } \\ \text { f. marah, 'BE angry' } & \text { marah-i } i(X) & \text { 'to scold } X \\ \text { g. takut, 'BE afraid' } & \text { takut(-nakut)-i*(X) } & \text { 'to try to scare } X \text { ' }\end{array}$

The distinctions between frighten verbs, (88), and fear verbs, (89), are made blurred, by the occurrence of senang, curiga, and takut in both groups. ' $X$ ', the THEME in (88) may be covert, i.e., implied, and it is obligatorily present in (89). The only example available for a psych-predicate that does not take any $v \mathrm{P}$-aspect, and hence, any object, is shown in (90): iri, 'BE envious', is purely a state predicate (As a reminder, unaffixed deadjectival predicates in $\mathrm{BI}$ are state predicates).

(90) Group3, takes neither $v$ P-aspect:

$$
\text { iri, 'BE envious' *iri-kan }(X) \quad \text { *'iri-i }(X) \text { ' }
$$

Predicates of Groupl (88) are non-agentive: they do not take a persuade clause (91b) or adverbial that means deliberately, (91c). In contrast, apart from being agentive (taking persuade clause and the adverbial deliberately), predicates of Group2 (89) behave like ordinary, un-derived, verbs, in that they can take a PATIENT object. As a reminder, PATIENT objects are objects that do not undergo change. The difference between the THEME (i.e., the argument ' $X$ ' of (88)) and the PATIENT, (89) above, can also be shown in the following examples, (91a) and (92a). Examples in (91) use senang1 (i.e., senang of Groupl) 'BE glad', and in (92) use senang2 (senang of Group2) 'to like'.

(91)a. Kelakuan John sangat meN-senang-kan Maria [senang1] behaviour J EMPh ACT-glad-KAN M 'John's behaviour pleases Maria very much'

b. *Tina meN-bujuk John untuk meN-senang-kan Maria $\mathrm{T}$ ACT-persuade $\mathrm{J}$ to ACT-glad-KAN M

'Tina persuades John to please Maria'

c. *Dengan sengaja kelakuan-nyalJohn sangat meN-senang-kan Maria with intention behaviour-3sg/J EMPh ACT-glad-KAN M 'Deliberately/intentionally, John/his behaviour pleases Maria very much' 


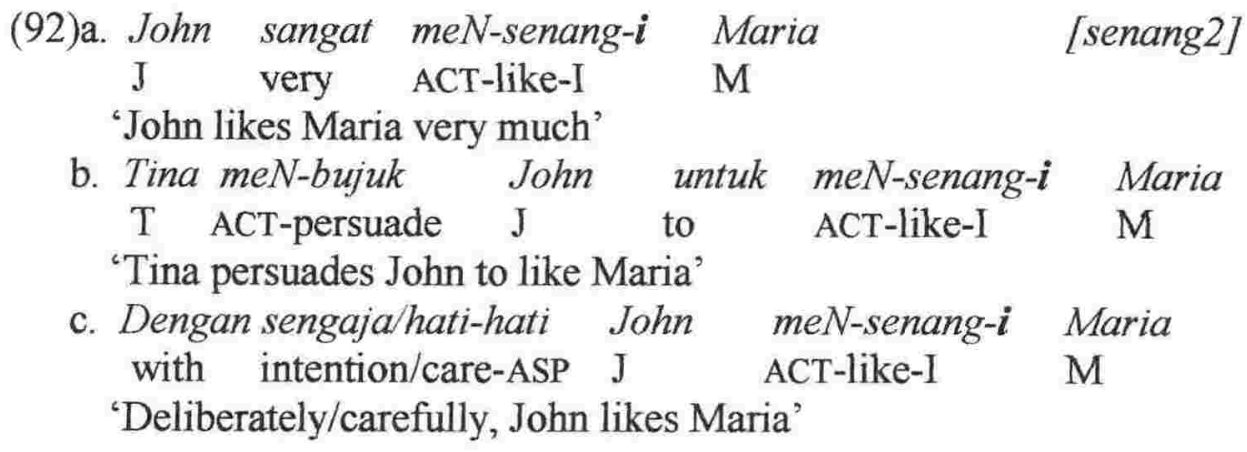

To anticipate our future discussion with respect to the BI VOICE, I shall repeat now that the BI frighten verbs (with the kan-aspect only) as shown in example (91a) do not have a PASSIVE form, (93b). The example (91a) is repeated as (93a).

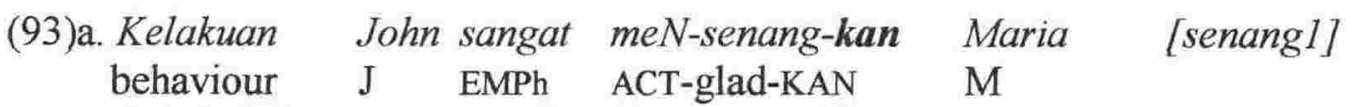
'John's behaviour pleases Maria very much'

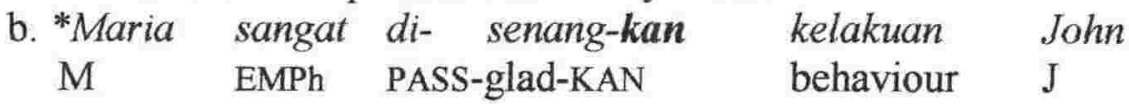
'Maria is pleased by John's behaviour very much'

In (93a) kelakuan John 'John's behaviour' is a CAUSER, and Maria is a THEME that experiences a psychological state (senangl is a "THEME Experiencer" predicate). In contrast, the BI fear verbs, as shown in example (92a) have a PASSIVE form. Example (92a) is repeated here as $(94 a)$.

$\begin{array}{llll}\text { (94)a. John sangat meN-senang-i } & \text { Maria } & \text { [senang2] } \\ \mathrm{J} & \text { very ACT-like-I } & \mathrm{M} & \\ \text { 'John likes Maria very much' } & & \\ \text { b. Maria sangat di- senang- } i & \text { John } & \text { [senang2] } \\ \text { M } & \text { very PASS-like-I } & \mathrm{J} & \\ \text { 'Mary is liked by John very much' } & & \end{array}$

With senang2, that is, with the $i$-aspect only Group2, the argument Maria in (94) is a PATIENT. This argument does not undergo change. Maria may not even be aware that John in both (94a) and (94b) likes her. I shall emphasise that John in $(94 a, b)$ is a volitional AGENT, as shown in (92b) the sentence takes deliberately/carefully adverbial. 
In contrast, kelakuan John 'John's behaviour' (93a), the cause of change, is a nonvolitional CAUSER. Thus, senangl, 'glad', and the rest of Groupl, take a CAUSER as the subject, while senang2, 'to like', and the rest of Group2, take an AGENT as the subject, shown in examples (92). Although both groups are of state of mind, they have different patterns, (95) and (96).

(95) Groupl, frighten verbs:

CAUSER predicate-kan THEME

(96) Group2, fear verbs:

AGENT predicate- $i \quad$ PATIENT

The dichotomy is, in fact, consistent with the notion, that with kan-aspect the argument undergoes change. There is no change to the object argument in Group2, for instance, (92). In (92) there is no information with respect to Maria, as to whether the fact that John likes her very much actually affects her. From the expression, (92a,b), it is not even clear whether Maria is aware of the fact that John likes her. The state of Maria's mind does not enter into the expression.

\subsubsection{Summary}

The kan-predicates exemplified in this section in general show striking similarities. With a few exceptions, kan-predicates that are noun-based express the outcome of the event: some express location as the final destination of the translocation, some express the final form of the THEME, including the final form of the reclassification of the THEME. Adjective-based kan-predicates, be that of common adjectives or of the psychological ones, express the final state of change. The reclassification of THEME with adjectivebased kan-predicates is interpreted as expression of (final) state-like. This is on a par with the noun-based reclassification of THEME as expression of final form.

Some noun-based kan-predicates express manner of movement. With these predicates the object is used as an instrument in the same manner of that expressed in the 
predicate: the manner in which the THEME moves or is moved must match the manner of the instrument expressed in the kan-predicate. In other words, the THEME is cognate with the kan-predicate through manner. This constitutes a distinct group of noun-based kanpredicates, which in this case, the kan-predicate of manner does not express the outcome of the event.

The notion that the kan-aspect encodes change on the internal direct argument is strongly supported by the existence of direction of movement, which is expressed in the kan-predicate, where the final destination of the translocation may or may not be included in the expression (by means of a prepositional phrase). What matters is that the path of the shift to be travelled through by the THEME is expressed in the kan-predicate. Adopting Gruber's (1970: 58) terminology, I call the occurrence "expression of direction".

Change of Type1 can be tabularised as follows.

(97) Change of Typel

\begin{tabular}{|l|l|l|l|}
\hline expression & kan-predicate & THEME & category \\
\hline of final destination & penjara-kan & pencuri & denominal \\
\hline of final form & jail-KAN & thieves & \\
\hline & abu-kan & jenazah & denominal \\
\hline reclassification of THEME & ash-KAN & corpse & \\
\hline & dewa-kan & seseorang & denominal \\
\hline with a manner component & ayun-kan & saki & unspecified \\
\hline & swing-KAN & legs & \\
\hline of instrument used & lap-kan & kain basah & denominal \\
\hline & rag-KAN & cloth wet & \\
\hline body parts as instruments & angguk-kan & kepala & unspecified \\
\hline & nod-KAN & head & \\
\hline directional preposition & ke-samping-kan & persoalan & P+denominal \\
\hline & to-aside-KAN & problem & \\
\hline of final state & kental-kan & kuah & de-adjectival \\
\hline & thick-KAN & gravy & \\
\hline of final state of mind & jengkel-kan & (saya) & de-adjectival \\
\hline & annoy-KAN & 1 sg & \\
\hline
\end{tabular}


Some important points are observed, which are useful for the syntactic analysis of BI:

(i) the kan-aspect requires that the THEME be present; with psych-predicates, however, the THEME can be left covert, but is implied;

(ii) the kan-aspect requires either an AGENT or a CAUSER as an external argument; with the psych-predicates of frighten verb class, the external argument is consistently a CAUSER; with the psych-predicates of fear verb class, the external argument is consistently an AGENT;

(iii) in BI, a PASSIVE with kan-aspect cannot derive if the external argument is a nonAGENT. 


\subsection{Change of Type 2: kan-aspect with verbs}

In Section 3.2 I described the kan-aspect occurring with derived predicates (with denominals, de-adjectivals, and with directional prepositions) and showed that the notion of change holds through. In this section I will show that change occurs with both intransitive and transitive verbs. With the kan-aspect the predicate is transitive and the THEME is obligatorily present as the predicate's complement.

Whether or not the distinction between predicates that are derived (previous section) and predicates that are non-derived or verb-based (this section) plays a significant role in terms of change remains to be seen. There is a good reason to separate verb-based predicates from the rest: some verbs already contain certain components such as movement, some include manner in which the action is usually done, and so on, without the help of the suffix - kan

Without the kan-aspect, an event involving verbs such as meN-buat 'to make'; meN-bangun 'to build', 'to erect', 'to found'; meN-beli 'to buy', and so on, already contains change as event characteristic. With these verbs, the kan-aspect extends the path for the object to travel through: the path of change has a transit point (as a shorthand term, I call the whole path that contains a transit point "transit path"). Different from these verbs, some verbs such as meN-beri 'to give' and meN-kirim 'to send' require that the kan-aspect be used to indicate the translocation of the object. With these verbs, the path of change is direct and has no transit point.

Most relevant for the discussion in the present section is the continuation of the notion that kan-aspect selects THEME as the core argument. An important issue to be dealt with is the question of whether or not the lexical characterisation of the verb-base, such as intransitive (whether unergative or unaccusative), transitive, and ditransitive, provides constraints, and if it does, what sort of constraints it puts on the derivation.

It is generally accepted in the literature that there are two distinct classes of intransitive verbs: the first class is unaccusatives (or ergatives in Burzios's 1986 terms), 
where the surface subject of the clause is actually the object of the predicate (Perlmutter and Postal 1984, and Burzio 1986, Baker 1988, Hale and Keyser 1993, 1998, Wyngaerd 1996); and the other is unergatives where the verb does not subcategorise for an object.

The present analysis is in support of the theory that the subject of an unaccusative sentence is not the $v \mathrm{P} / \mathrm{VP}$ external argument (Perlmutter and Postal 1984, and Burzio 1986, Baker 1988, Hale \& Keyser 1993, Chomsky 1995, Wyngaerd 1996). The distinction between the THEME and the external argument, in particular the AGENT, will be immensely useful for the discussion to come, regarding the argument roles that are involved when it is the $i$-aspect that is present, instead of the kan-aspect.

Hale and Keyser (1993: 76) suggest that unergative verbs are hidden transitives, and the ('D-Structure or S-Structure') subject of an unergative verb is a "true external argument". If that is the case, then the external argument should occupy the [Spec-vP] position, rather than [Spec-VP], as suggested also by Chomsky (1995: 315), so that, like the external argument of transitive verbs, the external argument of unergative verbs "cannot be lower than [Spec, v]". In Chomsky's view, "only unaccusatives lacking agents would be simple VP structures", 17)

I assume for BI in Chapter 2 (refer diagram (7)), following Hale and Keyser (1993), that in the presence of the kan-aspect, the THEME argument occupies the specifier position of the simple VP structure. This assumption fits well with the notion that this position should not be occupied by a "true external argument" as Hale and Keyser (1993: 76) call it. The immediate implication is, if we accept the notion that the argument of an unaccusative occupies the [Spec-VP] as suggested by Chomsky (1995), the subject of an unaccusative undergoes change. This matter will become clear as we proceed. The second implication is that the occupant of [Spec-VP] in unaccusative is not a PATIENT.

\footnotetext{
17) My interpretation of this last premise is that it does not mean that there are unaccusative verbs that assign an AGENT role.
} 
In BI, some verbs can occur unaffixed (i.e., either without prefix or suffix, or without suffix), and the constructions formed are intransitive. A simple method of description is to say that the action involving these intransitive verbs is usually done for one's purposes (Johns 1977, Sneddon 1996, among others) as for instance lari 'to run', pergi 'to go', meN-nyanyi 'to sing', meN-tari 'to dance', mandi 'to wash/have a shower' and so on. However, given that there are two types of intransitive verbs, those that occur in unergative constructions can be employed with a purpose, and those that occur in unaccusative constructions cannot.

What follows is a description of the lexeme $B A N G U N$, which can be used either transitively or intransitively. The description is organised as follows. To start with, this lexeme is shown to occur as an unaccusative, Section 3.3.1. Section 3.3.2 describes the lexeme as it occurs in unergative constructions. The last sections, Section 3.3.3, and Section 3.3.4, show the lexeme in transitive environments. In all, the first three sections assume that BANGUN represents a verb in three different guises (the unaccusative bangun 1 , the unergative bangun 2 , and the transitive bangun 3 ). ${ }^{18)}$

\subsubsection{The unaccusative $B A N G U N$}

The verb bangun 1 occurs as an unaccusative 'to wake up', e.g., from sleep, daydream, etc. To wake up from a sleep may involve a change from one physical or mental state to another. But to wake up from a daydream may only involve one mental state changing to another.

\footnotetext{
${ }^{18)}$ The three are semantically related. However, I shall not be concerned about the semantic relations between them since it is beyond the scope of the present discussion. For simplicity reasons we can assume the existence of bangun 1, bangun2 and bangun3. Rappaport Hovav and Levin (1998: 100ff) argue that the verb's range of occurrences rather than the meaning of the individual verb define the semantics of a verb. Arad (1998a) suggests that the semantics of a verb is not entirely defined by the lexicon; the environment a verb occurs in helps determine the interpretation. As we will see immediately, some core meaning could be associated with the root and that other components of the meaning would be supplied compositionally by the structure in which it appears.
} 
Although the prefix ter- is best discussed in the later chapters as part of the derivation above $v \mathrm{P}$, it enters into the present discussion because it occurs with unaccusative and unergative constructions. I will claim that the prefix realises a Voice head indicating that the event happens unintentionally. The aspectual property of event structures (of $v \mathrm{P}, \mathrm{VP}$ ) puts constraints on the derivation involving the VOICE aspect of ter-.

In the present section we will be discussing the prefix ter-in terms of event structure, rather than as a PASSIVE prefix (cf. for example, Johns 1977, Sie 1988, Sneddon 1996, Sukarno 1996 among others, who include ter- as one of the passive affixes). As it turns out, discussing ter- under BI PASSIVEs is untenable, as our analysis reveals. Thus, for example, with the unaccusative jatuh 'to fall' and the unergative duduk 'to sit', one cannot form a PASSIVE from the unaccusative or unergative, respectively. Analysing the prefix in terms of intentionality of the event captures the essence of ter-. One may see the sentence formed with ter-as PASSIVE-like, especially the sentence with a transitive verb. But unaccusative forms are also PASSIVE-like, in that, the surface subject is in fact the internal argument.

\subsubsection{The verb bangun as a bare unaccusative, and with the prefix ter-}

This verb occurs as an unaccusative to mean 'to wake up', as in waking up from sleep, (98a) and (98b), and it cannot appear when the event of waking up is described with other people's intentions, without including the kan-aspect, (98c). To contrast (98c), the grammatical form is provided, (98d), where the change of state is included in the expression. ${ }^{19)}$

\begin{tabular}{|c|c|c|}
\hline $\begin{array}{l}\text { (98)a. Adik } \\
\text { younger sibling }\end{array}$ & $\begin{array}{l}\text { bangun } \\
\text { wake (up) }\end{array}$ & $\begin{array}{l}\text { dari tidur-nya) } \\
\text { rom his/her sleep }\end{array}$ \\
\hline \multicolumn{3}{|c|}{ 'Little brother/sister woke (up) (from his/her sleep)' } \\
\hline $\begin{array}{l}\text { b. Adik } \\
\text { younger sibling }\end{array}$ & $\begin{array}{l}\text { ter-bangun } \\
\text { TER-wake (up) }\end{array}$ & $\begin{array}{l}\text { (dari tidur-nya) } \\
\text { from his/her sleep }\end{array}$ \\
\hline "Little brother/sis & /was woken (up) & (from his/her sleep)' \\
\hline
\end{tabular}

19) I use BE + passive participle in the English gloss of (98b) and $\left(99 \mathrm{~b}, \mathrm{~b}^{\prime}\right)$ to show the difference between forms with and without ter-. This PASSIVE-like form is different from those with the prefix di- where an AGENT is required as an argument of the oleh by-phrase. 


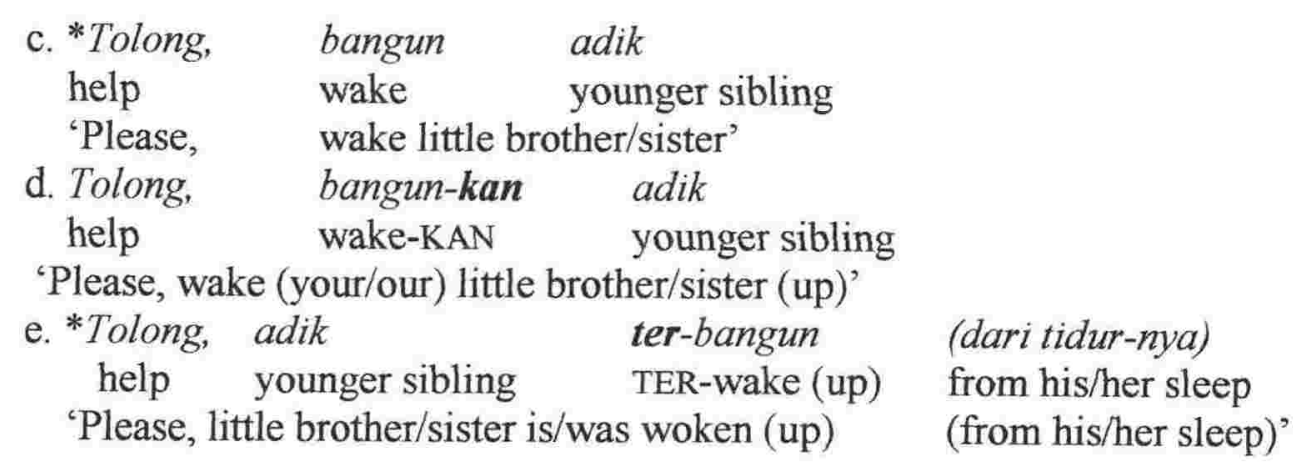

Suffice it to say that both (98a) and (98b) are unaccusative because the subject is a THEME: the argument adik 'younger sibling' undergoes change of state, namely, from being asleep to being awake. The usual tools for testing (such as, purpose PP, intentionality, adverbial 'carefully', for instance) can also be used, and as expected, both will pass the test, $\left(99 \mathrm{a}, \mathrm{a}^{\prime}\right)$ and $\left(99 \mathrm{~b}, \mathrm{~b}^{\prime}\right)$. What follows also shows that the verb cannot be used with one's intentions (Example (98c) shows that it cannot be used with other people's intentions). ${ }^{20)}$

(99)a. *Adik

bangun (dari tidur-nya) tanpa alasan younger sibling wake (up) from his/her sleep without reason 'Little brother/sister woke (up) (from his/her sleep) without any reason'
a'. *Adik bangun (dari tidur-nya) supaya tidak ter-lambat younger sibling wake (up) from his/her sleep in order NEG TER-late 'Little brother/sister woke (up) (from his/her sleep) in order not to be late'
b. *Adik ter-bangun (daritidur-nya) tanpa alasan younger sibling TER-wake (up)(from his/her sleep) without reason 'Little brother/sister was woken (up) (from his/her sleep) without any reason'
b'. *Adik ter-bangun (daritidur-nya) supaya tidak ter-lambat younger sibling TER-wake up from his/her sleep in order NEG TER-late 'Little brother/sister was woken up (from his/her sleep) in order not to be late'

\footnotetext{
20) This is an alternative approach to those that suggest that external versus internal causes play a part in determining unaccusativity (for instance, McKoon \& MacFarland 2000, Rappaport Hovav \& Levin 1998, Levin and Rappaport Hovav 1995, among others). In BI, when it is definitely an external CAUSE that is involved in the change of state predicates, or change in general, the suffix -kan must be used. McKoon \& MacFarland (2000: 837) note that one of their studies 'shows that the probabilities of occurrence [of the tested verbs, WS] in transitive and intransitive sentences do not distinguish externally from internally caused change-of-state verbs'.
} 
Recall the discussion on the psych-predicate with ibu sedih 'mother is/was sad', of example (81), where the state predicate sedih 'sad' cannot be involved in a process: it cannot occur as *Ibu meN-sedih 'mother is/was becoming sad', and thus, the primitive BECOME cannot be included in the template. Like sedih 'sad' in example (81), the predicate bangun 'wake (up)', examples (98a) and (99a,a'), cannot be involved in a process: *Adik meN-bangun to mean 'little brother is waking up' is not allowed. Note also that all examples in (99) can be modified with prepositional phrases that indicate a cause (either internal or external cause). Those reason or intention prepositional phrases can be substituted with cause prepositional phrases, and the sentences become acceptable, just like the state predicates discussed in Section 3.2.6. Both sedih 'sad' and bangun 'wake (up)' in the examples are used to express an end-state. The question here is what difference the prefix ter- makes, (98a) against (98b), or (99a,a') against (99b, b').

While both (98a) and (98b) are unintentional, as shown in (99a,a') and (99b, b'), the waking up in (98a) can be construed as if it was time (perhaps because of the usual time of waking up, perhaps also due to his/her biological clock) for the little brother/sister to wake up; the waking up in (98b) is definitely adversative, perhaps due to an outside interference, such as a loud noise, also perhaps because of a bad dream, which is presumably an internal cause. Whatever the cause of the waking up is, external or otherwise (refer footnote 20), it is not included in the expressions. What is crucial is the interpretation that the event of waking up of (98b), when the prefix ter-appears, happens or has happened unexpectedly. A higher layer aspect - of those external to $v \mathrm{P}-$ such as the [+PERFECTIVE] sudah 'have', and baru 'just', can occur with (98a) but only baru can occur with (98b). Thus, not only is the event of (98b) against one's will - or, perhaps just without involving one's will - it is also unexpected. What we have here is, in addition to the role of the prefix ter-, the event in the predicate puts some constraints on the higher layer aspects. Examples (98a) and (98b) are modified into (100a) and (100b) respectively. Example $\left(100 b^{\prime}\right)$ is what is not allowed, namely, the perfective sudah in an event with ter- 


\section{(100)a. Adik baru/sudah bangun (daritidur-nya) \\ younger sibling PERF wake (up) from his/her sleep \\ 'Little brother/sister just woke (up) from his/her sleep' [with baru] \\ 'Little brother/sister has woken (up) from his/her sleep' [with sudah]}

\begin{tabular}{|c|c|c|c|}
\hline $\begin{array}{l}\text { b. Adik } \\
\text { younger sibling } \\
\text { "Little brother/sis }\end{array}$ & $\begin{array}{l}\text { baru } \\
\text { PERF } \\
\text { ter was }\end{array}$ & $\begin{array}{l}\text { ter-bangun } \\
\text { TER-wake (up) } \\
\text { woken (up) }\end{array}$ & $\begin{array}{l}\text { (dari tidur-nya) } \\
\text { from his/her sleep } \\
\text { (from his/her sleep)' }\end{array}$ \\
\hline $\begin{array}{l}\text { b'. *Adik } \\
\text { younger sibling } \\
\text { 'Little brother/sis }\end{array}$ & $\begin{array}{l}\text { sudah } \\
\text { PERF } \\
\text { er has }\end{array}$ & $\begin{array}{l}\text { ter-bangun } \\
\text { TER-wake (up) } \\
\text { woken (up) }\end{array}$ & $\begin{array}{l}\text { (dari tidur-nya) } \\
\text { from his/her sleep } \\
\text { (from his/her sleep)' }\end{array}$ \\
\hline
\end{tabular}

The perfective MODAL sudah 'have' is used with a sense that the event is expected to happen, and it has happened (I will come back to the role of features [ \pm expected] of the BI MODAL selection in Chapter 5). The same reasoning also applies to the event involving the verb jatuh 'to fall', which is also unaccusative, in the following examples, (101). The sentence takes sudah only if the fall is expected or is waited for, (101a), but not when it is an accident, (101b). Like ter-bangun, $(100 \mathrm{~b}, \mathrm{c})$, ter-jatuh only takes baru, (101d).

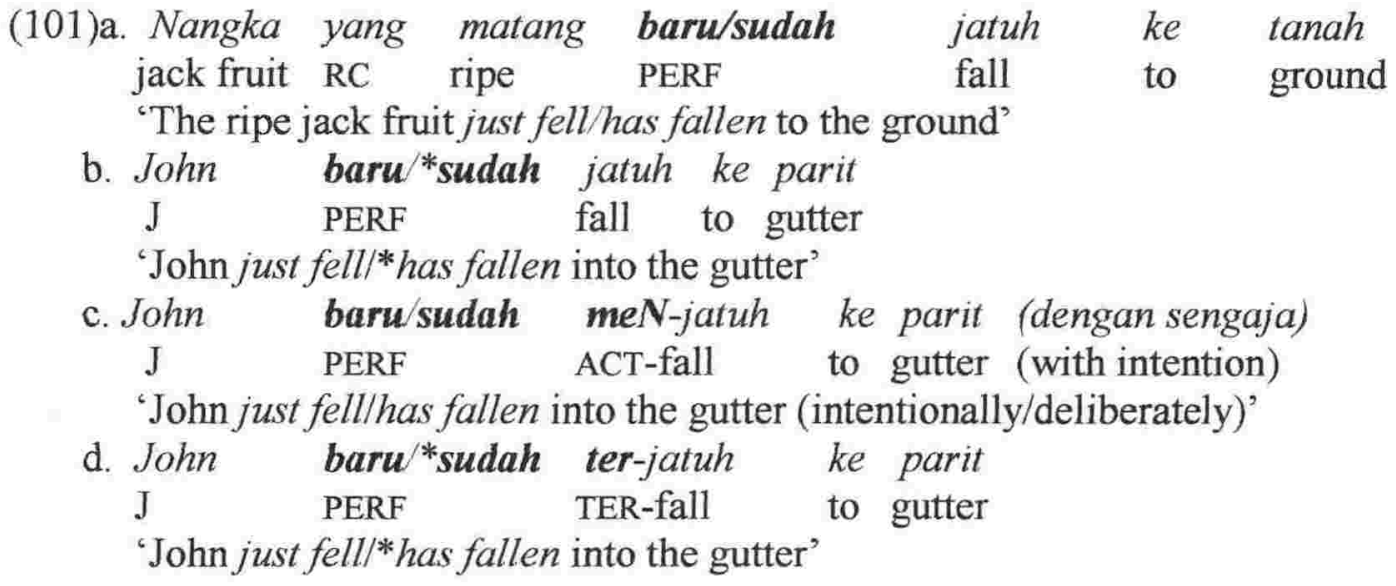

In (101c) the event of falling is an intentional act, done by the AGENT John (we set aside the question of whether John is in fact an internal agent, namely, whether it is based at [Spec-VP] or [Spec-vP], but see Chapter 5 on the meN-unergative). What is important for now is the interpretation that the fall is deliberately done, and the sentence takes both perfective baru and sudah. 
To conclude, to use the perfective MODALs (baru and sudah in our examples) the features [ \pm expected] must be considered. As we have seen, the absence or the presence of intentionality in the event interacts with the use of the perfective [+expected] sudah or the perfective [-expected] baru, examples (100b') and (101b,d). I will come back to the BI $v$ P-external aspect in Chapter 5. What matters now is the intentionality of the event, that is, even though the prefix may be involved in a PASSIVE derivation, the event expressed with ter- is unintentional in nature.

\subsubsection{Kan-aspect with the unaccusative base BANGUN}

Crucial for the present section is what happens if a cause of the waking up is included in the expression, such as shown in the following examples, (102), where the event involving an AGENT $i b u$ 'mother' is intentional, with the internal argument adik 'younger sibling' included, and thus, the complex predicate meN-bangun-kan 'to wake up someone' now can take the argument adik as its complement.

(102)a.Ibu meN-bangun-kan adik tanpa alasan
mother ACT-wake -KAN younger sibling without reason
'Mother woke up little brother/sister without any reason'
b. Ibu meN-bangun-kan adik supaya tidak ter-lambat
mother ACT-wake -KAN younger sibling in order NEG TER-late
'Mother woke up little brother/sister in order not to be late'

We shall maintain that the base of the predicate bangun $1,(102 a)$ and (102b), "remains" unaccusative, 'to wake up'. What happens is that the AGENT $i b u$ 'mother' makes the THEME adik to wake up, just like in example (91) of Subsection 3.2.6.2 (Change of State: Psych-Predicates and Predicates of cognition), except here we have an AGENT; in (91) it is a CAUSER: kelakuan-nya 'his behaviour'. That is not to say that the complex predicate in (102) cannot take a CAUSER, because it can, (103a), and the effect is of interest here.

Firstly, the sentence (103a) does not have a 'canonical' PASSIVE counterpart, (103b). Example (104b) shows the PASSIVE counterpart of (102), repeated here as (104a). 
Secondly, with a CAUSER such as keributan di luar 'noises outside', (103a), the sentence then cannot take a reason PP, thus, unlike sentences with the AGENT ibu 'mother', in (104a). However, the non-agent keributan di luar 'noises outside' can be included as an argument of a cause prepositional phrase or "PP-cause", (103b'), where the event of waking up is unexpected (recall example (100b)). The sentence (103b') is usually used to express that we do not want adik 'younger sibling' to wake up, but he/she wakes up anyway because of the noises outside.

(103)a. Keributan di luar meN-bangun-kan adik noises in outside ACT-wake -KAN younger sibling (without reason) 'Noises (that come from) outside woke up little brother/sister'
b. *Adik di-bangun-kan oleh keributan
di luar younger sibling PASS-woke-KAN
by noises

'Little brother/sister was woken up by noises from outside'
b'. Adik
ter-bangun
karena
keributan
younger sibling TER-wake
because noises in outside

'Little brother/sister was woken up because of noises from outside', i.e., woke up
(104)a.Ibu meN-bangun-kan adik tanpa alasan
mother ACT-wake -KAN younger sibling without reason
'Mother woke up little brother/sister without any reason'
b. Adik
di-bangun-kan
oleh ibu
(tanpa
alasan)
younger sibling PASS-woke-KAN
by mother(without reason)
'Little brother/sister was woken up by mother (without reason)'

The oleh by-phrase can be used in (104b), which is the PASSIVE alternant of (104a), but not in (103b), the hypothetical PASSIVE counterpart of (103a). This phenomenon must also be considered for the discussion with respect to the prefix $m e N-$, which we shall setaside until Chapter 5 (of VOICE and transitivity). Recall also the use of the prefix $m e N$ - in relation to de-adjectivals without the kan-aspect (meN-panjang 'to lengthen (as if by itself)', meN-kecil 'to shrink', etc.), where no cause is included. To express overtly an AGENT such as ibu 'mother', like in (102)/(104a), or a CAUSER such as keributan di luar 'noises outside', (103a), as the surface subject, a "causal relation" (Hale and Keyser's 1993 term) must exist within the predicate. Hale and Keyser (1993: 69-73) and also Chomsky (1995), suggest that the causal relation between the predicate and its object forces the use of an AGENT. However, as we have seen in example (107a), a CAUSER may 
occur in place of the AGENT. Hale and Keyser (1998: 111), who discuss only the verb and its complement, state that

"The external argument of the transitive enters into the picture only when the verb is in fact transitive and assigns case to the internal argument. Burzio's generalization is a natural consequence of the framework as it functions in these cases."

We take it that Hale and Keyser's (1998) "external argument" includes both AGENT and CAUSER, where "external" simply means outside the VP.

The fact that the form meN-bangun-kan 'to wake (up)' in (103a) can take either an AGENT $(102) /(104 a)$ or a CAUSER (103a) is important to consider. Recall that deadjectivals (of common adjectives) with the kan-aspect take only an AGENT as the external argument (3.2.6.1), while psych-predicates with kan-aspect take only a CAUSER as the external argument (3.2.6.2). What we have here is that the unaccusative bangun 1 'to wake (up)' is like, or can behave like, psych-predicates. Apart from taking a CAUSER as an external argument, just like the psych-predicates, bangun 1 is a state - or "end-state" to be precised - predicate that appears not to be involved in a process.

Putting the discussion back on the track, when the event of waking up little brother/sister is caused by the AGENT mother, (102)/(104a), or by the CAUSER noises from outside, (103a), the change is encoded by the kan-aspect. In addition, the base bangun as expressed in the predicate is in fact the end-state: in the unaccusative forms, examples (98) and (99), it is a final state expression, and in the transitive forms, examples (102), (103a) and (104a), it is a final state involving change. The latter is reminiscent of the outcome of our discussion with respect to the kan-predicate that expresses the final destination of the shift (3.2.1), the final form of the THEME (3.2.2), and the final state involving de-adjectivals (3.2.6).

In summary, the expression in (102) must be interpreted as mother makes little brother/sister wake up. In both (98a) and (98b), little brother/sister woke up, but whatever 
causes him/her to wake up is not stated in the expression, perhaps because there is no obvious cause, or perhaps cause is not relevant, and no kan-aspect is involved. In (103a), the cause of waking up is stated, but it is different from that of (102), in that this cause is not a volitional AGENT.

If we follow the theory put forward in the literature, then the change, non-change and causal relations of the BI examples above can be summarised using a standard template of lexical semantic representation (or "LSR", for instance, Lieber 1998, Rappaport Hovav \& Levin 1998: 125-126, among others). In the LSR (105) below, template (i) shows state predicates (example (81), template (84)), (ii) unaccusatives, (iii) kan-aspect with unaccusatives.

(105) The LSR of BI state predicates, unaccusatives, and the unaccusative-based kan-predicates:

(i) Ibu sedih

$(x \quad$ STATE $>)$

(ii)a. Adik bangun

$($ BECOME $(\mathrm{x}<$ STATE $>))$

b. Adik ter-bangun

$($ BECOME $(\mathrm{x}<$ STATE $>))$
Mother is $s a d$

$x$ : ibu, 'mother'; STATE: sedih, 'sad'

Little brother/sister is woken (up)

$x$ : adik, 'little brother'

STATE: bangun, 'wake up', adik enters a new state

CAUSE $=$ empty

Little brother/sister is woken (up)

$x$ : adik, 'little brother'

STATE: bangun, 'wake up', adik enters a new state

CAUSE $=$ empty

(iii) Ibu/keributan diluar meN-bangun-kan adik

Mother/noises outside ACT-wake-KAN little brother/sister

$((\alpha)$ CAUSE $\quad($ BECOME $(x<\operatorname{STATE}>)))$

The event in (iii) contains two sub-events: in the sub-event with $\alpha$, i.e., with $I b u$ suarasuara 'mother/noises', there is a cause of the change; and in the sub-event with $x$ : i.e., with adik' 'little brother', adik enters a new state, see (ii). 
There is a slight problem with the template represented in (ii), in that the prefix teris shown as if it is optional or redundant. The template does not distinguish between an event with and without the prefix ter-. Two immediate problems with template (iii) are that, firstly, the subevent with $\alpha$ may contain a CAUSER as against AGENT (which can also be seen as a cause). And secondly, when a predicate contains both a prefix (e.g., meN-) and a suffix (e.g. $-k a n$ ) like in our examples above, then we have a question, as to how to relate the template such as (105)-(iii) above with what we have discussed so far: the suffix - kan marks a $v$-aspect (kan-aspect) indicating change with variations that include change of state, having the template (BECOME $(x<$ STATE $>))$.

As we have seen, with AGENT such as $i b u$ 'mother', (102)/(104a), the event of waking up of the subevent with $x$ is a result of ACT (the AGENT intends to bring about the event). With CAUSER such as keributan di luar 'noises outside', (103), the subevent with $x$ is a result of 'HAPPEN-ing' (the CAUSER happens to trigger the event: notated as 'HAPPEN' for short). Recall that (103a) cannot have a PASSIVE form and a reason prepositional phrase. Thus, the template for $(102) /(104 a)$ should be different from that of (103a), shown as (106) and (107) respectively.

(106) $\left(\left(\right.\right.$ Ibu $\left.{ }_{A C T}\right)$ CAUSE (BECOME $($ adik< $<$ bangun $\left.\left.>)\right)\right) \quad i b u$ is an AGENT

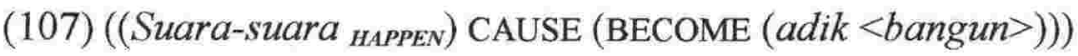
suara-suara is a CAUSER

Recall also (Section 3.2.6) that the prefix meN- with de-adjectivals gives the interpretation of (BECOME ( $<<$ STATE $>$ )), for instance, kuning 'yellow', meN-kuning: 'to become yellow'; kecil 'small', meN-kecil: 'to become small', 'to shrink'; pucat 'pale', meN-pucat: 'to become fade'; cair 'liquid (adjective)', meN-cair: 'to become liquid', 'to melt', and so on. I will come back to this matter in Chapter 5. 


\subsubsection{Basic structures}

What follows, (108), is the simplest predicational structure in syntax, the unaccusative structure (as suggested by, for instance, Chomsky 1995, Hale and Keyser 1998), to show the structure with bangunl and jatuh 'to fall'. The structure (109) shows bangun1 and jatuh with the Voice head ter-, and (110) bangun 1 with the kan-aspect. I assume (following, for instance, Radford 1997, Hale and Heyser 1998, Chomsky 1995, Travis 2001) without reservations the tree diagrams to ease the understanding of Sub-sections 3.3.1.1 and 3.3.1.2 above. It will become apparent as we proceed as to why we adopt the style of tree representation, in particular, Section 3.4 will introduce the use the Larsonian $v$ P-shell.

(108). The unaccusative bangunl and jatuh:

John bangun/jatuh 'John woke up/fell'

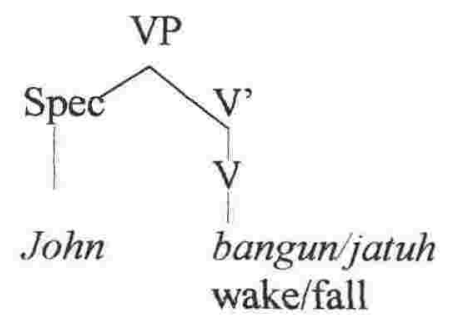

(109) bangunl and jatuh with ter-:

John ter-jatuh 'John fell' and John ter-bangun 'John woke up' (both are an accident)

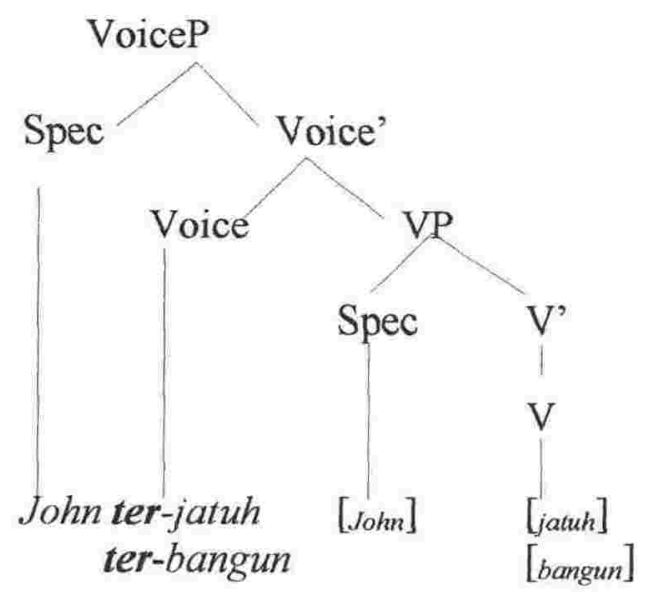


(110) bangunl with the kan-aspect: $v$ P transitive

Ibu meN-bangun-kan adik $\quad$ (Ibu is an AGENT)
mother ACT-wake-KAN sibling
'Mother woke up little brother/sister'

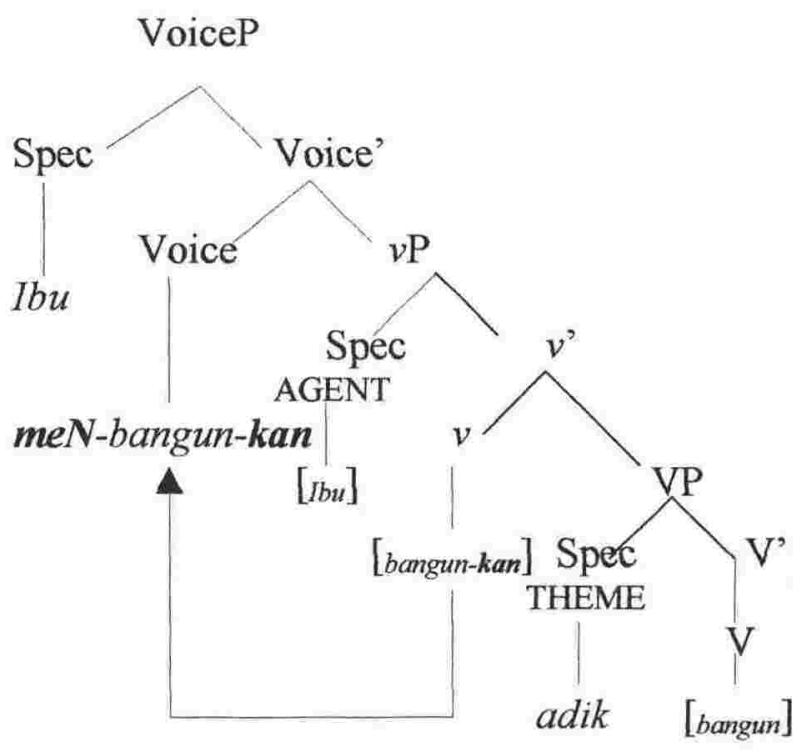

The interpretation for (109), where ter- is used, is that the waking up or the fall is unambiguously an accident. In (110) adik at [Spec-VP] has the interpretation of a THEME (adik undergoes change of state).

\subsubsection{The verb bangun as an unergative}

The verb bangun also occurs as an unergative (= bangkit, obsolete), 'to get up', e.g., from bed, from a chair, etc., namely, from one physical position to another. This type of unergative is different from those of de-nominal unergatives (e.g., kata 'word', ber-kata: 'to speak'; jalan 'road', ber-jalan: 'to walk'; diri 'self', ber-diri: 'to stand', etc.), where the prefix ber-occurs to "strengthen" the incorporated lexical nouns so they can function as a predicate, in parallel with the requirement of the prefix $m e N$ - for de-adjectivals (Section 3.2.6.1). I assume that bare unergative verbs can appear without affixes because they do not need an affix to function as verbs. For example, because it is possible to use, or perceive, jalan as a verb to mean 'to walk', rather than as a noun 'road', then some speakers in informal register sometimes drop the prefix ber-, as in jalan ke kota, 'to walk 
to the city', but the prefix ber- cannot be dropped from ber-diri 'to stand', ber-kata 'to speak' and so on. On the other hand, verbs of motion, bare verbs, that is, do not take the prefix ber-, for instance, pergi 'to go', *ber-pergi; datang 'to come', *ber-datang; bangun 2 'to get up', *ber-bangun; duduk 'to sit', *ber-duduk and so on. To enable these verbs to take ber- they must be 'nominalised'. This description may sound 'circular', which is not: it is simply that the prefix ber-takes a noun or a nominalised element (It is also claimed by Hale \& Keyser 1993, 1998: 113, that English unergatives are denominals). We will discuss only the last two verbs, bangun2 'to get up' and duduk 'to sit' in the immediate subsection that follows (3.3.2.1).

We have two types of unergative: one type is derived from a noun and requires berto indicate unergativity such as ber-kata [BER+word] 'to speak', ber-jalan [BER+road] 'to walk', and the other type is a verb that is inherently unergative such as bangun 2 'to get up' and duduk 'to sit'. Despite the difference between the two types, however, both have something in common: (i) the action can be done for one's purposes, and (ii), the event expresses an ACT, as opposed to HAPPEN as described for event with unaccusative base (the distinctions between these two events have been discussed, for instance, in Tenny 1987, Arad 1998a, Ritter and Rosen 1998, among others).

\subsubsection{The verb bangun as a bare unergative}

In this section I demonstrate that the verb bangun also occurs as unergative to mean 'to get up' (as bangun2). As bangun2 this verb can take the prefix ter-, and this fact raises a question as to whether intentionality as discussed in Section 3.3.1 belongs to VOICE, or otherwise to the event structure.

While the act of waking up from asleep in (98a) and (98b) with bangun 1 is unintentional, shown in (99a) and (99b), the getting up from a chair, (112a) below with bangun 2 is intentional, and the construction takes a reason PP. The phrase dari kursinya 'from his/her chair' is included only to disambiguate the waking up (bangun 1 ), such as (107), and the getting up (bangun2). To see the contrast, examples (103a,b) are repeated here as (111b) and (112b) respectively. The sentence in (111a) takes a reason PP, but not 
(111b). I take it that (111a) is unergative. With the prefix ter-, however, (112a) and (112b), the sentences do not take a reason PP, despite the difference that (112a) is unergative-based and (112b) is unaccusative-based.

\begin{tabular}{|c|c|c|c|}
\hline $\begin{array}{l}\text { (111)a. Adik } \\
\text { younger sibling }\end{array}$ & $\begin{array}{l}\text { bangkit/bangun } \\
\text { get up from h }\end{array}$ & $\begin{array}{l}\text { (dari kursi-nya) } \\
\text { is/her chair }\end{array}$ & $\begin{array}{l}\text { tanpa } \\
\text { without }\end{array}$ \\
\hline
\end{tabular}
b. *Adik
bangun (dari tidur-nya)
tanpa alasan
younger sibling wake (up) from his/her sleep without reason
'Little brother/sister woke (up) (from his/her sleep) without any reason'

(112)a. Adik

ter-bangkit/-bangun (dari kursi-nya)

younger sibling TER-get up from his/her chair

(*tanpa alasan)

'Little brother/sister got up (from his/her chair) (without reason)'
b. Adik
ter-bangun (dari tidur-nya)
(*tanpa alasan)
younger sibling TER-wake (up)(from his/her sleep) without reason
'Little brother/sister was woken (up) (from his/her sleep) (without reason)'

It must be said that the role of the argument adik is that of AGENT in both (111a) and (112a). The difference is, in (111a) adik is in control of the action, while in (112a) adik does not have control over the situation. I shall claim that this AGENT remains volitional in (112a), although the ACT of getting up from the chair is done 'absentmindedly'. Like the examples shown in (98) and (99) for the verb bangunl 'to wake up', here in (112a) adik got up from the chair unintentionally, perhaps s/he is in a state of shock. As another example of unintentional ACT, we also have ter-duduk 'to sit down unintentionally', (113).

(113) Ibu ter-duduk meN-dengar berita sedih itu
mother TER-sit ACT-hear news sad the
'Mother fell on the seat upon hearing the sad news'

Both examples (112a) and (113) only appear to be unaccusative, because neither takes an intentional or adverbial PP that means 'carefully', simplified in (114a) and (115a), which is in contrast with the unergative (114b) and (115b). 


\section{(114)a. Adik ter-bangkit/-bangun (*dengan sengaja/*dengan hati-hati) younger sibling TER-get up with intention/ with care 'Little brother/sister got up intentionally/carefully'}
b. Adik bangkit/-bangun
dengan
sengaja/ dengan hati-hati
younger sibling get up
with intention/ with care
'Little brother/sister got up intentionally/carefully'
(115)a. Ibu ter-duduk (*dengan sengaja ${ }^{*}$ dengan hati-hati) mother TER-sit with intention/care-ASP 'Mother fell on the seat intentionally/carefully'
b. Ibu duduk dengan sengaja/ dengan hati-hati mother sit with intention/care-ASP 'Mother sat down intentionally/carefully'

Thus, what our examples (112)-(115) show that ter- is non-agentive - apart from the fact that we have bangun 1 and bangun 2 . The unintentionality of ter-leads me to assume that this prefix is a realisation of the Voice head. In the case of unaccusative base bangun 1 (as in the tree diagram (108) Sub-section 3.3.1.3) we have ter+VP because the specifier of the verb is projected and we do not have a $v \mathrm{P}$.

However, with the unergative base bangun2 and duduk 'to sit (down)' (tree diagram $(116 \mathrm{a}, \mathrm{b})$ below), we can have ter $+v \mathrm{P}$ with bangun 2 and duduk 'to sit', (117) below. On the surface, it is the prefix ter-, of (114a) and (115a), that makes the difference: adik 'younger sibling', and ibu 'mother', in (114a) and (115a) appear to be THEMES (if we hold the view that the surface subject of unaccusatives is a THEME). In all the cases, however, the arguments adik 'younger sibling' (114) and ibu 'mother' (115) must raise to check a position, which I assume for now to be the [Spec-VoiceP], diagrams (116c) and $(117 \mathrm{a}, \mathrm{b})$ 
(116) The $v \mathrm{P}$ tree diagrams of the unergative bangun2 'to get up' and duduk 'to sit':
a. Adik bangkit/-bangun dari kursi younger sibling get up from chair 'Little brother/sister got up from the chair'

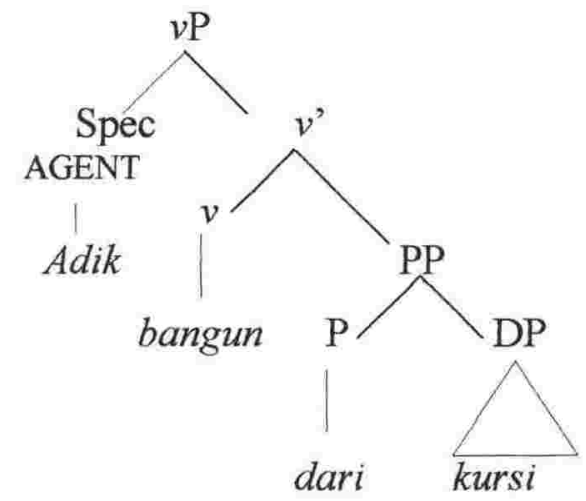

b. Ibu duduk di kursi mother sit on chair

'Mother sat on the chair'

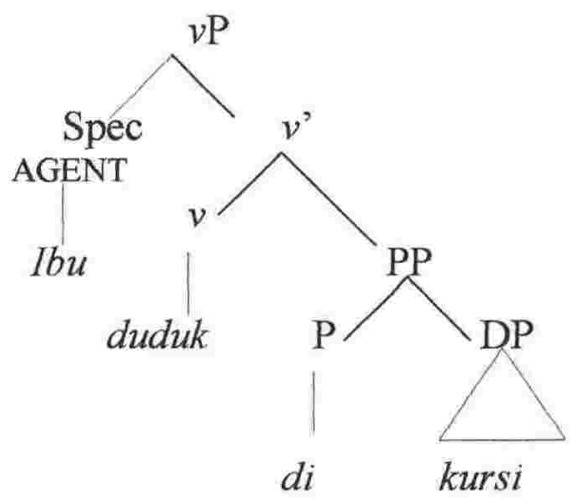


c. bangkit/bangun 2 with the Voice head empty (indicated by ' $O$ '):

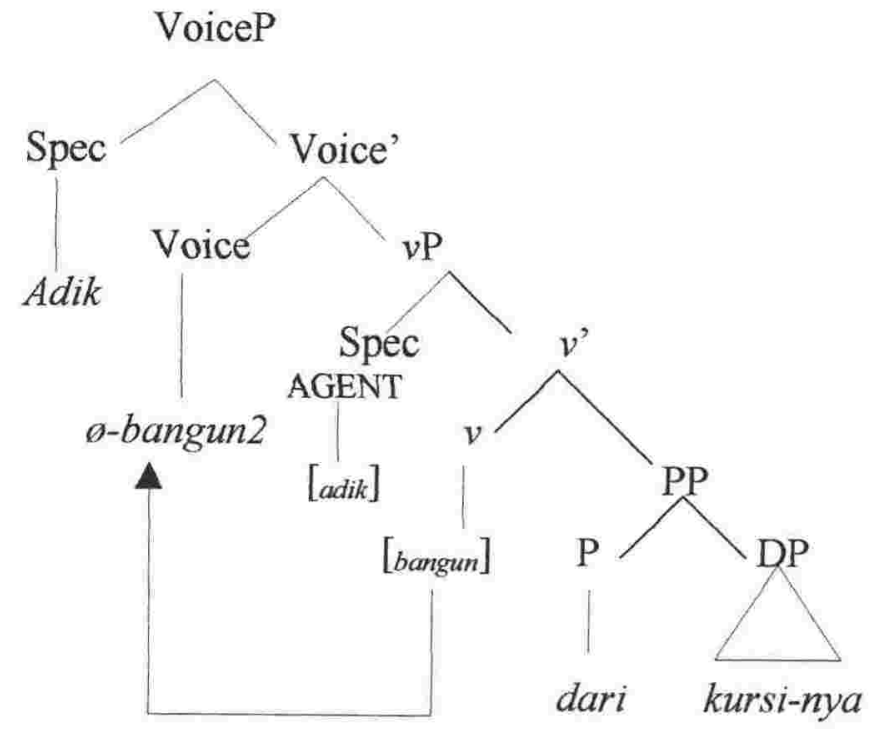

(117) Tree diagrams of the unergative bangun 2 and $d u d u k$ with ter-
a. Adik ter-bangun dari kursi-nya sibling ACT-get up from chair-3sg
(Adik is an AGENT)
'Little sister got up unintentionally from her chair'

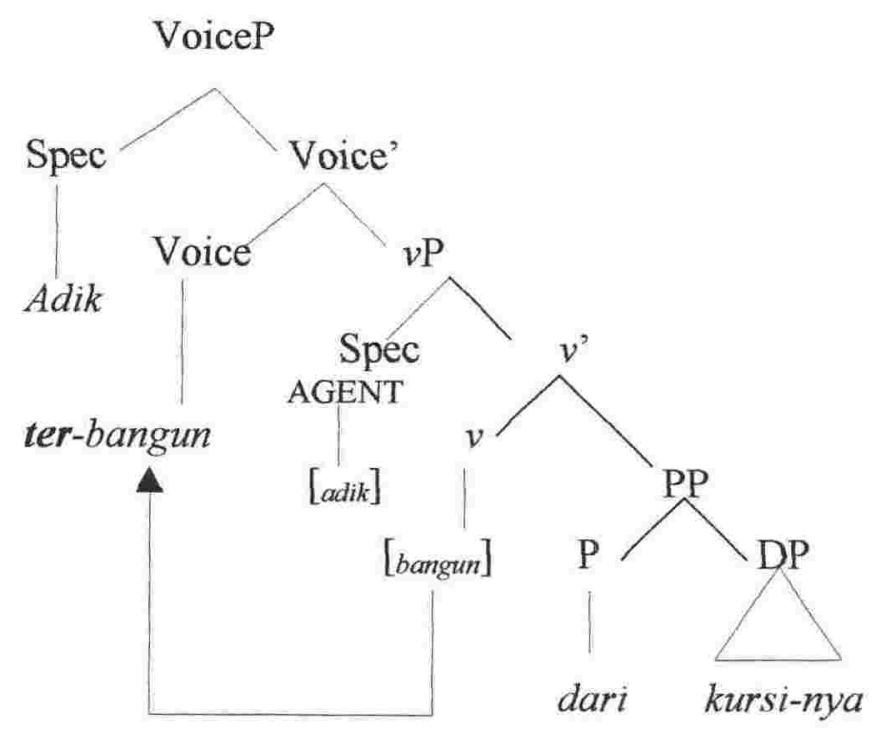




\section{b. Ibu ter-duduk di kursi mother TER-sit on chair \\ 'Mother sat down unintentionally on the chair'}

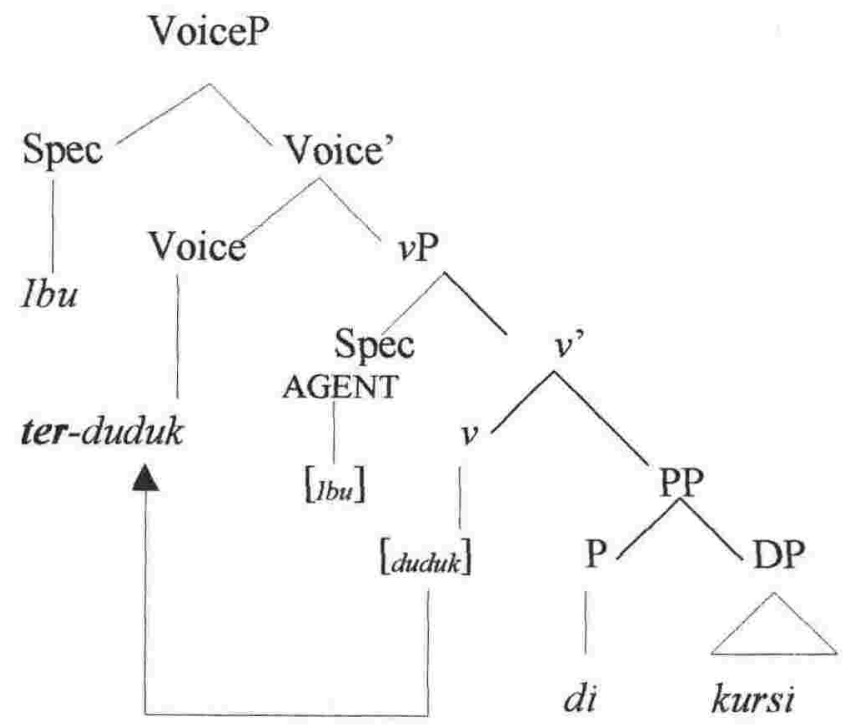

In the present analysis the external arguments adik (117a) and ibu (117b) are not "internalised", and the predicate is not "de-unergativised", on a par with the notion that "there is no such a thing as de-transitivization" process in syntax (Hale and Keyser 1998, Bowers 2002). The difference between the structure without ter- at Voice ${ }^{\circ},(116 \mathrm{c})$, and the structure with the ter-, $(117 \mathrm{a}, \mathrm{b})$, is that in the latter an AGENT participates in the event.

In sum, we shall maintain that ter- only encodes unintentionality, but does not actually determine the characteristic of a structure being unaccusative (As it happens, the tests we use for unaccusativity also work for unintentionality). We have in our examples something that happens as an accident. Perhaps this intentionality also covers an ACT that is done 'absent-mindedly', in parallel with the English 'John opened the door/sat down/got up absent mindedly', but we would not want to call the verbs in this structure uncaccusative. In effect, I shall claim that the intentionality encoded by the prefix terbelongs to VOICE, rather than to the event structure. BI VOICE, I claim, is external to the 
$\mathrm{VP}$ and to the $v \mathrm{P}$. The prefix can be used with event structures involving the VP as well as the $v \mathrm{P}$.

There are verbs in BI that cannot be involved in such an unintentional event, for example, verbs such as datang 'to come', pergi 'to go', lari 'to run', and so on, examples that follow, in (118). This non-occurrence explains why these verbs never have the prefix ter-. On the other hand, there are verbs - that is, when kan-aspect is not used - that

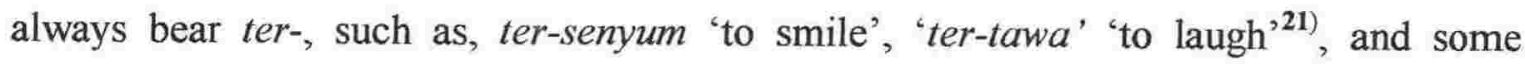
psychological predicates (non-action), such as, ter-tegun 'BE astounded', ter-sentuh 'BE touched', ter-haru 'BE moved' and so on. The intuition is, the more effort an action requires (datang 'to come', pergi 'to go', lari 'to run'), the more unlikely it is that the event is non-intentional. Conversely, if an activity is easily done, like for instance to sleep, to sit down and so on, a non-intentional event readily occurs. In fact, tidur 'to sleep', like bangun 'to wake up', is unaccusative; we can also have ter-tidur 'to fall asleep', which is against one's intention.

The examples in (118) below show the use of datang 'to come'. The verb can take the AGENT mereka 'they', (118), or the non-AGENT berita itu 'the news', (119). The intentionality is irrelevant for the non-AGENT in sentence (119a). Even when relevant, i.e., there is an AGENT included in the expression, (120a), the event still cannot be unintentional, sentence $(120 \mathrm{~b})$, where the intentional passive $d i$ - is used instead.

(118)a. (Dengan) Sengaja mereka datang (untuk meN-bantwhari Rabu)
with intention $3 \mathrm{pl}$ come to ACT-help/day Wednesday
'Intentionally, they came (to help/on Wednesday)'
b. *Mereka ter-datang (untuk meN-bantwharu Rabu)
$3 \mathrm{pl}$ TER-come to ACT-help/day Wednesday
'They (accidentally) came (to help/on Wednesday)'

21) The verb is ter-tawa; tawa cannot occur bare as a verb because it is a noun, 'a laugh'. However, it is unlike the English verb to laugh, to mean to [DO] laugh (Hale and Keyser 1993). In BI ter-tawa is an accident, and because it is an accident, the prefix $k e$ - indicating that the event is an experience can sometimes be used instead: ke-tawa, the person is having a laugh as an experience. Interestingly, the BI meN-tangis 'to weep', is like the English to laugh, that is, one can [DO] weep. 


(119)a. ("Sengaja) Berita itu datang hari Rabu
intentionally news the come day Wednesday
'The news came on Wednesday'
b. *Berita itu ter-datang hari Rabu
news the TER-come day Wednesday
'The news (accidentally) came on Wednesday'

(120)a. Sengaja mereka meN-datang-kan berita itu hari Rabu
intentionally $3 \mathrm{pl}$ ACT-come-KAN news the day Wednesday
'Intentionally they brought the news on Wednesday'
b. Sengaja berita itu di-datang-kan hari Rabu
intentionally news the PASS-come-KAN day Wednesday
'The news was intentionally brought (in)/delivered on Wednesday'

What we see from the examples (112) to (120) is the notion of volition (belonging to an AGENT) and intentionality (of an event) are quite separate. The main point in the discussion is about the intentionality of the event, rather than the features [ \pm volitional], [ \pm sentient] of the argument. Thus, an AGENT - which is necessarily [+volitional] - may be involved in an unintentional event, just like in the English translation John unintentionally closed the door, (121a). The BI equivalence of John cut his finger, however, requires the use of the prefix ter- on the predicate, to indicate that the event happens unintentionally, (121b). ${ }^{22)}$

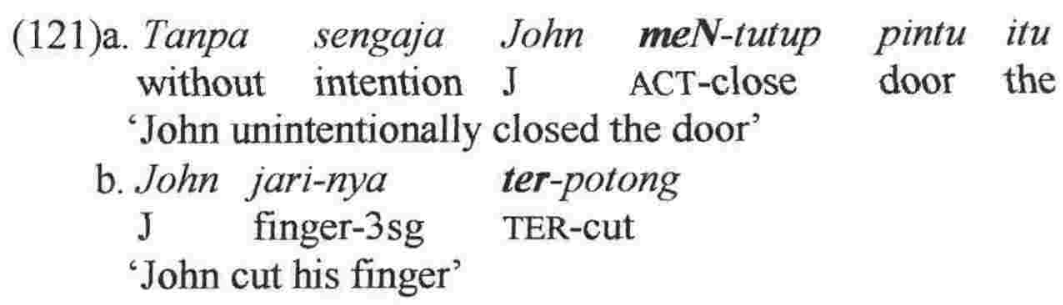

There does not seem to be a contrast between what is expressed by the infinitival untuk meN-bantu 'to help', and hari Rabu 'on Wednesday', in each example in (118). The fact that they came on Wednesday, as against any other day, for instance, only indicates that the ACT is done deliberately (supposing there is some particular

\footnotetext{
${ }^{22)}$ In (119b) the argument jari-nya 'his finger' is an inseparable possession of the non-AGENT John (recall
} Sub-sections 3.2.4.2 and 3.2.6.2 regarding 'part-whole relation'). 
significance to come on that day). If they come on the wrong day without them being aware of it, then the adverbial dengan sengaja 'with intention', of (118a), can be changed into tampa sengaja 'without intention', as in (122a) below. The adverbial tanpa sengaja modifies the whole sentence - unlike the VOICE ter- that modifies the predicate - and clashes with the infinitival that expresses reasons. However, the change into tanpa 'without', cannot rescue (119b), as shown in the following, (122b).

(122)a. Tanpa sengaja mereka datang (hari Rabu*untuk meN-bantu)
without intention $3 \mathrm{pl}$ come day Wednesday/toACT-help
'Unintentionally, they came (on Wednesday/?to help)'
b. *Tanpa sengaja mereka ter-datang (haru Rabu untuk meN-bantu)
without intention $3 \mathrm{pl}$ TER-come day Wednesday/to ACT-help
'Unintentionally, they (accidentally) came (on Wednesday/to help)'

Like events with datang 'to come', events with pergi 'to go', 'to leave', cannot be unintentional: ter- is not allowed in the predicate, (123).

\section{a. Anak-anak sudah pergi ke/dari sekolah child-child PERF go to/from school}

'The children have gone to/from school', i.e., they have left
b. *Anak-anak
sudah
ter-pergi $\mathrm{ke} /$ from
sekolah
child-child PERF TER-go to/from school
'The children have (unintentionally) gone to/from school'

In contrast with datang 'to come', pergi 'to go', lari 'to run' (that require efforts) an effortless ACT such as laughing (ter-tawa) can easily produce uncontrollable side effects, like giggling (123), or loud laughter (124); weeping (meN-tangis) can produce uncontrollable sobbing, (125).
(123) MeN-dengar banyol-an
itu penonton ter-tawa
ter-pingkal-pingkal ACT-hear humour-NOUN DEM audience TER-laugh TER-giggle-ASP 'Upon hearing the humour, the audience laughed and giggled' (i.e., with uncontrollable giggles) 
(124) Penonton ter-tawa ter-bahak-bahak audience TER-laugh TER-'ha, ha'-ASP

"The audience laughed and "ha, ha" " (i.e., with uncontrollable 'ha, ha')

(125) Kata-kata-nya meN-buat Wulan meN-tangis ter-sedu-sedu word-word-3sg ACT-make W ACT-weep TER-sob-ASP 'His/her words made Wulan wept and sobbed uncontrollably'

Those verbs bearing the suffix ter- at the end of each sentence, in (123)-(125), terpingkal-pingkal 'to giggle uncontrollably', ter-bahak-bahak 'to laugh loudly and uncontrollably', and ter-sedu-sedu 'to sob uncontrollably', can serve as the main verb for each sentence, $(126)-(128)$.

(126) Penonton ter-pingkal-pingkal

audience TER-giggle-ASP

'The audience giggled uncontrollably'

(127) Penonton ter-bahak-bahak

audience TER-'ha, ha'-ASP

'The audience "ha, ha" uncontrollably"

(128) Wulan ter-sedu-sedu

W TER-sob-ASP

'Wulan sobbed uncontrollably'

To conclude, predicates bearing the VOICE ter-are unambiguous of intentionality, namely, the lack of it.

\subsubsection{Kan-aspect with the unergatve bangun2, 'to get up':}

When the kan-aspect is used involving the unergative verb bangun2 'to get up', of (111a) or duduk 'to sit down', of (115b), the resulting structure does not show any difference from that with the unaccusative verb bangun 'to wake up', of (110). With the kan-aspect, the structure is transitive; in addition, it also includes an internal argument that undergoes change. Examples (114b) and (115a) are repeated as (129a,b), and the resulting modification with kan-aspect as $(130 \mathrm{a}, \mathrm{b})$, respectively. 
(129)a. Adik bangkit/bangun

(dari kursi-nya) tanpa alasan younger sibling get up from his/her chair without reason

'Little brother/sister got up (from his/her chair) without reason'

b. Ibu duduk dengan sengaja/hati-hati mother sit with intention/care-ASP 'Mother sat down intentionally/carefully'

(130)a. Ibu meN-bangkit-kan/meN-bangun-kan nenek dengan hati-hati mother ACT-get up-KAN grandmother with care-ASP 'Mother carefully helped grandma to get up/sit up/stand up'

b. $I b u$ meN-duduk-kan si kecil mother ACT-sit-KAN PERS small dengan hati-hati

'Mother carefully put/made the small one sit' with care-ASP

The interpretation for (130) is that it is nenek 'grandmother', (130a), or si kecil 'the small one', (130b), and not ibu, 'mother', which sat, who got up, or was made to sit. In (129b), it is $i b u$ 'mother', who does the activity of sitting. There is a question which is difficult to answer only by comparing the surface forms, as to how (129) relates to (130), that is, are the argument relations similar to those unaccusatives and their transitive counterparts? Like the VOICE prefix ter-, and the lack of it, discussed in relation to examples $(112 \mathrm{a}) /(114 \mathrm{a})$, here one thing is sure, that the derivations of (129) involves an empty Voice head, recall structure $(116 \mathrm{c})$. In other words, the verb can occur bare, because it has the characteristic of being unergative. And again, a closer syntactic analysis of VOICE Phrases in relation to $v \mathrm{P} / \mathrm{VP}$ is needed (Chapter 5). Compare the tree structure of the unergative duduk 'to sit' (131) with that of the transitive duduk-kan 'to make/PUT someone/something to sit' (132).

(131) Ibu duduk di kursi mother sit on chair 'Mother sat down on the/a chair' 


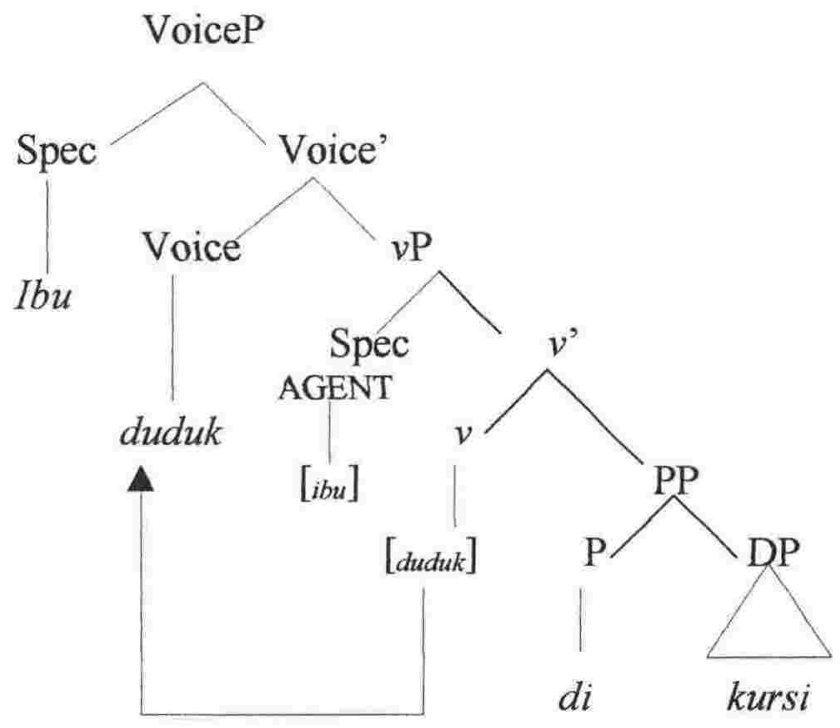

(132) Ibu meN-duduk-kan si kecil di kursi mother ACT-sit-KAN PERS small on chair 'Mother carefully put/made the small one sit'

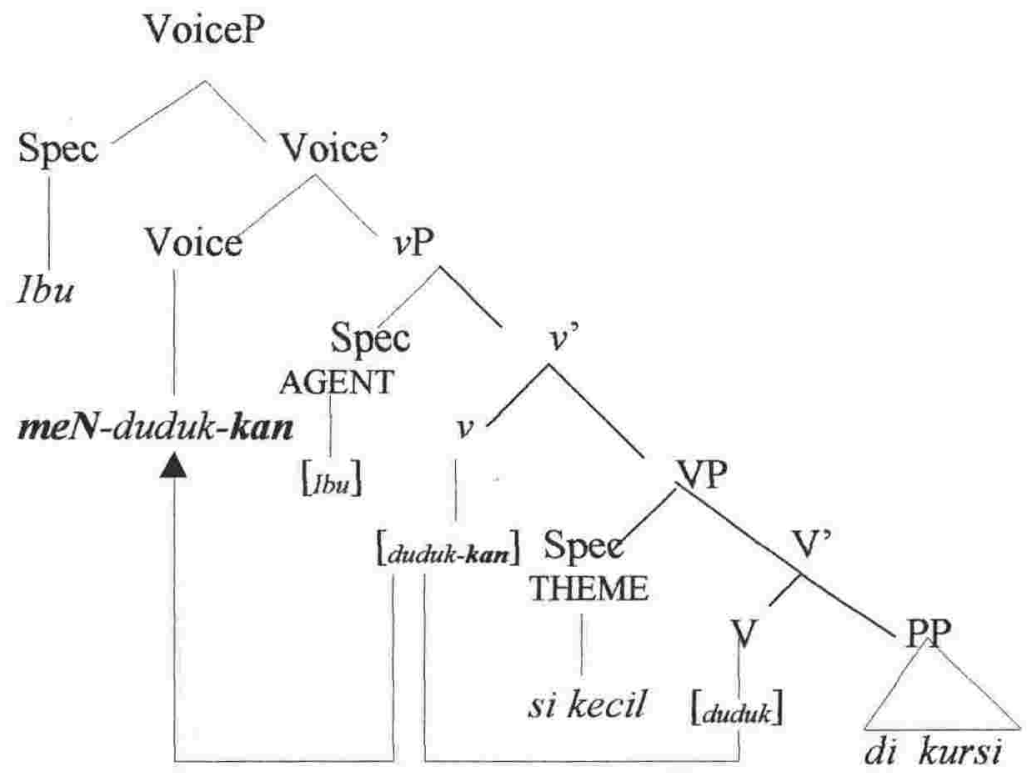

Without the kan-aspect, the forms in (129) cannot use the VOICE $m e N$ - that indicates volition, (133) and (134). 
(133)a. *Ibu meN-bangun

mother ACT-get up

'Mother got up/was in the process of getting up'

b. *Ibu meN-duduk

mother ACT-sit

'Mother sat/was in the process of sitting down'

(134)a. *Ibu meN-bangun nenek

mother ACT-get up grandmother

'Mother got up grandmother'

b. *Ibu meN-duduk si kecil

mother ACT-sit PERS small

'Mother sat the small one'

Conversely, with the kan-aspect, the complex predicate takes the arguments nenek 'grandmother' and si kecil 'the small one' (135) and (136) below. Examples (135) show the form without the Voice head $m e N$ - in a direct imperative, and examples (136) (more or less the same with $(130 \mathrm{a}, \mathrm{b}))$ show the complex predicates complete with the Voice head meN-.

(135)a. Bangun-kan nenek dari kursi! get up-KAN grandmother from chair

'Help grandma get up/sit up/stand up from the chair!'

b. Duduk-kan si kecil di kursi! Sit-KAN PERS small on chair

'Put/sit the small one on the chair!'

(136)a. Ibu meN-bangkit-kan/meN-bangun-kan nenek dari kursi-nya mother ACT-get up-KAN grandmother from chair-3sg 'Mother helped grandma to get up/sit up/stand up from her chair'

b. Ibu meN-duduk-kan si kecil di kursi mother ACT-sit-KAN PERS small on chair

'Mother put/made the small one sit on the chair' 
The predicates meN-bangkit-kan 'to make/help someone get up' and meN-dudukkan 'to put/make someone sit' in (135) and (136) are transitive, just like meN-bangunkan 'to wake up someone' of example (104) where the unaccusative bangun1 occurs in a transitive environment, or, "causativises" (the term used by, for instance, Hale and Keyser 1998, Pylkkänen 2002).

Comparing the surface forms of (133)-(136), we see a morphological bracketing: $v \mathrm{P}$-aspect takes precedence over VOICE (i.e., change must occur first before the Voice head $m e N$ - can be used), shown in (137a)-(137c), with the syntactic bracketing shown as (137d), based on the tree structure (132).
(137)a. *meN-(duduk)
b. (duduk-kan)
c. (meN-(duduk-kan))
d. [volce $m e N-[v \mathrm{P}[\mathrm{vp} d u d u k]-k a n]]$ tree structure (132)

In Pylkkänen's (2002) terms rule ordering such as (137b) and (137c) shows that CAUSE must apply first as "STEP ONE" before VOICE can be applied, as "STEP TWO", in the derivation. That is more or less what we have in the derivation of BI transitives with the kan-aspect. In this case, Pylkkänen's (2002) CAUSE is our v-kan.

To anticipate the discussion in the section that immediate follows (section 3.3.3), compare the bracketing in (137) above with the following, (138), for the transitive bangun 3 'to build', 'to make', 'to erect', 'to create', 'to found'. Examples will be provided in each sub-section. The two, (137) and (138), look similar, except meN-bangun in (138a) is well formed.

(138)a. meN-bangun (here meN-is obligatory: *bangun is not allowed for bangun3)
b. (bangun-kan)
c. (meN-(bangun-kan $))$
d. [vorce $m e N-[v \mathrm{p}[\mathrm{vp}$ bangun]-kan] ]. 


\subsubsection{The transitive bangun}

Different from bangun1 'to wake up', (section 3.3.1), and bangun2 'to get up', (section 3.3.2), the following verb bangun3 'to build', 'to erect' 'to found', cannot occur bare; it requires at least either the prefix $m e N$-, the suffix -kan, or both. With the prefix $m e N-$, the verb is transitive: this verb takes a complement even without kan-aspect.

Even without the kan-aspect, an event involving verbs such as meN-buat 'to make'; meN-bangun 'to build', 'to erect', 'to found'; meN-beli 'to buy', and so on, already contains change as event characteristic. With these verbs, the kan-aspect adds another path for the object to travel through: the path of change now contains a 'transit point'. I shall call this path transit path of change. Different from these verbs, some verbs such as meN-beri 'to give' and meN-kirim 'to send' require that the kan-aspect be used to indicate the translocation of the object. With these verbs, the path of change encoded by the kanaspect is direct and does not have a transit point.

\subsubsection{The transitive bangun without kan-aspect}

We have touched upon the verb bangun that means 'to wake up', unaccusative (or bangun 1), and bangun that means 'to get up', unergative (or bangun2). When we select the verb bangun 3 to mean 'to build something', because it is transitive, it takes an object as a complement. For example, in (139a) below, the verb takes the object kandang ayam 'chicken shed', as a complement. In (139b), because the verb is intransitive (i.e., bare), it cannot take an object, and regardless of whether it is unaccusative or unergative, it cannot mean to build.

(139)a. Ayah meN-bangun kandang ayam
father ACT-build shed chicken
'Father built a chicken shed', or, 'Father builds chicken sheds'
b. *Ayah bangun kandang ayam
father build shed chicken
'Father is waking up (?)/getting up (?) a chicken shed'

With this class of verbs (i.e., make/build/buy) it is immediately clear that the object kandang ayam 'chicken shed' in (139a) is a THEME, (or, an "incremented THEME" in 
Dowty's 1991 terms, in that, the chicken shed takes shape gradually). Gruber (1970), also Hale and Keyser (1993), argue that with the verb make/build, the form of the object is changed either from nothing to existence, or from one form to another. The present work uses THEME as a convenient term that represents an argument undergoing change (following Dowty 1991, Hale \& Keyser 1993). Up till now we have discussed change involving predicates that require the kan-aspect. What we have here is that in $\mathrm{BI}$, this class of verbs can occur without the kan-aspect, and yet the change on the object can be inferred.

The incremental change on the object kandang ayam 'chicken shed' is inferred, through the inherent characteristic of the predicate bangun 3 'to build', namely, even without the use of the kan-aspect. In the sub-section that follows, 3.3.3.2, I discuss the kan-aspect with transitive verbs, including bangun3.

\subsubsection{The transitive bangun with the kan-aspect}

The argument ayah 'father', in the previous example, (139a), is an AGENT of an accomplishment class of event. As we have seen, even without the kan-aspect, the THEME such as kandang ayam 'chicken shed' in (139a) undergoes change, incrementally. Does it mean that kan-aspect is optional in such cases? The answer is negative. In this case, the boundedness of the event, can be used to explain the difference, namely, the event with the kan-aspect such as in (140a) below is bounded, because it has endpoints, and without the $k a n$-aspect as in $(140 \mathrm{~b})(=(139 \mathrm{a}))$ it is unbounded. Boundedness is another prominent characteristic of the kan-aspect that we should include in our discussion. ${ }^{23}$ )

\section{(140)a. Ayah meN-bangun-kan kandang ayam father ACT-build-KAN shed chicken}

'Father built a chicken shed' (but not 'Father builds chicken sheds')

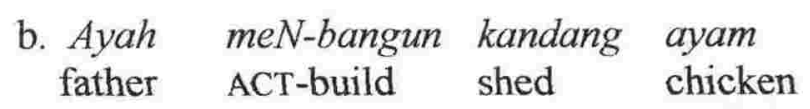

'Father built a chicken shed', or, 'Father builds chicken sheds'

\footnotetext{
${ }^{23)}$ However, I do not intend to prove that every event with the kan-aspect is bounded. Suffice it to say that events with the kan-aspect generally have bounded senses because, as we have exemplified in the previous section (the whole section 3.2), the kan-aspect encodes change of state, change of location, final state, final destination and so on.
} 
In terms of time reference, the expression in (140a) is different from that of (140b), in that the event of the former happens at that particular moment in time only, in relations with the time of utterance (or, it has a "semelfactive reading" the event happens once only, Tenny 1987). But without the kan-aspect on the predicate, it can also be inferred that ayah 'father', (140b), builds chicken sheds as a habit, or as an occupation (habitual reading).

The sentence (140a) can be modified with dalam waktu sepuluh tahun 'in ten years' and (140b) with selama sepuluh tahun 'for ten years', and thus bounded in (140a) and unbounded in (140b). ${ }^{24)}$ The example (140a) is repeated and modified as (141) and the contrasting example (140b) is modified as (142).

(141)a. Ayah meN-bangun-kan

father ACT-build-KAN shed

\section{kandang ayam}

$\frac{\text { dalam waktu }}{\text { in time }}$

chicken

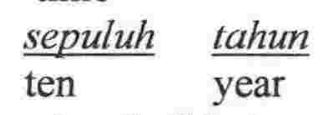

'Father built a chicken shed in ten years' (i.e., he is a very slow builder)

b. *Ayah meN-bangun-kan kandang ayam shed chicken for ten year
father ACT-build-KAN selama sepuluh tahun
'Father built a chicken shed for ten years'

(142)a. Ayah meN-bangun kandang ayam selama sepuluh tahun
father ACT-build shed chicken for ten year
'Father built chicken sheds for ten years'
b. *Ayah meN-bangun kandang ayam
father ACT-build shed chicken in time ten year
'Father built chicken sheds in ten years'

With the kan-aspect, the events such as represented in (141) are bounded. However, this is not to say that to be bounded an event must have the kan-aspect. We must bear in mind

\footnotetext{
${ }^{24)}$ In this instance we also gain the interpretation of plurality of the object through the event: it is singular in (140a) only because the event is bounded, but it can be singular or plural in (140b) because the event is unbounded (In BI plurality of object may, sometimes, depend on the event, namely whether it bears iterative or semelfactive reading, and vice versa, if the THEME is plural or is incremented, the event may be iterative).
} 
that boundedness can be characterised also by another factor, such as the use of complete DPs, consider (143) and (144) below. Note that in examples (141) and (142) above no definite or indefinite article is used for the object kandang ayam 'chicken shed'. The result would be different if 'complete' DPs were given, that is, the interpretations of boundedness are not independent of the distinction between definite and indefinite DP. With the DP argument, indicated by sebuah 'classified indefinite article $a$ ' (notated as "aCLASS" (143), or itu 'DEMonstrative that', the result is the opposite of those of (141) and (142)).

(143)a. *Ayah meN-bangun se-buah kandang ayam selama sepuluhtahun father ACT-build a-CLASS shed chicken for ten years 'Father built $a$ chicken shed for ten years'

b. Ayah meN-bangun se-buah kandang ayam dalamwaktu sepuluh tahun father ACT-build a-CLASS shed chicken in time ten year 'Father built $a$ chicken shed in ten years'

$\begin{array}{cllll}\text { (144)a. * Ayah meN-bangun kandang ayam } & \text { itu selama } & \text { sepuluh tahun } \\ \text { father ACT-build } & \text { shed chicken DEM for } & \text { ten years }\end{array}$ 'Father built that chicken shed for ten years'

b. Ayah meN-bangun kandang ayam itu dalam waktu sepuluh tahun
father ACT-build shed chicken DEM in time ten years
'Father built that chicken shed in ten years'

In contrast with the unbounded event of (142), with the DP arguments sebuah kandang ayam 'a chicken shed', and kandang ayam itu 'that chicken shed', (143) and (144) are bounded (Note again, that sentences (143b) and (144b are acceptable without the kanaspect, firstly because the verb bangun 3 is transitive therefore takes an object complement, and secondly, because the verb bangun 3 already contains a change component, as argued earlier at the beginning of the present section).

Boundedness, however, is not the only characteristic related to the kan-aspect. Another characteristic is, for certain verbs (make/build/bury) with the kan-aspect the path of change has a transit point, (140a) and (141a). No transit point in the path of change is interpreted from the examples without the kan-aspect, (140b), (142) and (144) above. I 
propose that this transit point of the path of change is viewed only as a variant of path of change (see Section 3.3.3.3 for the distinction).

To explain the transit point of change of example (140a)/(141a), firstly we must see that the sentence is ambiguous, with two readings:

(i) ayah 'father' is building the chicken shed for somebody else (benefactive interpretation);

(ii) ayah is having the chicken shed built by somebody else ("workshop verb" interpretation).

In the first interpretation ( $i$ ) ayah is the AGENT who does the building, whereas in the second interpretation (ii) ayah is a facilitator AGENT, i.e., he does not do the ACT of building. There is no way to tell from the sentence (140a) alone what type of AGENT ayah is, and thus, the two interpretations are highly context dependent (this includes also the discourse as well as some knowledge of the world, for instance some local culture).

The transit point of change makes it possible to include kan-aspect in the double interpretation above. The occurrence is widespread, not just with those of transitive verbs, for instance, with a derived predicate that means the change of state from being not clean, into the final state clean, as in the following example, (145), namely, with a deadjectival (refer back to Section 3.2.6). In fact, we can have three readings from (145).

(145) John sedang meN-bersih-kan gigi

J PROG ACT-clean-KAN tooth

'John is cleaning (-?-) teeth'

The first interpretation, which is the most possible, is that John is making his own teeth clean. The second interpretation is, John is making somebody else's, or, the teeth of something (e.g., such as the teeth of a chainshaw, of a dog, etc.) clean, and the third, John has gone to the dentist to have his teeth cleaned, in a manner similar to going to have his hair cut (John is not the direct AGENT). 
To maintain the essence of the kan-aspect, the present discussion argues that the path of change (for instance the change of location and change hand) can have a transit point. We have discussed in Section 3.2.4 how an object moves or is moved, which includes also instrument objects and body parts as instruments. I have also argued in Section 3.2.4 that it is the manner of movement that is expressed in the kan-predicate. Given the possibility that there are various manners of movement, which indicates also the various forms of aspectual path, the notion of transit is hardly a new phenomenon. It is the transit point of change of the kan-aspect that makes it possible to have a "workshop verb" interpretation, as well as a benefactive interpretation. It is also important to take into consideration the use of the appropriate preposition for the non-argument (in PP, see Kayne 2001), in particular, whether it is untuk 'for', ke 'LOCATIVE to', or kepada 'DATIVE to', section 3.3.3.3 below.

\subsubsection{Kan-aspect and benefactivity: transit point in the path of change}

I will argue in this section, (i), that the suffix - kan is not a "benefactive marker" (contra, for instance, Chung 1976, Sneddon 1996), and (ii), that with some verbs, the path of change in the event can have a transit point. The lexical property of the verb determines whether the path of change is direct or having a transit point. And thus, it is not necessary to have the notion that a suffix, such as -kan, can grammatizise to indicate benefactivity (cf. Margetts 2002, in which she discusses a suffix of another Austronesian language with the same phenomenon, and suggests the possibility of grammatization of the suffix).

To deal with issue (i), namely, of whether the suffix -kan "marks benefactivity", we can start with the simple change involving a de-adjectival kan-predicate, for example, meN-bersih-kan 'to make something clean', 'to clean something', discussed briefly in Section 3.3.3.2. Whatever ACT is involved in the event with meN-bersih-kan, the final state of the object is stated as bersih 'clean', and the change of state is marked by the suffix $-k a n$. We shall demonstrate that there is nothing benefactive about the suffix $-k a n$. For instance, one of the strategies employed by the speaker to express benefactivity is to 
say that the object that is being cleaned in meN-bersih-kan is not his/her own, and thus, a possessive indication by any means can indicate "benefactivity" (Margetts 2002). The first example, (146), says that in the event, the state of the argument mobil itu 'that car', is changed from not clean into clean. It does not say whose car it is, but the kan-predicate expresses the change of state. The demonstrative itu 'that' of (146a) is substituted with ibu-nya 'his mother' in (146b).

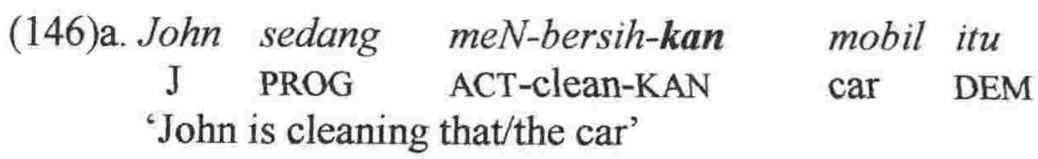

$\begin{array}{llll}\text { b. John sedang meN-bersih-kan } & \text { mobil } & \text { ibu-nya } \\ \text { J PROG ACT-clean-KAN } & \text { car } & \text { mother-3sg } \\ \text { 'John is cleaning his mother's car' } & & \end{array}$

From the sentence (146a) there is no way to tell that the suffix -kan indicates benefactivity. What the sentence says is just that the AGENT John is in the process of bringing about the event in which the state of the car is changed from being not clean into clean state. In sentence (146b) we gain the interpretation of benefactivity from the DP mobil ibunya 'his mother's car', rather than from the suffix - kan. We are satisfied with the fact that it is the difference between the DP objects mobil itu 'that car' (146a) and mobil ibunya 'his mother's car' (146b) that gives the interpretation of non-benefactive versus benefactive interpretations, respectively, rather than the suffix -kan.

Furthermore, without the suffix -kan, the sentences are ungrammatical, (147a,b), and thus, the change must be stated.

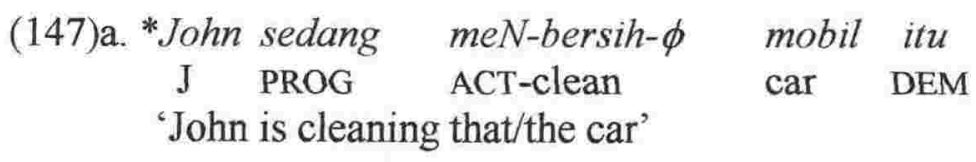

\begin{tabular}{|c|c|c|c|c|}
\hline b. *John & sedang & $m e N-b e r s i h-\phi$ & mobil & $i b u-n y a$ \\
\hline J & PROG & ACT-clean & car & mother-3sg \\
\hline
\end{tabular}


It can only be inferred from (147b) that ibu 'mother', in mobil ibu-nya 'his mother's car', is a beneficiary. However, it is not correct to say that $i b u$ is a beneficiary, as in Johns' (1977) terms, since the whole DP his mother's car is a THEME, and mother is only a part of it. I shall emphasise (again), that in the events of examples (146a) and (146b) both the arguments mobil itu 'that car', and mobil ibu-nya 'his mother's car', undergo change into a clean state, regardless of the possessor. Without the kan-aspect, the sentences, $(147 \mathrm{a}, \mathrm{b})$, are ungrammatical. Even when the benefactive untuk for-phrase is included, the sentence remains ungrammatical, (148).

(148). *John sedang meN-bersih- $\phi \quad$ mobil untuk ibu-nya
J PROG ACT-clean car for mother-3sg
'John is cleaning car for his mother'

Thus, in sentences $(147 \mathrm{a}, \mathrm{b})$ and (148) the kan-aspect is needed to indicate the change of state.

Whereas the examples with the kan-aspect in $(146 \mathrm{a}, \mathrm{b})$ show that the difference in benefactive interpretations is gained through the difference of the DP objects, the use of the untuk 'for' prepositional phrase, (149) below, can also give benefactive interpretation. This is another strategy (besides the possessive DP in (146b)) employed by the speaker to express benefactivity, namely, by adding a prepositional phrase with untuk 'for' in the sentence. The following description of sentences involving membelikan 'to buy something for someone', can also be used to account for other kan-predicates such as, membuatkan 'to make something for someone', mengambilkan 'to take something for someone', membawakan 'to carry something for someone', membangunkan 'to build something for someone', and so on.

To start with, I shall show that the so called "benefactive -kan" (for instance, Chung 1976, Johns 1977, Sneddon 1996, Kaswanti Purwa 2002) is not in complementary distribution with the benefactive preposition untuk 'for' (neither is it with the dative preposition kepada 'to', not shown here, but see Chung 1976, Baker 1988), (149b,c). 


$\begin{array}{llll}\text { (149)a. Ibu meN-beli se-buah baju } & *(\text { untuk }) & \text { Fatimah } \\ \text { mother ACT-buy a-CLASS shirt/dress } & \text { for } & \text { F } \\ \text { 'Mother bought a shirt/dress for Fatimah' } & & \end{array}$

b. Ibu meN-beli-kan se-buah baju *(untuk) Fatimah mother ACT-buy-KAN a-CLASS shirt/dress for F 'Mother bought a shirt/dress'

$\begin{array}{lllll}\text { c. Ibu meN-beli-kan } & \text { (untuk) Fatimah } & \text { se-buah } & \text { baju } \\ \text { mother ACT-buy-KAN } & \text { for F } & \text { a-CLASS } & \text { shirt/dress } \\ \text { 'Mother bought a shirt/dress' } & & & & \end{array}$

The example (149c) shows that the preposition untuk 'for' can be overt or covert, which is overlooked by Chung (1976), Johns (1977), Den Dikken (1995), Sneddon (1996), and Kaswanti Purwa (2002). In (149b) the suffix -kan co-occurs with the obligatory preposition. I will come back to the structure (149c) in Chapter 4, to discuss this 'illusory double-object construction'. But notice that in both (149a) and (149b) the preposition untuk 'for' is obligatory, whereas in (149c) it can be covert. I assume that in (149c) one of them - either it is the suffix - kan or the preposition untuk - is redundant. But see examples below, in particular, examples with the preposition kepada, 'DATIVE to'. In sum, sentences in examples (149a-c) show that the suffix -kan is not in a complementary distribution with the preposition untuk 'for'.

Now I shall show an example of a direct path using the same verb beli 'to buy', (150).
(150) $\mathrm{Ibu}$
meN-beli se-buah baju
mother ACT-buy a-CLASS shirt/dress

'Mother bought a shirt/dress'

In (150) it is not stated whom mother bought the shirt for, but quite likely it is for herself, although we do not have information about it. Either with the kan-aspect, such as in (146a), or without the kan-aspect, (150), the benefactive interpretation is not available. In the event so expressed in (150) the shirt/dress changes hand (by laws of transaction) and is not explicitly encoded by kan-aspect in the linguistic expression. Crucially, this 
translocation can be seen as having a simple, direct path. Examples that follow, from (151) onwards, show some other possible occurrences with the main events similar to the one expressed in (150).

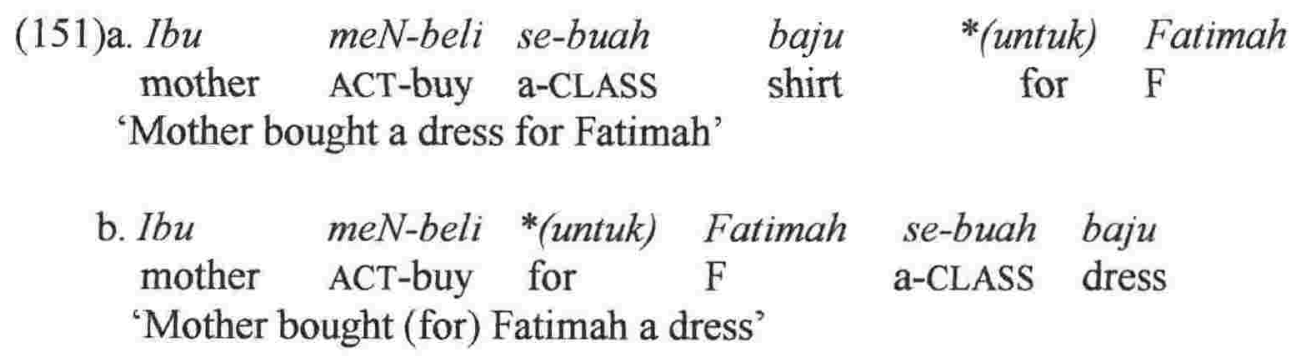

In (151a), benefactivity is expressed by means of the benefactive preposition untuk 'for'; no so-called "benefactive -kan" is marked on the predicate. Note that in both examples in (151), the benefactive preposition untuk 'for' is not optional (With the kan-aspect, only in (151b) is the preposition untuk optional, example (149c)). Therefore, we do not have to have the suffix -kan to express benefactivity (recall also example (148b)): It is the prepositional phrase that expresses benefactivity by means of the preposition untuk 'for'. 25)

If the untuk 'for' prepositional phrase is sufficient for expressing benefactivity, then the question is why do we use the suffix -kan at all? The answer is, the suffix encodes the path of change - which in this case the second path of change - namely, the first path is from the place of purchase to $i b u$ 'mother', and the second is from $i b u$ 'mother' to

25) In BI we also have expressions involving untuk 'for' which are similar to the "directional prepositions" discussed in Section 3.2.5:
(i) $\mathrm{Ibu}$
meN-untuk-kan baju
ini *(untuk)
Fatimah
mother ACT-for-KAN dress this for
F

'Mother designates this dress for Fatimah'

Where the benefactive preposition untuk 'for' is selected as a verb that means similar to the English 'to designate'. Note that the PP untuk Fatimah is obligatorily present. This provides a piece of evidence that the PP with untuk is selected/entered independently of the kan-predicate meN-untuk-kan. On the other hand, we also have:

(ii) Baju ini untuk Fatimah

dress this for $\mathrm{F}$

'This dress is for Fatimah'.

The form (ii) is what I call "PP construction" (see Section 3.4.2). 
Fatimah. This question brings us to the second issue to deal with, namely, with respect to the path that is direct versus the path that has a transit point.

To elucidate the matter, let us compare the kan-aspect when used with the verbs beli 'to buy' $(152 \mathrm{a}=150)$ and beri 'to give' $(152 \mathrm{~b})$ with the assumption that it is the verb's lexical property that determines the direct versus transit paths of change. In (152) the kan-aspect is not used, and with beri 'to give' (152b) the sentence is unacceptable. Even when the path of translocation is indicated, i.e., by means of the preposition kepada 'DATIVE to', (152c), the sentence is unacceptable.

\section{(152)a.Ibu meN-beli se-buah baju mother ACT-buy a-CLASS dress 'Mother bought a shirt/dress'}

b. *Ibu meN-beri se-buah baju mother ACT-give a-CLASS dress 'Mother gave a dress' mother ACT-give ART-CLASS 'Mother gave a dress to Fatimah'
c. ${ }^{*} I b u \quad m e N$-beri se-buah
baju ke-pada Fatimah
d. $I b u$ meN-beri-kan se-buah baju ke-pada Fatimah mother ACT-give-KAN ART-CLASS dress to-DAT F 'Mother gave a dress to Fatimah'

In (152a) the event of buying is accomplished (and it is an accomplishment class of event): the translocation of the object sebuah baju 'a dress' is complete, namely, as mentioned before, from the place of purchase to ibu 'mother' (one path). Whereas for the verb beri 'to give' in (152b), the fact that the GOAL of the translocation is stated as in (152c) does not rescue the sentence - to assume that because the verb beri 'to give' is a ditransitive verb it requires that the GOAL be stated. The kan-aspect is required to mark the translocation, (153a). 


(153)a. Ibu meN-beri-kan se-buah baju ke-pada Fatimah
mother ACT-give-KAN a-CLASS
'Mother gave a dress to Fatimah'
b. Ibu meN-beri-kan *(ke-pada)

Unlike with the verb beli 'to buy', (149c) where the preposition untuk 'for' can be covert when next to the kan-predicate, here with the verb beri 'to give' the preposition kepada 'DATIVE to' in (153b) is obligatory.

By using the kan-aspect for both verbs (beli 'to buy' and beri 'to give'), we will see the difference in terms of the path that is travelled through by the object sebuah baju 'a dress'. With the kan-aspect added to the predicate meN-beli 'to buy' of (152a), the path has a transit point, that is, another path is added to the path that already exists, serving as an "extension": the path of translocation is now from the place of purchase to $i b u$ and then to Fatimah, (154a) below (I use "transit path" henceforth as a convenient term to refer to a path that has a transit point, as against the "direct path"). Whereas with the predicate meN-beri-kan 'to give something' (154c), the path is direct, and the object travels through a single path, namely, from $i b u$ to Fatimah.
(154)a. Ibu meN-beli-kan se-buah baju untuk Fatimah (transit path) mother ACT-buy-KAN a-CLASS dress for F 'Mother bought a dress for Fatimah'
b. *Ibu meN-beli-kan se-buah baju kepada Fatimah (direct path) mother ACT-buy-KAN a-CLASS dress to F 'Mother bought a dress to Fatimah'
c. Ibu meN-beri-kan se-buah baju kepada Fatimah (direct path) mother ACT-give-KAN a-CLASS dress to F 'Mother gave a dress to Fatimah'
d. *Ibu meN-beri-kan se-buah baju untuk Fatimah (transit path) mother ACT-give-KAN a-CLASS dress for F 'Mother gave a dress for Fatimah'

In (154c) the direct preposition kepada 'DATIVE to' must appear instead of the benefactive untuk 'for' as in (154a). Note that the benefactive preposition untuk 'for' in 
itself has a transit point, as against kepada 'DATIVE to' or ke 'LOCATIVE to', which are direct. Voskuil (1996:158-163) makes the distinction between "cause-related preposition" (notated as $\mathrm{P}_{\text {ben }}$ or $\mathrm{P}_{\text {make-for }}$ ) for the former, and "path-related preposition" (notated as $\mathrm{P}_{\text {dat }}$ or $P_{\text {give-to }}$ ) for the latter. In our terms here, both are path-related, in fact, both indicate a path that leads to the event terminus (following Tenny 1987, Arad 1998, among others): one is a transit path (untuk) and the other direct (ke+location, kepada+person). Thus, in our terms, Fatimah in both $(154 \mathrm{a}, \mathrm{c})$ is in fact the (final) GOAL of the translocation.

With this distinction in mind, we can then see that a kind of feature matching takes place, that is, the notional direct path of the kan-aspect with its appropriate preposition kepada 'DATIVE to' and the transit path with its appropriate preposition untuk 'for'. We shall conclude firstly that it is the lexical property of the verb that gives the kan-aspect the distinction between the direct versus transit path. Secondly, we see that the direct versus transit features of the preposition matches the direct versus transit path of change of the kan-aspect. This seems correct, since the prepositions are not interchangeable, $(154 b, d)$.

While in $(154 b, d)$ the feature matching does not take place, in the examples (155) that follow the prepositional phrases are covert, and the sentences are acceptable, even with the ditransitive verb (155b). Both events are accomplished even without a GOAL.

(155)a.Ibu meN-beli-kan se-buah baju (untuk Fatimah) mother ACT-buy-KAN a-CLASS dress for F 'Mother bought a dress (for someone)'

b. Ibu meN-beri-kan se-buah baju (kepada Fatimah) mother ACT-give-KAN a-CLASS dress to F 'Mother gave a dress (to someone)'

With the kan-aspect, with the verb beli 'to buy' and beri 'to give' the prepositional phrase that contains the argument Fatimah does not even have to be present, (155a,b), leaving the benefactive and dative interpretation to the discourse. The THEME sebuah baju 'a dress' must be overt, $(155 \mathrm{a}, \mathrm{b})$ and $(156 \mathrm{a}, \mathrm{b})$ below, whereas the so-called "beneficiary" 
Fatimah alone in (156c) is not sufficient to make the sentence grammatical, not even when it is included in a prepositional phrase, (156d).

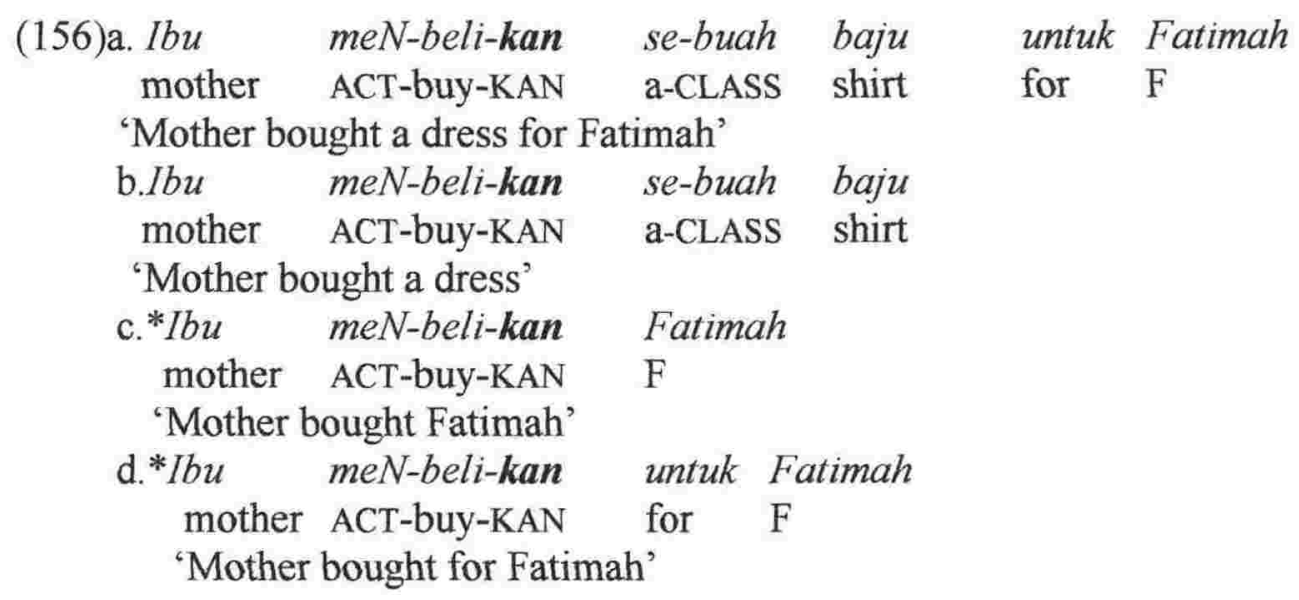

This raises a serious question regarding the view that the suffix - kan is a "benefactive marker". If the suffix -kan was a benefactive marker, then $(156 \mathrm{c}, \mathrm{d})$ should be acceptable, because both the so-called "benefactive marker" and the beneficiary are present, but they are ungrammatical. Recall also the examples in (151) where we gain the interpretation of benefactivity through the preposition untuk 'for', and not from the suffix - kan (because the suffix is not present). What we have in examples (156) is the fact that with the kanaspect, the THEME, which is crucially the object of the v-kan, must be present. And crucially, the so-called beneficiary Fatimah in the examples above is not the object of the v-kan.

In conclusion, the kan-aspect encodes the change(s) of location of the object sebuah baju 'a dress', which in this case moves from the place of purchase to the hand of ibu 'mother', which in turn, to the hand of Fatimah. In (156b) the final destination of the shift (i.e., the GOAL) is not stated but understood to be someone else other than $i b u$ 'mother', because with the kan-aspect (with the verb beli 'to buy', that is), the act of buying cannot be done for oneself, notice example (158c) below.

(157)a. Ibu meN-beli se-buah baju
mother ACT-buy a-CLASS shirt/dress

'Mother bought a shirt/dress' 
b. Ibu meN-beli se-buah baju untuk Fatimah
mother ACT-buy a-CLASS shirt/dress for $\mathrm{F}$
'Mother bought a shirt/dress for Fatimah'

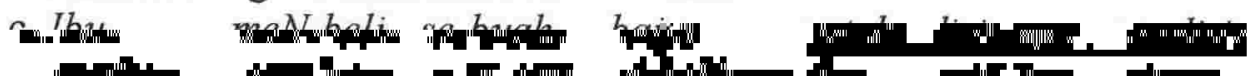

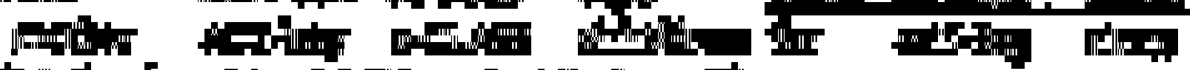

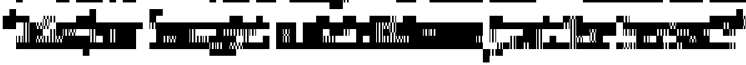

(n)

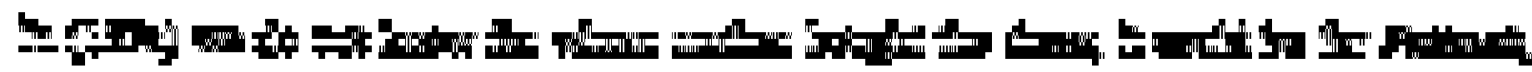

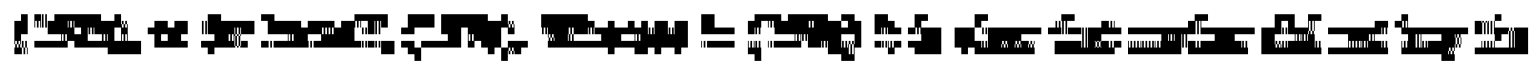

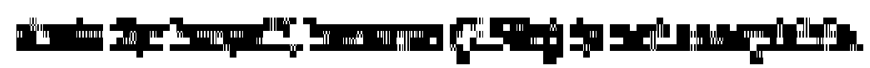

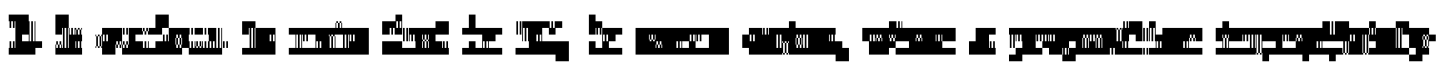

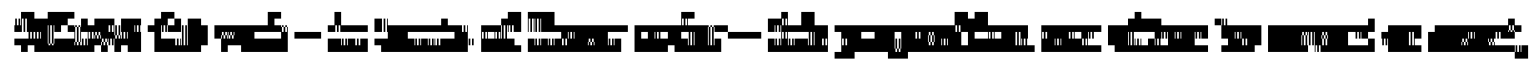

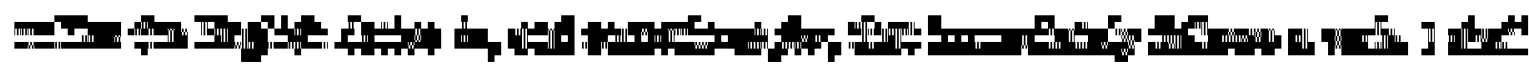

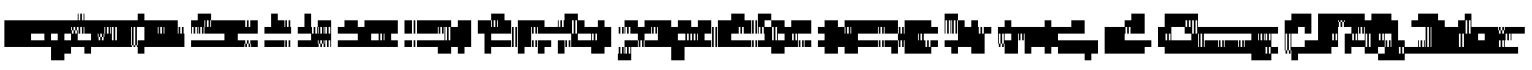

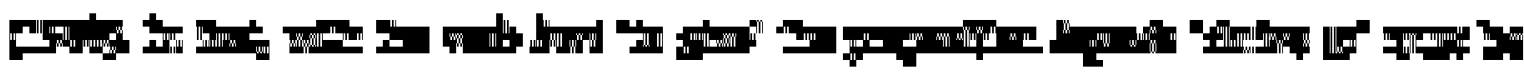

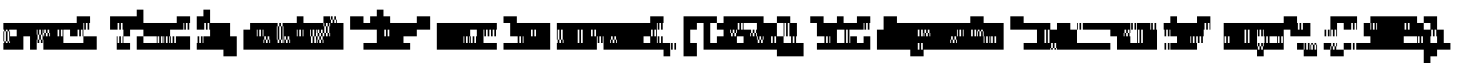

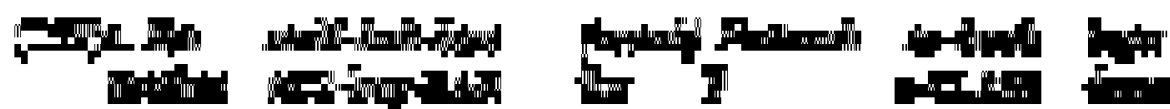

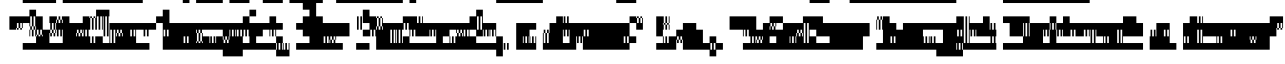

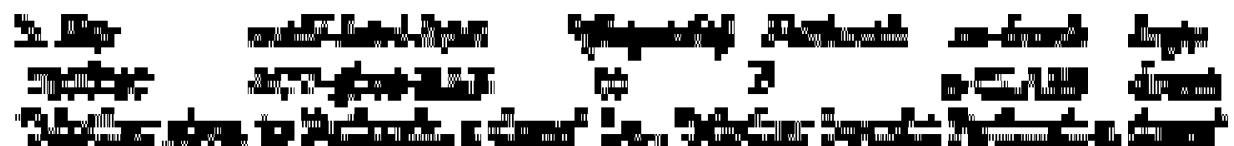

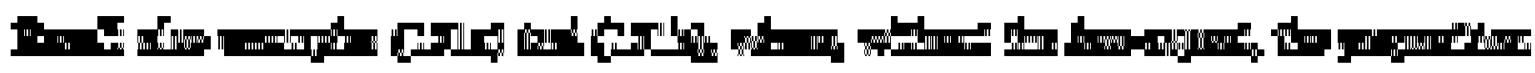
nated by 
Therefore, I shall claim that the optional versus obligatory presence of the prepositions such as in (159a) versus (159b) is determined by the presence or the absence of the transit point. At PF, the preposition untuk 'for' of (159a) may or may not be pronounced, while kepada 'dative to' of (159b) must be. The condition of the "deletion" at PF is determined by the interpretations of transit point (159a) versus direct path of change, (159b).

The argument Fatimah, whether or not it is introduced by the preposition untuk 'for', (159a), remains peripheral, in comparison with sebuah baju 'a dress'. This view is consistent with our analysis (Section 2.3.1) that with the kan-aspect, the THEME, such as sebuah baju, is the primary argument and must be overt. This is also the position taken by Vamarasi (1999:75-76) in rejecting Chung's (1976) and Baker's (1988) view that the suffix -kan "registers" benefactivity. The present analysis also counters Johns (1977: $226,227)$ that treats Fatimah, (159a), as the "primary object" or "beneficiary" and sebuah baju as "secondary object" or "goal". The following examples, repeated from (156), show that Fatimah does not have to be overt, but sebuah baju must be, (160).

(160)a. *Ibu meN-beli-kan (untuk) Fatimah
mother ACT-buy-KAN for F
'Mother bought, for Fatimah'/'Mother bought Fatimah'

b. Ibu meN-beli-kan se-buah baju mother ACT-buy-KAN a-CLASS shirt 'Mother bought a dress (for someone)'

Thus, the sentence (160b) cannot do without the THEME, whereas the presence of the prepositional phrase (untuk) Fatimah '(for) Fatimah' alone, (160a), is not enough. The fact that the THEME must be present, (160b), but not the so-called beneficiary, (160a), is also overlooked by Chung (1976) and Johns (1977).

Occurrences where the preposition untuk 'for', is obligatory such as shown as in (151a,b), but not as in (159a), lead Chung (1976) and Johns (1977) to a conclusion that 
-kan is a benefactive marker, namely, Fatimah is a beneficiary (neither Chung nor Johns is aware that the preposition in (159a) is optional). For convenience, examples (151b) and (158a) are repeated as the following (161a) and (161b), respectively, with the preposition untuk excluded in (161b) to see what they mean, showing the origin of the term "benefactive marker -kan".

$\begin{array}{clll}\text { (161)a. Ibu meN-beli *(untuk) } & \text { Fatimah } & \text { se-buah baju } \\ \text { mother ACT-buy for } & \text { F } & \text { a-CLASS } & \text { dress } \\ \text { 'Mother bought Fatimah a dress' } & & \\ \begin{array}{llll}\text { b. Ibu meN-beli-kan } & \text { Fatimah } & \text { se-buah baju } \\ \text { mother ACT-buy-KAN } & \text { F } & \text { a-CLASS dress }\end{array}\end{array}$

'Mother bought, for Fatimah, a dress'/ i.e., 'Mother bought Fatimah a dress'

Understandably, by comparing the surface structures, (161a) with (161b), it is easy to draw a conclusion, to say that the suffix - kan replaces the preposition untuk 'for'. This is also the position taken by Baker (1988) in his notion of Preposition Incorporation. Baker goes even further suggesting that the suffix has actually undergone a phonological change through the incorporation, namely, from the dative preposition kepada 'to', to the suffix $-k a n$. However, recall the examples $(159 \mathrm{a}, \mathrm{b})$ where the preposition untuk is optional, (159a), whereas kepada (159b) is obligatorily present.

I shall maintain that Fatimah can be called a beneficiary only because it is the object of the benefactive preposition untuk 'for'. And I shall maintain that Fatimah is in fact the final GOAL, the end of a path that has a transit point. I also disagree with the notion that the suffix replaces the preposition untuk 'for', or kepada 'DATIVE to'. To make Chung's (1976) and Baker's (1988) arguments even more untenable, the preposition kepada must be overt with the verb beri 'to give' as in the following example, $(162 b)(=(159 b))$.

$\begin{array}{ccllll}\text { (162)a. }{ }^{*} I b u & \text { meN-beri-kan } & \text { o } & \text { Fatimah } & \text { se-buah baju } \\ \text { mother ACT-give-KAN } & \ldots & \text { F } & \text { a-CLASS } & \text { dress } \\ \text { 'Mother gave Fatimah a dress' } & & & & \end{array}$




\begin{tabular}{|c|c|c|c|}
\hline $\begin{array}{l}\text { b. Ibu } \\
\text { mother }\end{array}$ & $\begin{array}{l}\text { meN-beri-kan } \\
\text { ACT-give-KAN }\end{array}$ & $\begin{array}{l}\text { ke-pada Fatimah } \\
\text { to-DATIVE F }\end{array}$ & $\begin{array}{l}\text { se-buah } \\
\text { a-CLASS }\end{array}$ \\
\hline
\end{tabular}

The preposition kepada 'to' must be present as shown in (162b) because without it, as in (162a), Fatimah is a THEME, and sebuah baju 'a dress' then does not receive a Full Interpretation. The fact that it must be present shows that the preposition is not incorporated, and neither does the suffix - kan "mark" DATIVE.

To summarise, I would propose, that the predicate beli-kan involves a transit point in the path of change, namely, from the location of purchase to Ibu 'mother' (direct path), then from ibu to Fatimah (extended path). With beri-kan, 'to give', only a single direct path is used. In the following descriptions, (163) and (164), the arrow indicates the path that is travelled through by the translocation of the THEME baju, 'shirt/dress'.

(163)a.Ibu meN-beli sebuah baju 'Mother bought a shirt/dress'

Single, direct path of change:

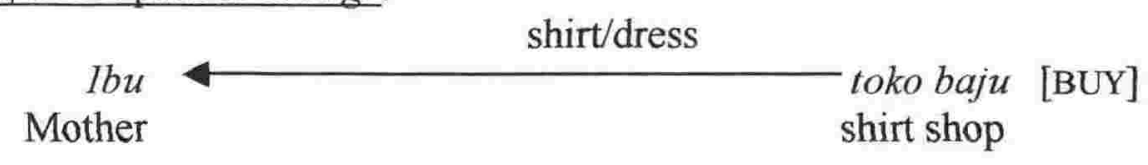

b. Ibu membeli-kan sebuah baju untuk Fatimah 'Mother bought a shirt/dress for Fatimah'

Transit, Ibu as a transit point:

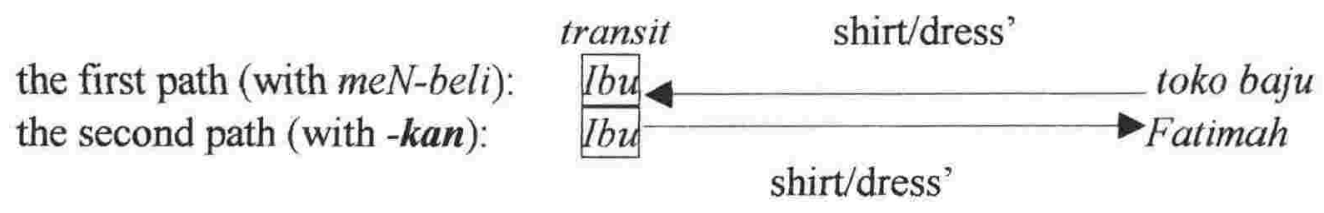

The second path (with -kan) is like the predicate meN-beri-kan, of example (153c), shown here as (163). 
(164) Ibu meN-beri-kan sebuah baju kepada Fatimah 'Mother gave a dress to Fatimah'

a single direct path:

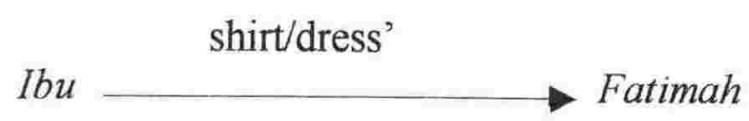

Thus, both (163a) and (164) contain a single direct path, except they have different directions.

\subsubsection{Summary}

The kan-aspect does not distinguish the predicates that are derived (Section 3.2) from those that are non-derived, in that, in both cases, with the kan-aspect the predicate is transitive. Except for the psych-predicates, in both cases the THEME is obligatorily present as the predicate's complement.

The present section discusses the prefix ter- not in terms of passive. The prefix ter-, which I assume realises a Voice head indicating that the event happens unintentionally, can occur with unaccusative, unergative, and transitive-based verbs, providing it is possible for the event to happen unintentionally. I conclude that ter-is external: it is external to VP (involving the unaccusative bangun 1 ), and external to $v \mathrm{P} / \mathrm{VP}$ (involving the unergative bangun2), which matches with the view that VOICE is external to $v \mathrm{P}$ (Ouhalla 1991, Cinque 1999, Bowers (2002), Pylkkänen (2002), among others). Therefore, we shall include the ter-derivation above the $v$ P-layer (for Chapter 5 ). 
The external argument of the non-derived predicates could be an AGENT or a CAUSER. We discover that the unaccusative-based bangun 1 'to wake up' behaves like the psych-predicates, in that it takes a CAUSER as the external argument.

Some events involving transitive verbs such as meN-buat 'to make', meN-bangun 'to build', meN-beli 'to buy' and so on, already contain change as an event characteristic. With these verbs, the kan-aspect adds another path for the object to travel through. With other transitive verbs, such as meN-beri 'to give' and meN-kirim 'to send', however, the $k a n$-aspect must be used to indicate the translocation of the object. Thus, we have two distinct paths of change involving the kan-aspect: for the former group, we term the path of change as having a transit point, and a direct path for the latter group.

I argue in the present section that the benefactive interpretation with or without involving the kan-aspect is context dependent. Further, with Vamarasi (1999), I argue that the suffix - kan does not register what Chung (1976) calls "benefactive/dative shift". In our terms, the event involving the former group of verbs already contains the change characteristic, and adding the suffix - kan to the predicate extends the notional path. Our analysis converges with that of Kana Vamarasi's - despite the difference in framework in that, the so-called beneficiary argument remains as what she calls an "adjunct", which is what we term as a prepositional, optional, argument. In sum, the suffix - kan is not a "benefactive marker".

The notional change of Type 2 demonstrated in this section can be tabularised as follows. 
(165) Change of Type2, verbs with -kan

\begin{tabular}{|l|c|}
\hline verb class & change \\
\hline 1. unaccusatives: & \\
\hline bangun1 bangun-kan to MAKE/CAUSE someone to wake up & of state \\
\hline \begin{tabular}{|l|}
${ }^{*}$ meN-bangun \\
\hline ter-bangun BE woken up
\end{tabular} \\
\hline jatuh-kan to MAKE/CAUSE to fall & \\
\hline meN-jatuh to fall intentinally & of location \\
\hline ter-jatuh to fall unintentionally & \\
\hline
\end{tabular}

\begin{tabular}{|l|c|}
\hline 2. unergatives: & \\
\hline bangun2 bangun-kan to MAKE/HELP someone get up & of position \\
\hline${ }^{*}$ meN-bangun & \\
\hline duduk tuduk-kan to MAKE/HELP someone sit & of position \\
\hline${ }^{*}$ meN-duduk & \\
\hline ter-duduk to sit unintentionally & \\
\hline
\end{tabular}

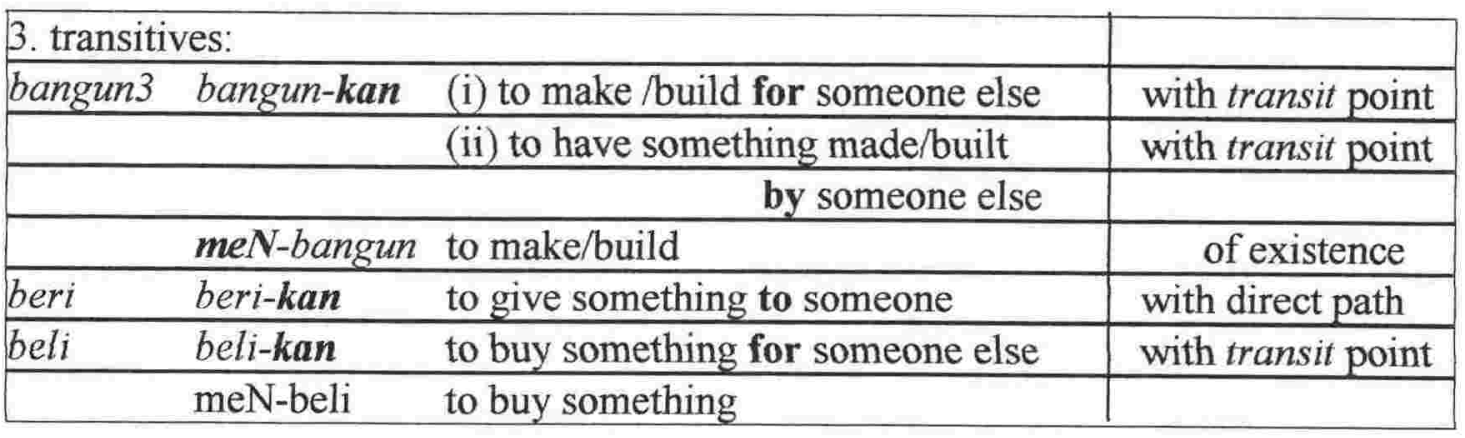




\subsection{Derivations/Syntactic Analysis of kan-predicates}

\subsubsection{The $v \mathrm{P}$ shell}

Since Larson's (1988) analysis of double/object constructions involving the English verb give, his VP-shell has been developed, refined, and used in syntax with various emphases, and each analysis proposes some sort of modification. For instance, Hale and Keyser (1993), suggest that object complements are the specifier of the verb of the lower VP. Their emphasis is on the lexical relational structures, with Baker's (1988) idea of incorporation (Grammatical Function changing) used to argue that lexical-syntax is made possible by means of the theory of head movement. Although the idea of incorporation has been modified into what they call "conflation", Hale and Keyser (1998) maintain that the object complement of the verb is its specifier. Different from Hale and Keyser (1993) and (1998), Pesetsky (1995) uses the shell to show different derivations involving Object and Subject experiencers. He proposes that object complements are the specifier of the verb's sister, i.e., the [Spec-XP]. Chomsky (1995) suggests that not only is the shell useful for the 'light verbs' analysis, it is also useful for analysing verbs that contain a cause feature. According to Chomsky (1995), if a verb has several internal arguments, then we have to postulate a Larsonian shell. I shall adopt Chomsky's (1995) " $v$ P" shell notation to distinguish the whole shell, the $v \mathrm{P}$, from the lower VP. Arad (1998) terms the $\nu \mathrm{P}$-shell as a syntax-lexicon interface. The higher part of the $v \mathrm{P}$-shell has also been used as, or substituted with, other phrases, such as, for instance, an "Aspect Phrase" (Travis 2000), "Focus Phrase" (for instance, Ritter and Rosen 1998), "Predicate Phrase" (Bowers 1993). Bowers (2002: 183) splits the functions of the light verb category $v$ into $v / \operatorname{Pr}(=$ predicated) and $v / \operatorname{Tr}(=$ transitivity).

Basically, Larsonian type VP-shell variations have something in common, namely, the overt V raising to $v$, although some researchers have suggested the use of the structure 
for lexical decomposition (for instance, Richards 2001, Wunderlich 1997). With the notion that the object complement undergoes change, the present section aims to show that the suffix $-k a n$ is positioned at the head $v$, as the $v_{C H A N G E}$ (notated as ' $v$-KAN') rather than $v_{C A U S E}$, because CAUSE only makes up a part in the notion of change. Once the verb raises to occupy the head $v$, the object complement is now the specifier of the verb's sister. Thus, basically, Hale and Keyser $(1993,1998)$ and Pesetsky (1995) are talking about the same thing, that is, [Spec-VP] is the base position for the THEME.

\subsubsection{Derivations with the $k a n$-aspect}

We can start from a simple declarative "verbless" sentence, where, I assume, it is the notional translocation that heads the structure, even though there is no verb serving as a head. In BI it is possible - in fact, it is preferable (Sukarno 1996: 125, after Abbas 1985: 215-216) - to leave the verb out, with a condition that the feature of the covert, or implied, verb matches the $[ \pm$ MOTION] feature of the preposition that follows. In the examples that follow, (166), the implied verbs are parenthised.

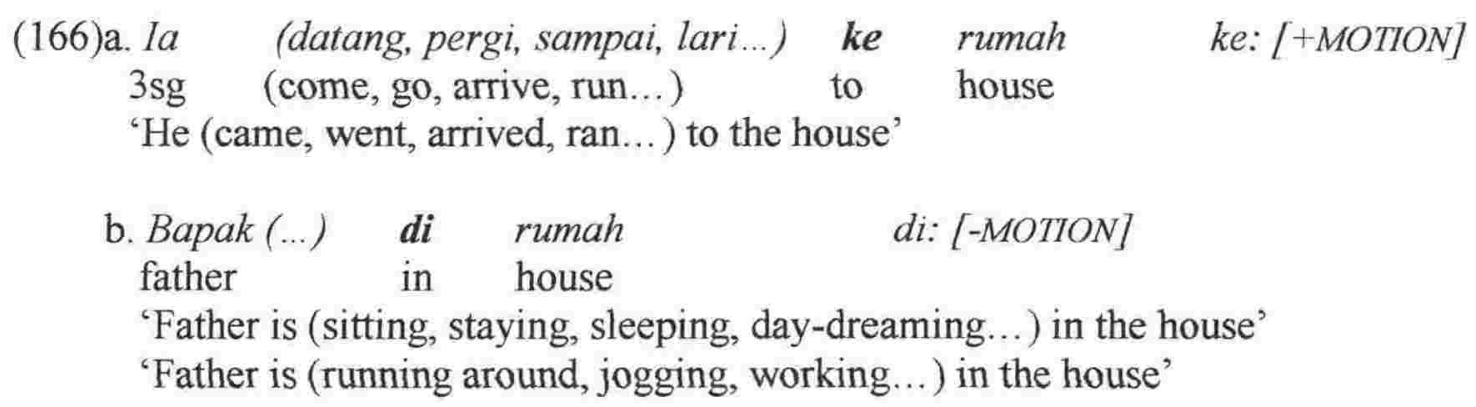

In keeping with the notion of change, I shall take this opportunity to redefine the concept of motion, that is, although in the second English translation of (166b) father is actually running around, or jogging in the house he remains within the confines of the house: he does not undergo translocation relative to the other argument, the house, that is, although he moves around, he does it inside the house. 
If the preposition contains directional translocation, and the verb is also directional (such as turun 'to descend', naik 'ascend', and so on, Section 3.2.5), either the verb or the prepositional phrase is better not expressed. Otherwise the sentence becomes redundant and affected, (167a) and (168a), although acceptable. ${ }^{26)}$ Examples (167b,c) and (168b,c) are what normally occur: they are good, natural sentences.

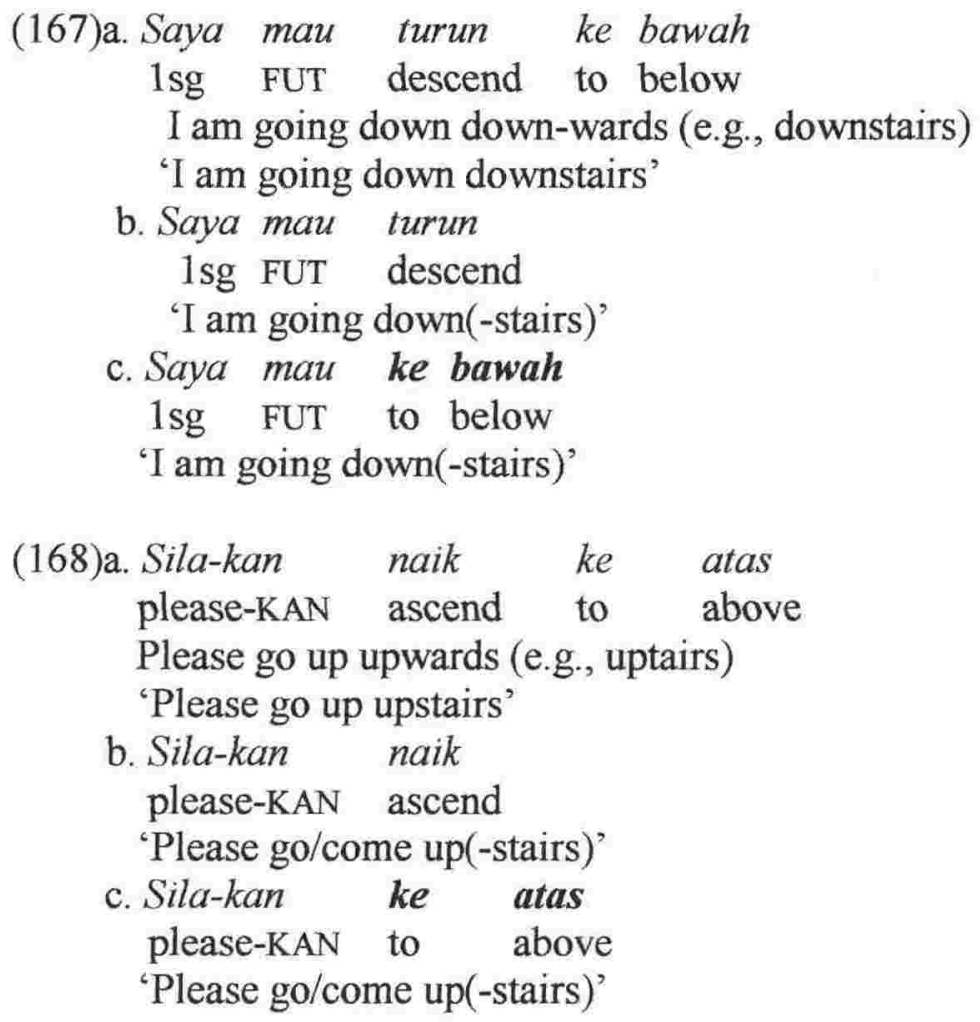

I shall call examples (167c) and (168c) above PP constructions. The following example, (169a), is a PP construction with John as an argument, which I assume to be the specifier of the phrase. This construction is used to indicate that the argument John MOVEs to the gutter. The movement is not specified by the verb: he could be running down, jumping

26) If a contrast is needed, as in for instance 'I am going down to Christchurch' (and not to Dunedin) (i), or 'I am going up to Auckland' (and not to Hamilton) (ii), then both the verb and the location can appear, although either one is sufficient, (iii). Note that all the examples in (167)-(168) are acceptable.

(i) Saya mau turun ke Christchurch

(ii) Saya mau naik ke Auckland

(iii) Saya mau turun (if it can be understood to be to Christchurch)/Saya mau ke Christchurch 
into, descending carefully, or just falling into the gutter. The assumed tree structure for the sentence is shown as (169b). This syntactic analysis can also be used to account for occurrences such as Baju ini untuk Fatimah 'This dress (is) for Fatimah' (the example (ii) given in footnote 24). I will put aside the higher layers of derivation such as VoiceP, IP and so on for Chapter 5.

(169)a. John ke parit 'John to the gutter'.

b. Tree structure

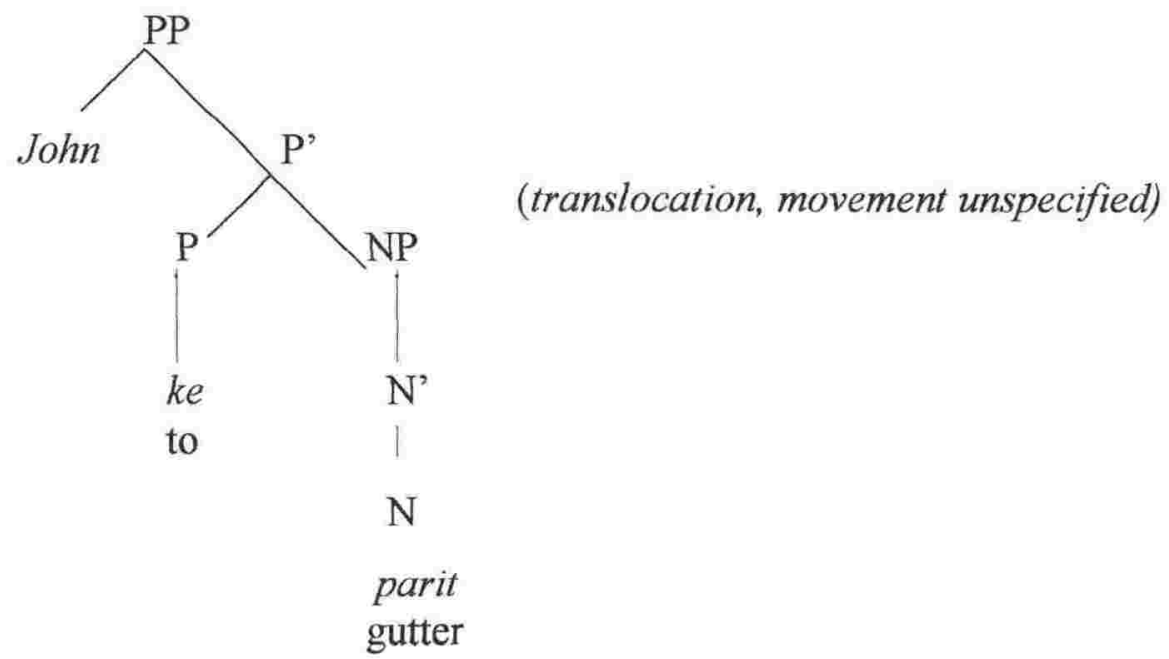

The tree structure, (169b), is of the simplest expression involving a movement of some sort. It must be noted that the expression occurs naturally. The translocation is indicated by the [+MOTION] preposition ke 'to'. The preposition also indicates the direction of movement, and the argument parit 'gutter', is the terminus (GOAL).

To specify the movement of the argument John of (169) above, let us select the verb jatuh 'fall', to occupy the V head of the VP, which is the lower part of $v \mathrm{P}$ (for GF change or incorporation, refer back to the appropriate sections regarding the deadjectivals, de-nominals and so on; for a more elaborate analysis, see Hale \& Keyser 1993). The selected verb jatuh merges with the PP John ke parit, of (169), involving the following process, (170). 


\section{(170)1. Select jatuh \\ 2. Select PP John ke parit \\ [V] \\ 3. Merge [V] jatuh with [PP] John ke parit}

Once the selected verb jatuh merges with the PP, the object John is forced to move to [Spec-VP] from the [Spec-PP] position for Full Interpretation by means of a copy process, (171).

(171) Move John to [Spec-VP]

COPY

The immediate result would be (172), John jatuh [John] ke parit, 'John fell [John] into the gutter'.

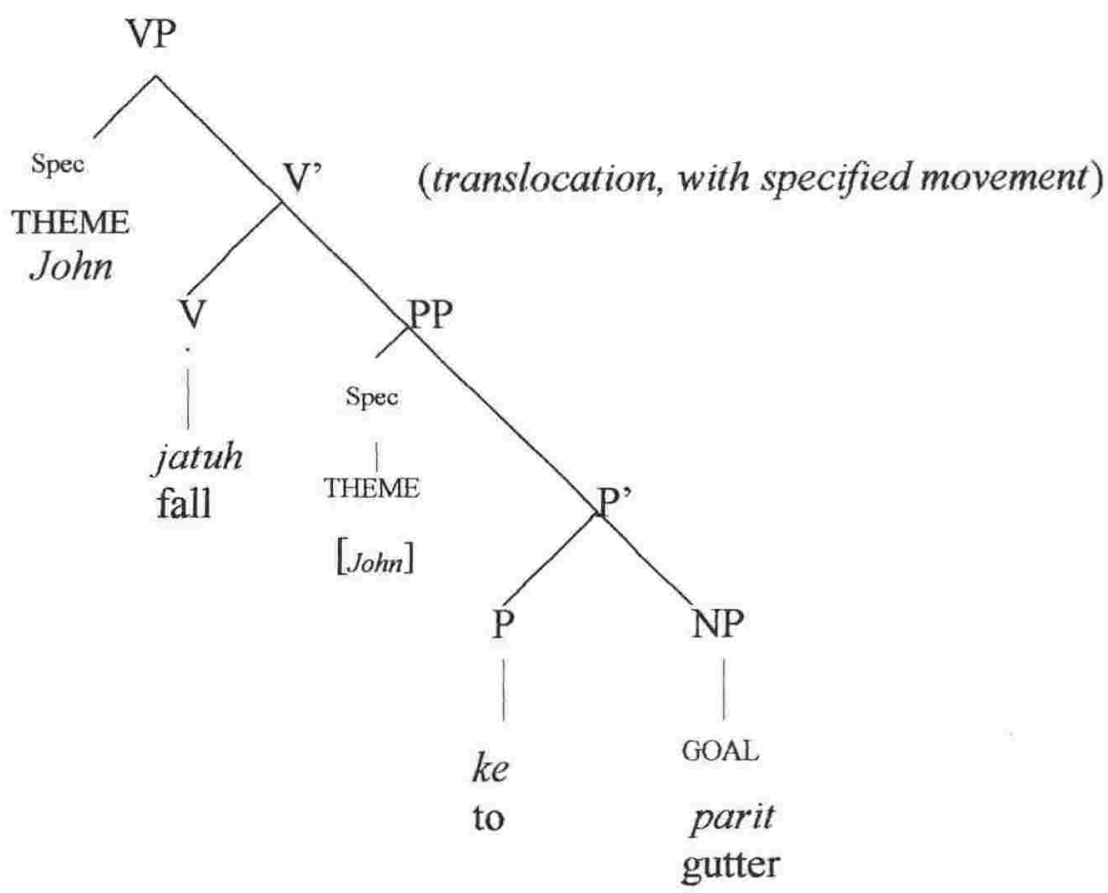

In the above tree structure, (172), the object John has been copied from the lower position, [Spec-PP]. This is an instance of "derived subject" for the "voiceless" (i.e., it is not stated that the fall is unintentional) unaccusative jatuh 'to fall' (recall our discussion in Section 3.3.2.1 regarding unaccusative verbs without the prefix ter-). The selection of the verb jatuh to occupy $\mathrm{V}$ is motivated by the need to specify the movement that is 
indicated by the preposition ke 'locative to' (although either John jatuh 'John fell' or John ke parit 'John (MOVES) to the gutter' is sufficient, recall the (c) examples of (167) and (168)). The difference between (169b) and (172) is that in (172) the translocation is specified as jatuh 'to fall'. The forced move of the argument John does not change its status as a THEME. The mechanism fits well with the notion of a position for the THEME: the verb jatuh 'fall' projects a specifier at VP (see Hale and Keyser's 1998:113 discussion regarding the [Spec-VP] as the base of the surface subject of a "monadic" construction such as John fell).

The structure shown as (172) does not involve the kan-aspect. In order to show the kan-aspect, we must add another layer of derivation, namely the higher part of the shell, (173). For the higher part of $v \mathrm{P}$, headed by $v$, I shall keep the object John as an example of an object that is undergoing movement, namely, the falling to the gutter as in (172).

(173)

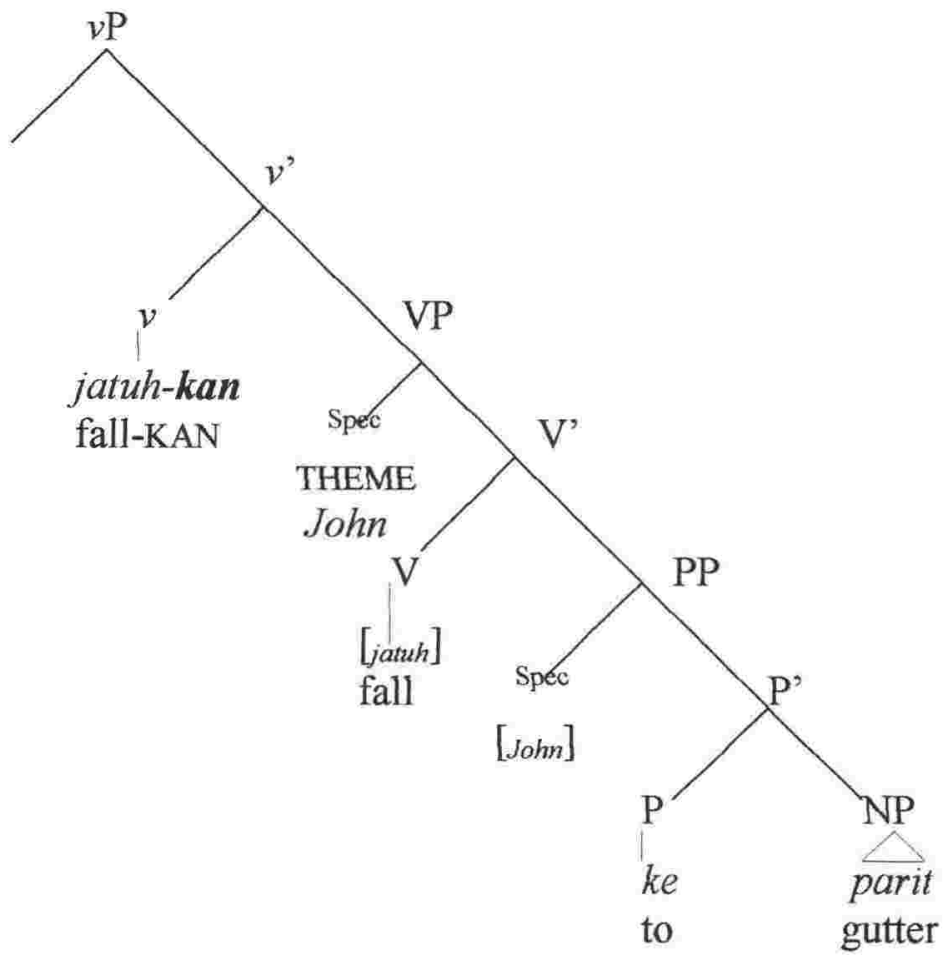

$\begin{array}{llll}\text { Jatuh-kan } & \text { John } & \text { ke } & \text { parit } \\ \text { fall-KAN } & \mathrm{J} & \text { to } & \text { gutter }\end{array}$

'Throw John into the gutter' 
The difference between $\mathrm{V}$ of $\mathrm{VP},(172)$, and $v$ of $v \mathrm{P},(173)$, is that now we have a functional head, as assumed in the present discussion to be encoding an aspect, and this functional head is realised as -kan. This assumption has a strong theoretical base. For instance, Baker (1997), based on Travis [1994] (2000), suggests that a functional projection above the VP is needed (see also Chomsky 1995, Radford 1997). He argues that some languages, including Japanese, have a morpheme that indicates CAUSE on the predicate. Travis [1994] (2000) suggests that $v$ P-aspect selects a specific argument, which in our case is the object John as a THEME. Chomsky (1995) (and also Arad 1998, Wyngaerd 1996, amongst others) concludes that $v_{\mathrm{CAUSE}}$ (that includes transitives, light verbs, unergatives) must be higher than [Spec-VP]. Bowers (2002) proposes that the head $\operatorname{tr}$ (=transitivity) as a functional category is located between $v / \operatorname{Pr}(\operatorname{Pr}=$ Predicated) and VP. Since kan-aspect in all our data in the present chapter characterises transitivity (or, "transitive CAUSE", Pylkkänen 2002), there is no reason why we should not use the suffix $-k a n$ as a transitive head. In the present discussion the head $v$ containing aspect is simply interpreted as $v_{\text {kan, }}$, rather than inserting a $T r \mathrm{P}$ between $v \mathrm{P}$ and VP as proposed by Bowers (2002:186). Recall that the kan-aspect "selects" - to use Travis' (2000) term - i.e., takes as a complement a THEME. The following structure, (174), is taken from Chomsky (1995). As mentioned earlier on, according to Chomsky (1995), if a verb has several internal arguments, then we have to postulate a Larsonian shell, where 'small' $v$ is a position to which $\mathrm{V}$ overtly raises.

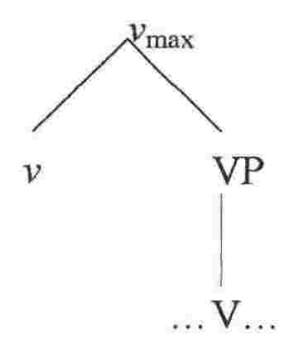

The small $v$ is a position for transitive verbs, or light verbs, as well as for verbs bearing a cause, or $v_{\text {CAuse }}$ (for instance, Hale \& Keyser 1993, Chomsky 1995, Baker 1997, Radford 1997, Travis 2000), including Psych-predicates (Arad 1998) and unergatives (Chomsky 
1995; for a different view, see Bowers 2002). The big $\mathrm{V}$ is for unaccusative only (Chomsky 1995:315-316), that is, when the $v \mathrm{P}$ does not project. This is also our definition for what an unaccusative is. Three points from the present discussion of $v \mathrm{P}$ aspect must be remembered:

(i) $v \mathrm{P}$-aspect is internal, in that it is assigned within the $v$-VP-configuration;

(ii) $v \mathrm{P}$-aspect is characterized by transitivity, including the psych-predicates with a CAUSER;

(iii) vP-aspect "selects" the primary argument; for the kan-aspect, this argument occupies [Spec-VP].

The central notion is that [Spec-VP] of (173) is occupied by THEME. This is in the same line with the notion that the internal arguments occupy the positions of specifier and complement of V (before Spell-Out, that is, for instance, Chomsky 1995, Bowers 1993, amongst others). Internal arguments are those that do not occupy [Spec- $v \mathrm{P}]$; those that do are external, and are not included in the aspectual path, which in our case means that they are outside the path of change (following Tenny 1987 and Arad 1998).

In summary, the following structure, (175), provides the basic tree structure for kanaspect, based on what has been suggested in the literature, such as (174) above.

(175) The basic tree diagram with kan-aspect:

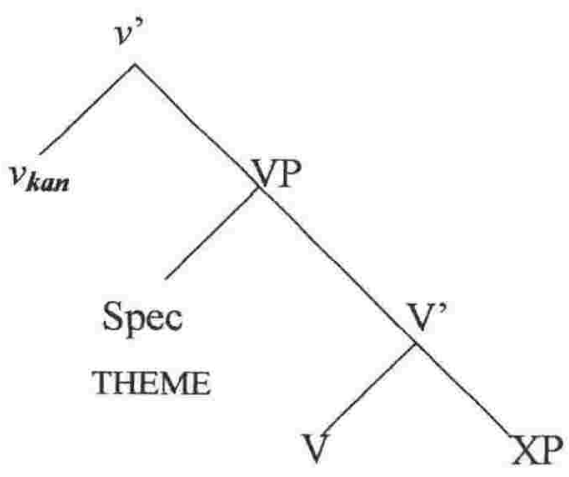


To demonstrate how the present discussion relates to what has been proposed in the literature, consider the following tree structures, (176) and (177), where spray/load verbs are used.

(176) load, muat

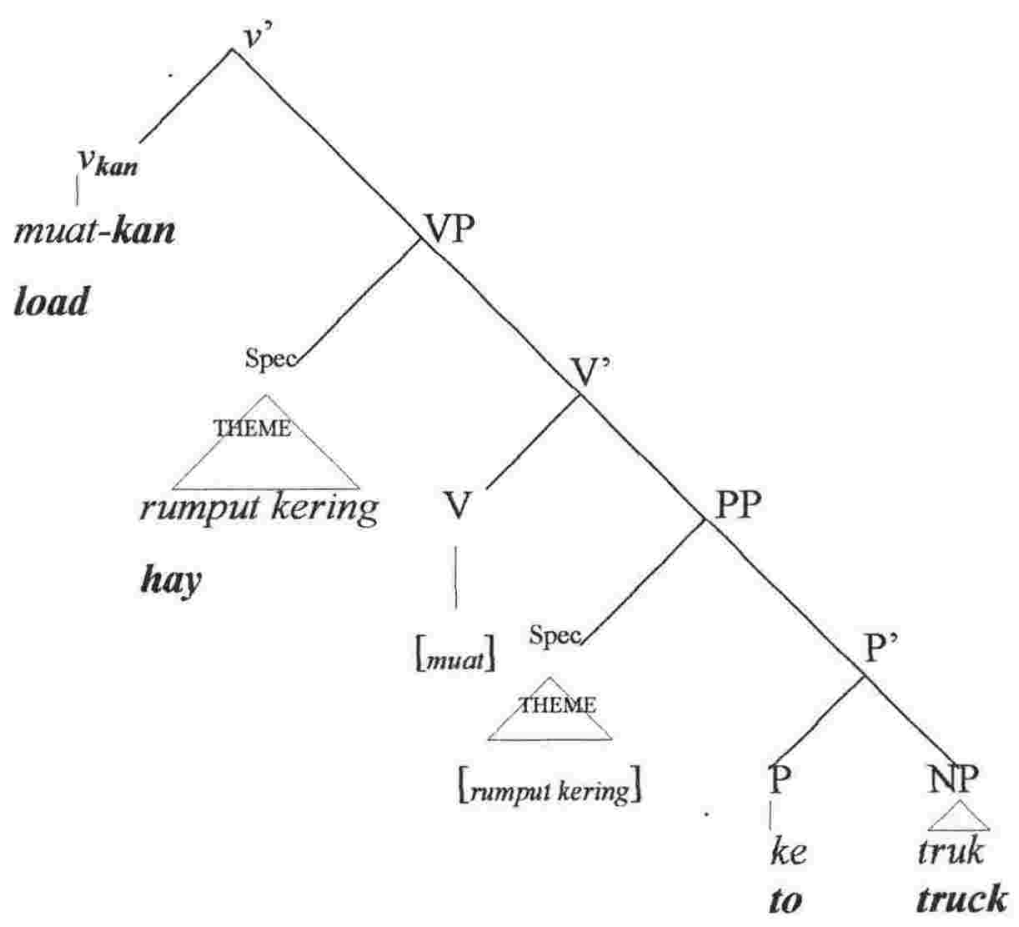

$\begin{array}{lll}\text { Muat-kan rumput } & \text { kering } & \text { ke truk } \\ \text { Load-KAN grass } & \text { dry } & \text { to truck }\end{array}$

'(To) Load the hay into the truck'

From the diagram (176):

(i). The lexical $\mathrm{V}$ is copied to the functional head, resulting in a verb with aspect, $v_{\text {kan }}$;

(ii). The label shows THEME - object correlation, in [Spec-VP].

The implication for the English example Load the hay into the truck, (176), is that the verb load bears an aspect, which is proposed in the present work as kan-aspect for Bahasa Indonesia, and the hay, in this instance, is a THEME because it is the argument that 
undergoes translocation (as against the truck that is stationary). The preposition to indicates the path for the object hay to travel through, until reaches its GOAL the truck (Gruber 1970, Tenny 1987, amongst others). However, the PP 'to the truck' is optional, that is, the expression 'Load the hay' is complete even without it, but the $v \mathrm{P}$-aspect must be included. The same reasoning also applies to Spray paint on the wall, as in the following, (177).

(177) spray, semprot

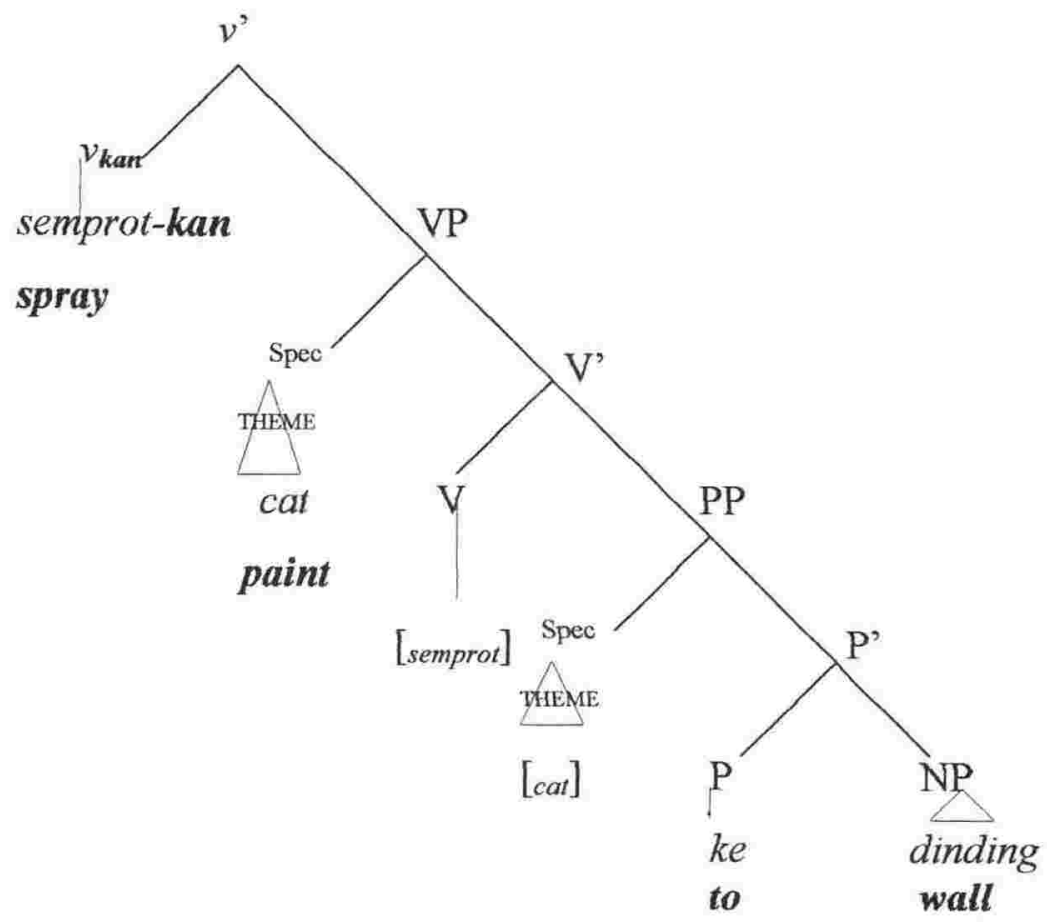

$\begin{array}{lll}\text { Semprot-kan cat } & k e & \text { dinding } \\ \text { Spray-KAN paint } & \text { on(-to) } & \text { wall } \\ \text { '(To) Spray paint on the wall' } & & \end{array}$

I have included expressions such as (178), with the English counterparts such as (179).

(178) Muat-kan rumput kering ke truk

Semprot-kan cat ke dinding 
(179) Load the hay into the truck

Spray paint on the wall

The chapter that follows, Chapter 4, will include the alternative forms, such as (180), with the English counterparts, (181).

(180) Muat-i truk dengan rumput kering

Semprot-i dinding dengan cat

(181) Load the truck with hay

Spray the wall with paint

\subsection{Summary and remarks}

\subsubsection{Summary}

This chapter claims that the BI predicate suffix - kan encodes a $v \mathrm{P}$-aspect, referred to as $k a n$-aspect. The primary information given in an event involving kan-aspect is that the object undergoes change of some sort. For convenience, this paper adopts the terminology used in Dowty (1991) and Hale \& Keyser (1993), namely, to call the argument that undergoes change THEME. Change occurs with derived predicates (Section 3.2) and with verbs (Section 3.3).

The many variations of path of change are exemplified using simple examples. Because the variations are found in different linguistic expressions, I have loosely grouped change according to expressions that are similar, and discovered that the patterns are consistent within each group, and also comparable with those of other groups. Overall, the notion of change is a good cover term for change of location (displacement, shift), change hands, change of state, and reclassification of an object.

Change encoded by the kan-aspect requires a cause: this can be an AGENT, and the event is a result of ACT (the AGENT intends to bring about the event). If the cause is a non-AGENT, also termed as a CAUSER (i.e., a 'real cause'), the event is a result of 
HAPPENing (the CAUSER happens to trigger the event). Psych-predicates with kan-aspect (frighten verbs) are special, in that, they only take CAUSERs, and the constructions formed do not have a PASSIVE counterpart. On the other hand, fear verbs cannot be involved in events with the kan-aspect, they occur only with $i$-aspect (see also the next chapter, Chapter 4). Common de-adjectivals can be used even when the CAUSE is not specified in the expression: the constructions pattern with the English middles. However, when the kan-aspect is used with de-adjectivals, an AGENT is required.

Change implies paths. For the change of location, there is a path to be travelled through by a moving object. Some objects reach their final destination (GOAL). The final destination can be expressed in the kan-predicate (Section 3.2.1), in the style of what Hale \& Keyser (1993) call "location verbs". However, some objects do not reach their GOAL. In some cases, it is the path to be travelled through by a moving object that is expressed in the kan-predicate, as "expression of direction", which is "elaboration of the expression of Goal" (Gruber 1970:58), discussed in Section 3.2 .5 as a path without an end-point/terminus. Alternatively, the final destination can be included by means of a prepositional phrase, introduced by the appropriate preposition, such as, $k e$ 'locative to', and kepada 'dative to'. The argument that is introduced by these prepositions participates in the event by providing an event terminus (following Tenny 1987).

Prepositional arguments receive secondary importance (Dowty 1991), and do not have to be overt. The present work claims that in an event with kan-aspect, the THEME, which cannot be introduced by any preposition, is the primary, core argument. Syntactically THEME is assumed to occupy [Spec-VP] of the vP-shell (Section 3.4). Except for the psych-predicates, the THEME must be overt when kan-aspect is present. With the psych-predicates the THEME may be covert, similar to the English John is embarrassing (John meN-malu-kan [pro], but not *John embarrasses [pro]) as against John embarrasses me (John meN-malu-kan saya). I argue (Section 3.2.6.2) that John is neither an AGENT nor a CAUSER: John is the inseparable possessor of something that is embarrassing. 
Both denominal and de-adjectival kan-predicates may express the outcome of the change as the final state, although it may be only the view of the object that is changed, rather than the argument itself. For instance, for the denominals we have examples such as to regard somebody or something as a god, as a father, a stepson, and so on, where in actual fact this person or thing is not such. For the de-adjectivals we have examples such as to regard somebody as stupid, great, small, and so on. For both, I use the term "reclassification" of argument.

The term 'part-whole relation' is used, as a cover term to include the moving instrument used in the expressions containing a MANNER component, as well as for cognate objects in unergatives. How the THEME moves or is moved is expressed in the kan-predicate by means of inclusion of the manner in the predicate. Like Hale \& Keyser (1993), this chapter recognises unergatives as denominals. In all the variations exemplified in the chapter, the notion of change holds through.

The aspectual path that is travelled through in the event with kan-aspect is not always direct and straight. Sometimes a path is direct (which can be supported by the preposition ke 'locative to', or kepada 'dative to'), and sometimes it has a transit point (can be supported by the preposition untuk 'for'). When it has a transit point, we gain the interpretation that there is a sense of benefactivity in the event. However, because the notion of change is consistently applicable for all cases with the kan-aspect, the present work proposes that it is not necessary to taxonomise kan-predicates, and it is not necessary to classify the suffix $-k a n$ as a benefactive marker. Benefactivity only makes up one of the variations of path of change.

\subsubsection{Remarks}

For descriptive purposes, I have grouped the kan-predicates into two main categories, namely, those that are assumed to be derived (de-nominals, de-adjectivals, directional prepositions) and those that are not derived. I have also attempted to see if it matters to 
have the base of the kan-predicate as transitive or intransitive. The overall conclusion is that kan-aspect does not distinguish the base of a predicate, whether it is a derived or non-derived, whether it is transitive or intransitive.

It is not surprising to discover that kan-aspect is characterized by transitivity, since a THEME is required to be overt in the event. And it is not surprising that kan-aspect does not distinguish the base, derived or non-derived, because, put simply, its function is to encode that the object complement undergoes change. It is necessary, however, to make a distinction between properties of some lexical predicates versus properties of structures in which such predicates may appear. For instance, there are verbs that always have a $\nu \mathrm{P}$ above them and there are those that may or may not have a $v \mathrm{P}$ above them, as noted also by Arad (1998). In Hale and Keyser's (1998:113) terms, some verbs do not project a specifier ([Spec-VP]). These verbs must move to the head $v$ of the $v$ P. Those that project a specifier may remain, as an unaccusative.

With an unaccusative, the $v \mathrm{P}$ is not projected (a $v \mathrm{P}$ shell is unnecessary). The notion that the subject of an unaccusative is a "derived" one, i.e., it is an underlying object, remains valid, because [Spec-VP] is a position designated for an object. The (surface) subject of an unergative, on the other hand, must appear, or, "forced to appear" (Hale and Keyser 1998:113) at [Spec-vP] because the [Spec-VP] is not projected.

The occurrence of some prefixes depends on the suffix $-k a n$, but $-k a n$ occurs independently of prefixes. The explanation is that the suffix marks a predicate's internal aspect, whereas prefixes are external to $v \mathrm{P}$. I have assumed in this chapter, following Ouhalla (1991), Cinque (1999), and Pylkkänen (2002), that BI prefixes realise a Voice head, which is higher in the derivation than the $v \mathrm{P}$. It is therefore my aim to demonstrate, in the chapter to come (Chapter 5: VOICE and Transitivity) how aspectual properties of predicates relate to VOICE.

The present chapter shows that the suffix $-k a n$ is functional (Section 3.5). It represents an "abstract entity" (after Hale and Keyser 1998). Because it is an abstract 
entity, it must be looked for beyond that which meets the eye. We have discussed the suffix -kan in terms of its aspectual property, namely, it encodes change as an event characteristic. We analyse the suffix through the correlation between semantics, syntax and morphology. In so doing, the present chapter provides an alternative analysis to those that analyse the suffix within Morphology alone (Tarigan 1985, Sneddon 1996, Voskuil 1996, among others), or to those syntactic analyses that focus exclusively on the so-called 'Dative alternation' (Chung 1976, Baker 1988, Den Dikken 1995). The suffix - kan does not have "as many functions as the environment it occurs in" as argued for by Voskuil (1996:4-6). Instead of assigning several different functions to the suffix, this chapter proposes a single function, namely, as a $v$ P-aspect marker. 


\section{Chapter 4}

\section{$i$-aspect}

\subsection{Overview}

In Chapter 3 I discussed in detail the first kind of BI $v$ P-aspect, kan-aspect. Various kinds of examples were provided, covering both derived and non-derived predicates, and the notion of change was held throughout. In this chapter I will discuss $i$-aspect, by means of comparison with the kan-aspect. Different from kan-aspect, this aspect does not implicate any change affecting the primary internal argument. I will show in this chapter that $i$ aspect is in a stark contrast with kan-aspect. To enable us to see the contrast, some of the examples from Chapter 3 are reused, with the $i$-aspect shown to substitute for the kanaspect.

This chapter argues that the $\mathrm{BI}$ suffix $-i$ is not in free variation with $-\varnothing$; neither is it synonymous with the suffix $-k a n$. This analysis is novel in the present work. I will show that $k a n$-predicates and $i$-predicates are in opposition with each other. The present work also proposes an alternative view to Chung's (1976) analysis that argues that the suffix -kan is "applied" after "dative shift", as well as to Den Dikken's (1995) view that the BI double-object construction is "transformationally related" to the dative construction, in that the BI (and English) double-object construction is derived from the dative construction counterpart. Neither Chung (1976) nor Den Dikken (1995) discusses the 
forms with the suffix $-i$. As far as I am aware, the analysis to be presented here has not previously been proposed in the literature.

In the present chapter, the crucial part the two aspects play in the derivation is explained in terms of the argument selection - i.e., what type of object is taken or subcategorised for as the complement of the predicate - without suggesting that one expression is derived from the other. The argument selection is argued in this chapter to be as simple as saying that kan-aspect selects a THEME, while $i$-aspect selects a nonTHEME PATIENT.

The use of the term "applicatives" referring to the suffixes $-k a n$ and $-i$ in the literature (for instance, Chung 1976, Johns 1985, Sneddon 1995, Musgrave 2000) implies that, in the case of BI, forms with $i$-aspect are derived from those with kan-aspect; namely, the argument that is introduced by a preposition (of the kan-aspect) is "promoted" to become an "Object" (of the $i$-aspect). The present work keeps away from the notion of argument demotion/promotion that applies to the kan-aspect and $i$-aspect alternation. In all the forms examined, primary and secondary internal arguments and external arguments are all clearly distinguishable from each other. A different set of participants are involved in each event - in other words, kan-predicates have a different "argument structure" from that of $i$-predicates. I maintain that both kan-and $i$-forms are basic and not derived from each other.

In $\mathrm{BI}$, the derivation of the $v \mathrm{P}$ consistently involves different secondary internal argument: the kan-aspect having the PP ke/kepada to-phrase, the $i$-aspect having the PP dengan with-phrase. The verbs kirim 'send', beri 'give' and pinjam 'lend/borrow' are idiosyncratic, in that the secondary internal argument involved in the $i$-form can occur without being introduced by the preposition dengan 'with', which makes this argument primary-like.

The present chapter places the so-called "DAC/DOC (DAtive Construction/Double $O$ bject Construction) with respect to the two $v \mathrm{P}$-aspects, $k a n$-aspect versus $i$-aspect. I will 
demonstrate that the data commonly used in the literature for English do not have corresponding minimal pairs in BI; namely, they do not belong to the same predicate. One of the implications for our BI $v \mathrm{P}$-aspect analysis, namely, that of having two opposing $v \mathrm{P}$-aspects, is that the so-called dative/double object constructions can be seen through this light: the dative/double object constructions show contrasting forms of $v \mathrm{P}$ aspect alternation. In simple terms, DAC belongs to the kan-aspect, and DOC to the $i$ aspect; there is no DOC with the kan-aspect, and conversely, there is no DAC with the $i$ aspect. It all falls into the notion of change versus non-change in general. It will be concluded that different $v \mathrm{P}$-aspects are involved in different paths of derivation. Finally, despite the differences - or the contrasts, the two aspects share a common ground, namely, both are characterised by transitivity.

This chapter is organised as follows. Section 4.1 shows that in contrast with the kan-aspect, with the $i$-aspect the primary internal argument does not undergo change. To be included in this section is data showing that the suffix $-i$ is neither in free variation with $\varnothing$ nor is it synonymous with the suffix -kan. Section 4.2 compares the two forms, the form with $-k a n$ and the form with $-i$, in terms of $v$ P-aspect alternation. There are cases where the $v \mathrm{P}$-aspects do not alternate; these include the cases with psych-predicates and predicates of cognition, with common-adjectives, and with the transit path of change. As a part of $v \mathrm{P}$-aspect alternation, I will include in this section preposition alternations for the secondary internal arguments. Section 4.3 presents structures with the $i$-aspect, including the $\mathrm{BI}$ double-object structure for the verbs send/give/lend. Section 4.4 summarises the present chapter.

\subsection{The BI $i$-aspect and the lack of change}

In the literature, the suffix $-i$ is often overlooked, and when it appears in the discussion, it is regarded as an "optional" suffix. Sometimes the term "optional" means that the suffix is an alternative to $-\varnothing$ (for instance, Sneddon 1996: $92 \mathrm{ff}$. where the suffix $-i$ is viewed just like the suffix -kan, in that it has - $\varnothing$ as an "option", p. 84) or as an alternative to the suffix -kan (for instance, Chung 1976: 55-56 argues that the other alternative to -kan is -ø). Describing the suffix as an alternative to $-k a n$, in effect, implies that predicates with $-i$ 
can be synonymous with predicates with -kan, ignoring the possibility that they have different syntactic structures (for instance, Sneddon 1995: 96-97, Voskuil 1996: 219-261 (passim); Tampubolon 1983 analyses both suffixes as a causative marker). In a more recent work attention is paid to the prefixes, namely meN-versus $d i$ - on derived and underived verbs (e.g., Musgrave 2000). No specific explanation is given in this last work, regarding what Musgrave terms "applicative suffixes" for both $-k a n$ and $-i$.

The following points provide the basis of our analysis: In Section 4.1.1 I will demonstrate that the suffix $-i$ is not optional. In Section 4.1.2 I argue that kan- and $i$ predicates are not synonymous. Section 4.1 .3 shows that, with $i$-aspect, there is the lack of change on the primary internal argument.

\subsubsection{The suffix $-i$ is not in free variation with $-\bullet$}

Firstly, a suffix is optional to $-\varnothing$, if it can be dropped without changing the intended meaning of an expression (or, conversely, if the occurrence of the affix does not change the meaning to the intended expression). Secondly, if the suffix $-i$ is an "option" of $-k a n$, then one must explain in what way it is an option. Chung (1976: 55) states that,

"...there seems to be a general movement towards eliminating $-i$ and $-\sigma$ in favor of $-k a n$. For many younger speakers, there are no verbs that take $-i$ when Dative has applied, and only a few (including beri 'give', kasih 'give', bajar, 'pay') that take - $\bullet$ instead of -kan."

I disagree with the above statements for two reasons. Firstly, for Chung's first sentence, of course, $-i$ and $-\varnothing$ are impossible when $-k a n$ is obligatory: they cannot occur in a kanaspect environment. Secondly, the two aspects should be analysed separately. The present sub-section argues that the suffix $-i$ is not an alternative to $-\varnothing$.

To show that the suffix $-i$ is not an alternative to $-\sigma$, we must at the same time look at the prefix meN-. If we look for a BI "transitive marker", it is the suffix $-i$ (or $-k a n$ ) that marks transitivity, rather than the prefix $m e N$ - (Voskuil 1996). In Voskuil's terms, the prefix $m e N$ - is "related" to transitivity, but it does not mark transitivity (against Chung 1976 who treats the prefix $m e N$ - as a transitive marker). Recall our discussion in Chapter 
3 regarding the morphological and syntactic bracketing for the suffix - kan where we see that the suffix must be used before the VOICE prefix $m e N$ - can be added. To use Pylkännen's (2002) terms, the suffix -kan is involved in the "STEP1" derivation, which is within the $v \mathrm{P}$, whereas the Voice prefix $m e N$ - is involved in the "STEP2" derivation, which is above the $v$ P. I will show that the same bracketing (or, rule ordering) applies also to $i$-predicates. At the same time we will show that the suffix $-i$ occurs in a transitive environment, whereas -0 occurs in an intransitive environment. In simpler terms, to "add" or include in the expression an internal argument to the intransitive predicate we need the suffix $-i$ (or $-k a n$ ) rather than the prefix meN-. The prefix $m e N-$ is needed to relate the external argument with the predicate in the expression. Recall also our examples of predicates with meN- that are intransitive (e.g., meN-tangis 'to cry', meNtari 'to dance' and so on, which take cognate objects only if the kan-aspect is used), and predicates with $m e N$ - that indicate a process (e.g., meN-panjang 'to turn/become long (by itself)', meN-kuning 'to turn/become yellow (by itself)' and so on). Thus, our view in this respect fits well with what is argued for by Voskuil (1996), in that it is the suffix $-i$ (or $k a n$ ), and not the prefix $m e N-$, that characterises the predicate as being transitive.

Consider for instance, the unergative $d u d u k$ 'to sit' (refer back sub-section 3.3.2.1), used in the example that follows, (1), to show that without the suffix the predicate cannot take another argument.

(1)a. Peter duduk

$\mathrm{P} \quad$ sit

'Peter sat/was sitting'

b. *Peter duduk bantal

$\mathrm{P}$ sit pillow/cushion

'Peter sat/was sitting pillow/cushion'

c. *Peter meN-duduk bantal

$\mathrm{P} \quad \mathrm{ACT}$-sit pillow/cushion

'Peter sat/was sitting a pillow/cushion' 
The argument bantal 'pillow/cushion', in (1b) and (1c), does not receive a Full Interpretation, because as an unergative the predicate cannot select it as an internal argument. It must be noted, that if the prefix meN-marks the predicate $d u d u k$ 'to sit' as being transitive, then (1c) should be allowed, but it is not. In order for bantal to appear as an internal argument, the suffix $-i$ is needed, $(2 a)$, contrasts with $(2 b=1 c)$.

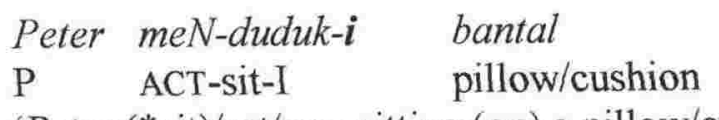

'Peter sat/was sitting a pillow/cushion'

In (2a) the suffix is obligatory, otherwise the sentence is unacceptable, $(1 c) /(2 b)$. By comparing the ungrammatical sentence $(2 b)$, with the grammatical $(2 a)$, we see that it is the suffix $-i$ that is needed, rather than the prefix meN-. The voice prefix meN-is needed to include the external argument Peter, to state that it is Peter who performs the ACT of sitting (on) the pillow. Without the voice prefix $m e N$ - the sentence is ungrammatical, (3).

\section{(3) *Peter duduk-i bantal \\ P sit-I pillow/cushion \\ 'Peter sat the pillow'}

In contrast, without the voice prefix $m e N$ - and the external argument Peter, but with the suffix $-i$ alone, the sentence is grammatical as an imperative, (4).

$\begin{array}{lll}\text { (4) Duduk-i } & \text { bantal } & \text { itu } \\ \text { sit-I } & \text { pillow/cushion } & \text { DEM } \\ \text { 'Sit that pillow (on)' } & \end{array}$

In (2a) and (4) the $i$-aspect selects bantal 'pillow/cushion' as an internal argument (the preposition 'on' is required for a good English translation, which can be misleading, because the direct internal argument then can be misinterpreted as an object of the preposition). The argument bantal 'pillow/cushion' may occur as an object of a 
preposition for (1a,b) but not for (1c), for instance of the preposition di 'in, on, at' as in the example (5).
(5) Peter duduk
P ACT-sit
di bantal
on pillow
'Peter sat/was sitting on a pillow/cushion'

However, the relation between the predicate and the object in (5) is restricted, namely, bantal 'pillow/cushion' only provides a location of the sitting, and is the object of the preposition $d i$ 'on'. Conversely, the preposition cannot occur when this argument acts as a direct object, (6), i.e., the suffix cannot co-occur with the preposition. In other words, when the suffix $-i$ appears, the internal argument must appear as a direct object, as shown in (2a) and (4).

$$
\begin{aligned}
& \text { *Peter meN-duduk-i di bantal } \\
& \text { P ACT-sit-I } \quad \text { on pillow/cushion } \\
& \text { 'Peter sat/was sitting on a pillow/cushion' }
\end{aligned}
$$

To include the argument Peter as a willing active participant in the event (6), as an AGENT, the predicate must be transitive. Conversely, the VOICE $m e N$ - cannot be used unless the predicate is transitive, that is, the argument bantal 'pillow/cushion' in (6) must not be introduced by any preposition. In (6) the interrelation between the predicate and the argument bantal is restricted/obstructed by a preposition. This explanation fits well with Voskuil's (1996) proposal, that the voice prefix meN- is related to transitivity (as "STEP2" derivation in Pylkannen's 2002 terms), but it does not actually mark transitivity. The nature of this interrelation, and the inclusion of the argument in the event, such as Peter of the acceptable examples (1a), (2a) and (5) above, in the configuration will be discussed in detail in the next chapter, Chapter 5 .

To conclude, apart from the fact that the suffix $-i$ is in a complementary distribution with the preposition, which in the examples (5) and (6) above is $d i$ 'on', the suffix $-i$ selects a direct internal argument, (2a) and (4); in other words, the suffix is not an alternative to $-\varnothing$ (As a reminder, without the suffix, the predicate $d u d u k$ in (1a) and (5) is 
unergative, section 3.3.2). To say that the suffix $-i$ is "optional" would be incorrect, because in this case the transitive form is not optional.

Thus, $d u d u k$ can occur intransitively (without the suffix $-i$ ) and transitively (with the suffix $-i$ ), putting together the good sentences, we have the following examples, (7a) and $(7 \mathrm{~b})$.

$\begin{array}{cll}\text { (7)a. Peter duduk } & *(\text { di }) & \text { bantal } \\ \mathrm{P} & \text { sit } & \text { on pillow }\end{array}$

'Peter sits/sat/was sitting on a pillow/cushion'

b. Peter meN-duduk-i (*di) bantal

$\mathrm{P} \quad$ ACT-sit-I on pillow/cushion

'Peter (*sits)/sat/was sitting (on) a pillow/cushion'

Apart from the distinction between the intransitive (without $-i$ ) and transitive (with $-i$ ) forms above, the difference can also be explained in terms of $v \mathrm{P}$-aspect (the non-habitual reading of $(7 \mathrm{~b})$ will be apparent as we progress). But before explaining the difference, consider examples that make the suffix appear optional, (8).

(8) a. Tony masuk (ke) rumah

$\mathrm{T}$ enter to house

'Tony entered the house' i.e., he is/was inside the house

b. Tony meN-masuk-i (*ke) rumah

T ACT-enter-I to house'

'Tony is/was entering the house' i.e., he is/was stepping in

The same reasoning we use to distinguish the non-occurrence versus occurrence of $-i$ in the previous examples (1a) and (2a), i.e., by means of using the distinction between the transitive versus the intransitive forms, respectively, can also be used here for explaining 
the difference between (8a) and (8b). ${ }^{1)}$ In this case, we will show, firstly, that there is a covert preposition between masuk 'enter' and rumah 'house' in (8a). And secondly, the difference can also be explained in terms of what effects the $v \mathrm{P}$-aspect puts on the $v \mathrm{P}$ external aspect.

The first way of seeing the difference is by assuming that (8a) is intransitive, and (8b) transitive. It is important to note for now that like bantal 'pillow/cushion' of example (7a), here rumah 'house', in (8a), is not a direct internal argument (the English translation makes it sound as if it is). But in (8b), rumah 'house' is a direct internal argument: it is a PATIENT (and so is bantal 'pillow/cushion' in (7b)). We want to explain the difference between the (a) and the (b) examples of (7) and (8) by showing that on the surface, the preposition in (8a) can be covert. Unlike duduk 'to sit', (7a), masuk 'to enter' (8a), lexically has a MOVE component (As a note, the preposition di 'on' in (7a) cannot be dropped, thus unlike the uniquely specified preposition in (8a) which is similar to the English Let's go home or He will come home soon in contrast with Let's go to his house or He will come to my house soon). Recall the discussion regarding the choice between the VP and the PP constructions, sub-section 3.4.2 "Derivations with the kan-aspect". We shall use the options - in this case of $(8 a)$ - to show that the object in (8a) is not an internal argument because of the preposition drop. In the following examples, (9a) uses a PP construction, while (9b) uses a VP with a PP included as optional.

(9) a. Tony ke rumah

$T$ to house

'Tony (entered/came/ran...) to the house'

1) That is, to use the ACTIVE voice prefix meN- the suffix $-i$ must appear (ii) before meN-can be added (iii), i.e., to include Tony as the AGENT. The existing interrelations are underlined.
(i) Tony masuk
vs. *Tony meN-masuk
$T$ enter
T ACT-enter

'Tony entered'

(ii) Masuk-i rumah enter-I house

'Enter the house'

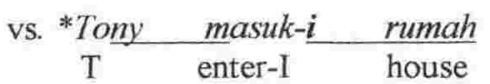

(iii) Tony meN-masuk-i rumah

$\mathrm{T} \quad$ ACT-enter-I house

vs. * Tony meN-masuk rumah

'Tony is/was entering the house'

I shall come back to this matter in Chapter Five 


\section{b. Tony masuk (ke rumah) \\ $\mathrm{T}$ enter to house \\ 'Tony entered (into the house)'}

The stylistic options for both examples, (9), which can be assumed to be the "split" of (8a) (refer back sub-section 3.4.2 regarding VP, PP and the translocation concept), are as follows, namely, by means of a focus operation involving the emphatic (EMP) head-lah.

(10)a. Ke rumah, masuk-lah/datang-lah/lari-lah... to house, enter-EMP/come-EMP/run-EMP T 'Into the house entered/came/ran... Tony'

Tony $\mathrm{T}$

(

'Into the house entered/came/ran... Tony' $\begin{array}{clll}\text { b. Masuk-lah/datang-lah/lari-lah ... } & \text { Tony } & \text { ke } & \text { rumah } \\ \text { enter/EMP/come-EMP/run-EMP } & \mathrm{T} & \text { to house }\end{array}$ 'There entered/came/ran... Tony into the house'
c. Ke rumah-lah Tony
'Into the house, entered/came/ran... Tony'

All the styles in (10) cannot leave the preposition ke 'to/into', empty. And thus, in conclusion, the preposition $k e$ in ( $8 \mathrm{a}$ ) can be covert but not $d i$ in (7a), which is also to say that rumah 'house', is not a PATIENT. Examples in (8) are repeated here as (11).

(11)a. Tony masuk (ke) rumah
T enter to house
'Tony entered into the house' $\quad$ i.e., he is/was inside the house
$\begin{array}{lll}\text { b. Tony meN-masuk- } i \quad\left({ }^{*} k e\right) & \text { rumah } \\ \mathrm{T} \text { ACT-enter-I to } & \text { house } \\ \text { 'Tony is/was entering the house' } & \text { i.e., he is/was stepping in }\end{array}$

The second way of explaining the difference between (11a) and (11b) is by looking at the difference emphases in interpretation. The first, and most obvious, difference in interpretation is that in (11a) Tony is already in the house, while in (11b) he is still entering the house. In (11a), there is a sense that the truth of the statement requires some sort of evidence that Tony has been inside the house, perhaps by giving evidence that, for 
instance, all the lights in the house were/are on, or other signs that can be used to state that Tony entered the house. Expression (11b), on the other hand, puts the emphasis on the process of Tony entering the house. In the event so described, this process can be interrupted or stopped, as in the following example, (12), which uses the same predicate as that of (11b). In BI, the existential ada 'there BE', can be used to begin an expression of statement, (12). Because the statement is not about a process of an event, it is odd to say that the process is interrupted, (12b).

(12)a. Ada pencuri masuk (ke) rumah
there thief enter to house last night
'A burglar broke into the house (last night)'
b. *Pencuri
itu
ter-tangkap ketika
masuk (ke) rumah
thief
DEM TER-catch when
enter to house

'The burglar was caught (i.e., he/she got caught) when entered the house' (i.e., $\neq$ when entering the house)

The example (12a) is a statement that is usually used after a burglary incident. The thief broke in and now has gone. The statement is usually based on evidence, and the event cannot be interrupted, (12b). With the $i$-aspect, it is grammatical to say that the burglar was caught in the act, (13).
(13) Pencuri itu ter-tangkap ketika (sedang) thief DEM TER-catch when PROG
meN-masuk-i (*ke) rumah 'The burglar was caught as he/she was entering the house'

In (13) there is a process in the event of entering the house, and thus, there is also a process involved in the previous examples, examples (6b) and (8b), i.e., in Peter menduduki bantal 'Peter was sitting the pillow' but not in Peter duduk di bantal 'Peter sat on the pillow' and in Tony memasuki rumah 'Tony was entering the house' but not in Tony masuk (ke) rumah 'Tony entered to the house'. The latter, but not the former, can also imply that Peter often, sometimes, or always, sits on a pillow. In the former, the event happens only at a particular time. This is yet another common ground shared by 
both $i$-aspect and kan-aspect, namely, a description of an event that happens at a particular time. In sum, the suffix $-i$ is not in free variation with $-\varnothing$. ${ }^{2}$

\subsubsection{Kan- and $i$-predicates are not synonymous}

The previous sub-section, 4.1.1, argues that the suffix $-i$ is not in free variation with $-\varnothing$. The present sub-section argues that $-i$ is not in free variation with $-k a n$. Describing the suffix as an alternative to $-k a n$, in effect, implies that predicates with $-i$ can be synonymous with predicates with - kan, ignoring the possibility that they have different syntactic structures (for instance, Sneddon 1995: 96-97, Voskuil 1996: 219-261 (passim); Tampubolon 1983 analyses both suffixes as causative markers). Here I shall argue that the suffix $-i$ is not just an "option" to -kan (as stated in Chung 1976: 55) without any syntactic effect; the nature of the choice between the suffixes must be explained in terms of the difference in derivation.

We start with an example taken from Voskuil (1996: 219-261, passim). Voskuil gives two long lists of BI predicates, one with the suffix -kan, the other with $-i$. (In his lists, the predicates that are considered synonymous are clearly marked.) In Voskuil's view, the predicate mengagumi, for instance, is synonymous with mengagumkan, both mean 'to BE amazed'. These predicates have been taken in isolation. Analyses that put strong emphasis on word-formation (also Tampubolon 1983, Johns 1985, Sneddon 1996) fail to see the distinction between the occurrence of $-k a n$ in (a) and of $-i$ in (b) in the following example (14), from Voskuil (1996).

(14) base/root: kagum 'to BE amazed'

(a) meN-kagum-kan

(b) meN-kagum- $\boldsymbol{i}$

2) I am indebted to a reader who pointed out that in the examples with a verb of motion $+k e$ the endlocation is entailed, while a verb of motion in $i$-aspect with a direct object does not entail attainment of the GOAL. In other words, the $i$-aspect is compatible with unboundedness, progressivity or noncompletion of an event (the data show interruption of a non-completed event). However, the discussion provided here is sufficient to show that $-i$ is not in free variation with $-\varnothing$. 
Either because the affixes carry no meaning (Voskuil 1996), because both $-k a n$ and $-i$ mean 'to make', 'to cause' (Tampubolon 1983, Johns 1985), or, because the affixes have a function as a causative marker (Sneddon 1996), the resulting analysis is the same: mengagumkan and mengagumi are considered synonymous. That is, both mean 'to cause (someone) to admire'. Interestingly, Voskuil's analysis is all based on the meaning (from dictionary-data) of the root kagum 'to be amazed', rather than 'to admire'. This is misleading, because, by putting them in sentences, one can see that they are not synonymous, as shown in the following examples (15).

\begin{tabular}{ll} 
(15)a. Saya meN-kagum-kan & \multicolumn{1}{c}{ kamu } \\
1sg ACT-admire-KAN & \multicolumn{1}{c}{2 sg } \\
'I am admirable to you' & i.e., I make/cause you admire (me) \\
b. Saya meN-kagum- $i$ & kamu \\
1sg ACT-admire- 1 & $2 \mathrm{sg}$ \\
'I admire you' &
\end{tabular}

By giving a context for each and putting them side by side, (15), we see that - kan and $-i$ give exactly the opposite effects in terms of the argument relations of the complex predicate.

As another example, consider (16), from (Johns 1985, Sneddon 1996).

(16) meN-kirim-kan $=$ meN-kirim-i $=$ 'to send'

If $-i$ were synonymous with $-k a n$, then there should be forms such as the following, (a) and (b) of (17) and (18).

(17)a. Ibu meN-kirim-kan se-pucuk surat ke-pada Sandy mother ACT-send-KAN a-CLASS letter to-DATIVE S 'Mother sent a letter to Sandy'

b. *Ibu meN-kirim-i se-pucuk surat ke-pada Sandy mother ACT-send-I a-CLASS letter to-DATIVE S 'Mother sent a letter to Sandy' 


$\begin{array}{llll}\text { (18)a. Ibu meN-kirim-i } & \text { Sandy } & \text { se-pucuk surat } \\ \text { mother ACT-send-I } & \text { S } & \text { a-CLASS letter } \\ \text { 'Mother sent Sandy a letter' } & & \\ \text { b. *Ibu meN-kirim-kan } & \text { Sandy } & \text { se-pucuk surat } \\ \text { mother ACT-send-KAN } & \text { S } & \text { a-CLASS letter } \\ \text { 'Mother sent Sandy a letter' } & & \end{array}$

However, both (17b) and (18b) are unacceptable, and putting together the good examples of (17) and (18) we notice the different linear orders (19). While (17) and (18) each contains a good minimal pair, the sentences in (19) below do not make a minimal pair, but both are good sentences.

(19)a. Ibu meN-kirim-kan se-pucuk surat
mother ACT-send-KAN a-CLASS letter
'Mother sent a letter to Sandy'
b. Ibu meN-kirim-i Sandy $\quad$ se-pucuk surat
mother ACT-Send-I S
'Mother sent Sandy a letter'

To say that the suffix $-i(19 \mathrm{~b})$ is just an alternative to -kan (19a) - ignoring the possibility that the two forms are actually syntactic alternants - is a serious mistake. I shall not go on to prove that (19a) and (19b) have different interpretations, but see Arad (1998) on the interpretation differences between the dative such as (19a) and the double object construction (19b). The pair (19) will come up again from time to time in the future sub-sections because they are important for our discussion regarding $v \mathrm{P}$-aspect alternations that includes also the dative-double object construction.

I propose that each form in (19) is basic and not derived from the other. The crucial difference between (19a) and (19b) as argued for throughout the present work is accounted for in terms of the difference between the two $v \mathrm{P}$-aspects. With the kan-aspect such as shown in (19a), the primary internal argument sepucuk surat 'a letter' undergoes change, namely, change of location, whereas with the $i$-aspect $(19 \mathrm{~b})$, the primary internal argument Sandy is stationary. In (19a) Sandy is a GOAL (the final destination of the change, the event terminus, the target, the "human location") whereas in (19b) Sandy is a PATIENT (To be consistent, here Sandy is not a GOAL, refer back the discussion on 
examples (2a), (7b) and (8b)). The difference in terms of "roles" of the argument Sandy above supports our proposal that each form in (19) is not derived from the other.

All those arguments adjacent to the suffix $-i$ in good sentences such as shown from (15)-(19) above have something in common, namely, they do not undergo change. The section that immediately follows shows some more contrasts.

\subsubsection{The $i$-aspect and the lack of change}

The present sub-section argues that without the presence of kan-aspect the object is stationary and/or unchanged. As a reminder, I adopt Dowty's (1991) notion of entailments, we call the stationary object PATIENT. Because of the non-changing property of the $i$-aspect - i.e., the primary internal argument does not undergo change - I argue that it is possible to express the THEME in the $i$-predicate as a "locatum" argument (Hale and Keyser's 1993, 1998 term).

We will reuse some examples from Chapter 3 . In so doing, we can also see the contrast between kan-aspect and $i$-aspect. For instance, if the PATIENT is more important in the expression, rather than the THEME, then $i$-aspect is used. The following examples (20)-(22) are taken out from examples (25) and (26), section 3.2.4 (Kan-predicate with a MANNER component), with the $i$-aspect for the (b) examples replacing the kan-aspect. We keep the English translation as close as possible to the BI data, which may sound odd.

(20) air 'water'
a. tuang-kan
air (ke ember) (to bucket)
'(To) pour some water (to the bucket)'
pour
water
(dengan air)
b. tuang- $\boldsymbol{i}$ ember (with water)
'(To) pour the bucket (with water)'

(21) padi, 'rice'
a. tuang-kan pour padi (ke karung) '(To) pour rice (into the bag)' 


$\begin{array}{lll}\text { tabur-kan } & \text { padi } & \text { (ke lahan) (To) sprinkle rice (onto the prepared soil)' } \\ \text { sprinkle } & \text { rice (to soil) }\end{array} \quad$ (T)
pour bag (with rice)

$\begin{array}{lll}\begin{array}{l}\text { tabur- } i \\ \text { sprinkle }\end{array} & \begin{array}{l}\text { lahan } \\ \text { soil }\end{array} & \begin{array}{l}\text { (dengan padi) } \\ \text { (with rice) }\end{array}\end{array}$

$\begin{array}{lll}\begin{array}{ll}\text { (22)a. alir-kan } \\ \text { flow }\end{array} & \begin{array}{l}\text { air } \\ \text { water (to field) }\end{array} & \text { '(To) flow water (to the field)' } \\ \begin{array}{ll}\text { b. alir-i } \\ \text { flow }\end{array} & \begin{array}{l}\text { sawah (dengan air) } \\ \text { field (with water) }\end{array} & \text { (To) flow the field (with water)' }\end{array}$

In all the (a) examples of $(20)-(22)$, where the kan-aspect is used, the core argument air 'water', or padi 'rice' undergoes change in the form of translocation. In all the (b) examples, the core argument ember 'bucket', or karung 'bag', or lahan 'prepared soil', or sawah 'field' is stationary. The resulting events, such as, what happens to the bucket when it is poured with water, or when the bag is poured with rice, is not stated in the expression. The bucket may become full or half-full, the bag ruptures, the field is flooded or just wet, and so on. However, that is beside the point, and besides, results can be expressed by other means, for instance, by the addition of a small clause such as sampai penuh 'until full' and so on. To state the completeness of the event, different lexical items are used: the (a) examples (with kan-aspect) usually take sampai habis 'until there is nothing left', and the (b) examples (with the $i$-aspect) take sampai selesai 'until finish'.

On the understanding that the THEME is an argument that undergoes change during the event, and the PATIENT is an argument that is stationary and/or unchanged, we can state that kan-aspect selects a THEME and $i$-aspect selects a PATIENT. Thus I claim that the only difference between the (a) and (b) examples of (20) - (22), in terms of vP-aspect, is the argument selection, and that is the crucial part the $v \mathrm{P}$-aspects play in the derivation, without suggesting that one expression is derived from the other. 
A very important point to note from the examples (20)-(22) is the co-occurrence of the appropriate prepositions with the appropriate $v \mathrm{P}$-aspect; namely, with the kan-aspect of the (a) examples we have the preposition ke 'locative to' that introduces the GOAL. With the $i$-aspect of the (b) examples we have the preposition dengan 'with' that introduces the THEME. Thus, we have two different frames, shown below: [kan - ke] frame (23) and [ $i$-dengan] frame (24). We will come back to these frames in section 4.3, in particular while discussing the different prepositions involving secondary internal arguments.

(23) $[k a n-k e]$ frame:

PREDICATE - $\boldsymbol{k}$ an THEME PP: $\boldsymbol{k} \boldsymbol{e}$ GOAL
'LOCATIVE to'

(24) $[i$ - dengan $]$ frame:

$$
\text { PREDICATE }-\boldsymbol{i} \text { PATIENT PP: dengan THEME }
$$

From the discussion in Chapter 3, we see that there is something significant with the kan-aspect, in that, the THEME is never expressed in/by/as the kan-predicate: expressions like to butter the toast (butter is the argument that undergoes change, but is expressed in/by/as the predicate), to water the plants, to salt the stew, to gut/skin/bone the fish, and so on, in BI belong to the $i$-aspect, (25).

Udara kering, sudah waktu-nya kita meN-air-i tanam-an
air dry PERF time-3sg $1 \mathrm{pl}$ ACT-water-I plant-NOUN
'The air is dry, the time has come we water the plants'

In (25) the $i$-predicate "contains" air 'water' as the THEME, while the internal argument tanaman 'plant' is stationary. In Dowty's (1991: 550) terms, which in turn are taken from Jackendoff [1987] (1990), in to water the plants as exemplified in (25) "the THEME is completely expressed by the verb". In Hale and Keyser's $(1993,1998)$ terms, mengairi tanaman 'to water the plants' is a "locatum" predicate. Both terminologies refer to the same thing. The following paradigms (26) provide other examples of THEMEexpression/locatum predicate. 


\begin{tabular}{lll} 
6. & \multicolumn{2}{l}{ PUT-sense } \\
garam- $i$ & $\begin{array}{l}\text { sayur } \\
\text { salt }\end{array}$ & $\begin{array}{ll}\text { stew } \\
\text { b. }\end{array}$ \\
& $\begin{array}{l}\text { atap- } \boldsymbol{i} \\
\text { roof }\end{array}$ & $\begin{array}{l}\text { houmah } \\
\text { house }\end{array}$ \\
c. & $\begin{array}{l}\text { bedak- } \boldsymbol{i} \\
\text { powder }\end{array}$ & $\begin{array}{l}\text { muka } \\
\text { face }\end{array}$
\end{tabular}

TAKE/remove-sense

d. bulu-i ayam
feather chicken

$$
\begin{array}{ll}
\text { e. rumput- } \boldsymbol{i} & \text { ladang } \\
\text { weed } & \text { garden }
\end{array}
$$

f. $\quad$ kulit-i pisang

In (26) either it is of the sense of PUT/GIVE (a-c) or of the sense of TAKE/remove (d-f), what is expressed in the predicate - e.g., garam 'salt' (26a), bulu 'feathers' (26d), and so on - undergoes change; namely, the change of location. In all cases the internal arguments of the $i$-predicate are stationary. Thus, the difference between "location" predicates of Chapter 3 (e.g., 'to jail the thieves') and "locatum" predicates (both are Hale and Keyser's 1993, 1998 terms) is that in BI the former belong to the kan-aspect (section 3.2.1, expression of final destination), the latter to the $i$-aspect, examples (25) and (26) above. Because the THEME is "completely expressed" by/in the $i$-predicate of the locatum type (26), we cannot have the preposition dengan 'with' that introduces the THEME. The preposition can be used to introduce the instrument of, for instance, watering the plants, (27). Dengan in this case means 'by means of' or 'using' or just 'with'.

(27) Sudah waktu-nya kita meN-air-i tanam-an denganpakai selang
PERF time-3sg 1pl ACT-water-I plant-NOUN with/use hose
'The time has come we water the plants with/using a hose'

In (27) the object selang 'hose' only provides the path of movement that is taken by the THEME air 'water' to travel to tanaman 'plants', but should not be called a THEME such as in the (24) frame. Selang 'hose', the object of the preposition denganpakai 'with/using' does not have the same role as the THEME of the (b) examples of (20)-(22).

\subsection{Kan-aspect and $i$-aspect alternation: an alternation of paths of derivation}

I have argued in sub-section 4.1 .3 that the difference between the form with kan-aspect and the form with $i$-aspect must be seen in terms of argument selection; namely, each $v \mathrm{P}$ aspect selects a special primary internal argument. I have also suggested that the form of 
each $v$ P-aspect is necessarily not derived from the other, and thus, each has an independent path of derivation.

The present section introduces the notion of $v \mathrm{P}$-aspect alternation. The derivational matters such as transformational relations versus independent derivations, including the so-called dative-double object alternation and its background in the literature will be discussed in the section that immediately follows, section 4.3 .

\subsubsection{Aspect alternations}

In describing the contrast between the two $v \mathrm{P}$-aspects I have used different objects as the core arguments, refer back to examples (20)-(22). What can happen if we use the same object makes an interesting observation, apart from making a true minimal pair. We select setiap orang 'everybody' as the core argument for both aspects in (28). The kanpredicate in (28a) is taken out from examples in section 3.2 .5 as an expression of direction. The following examples are provided without English translation to see them more clearly as a minimal pair (see (29) for the translation).

$\begin{array}{ccc}\begin{array}{c}\text { (28)a. Jangan } \\ \text { NEG }\end{array} & \begin{array}{c}\text { meN-(ke)-belakang-kan } \\ \text { ACT-(to)-back- KAN }\end{array} & \begin{array}{l}\text { setiap orang } \\ \text { every body }\end{array} \\ \begin{array}{c}\text { b. Jangan } \\ \text { NEG }\end{array} & \begin{array}{l}\text { meN-(*ke)-belakang-i } \\ \text { ACT-(to)-back- I }\end{array} & \begin{array}{l}\text { setiap orang } \\ \text { every body }\end{array}\end{array}$

Both expressions in (28) mean Do not put everybody behind you. Considering the action or event, we can ask a question as to what the expressions mean (for both the English and BI). Do we mean "Do not take everybody, lifted, shifted them one by one, and put them behind us", or, just "do not turn around"? In BI the former is expressed as in (28a), where everybody moves except you; the latter as in (28b), where only you move, repeated in the following examples with the English translation.

\footnotetext{
(29)a. Jangan meN-(ke)-belakang-kan setiap orang

NEG ACT-(to)-back- KAN every body

'Do not put everybody behind you'

Prohibited action: to shift everybody to a place behind you; one by one (everybody moves but not you)
} 


$\begin{array}{lll}\text { b. Jangan meN-(*ke)-belakang-i } & \text { setiap orang } \\ \text { NEG ACT-(to)-back- I } & \text { every body } \\ \text { 'Do not put everybody behind you' } & \\ \text { Prohibited action: to turn around (you move) }\end{array}$

By giving the same object as a selected argument of the predicate, the $v \mathrm{P}$-aspect can be seen more clearly: the argument setiap orang in (29a) undergoes change of location, and it is stationary in (29b).

The contrast in terms of $v \mathrm{P}$-aspect can be seen also in the following examples, (30) and (31), using the same idea that a good minimal pair shows a contrast.

(30) Ini surat dokumen saya,

DEM letter document 1sg

'This is my document,

a. sila-kan ibu meN-tanda-tangan-kan-nya

please-KAN mother ACT-sign-hand-KAN-3sg

please (madam) have it signed' (i.e., give it to someone to sign, "delegate it")

b. sila-kan ibu meN-tanda-tangan-i-nya

please-KAN mother ACT-sign-hand-I-3sg

please (madam) sign it' (i.e., sign it yourself)

(31)a. Minggu depan Pak Parto akan meN-kawin-kan anak-tiri-nya week front Mr.P FUT ACT-marry-KAN daughter-step-3sg

'Next week Mr. Parto will marry his stepdaughter off'

b. Minggu depan Pak Parto akan meN-kawin-i anak-tiri-nya

week front Mr. P FUT ACT-marry-1 daughter-step-3sg

'Next week Mr. Parto will marry his step-daughter'

In the (a) examples of (30) and (31) the document and the stepdaughter undergo change by being given away, the document is to be signed by someone other than $i b u$ 'mother', 'madam' (as a $2^{\text {nd }}$ person singular), and the other is to be married by someone other than Pak Parto 'Mr. Parto'. In the (b) examples the document and the stepdaughter are PATIENTS, one "suffered" from being put a signature (signed) on, and the other "suffered" from being married. A very important point to remember is that we have a CAUSE interpretation only in the (a) examples, but not in the (b) examples (ref. section 3.4 .2 
where we use the head $v_{-k a m}$ in the tree diagram to represent what Chomsky 1995 calls "v $\left.v_{\text {CAUSE }} "\right)$.

In the theory proposed by, for instance, Ritter and Rosen (1998), Travis (2001), ibu 'mother' in (30a) example does not sign the document and Pak Parto 'Mr. Parto' in the (31a) example does not marry his stepdaughter. But they do in the (b) examples. However, it is not always the case with the $i$-aspect that the argument that precedes the $i$ predicate performs the ACT, i.e., as an AGENT of an accomplishment class of event such as (31b), and (32b) below. In an achievement class of event such as (32c) below sebutir kelapa 'a coconut' is not an AGENT, compare (32c) with (31b) and (32b).

(32)a. Se-ekor kera meN-jatuh-kan se-butir kelapa ke atap rumah
a-CLASS monkey ACT-fall-KAN a-CLASS coconut to roof house
'A monkey dropped a coconut on the roof'

$\begin{array}{lllll}\text { b. Se-ekor kera meN-jatuh-i } & \text { atap rumah } & \text { dengan } & \text { se-butir } & \text { kelapa } \\ \text { a-CLASS monkey ACT-fall-I } & \text { roof house } & \text { with } & \text { a-CLASS } & \text { coconut } \\ \text { ?'A monkey fell the roof with a coconut' } & & \end{array}$
c. Se-butir
kelapa meN-jatuh-i
atap rumah
a-CLASS
coconut ACT-fall-I
roof house
?'A coconut fell the roof' ( $\neq$ 'A coconut fell on the roof', ref. (170) of 3.4.2)

In both $(32 \mathrm{a}, \mathrm{b})$ we have the argument seekor kera 'a monkey' that performs the ACT of dropping a coconut (32a) and "falling" a roof (32b), and both are of the accomplishment class of event. The argument seekor kera 'a monkey' in this case only initiates the events but does not itself fall on the roof. This is on a par with (30a) and (31a) where we have the argument ibu 'mother' and Pak Parto 'Mr. Parto' as facilitator AGENTs (these AGENTs do not perform the actual ACT of signing the document or marrying the stepdaughter, although they may be interpreted as initiating the event). For simplicity, we shall use the term AGENT to cover both initiator and facilitator AGENTS. The point to note is the argument sebutir kelapa 'a coconut' in (32c) is different from the AGENTs of $(32 a, b)$, in that, in (32c) it directly participates in the event as an object that falls on the roof, just like the other coconuts in $(32 \mathrm{a}, \mathrm{b})$ which are THEMEs. The form $(32 \mathrm{c})$ is 
unexpected because sebutir kelapa 'a coconut' appears to be an internal argument, yet the predicate bears the active voice meN-. The distinction between an AGENT (30b), (31b), (32b) and an argument that appears like an AGENT (32c) - because the form has meN- is a delicate matter, and we will treat this carefully, taking into account that some predicates such as jatuh 'to fall' (32) are unaccusative.

We have discussed the form (32a) that is clearly different from that of (32b) in terms of (internal) argument selection, but we do not know yet the status of (32c), in particular, how the form is related to $(32 \mathrm{~b})$. What we have here is a question with respect to the argument sebutir kelapa 'a coconut' (32c). The status of this elusive argument sebutir kelapa in (32c) is a mystery. Is it an AGENT, a CAUSER, or a THEME? To find the answer to this question, there are some points to consider carefully. In terms of agentivity, sebutir kelapa 'a coconut' is not an argument that initiates the event; but rather, it is an object that happens to fall on the roof. In (32b) the monkey did not fall, but in $(32 \mathrm{c})$ the coconut did fall, although both arguments are involved in the event with exactly the same $i$-predicate. Thus, sebutir kelapa 'a coconut' is not an AGENT (It is also possible to "persuade" the monkey to drop the coconut, but it is impossible to persuade the coconut to fall). The (32c) form appears to be related to the tree diagram (170) of subsection 3.4.2, perhaps as an alternative expression, because of the unaccusative base jatuh 'to fall' that bears a move component. The diagram (170) is repeated here, (33), with kelapa 'coconut' and atap rumah 'the roof' added as a parallel to John and the gutter (sub-section 3.4.2 discusses John jatuh [John] ke parit 'John fell [John] into the gutter'). 


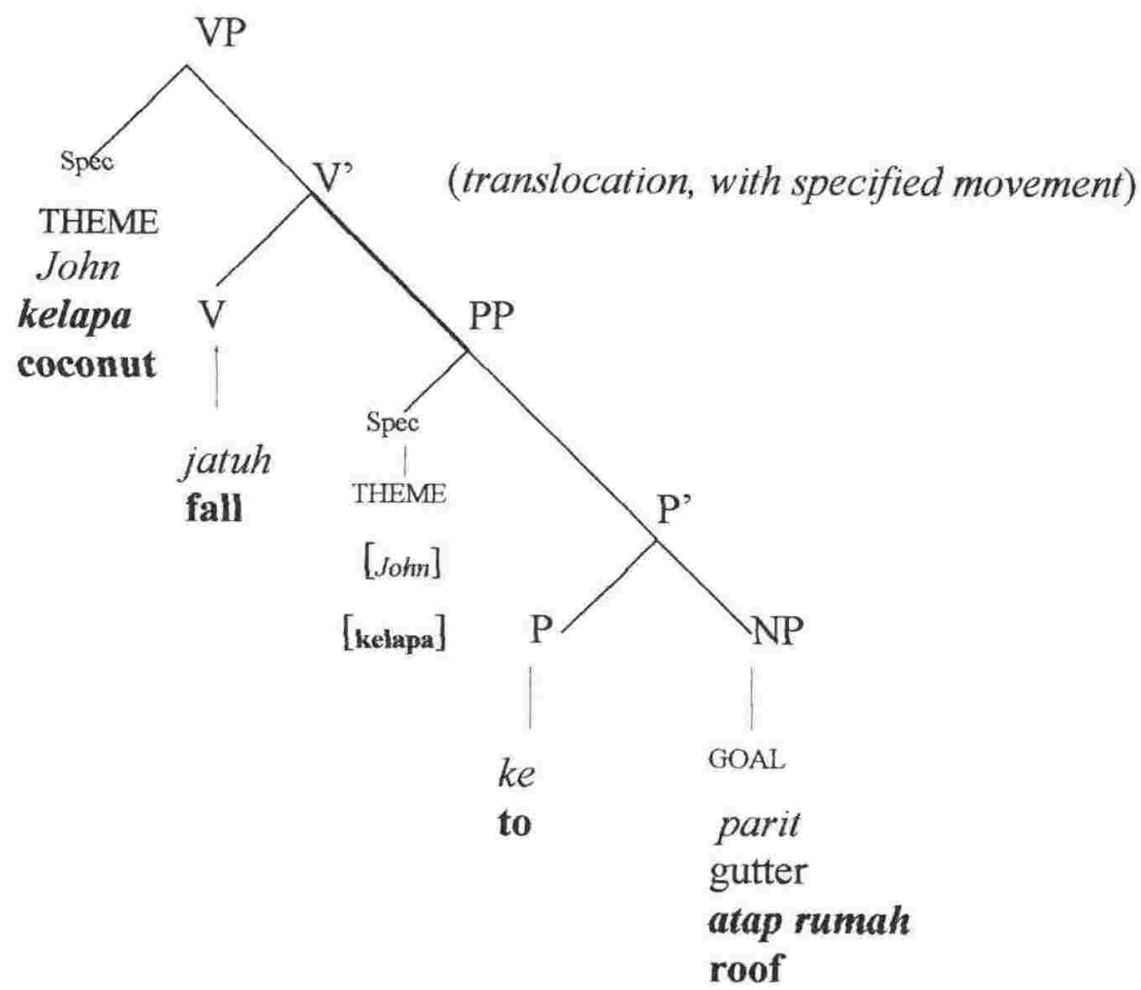

We want to maintain that the form (32c) - with the $i$-aspect - requires a different base from that shown in the tree diagram (33). Thus, if we want to assume that the object coconut in (32c) is a THEME (rather than an AGENT) some points must be considered. Firstly, the argument atap rumah 'the roof' of (32c) is not an argument of a PP such as in (33), and thus, the path of translocation is not indicated by any preposition. Secondly, and more importantly, there is no cause interpretation available in the final form of $i$-aspect, such as shown in the (b) examples of (30), (31) and (32). It follows that in (32c) the argument sebutir kelapa 'a coconut' is not a CAUSER. To conclude, because it is neither an AGENT nor a CAUSER, the argument sebutir kelapa 'a coconut' in (32c) must be a THEME.

Sebutir kelapa 'a coconut' as a THEME such as in (32c) cannot occur in the kanaspect environment ( $34 \mathrm{~b}$ ), below, because the form then gives the interpretation that atap rumah 'the roof' is the THEME. 


(34)a. Se-butir kelapa meN-jatuh-i atap rumah
a-CLASS coconut ACT-fall-I roof house
?'A coconut fell the roof'( $\neq$ 'A coconut fell on the roof', ref. (170) of 3.4.2)
b. *Se-butir kelapa meN-jatuh-kan atap rumah
a-CLASS coconut ACT-fall-KAN $\quad$ roof house
'A coconut MAKE-fall the roof' (i.e, dropped the roof)

And thus, the form with $i$-aspect in (34a) does not have (34b) as an alternant (Sub-section 4.2 .2 below provides more examples of $v \mathrm{P}$-aspect that does not alternate). The ( $34 \mathrm{~b}$ ) form is unacceptable also because the argument coconut cannot participate as an AGENT or a CAUSER, to mean that it causes the roof to fall. Therefore, we must assume that [Spec- $v \mathrm{P}$ ] of (34a) is empty. Because it is empty, the internal argument can appear as the surface subject.

Calling the object sebutir kelapa 'a coconut' (32c) THEME is feasible only if we have two independent derivations: one with the kan-aspect where the THEME is selected by the $v$-kan, and the other is with the $i$-aspect where the THEME coconut of (32c) is independently entered in the derivation perhaps as a select - merge operation, or otherwise as a select - move operation from some unknown position straight to the [SpecVoiceP] (then further up to the [Spec-AspP]). The former operation is relatively free, i.e., not motivated by the fact that the predicate has the cause $v$-kan such as the latter, which in effect the argument sebutir kelapa is neither interpreted as an AGENT nor a CAUSER.

Alternatively, if $[\mathrm{Spec}-v \mathrm{P}]$ is empty, the object of the PP dengan with-phrase raises to this empty position, in the style of Pesetsky (1995: 202-204). The operation is possible if and only if the $\mathrm{P}$ head (dengan) is empty. Assume for now that in the case of $i$-aspect the PATIENT is based at [Spec-VP], adopting Pesetsky (1995: 197), Arad (1998: 89-90), McGinnis (2001: 338). As a note for diagrams (35a,b) below (that is, if we adopt Pesetsky's (1995: 202-204) structure) in the case of v-i there is no CAUSE. Assuming the THEME moves to [Spec- $v \mathrm{P}]$ yields (35b). 
(35)a.
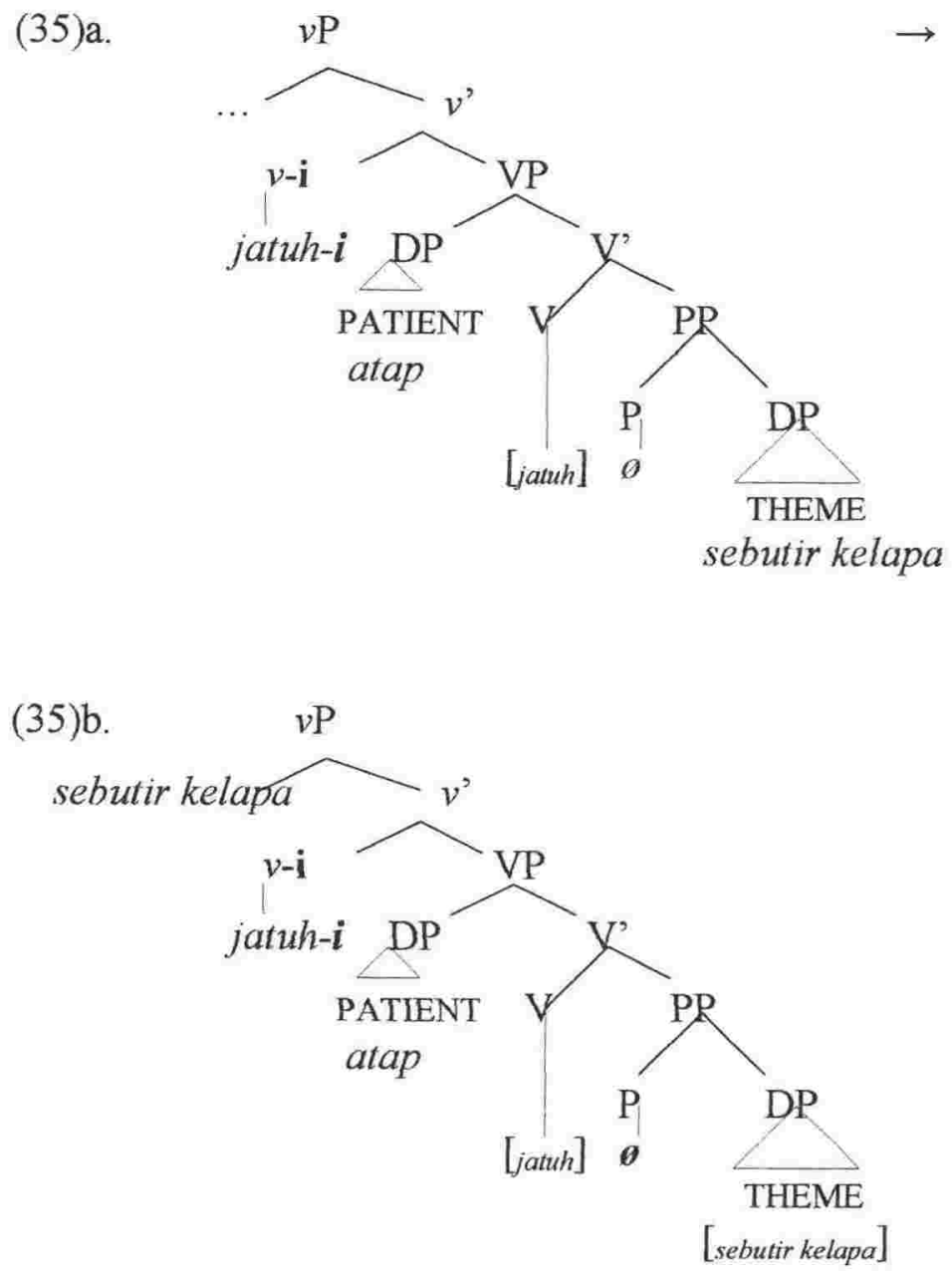

However, movement of the THEME sebutir kelapa 'a coconut' to [Spec-vP] in (35b) raises questions about the status of the position, namely, as a position that is reserved for external arguments (AGENT or CAUSER). Therefore, a move operation of the THEME straight to [Spec-VoiceP], (36) below, is more plausible than (35b) as argued for by Pesetsky (1995: 197), i.e., where the THEME is raised to [Spec- $\nu$ P]. 
(36)
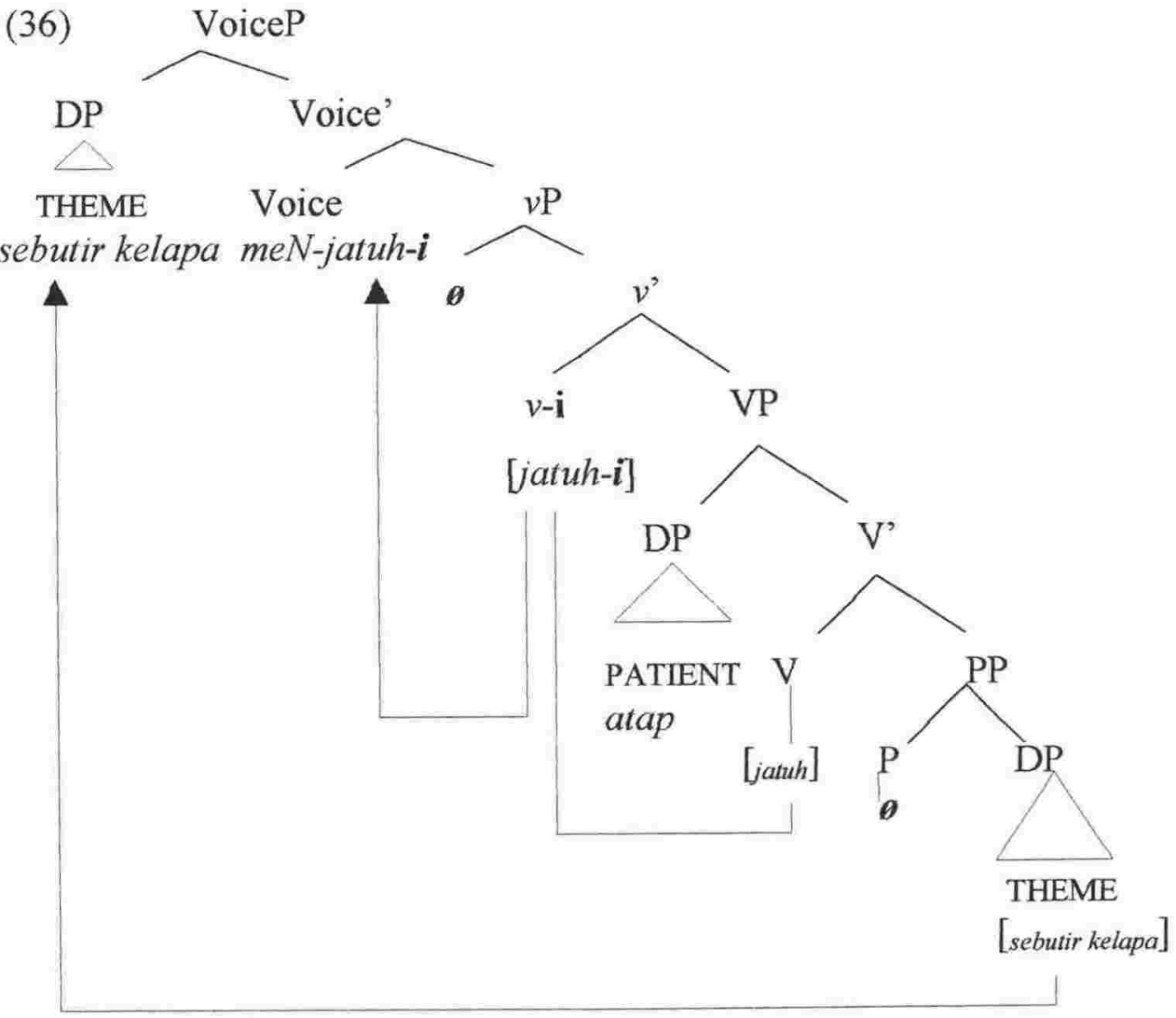

To conclude, examples such as (32c), repeated below as (37), can be presented using Pesetsky's (1995: 197) structure with the condition that sebutir kelapa 'a coconut' raises directly to [Spec-VoiceP], as a "THEME subject" as shown in (36).

$\begin{array}{ll}\text { (37) Se-butir kelapa meN-jatuh-i atap rumah } \\ \text { a-CLASS coconut ACT-fall-I } & \text { roof house } \\ \text { ?'A coconut fell the roof' } & \end{array}$

Dowty (1991: 574) succinctly suggests that: “ $\ldots$ movement is apparently an agent property only when not caused by another participant in the event named by the verb". Dowty's assumption fits well with our kan-aspect - $i$-aspect distinction. That is, if a participant causes the change in the event so named by the verb, we have the kan-aspect, and the change property belongs to the primary internal argument THEME. In contrast, we have the $i$-aspect if the primary internal argument does not undergo change, such as the document (30b), the stepdaughter (31b), and the roof (32a,b). However, we have seen that sebutir kelapa 'a coconut' that may appear like an AGENT in (32c) is a THEME. 
The unexpected form such as (32c) is common both in English (38) below, from Dowty (1991: 547), and in BI, (39).

(38)a. The cloud passed the tree

b. Water filled the tank

(39)a. Awan gelap meN-lewat-i bumi could dark ACT-pass-I earth 'Dark could pass the earth'

b. Air meN-alir-i sawah water ACT-flow-I field

'Water flowed the field'

In Dowty's (1991) account, the cloud and the water in the English examples (38a,b) are AGENTs that undergo movement. In our account, the dark cloud and the water in the BI examples $(39 a, b)$ are THEMES.

Notice however, the BI predicate lewat 'to pass' (which also means 'through') and alir 'to flow' both bear the move component, just like the jatuh 'fall' in (32c). Our view that the base of the predicate makes possible the existence of the forms $(32 c)$ and $(39 a, b)$ seems to be on the right track, since for example, with the predicate memukul 'to hit' and mencium 'to kiss' it is impossible in BI to have forms like those of (32c) and (39). Consider (40) and (41) (The gloss "PERS" indicates "a person").

(40)a. Si Amir sedang meN-pukul-i meja dengantongkat itu PERS A PROG ACT-hit-I table with stick DEM

'Amir is hitting the table with the stick'

b. *Tongkat itu sedang meN-pukul-i meja

Stick DEM PROG ACT-hit-I table

'The stick is hitting the table'

(41)a. John sedang meN-cium-i Mary dengan hidung-nya $J$ PROG ACT-sniff-I M with nose-3sg 'John is kissing Mary with his nose' (sniffing is the BI traditional form of kissing) 


\section{b. *Hidung-nya sedang meN-cium-i Mary nose-3sg PROG ACT-sniff-I M \\ 'His nose is kissing Mary'}

In sum, lewat 'to pass' and alir 'to flow' as bases are acceptable to occur with $-i$ in the forms of $(39 \mathrm{a}, \mathrm{b})$, but pukul 'to hit' and cium 'to kiss' are not, (40b) and (41b).

To come back to the main point of the discussion, the contrast in interpretation between the kan-aspect and $i$-aspect can be seen clearly if we have the same object filling different argument roles, (42), by using the predicate that means 'to pass' such as in (39a).

(42)a. Jangan suka meN-lewat-kan waktu

NEG.IMP like ACT-pass-KAN time

'Don't make it a habit to let the time pass by'

$\begin{array}{lll}\text { b. Jangan suka meN-lewat-i } & \text { waktu } \\ \text { NEG.IMP like ACT-pass-I } & \text { time }\end{array}$

'Don't make it a habit to go/pass through time'

Although both $(42 \mathrm{a}, \mathrm{b})$ mean do not make 'killing time' a habit, in (42a) it is the time that undergoes movement by means of passing by, and in $(42 \mathrm{~b})$ it is the implied $2^{\text {nd }}$ person singular/plural that passes by through the time (consider time as a path or a tunnel). In sum, waktu 'time' occurs as a THEME in (42a) but as a PATIENT in (42b), and each occurrence belongs to its own $v \mathrm{P}$-aspect.

\subsubsection{The $v \mathrm{P}$-aspect that does not alternate: unavailable arguments}

The following three sub-sections (4.2.2.1-4.2.2.3) present some facts about $v \mathrm{P}$-aspect alternation. The reasons as to why certain occurrences are impossible are proposed in terms of the availability of certain arguments, although the notion of change versus nonchange holds through. The notion of change in BI seems to correlate with the occurrence of AGENT versus CAUSER, and of PATIENT versus THEME, not in respective order. BI Psych-predicates with kan-aspect are thus special because they can occur only with a 
CAUSER as the external argument. Thus, here we reiterate what we have discussed in Chapter 3 (3.2.6: De-adjectivals and final state, and 3.3.3: transit path of change). Most examples in the following three sub-sections are taken from the afore-mentioned subsections of Chapter 3. An important implication drawn from the discussion is that the suffix $-i$ is not causative, which is contrary to what is previously believed (by for instance, Johns 1985, Tampubolon 1985, Sneddon 1996).

\subsubsection{Psych-predicates: frighten and fear verbs}

In sub-section 3.2.6.2 we discussed two different groups of examples. The psychpredicates of Groupl (frighten verbs), take only the kan-aspect, involving a CAUSER and a THEME as participants. The psych-predicates of Group 2 (fear verbs), take only the $i$ aspect with AGENT and PATIENT as participants in the event. We have also seen that some state (of mind) predicates such as senang can occur in both groups (as senangl 'BE pleased' and as senang2 'to like, BE fond of'). The predicate curiga behaves similarly (curigal 'BE suspicious', curiga2 'to suspect'). In this sub-section we elaborate more on this particular phenomenon.

The following BI examples support our view that each $v \mathrm{P}$ is derived independently. Consider again some state predicates of Groupl such as sedih 'sad', takut 'afraid' and bosan 'bored' shown in (43) where no change of state is implicated.

(43) State:
a. Ibu sedih mother sad 'Mother is sad'
b. Anak-anak takut child-PL afraid
'The children are afraid'
c. Saya bosan
1sg bored
'I am bored'

With the kan-aspect the change of state is implicated. 
(44) Change of state
a. Berita itu meN-sedih-kan ibu news DEM ACT-sad-KAN mother
'The news saddened mother' (made mother sad)
b. Suara-nya meN-takut-kan anak-anak voice-3sg ACT-afraid-KAN child-PL
'His voice scared the children' (made the children afraid)
c. Cerita-nya meN-bosan-kan saya
Story-3sg ACT-bored-KAN 1sg
'His story bored me' (made me bored)

That is, in (44) ibu 'mother', anak-anak 'children' and saya '1sg' are THEMEs, and berita $i t u$ 'the news', suara-nya 'his voice' and cerita-nya 'his story' are CAUSERs. The vPaspect of (44) does not alternate with $i$-aspect. Compare (44) and (45): the $i$-aspect in (45) below cannot be used in the same manner as in (44) above. In addition, ibu or anak-anak or saya that occur as a THEME in (44) cannot occur as a PATIENT in (45).

(45) Change of state cannot be encoded with $-i$
a. *Berita itu meN-sedih-i ibu news DEM ACT-sad-I mother
'The news saddened mother'
b. * Suara-nya meN-takut-i anak-anak voice-3sg ACT-afraid-I child-PL
'His voice scared the children'
c. * Cerita-nya meN-bosan-i saya story-3sg ACT-bored-I 1sg 'His story bored me'

Even when a potential AGENT replaces the CAUSER of (45) the sentences remain ungrammatical, with $-i,(46)$.

$\begin{array}{cll}\text { (46)a. *John } & \text { meN-sedih- } i & i b u \\ \mathrm{~J} & \text { ACT-sad-I } & \text { mother } \\ \text { b. *Badu } & \text { meN-takut-i } & \text { anak-anak } \\ \mathrm{B} & \text { ACT-afraid-I } & \text { child-PL } \\ \text { c. }{ }^{*} \text { David } & \text { meN-bosan-i } & \text { saya } \\ \mathrm{D} & \text { ACT-bored-I } & 1 \mathrm{sg}\end{array}$

Therefore, the kan-aspect with the psych-predicates of (44) does not alternate with the $i$ aspect. In each event with the psych-predicates of (44) a CAUSER and a THEME appear. In 
other words, a PATIENT and an AGENT are not available in the event involving those psych-predicates. The same reasoning applies also to the inverse; namely, the $i$-aspect of psych-predicates of Group2 does not alternate with the kan-aspect.

The strict requirement of each $v \mathrm{P}$-aspect is particularly more visible if we view the occurrences of predicates senangl 'BE pleased, BE fond of', senang2 'to like, BE fond of' and curigal 'BE suspicious', curiga2 'to suspect' as indicating a distinction between the frighten verbs and the fear verbs (We call them "senangI", "curigal" because these predicates belong to Groupl, and so on). The arguments that are required by senangl and curigal are clearly different from those of senang2 and curiga2. For instance, even when a PATIENT is available, an AGENT must also appear, (47d) below, and not a CAUSER $(47 \mathrm{c})$.

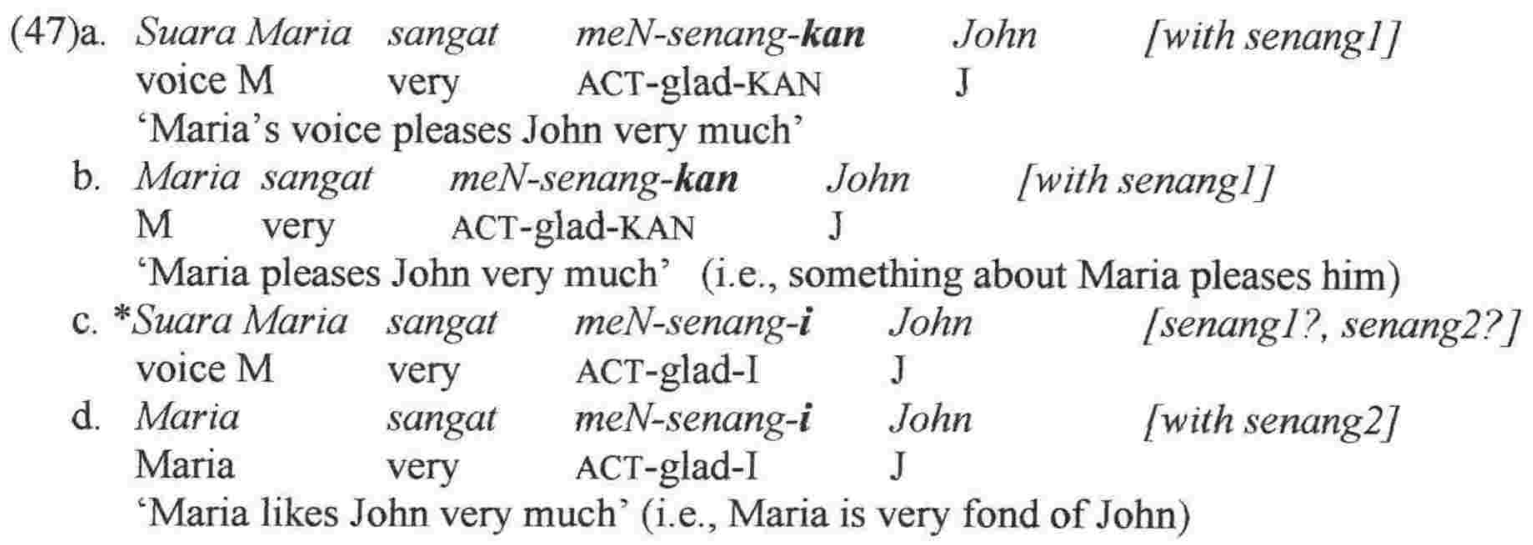

I have argued in Chapter 3 that in sentences such as (47b) it is not actually Maria per se that pleases John, but rather, something about Maria, such as her voice in (48a) below as an inseparable possession of Maria - or perhaps a characteristic property of Maria. The same phenomenon can be seen also in events with curigal 'BE suspicious' and curiga2 'to suspect', (48). In (47d) and (48d) it is Maria rather than her voice that likes or suspects John.

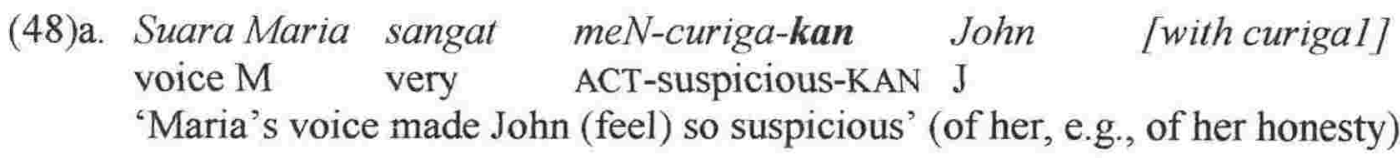




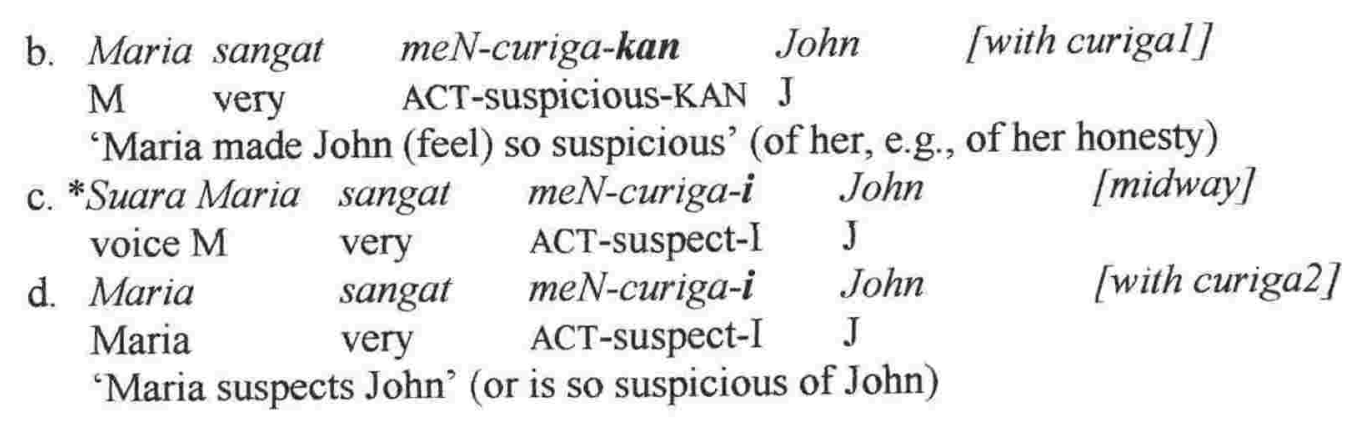

To conclude, the two $\nu \mathrm{P}$-aspects alternate only if the required arguments are available, as shown in (47a), (47d), (48a), and (48d). With the kan-aspect in (47a) and (48a) we have a CAUSER and THEME, and with the $i$-aspect in (47d) and (48d) we have an AGENT and a PATIENT. In other words, it is possible to have a primary internal argument that does not undergo change for the psych-predicate such as senang2 'glad, BE fond of', (47d) and curiga2 'to suspect, BE suspicious' (48d). Recall that John in (47d) may or may not be aware that Maria is very fond of him, and in (48d) he may or may not be aware that Maria is suspicious of him. There is no information regarding John's state of mind in either (47d) or (48d) (refer back sub-section 3.2.6.2).

A very important implication that can be drawn from the discussion in the present sub-section is that because with the $i$-aspect there is no change implicated on the object PATIENT, we have the role of an AGENT as the external argument, and not a CAUSER role. In effect, the suffix $-i$ is not a "causative marker" (cf. Tampubolon 1985). In terms of change versus non-change, we have a dichotomy of argument structure: the $i$-aspect, (50) below, 'negates' the kan-aspect (49). Both (49) and (50) show the types of argument involved, and both are based on the surface orders.

(49) The kan-aspect, property: change

AGENT/CAUSER PREDICATE-kan change THEME

(50) The $i$-aspect, property: non-change

non-CAUSER PREDICATE- $i$ non-change non-THEME

(The non-CAUSER is an AGENT, and non-THEME is a PATIENT) 


\subsubsection{Common adjective $k a n$-predicates}

What is outlined in sub-section 4.2.2.1 above can also be applied to the present subsection, namely that a PATIENT is not available in a change environment. The present sub-section demonstrates that the fact that the suffix $-i$ is not a causative marker can also be used for explaining why with common adjectives there is no $i$-alternation for the kanpredicate. The BI common adjectives are grouped as:

(i) dimensions: panjang 'long', pendek 'short', ...

(ii) colours: merah 'red', hijau 'green', ...

(iii) tastes: asin 'salty', manis 'sweet'...

(iv) forms: kental 'thick', cair 'liquid', beku 'frozen', ...

The following examples (51) are taken from sub-section 3.2.6.1 (Change of state with common adjectives, examples (64)).
(51)a. Ibu sedang meN-kental-kan kuah-nya mother PROG ACT-thick-KAN gravy-3sg 'Mother is thickening the gravy'
b. Anak-anak meN-cair-kan salju-nya child-PL ACT-liquid-KAN snow-3sg 'The children melt the snow'
c. John akan meN-panjang-kan jenggot-nya $\mathrm{J}$ FUT ACT-long-KAN beard-3sg
'John is going to let his beard grow long'
d. Sebelum pergi, Ira sibuk meN-merah-kan pipi-nya before go I busy ACT-red-KAN cheek-3sg 'Before she left, Ira was busy making her cheeks red'

In (51) the arguments kuah-nya 'the gravy' (51a), salju-nya 'the snow' (51b), jenggotnya 'his beard' (51c) and pipi-nya 'her cheeks" (51d) are THEMEs. Assuming we select these arguments as PATIENTs as we have done in sub-section 4.2 .1 (i.e., using the same object that can fill the role as a THEME or as a PATIENT to see the $v \mathrm{P}$-aspect alternation), and replace the suffix -kan with $-i$, all the forms are bad, (52).

(52)a. *Ibu sedang meN-kental-i kuah-nya
mother PROG ACT-thick-I
'Mother is thickening the gravy'


b. *Anak-anak meN-cair-i salju-nya child-PL ACT-liquid-I snow-3sg

'The children melt the snow'

c. *John akan meN-panjang-i jenggot-nya $\mathrm{J}$ FUT ACT-long-I beard-3sg 'John is going to let his beard grow long'

d. *Sebelum pergi, Ira sibuk meN-merah-i pipi-nya before go I busy ACT-red-KAN cheek-3sg 'Before she left, Ira was busy making her cheeks red'

The change of state in the examples (52) cannot be encoded by the $i$-aspect, only by the kan-aspect, (51). Recall that common adjective predicates like those in (51) express the final state of the selected object THEME. Having the suffix $-i$ on the state predicates such as in (52) is thus contradictory.

The kan-aspect forms of the de-adjectivals in (51) above are represented syntactically in (53b) below. The contrast with the $i$-aspect can be seen from comparing (53b) with (54) where the psych-predicates of Group2 (senang2 'to like' and curiga2 'to suspect') are used. Notice the contrast between the THEME selection with the kan-aspect (53b) and the PATIENT selection with the $i$-aspect (54). Here in both (53b) and (54) the argument that is selected is shown as occupying [Spec-AP], and both are based on the change/non-change interpretation.

(53)a. kuah-nya kental 'the gravy is thick' ( $\neq$ thick gravy)

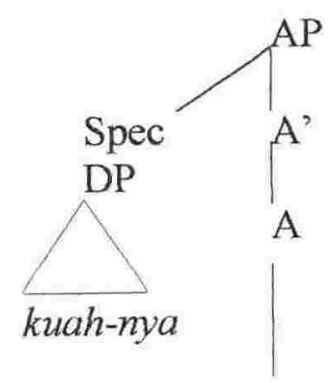

the gravy kental

thick 
(53)b. With the kan-aspect: kental-kan kuah-nya 'to thicken the gravy'

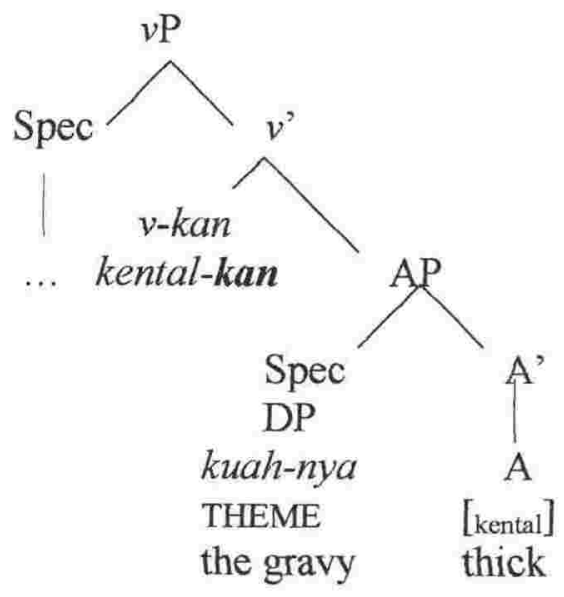

The proposition of the AP in (53a) is gravy THICK ( $\neq$ thick gravy). The proposition at $v \mathrm{P}$ in (53b) is MAKE THICK gravy, i.e., MAKE gravy BECOME THICK.

In contrast with kental-kan 'to thicken' of (53b), senang2 'to like', 'BE fond of' and curiga2 'to suspect', take a PATIENT object, (54) below. The structure (54) is presented here without any theoretical background explanation, but see section 4.3 below for the discussion on the structures with the $i$-aspect.

(54) With the $i$-aspect: senang-i John 'to like John' (47c) and curiga- $i$ John 'to suspect John' (48c)

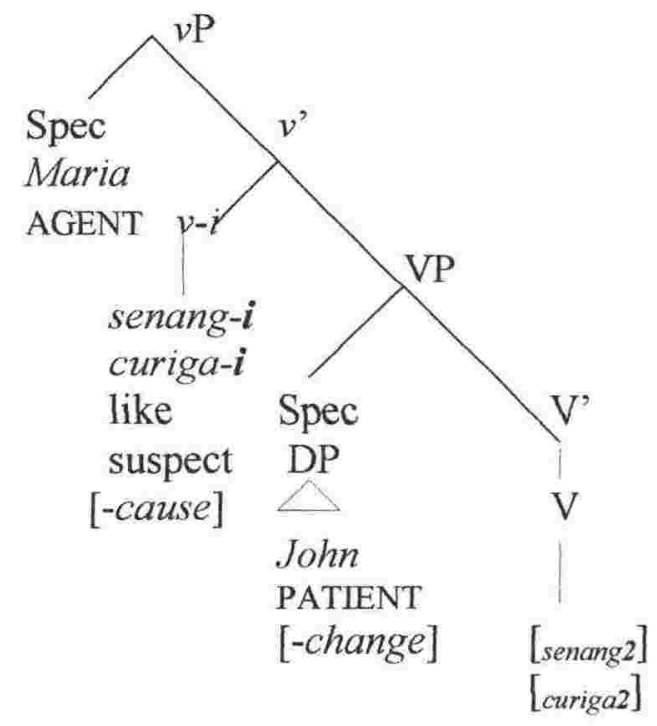

Maria is an 'AGENT-Experiencer' 
To note here is the status of the argument Maria in (54), which is an AGENT; yet different from the other AGENTs we have seen so far, in that, here we cannot persuade Maria to like or to suspect John. The AGENT in (54) thus has a [-volition] property. Dowty (1991: 572-573) argues that this type of AGENT has sentience and/or perception entailment alone. According to Dowty, which I follow here, this type of AGENT is allowed with "propositional attitude verbs, the stative perception verbs, and the stative psychpredicates". I have grouped some psych-verbs in the Group2 of the BI psych-predicates in Chapter 3, referred to as "fear verbs" all of which take only the $i$-aspect, with this type of AGENT. In Dowty's terms, sentience is intended to mean

"more than a presupposition that an argument is a sentient being; it is rather sentience with respect to the event or state denoted by the verb; the objects of verbs like elect, appoint, nominate and idolize, venerate and convict, acquit, exculpate are necessarily human but are not entailed to know or perceive the relevant event" (Dowty 1991: 573).

With respect to this type of AGENT, (54), I shall re-iterate an important point discussed in Chapter 3 (sub-section 3.2.6.2) regarding the distinction between the psychpredicates of Group1 and those of Group2. The psych-predicates of Group1, as I have argued, are of the type of frighten verbs, and only occur with the kan-aspect. Whereas Group 2 consists of the fear verbs, and can occur only with the $i$-aspect (both the terms "frighten" and "fear" verbs have been used by, for instance, Grimshaw 1990). Another term that has been used for this type of AGENT is "Subject Experiencer", used for instance, by Belletti and Rizzi (1988), Pesetsky (1995), Arad (1998) amongst others. Arad (1998) uses Belletti and Rizzi's (1988) distinction of two groups of psychpredicates, the so-called "Subject Experiencer" verbs (such as those in Nina fears/likes/adores the dog) and "Object Experiencer" verbs (such as in This dog frightens/disgusts/amuses Nina) to argue that only the latter can have three readings, namely, agentive, eventive and stative readings. It is important to note here that in our view, like in Arad's (1998: 180) account, the structure as depicted in (54) for fear verbs does not "deviate from standard transitive verbs". In our account, the structure (54) bears 
an AGENT interpretation, an AGENT that "experiences" a psychological state (Perhaps 'AGENT-Experiencer' predicates is a more accurate and consistent terminology).

Different from senang2 and curiga2 (54) above, senang1 'BE pleased' and curigal 'BE suspicious' take a THEME object, (55) below. For simplicity of tree diagram presentation, I put the CAUSER suara Maria 'Maria's voice' at the [Spec- $v \mathrm{P}]$, the same position with that of the 'AGENT-Experiencer' Maria in (54). The present discussion is about the positions of the THEME and the PATIENT.

(55) With the kan-aspect: senang-kan John 'to MAKE-please John' (48a) and curiga-kan John 'to MAKE-John suspicious' (49a)

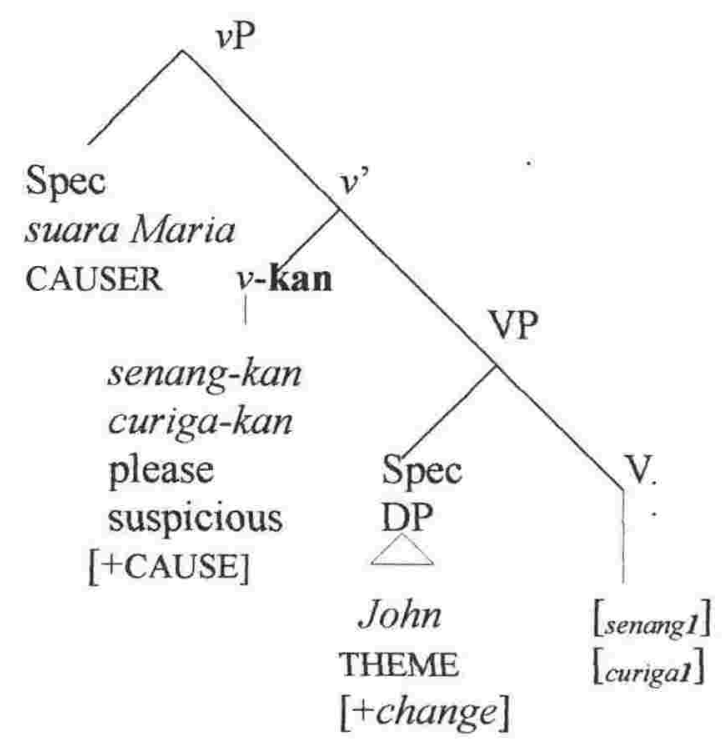

In (54) John is a PATIENT, but a THEME in (55). We see from the structures (54) and (55) that there are PATIENT-object and THEME-object correlations. See section 4.3 for the elaboration.

By considering the argument selection by the kan-aspect shown in ( $53 \mathrm{~b})$ and by the $i$-aspect, (54), we can see the contradiction in (56) below, when the $i$-aspect is used with the state predicates such as in the unacceptable forms (52). 
(56) With the $i$-aspect: *kental-i kuah-nya 'thick-I the gravy'

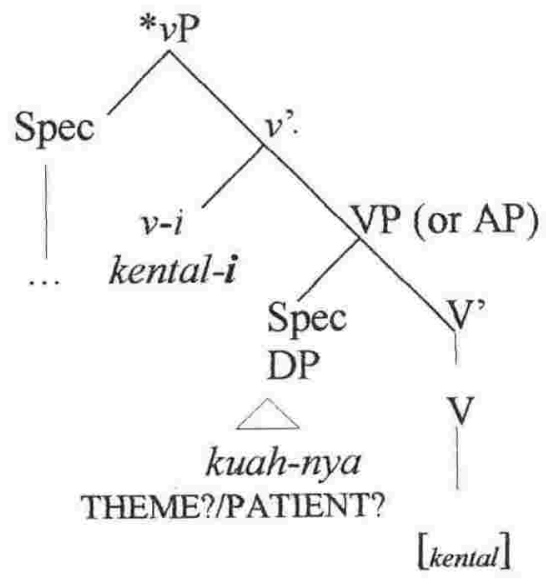

In (56) the THEME/PATIENT-object correlation is not clear. The use of the $i$-aspect in (56) is contradictory because the predicate kental 'thick' at the head $v$ is an expression of a final state (which is a state at the bottom V) where change is necessary. But the suffix $-i$ does not encode change.

\subsubsection{Transit path of change (with $k a n$-aspect only)}

As a final note on the $v \mathrm{P}$-aspect that does not alter, I present some examples related to the transit path of change. In Chapter 3 I have argued that some predicates encode change even when the kan-aspect is not in use - i.e., the notion of change applies to the VP, and the $v$-kan 'adds' or 'extends' the path of change. I have argued that verb-bases such as buat 'to make', bangun3 'to build' and beli 'to buy' contain the change component, and thus adding the suffix -kan to the verbs makes the path of change a transit path. In Vamarasi's (1999: 76) terms, for the class of verbs such as buat, bangun3, and beli, the suffix -kan may register the presence of a benefactive in the verb's argument structure. In our terms, for these verbs the kan-aspect encodes a transit path of change (either of the translocation concept or of 'benefactive'). As a reminder, a path of change is transit if the path towards the GOAL is not direct, that is, the translocation of the object includes/contains a "transit point". A simpler way of saying this is that the suffix extends the path. 
I shall demonstrate that because the verbs such as buat 'to make', bangun3 'to build', and beli 'to buy' contain the change component - that is, even without the kanaspect - as discussed in Chapter 3, they only select THEME, and thus, the kan-aspect with these predicates does not have an $i$-aspect alternant (with the $i$-aspect a PATIENT is selected). To put it simply, these verbs do not take the suffix $-i$, regardless of the linear orders, $(57 \mathrm{~b}, \mathrm{c}),(58 \mathrm{~b}, \mathrm{c})$, and $(59 \mathrm{~b}, \mathrm{c})$.

(57)a. Ibu meN-buat-kan kopi (untuk tamu) mother ACT-make-KAN coffee for guest 'Mother made some coffee (for the guest)'
b. *Ibu meN-buat-i kopi (untuk tamu) mother ACT-make-I coffee for guest 'Mother made some coffee (for the guest)'
c. ${ }^{*}$ Ibu meN-buat- $i$ tamu se-cangkir kopi mother ACT-make-I guest a-CLASS coffee
'Mother made the guest a cup of coffee'
(58)a. Ibu meN-beli-kan baju baru (untuk Fatimah) mother ACT-buy-KAN dress new for $F$ 'Mother bought a new dress for Fatimah'
b. *Ibu meN-beli-i baju baru (untuk Fatimah) mother ACT-buy-I dress new for $F$ 'Mother bought a new dress (for Fatimah)'
c. *Ibu meN-beli-i Fatimah se-buah baju baru mother ACT-buy-I F a-CLASS dress new
'Mother bought Fatimah a new dress'

\begin{tabular}{|c|c|c|c|c|c|c|}
\hline (59)a. & $\begin{array}{l}\text { Ayah meN-bangun-kan } \\
\text { father ACT-build-KAN }\end{array}$ & & $\begin{array}{l}\text { kandang } \\
\text { shed }\end{array}$ & $\begin{array}{l}\text { ayam } \\
\text { chicken }\end{array}$ & $\begin{array}{l}\text { luntuk } \\
\text { for }\end{array}$ & $\begin{array}{l}\text { kami } \\
1 \mathrm{pl}\end{array}$ \\
\hline & 'Father built a chicken sh & hed for us' & & & & \\
\hline b & $\begin{array}{l}\text { *Ayah meN-bangun-i } \\
\text { father ACT-build-I }\end{array}$ & $\begin{array}{l}\text { se-buah } \\
\text { a-CLASS }\end{array}$ & $\begin{array}{l}\text { kandang } \\
\text { shed }\end{array}$ & $\begin{array}{l}\text { ayam } \\
\text { chicken }\end{array}$ & $\begin{array}{l}\text { (untuk } \\
\text { for }\end{array}$ & $\begin{array}{l}\text { kami, } \\
1 \mathrm{pl}\end{array}$ \\
\hline & 'Father built a chicken sh & hed (for us & & & & \\
\hline & $\begin{array}{l}\text { *Ayah meN-bangun- } i \\
\text { father ACT-build-I }\end{array}$ & $\begin{array}{ll}\text { kami } & s \\
1 \mathrm{pl} & \mathrm{a}\end{array}$ & $\begin{array}{l}\text { se-buah } \\
\text { a-CLASS }\end{array}$ & $\begin{array}{l}\text { andang } \\
\text { ned }\end{array}$ & $\begin{array}{l}\text { ayam } \\
\text { chicken }\end{array}$ & \\
\hline
\end{tabular}

We cannot have kopi 'coffee', baju baru 'new dress', and sebuah kandang ayam 'a chicken shed' as PATIENTs, as shown in the (b) examples of (57)-(59). The verbs in (57)(59) above are different from the verbs beri 'give' and kirim 'send', where the direct 
internal arguments alternate (THEME alternates with PATIENT for the status of direct internal argument, with the kan- and $i$-aspect respectively, see Section 4.3 below). With the $i$-aspect in the (c) examples of (57)-(59) the arguments tamu 'guest', Fatimah, and kami ' $1 \mathrm{pl}$ ' should have the status of PATIENT. But the sentences are unacceptable. The bottom line is as simple as that the predicates that contain the change component (i.e., even when the kan-aspect is not used) such as buat 'make', bangun3 'build', and beli 'buy' above do not take the suffix $-i$; in effect, they only take a THEME. The use of the $i$ aspect with this type of verb is contradictory in nature.

To summarise, some predicates take only the suffix $-k a n$, some only the suffix $-i$, and some can take either one, with reasons outlined above (4.2.2.1-4.2.2.3). This simple fact is important if we want to maintain our assumption that each form bearing a $v \mathrm{P}$ aspect is basic and independently derived. We do not want to argue that a certain form is impossible just because a certain argument cannot be promoted or demoted from a certain position (section 4.3, below).

\subsubsection{Prepositions for the secondary internal arguments}

In sub-sections 4.2.2.1 (psych-predicates) and 4.2.2.2 (common adjectives) I examine events with a single internal argument. We must now turn to the secondary internal arguments, in particular to the occurrence of different prepositions. The discussion on prepositions leads us to the so-called DAC-DOC alternation. I shall use the terminology when appropriate to do so.

It is relevant to discuss in the present work double/object constructions, because in the literature the form that corresponds to the BI $i$-aspect is discussed in terms of the DAC-DOC alternation, either those of other languages or of BI. The present sub-section aims to show the "origin" of DOC in BI, i.e., what makes it possible for DOC to occur. Three important points must be observed.

(i) It is the idiosyncrasy of the verbs beri/kirim/pinjam 'give/send/lend' that the THEME as a secondary internal argument must not be introduced by the preposition dengan 'with'. 
(ii) The $v \mathrm{P}$-aspect alternation as discussed in the previous sections shows a consistent pattern. Thus, the so-called DAC-DOC alternation constitutes only a minor part of the general picture of the kan-aspect - $i$-aspect alternation. What is special about DOC is there is no preposition that introduces the secondary internal argument, as in (i).

(iii) As I have argued, any argument introduced by a preposition is optional in BI. In the case of DOC, both the internal arguments can be considered primary, because the second internal argument is not and cannot be introduced by a preposition.

With those three points, I aim to show that the DAC belongs to the kan-aspect whereas the DOC belongs to the $i$-aspect. I will also maintain that there is no cause interpretation available with the $i$-aspect.

I will start with two distinct preposition frames involving the secondary internal arguments. Sub-section 4.2.3.1 discusses the ke-dengan 'locative to-with' frame (GOAL versus THEME), with spray/load type predicates. Sub-section 4.2.3.2 discusses the kepada- $\varnothing$ 'dative to- $\emptyset$ ' frame (also GOAL versus THEME) with the predicates beri 'give', kirim 'send' and pinjam 'lend/borrow'. Finally, in sub-section 4.2.3.3 I demonstrate the occurrence of an 'illusory' DOC of the kan-aspect, and exemplify the true DOC that can occur only with the $i$-aspect.

\subsubsection{The $k e$ - dengan frame with spray/load predicates}

We shall re-iterate what has been discussed in sub-section 4.1.3, namely the existence of two frames (frames (23) with the kan-aspect and (24) with the $i$-aspect), repeated here as (60) and (61).

(60) $[k a n-k e]$ frame:

$$
\begin{array}{r}
\text { PREDICATE - } \boldsymbol{k} a \boldsymbol{n} \text { THEME } \\
\text { locative } t o
\end{array}
$$

(61) $[i-$ dengan $]$ frame:

$$
\begin{gathered}
\text { PREDICATE }-\boldsymbol{i} \text { PATIENT PP: dengan THEME } \\
\text { with }
\end{gathered}
$$


Both the prepositional arguments in (60) and (61) are optional, because the expressions are complete even without them, $(62 \mathrm{a}, \mathrm{b})$.

(62)a. Para petani meN-siram-kan air (ke lahan) PL farmer ACT-pour-KAN water to soil 'The farmers poured water (on the prepared ground)'

b. Para petani meN-siram-i lahan (dengan air) PL farmer ACT-pour-I soil with water 'The farmers poured the prepared ground (with water)'

I call the prepositional argument lahan 'soil' (62a) and air 'water (52b) above the 'secondary internal argument'. In BI, as we have seen in our examples so far, any prepositional argument is optional. To include the secondary internal arguments the prepositions ke 'locative to' (62a) and dengan 'with' (62b) must be present, (63a,b) below, that is, (62) above cannot have double-object construction.

(63)a. *Para petani meN-siram-kan air lahan PL farmer ACT-pour-KAN water soil

'The farmers poured water the prepared ground'

b. *Para petani meN-siram-i lahan air PL farmer ACT-pour-I soil water 'The farmers poured the prepared ground water'

The contrasting patterns as seen in (62a) as against (62b) are consistent, (64) and (65).

(64)a. Tukang kayu meN-semprot-kan cat ke dinding TUKANG wood ACT-spray-KAN paint to wall 'The carpenter sprayed paint on the wall' (TUKANG = English '-er'/ '-or')

$\begin{array}{llllll}\text { b. Tukang } & \text { kayu } & \text { meN-semprot-i } & \text { dinding } & \text { dengan } & \text { cat } \\ \text { TUKANG } & \text { wood } & \text { ACT-spray-I } & \text { wall } & \text { with } & \text { paint }\end{array}$ 'The carpenter sprayed the wall with paint' 
(65)a. Kuli-kuli meN-muat-kan rumput ke truk coolie-PL ACT-load-KAN hay to truck

'The coolies loaded the hay on the truck'
b. Kuli-kuli meN-muat-i
truk dengan
rumput
coolie-PL ACT-load-I truck with hay
'The coolies loaded the truck with hay'

And again, like (63), DOC cannot be formed from (64) and (65).

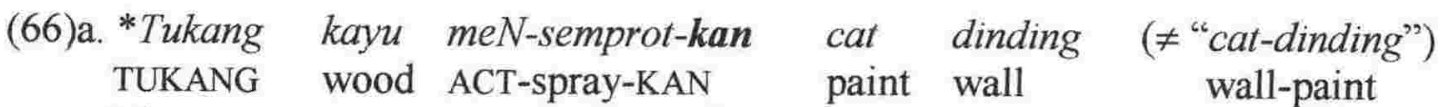

'The carpenter sprayed paint the wall'

$\begin{array}{llll}\text { b. *Tukang } & \text { kayu meN-semprot-i } & \text { dinding } & \text { cat } \\ \text { TUKANG } & \text { wood ACT-spray-I } & \text { wall } & \text { paint }\end{array}$

'The carpenter sprayed the wall paint'

(67)a. *Kuli-kuli meN-muat-kan rumput truk coolie-PL ACT-load-KAN hay truck

'The coolies loaded the hay the truck'
b. *Kuli-kuli meN-muat-i
truk rumput
coolie-PL ACT-load-I
truck hay
'The coolies loaded the truck hay'

All the grammatical (a) examples in (62)-(65) use the PP ke to-phrase, and all the grammatical (b) examples use the PP dengan with-phrase. The (a) examples have cause and locative interpretation, and the primary internal argument is a THEME. Whereas the (b) examples do not have a cause interpretation and the primary internal argument is a PATIENT. The ungrammatical examples (63), (66), and (67) show that DOC cannot occur because the preposition $k e$ 'locative to' and dengan 'with' are obligatory. In particular, note that in the ungrammatical (b) examples - with the $i$-aspect - the preposition dengan is obligatory, because we will compare them with the true DOC.

\subsubsection{The kepada - $\theta$ frame with give/send/lend predicates}

We now turn to the predicates beri 'give', kirim 'send', and pinjam 'lend/borrow'. With these verbs the secondary internal argument PP (kepada 'dative to' GOAL) does not alternate with the PP (dengan 'with' THEME). This is the BI DOC in the making. Different from in the previous sub-section (4.2.3.1) where we have the locative 
preposition $k e$, in the present sub-section we have the dative preposition kepada. The kepada - $\emptyset$ frame is strictly limited only to this type of predicate (beri 'give', kirim 'send', pinjam 'lend/borrow') and the DOC is formed only in the $i$-aspect environment. The following (a) examples of (68)-(70) can be called DAC, because now we have the dative preposition kepada, thus different from the previous examples with the locative preposition $k e$, where the term DAC is inappropriate. The (b) examples of (68)-(70) where the preposition dengan 'with' is not allowed can be called DOC.

(68)a.John meN-kirim-kan se-buah paket ke-pada Bob $\mathrm{J}$ ACT-send-KAN a-CLASS package to-DATIVE B 'John sent a package to Bob'

b. John meN-kirim-i Bob (*dengan) se-buah paket $J$ ACT-send-I B with a-CLASS package 'John sent Bob a package'

(69)a.Ibu meN-beri-kan se-buah baju ke-pada Fatimah mother ACT-give-KAN a-CLASS dress to-DATIVE F 'Mother gave a dress to Fatimah'
b. Ibu meN-beri-i Fatimah
(*dengan) se-buah baju mother ACT-give-I F with 'Mother gave Fatimah a dress'

$\begin{array}{lllll}\text { (70)a. Paul meN-pinjam-kan } & \text { mobil-nya } & \text { ke-pada } & \text { John } \\ \text { P } & \text { ACT-lend/borrow-KAN } & \text { car-3sg } & \text { to-DATIVE } & \mathrm{J} \\ \text { 'Paul lent his car to John' } & & & & \\ \text { b. Paul meN-pinjam-i } & \text { John } & \text { (*dengan) } & \text { mobil-nya } \\ \text { P ACT-lend/borrow-I } & \mathrm{J} & \text { with } & \text { car-3sg } \\ \text { 'Paul lent John his car' } & & & \end{array}$

Therefore, in BI the DAC belongs to the kan-aspect, (68a), (69a), and (70a), and the DOC to the $i$-aspect, (68b), (69b), and (70b). Call the DOC " $i$-DOC" to remind us that the form occurs only in the $i$-aspect environment, (71).

(71) BI $i$-DOC:

$\begin{array}{lllll}\text { a. John meN-kirim-i } & \text { Bob } & \text { se-buah paket } \\ \text { J ACT-send-I } & \text { B } & \text { a-CLASS } & \text { package } \\ \text { 'John sent Bob a package' } & & \end{array}$ 
b. Ibu meN-beri-i Fatimah se-buah baju mother ACT-give-I F a-CLASS dress

'Mother gave Fatimah a dress'
c. Paul meN-pinjam-i $P \quad$ ACT-lend/borrow-I
John mobil-nya
car-3sg
'Paul lent John his car'

By comparing the $i$-DOC and the $i$-non-DOC of 4.2.3.1 it appears that it is the preposition dengan 'with' that makes the difference, with the DP mobil-nya 'his car' (72a) as against the PP dengan rumput 'with hay' (72b).

$\begin{array}{clll}\text { (72)a. Paul } & \text { meN-pinjam-i } & \text { John } & \text { mobil-nya } \\ \text { P } & \text { ACT-lend-I } & \text { J } & \text { car-3sg }\end{array}$

'Paul lent John his car'

b. Kuli-kuli meN-muat-i truk dengan rumput coolie-PL ACT-load-I truck with hay 'The coolies loaded the truck with hay'

However, it is the idiosyncracy of the predicates in (71) that really makes the difference, because with send/give/lend predicates the event is not complete without including the other internal argument (73a) below, which is also to say that both internal arguments are primary, contrast with (73b).

\section{(73)a. *Paul meN-pinjam-i John $\mathrm{P} \quad$ ACT-lend-I J 'Paul lent John' \\ b. Kuli-kuli meN-muat-i truk coolie-PL ACT-load-I truck \\ 'The coolies loaded the truck'}

The fact that both internal arguments are primary does not change the status of the objects, as PATIENT or as THEME. For reasons of coherence, on the surface the PATIENT must immediately follow the $i$-predicate. The surface positions cannot be swapped over, (74). 
$\begin{array}{cllll}\text { (74)a. *John } & \text { meN-kirim-i } & \text { se-buah paket } & \text { Bob } \\ \mathrm{J} & \text { ACT-send-I } & \text { a-CLASS } & \text { package } & \text { B }\end{array}$

'John sent a package Bob'

b. *Ibu meN-beri-i se-buah baju Fatimah mother ACT-give-I a-CLASS dress F

'Mother gave a dress Fatimah'

c. *Paul meN-pinjam-i mobil-nya John

P ACT-lend-I car-3sg J

'Paul lent his car John'

The forms in (74) are bad because of the wrong argument selection - at $\nu \mathrm{P}$ as shown also on the surface - and not because of the lack of a preposition. In fact the dative preposition kepada is also barred from occupying the secondary position should the kan-aspect be otherwise used, (75), although grammatical in the English translation.

(75)a. *John meN-kirim-i se-buah paket ke-pada Bob $\mathrm{J}$ ACT-send-I a-CLASS package to-DATIVE B 'John sent a package to Bob'

b. *Ibu meN-beri-i se-buah baju ke-pada Fatimah mother ACT-give-I a-CLASS dress to-DATIVE F

'Mother gave a dress to Fatimah'

c. *Paul meN-pinjam-i mobil-nya ke-pada John

$\mathrm{P} \quad \mathrm{ACT}-\mathrm{lend}-\mathrm{I} \quad \mathrm{car}-3 \mathrm{sg}$ to-DATIVE J

'Paul lent his car to John'

In (75) the THEME (a package) to GOAL (to Bob) form that normally occurs in the kanaspect environment cannot occur in the $i$-aspect environment (Note the mismatch between the PP that encodes the translocation concept and the $i$-aspect that doesn't).

In conclusion, in the $\mathrm{BI} i$-DOC the preposition dengan 'with' is barred. On the surface, that is the only significant matter about the BI DOC. Looking closely, however, it is the idiosyncrasy of the predicates send/givellend that allows its formation. These "ditransitive" verbs can occur in DOC but only within the $i$-aspect environment. 
However, there is nothing different about the DAC of these verbs from the prepositional form of other kan-predicates, beyond the distinction between the locative to ke and the dative to kepada. The kepada - $\varrho$ frame with give/send/lend predicates $(77 \mathrm{a}, \mathrm{b})$ below are thus different from those of the ke - dengan frame with spray/load predicates (4.2.3.1) repeated in the following as $(76 a, b)$.

(76)a. [kan - ke] frame for spray/load verbs:

$$
\text { PREDICATE - kan THEME PP: } \boldsymbol{k} \boldsymbol{e} \text { GOAL }
$$

locative to

b. $[i$-dengan $]$ frame:

PREDICATE $-\boldsymbol{i}$ PATIENT PP: dengan THEME

with

(77)a. [kan - kepada] frame for give/sendllend verbs:

$$
\text { PREDICATE - kan THEME PP: kepada GOAL }
$$

dative to

b. $[i-\emptyset]$ frame:

$$
\text { PREDICATE }-\boldsymbol{i} \text { PATIENT DP: THEME (true DOC, } \boldsymbol{i} \text {-DOC) }
$$

\subsubsection{Covert preposition untuk 'for' at PF with transit path of change: an illusory DOC}

This sub-section demonstrates that there is no true DOC with the kan-aspect. What we have is a preposition untuk 'for' that can be covert at PF, in the case of what we have argued for as a transit path of change (because in this case the preposition untuk 'for', rather than ke 'locative $t o$ ' or kepada 'dative $t o$ ', introduces the secondary internal argument). We shall call the form 'illusory DOC'. As a reminder, transit path of change occurs only with the predicates that already contain a change component even without

\begin{tabular}{|c|c|c|c|c|}
\hline $\begin{array}{l}\text { (78)a. } \mathrm{Ibu} \\
\text { mother }\end{array}$ & $\begin{array}{l}\text { meN-buat-kan } \\
\text { ACT-make-KAN }\end{array}$ & $\begin{array}{l}\text { se-cangkir } \\
\text { a-CLASS }\end{array}$ & $\begin{array}{l}k o p i \\
\text { coffee }\end{array}$ & $\begin{array}{l}\text { untuk } \\
\text { for }\end{array}$ \\
\hline
\end{tabular}
the use of the kan-aspect (such as buat 'make', beli 'buy', bawa 'carry'). Consider (78) and (79) where the (a) examples are the more "comfortable way" of expression. 
bIbu meN-buat-kan (untuk) tamu se-cangkir kopi

mother ACT-make-KAN for guest a-CLASS coffee

'Mother is making, for the guest, a cup of coffee'

(79)a.Ibu meN-beli-kan sebuah baju untuk Fatimah mother ACT-buy-KAN a dress for $\mathrm{F}$

'Mother bought a dress for Fatimah'

b. Ibu meN-beli-kan (untuk) Fatimah sebuah baju mother ACT-buy-KAN for F a dress

'Mother bought, for Fatimah, a dress'

When the preposition untuk 'for' as in the (b) examples (78) and (79) above is not pronounced, because it is optional, the forms may sound like a DOC. However, it is only an illusion. This illusory DOC occurs presumably because of the property of the preposition untuk 'for' that can be covert when adjacent to the predicate - linearly speaking - or because of the transit path of change with certain predicates. However, recall our discussion in Chapter 3, where with make/buy predicates without the kanaspect, the preposition untuk 'for', must be overt, regardless of whether or not it is linearly next to the predicate. Therefore, we shall maintain that the optional presence of the preposition untuk 'for' such as in (78b) and (79b) is a PF matter. At PF, the preposition untuk 'for' of (78b) and (79b) may or may not be pronounced, while kepada 'dative $t o$ ' of the examples (80)-(82) below must be. It must be that the "condition of the deletion" and - this is important - of the "optionality" at PF is determined by the interpretations of transit (78) and (79) above versus non-transit (i.e., direct) path of change, (80)-(82), by definition.

The illusory DOC cannot be formed with the kan-predicate berikan 'give', kirimkan 'send' and pinjamkan 'lend', because the dative preposition kepada must be overt. The (a) examples of (80), (81) and (82) below are the more "comfortable way" of expression. The (b) examples have the preposed PP, and the arguments introduced by the preposition kepada 'dative $t o$ ' remain peripheral.

$\begin{array}{lllll}\text { (80)a. John meN-kirim-kan se-buah paket } & \text { ke-pada } & \text { Bob } \\ \text { J ACT-send-KAN a-CLASS } & \text { package } & \text { to-DATIVE } & \text { B } \\ \text { 'John sent a package to Bob' } & & & \end{array}$


b. John meN-kirim-kan *(kepada) Bob se-buah paket $\mathrm{J}$ ACT-send-KAN to B a-CLASS package 'John sent, to Bob, a package'

(81)a. Ibu meN-beri-kan se-buah baju ke-pada Fatimah mother ACT-give-KAN a-CLASS dress to-DATIVE F 'Mother gave a dress to Fatimah'
b. Ibu meN-beri-kan *(ke-pada)
Fatimah sebuah baju mother ACT-give-KAN to-DATIVE F a dress 'Mother give, to Fatimah, a dress'

(82)a. Paul

meN-pinjam-kan mobil-nya

ke-pada John

P ACT-lend-KAN car-3sg to-DATIVE J

'Paul lent his car to John'

$\begin{array}{cllll}\text { b. Paul } & \text { meN-pinjam-kan } & *(\text { ke-pada) } & \text { John } & \text { mobil-nya } \\ \text { P } & \text { ACT-lend-KAN } & \text { to-DATIVE } & \text { J } & \text { car-3sg }\end{array}$

'Paul lent, to John, his car'

Contrast the (b) examples of (80) - (82) with what we have in (71) with the $i$-aspect, repeated here as (83), (84) and (85).

(83)a. John meN-kirim-i Bob se-buah paket $\mathrm{J}$ ACT-send-I B a-CLASS package 'John sent Bob a package'

(84)a. Ibu meN-beri-i Fatimah se-buah baju mother ACT-give-I F a-CLASS dress 'Mother gave Fatimah a dress'
(85)a. Paul meN-pinjam-i John mobil-nya P ACT-lend-I J car-3sg 'Paul lent John his car'

Conversely, prepositional forms cannot be used with the $i$-aspect, (86), (87) and (88) below. This fact makes each form with the $i$-aspect (83)-(85) above a true DOC. 
(86)a. *John meN-kirim-i ke-pada

Bob se-buah paket

$\mathrm{J}$ ACT-send-I to-DATIVE B a-CLASS package

'John sent to Bob a package'

$\begin{array}{clllll}\text { b. *John meN-kirim- } i & \text { se-buah paket } & \text { ke-pada } & \text { Bob } \\ \mathrm{J} & \text { ACT-send-I } & \text { a-CLASS } & \text { package } & \text { to-DATIVE } & \text { B }\end{array}$

'John sent a package to Bob'

(87)a. *Ibu meN-beri-i ke-pada Fatimah se-buah baju mother ACT-give-I to-DATIVE F a-CLASS dress

'Mother gave to Fatimah a dress'

b. *Ibu meN-beri-i se-buah baju ke-pada Fatimah mother ACT-give-I a-CLASS dress to-DATIVE F

'Mother gave a dress to Fatimah'

$\begin{array}{lllll}\text { (88)a. *Paul meN-pinjam-i } & \text { ke-pada } & \text { John } & \text { mobil-nya } \\ \text { P } & \text { ACT-lend-I } & \text { to-DATIVE } & \mathrm{J} & \text { car-3sg } \\ \text { 'Paul lent to John his car' } & & & & \\ \text { b. *Paul meN-pinjam-i } & \text { mobil-nya } & \text { ke-pada } & \text { John } \\ \text { P ACT-lend-I } & \text { car-3sg } & \text { to-DATIVE } & \mathrm{J} \\ \text { 'Paul lent his car to John' } & & & & \end{array}$

In conclusion, DAC belongs to the kan-aspect and DOC to the $i$-aspect. We cannot have double object forms with the kan-aspect, and conversely, we cannot have (dative) prepositional forms with the $i$-aspect.

The occurrence of different prepositions for the secondary internal arguments is shown to be a part of $v \mathrm{P}$-aspect alternations; it is a part of the notions of change versus non-change, where with the kan-aspect the locative and dative prepositions "direct" the object undergoing change to its GOAL. The so-called DAC-DOC alternation is thus a part of the $v \mathrm{P}$-aspect alternation. It is the idiosyncracy of the predicates give/send/lend that makes it possible within the $i$-aspect to have the non-prepositional secondary internal argument (i.e., not introduced by the preposition dengan 'with'). We must keep this finding in mind, because our account of the $i$-aspect matches nicely to what is discussed in the literature with respect to the status of PATIENT in DOC. 


\subsection{Derivations with the $i$-aspect: the status of PATIENT as the primary internal argument.}

The previous two sections (4.1 and 4.2) provide sufficient evidence that each form - the form with the kan-aspect or the form with the $i$-aspect - is independently derived. The central notion of the present thesis is that the kan-aspect selects a THEME and the $i$-aspect selects a PATIENT as a primary internal argument. The argument selection argued for in the present work is done by the $v \mathrm{P}$-aspect "registration marker" (Larson 1988), or, "strong functional head" (Radford 1997), realised in BI by the suffixes $-k a n$ and $-i$. The suffixes are thus "functional" in that they select an argument, and each predicate - to include the derived and non-derived verbs - has a distinct argument structure.

I have shown the derivation involving the kan-aspect in Chapter 3. In the present section I will show the derivation with the $i$-aspect. We have sufficient evidence as shown in the preceding sections to suggest that each $v \mathrm{P}$-aspect is basic. I will start with the BI $i$-DOC in sub-section 4.3.1, considering the data that have been examined in the preceding two sub-sections (4.1 and 4.2). Sub-section 4.3.2 examines what have been

proposed in the literature with respect to DOC treatments, considering which are and which are not applicable for the BI analysis, in particular for the BI $i$-DOC. In subsection 4.3.3 I return to the $\mathrm{BI} i$-aspect.

\subsubsection{The BI $i$-DOC}

The present sub-section especially discusses the structure of the BI $i$-DOC because of the significance of DOC cross-linguistically in the literature, although, as we have seen in the previous two sub-sections, the BI $i$-DOC makes up only a minor variation within the $i$ aspect.

In the previous sub-sections we concluded that the DAC belongs to the kan-aspect and the DOC belongs to the $i$-aspect. It is thus an advantage of having each $v \mathrm{P}$-aspect as an independent derivation that we can account for the so-called dative/double object constructions without any difficulty. The dative/double object constructions conform to the general pattern of the $v \mathrm{P}$-aspect alternation. Because the consistent patterns also 
include the locative $k e$ "to" such as shown in (23), "dative" is too narrow a term. In the present analysis, each construction is basic and independently derived: we view each form as a $v \mathrm{P}$-aspect alternant.

In discussing the DAC-DOC in the present sub-section I avoid using the terms direct object ("DO") and indirect object ("IO") firstly because the terms can create confusion, apart from the lack of agreement amongst researchers dealing on the topic. Secondly, as argued for in the present work, the two surface forms are derived independently of each other. Thus, under the present approach, neither the THEME nor the PATIENT is a canonical "direct object" or a canonical "indirect object", because we have two distinct $v \mathrm{P}$-aspects that motivate two different paths of derivation. If pressed, with the kan-aspect, the THEME is the "direct object", but so is the PATIENT with the $i$-aspect. In order to show the THEME-object and PATIENT-object correlations, the term "primary internal argument" is maintained. The positions of the primary internal arguments I propose for both $v \mathrm{P}$-aspects are as follows, diagram (89a) for the kan-aspect and (89b) for the $i$-aspect (recall that both $v \mathrm{P}$-aspects characterise transitivity).

(89)a. v-kan:

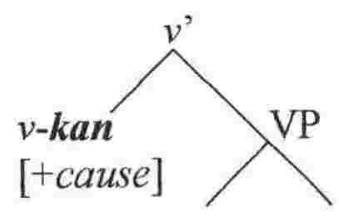

DP

THEME

[+change] (89)b. $\quad \underline{v-i}$ :

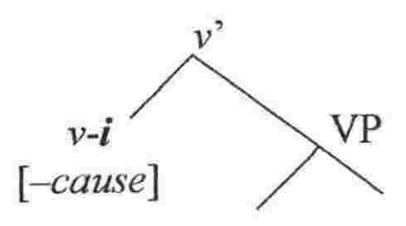

DP

PATIENT

[-change]

With the kan-aspect (89a) the argument at [Spec-VP] has a THEME interpretation (this is a familiar structure we have in Chapter 3 ) and with the $i$-aspect (89b) the argument [SpecVP] has a PATIENT interpretation. Under the present approach, both THEME and PATIENT are the primary internal arguments (and both are "direct objects", if pressed). The tree diagrams for both $\mathrm{BI} v \mathrm{P}$-aspects (89) correspond to the DAC-DOC as discussed in the 
literature, that is, the structure ( $89 \mathrm{a})$ corresponds to the DAC, and $(89 \mathrm{~b})$ to the DOC. The two structures presented in (89) have also been proposed by Arad (1998: 89-90). It must be emphasised that both structures (89) are basic, and any variation must be based upon these structures. This matter will become more apparent as we progress. The structure of the BI $i$-DOC, which is based on the $v-i$ structure of (89b) above, is shown as (90).

(90) $i$-DOC:

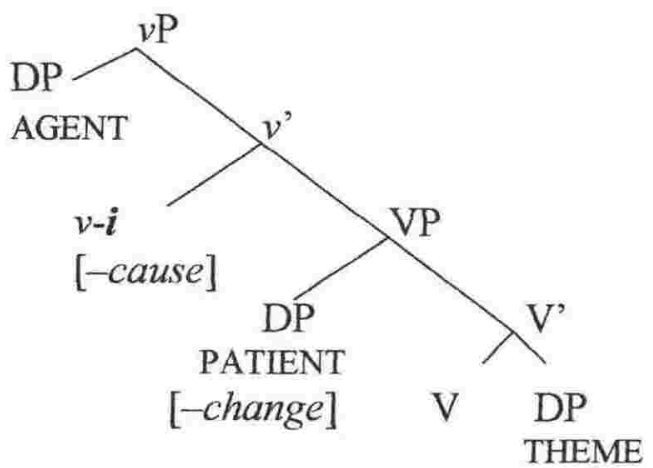

Applying an example of $i$-DOC from (71a) to the structure (90) we have (91a) below. Structure (91b) where the THEME is introduced by the preposition dengan 'with' is what is not allowed. Recall that non- $i$-DOC is not allowed with the predicates send/givellend (Sub-section 4.2.3.2). 
(91)a. $i$-DOC:

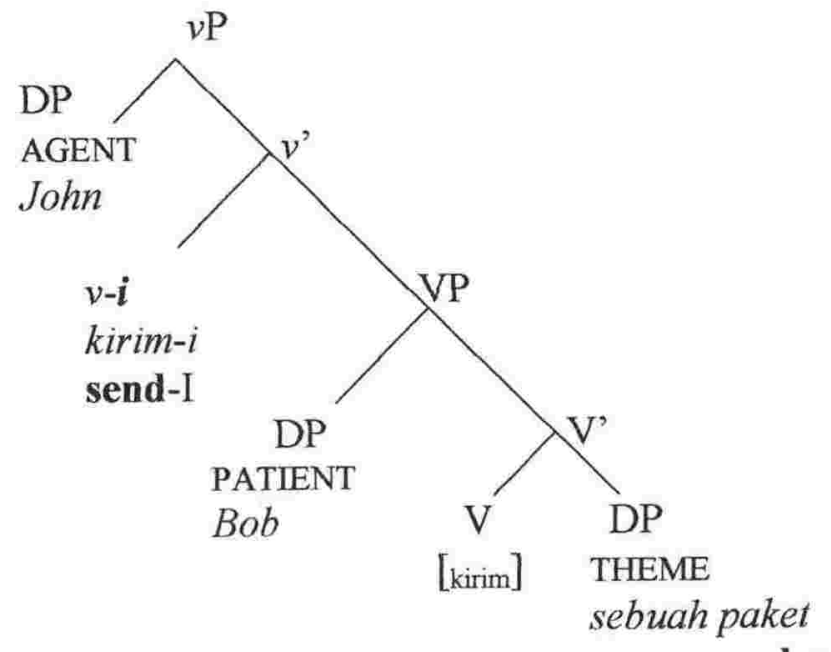

For the example (71a):

a package

John meN-kirim- $i$ Bob se-buah paket J ACT-send-I B a-CLASS package

'John sent Bob a package'

(91)b. non- $i$-DOC with send/give/lend:

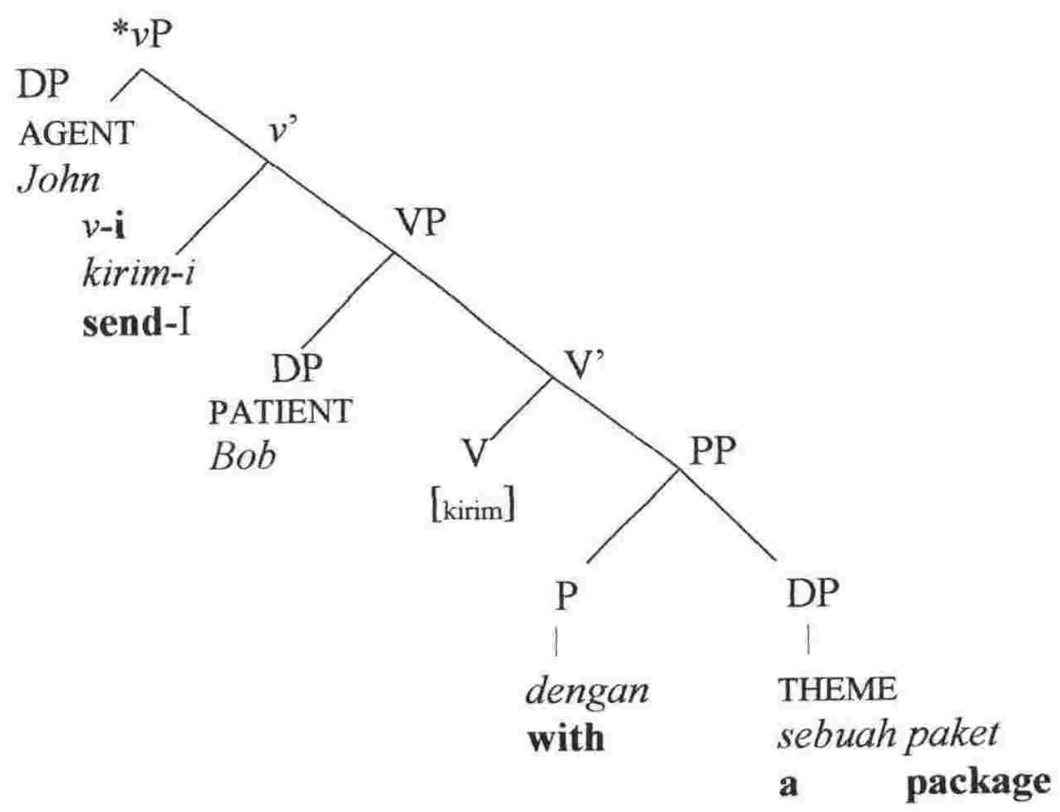

For:

*John meN-kirim-i Bob dengan se-buah paket J ACT-send-I B with a-CLASS package 'John sent Bob a package' 
Note that under the present approach, Bob at [Spec-VP] in $(91 \mathrm{a}, \mathrm{b})$ is interpreted as a PATIENT rather than a GOAL, to be consistent with the theory proposed here, namely, the terminology is consistent with the notion of change, which in this case, is the lack of change. The difference between the structures (91a) and (91b) is that in (91b) the complement of the copied verb kirim 'send' is a PP, and thus the THEME is introduced by the preposition dengan 'with'. Under the present theory, the THEME sebuah paket 'a package' in (91a) is not optional, because it is not, and it cannot be, introduced by a preposition. Hence the BI DOC is created.

\subsubsection{DOC in the literature}

We must now turn to DAC-DOC analyses in the literature, in particular to those that argue that each construction is basic and not derived from the other. The disagreements between the two types of analysis, namely, analyses that treat DOC as the basic form and thus the prepositional single-object equivalent as derived from it on the one hand, and those that treat DAC as the basic form and thus the DOC is derived from DAC on the other, will not be addressed in the present work. In all the constructions examined so far, primary and secondary internal arguments and external arguments are all clearly distinguishable from each other.

Despite the slight variations in emphasis and the degrees of detail, what the analyses to be looked at have in common is that researchers aim to show that the occupant of [Spec-VP] in DOC is an "IO" - which is a PATIENT in our terms - with the Larsonian $v \mathrm{P}$-shell as the basic structure. Of the literature on the topic available, only a handful can be cited here: (I) Arad (1998), (II) McGinnis (2001) and (III) Pesetsky (1995), in the order of preferred treatment. The three works cited here provide a strong support for the present analysis although they have different emphases. Arad demonstrates in detail that the English DAC and DOC have different interpretations and syntactic effects; McGinnis demonstrates that the two forms are encoded morphologically by two different morphemes across languages resulting in two distinct applicative analyses; Pesetsky proposes a [+affix] zero morpheme that occurs only in DOC (of 
English). The end of the present section will also include other proposals, with a brief comment for each. These include Larson (1988), Bowers (1993), and Den Dikken (1995).

\section{I. $\underline{\operatorname{Arad}(1998: 85-91)}$}

Arad provides the simplest analysis of DOC (92b) below. She argues that DAC has a "real different" interpretation from that of DOC, and that a transformational account is made less plausible (for details of analysis see Arad 1998: 89-90 and the references cited there). The structures proposed by Arad are as follows, (92a) is for DAC and (92b) is for DOC, they are presented here without any modification. My comments immediately follow.

(92)a. DAC

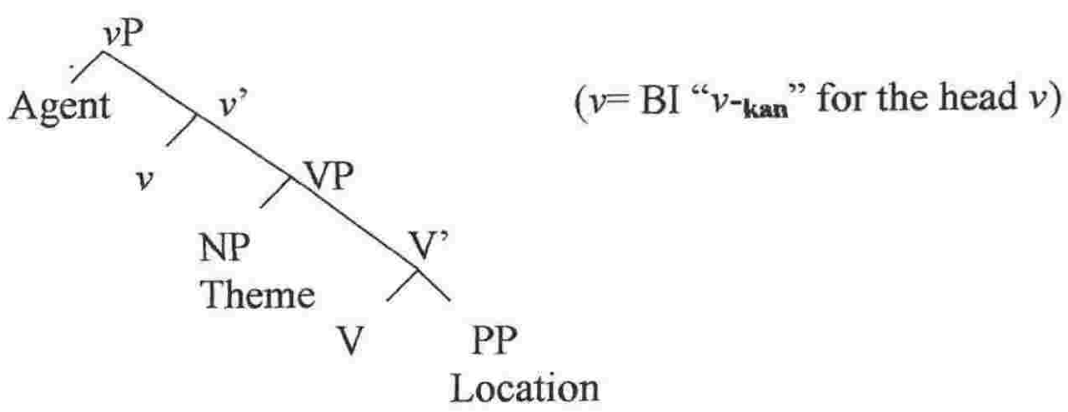

(92)b. DOC

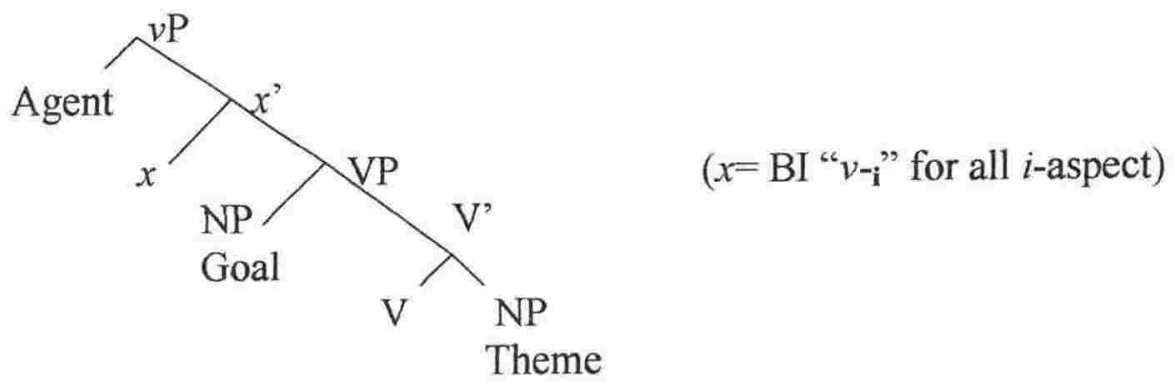

The diagram (92a) is familiar because we have been using it for the structures with the kan-aspect, and not just for the so-called DAC. I shall set (92a) aside. The structure (92b) needs some explanations. 
According to Arad, " $x$ " in (92b) is the head of the upper projection "in the case of DOC". With (92b), the Goal is necessarily interpreted as affected and the event is interpreted as fully "transmitted", but no such requirements exist with DAC. With DOC the subject may be interpreted as non-agentive. With DAC the subject is always agentive.

In the present terms, as I have argued, DOC belongs to the $i$-aspect. What Arad calls the head " $x$ " is what I call " $v-i$ ". In our terms, the Goal in (92b) is a PATIENT, which by definition does not undergo change, "affectedness" aside. Arad uses the term Goal presumably because in the DAC counterpart this argument is a Goal. Arad also calls the Goal in (92b) "indirect object". To be consistent with the notion that (92a) is a "separate beast entirely" (Tenny 1994: 81-83), we shall use the term PATIENT instead. With the kan-aspect in (92a) the THEME at [Spec-VP] is the "direct object", and with the $i$-aspect the PATIENT (Arad's Goal in (92b)) at [Spec-VP] is also the "direct object". Both are direct objects in the sense that they cannot be introduced by a preposition (which is true also for the THEME in the DOC (92b) above).

With the "common" $i$-aspect in general, [Spec-vP] can also have the interpretation of what I term as an 'AGENT-Experiencer' (from our data in 4.2.2.1, structure (54)), or as an empty position, no occupant, non-agentive (or, 'simply does not exist', and not as a PRO or pro, from data in 4.2.1, structure (36)). With the BI $i$-DOC, however, the subject must be interpreted as agentive, (93b), which is different from that of the English counterpart, (93a) below, from Arad (1988: 89).

(93)a. Cardamon pods gave the pudding a sharp, distinctive taste

b. *Kapulaga meN-beri(-i) puding suatu rasa yang tajam dan unik cardamon ACT-give-I pudding a taste COMP sharp and unique 'Cardamon gives the pudding a sharp, unique taste'

With the BI kan-aspect in general, we have an AGENT or a CAUSER as the external argument. With BI DAC, however, we only have an AGENT as the external argument, because in BI the occurrence is limited to the predicates send/givellend. Arad's 
description of both structures $(92 a, b)$ thus matches our analysis of the BI DAC-DOC alternation, in fact, of the kan-aspect and $i$-aspect alternation in general (except for the slight difference in terminology, which I regard as non-crucial for our purposes).

\section{McGinnis (2001: 333-349)}

McGinnis demonstrates that there are two types of DOC in Kinyarwanda (Bantu; Rwanda, Baker 1988): one that occurs as a "high applicative" or "E-applicative" and another that occurs as a "low applicative" or "I-applicative". Apart from the morphological distinction between the two - i.e., each is represented by a different affix, and has a different position in the verb complex, higher/lower - the two applicatives also differ in their intrinsic semantics. McGinnis' two types of DOC are shown here without any modification, (94a) for E-applicative, and (94b) for I-applicative.

(94)a. E-applicative

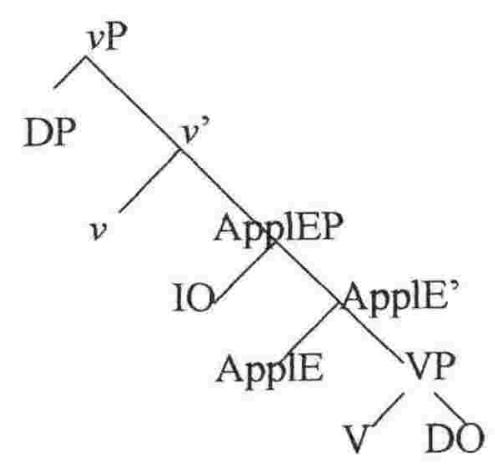

\section{b. I-applicative}

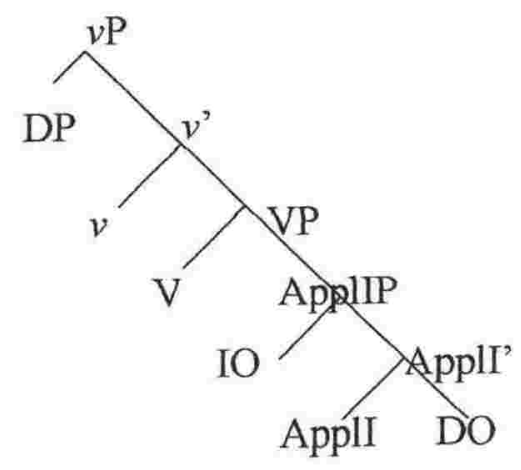

Under McGinnis" approach the "applicatives" belong or are attached to the "IO" (in the sense that both IOs are located at the specifier of the applicative phrase, [SpecApplEP] / [Spec-ApplIP]). In our analysis for BI both so-called applicatives (-kan and $-i$ ) are based at the $v$ head, and thus, are a part of the extended verb projection, and the so-called "IO" always specifies the VP. Nevertheless, McGinnis recognises that there are two distinct structures representing two distinct applicatives that have a wide range of syntactic consequences. McGinnis notes that the structure (94b) above has been proposed by Pesetsky (1995, see below). In the above structures each applicative head raises as a part of the verb raising operation. In (94a) the verb head raises, picks up the applicative 
head, and the two heads then adjoin at $v$. In (94b) the applicative head raises, picks up the $\mathrm{V}$ head, then the two heads adjoin at $v$. That is presumably why the two applicatives have different positions relative to the aspect head in the verb complex of Kinyarwanda, (95), although both are to the right of the verb.

(95)a. E-complex:

a-rá-som-er-a

SP-PRES-read-APPL-ASP 'BE reading something for somebody'

b. I-complex:

á-r-fig-ir-á-ho

SP-PRES-study-ASP-LOC 'BE studying something at a LOCATION'

(McGinnis 2001: 334)

In (95a) what is glossed as applicative precedes the aspect head, whereas in (95b) the locative follows the aspect. Assuming a mirror image analysis (for instance, Baker 1988, Pesetsky 1995), it appears that both applicatives are in fact higher than the verb, although, in (95a) it is lower than the aspect head, whereas in (95b) it is higher. If the surface ordering were treated as mirror image the corresponding structures would be as (96a) and (96b), respectively.

(96)a. E-applicative

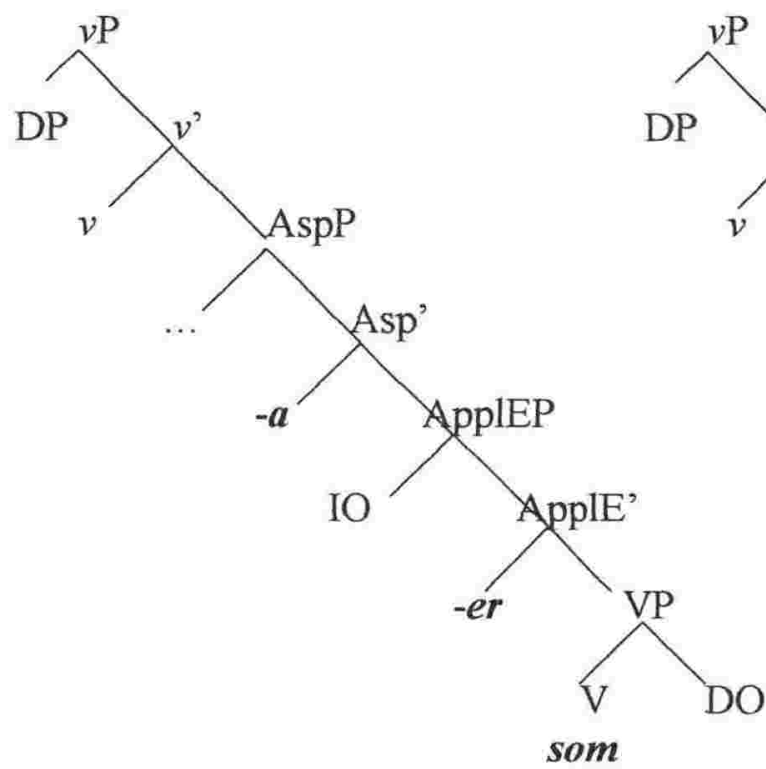

b. I-applicative

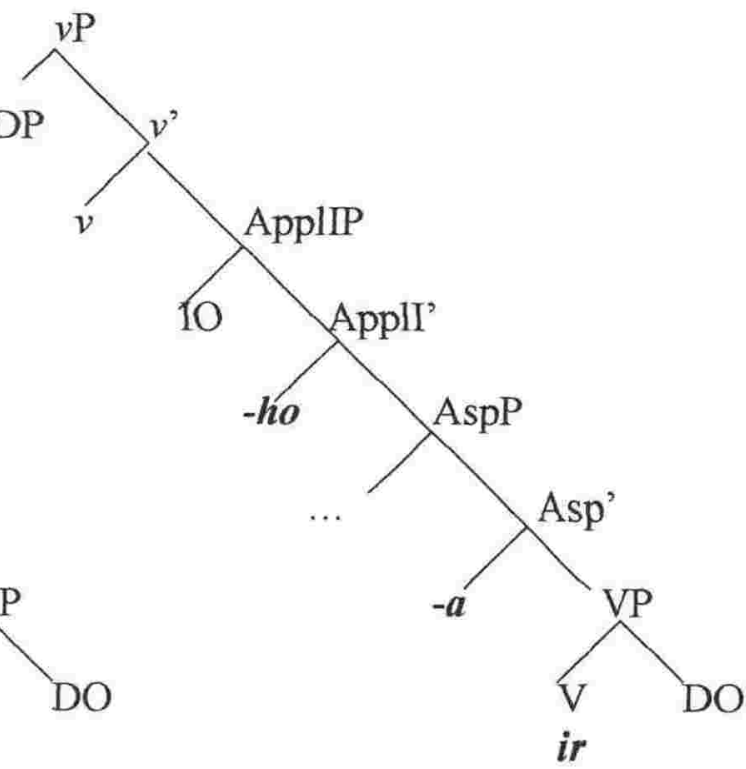


In either case, the IO is selected by the verb bearing different applicative heads: in (96a) the IO is selected by the verb with -er, and in (96b) by the verb with - ho. I shall point out that (96a) corresponds to (94a) for hierarchical ordering, but (96b) is different from (94b). Both verbs, in (96a) and (96b), bear the aspect head ( $-a$ is presumably the same with $-a$ ). The occurrence of these different applicative heads, I assume, is what makes it possible for the IO selection. The most important point to note is that McGinnis' data that yield structure such as (96a) correspond to the BI "illusive DOC" (sub-section 4.2.3.3, with the covert preposition untuk 'for', thus of the kan-aspect, or "benefactive" in McGinnis' data) and the data for (96b) correspond to the BI with $i$-aspect, which, as I mentioned earlier on, commonly termed also as a "locative suffix". The BI structures I propose are different from McGinnis's structures (94a,b) (see section 4.3.3 below).

The data presented by McGinnis (2001) for (96a) correspond to the BI data of the kan-aspect with transit path of change, where the preposition untuk 'for' is optional at PF. McGinnis' data for the structure (96b) correspond to the BI data of $i$-DOC. For the BI structures, however, there is no reason to assume two different positions of the $v \mathrm{P}$-aspect "heads" (following Chomsky 1995, Baker 1997, Radford 1997, Hale and Keyser 1998, Travis 2000, I treat each $v \mathrm{P}$-aspect as a functional head adjoined at $v$ ). Recall also that both BI suffixes characterise transitivity. What is shown as a DOC in Kinyarwanda, $(94 a) /(96 a)$, is in fact not a true DOC in BI (As I have argued, we cannot have a true DOC with the kan-aspect).

\section{Pesetsky’s (1995: 197-198, 256) DAC-DOC}

The main notion in Pesetsky's theory is the existence of "zero" prepositions, where zero means "unpronounced", in the sense that the $\mathrm{P}$ head is projected regardless of whether the preposition is zero/unpronounced or otherwise. When it is zero, the preposition is [+affix] and thus must be affixed to the main verb. This affixal zero preposition is notated as " $G$ affix". Pesetsky proposes different structures for the English DAC-DOC alternation, (97a) below is the DAC, and (97b) for the DOC. Note that in (97b) the head P is 
projected but zero, i.e., the preposition to is unpronounced. When it is pronounced, the derivation is illegitimate, (97c).

(97)a. The basic DAC à la Pesetsky for give a toy to John

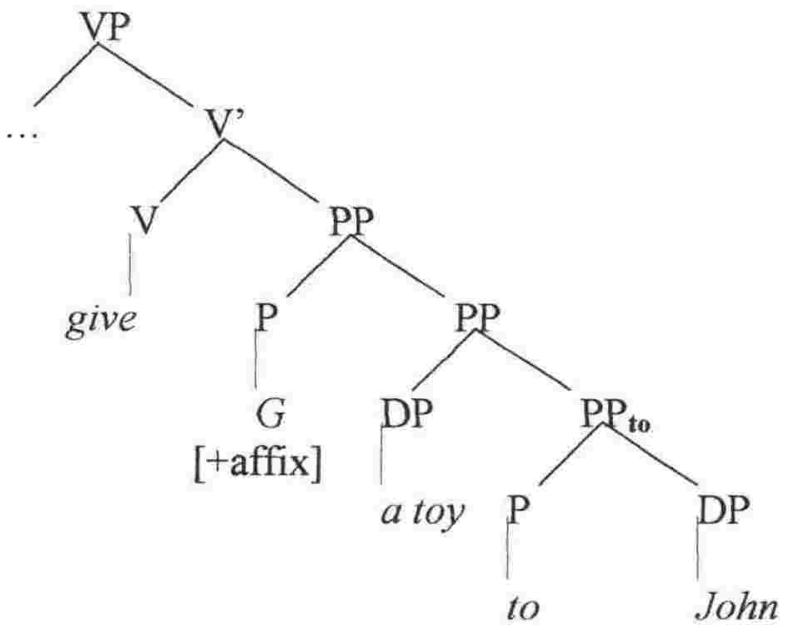

(Pesetsky 1995: 256)

(97)b. The basic DOC à la Pesestky for give John a toy ${ }^{3)}$

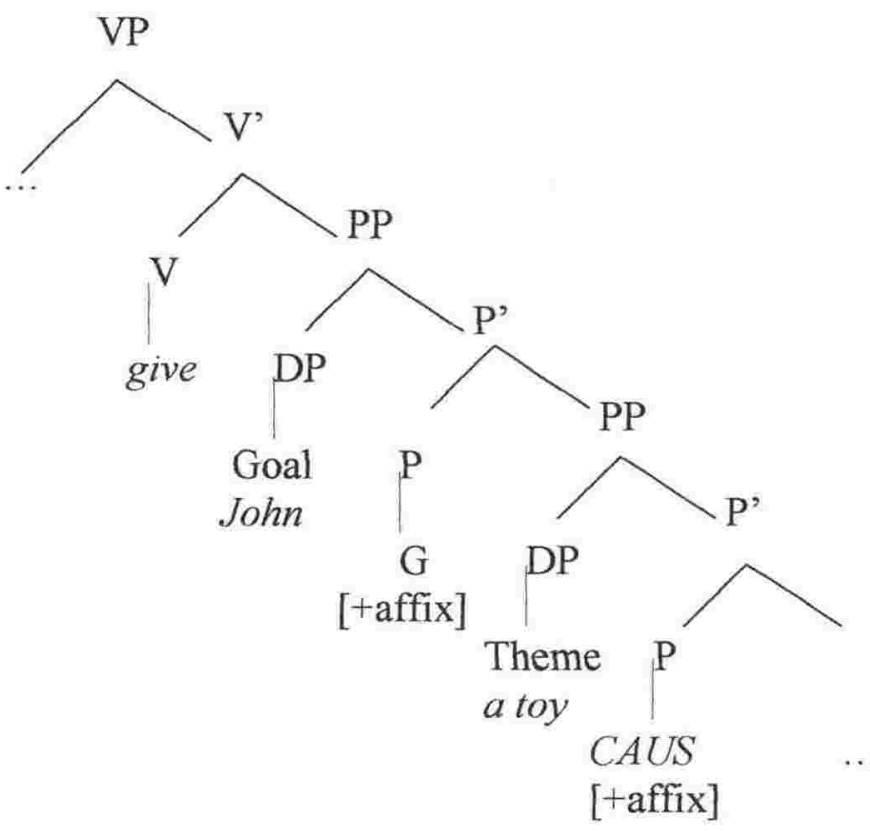

(Pesetsky 1995: 197)

3) The empty slot at the bottom of the tree is designated for "CAUSERs". These CAUSERs include AGENT and "THEME", and they are "external" arguments, Pesetsky's style. Under the present analysis what Pesetsky calls a "THEME" is a "CAUSER" (as against volitional AGENT), that is, in Pesetsky's analysis the news in The news anoyed John is notated as THEME. However, under Pesetsky's analysis, a toy in $(97 \mathrm{a}, \mathrm{b})$ is also a THEME. No definition is given with respect to the terminology. 
(97)c. * give John to a toy

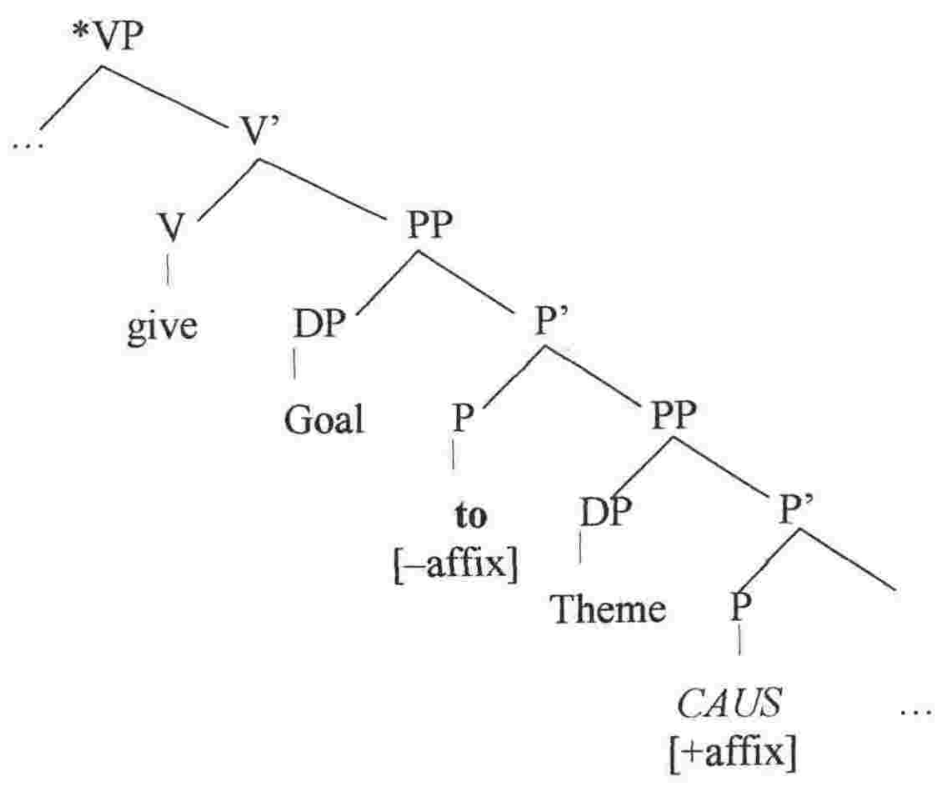

According to Pesetsky's theory, in (97c) CAUSE from the lowest head $\mathrm{P}$ has no acceptable way of moving to give because the [-affix] head blocked its movement and the structure does not have a legitimate outcome (which would violate the Head Movement Constraint). Of interest for the present work is the use of a zero preposition that makes the derivation legitimate for both DAC and DOC. In Pesetsky's analysis for the English DAC (97a) the [+affix] preposition is PP-adjoined, whereas in the English DOC (97b) this affix is located between the GOAL and the THEME. The present analysis argues that the head $\mathrm{P}$ in DOC simply does not exist (i.e., not just "zero" or "unpronounced"), which makes the difference between the DOC and other structures with the $i$-aspect. It is not that the preposition is optional, as defined by Pesetsky's "zero morpheme". In the BI $i$-DOC the sister of the verb in the lower shell is a DP rather than a PP. For the kan-aspect, however, as I have mentioned earlier on (sub-section 4.2.2.3), in BI the preposition untuk 'for' is sometimes unpronounced (at PF) - only in the case of transit path of change. 


\subsubsection{The basic structures of the BI $i$-aspect}

We shall now return to the BI $i$-aspect. I have adopted Arad's (1995) structure (92b) for the BI $i$-aspect (presented as structures (89)-(91) above). We must bear in mind the (only) difference between the BI $i$-DOC and other BI structures with the $i$-aspect, namely, the non-occurrence of a PP in the $i$-DOC as discussed in sub-sections 4.2.3.1 and 4.2.3.2. The basic structures should look like the following, (98a) for the $i$-DOC, (98b) for the "common" $i$-vP, and (98c) for the $i$-aspect with single internal argument.

(98)a. BI $i$-DOC:

b. BI common $i-v \mathrm{P}$ :

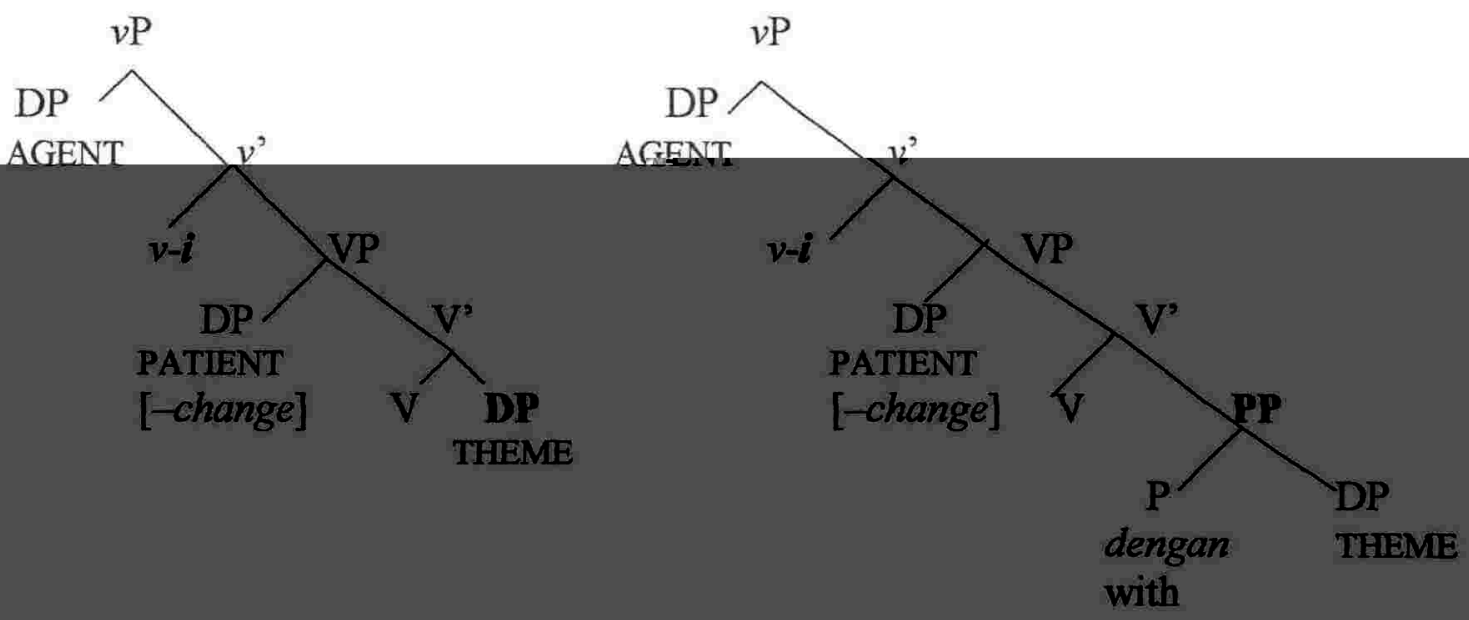

c. $i-v \mathrm{P}$ with a single internal argument:

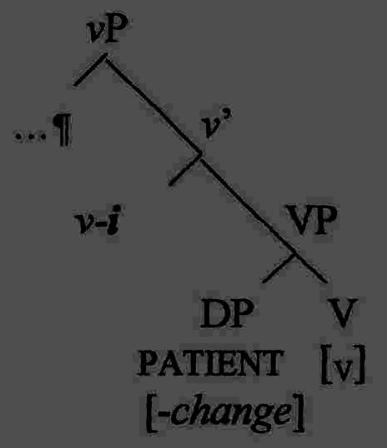

T: possible occupant at [Spec-vP]:

1. AGENT e.g., (2a), (7b), (8b)

2. [-volition] 'AGENT-Experiencer' e.g., (47d), (48d)

3. no occupant (4.2.1, (36))

e.g., "coconut fall (on) the roof"

In all the structures (98) [Spec-VP] has a PATIENT interpretation and a Move operation of $V$ to $v$ is involved, resulting in the transitive $v-i$. The variations we have in (98) are the 
result of idiosyncrasies of the verb. For the verbs send/give/lend, i.e., the BI $i$-DOC, (98a), there is no preposition introducing the THEME. The $v \mathrm{P}$ structure (98b) is for the load/spray types of verb. For the psych-predicates of fear verb group and other monotransitive predicates only one internal argument is shown, (98c).

In sum, I have shown the suffix $-i$ as based at the head $v$ (or adjoined, except the adjunction is not shown at $v$ ' for simplicity reasons), because with the $i$-aspect the verb is always transitive, just like kan-predicates. This is not to suggest that both suffixes are "transitivisers" as has been previously suggested. The structures (98) above show correlations: with the $i$-aspect [Spec-VP] is a PATIENT-object, and thus all are different from the kan-aspect discussed in Chapter 3, where [Spec-VP] is a THEME-object.

\subsubsection{Alternative analyses of DAC-DOC}

There are, of course, other logically conceivable analyses of DAC-DOC in the literature beside those cited in the previous sub-section. Three analyses will be briefly presented here with different reasons for each. (I) I include Larson (1988) here not just because his DAC-DOC analysis that has formed the base for the present day's vP-shell, but also because he notes that in languages other than English, there are what he terms "registration markers" that motivate the verb raising. We have seen that in BI we have two different "registration markers", the suffixes -kan and -i. (II) Bowers (1993), for his two distinct interpretations of DAC-DOC alternation. (III) Den Dikken (1995), because he analyses the BI suffix $-k a n$ as a particle, which according to him is the same as the English particles.

\section{Larson's (1988) DAC-DOC}

Under Larson's analysis, in the derivation the THEME of DAC (99a) below is demoted from $[$ Spec-VP] to the bottom of the structure of DOC (99b) as an adjunct (V'adjunction) just like the PP by-phrase in passives - i.e., (99b) is derived from (99a). That way the GOAL can be promoted from the verb's complement position to replace the 
demoted argument THEME. The operation resembles a passivisation in that era - in the framework that held passivisation involved demotion and promotion of arguments.

(99)a. DAC:

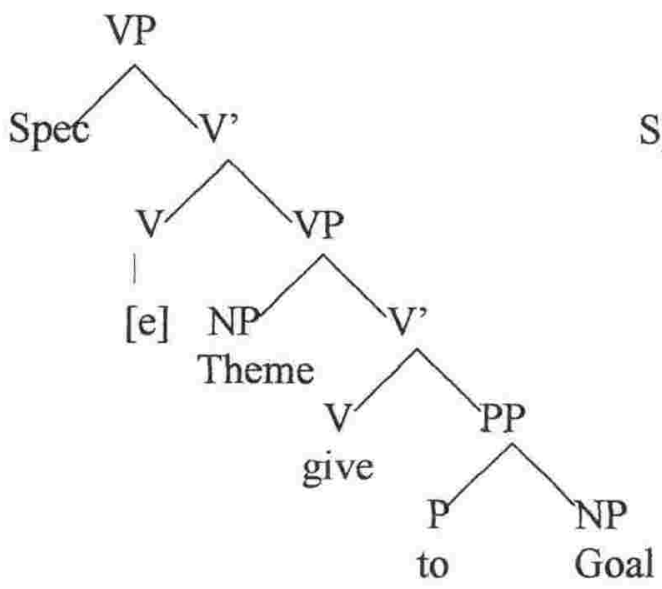

b. DOC:

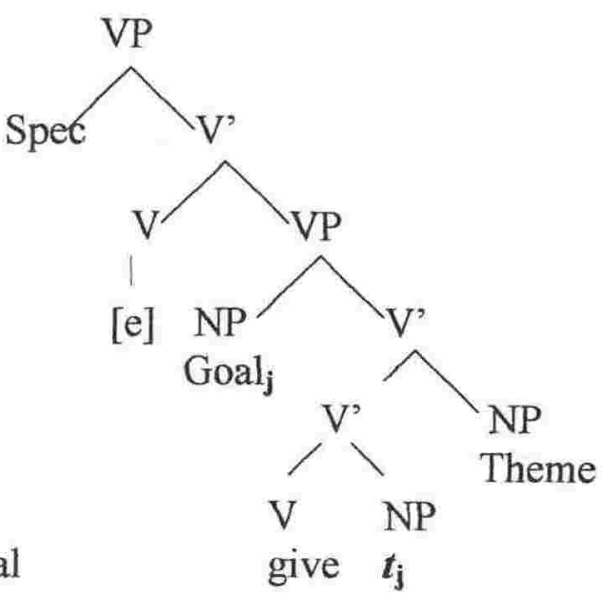

The lower VP of (99a) is passivised to become the lower VP of (99b), involving a V'adjunction. In Larson's analysis, the THEME in (99a) is demoted so that the [Spec-VP] position can be used to accommodate the promoted GOAL, as shown in (99b).

If we adopted (99b), in BI the upper V has to have the suffix $-i$. Likewise, (99a) has to be affixed with -kan. These two suffixes can serve as what Larson calls "registration markers". With these two markers, therefore, the so-called "VPpassivisation" is unnecessary. Essentially, as an end result, the structures $(99 \mathrm{a}, \mathrm{b})$ are not much different from Arad's diagrams (92a,b) above, except for the derivational relationship.

In Arad's (1998) analysis the GOAL at [Spec-VP] is selected by the head " $x$ ", which is $v_{-i}$ in BI. In Larson's (1988) terms, the THEME is demoted from [Spec-VP] down to the bottom NP. The GOAL is raised from the complement position, sister of V, to the [SpecVP]. This demotion and promotion of arguments is plausible only if we analysed the $\mathrm{DOC}$ as derived from the DAC or vice versa. In addition, of concern here is the 
movement from a theta position to another theta position. Thus, Arad's analysis is more consistent with views of uniqueness of argument-role positions.

\section{DAC-DOC à la Bowers (1993: 643-644)}

Bowers (1993) presents two distinct interpretations for each construction, (100b) for DAC and (101b) for DOC.

(100)a. John gave the book to Mary

b. The book belongs to Mary

According to Bowers, (100a) is "the lexicalized causative form of a surface sentence" such as (100b). Likewise, (101a) below is "the lexicalized causative form of a surface sentence" such as (101b).

(101)a. John gave Mary the book

b. Mary has/owns the book

Both the DAC and the DOC are conceived as bearing [+cause], (102).

(102)a. John cause the book give to Mary

b. John cause2 Mary cause1 the book give

In each case in (102) the verb give raises to where cause is. But only in the DAC the tranlocation/locative concept is projected, shown in (103a) with the sublexical [GO]. Whereas for the DOC, the structure bears either the sublexical [HAVE], (103b), or [WITH], (103c), based on the interpretation such as (101b) above. 
(103)a. DAC, with locative concept:

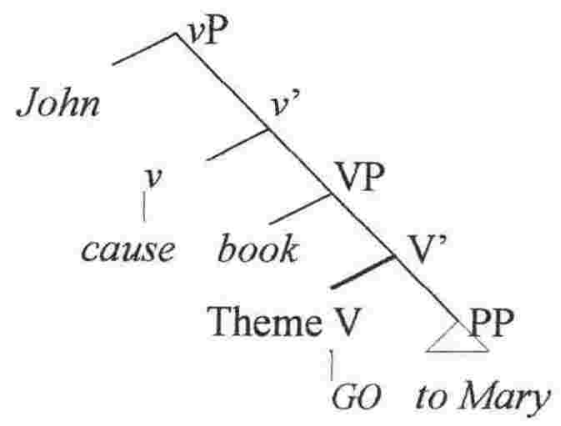

b. DOC:

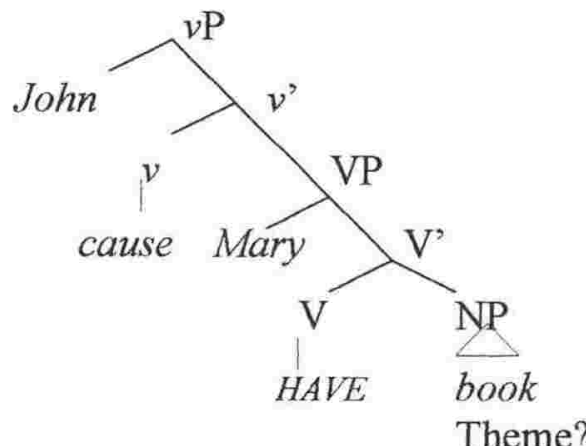

c. DOC:

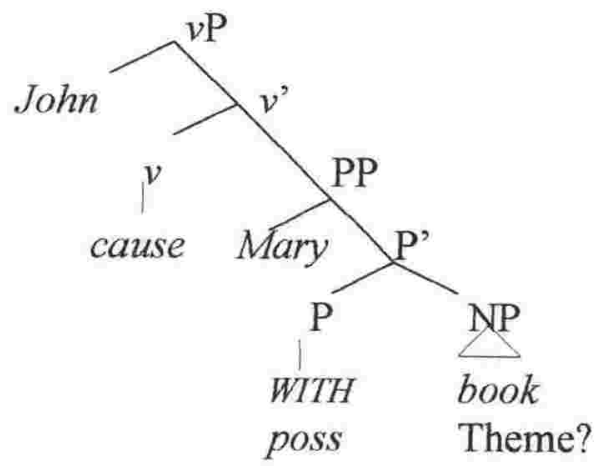

There is an apparent problem in structures (103b) and (103c): the direct object-Theme correlation is not clear. In our analysis the book in the (a) examples of (100) and (101) is a THEME, which is the specifier of VP. In $(103 \mathrm{~b}, \mathrm{c})$ the book is a complement, just like in the structures for with or dengan objects, (98b), 'BI common $i$-v $\mathrm{P}$ '. The structures $(103 \mathrm{~b}, \mathrm{c})$ are not really a "GO-type" event such as (103a), so neither Mary nor the book can be interpreted as a THEME, and here we do not want Mary to be interpreted as a THEME. There is also a question here as to whether [HAVE] and [WITH] could entail change.

\section{Den Dikken (1995: 111-133)}

Den Dikken categorically argues for a transformational analysis of what he calls the dative alternation. He argues for the transformational relationship between prepositional dative and double object constructions, illustrated in (104). 
(104)a. John sent a package to Bob

b. John sent Bob a package (dative construction)

(double object construction)

He approaches the analysis of examples like $(104 \mathrm{a}, \mathrm{b})$ from the point of view of similar constructions containing a verbal particle, off such as in (105).

(105)a. John sent a package off to Bob

b. John sent Bob off a package

According to Den Dikken

"The behaviour of triadic particle constructions argues for the postulation of a transformational relationship between dative and double object constructions, the latter being derived from the former, but it militates against Larson's (1988) influential implementation of this relationship..."

As a note, Den Dikken argues in his work that the BI suffix -kan is the same as the English off above, namely, the suffix -kan is a particle. He only considers -kan:

"Indonesian has another transitivising affix, $-i$, whose properties are non-trivially distinct from those of $-k a n$, and in some respects resemble those of Dutch bemore closely than -kan. The semantic contrast in (i) is illustrative in this connection:
(i)a. Parto menidurkan Ratna
Parto sleep-KAN Ratna
'Parto made Ratna sleep'
b. Parto meniduri Ratna
parto sleep-I Ratna
'Parto slept with Ratna'

In this pair, -kan seems a "real" causativiser, while $-i$ is like Duth be-in the Dutch rendering of the example in (ib), Ratna besliep Parto. That -kan is nonetheless not to be analysed as a causative morpheme is clear from examples like Parto menuliskan nama saya... [Parto wrote my name (for me)]" (Den Dikken 1995: 233).

The basic assumptions that form the backbone of his analysis are summed up in (106) below. The structures they give rise to are given in (107).

a. The double object construction is transformationally related to the prepositional dative construction [i.e., the DOC is derived from the DAC, WS].

b. The structure underlying dative and double object construction is as in [(107b)]. 
c. The transformation responsible for the derivation of the double object construction is PP-movement into the specifier position of SC2, and on to SpecSC1.

d. The (empty) P heading the moved dative PP is incorporated into the abstract copula heading the triadic verb's SC complement.

(107)a. DAC:

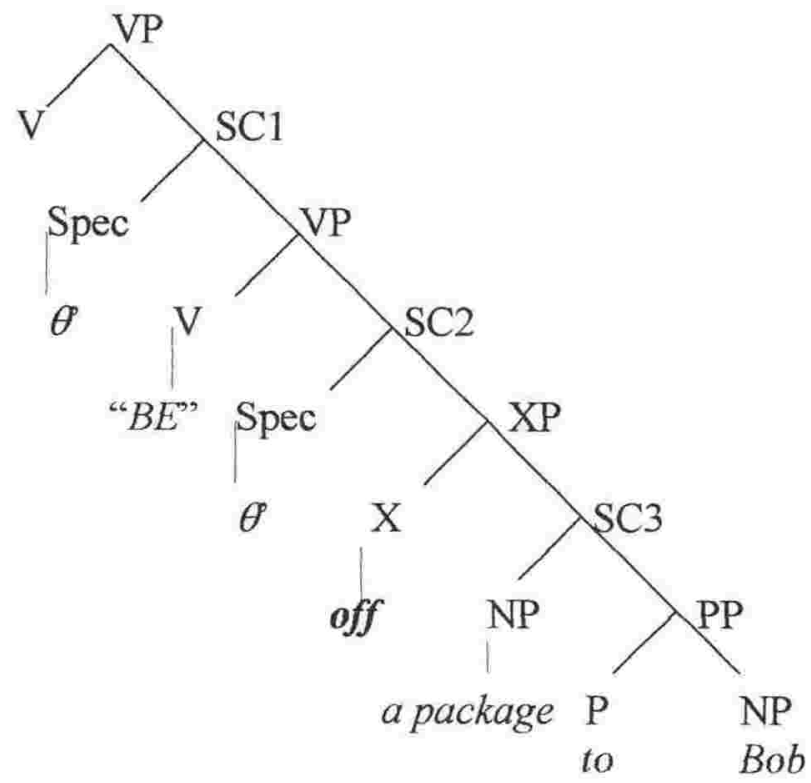

(Note that no VP has a specifier, only the SCs do)

(107)b. DOC:

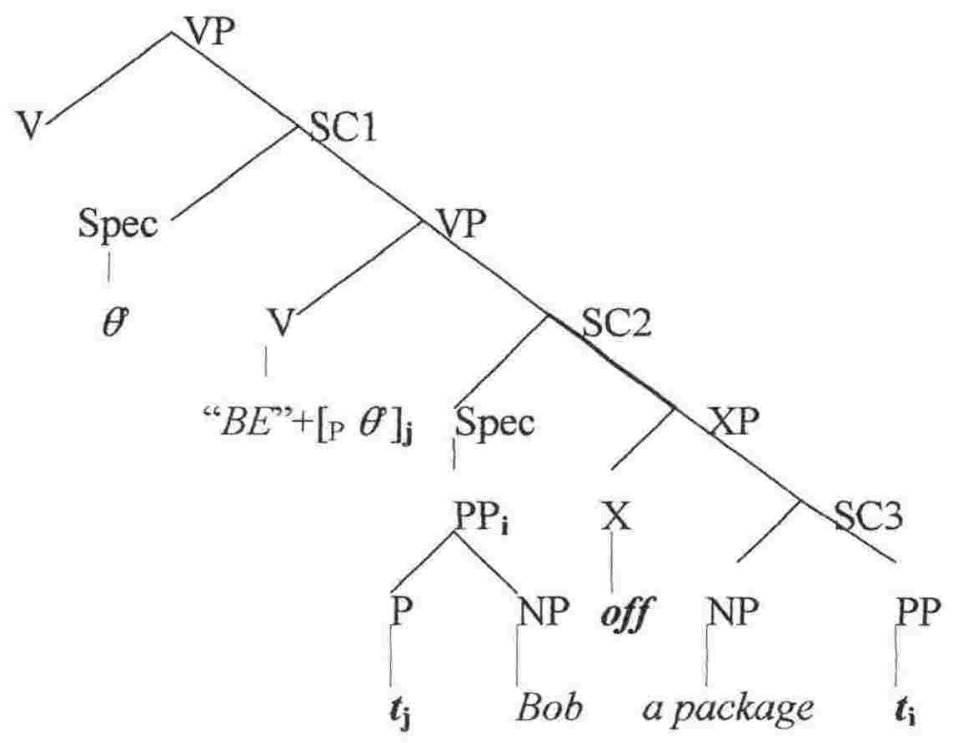


In simple terms, in (107b) the whole PP is moved to [Spec-SC2]. The structure (107b) may work for analysing the English DOC that includes the particle off. If the suffix -kan were "exactly the same" as off as Den Dikken argues, then the DOC cannot derive, because with the suffix - kan the preposition kepada 'to' is obligatory, and thus, in (107b) the node P cannot be "zero". The PP-preposing in (107b) may work with $-i$ instead of $-k a n$ (refer back Larson's DOC (99b) above) but it only proves that -kan is not "the same as the English particle off'. More importantly, Den Dikken's (1995) use of particles to show the true DOC for both English and BI fails to compare like to like: the English example (104b) is in fact the counterpart of the BI $i$-DOC, and we do not have any DOC with the suffix -kan.

I have just said that BI doesn't have DOC with -kan. One has to demonstrate, however, how and why there is no DOC with the kan-aspect. Let us assume that the structure (107b) works only if the suffix - kan is already at V as the target of the verb (send) movement, hence no particle head for BI, and the SCs are unnecessary, consider (108) below. As a warning, the following structure (108) for BI may not be the right one, since the forms used in the BI examples $(109 a, b)$ are those of PF, which I mentioned earlier on as "the not-so-comfortable way of expression". It is not clear as to how we derive the sentences $(109 \mathrm{a}, \mathrm{b})$ from the basic structure with kan-aspect - the structure (108) is not basic, i.e., it has undergone a move operation.

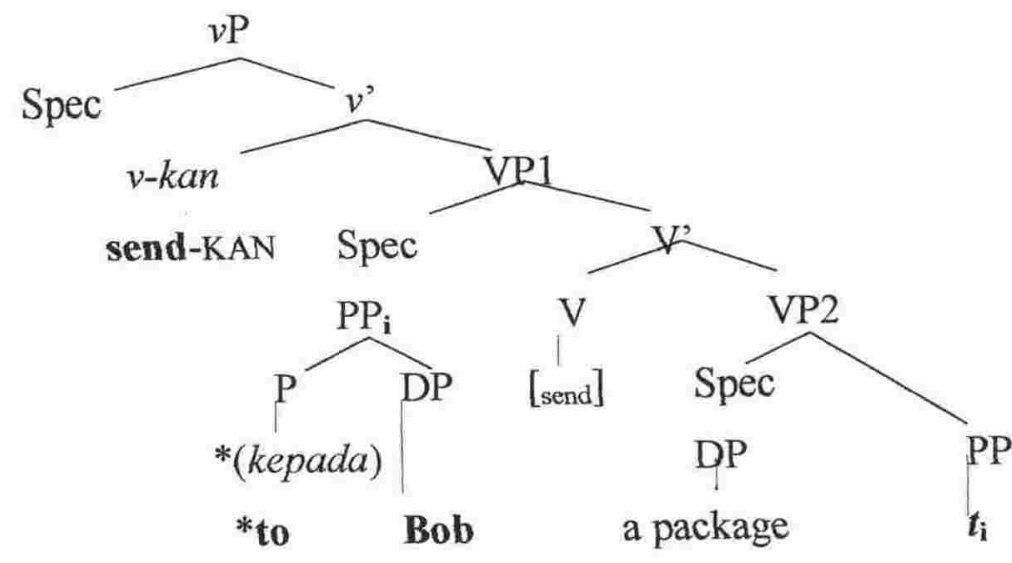


Notice that in (108) the preposition kepada 'DATIVE to' is obligatory (and unacceptable in English), and thus, Den Dikken's analysis as shown in (107b) closely resembles the BI surface "illusive DOC" as discussed in the previous sub-section - as repeated here, for the sentence (109a) below but not for (109b) - both with the kan-aspect.

(109)a. Ibu meN-buat-kan (untuk) tamu se-cangkir kopi mother ACT-make-KAN for guest a-CLASS coffee 'Mother is making for the guest a cup of coffee'

b. John meN-kirim-kan *(kepada) Bob se-buah paket $\mathrm{J}$ ACT-send-KAN to B a-CLASS package 'John sent to Bob a package'

In (109a) the preposition untuk 'for' can be covert but it does not make the form a true DOC, and we call the form an "illusory DOC", which can occur with the transit path of change, (110). If it is not transit, the preposition, like kepada 'DATIVE to' in (109b) is obligatory.

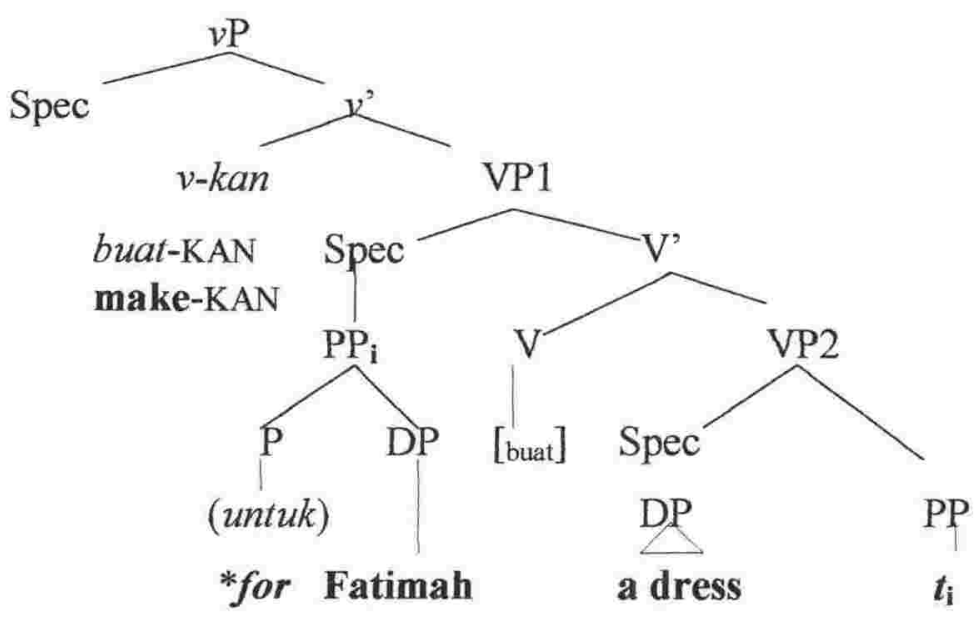

From the BI point of view, Den Dikken's structure (107b) remains DAC, that is, the structure is of course "transformationally related" to the same $v \mathrm{P}$-aspect, and he fails to show the true BI DOC diagram in his analysis. Den Dikken's example $(104 b=111 b)$ corresponds to our $\mathrm{BI} i$-DOC, (111a) below. It is a pity that he does not analyse the suffix 
$-i$, although he states that $-i$ properties "are non-trivially distinct from those of $-k a n$ " (Den Dikken 1995: 233).

(111)a.John meN-kirim-i Bob se-buah paket (BI true DOC, $i$-DOC) J ACT-send-I B a-CLASS package 'John sent Bob a package'

b. John sent Bob a package

(English true DOC)

We shall maintain that the BI $i$-DOC form in (111a) (= the English DOC (111b)) is a separate beast entirely from that of DAC in (104a).

To conclude, it is most sensible to adopt Arad's (1995) DOC structure (92b) for its simplicity. Arad's DOC is also closer to the Larsonian DOC in terms of the uniqueness of argument-role positions, although with a different motivation, i.e., without the so-called VP-passivisation. The BI $i$-DOC structure, however, is only a variant of the structure of the $i$-aspect in general, because DOC falls under the general picture of the $i$ aspect.

\subsection{Summary and remarks}

\subsubsection{Summary}

To conclude the discussion of $v \mathrm{P}$-aspect alternation I will sum up the main points I made:

1. There exist two contrasting $v \mathrm{P}$-aspects in $\mathrm{BI}$; each has its own argument structure. The so-called "location verbs" belong to the kan-aspect, while "locatum verbs" to the $i$-aspect. As indicated by the notation (" $v \mathrm{P}$ "), both forms - one with the suffix - kan and the other with $-i$ - are transitive (4.1.1).

2. Our data show that there are cases where a $v \mathrm{P}$-aspect does not have an alternant, because of the strict requirement that with the kan-aspect the primary internal argument must undergo change, and conversely, with the $i$-aspect the primary internal argument 
mustn't. Thus, we have a simple explanation as to why BI psych-predicates, frighten verbs (Groupl), only take the kan-aspect: because the predicate expresses the final state of change. With BI fear verbs (Group2) it is the inverse, thus the internal argument does not undergo change, and predicates of this group only take the $i$-aspect. There are cases where a predicate belongs to both groups (4.2.2.1). This fact also explains why predicates of common adjectives only take the kan-aspect (4.2.2.2). The kan-aspect encoding a transit path of change does not have an alternant, because the base contains a change component, it cannot take a PATIENT (4.2.2.3). In general, the reason why with some predicates the $\nu \mathrm{P}$-aspect does not alternate falls under the notion of change. I propose that the availability of an argument to occur with a particular $v \mathrm{P}$-aspect plays a crucial role in the derivation.

3. The BI prepositional form DAC belongs to the kan-aspect and the double-object form DOC to the $i$-aspect. The so-called DAC-DOC alternation is a part of the $v$ P-aspect alternation. It is the idiosyncracy of the predicates give/sendllend that makes it possible within the $i$-aspect to have the DOC structure.

4. From points (1)-(3) above, as well as from the discussion in the present work in general, we gain the dichotomy of the related terminologies used in the literature that can be included in the kan-aspect - $i$-aspect distinctions, amongst others:

$\begin{array}{lll}\text { kan-aspect } & v s & \text { i-aspect: } \\ \text { location verbs } & v s & \text { locatum verbs } \\ \text { object-experiencer verbs } & v s & \text { subject-experiencer verbs } \\ \text { DAC } & v s & \text { DOC } \\ \text { change } & v s & \text { non-change } \\ \text { THEME at [Spec-VP] } & v s & \text { PATIENT at [Spec-VP] }\end{array}$

5. The crucial part the two aspects play in derivations is explained in terms of the argument selection - i.e., what type of object is taken or subcategorised for as the complement of the predicate - without suggesting that one type of expression is derived 
from the other. The argument selection argued for in this section is as simple as that kanaspect selects a THEME, whereas $i$-aspect selects a non-THEME PATIENT. It has been shown that the $i$-predicate has a completely different argument structure from that of the $k a n$-predicate. The notion that $i$-predicates are transformationally related to the kanpredicates plays no part in the discussion.

6. The notion that the suffix $-i$ is locative is too narrow, because the suffix is also in complementary distribution with the prepositions kepada 'DATIVE to', dengan 'with', and in some cases there is no PP form - this complementary distribution also supports $\mathrm{P}$ interpretation. Within the predicate with the $i$-aspect there is no shift of location that is interpreted on the primary internal argument; that is why the preposition ke 'LOCATIVE to' cannot be present. Equally, with the $i$-aspect, there is no change of hands implied on the primary internal argument; therefore, the preposition kepada 'DATIVE to' cannot cooccur. The reason why with some predicates the $v \mathrm{P}$-aspect does not alter falls under the notion of change.

\subsubsection{Remarks}

I mentioned earlier on in Chapter 2 that in English the $v \mathrm{P}$-aspect, change in particular, is not morphologically encoded on the predicate. The distinction between $v \mathrm{P}$-aspects is not immediately clear in English. However, Arad (1998) shows in detail that there exist differences in interpretation between the DAC and the DOC. What is argued for in the present work is in fact not completely new, although novel for BI. Cross-linguistically, in the literature there are variations on the same theme. For instance, McGinnis (2001) provides a strong piece of evidence that there are two types of applicative, the one that is related to event structure (E-applicative), and the one that shows individual relations (Iapplicative). Her finding is most welcome for our discussion, since from the beginning of the present work, the so-called BI "applicatives" - marked by the suffixes - kan and - $i-$ are accounted for in terms of contrasts between the kan-aspect and the $i$-aspect. Larson (1998:373-374) suggests that what are commonly known cross-linguistically as applicative morphemes are in fact "registration markers" to "specify a manner or location role [of the verb]" which I have proposed in the present work as vP-aspects; Pesestky 
(1995) argues that there is what he calls a "zero morpheme" in English. This zero morpheme is $[+$ affix $]$ because it is zero. This affixal zero morpheme motivates the verb to raise to the upper $v \mathrm{P}$-shell. Radford (1997:201) suggests an "abstract causative light verb $\varnothing$ " for English, which is "affixal in nature (and so a strong head)". We have shown that what Radford calls " $\oslash$ " in English has two corresponding suffixes in BI. Baker (1997), based on Travis [1994] (2000), suggests that a functional head indicating a verbal aspect is needed at $v$ P. Travis calls this functional head "inner aspect". Baker's (1997) suggestion is based on the contrast between the English To load the hay on the truck and To load the truck with hay, considering the fact that the DOC * To load the truck hay cannot occur. He suggests that some languages other than English have a marker to indicate the distinction. The present work has shown not one marker, but two: the suffix $-k a n$ for the former sentence, and the suffix $-i$ for the latter. 


\section{Chapter 5}

\section{Higher layers of derivation, above $v \mathbf{P}$}

\subsection{Overview}

In Chapter 3 and Chapter 4 I discuss two different derivations involving the $v \mathrm{P}$. The main discussion in Chapter 3 is about the $\mathrm{BI} v \mathrm{P}$-aspect that encodes change, represented by the suffix -kan. When the kan-aspect is present, the argument at [Spec-VP] has a THEME interpretation. Chapter 4 discusses the $i$-aspect, where the argument at [Spec-VP] must be interpreted as a PATIENT, because the $i$-aspect does not encoded change. I have included in both chapters the discussion of BI unaccusative and unergative structures. The relevance of the discussion in the previous chapters will be apparent for the present chapter, in particular with respect to the BI Voice Phrase.

This chapter proposes the use of VoiceP, an intermediate layer between the AspP and the $v \mathrm{P}$. The present chapter is divided into two main parts. Partl discusses the BI VOICE and transitivity. In particular, I will discuss how the prefixes $m e N$ - and $d i$ - relate to the surface subject. Other morphological realisations of Voice heads, ber- and ter-, will also be included (sections 5.1 and 5.2). Part2 (section 5.3) discusses the layers that precede the VoiceP. The first layer to be discussed is the BI AspP, in particular the use of MODALs as realisations of the BI $v \mathrm{P}$-external aspect. In the derivation the MODAL merges with the VoiceP (sub-section 5.3.1). Sub-section 5.3.2 is concerned with the BI Whextractions, comparing these extractions with the BI Relative Clause. 


\subsection{BI VOICE}

\subsubsection{The Voice Phrase}

It has been suggested in the literature that there exists a functional category between the $\nu \mathrm{P}$ and the IP crosslinguistically (for instance, Ouhalla 1991, Cinque 1999), termed as $[ \pm$ PASSIVE]. In this sub-section I propose a Voice head as a functional category that precedes the $v \mathrm{P}$, as has also been proposed by Pylkkänen (2002). I will also propose following Cinque (1999) that the Voice head is separate from the head I ("INFL"), heading its own maximal projection. This latter proposal is in line with Ouhalla's (1991) analysis of passives, which argues that crosslinguistically, PASS(ive) always appears adjacent to the verb in the derived verbal complex while other functional heads have parametric variation with respect to their order of appearance (Ouhalla 1991: 94). In Ouhalla's terms, whether the verb complex (i.e., a verb which has been raised and inflected by the PASS head) raises further into the Tense head or not depends on the categorial feature of PASS head: verbs with "morphological PASS" will raise to join the Tense or Agr, or both, while verbs with "periphrastic PASS" (like the English or Romance PASS) remain in the Voice $^{\circ}$ position. ${ }^{1)}$ In other words, in languages like English and Romance the verb bearing the Voice marker does not raise further. ${ }^{2)}$ For both types, however, there is one common step in the derivation of both morphological and periphrastic passives, namely, the verb movement from $v$ of $v \mathrm{P}$ to $\mathrm{PASS}^{\circ}$. A similar proposal has been put forwards for some periphrastic types of PASS by Bowers (2002), although he uses a different terminology.

Bowers (2002: 183) proposes that the functions of $v$ be split into "Pr" (Predication relation) as the higher head and "Tr" (Transitivity) as the lower head.

\footnotetext{
1) Ouhalla (1991: 88ff.) distinguishes two types of PASS head: morphological passives ("passives which consist of a single verbal complex inflected for the passive morpheme") and periphrastic passives ("passives which consist of an auxiliary and a participle"). Ouhalla assumes that the former have the categorial feature [+V], while the latter [+N] (Ouhalla 1991: 95). In Pylkkanen's (2002: 76-78;90-91) terms, in English the Voice head and CAUSE are a unit syntactically only: they cannot combine with each other semantically.

2) The Minimalist approach offers the alternative that the movement of $v$ to the PASS head may be implemented at LF (Spell Out).
} 
The former assigns a $\theta$-role in its specifier position and the latter does not, but may contain a probe with $\phi$-features and assign accusative Case. Bowers (2002) suggests that " $\mathrm{Pr}$ " is used instead of $v$ (although sometimes notated as " $v / \mathrm{Pr}^{\prime}$ ) and " $\mathrm{Tr}$ " is optionally inserted, because it occurs only in transitive predicates. ${ }^{3)}$ Bowers (2002) maintains that the functional category "Pr", as a generalisation of the "light verb" $v$, represents the "predication relation" (which he defines as "a special subject relation to the predicate"). In Bowers (2002: 184) analysis, Tr is "a distinct substantive category that may optionally be selected by Pr, hence is located between Pr and V'. Bowers' (2002: 186) proposed structures are shown here in (1): (1a) for the transitive, (1b) for the unergative, (1c) for the unaccusative, and (1d) for the impersonal transitive.

(1)a: Transitive

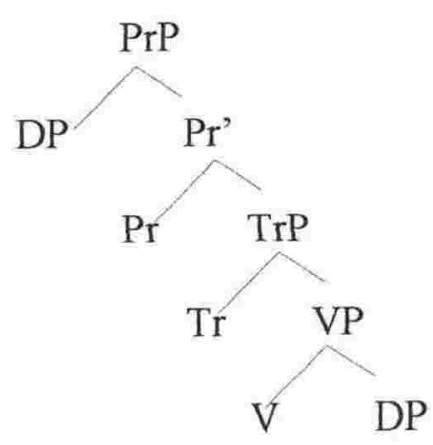

(1)c: Unaccusative

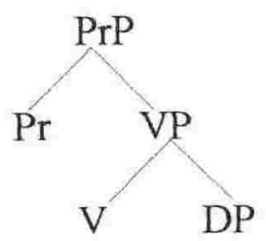

(1)b: Unergative

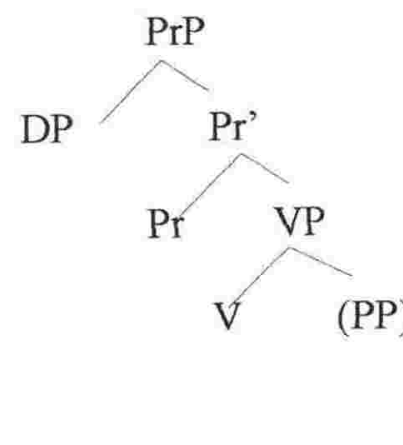

(1)d: Impersonal transitive

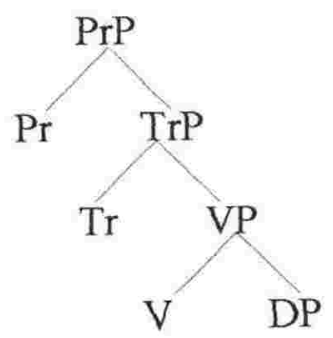

3) Bowers (2002: 183, footnote 1) acknowledges Kratzer's (1993) use of the term "Voice" for Pr. As indicated in the present work, his analysis of PASSIVE is what Ouhalla (1991) calls a "periphrastic type" of PASSIVE. 
In Bowers' (2002:185-186) theory,

"transitive verbs are those with an external argument in Pr [sic.] that selects $\operatorname{TrP}$; unergative verbs are those with an external argument in $\operatorname{Pr}$ that selects VP; unaccusative verbs are those without an external argument in Pr that selects VP".

Structure (1d) is that of a transitive that has no external argument (i.e., impersonal transitive). In terms of the structures proposed in (1), it would appear that transitive verbs are those with "an external argument in [Spec-PrP]" and "Pr selects TrP/VP". The structure shown in (1a) above appears to have been simplified, that is, not each phrase is shown to project a specifier. Clearly, the specifier of Tr in (1a) is projected: Pr has Spec (selected by Pr), but Tr doesn't (I assume that, from (2), the Specs are projected because the heads get checked). This is evident from the passive analysis of the transitive (1a), as (2) below (Bowers 2002: 210).

(2) Passive

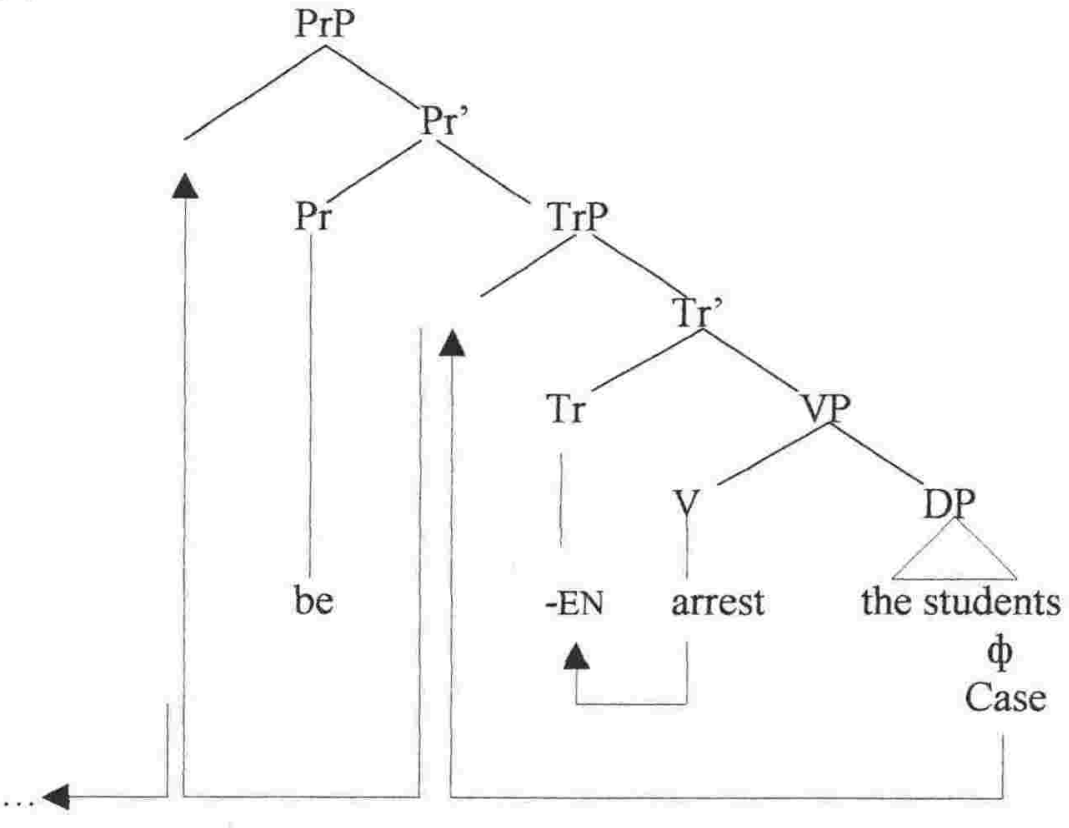

As a note, in Bowers' (2002) analysis, the object the students in (2) is obligatorily assigned nominative Case by $\mathrm{T}$ after successively raising to [Spec- $\mathrm{TrP}$ ], and then to [Spec-PrP], ending up in [Spec-TP] where its Case feature can finally be valued and deleted by the probe in T (the TP is not shown in the diagram). Bowers (2002) leaves 
open the question of whether Tr has an EPP-feature when it is realised as -EN. If it does not, then the thematic object will move directly to [Spec-PrP]. The object the students, in (2), is forced to raise successively up, because there is no probe in $\operatorname{Tr}$ with matching $\phi$ features that can value and delete its uninterpretable Case feature. In an ACTIVE sentence Tr contains a probe (with $\phi$-features), but in a PASSIVE sentence it contains the passive morpheme -EN instead of $\phi$-features. The insertion - because in Bowers' terms $\mathrm{Tr}$ is optional - of the TrP between the Pr and VP, in the structure (1) or (2) gives a striking resemblance to what is being proposed in the present work, namely, the projection of $v$ between Voice and VP. In effect, Tr is our $v$ transitive.

I have argued in the previous chapters that the BI $v$-kan and $v-i$ are always transitive, which fits well with what has been suggested in the literature that $v$ represents transitive or potentially transitive verbs (for instance, Chomsky 1995, Hale and Keyser 1998, amongst others). In this chapter I propose after Ouhalla (1991) and Cinque (1999) that the functional category Voice be added to precede the $v \mathrm{P}$ - rather than instead of the transitive $v$ as Bowers (2002) has suggested (even though the end-result is the same). The apparent advantage of having an additional functional head - the added Voice head in our case, or the added Tr head in Bowers (2002) analysis - is that the ACTIVE/PASSIVE derivations can be accounted for without any argument demotion or/and promotion. Most importantly, the interpretation of external (AGENT/CAUSER) and internal arguments (THEME and PATIENT) can be represented systematically within the $v \mathrm{P}$ (Hale and Keyser 1993, 1998, Arad 1998, amongst others, show "thematic relations" in $v \mathrm{P}$, Chomsky 1995 terms the $v \mathrm{P}$ the "Base Structure" or "Thematic Structure"). My main aim for the present section is to show that the "thematic relations" can be kept intact even though the paths of derivation can be different, as for instance in ACTIVE and PASSIVE derivations (with the $\mathrm{BI}$ prefixes $m e N$ - and $d i$ - respectively), on a par with what I have argued for in Chapter 4 with respect to the DAC/DOC derivations. Without an additional Voice head, externalinternal domains of the $\nu \mathrm{P}$ are confused, as in the following analysis of BI ACTIVE (4a) and PASSIVE (4b) structures which are taken without any modification from Postman (2001/2002), which she claims after Bowers (1993). Postman provides the basic clause structure of BI, as in (3). 
(3) Basic clause structure of BI à la Postman (2001: 408)

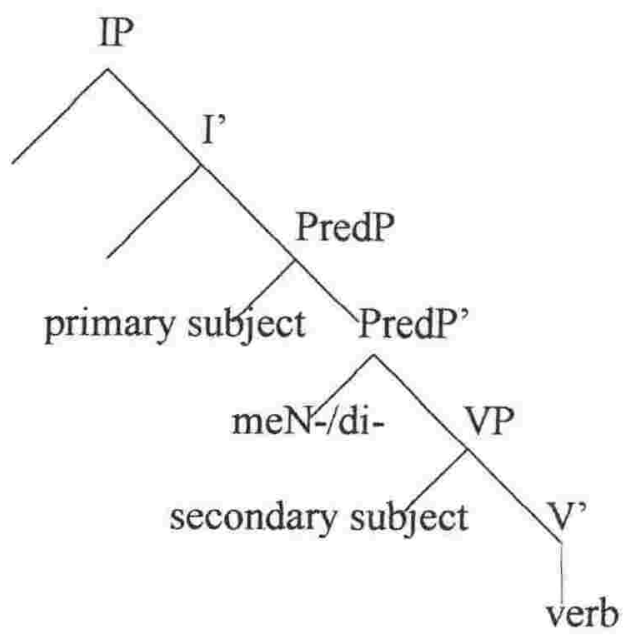

In Postman's structure for BI (3) the heads $m e N$ - and $d i$ - are positioned between the "primary subject" (i.e., external argument) and the "secondary subject" (i.e., internal argument) - both terms are adopted from Bowers (1993). The ACTIVE and PASSIVE structures are derived by selecting a Pred head, either meN- or $d i-$, then by raising one of the "subjects" (primary or secondary) to the [Spec-IP], (4a) and (4b) respectively.

(4)a. ACTIVE (Postman 2001: 408)

Nando mendorong Allen

Nando AT-push Allen

'Nando pushes Allen'

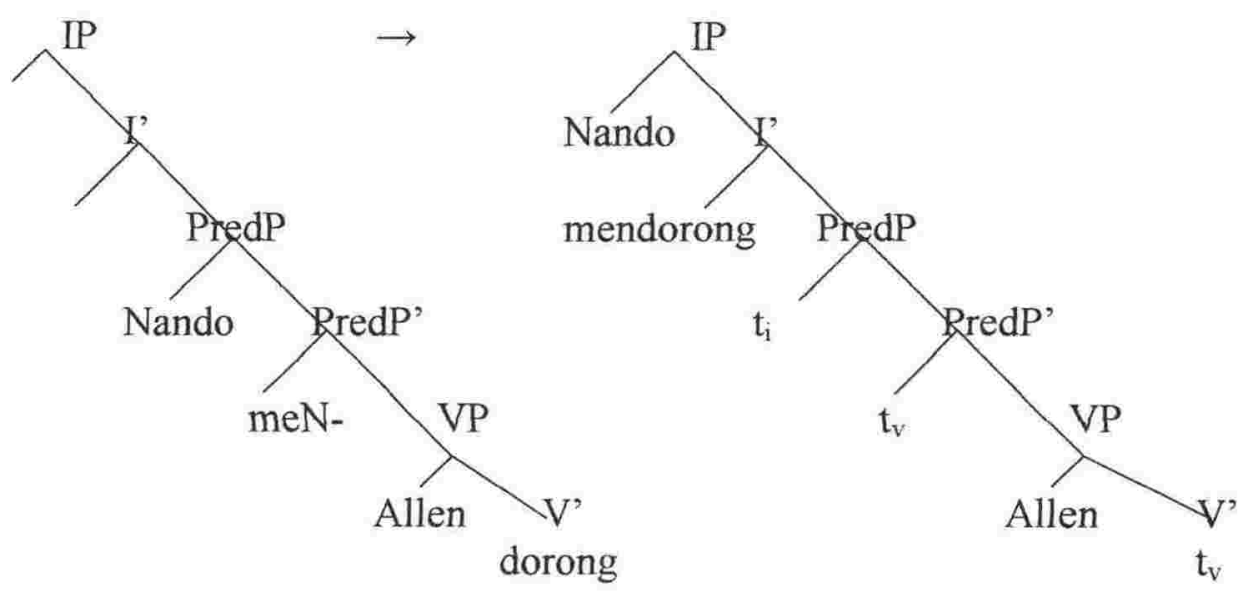


(4)b. PASSIVE (Postman 2001: 409)

Susan dicium Nando

Susan PT-kiss Nando 'Susan is kissed by Nando'
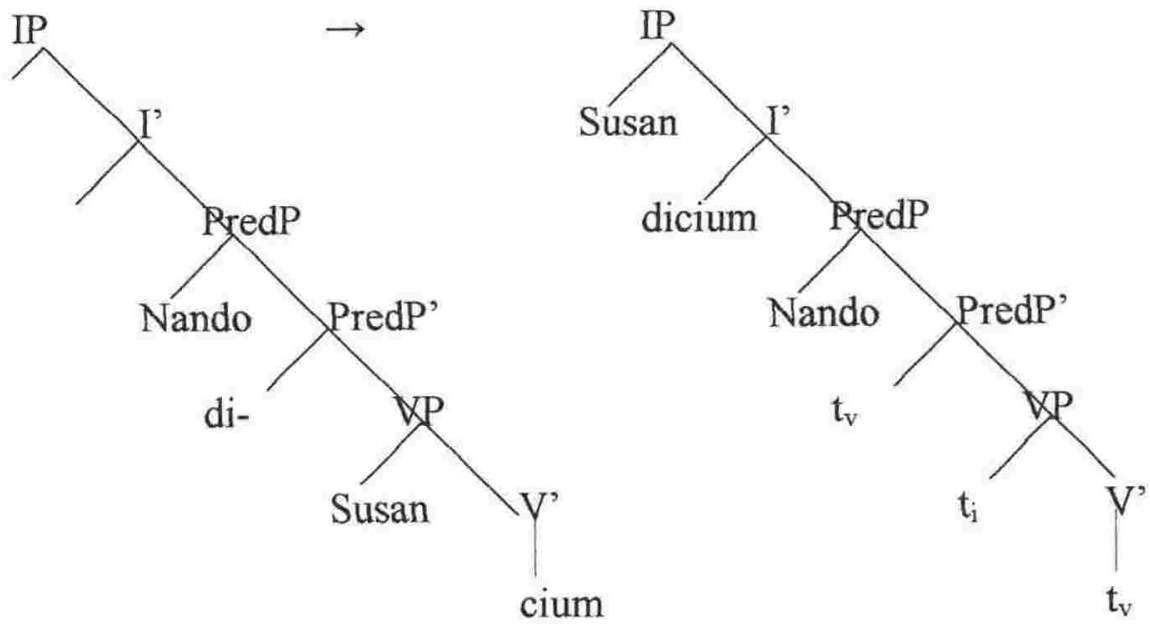

From Postman's analysis (3)-(4) above it is not clear what sort of constraint, if any, is used to prevent the unwanted derivations such as (5a) below as against (4a), and (5b) as against (4b). Note that according to Postman in (4b) "Susan can move past Nando since verb raising renders both NPs equidistant from [Spec, IP]" (which Postman claims after Chomsky 1995).

\section{(5)a. ACTIVE}

The intended derivation:

Nando mendorong Allen

Nando AT-push Allen

'Nando pushes Allen'

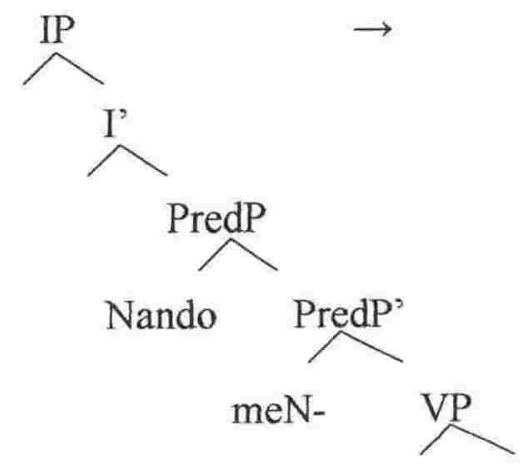

Allen
The possible result:

Allen mendorong Nando

A AT-push $\mathrm{N}$

'Allen pushes Nando'

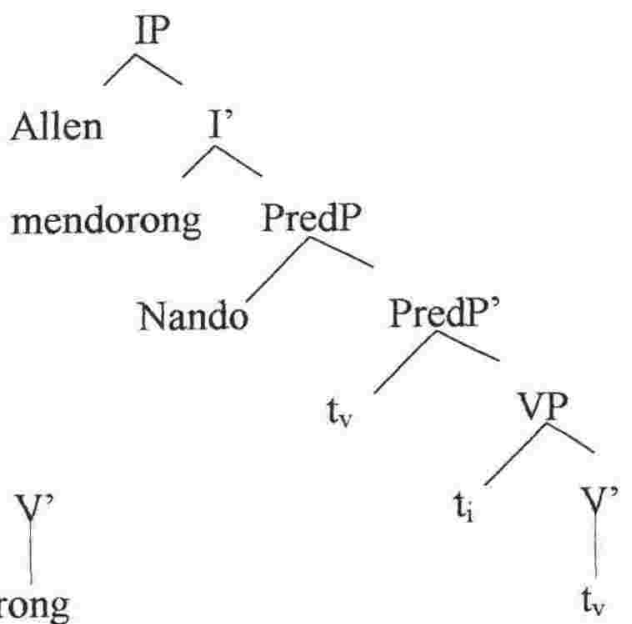


The resulting derivation in (5a) is 'Allen pushes Nando' and not 'Nando pushes Allen', but according to the basic clause structure (3), both are legitimate, and the movement of Allen past Nando is legitimate because both subjects are equidistant from [Spec-IP]. Another unwanted derivation can also occur instead of (4b) as in (5b), without involving the equidistant theory.

(5)b. PASSIVE

The intended derivation:

Susan dicium Nando

Susan PT-kiss Nando

'Susan is kissed by Nando'

The possible result:

Nando dicium Susan

$\mathrm{N} \quad$ PT-kiss S

'Nando is kissed by Susan'

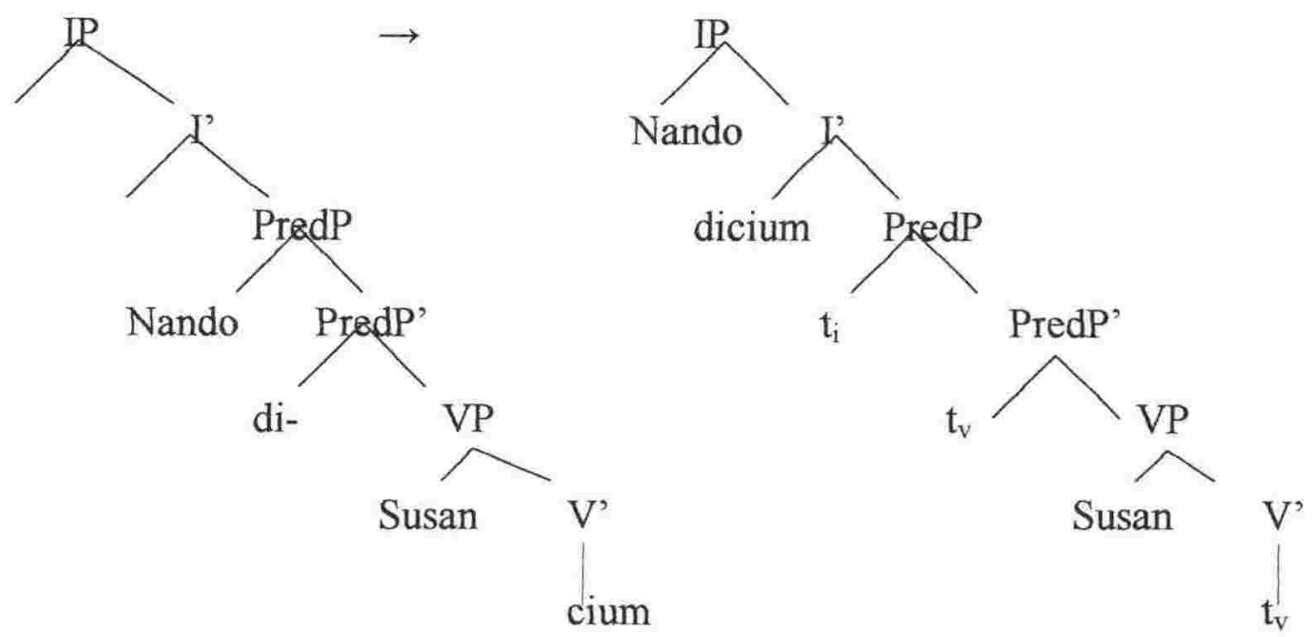

The result of the unwanted derivation shown in (5b) is 'Nando is kissed by Susan' rather than 'Susan is kissed by Nando'. In (5a) and (5b) both Allen and Nando are legitimate subjects, because, as Postman (2001) argues, each can raise to [Spec-IP] and is assigned subject Case by $\mathrm{I}^{\circ}$. In sum, the basic structure of $\mathrm{BI}$ as shown in (3) above is too powerful, and is made even more powerful by the equidistant theory. What is proposed throughout the present work is that we keep VOICE and transitivity as two separate heads, as has also been argued for by Bowers (2002) and Pylkkänen (2002). We gain the interpretation of thematic relations from the $v \mathrm{P}$ alone, and the ACTIVE/PASSIVE derivations do not, and should not, change these relations. Most importantly, the structure (3) lacks transitivity, thus, there is a good reason to "insert" the head $\operatorname{Tr}$ (Bowers 2002, as shown in (1a) above) for transitive verbs such as dorong 'to push' and cium 'to kiss'. The 
problem with using English style VoiceP/PredP is that in English the Voice head is "bundled" up together with the causative/Tr head into one syntactic head, the causal relation and the argument role are packaged into one morpheme (Pylkkänen 2002). In other words, the English CAUSE/Tr is "Voice-bundling" (Pylkkänen 2002: 90,91).

It is worth noting, that while in other languages (for instance English or Romance) the ACTIVE VOICE has a default value (Ouhalla 1991, Bowers 2002, Pylkkänen 2002), in BI both PASSIVE and ACTIVE VOICES are realised, in the sense that both of these VOICES have a single functional projection, with $d i$ - and $m e N$ - respectively as the heads (i.e., $\mathrm{BI}$ prefixes $d i$ - and $m e N$ - are simply alternative realisations of Voice ${ }^{\circ}$ ). I shall continue to use the term "Voice" and "Voice Phrase" because they are more conventional than "Predication" and "Predication Phrase". They are also useful for the analysis of Austronesian languages, as also suggested by Himmelmann (2002).

Himmelmann (2002: 14) suggests the term "Voice" instead of other terms such as "Focus", "Topic" and so on. ") The term "Voice" can be useful, because it avoids misunderstandings related to the pragmatic meanings of the term "Focus". Himmelmann (2002) also notes that there are currently two major approaches to the analysis of VOICE phenomena in western Austronesian languages. On the one hand, there are various proposals for an ergative analysis of Philippine languages as well as a substantial number of other western Austronesian languages (Indonesian, South Sulawesi, Uma, Balinese etc.). In these approaches, one of the VOICES is analysed as the basic unmarked construction for transitive clauses while another voice (usually the so-called actor"focus"/-"topic") is analysed as an antipassive. On the other hand, there is a fairly broad and heterogeneous set of approaches which analyse voice-related phenomena in western Austronesian languages as "valency-neutral alternations" (another term is "symmetrical voice systems"). The basic tenet of these approaches, as Himmelmann notes, is that the

4) An elaborate study on the related terminology is provided by Blust (2002) where he lists different terminology applied to western Austronesian languages, e.g., "voice" = "focus" = "topic" etc. Other related terminology for the BI prefixes $m e N$ - and $d i-$ : "Agent-Topic" (AT) for meN-versus "Theme-Topic" (TT) and "Patient-Topic" (PT) for di- (e.g., Guilfoyle, Hung and Travis 1992, Postman 2001/2002). I use the term "VOICE" to indicate the subject predicate relation, which in BI is realised morphologically. 
different voices found in these languages do not change the overall transitivity of the constructions in which they occur. Instead, a change of voice signals a change in the surface alignment of semantic roles and syntactic positions. As I have already mentioned above, I propose following Bowers (2002) that VOICE and transitivity are two separate heads, which explains why different VOICEs do not change the overall transitivity of the constructions in which they occur. I shall argue, however, that some morphological realisations of Voice head can only occur in certain constructions.

\subsubsection{The BI Voice Phrase}

It has been argued for in the literature that the simplest predicational structure in any language is the unaccusative structure (for instance, Chomsky 1995, Hale and Keyser 1998). Consider the unaccusative jatuh, (6), from Chapter 3, with the structure as suggested by Hale and Keyser (1998).

(6) John jatuh 'John fell'

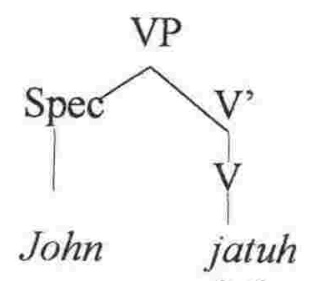

fall

In (6) the event of John falling is usually interpreted as an accident, even though it may not be, there is no information of the contrary. The sentence John jatuh can be modified, (7a), to indicate that the event is an accident, or $(8 \mathrm{a})$ to indicate that the event was intended to happen.

(7)a. John jatuh karena lalai

$\mathrm{J}$ fall because unalert

'John fell because of (his own) carelessness'

b. John ter-jatuh karena lalai

$J$ TER-fall because unalert

'John fell because of (his own) carelessness' 


\section{c. *John meN-jatuh karena lalai \\ $\mathrm{J}$ ACT-fall because unalert \\ 'John fell because of (his own) carelessness'}

(8)a. John jatuh supaya di-kasihan- $i$

$\mathrm{J}$ fall in order PASS-pity-I

'John fell in order to gain sympathy'

b. *John ter-jatuh supaya di-kasihan-i

$\mathrm{J}$ TER-fall in order PASS-pity-I

'John fell in order to gain sympathy'

c. John meN-jatuh supaya di-kasihan-i

$\mathrm{J}$ ACT-fall in order PASS-pity-I

'John fell in order to gain sympathy'

Note, that another form of non-accident is when John is pushed, (9a), and this form does not take ter-, (9b).

(9)a. John jatuh karena di-dorong

$\mathrm{J}$ fall because PASS-push

'John fell because he was pushed'

b. *John ter-jatuh karena di-dorong

$\mathrm{J}$ TER-fall in order PASS-pity

'John fell because he was pushed'

Thus, in BI the unaccusative verb jatuh 'to fall' of (6a) may undergo a displacement up to the Voice ${ }^{\circ}$, adjoined to ter-, (7b), or to $m e N-,(8 \mathrm{c})$, the structures of which are shown as (10) and (11) below, giving a more unambiguous interpretation than (6), as shown in (7) and (8).

(10) John ter-jatuh 'John fell' (an accident)

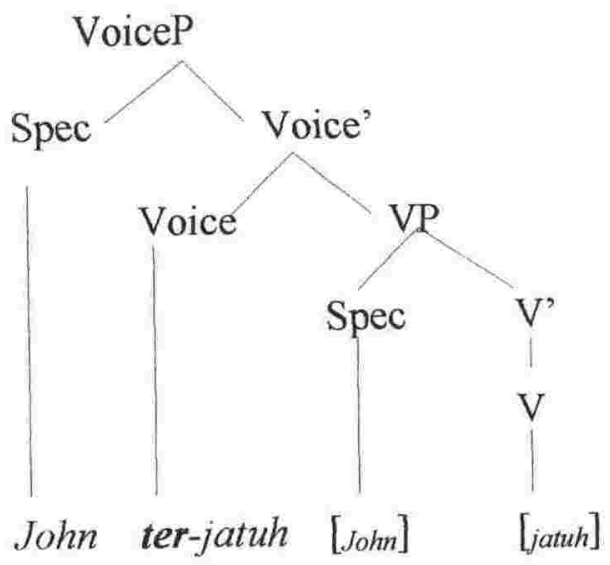


(11) John meN-jatuh 'John fell' (not an accident, John is an AGENT)

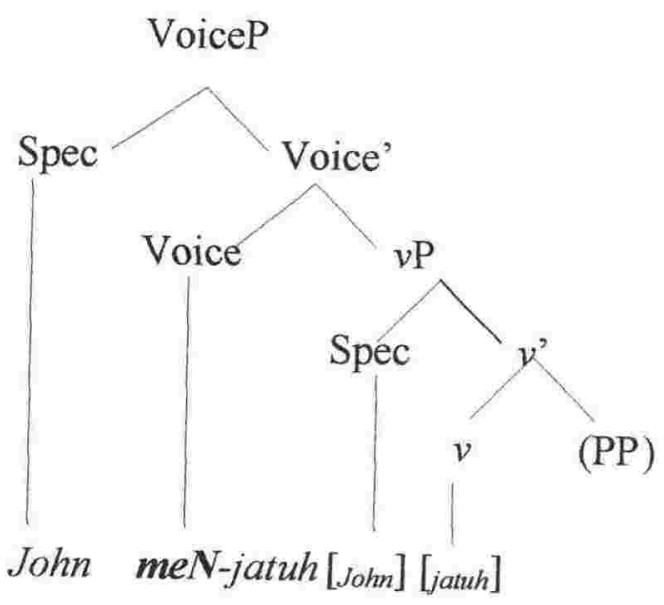

The interpretation for (10), where ter- is used, is that the fall is unambiguously an accident. Whereas for (11), where $m e N$ - is used, the interpretation is that John deliberately makes the falling happen. Based on this agentive interpretation, I shall say that the sentence John meN-jatuh is not an unaccusative. The structure (11) is that of the $m e N$-unergative containing the sublexical [DO], as in 'John did a fall nicely' as against 'John had a fall (?nicely)' (I will discuss the two BI unergatives in sub-section 5.2, but for now, notice the occurrence of $v$ instead of $\mathrm{V}$ in (11)). This is a case where an unaccusative verb occurs in an unergative environment (this occurrence is what Arad 1998 calls "unergativised unaccusative", although she disagrees with the notion).

I propose for BI the unaccusative structure as (12) below, comparable with Bowers' (2002) unaccusative (1c) above. The ambiguity of the sentence when the verb is not affixed with a Voice head makes it possible to include $\sigma$ in both intransitive structures, because the interpretation can be either that of unaccusative (7a) or unergative (8a). As a reminder, with the $v \mathrm{P}$-aspect (with the kan-aspect or the $i$-aspect), the complex meNjatuh-kan or meN-jatuh-i 'to fall $\mathrm{CAUSE}_{\mathrm{C}}$ something' or 'to fall on something' is transitive, refer back Chapter 3 and Chapter 4. 
(12) Unaccusative

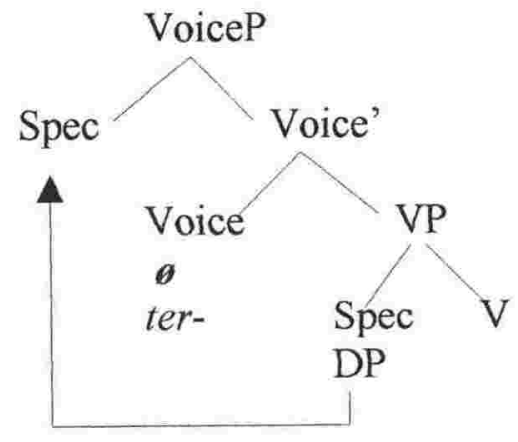

The VOICE prefix $m e N$ - also occurs in other environments, not just in transitives and intransitives. As already noted (sub-section 3.2.6.1), it occurs with an adjective (13) as well as with a noun (14) below, as in Pipinya memerah 'Her cheeks redden', (13) and Orang-orang menyemut 'The crowd looks/behaves like ants', (14). In (13) and (14) the categories (Adjective and Noun) are retained. Note that the constructions (13)-(16) correspond to the English middles such as the gravy thicken, the sky reddens and so on.

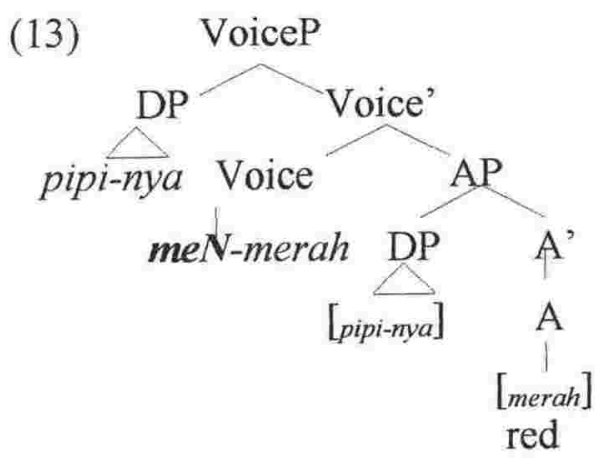

'Her cheeks redden'
(14)

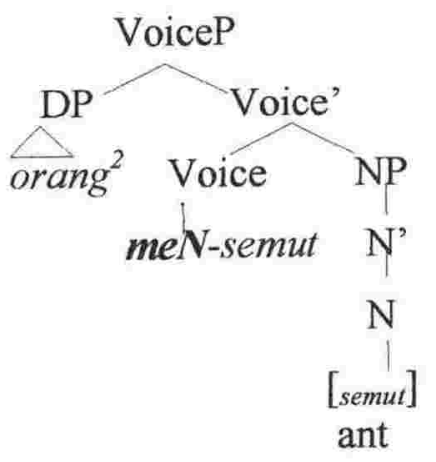

'The crowd behaves/looks like ants'

Or, alternatively, the adjective merah 'red' and the noun semut 'ant' are "conflated", (15) and (16) below, respectively, using the mechanism suggested by Hale and Keyser (1998, 2002). 
(15) With a conflation $\mathrm{A} \rightarrow \mathrm{V}$ (See Hale and Keyser 2002: 48ff for the discussion on conflations)

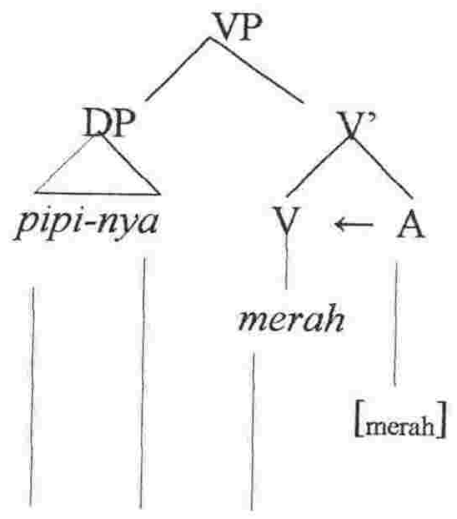

cheek-3sg red

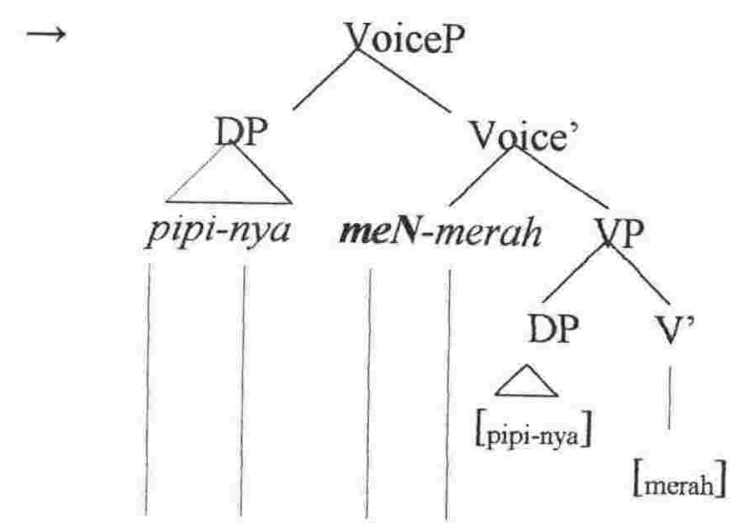

cheek-3sg ACT-red

(16) With a conflation $N \rightarrow V$ (See Hale and Keyser 2002: 48ff)

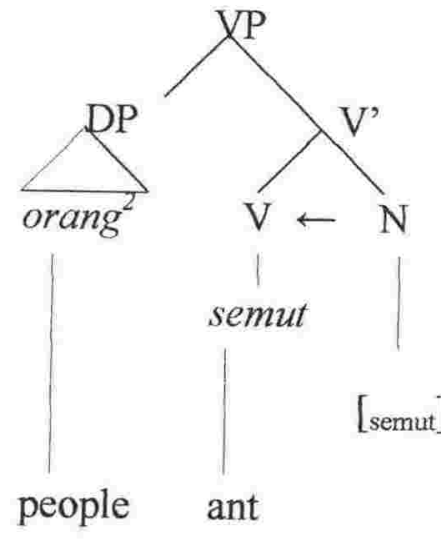

people ant

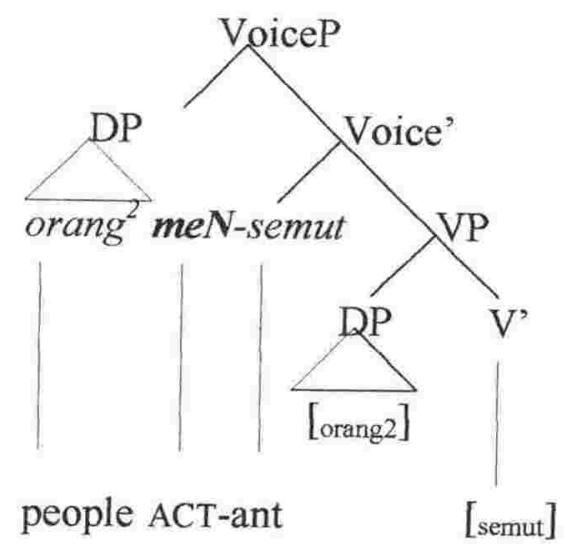

people ACT-ant

If we follow Hale \& Keyser's $(1998,2002)$ theory of "conflation" process the adjective merah 'red' (13) and the noun semut 'ant' (14) are "conflated" at the start of derivation. I take no position in this case as to whether the adjective or the noun in $(13) /(14)$ is made into a verb first in order to take the prefix $m e N$ - or otherwise it is the prefix $m e N$ - that makes the adjective or the noun a verb, which is what is argued for by Bowers (2002). In 
Pylkkanen's (2002) typology, in languages that have Voice as a separate head from transitivity, like Finnish, Japanese - and I shall add, BI - the Voice head may select roots. Note however, that I have argued in the previous chapters that in most cases in BI the prefix meN-cannot occur if the suffix $-k a n$ or $-i$ is not used, and that these suffixes appear to "transitivise" the predicate, which fits well with Pylkkänen's (2002) description that CAUSE (of $v$ ) must take place as "the first step" before Voice head can apply as "the second step", even in "Voice-bundling" languages. In Hale and Keyser's (2002: 54-58) account, this "predicative function" is situated below V, changing the adjective or the noun into a verb. Using Hale and Keyser's (2002) terms, the BI - kan and - $i$ are "causes" or "transitivising light verbs", which is the $v$. As a reminder, BI verbs that can be categorised lexically as unaccusative, unergative or transitive take or can take the vOICE prefix meN-.

Therefore, the Pr structures proposed by Bowers (2002) as shown in (1) correspond to BI VoiceP, in particular, the ACTIVE VOICE $m e N$-. The difference is that in English, as examined by Bowers, the head $\operatorname{Pr}$ is not realised by a morphological affix. I therefore propose that the BI "voice system", (17) below, is on a par with (1) above. In (17) the BI prefixes, as the morphological realisations of the Voice head, are indicated in each structure. It is important to note that, as argued for by Bowers (2002), here we also argue that only the transitive (1a)/(17a) below can derive a PASSIVE sentence (the structure where $d i$ - occurs). I shall argue, however, that the "Impersonal Transitive" structure as shown in (1d) above is not needed, based on the interpretation of [Spec- $v \mathrm{P}]$ arguments, namely whether the external argument is an AGENT, a CAUSER, or $\emptyset$ (Chapter 4). In BI personal transitives take $m e N$ - and $d i$ - whereas impersonal transitives take $m e N$ - and $t e r-$. In effect, Bowers (2002) structures (1a) and (1d) are reducible to (1a). The distribution of the BI VOICE morphology will be discussed in detail in Section 5.2. 
(17) BI Voice Phrases

(17)a: Transitive

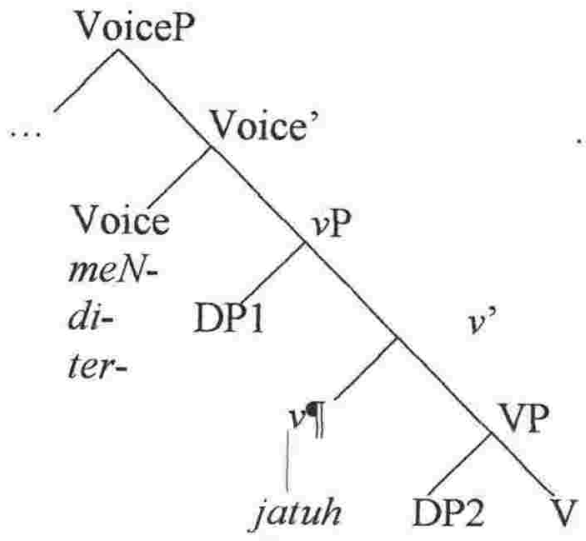

fall (17)b: Unergative

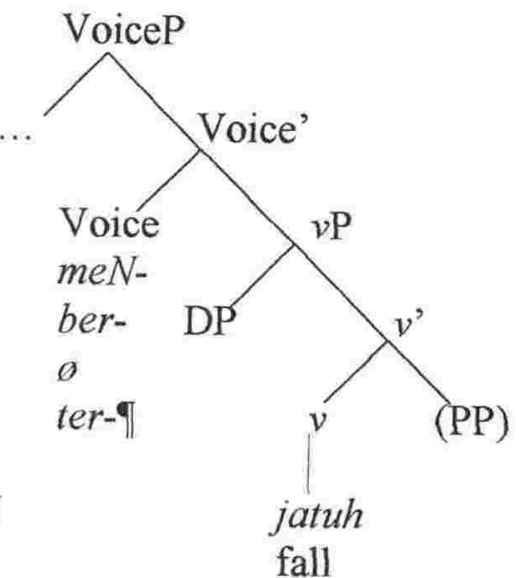

( v I: v-kan, $v-i, v-\varnothing)$

e.g., meN-jatuh-kan/-i

di-jatuh-kan-i

e.g., meN-jatuh

ter-jatuh-kan

meN-cium- $\emptyset$ 'to kiss'

Texceptional, e.g., ter-duduk (3.3.2.1)

(17)c: Unaccusative

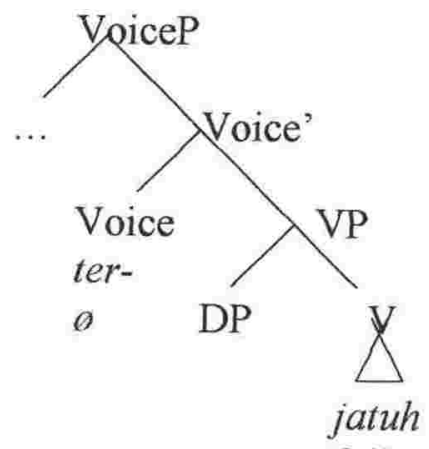

e.g., ter-jatuh

fall

ø-jatuh

o-pecah/o-patah/o-putus 'to break'

Note the occurrence of meN- in both (17a) and (17b), and of ter- in both (17a) and (17c).

In summary, unaccusative construction does not project a $v \mathrm{P}$. The verb jatuh 'to fall', which we argued earlier on as unaccusative, occurs in all constructions above. Like 
the adjective merah 'red' $(13) /(15)$ and the noun semut 'ants' $(14) /(16)$, the predicate jatuh 'to fall' can also take the ACTIVE Voice head meN-, as in John menjatuh 'John (deliberately) [DO] fell', (11) above. While meN- can occur in both transitive and intransitive environments $(17 \mathrm{a}, \mathrm{b})$, the PASSIVE Voice head di-can occur only if the predicate is transitive, (17a), either derived (with the $v \mathrm{P}$-aspect $-k a n$ or $-i$ ) or underived verbs such as dorong 'push' and cium 'kiss' above. From the general picture (17a-c) we see that the PASSIVE $d i$ - does not receive equal treatments with the ACTIVE $m e N-$. Even in (17a) the ACTIVE $m e N$ - and the PASSIVE $d i$ - are not equal, because $m e N$ - has $d i$ - and teras its PASSIVE counterparts, with the personal and impersonal PASSIVES distinction. I shall demonstrate the only occurence where $m e N$ - and $d i$ - are equal (sub-section 5.1.3, transitive sentences with the kan- and $i$-aspects). At this stage, I shall point out that the so-called "voice system" in BI is not just an ACTIVE/PASSIVE derivation, as is made clear in $(17 \mathrm{a}-\mathrm{c})$.

By disregarding the overall transitivity of the constructions in which the Voice head is distributed, we have the BI VoiceP as shown in (18) with the possible morphological realisations shown at the Voice ${ }^{\circ}$.

(18) The BI VoiceP

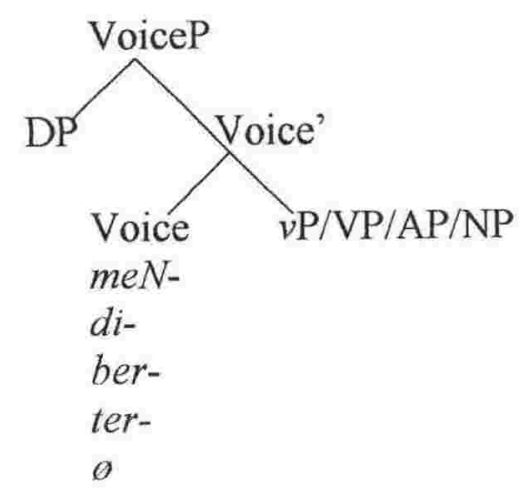

The following sub-section (5.1.3) discusses the only occurences where meN- and $d i$ contrast with each other, in the VoiceP containing the $v \mathrm{P}$ structure (17a). I will come 
back to the impersonal transitive structure involving ter- $(17 a)$, and the structures $(17 b, c)$ in section 5.2 .

\subsubsection{BI VOICE $+k a n$-aspect and VOICE $+i$-aspect ("VOICE $+v P$ ", transitive)}

So far I have assumed throughout the present work that the suffix meN- represents an ACTIVE VOICE and I shall continue to do so. Likewise, in the present sub-section I assume that the suffix di- realises the PASSIVE Voice head. As mentioned in the preceding sub-sections, unlike the prefix $m e N$ - that can occur with intransitive predicates and with adjectives or nouns, the prefix $d i$ - can only occur if the predicate is transitive. The present sub-section only discusses the transitive structure complete with the $v \mathrm{P}$ aspect.

In Chapter 3 and Chapter 4, we have seen "head-Spec" relations within the $v \mathrm{P}$. The head $-k a n$ or $-i$ is located above the verb, and the verb moves up to left-adjoin with the constant functional head, (19).

(19)a. Transitive $v$-kan:

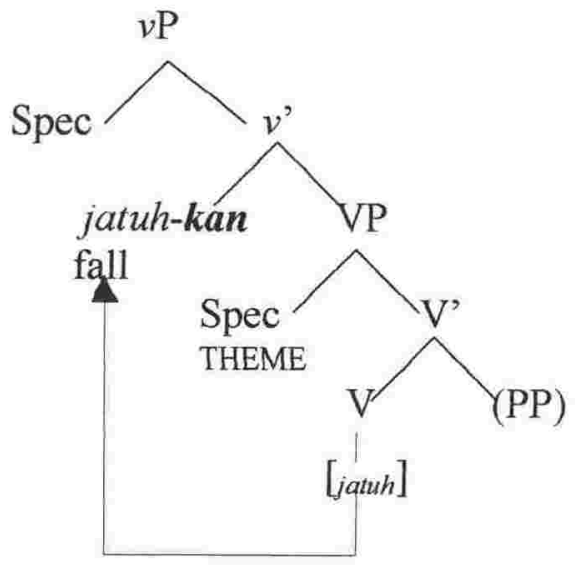

b. Transitive $v-i$ :

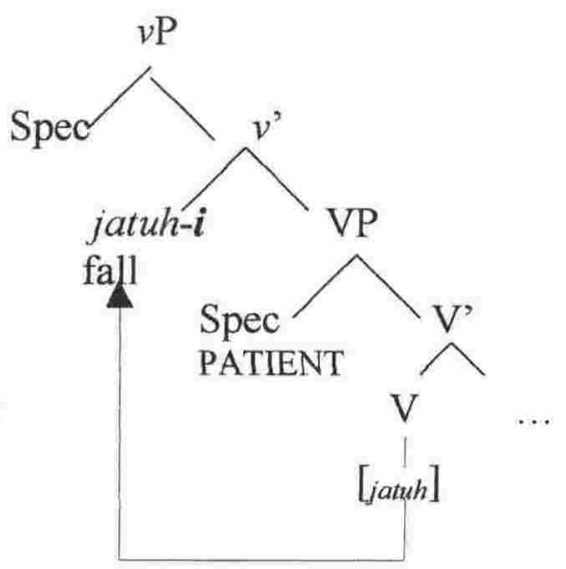

In this instance, the suffixes function as "relators" (Voskuil's 1996 terminology), in that, they help relate the predicate to the object at [Spec-VP], (20) below, so as to indicate that the argument bears a special object relation to the predicate (Bowers' 2002:183). The 
dashed lines in (20) and (21) only indicate relations, and in no way should they be read as a direction of movement.

(20)a. Transitive $v$-kan with THEME:

b. Transitive $v-i$ with PATIENT:
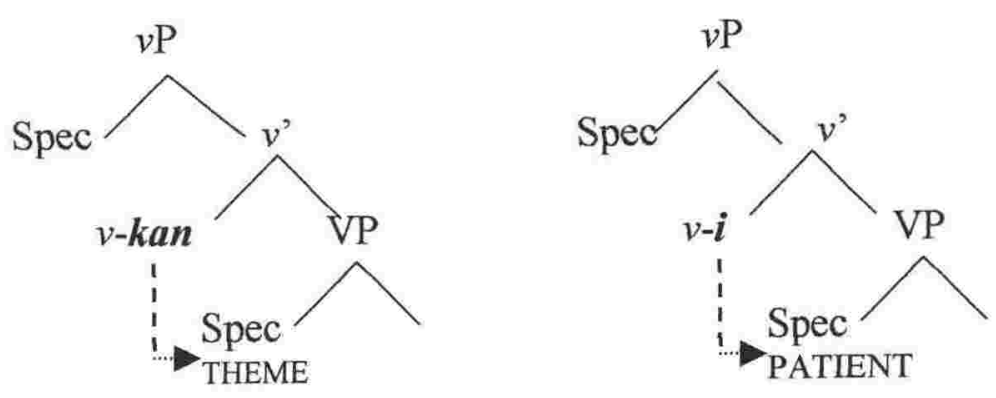

When the kan-aspect appears, (20a), [Spec-VP] has a THEME interpretation. Whereas if it is the $i$-aspect that appears, $(20 \mathrm{~b})$, the argument at [Spec-VP] must be interpreted as a PATIENT.

In the present chapter I shall show some "Spec-head" relations, where the moved incorporated elements ( $v$-kan, $v-i)$ are right adjoined to the constant functional head, (21), the Voice head $m e N-$ (21a) or di- (21b).

(21)a. Voice meN-
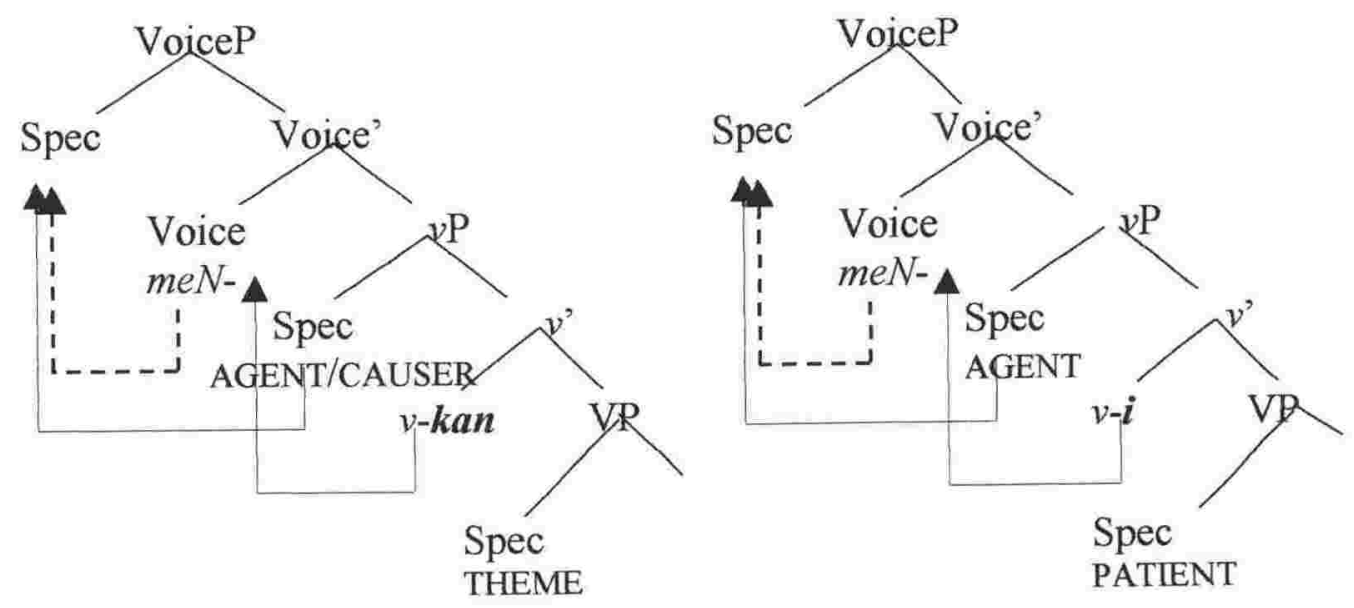
(21)b. Voice di-

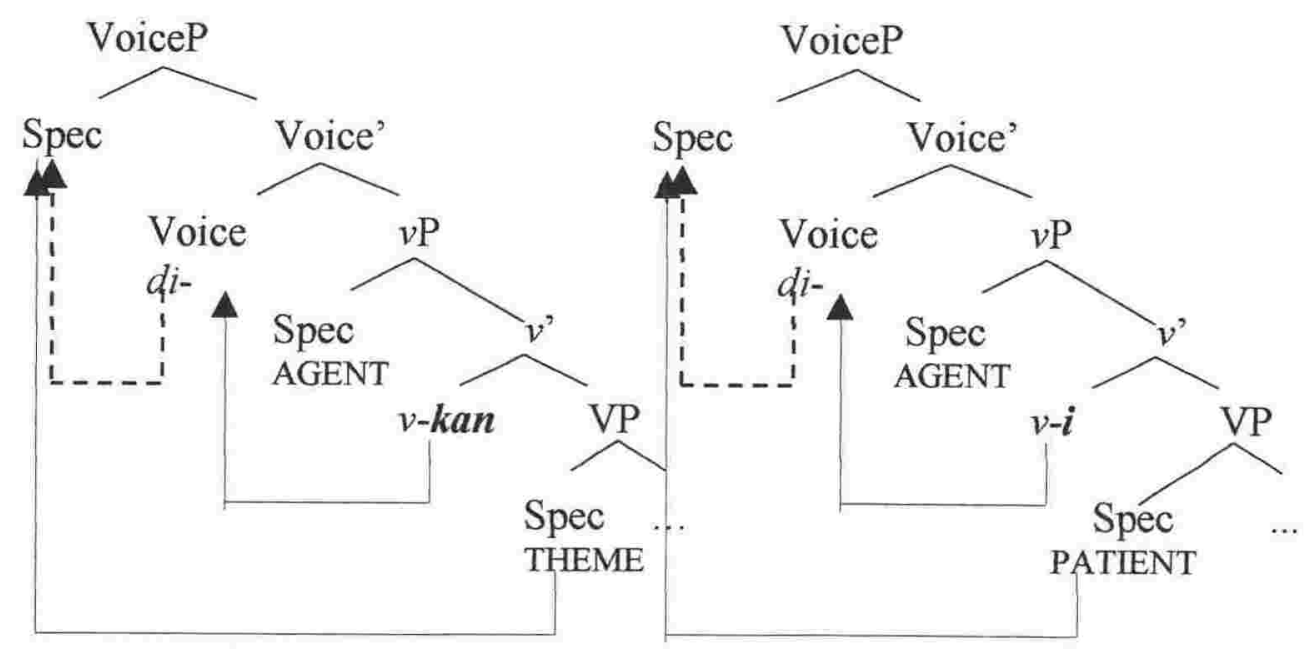

In this instance, the prefixes meN- (21a) and $d i$ - (21b) relate the subject at [Spec-VoiceP] to the raised predicate. In (21a) the AGENT/CAUSER moves from [Spec- $v$ P] to [SpecVoiceP] and the ACTIVE Voice head meN- must be used. In (21b) the THEME or the PATIENT moves to [Spec-VoiceP] from [Spec-VP] and the PASSIVE Voice head di-must be used. Thus, in (21) we have two options of Spec-to-Spec movement, one from [Spec$v \mathrm{P}],(21 \mathrm{a})$, and the other from [Spec-VP], (21b), as well as two options of Voice, appropriately. In either case, in $(21 \mathrm{a}, \mathrm{b})$, the transitive verb - either it is the $v$-kan or the $v$ $i$ - moves to the Voice head position, regardless of which Voice prefix will be used. Therefore, we have two ACTIVE constructions, one with - kan and the other with - $i,(21 \mathrm{a})$, and two PASSIVE constructions, one with $-k a n$ and the other with $-i$, (21b). The use of $m e N$ - and $d i$ - prefixes is dependent on which specifier is moved to [Spec-VoiceP], but in the derivation, $v-k a n$ and $v-i$ are independent of these prefixes. As mentioned above in the introduction, the use of different Voice heads such as meN-versus $d i$ - does not change the overall transitivity of the constructions in which they occur, which Himmelmann (2002: 14) notes as "valency-neutral alternations" or "symmetrical voice systems". Comparing the structures (21a) with (21b) we see that the two VOICEs in fact do not alter the transitivity, and they are "symmetrical" in the sense that $m e N$ - and $d i$ - are equal (only in this particular environment, because, as we will see later on in section $5.2, \mathrm{meN}$ - and di- are not equal). I argue that the BI VOICE is not just about ACTIVE versus PASSIVE constructions. Basically, the difference between (21a) and (21b) is, in the ACTIVE VOICE 
(21a) the AGENT or the CAUSER is the syntactic pivot, whereas in PASSIVE VOICE (21b) the THEME or the PATIENT (both can be referred to as "the undergoer") is the syntactic pivot, but both constructions share the same thematic relations. Another term that can be employed for $(21 \mathrm{a}, \mathrm{b})$ occurrences is that meN- "introduces"/ "names" the external argument as a subject, whereas $d i$ - "introduces"/ "names" the internal argument as a subject (Pylkkänen's 2002 terms).

The following sub-section (5.1.4) applies the data from the previous chapters to the transitive structures (21a) and (21b).

\subsubsection{Two ACTIVES, two PASSIVES (DAC-DOC revisited)}

Chapter 4 proposes two separate syntactic operations of the two $\mathrm{BI} v \mathrm{P}$-aspects, one with the $k a n$-aspect and the other with the $i$-aspect, and the two are independent of each other. In sub-section 5.1.3 I have shown two ACTIVE derivations with the Voice head meN-, (21a) and two PASSIVE derivations with the Voice head di-, (21b). In the present section I will continue to demonstrate that each $v \mathrm{P}$-aspect has its own ACTIVE/PASSIVE forms. In so doing, I shall use examples of two opposing derivations of passive forms.

I have argued in sub-section 4.2.1 that sentences such as in (22) below do not make a (good) minimal pair, and they are good sentences. In saying that each $v \mathrm{P}$ form is basic, we analyse the (a) and (b) forms of (22) below separately. Each form has its own passive alternant, which is not to say that the passive forms are derived from the active counterparts, or vice versa.

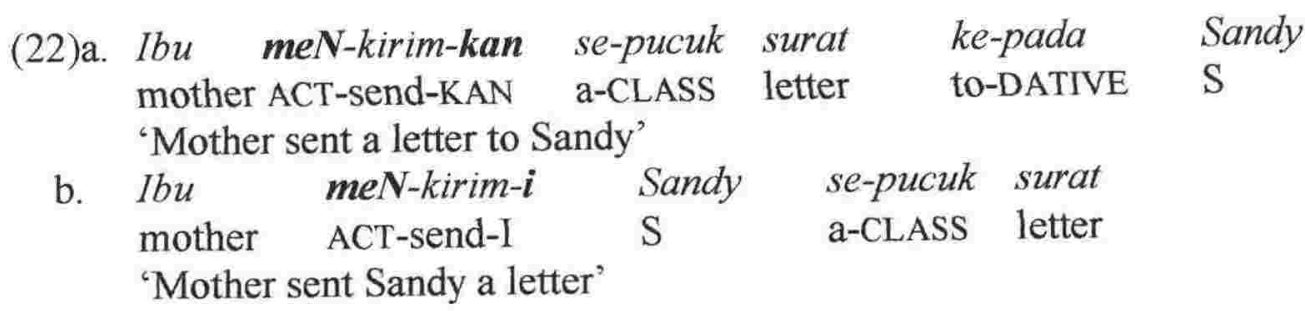

In discussing the ACTIVE/PASSIVE forms, two important points must be kept in mind: 
(i) The PASSIVE form with the kan-aspect has the corresponding ACTIVE form with the kan-aspect. Thus, "keep" the kan-aspect intact, in particular, bear in mind that in the $v \mathrm{P}$ derivation the THEME is selected by the kan-aspect;

(ii) The PASSIVE form with the $i$-aspect corresponds with the ACTIVE form with the $i$ aspect. Thus, keep the same $v \mathrm{P}$-aspect. In the $v \mathrm{P}$ derivation the PATIENT is selected by the $i$-aspect.

We will show first an example of the PASSIVE form with the kan-aspect, and see the characteristic of the form. And then we will also show an example of the PASSIVE form with the $i$-aspect, and see the characteristic of the form. We shall use the sentence (22a) as the ACTIVE form, (23a), and the PASSIVE form is shown as (23b).

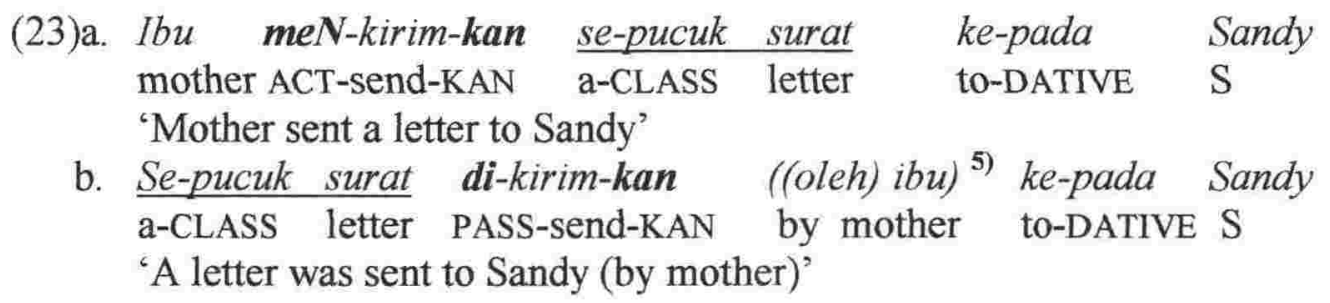

The examples (23a) and (23b) show an ACTIVE/PASSIVE VOICE forms with the kanaspect. The main thesis of the present work is the kan-aspect selects a THEME. The PASSIVE derivation with the kan-aspect thus must be "THEME-focused" ("focus" in Rizzi's 1997 sense, i.e., it is propositional rather than discoursal), in that, in the derivation it is the THEME from [Spec-VP] that moves to the subject position. The linear order of (23b) has the THEME as the surface subject, underlined in the example, followed by the predicate with the PASSIVE VOICE prefix $d i$ - (24) below. Notice that the kan-aspect is used.

(24) THEME

\section{di-PREDICATE- $k a n$} 5) In the surface form, the PP oleh by-phrase is optional, and if it appears, the preposition oleh 'by' is also
optional if the PP is positioned adjacent to the PASSIVE predicate. 
Contrast the pair in (23) with the pair in (25) below, which is an ACTIVE-PASSIVE VOICE alternation with the $i$-aspect. The PATIENTs in the following examples (25) are underlined.

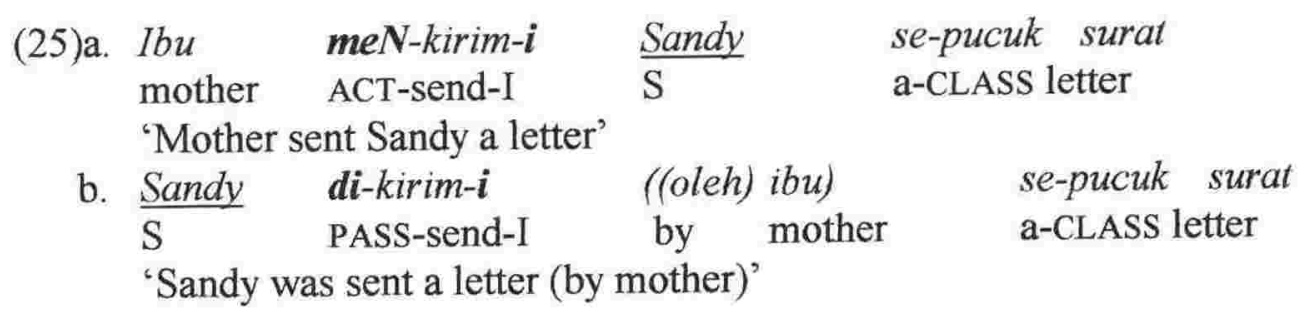

The main thesis is the $i$-aspect in (25) selects a PATIENT. The passive derivation with the $i$-aspect thus must be "PATIENT-focused". The linear order of (25b) has the PATIENT as the surface subject, underlined in the example, followed by the predicate with the passive VOICE prefix $d i$-, and the $i$-aspect is used, (26).

\section{(26) PATIENT $d i$-PREDICATE- $i$}

Comparing the two PASSIVES - (24) with (26) - we see that they bear the opposing $v$ Paspects, $(27)$ below. What the linear orders $(27 a, b)$ have in common is that both have the VOICE prefix $d i-$, and the primary internal arguments, the THEME (25a) and the PATIENT (25b), are "pivoted", that is, they are positioned as the subject that appears in the order. Thus, $(27 a, b)$ show the two PASSIVEs. The linear orders of the ACTIVE counterparts of (27) are shown as (28), as the two ACTIVEs.

$\begin{array}{cl}\text { (27)a. THEME } & d i \text {-PREDICATE- } k a n \\ \text { b. PATIENT } & d i \text {-PREDICATE- } i\end{array}$

(28)a. AGENT meN-PREDICATE-kan THEME b. AGENT $\boldsymbol{m} \boldsymbol{N} \boldsymbol{N}$-PREDICATE- $\boldsymbol{i}$ PATIENT 
In (28a) the CAUSER is not included to take into account its occurrence with the psychpredicates. I will come back to the ACTIVE/PASSIVE derivations involving the psychpredicate in section 5.2 .

The two ACTIVEs, examples (22a,b), are represented using the structures (21a), as $(29 \mathrm{a}, \mathrm{b})$ below. The two PASSIVE counterparts, (23b) and (25b), are represented as (30a,b) below, using the structures (21b).

(29)a. Voice head $m e N$ - with the kan-aspect:

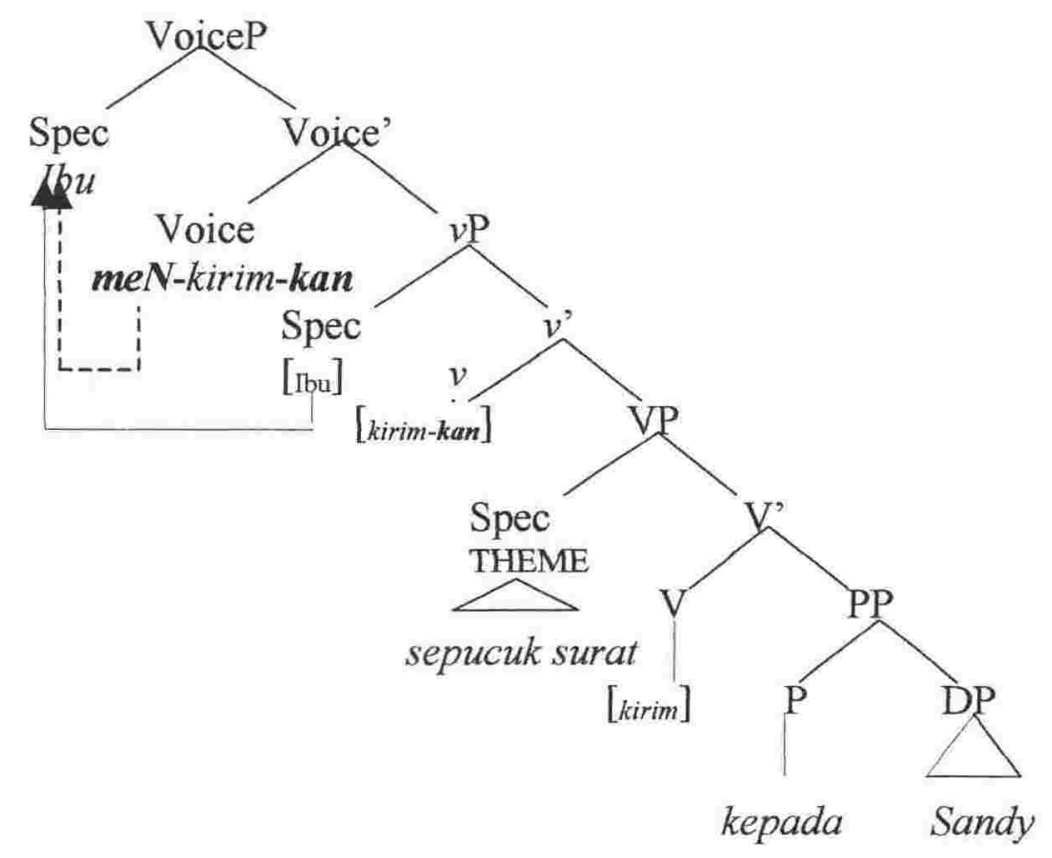

(29)a. Ibu meN-kirim-kan se-pucuk surat ke-pada Sandy mother ACT-send-KAN a-CLASS letter to-DATIVE S 'Mother sent a letter to Sandy' 
(29)b. Voice head meN- with the $i$-aspect:

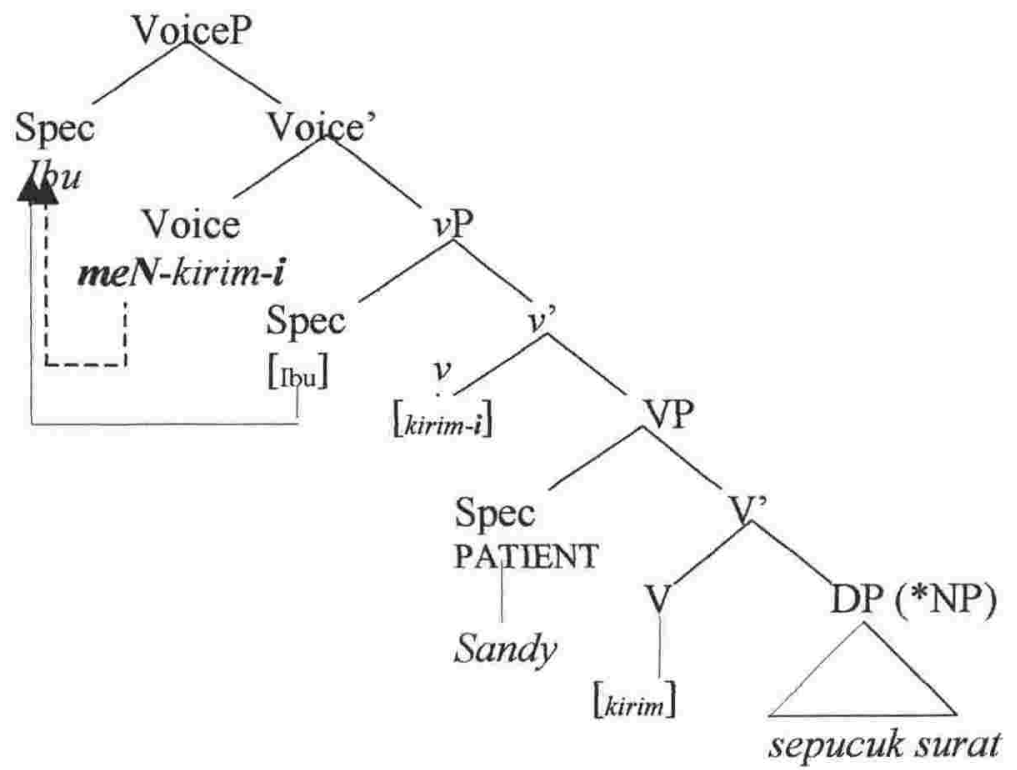
(29)b. Ibu meN-kirim-i Sandy se-pucuk surat mother ACT-send-I S a-CLASS letter 'Mother sent Sandy a letter'

(30)a. Voice head di- with the kan-aspect:

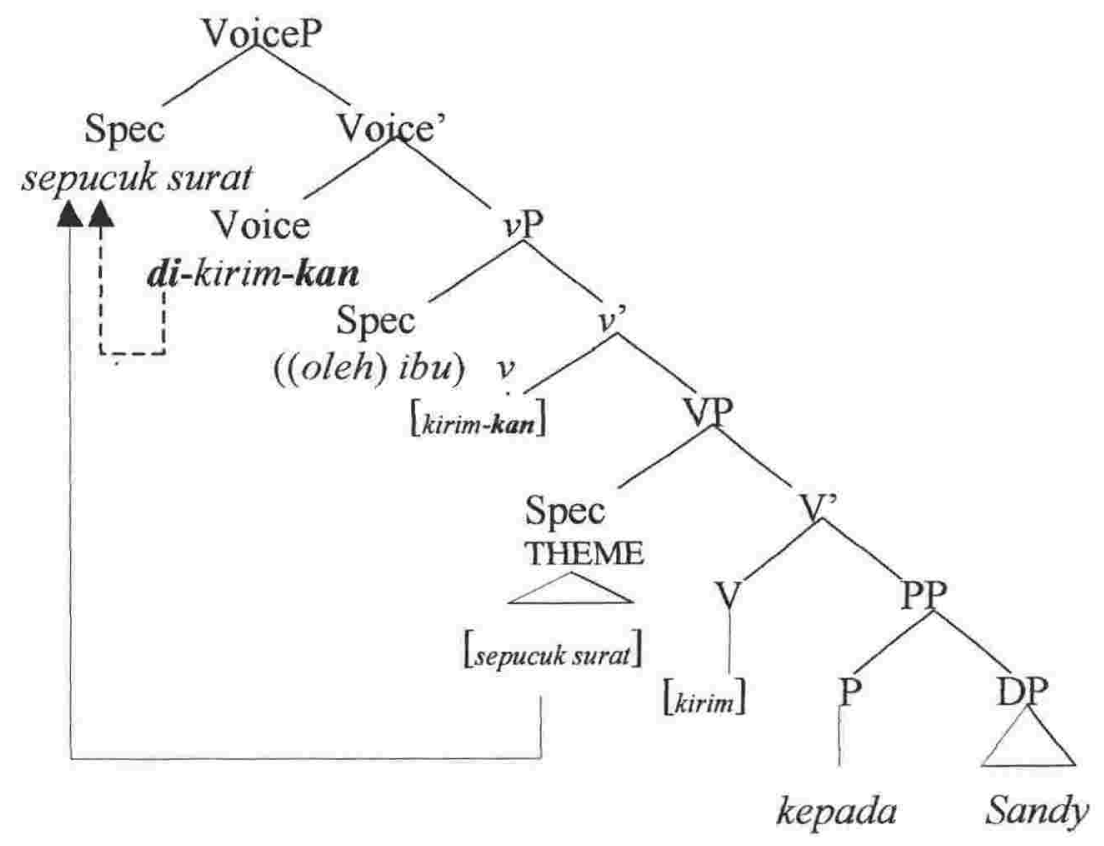




\section{(30)a. Se-pucuk surat di-kirim-kan ((oleh) ibu) ke-pada Sandy a-CLASS letter PASS-send-KAN by mother to-DATIVE S 'A letter was sent to Sandy (by mother)'}

(30)b. Voice head $d i$ - with the $i$-aspect:

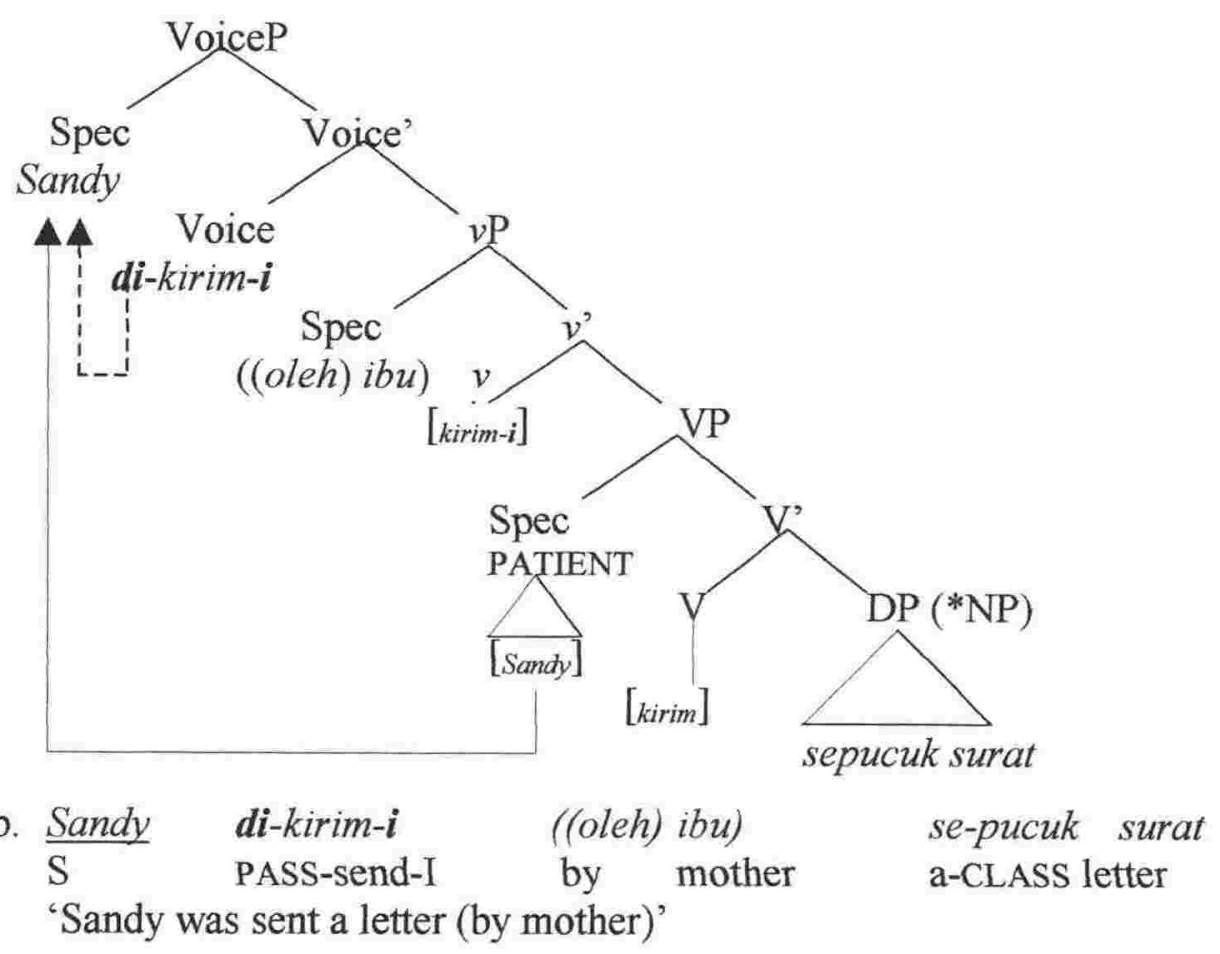

The subject-predicate relation is indicated in all the structures, $(29 a, b)$ and $(30 a, b)$, by the dashed line (refer back examples (20)-(21) for this relation). The subjects of (29a,b) are shown to have different "origins" from those of $(30 \mathrm{a}, \mathrm{b})$ : with the Voice head $m e N-$, the structures show [Spec- $v \mathrm{P}]$ subjects, whereas with the Voice head $d i-$, the structures show [Spec-VP] subjects.

In a PASSIVE derivation, it is the argument that occupies [Spec-VP] that undergoes a Move to the subject position. Vamarasi (1999) has argued for this simple derivation also, although in her relational grammar theory a different terminology is used, such as, the "initial2 is advanced to the final1". In our terms, the "initial2" is the position that has the interpretation of a THEME (30a) or a PATIENT (30b). 
We shall maintain that the active forms such as shown in $(22 \mathrm{a}, \mathrm{b})$ are not transformationally related to each other. I do not analyse the PASSIVE form with $-i$ as the result of a derivation using some kind of syntactic operation to change the active form with $-k a n$, i.e., (31b) below cannot derive from (31a). The good form from (23b) is repeated here as (31c) to contrast with (31b).

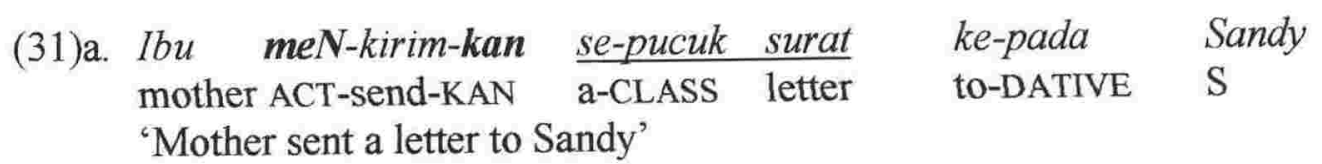
b. * Se-pucuk surat di-kirim-i ((oleh) ibu) Sandy a-CLASS letter PASS-send-I by mother S 'A letter was sent Sandy (by mother)'
$\begin{array}{llllll}\text { c. Se-pucuk surat di-kirim-kan ((oleh) ibu) } & \text { ke-pada } & \text { Sandy } \\ \text { a-CLASS letter PASS-Send-KAN by mother to-DATIVE } & \text { S }\end{array}$ 'A letter was sent to Sandy (by mother)'

Notice that in the good sentences (31a) and (31c) the PP kepada Sandy 'to Sandy' is unaffected by PASSIVE derivation. What we see from comparing (31a) and (31c) is that the PASSIVE only involves the primary internal argument - defined in Chapter 3 as an internal argument that is not introduced by a preposition. We have argued previously that in BI any argument introduced by a preposition is optional.

In sum, our account for each PASSIVE form involving each $v \mathrm{P}$-aspect is straightforward: "keep the $v \mathrm{P}$-aspect intact". The PASSIVE derivations as we describe here involve mainly the operation of moving the primary internal argument - i.e., from [SpecVP]. Because each $v \mathrm{P}$-aspect is independently derived, in effect, the passive form of each is also independently derived. Apart from arguing that the $i$-aspect is not derived from the kan-aspect counterpart and vice versa, I also argue that the PASSIVE form is not derived from its ACTIVE counterpart. 


\subsection{The distribution of BI VOICE morphology: $m e N-$, ber-, and ter-}

I have shown in the structures (17) above that the functional head Voice is obligatory in BI clause structure, on a par with what is argued for by Bowers (2002), for $\mathrm{Pr}$, that $\mathrm{Pr}$ occurs in all environments, (1). I have also shown the BI Voice and $v$ as two separate heads, and thus, to use Pylkkänen's (2002) terms, they are "un-bundled". Bowers (2002) also argues that PASSIVE only occurs in agentive transitive (2). I have shown that the BI VOICE prefix $m e N$ - occurs in both transitive and intransitive environments (5.1.2), whereas the PASSIVE $d i$ - only occurs in transitive environment (17a). The prefix $m e N$ can also occur with an Adjective Phrase (13/(15) as well as with a Noun Phrase (14)/(16).

In this section I lay out in more detail the distribution of the Voice prefixes using sentences they normally occur in. I will demonstrate that the functional head Voice is also realised by other prefixes, namely, ber- and ter-. I propose that the so-called "Voice System" in BI is not just as simple as a system of the prefix meN-versus di-, or to be precise, of ACTIVE versus PASSIVE derivations as discussed in sub-section 5.1.3 above.

This section is organised as follows. Sub-section 5.2.1 discusses the distribution of the Voice heads $m e N$ - and ber-. Sub-section 5.2.2 discusses the distribution of ter-. Subsection 5.2.3 demonstrates that in the complex predicate ber- $\sqrt{ }-k a n$ the stative reading of the predicate $b e r-\sqrt{ }$ is retained, and in the complex ter- $\sqrt{ }-k a n$ the non-agentive reading of ter- $\sqrt{ }$ is retained. Sub-section 5.2.4 discusses the BI ACTIVE and PASSIVE VOICES with frighten and fear verbs. Sub-section 5.2.5 summarises our discussion of the BI Voice Phrase.

\subsection{1. $m e N$-unergative and ber-unergative}

In this sub-section I show that BI has two different types of unergative: those with the Voice head $m e N$ - (meN-unergative) and those with the Voice head ber- (ber-unergative). The former are unergatives having the sublexical [DO], and the latter are unergatives having the sublexical [HAVE]. We will see that only the meN-unergatives have the potential to take cognate objects, that is, with the use of the kan-aspect. 
I will start with examining the different characteristics of the two unergatives by using minimal pairs where $m e N$ - and ber-can occur. We will see that the two unergatives are distinguishable by giving two different sublexicals: those with meN- have the sublexical [DO] (i.e., to DO an ACT) and those with ber- have the sublexical [HAVE] (i.e., to HAVE something, including an ACT).

The following lists are not intended to be exhaustive, but they should be sufficient to show differences. Note that to derive a real unergative, either with $m e N$ - or with ber-, the root must be a noun or a nominalised element. Like in the English unergatives (Kearns 1988, Hale and Keyser 1993, 1998), BI unergatives are all denominals.

Some unergative verbs only take $m e N$-, Group I below, some only take ber-, Group II, some can take both, Group III, and some take neither, Group V. Unergatives with $m e N$ - (Group IV) that have verb-root below are not real unergatives - they are "hidden transitives" (Chomsky's 1995, Hale and Keyser's 1998 term) in that, they have a covert object. We also have underived (or "pure") unergative verbs, they are verbs that can be classified as unaffixed unergative, Group V.

Group I. With meN- only:

menangis 'to cry', menari 'to dance', menjatuh 'to fall', menaik 'to ascend', menurun 'to descend'

In this group we have what Hale and Keyser (1998) analyse as '[DO] cry'

Group II. With ber- only: (a) with a noun root, (b) with a nominalised base

(a). berlari 'to run', berenang 'to swim', berkata 'to speak', berjalan 'to walk', berliku(-liku), beranak 'to have child(ren)', bercucu 'to have grand(s)', berumah 'to have a house', berkaki 'to have legs', berkepala 'to have a head', bernafas 'to breath' (b). berjatuhan 'to fall', berdatangan 'to come', be(r)pergian 'to go', berpukulan 'to hit each other', berciuman 'to kiss each other', berlarian 'to run around'

Group III. With both meN- and ber-:

nyanyi: menyanyi 'to do a song', bernyanyi 'to have a song to sing'

tiup: meniup, bertiup 'to blow'

akar: mengakar 'to root', berakar 'to have roots'

batu: membatu 'to become like rock', berbatu 'to have/contain rocks'

garam: menggaram 'to become like salt', bergaram 'to contain salt' 
Group IV. With $m e N$ - that occur in both intransitive and transitive (i.e., verbs with $m e N$ that occur 'intransitively', with understood/identifiable objects):

(meN-)makan 'to eat', (meN-)minum to drink', (meN-)mancing 'to fish', menyokong 'to support', menyisir 'to comb', menyapu 'to broom'

(Note on the bracketed ' $(\mathrm{meN-}$ )': if the root starts with $/ \mathrm{m} /$ sound the prefix is optionally pronounced)

Group V. Neither ("pure" unergative):

duduk 'to sit' *menduduk, *berduduk

bangun 'to get up' *membangun, *berbangun

masuk 'to enter' *memasuk, *bermasuk

datang ${ }^{6}$ ' to come' *mendatang, *berdatang

pergi 'to go, to leave' *memergi, *berpergi

We start with the characteristics of each. Some of the ber- verbs appear as adjectives, like the corresponding English adjectival nominals (or 'depictives'). All the examples (32) give an indication of 'having something' (note that the following examples are non sentences, and the verbs refer not to action but to states).

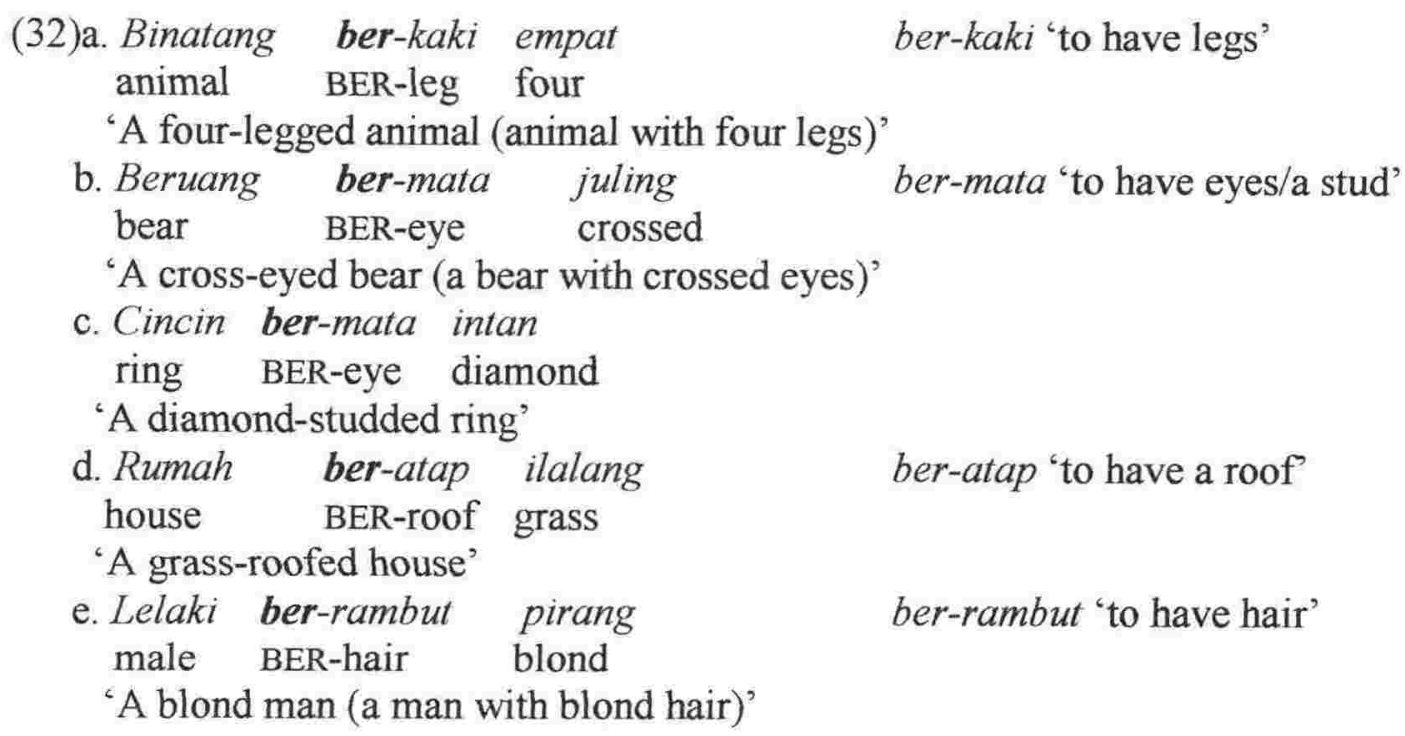

\footnotetext{
6) datang 'to come' can occur with meN-: $\underline{\text { waktu }}$ meN-datang 'time to come', 'in future'; makan 'to eat',
} (meN-)makan waktu 'time consuming'. I shall put these occurences aside, they occur only as metaphors. 
Some of the ber-unergative verbs are lexically reflexive, i.e., doing something for the 'benefit' of oneself, (33), or doing something to each other with cooperation, (34), as a joint ACT (See also Sneddon 1996). In (33) and (34) the meN-counterparts do not occur as unergative.

(33) Activity for oneself (or 'hygiene' verbs):

a. keramas 'a hair wash/shampoo', ber-keramas (*meN-keramas) 'to wash own hair'

b. cermin 'a mirror', ber-cermin ('meN-cermin) 'to look at oneself in the mirror'

c. sisir 'a comb', ber-sisir (*meN-sisir) 'to comb one's hair'

d. dandan 'dress', ber-dandan (*meN-dandan) 'to dress up'

(34) Involving cooperative actions (or 'reciprocals'):

a. kelahi 'a fight', ber-kelahi (*meN-kelahi) 'to fight (i.e., to HAVE a fight with each other)'

b. perang 'a war', ber-perang ('meN-perang) 'to wage war (against each other)'

c. cerai 'a separation', ber-cerai ( 'meN-cerai) 'to get/HAVE a divorce'

a. senggama 'a sexual act', ber-senggama (*meN-senggama) 'to HAVE sex (with each other)'

Compare the reflexive ber-cerai 'to get/HAVE a divorce' $(35 \mathrm{a}, \mathrm{b})$ with the non-reflexive transitive meN-cerai istri/suami 'to divorce wife/husband' (36). With meN-cerai istri/suami only one party is considered a willing AGENT. In $(35 \mathrm{a}, \mathrm{b})$ meN-unergative is unacceptable.

(35)a. Parto dan Siyem sudah ber-cerai

( ${ }^{*}$ meN-cerai)

$\mathrm{P}$ and $\mathrm{S}$ PERF BER-divorce

'Parto and Siyem are (now) divorced/got/had a divorce'
b. Parto akan ber-cerai dengan Siyem (*meN-cerai)
$P \quad$ FUT BER-divorce with $\mathrm{S}$
'Parto are getting/having a divorce with Siyem'

In (36a) and (36b) both Parto and Siyem agree to have a divorce, contrast with (36) below, where ber-unergative is unacceptable. 


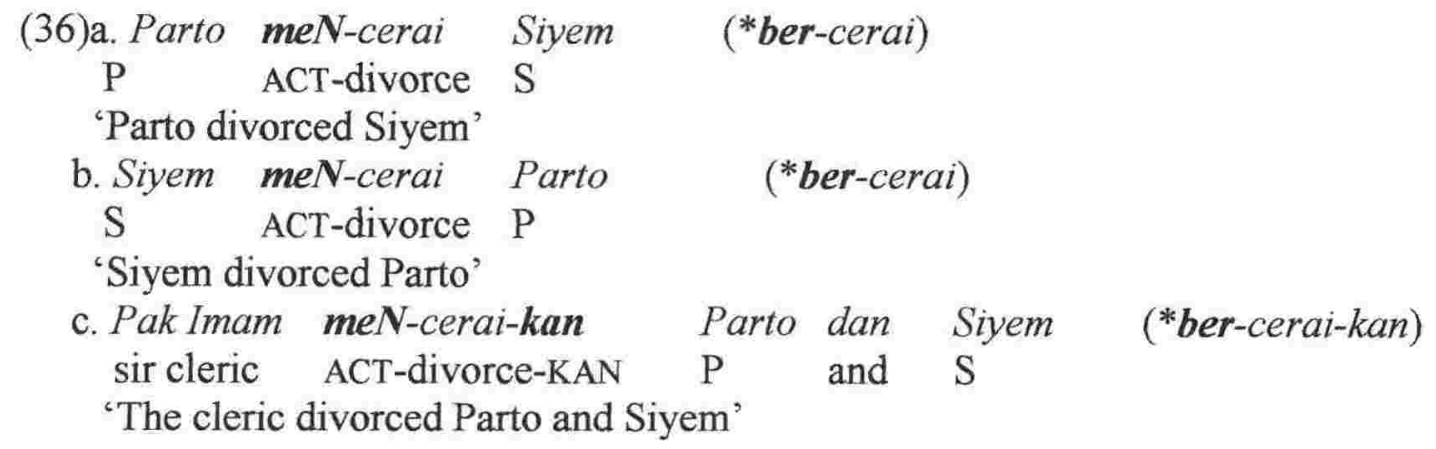

It is understood that in (36a) only Parto is the willing AGENT who [DO] the divorce, and Siyem is forced to accept the divorce. Conversely, in (36b) it is Siyem that is the willing AGENT and [DO] the divorce, but not Parto. In (36c) the imam 'religious cleric' acts as a facilitator AGENT that separates Parto and Siyem, who has the consent to perform the act. In all the cases in (36a-c) the predicates contain the sublexical [DO], whereas in $(35 \mathrm{a}, \mathrm{b})$ the predicates contain [HAVE], as is apparent also in the English translation. Another strategy (besides with ber- (33) and (34)) for expressing activities for the 'benefit' of oneself is by using a transitive structure, (37).

(37)a. John meN-jatuh-kan diri(-nya sendiri)
J ACT-fall-KAN self-3sg own
'John fell himself' i.e., he dropped his own self

b. Ira meN-sisir rambut-nya sendiri

I ACT-comb hair-3sg own

'Ira combed her own hair'

While ber-sisir 'to HAVE a comb' occurs as unergative reflexive (33c), meN-sisir 'to DO comb' occurs only as transitive, meN-sisir rambut 'to comb hair', (37b). In (37a,b) above the reflexive interpretation is gained from the argument self and one's own. Recall the structure John meN-jatuh 'John (deliberately) fell'/ 'John DO a fall' as unergative, (11) above. We may gain a reflexive interpretation from (11) because there is no other argument possible beside John's self, thus, in a way, John meN-jatuh as unergative is a "hidden reflexive", contrast with (37a) above. 
The root of the 'ber- only', group (II), is always a noun (i.e., can be classified as a noun) or a nominalised element, whereas the root of the 'meN- only', groups (I) and (IV), can be a verb or a noun. Some $m e N$-unergatives are potentially transitive (group IV), but ber-verbs are never transitive. To see more clearly the characteristics of $m e N$-and berunergatives, I put both in the same environments as minimal pairs considering occurrences where it is possible to have $m e N$ - or ber-, group (III).

(i) Both meN- and ber- can occur with a depictive item (an adverbial, or an adjective), (38).

(ii) Only structures with $m e N$ - can take a depictive noun (or 'specification of cognate object'), (39b).

(iii) If the structure takes a 'real object' then the verb is potentially transitive (as a transitive verb occuring 'intransitively'), and not a true unergative, (41), contrast with the unergative, (40).

(i). With a depictive lembut 'soft', adjective, adverbial:

(38)a. Angin ber-tiup lembut
wind BER-blow gentle
'The wind blows gently'
b. Angin meN-tiup lembut
wind ACT-blow gentle
'The wind blows gently"

(ii). Structures with $m e N$ - can take a depictive noun (or 'specification of cognate object'), but not structures with ber-, (39).

(39)a. *Paul ber-nyanyi Yellow Submarine di kamar mandi

$\mathrm{P}$ BER-sing in room bath

'Paul sang "Yellow Submarine" in the bathroom' [HAVE "Yellow Submarine"]
b. Paul meN-nyanyi Yellow Submarine di kamar mandi
$\mathrm{P}$ ACT-sing in room bath
'Paul sang "Yellow Submarine" in the bathroom' [DO "Yellow Submarine"]


In (39b) Yellow Submarine is the name of a song. The name depicts, or specifies a cognate object. The same structure, however, cannot take a cognate object such as a song, (40b).

\begin{tabular}{|c|c|c|c|c|}
\hline (40)a. *Paul & ber-nyanyi & se-buah & di kamar & $r$ mandi \\
\hline $\mathrm{P}$ & BER-sing & a-CLASS & in room & bath \\
\hline
\end{tabular}
b. *Paul meN-nyanyi se-buah lagu di kamar mandi $\mathrm{P}$ ACT-sing a-CLASS song in room bath 'Paul sang/[DO] a song in the bathroom'

Thus, neither ber-nyanyi nor meN-nyanyi is potentially transitive, they cannot even take a cognate object. These verbs are unergative, and only one, meN-nyanyi, takes a depictive noun, (39b). It turns out, that meN-tiup 'to blow' of (38b) above is not an unergative, as tested in (41b) below, because it takes an object such as daun-daun 'leaves'.

(iii). meN-tiup 'to blow' is not a true unergative:
(41)a. *Angin
ber-tiup daun-daun
wind
BER-blow leave-PL
'The wind is blowing the leaves'
b. Angin
wind
meN-tiup daun-daun
ACT-blow leave-PL
'The wind is blowing the leaves'

The verb meN-nyanyi in (39b) can take a depictive noun, but not a cognate object (40b). To take a cognate object such as sebuah lagu 'a song', the verb must be 'transitivised', with the kan-aspect as shown in (42) below.
(42)a. Paul
$\begin{array}{lll}\text { meN-nyanyi-kan } & \text { se-buah lagu } \\ \text { ACT-sing-KAN } & \text { a-CLASS song }\end{array}$
di kamar mandi
$\mathrm{P} \quad \mathrm{ACT}$-sing-KAN a-CLAS
'Paul sang a song in the bathroom'
b. *Paul ber-nyanyi-kan se-buah lagu di kamar mandi $P$ BER-sing-KAN a-CLASS song in room bath 'Paul sang a song in the bathroom' 
Thus, only the meN-unergative meN-nyanyi 'to DO a song' (42a) has the potential to take cognate objects, with the addition of the kan-aspect.

Like meN-nyanyi 'to DO a song', meN-tari 'to DO a dance' can only take a depictive noun, but not a cognate object, (43b). The verb in (43a) is transitive, and unergative in (43b-d).

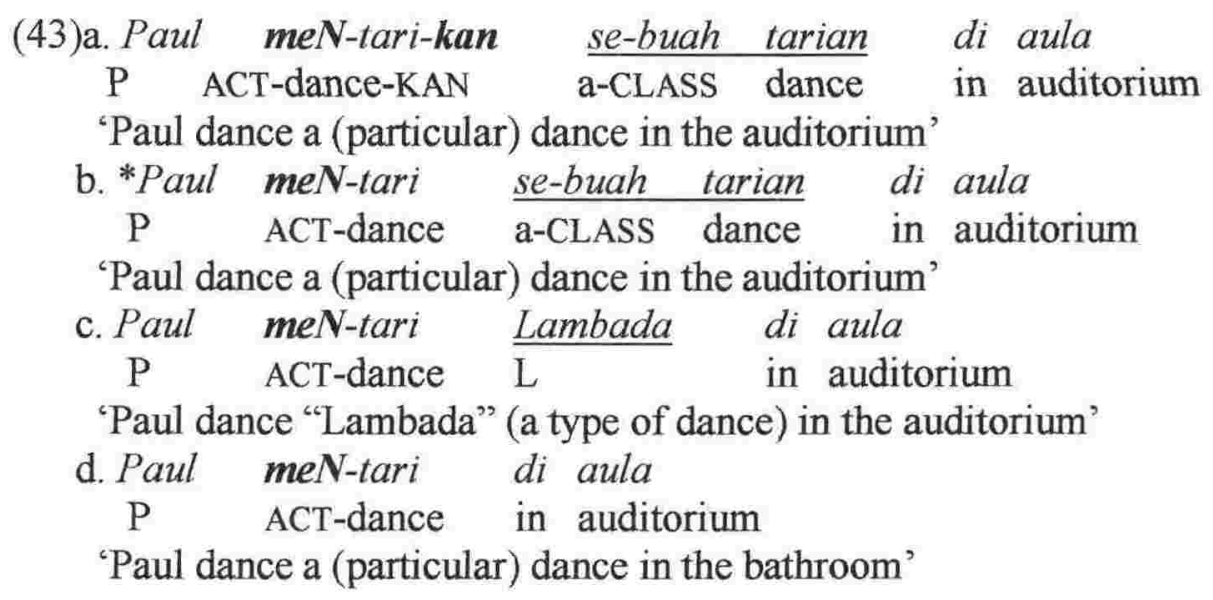

The examples (38)-(41) above also show that with the ber-unergative we cannot have an overt DP, not even an implicit one. In other words the internal argument of berunergative simply does not exist as a complement. The conflated noun (into predicate) itself is the complement of the head ber- [HAVE]. An argument that does not exist cannot be questioned, (44), contrast with (45).

$$
\begin{aligned}
& \text { (44)a. *Angin sedang ber-tiup APA? } \\
& \text { wind PROG BER-blow WHAT } \\
& \text { 'What is the wind blowing?' } \\
& \text { b. *Paul ber-nyanyi APA di kamar mandi? } \\
& \text { P BER-sing WHAT in room bath } \\
& \text { 'What is Paul singing in the bathroom?' }
\end{aligned}
$$

(45)a. Angin meN-tiup APA? wind ACT-blow WHAT

'What did the wind blow?'
b. Paul meN-nyanyi APA
di kamar mandi?
$\mathrm{P}$ ACT-sing WHAT in room bath
'What did Paul sing in the bathroom?' 


\section{c. Paul meN-nyanyi-kan APA di kamar mandi? \\ $\mathrm{P}$ ACT-sing-KAN WHAT in room bath \\ 'What did Paul sing in the bathroom?'}

The specification of cognate objects of meN-nyanyi 'to sing' (39b) and meN-tari 'to DO a dance' $(43 \mathrm{c})$, repeated here as $(46 \mathrm{a}, \mathrm{c})$, cannot undergo a displacement to the [SpecVoiceP] position in PASSIVE, (46b) and (46d), respectively.

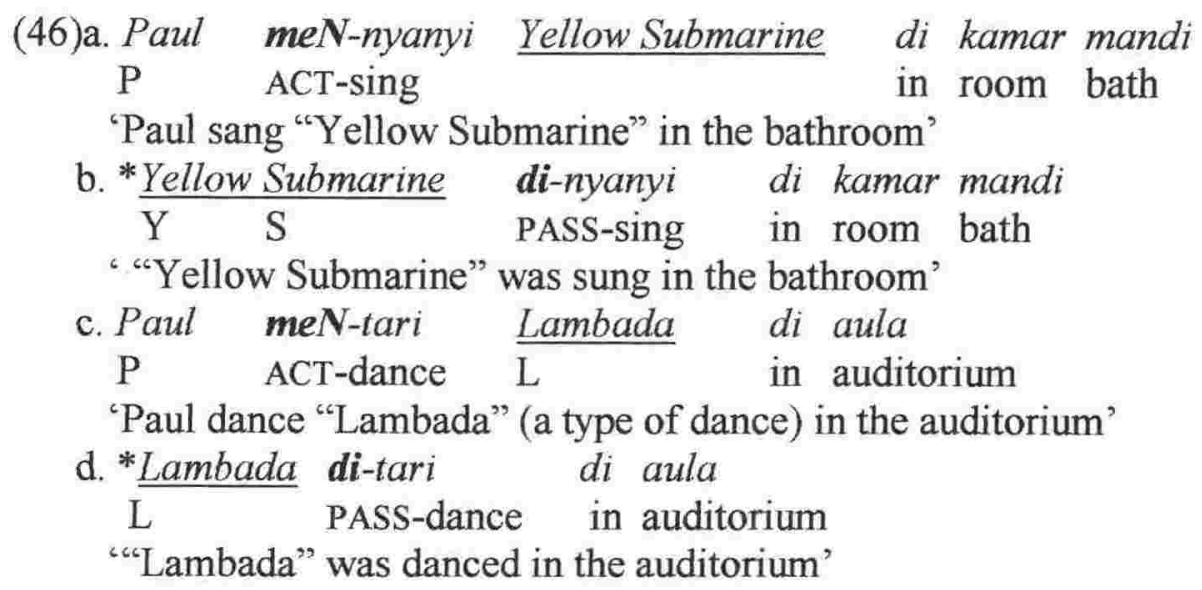

The non-occurrence of PASSIVES shown in $(46 \mathrm{~b}, \mathrm{~d})$, and the occurrence of depictive objects only, (39b) and (43c), lead us to conclude that the verbs meN-nyanyi to DO a song' and meN-tari 'to DO a dance' are unergatives. In Hale and Keyser's (1993) terms, the verbs to sing and to dance bear the sublexical [DO]. In our terms, however, we have two distinct activities of BI unergatives. The verb meN-tari 'to DO dance', for instance, is used for a more formal [DO] a dance than that of informal [HAVE] a dance (Note that we do not have *ber-tari). In BI, expressions such as the informal 'to HAVE a dance' is used for a different type of dance, for instance for social dances such as 'disco dances' where ber- is used: ber-joged/ber-disko, ber-dansa, ber-dang-dut, ber-lambada, ber-cha-cha, ber-a-go-go, and so on, depending on the types of accompanying music.

We have in our examples (32) above, the prefix ber-indicates 'to have something' such as to have blond hair, a head, legs and so on, and the complex predicates refer not to actions but rather, to states. Now we also have ber- indicating 'to HAVE an ACT' such as ber-dansa 'to HAVE a dance (a social, informal, dance)', where the ACT is 
leisurely/casually done. Other occurrences includes ber-renang 'to HAVE a swim', berjalan 'to HAVE a walk', ber-tandang 'to visit somebody without any particular reason', ber-gadang 'to stay awake all night without any purpose', and so on. Sneddon (1996) discusses the differences between the two intransitives also in terms of for whom and how an act is done: with ber- the act is done in a leisurely way for one's purposes, while with $m e N$ - it may also be for other people, and is not a leisure activity. Both true unergatives, however, do not derive a PASSIVE, because the real object [Spec-VP] does not appear, (47). ${ }^{7 \text { ) }}$

(47) True unergatives do not passivise:

a). meN-unergative:

menangis, *ditangis 'to cry'

menari, *ditari 'to dance'

menyanyi, *dinyanyi 'to sing'

b). ber-unergative:

berenang, *direnang 'to have a swim'

berjalan, *dijalan 'to have a walk'

bergadang, *digadang 'to stay awake'

datang, *didatang 'to come'

pergi, *dipergi 'to go'

${ }^{7)}$ For simplicity, I leave open the status of cognate objects. We can assume, however, that the depictive object of the $m e N$-unergative is a part of the conflated noun in the denominal predicate, like for instance, in meN-tari Bali 'to DO a Balinese Dance', (i), contrast with meN-tari-kan tarian Bali 'to dance a Balinese dance, (ii):
(i) Mereka
$3 \mathrm{pl}$ PROG ACT-dance B COMP modern
'They are (*modern) Balinese dancing' (Lit. Balinese which is modern)
(ii) Mereka sedang meN-tari-kan tarian Bali (yang modern)
3pl PROG ACT-dance-KAN dance B COMP modern
'They are performing a (modern) Balinese dance' (Lit. Balinese dance which is modern) 
In summary, BI has two different types of unergative: one bears the Voice head meN-, the other ber-. With ber- the ACT is done casually, such as have a swim, have a dance. There are verbs with $m e N$ - that appear like unergatives, but they are actually transitive verbs that occur without an overt object. The Voice head ber-cannot occur in transitive structures. The proposed BI unergative (17b) is repeated here, (48).

(48) BI unergative:

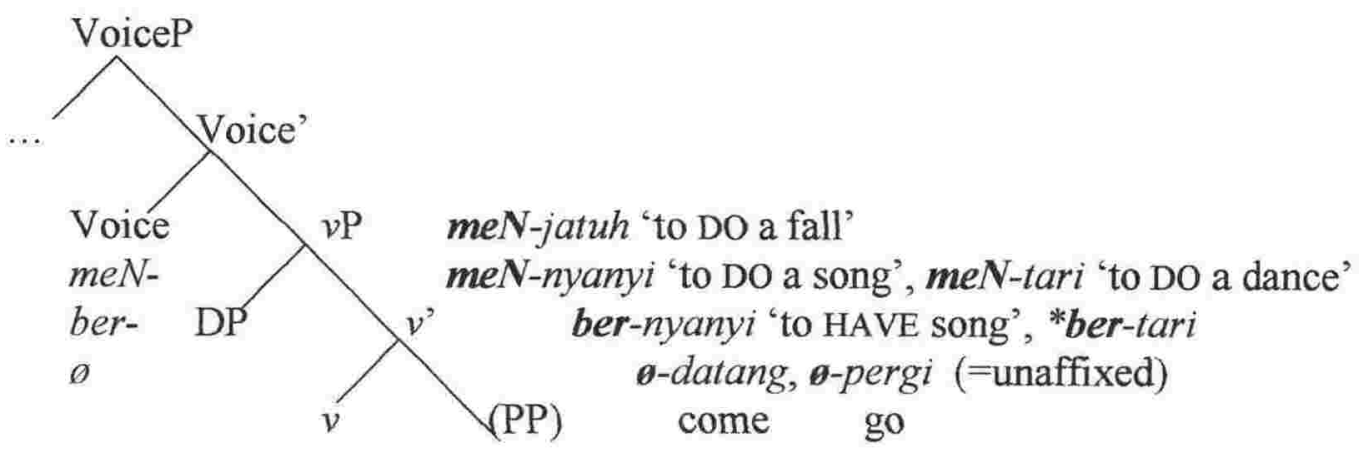

\subsubsection{The BI impersonal transitive (di-versus ter-, personal versus impersonal)}

We have discussed in sub-section 5.1.2 the Voice head ter-with the unaccusative jatuh 'to fall', where in the event of John ter-jatuh 'John fell', the fall must be interpreted as unintentional. In contrast, in the event of John meN-jatuh 'John did a fall', the fall must be interpreted as a deliberate ACT. In this sub-section I discuss the distribution of ter- in impersonal transitive structures. Consider the BI unaccusative verbs that mean 'to break': pecah (for solid objects that have a surface), patah (for solid objects with a length) and putus (for flexible objects with a length). While pecah, patah and putus can all occur unaffixed, as unaccusative, (49), only putus takes ter-, (50c).
(49)a. Gelas-nya pecah tumbler-3sg break "The tumbler broke"
b. Tangkai-nya patah stick-3sg break
'Its handle broke'




\section{c. Tali-nya putus string-3sg break \\ 'The string broke'}

\section{(50)a. *Gelas-nya ter-pecah tumbler-3sg TER-break \\ 'The tumbler broke' \\ b. *Tangkai-nya ter-patah stick-3sg TER-break \\ 'Its handle broke' \\ c. Tali-nya ter-putus string-3sg TER-break 'The string is broken/cut'}

The breaking of the tumbler (50a) or of the stick (50b) is easily unintentional, while in (50c) an effort (by an AGENT) is required to break the string. As before, with the unaccusative jatuh vs ter-jatuh 'to fall', where with the Voice head ter- the fall is unambiguously an accident, here we have putus vs ter-putus 'to break', (49c) vs (50c), which is also unambiguously an accident. While in both occurrences (the falling and the breaking) are understood to be unintentional, in the latter there is a sense that somebody unintentionally cut the string. Consider again John ter-jatuh 'John fell' (51a) to contrast with Tali-nya ter-putus 'The string is broken', (51b).

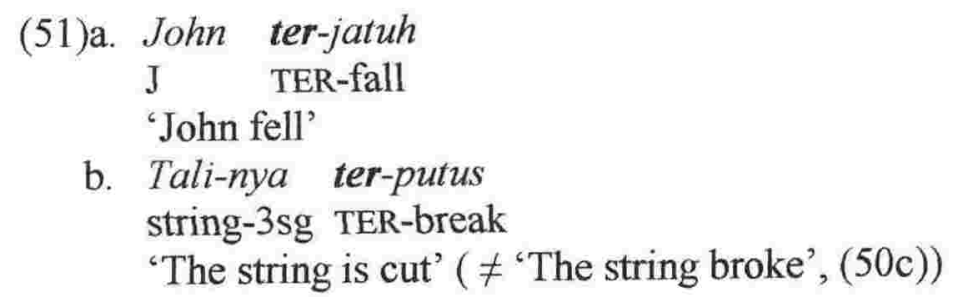

The interpretation that somebody unintentionally cut the string in (51b) can be contrasted with the intentional one, (52), where the PASSIVE Voice head di-is used.
(52). Tali-nya di-putus string-3sg PASS-break
'The string is cut' 
What makes the structure with ter- (51b) appear like an unaccusative is the nonoccurrence of an AGENT, (53b), as against (53a) with $d i$-. Although both are understood to have an AGENT, the AGENT with ter- in this case cannot be made explicit.

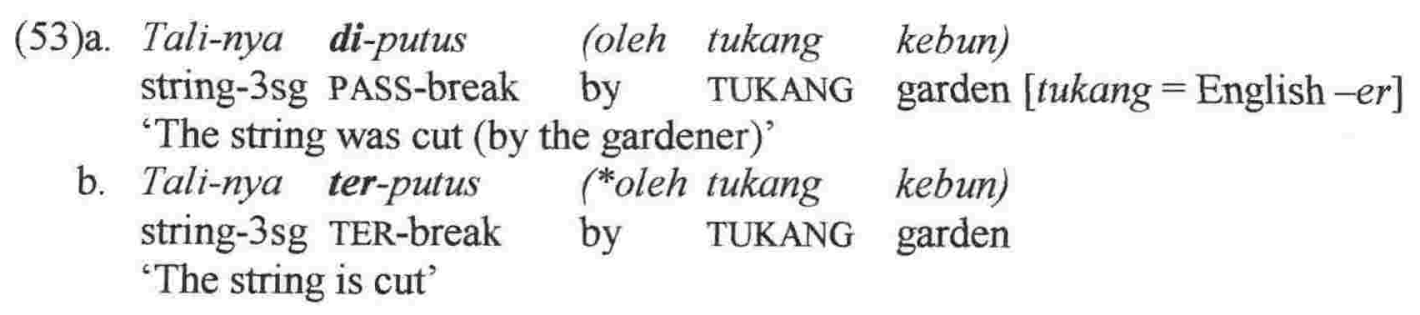

The crux of the discussion is obviously that if the event does not involve an AGENT we cannot have the notion of intention. In a single argument predicate where this sole argument is not an AGENT - i.e., unaccusative, (49) - there is no notion of intention. However, in both $(53 \mathrm{a}, \mathrm{b})$ an external CAUSE/force is involved, and we have the interpretation that the string was accidentally cut only in (53b). What we have here in (53) is a mild contrast between the agentive (with $d i$-) versus the non-agentive (with ter-) transitive, or, adopting Bowers' (2002) terminology, personal versus impersonal transitive, respectively. The pattern shown in (53) is consistent, (54) and (55).

(54)a. Pintu-nya di-buka (oleh Sar) door-3sg PASS-open by $\mathrm{S}$ 'The door is opened (by Sar)'

b. Pintu-nya ter-buka (*oleh Sar) door-3sg TER-open by $\mathrm{S}$ 'The door is open(-ed) (by Sar)'

(55)a. Jari-nya di-potong (oleh dokter) finger-3sg PASS-cut by doctor 'His finger was cut (by the doctor)'

b. Jari-nya ter-potong (*oleh dokter) finger-3sg TER-cut by doctor 'His finger was cut (by the doctor)' 
Although the by-phrase only appears in the (a) examples of (55) and (56) above, both diand ter-verbs can take untuk for-phrases, (56), but only the verb with ter- is a good candidate for adjectivals, as well as as a secondary predicate, (57).

(56)a. Pintu ini di-buka untuk semua orang door DEM PASS-open for all person 'This door is opened for all'

b. Pintu ini ter-buka untuk semua orang door DEM PASS-open for all person 'This door is open for all'

(57)a. Semua orang akan di-sambut dengan all person FUT PASS-greet with 'All will be welcomed with an open door'

b. *Semua orangakan di-sambut dengan pintu di-buka all person FUT PASS-greet with door PASS-open 'All will be welcomed with an opened door'

c. Para pemberontak akan di-sambut dengantanganter-buka PL rebel FUT PASS-greet with hand TER-open 'The rebels will be welcomed with open arms'

d. *Para pemberontak akan di-sambut dengan tangan di-buka PL rebel FUT PASS-greet with hand PASS-open 'The rebels will be welcomed with opened arms'

To note here is the similarity between the ter-verb - but not the $d i$-verb - and the berunergative, that is, beside occuring as a secondary predicate, they both refer not to action but to state.

To conclude, in the impersonal transitive there is no AGENT. Structurally, with ter- in general, either it is of unaccusative or of impersonal transitive, at the VoiceP layer the subject is moved up from [Spec-VP], i.e., which is an internal argument, either because $[\mathrm{Spec}-v \mathrm{P}]$ is empty, or because the $v \mathrm{P}$ is not projected, $(58)$, with sentences provided in (59). 
(58) BI impersonal transitive:

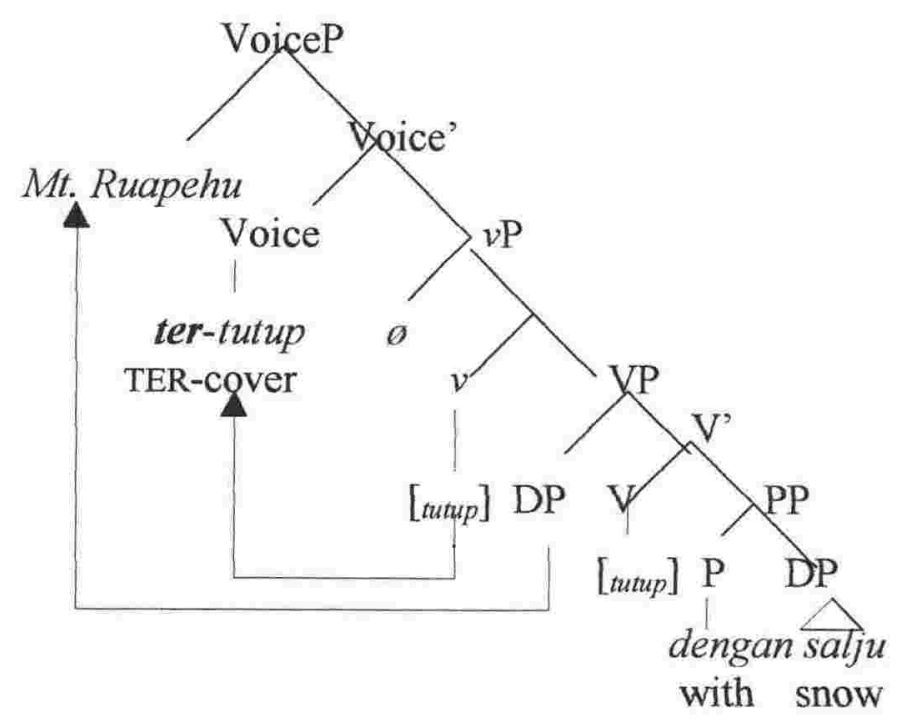
(59)a. Mt. Ruapehu ter-tutup (dengan) salju mount $\mathrm{R}$ TER-cover with snow 'Mt. Ruapehu is covered with snow'
b. Langit ter-tutup (dengan) awan gelap sky TER-cover with cloud dark 'The sky is covered with dark clouds'
c. Jalan-nya ter-tutup (dengan) pasir road-3sg TER-cover with sand
'The road is covered with sands'

Whoever covers the mountain with snow, or the sky with dark clouds, or the road with sands, does not enter the interpretation. The sentences in (59) do not have the ACTIVE meN- counterpart, (60) below, because [Spec- $v$ P], the position for AGENT/CAUSER, is empty, (58).
(60)a. *Salju meN-tutup Mt Ruapehu snow ACT-cover MR 'Snow covers Mt. Ruapehu'
b. *Awan gelap meN-tutup langit cloud dark ACT-cover sky 'Dark clouds cover the sky'




\section{c. *Pasir meN-tutup jalan sand ACT-cover road 'Sands cover the road'}

I have argued in Chapter 4 that the argument salju 'snow' as in (59a) is neither an AGENT nor a CAUSER, and I have assumed that the position [Spec- $v \mathrm{P}]$ is empty. It is impossible to find an AGENT that has (an) intent to bring about the event of covering the $M t$. Ruapehu with snow, (59a). There is no intention on the part of the snow to bring about the event of covering the mountain. The sentences in (60) can be rescued with the $i$ aspect, (61).

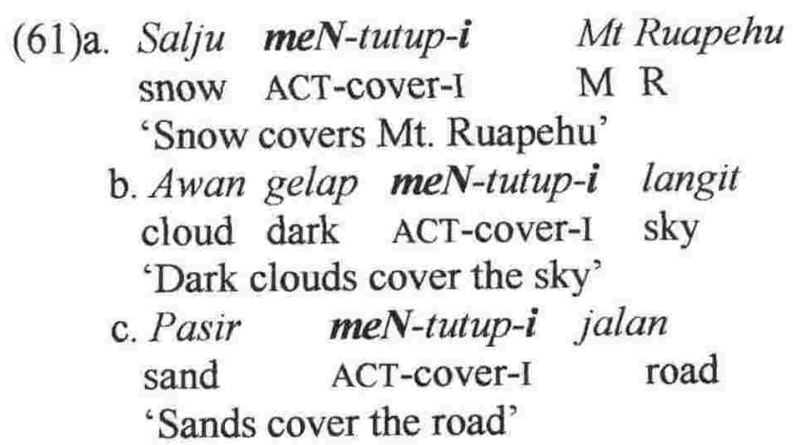

In the context of AGENT/CAUSER versus THEME, I concluded in Chapter 4 that the subjects salju 'snow' (61a), awan gelap 'dark clouds' (61b), and pasir 'sands' (61c), are THEMES. One of the main points argued for in Chapter 4 is that a THEME cannot occupy the surface subject position unless the $i$-aspect is at work. This seems correct, because sentences in (60) are acceptable only with the $i$-aspect, (61).

\subsubsection{Predicates with -kan: ber- $\sqrt{-k a n}$ and ter- $\sqrt{ }-k a n$}

There has been no mention of $-k a n$ or $-i$ in the discussion of the Voices ber- and ter- so far. This sub-section demonstrates that the prefixes ber-and ter-can co-occur with the suffix -kan as secondary predicates (in a small clause, an adjunct, or perhaps as an adverbial). In the complex predicate ber- $\sqrt{ }-k a n$ the stative reading of the predicate ber- $\sqrt{ }$ is retained, and in the complex ter- $\sqrt{ }$-kan the non-agentive reading of ter- $\sqrt{ }$ is retained. 


\subsubsection{1. ber- $\sqrt{ }$-kan}

The complex ber- $\sqrt{ }-k a n$ has two characteristics: one is the characteristic of being a berunergative (a state) and the other being a denominal kan-predicate (a light verb that takes a cognate object as a complement). The "meaning" of the predicate ber- $\sqrt{ }-k a n$ can be explained in terms of a combination of these two characteristics (Sneddon 1996:110112). For instance, in ber-senjata-kan 'armed with something', we have 'to HAVE a weapon' as the first characteristic and 'to use something as a weapon' as the second. I aim to show that the analysis of kan-aspect used in conjunction with ber-unergative is consistent with the two phenomena discussed in the previous sections, firstly, berunergative does not take an object (because the object is conflated as the verb), and secondly, with the kan-aspect, the change may contain a manner component (discussed in Chapter 3). In other words, it is possible for the kan-aspect (with the characteristic of being transitive, having CAUSE interpretation, and encoding change) to co-occur with the ber-unergative, forming a single complex predicate. In (62) below, a simple English translation is given for each complex predicate.

\begin{tabular}{|c|c|c|}
\hline $\begin{array}{c}\text { a. ber-senjata-kan } \\
\text { arm }\end{array}$ & $\begin{array}{l}\text { pedang } \\
\text { sword }\end{array}$ & 'BE armed with a sword' \\
\hline $\begin{array}{l}\text { b. ber-mandi-kan } \\
\text { bath }\end{array}$ & $\begin{array}{l}\text { sinar bulan } \\
\text { light moon }\end{array}$ & 'BE bathed in moonlight' \\
\hline $\begin{array}{c}\text { c. ber-atap-kan } \\
\text { roof }\end{array}$ & $\begin{array}{l}\text { ilalang } \\
\text { grass }\end{array}$ & 'BE roofed with grass' \\
\hline $\begin{array}{c}\text { d. ber-hias-kan } \\
\text { ornament }\end{array}$ & $\begin{array}{l}\text { bintang-bintang } \\
\text { star-PL }\end{array}$ & 'bedecked with stars' \\
\hline
\end{tabular}

However, by using Sneddon's (1996) analysis, we have two characteristics for each of the ber- $\sqrt{-k a n}$ of (62): (63) is the first, with ber-unergative, and (64) is the second, with the kan-aspect.

(63) Without -kan, ber-unergative:
a. ber-senjata
arm
e.g. pasukan ber-senjata contingent arm 
b. ber-mandi

bath/wash

e.g. langit ber-mandi sky

bath

c. ber-atap

roof

e.g. rumah/gubug ber-atap house/hut

roof 'to have a bath/a wash'

'bathed sky'

'to have a roof' d. ber-hias

ornament

e.g. Ria ber-hias 'to have make up on'/"to decorate oneself'

'Ria put on make up'

(64) With -kan, transitive with the kan-aspect encoding change with a manner component:

a. senjata-kan pedang 'to use swords as a weapon' weapon-KAN sword

b. mandi-kan sinar bulan 'to use moonlight as a bath' bath-KAN light moon

c. atap-kan ilalang 'to use grass as a roof' roof-KAN grass

d. hias-kan bintang-bintang 'to use stars as a decoration' decorate-KAN star-PL

The characteristic of being a state, non-action predicate is retained, as is apparent in the following sentences, (65), using the complex ber- - -kan of (62) above.

$\begin{array}{cllll}\text { (65)a. Dengan ber-senjata-kan } & \text { pedang prajurit maju } & \text { ke muka } \\ \text { with BER-weapon-KAN } & \text { sword } & \begin{array}{l}\text { soldier } \\ \text { move to front }\end{array}\end{array}$ 'Armed with swords, the soldiers move forwards'

b. Malam indah ber-mandi-kan sinar bulan night beautiful BER-bath-KAN light moon 'The night is beautiful bathed in the moon light'

c. Rumah-nya gubug ber-atap-kan ilalang house-3sg hut BER-roof-KAN grass

'The house is a hut with a grass roof' 


\section{c. Langit cerah ber-hias-kan bintang-bintang \\ sky bright BER-decoration-KAN star-PL \\ 'The sky is bright bedecked with/in stars'}

In sum, our analysis of kan-aspect used in conjunction with ber-unergative is consistent with the two phenomena discussed in the previous sections, firstly, berunergative does not take an object (because the object is conflated as the verb), and secondly, with the kan-aspect, the change may contain a manner component (discussed in Chapter 3). In other words, it is possible for the kan-aspect (with the characteristic of being transitive, having CAUSE interpretation, and encoding change) to co-occur with the ber-unergative, forming a single complex predicate.

\subsubsection{The predicate $t e r-\sqrt{ }-k a n$ as a negative polarity item (NPI)}

In this sub-section I will demonstrate that the occurrence of ter- $\sqrt{-}-k a n$ is restricted as secondary predicates (in a small clause), in particular, as an NPI. The negation head tak must appear, the (b) examples; the predicate cannot occur as a main verb, both (c) and (d) examples.

(66)a. Tidur-nya nyenyak tak ter-bangun-kan sleep-3sg soundless NEG TER-wake-KAN 'His sleep is soundless unwakeable'

b. *Tidur-nya nyenyak ter-bangun-kan sleep-3sg soundless TER-wake-KAN 'His sleep is soundless wakeable'

$\begin{array}{cll}\text { c. }{ }^{*} \text { Tidur-nya } & \text { tak } & \text { ter-bangun-kan } \\ \text { sleep-3sg } & \text { NEG } & \text { TER-wake-KAN }\end{array}$ 'His sleep is unwakeable'

d. *Tidur-nya ter-bangun-kan sleep-3sg TER-wake-KAN 'His sleep is wakeable'

(67)a. Hati-nya gembira tak ter-kata-kan heart-3sg glad NEG TER-word-KAN

'He is so glad undescribeable' (undescribably glad)

b. *Hati-nya gembira ter-kata-kan heart-3sg glad TER-word-KAN 'He is so glad describeable'

c. *Hati-nya tak ter-kata-kan heart-3sg NEG TER-word-KAN 'His heart is undescribeable' 


\section{d. *Hati-nya ter-kata-kan heart-3sg TER-word-KAN \\ 'His heart is describeable'}

\section{(68)a. Tentara kerajaan Amrta kuat tak ter-kalah-kan} army kingdom A strong NEG TER-defeat-KAN 'The army of Amrta kingdom is strong undefeatable' (undefeatably strong)
b. *Tentara kerajaan Amrta kuat ter-kalah-kan army kingdom A strong TER-defeat-KAN

"The army of Amrta kingdom is strong defeatable'
c. *Tentara kerajaan Amrta tak ter-kalah-kan army kingdom A NEG TER-defeat-KAN 'The army of Amrta kingdom is undefeatable'
d. *Tentara kerajaan Amrta ter-kalah-kan army kingdom A TER-defeat-KAN 'The army of Amrta kingdom is defeatable'

The occurrence of tak ter- $\sqrt{ }-k a n$ as a secondary predicate in the examples (66)-(68) above is what Pylkkänen (2002:89-90) calls "unaccusative causative". Sneddon (1996:112) calls it "abilitative", corresponding to the English [V-able], in this case, [un-V-able]. Pylkkänen uses occurences like (66)-(68) above to argue that the functional elements CAUSE and VOICE are independent of each other, and Pylkkänen concludes that both structures (69a,b) below are possible (As a reminder, Pylkkänen's (2002) "CAUSE" head is Bower's (2002) "Tr", our v-kan).
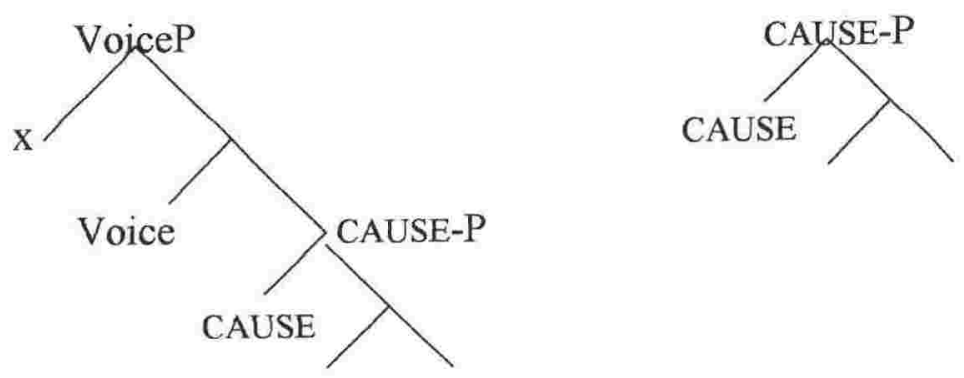

As we have seen in the BI examples, however, we have two different distributions of the Voice head ter-: one is with the unaccusative (sub-section 5.1.2, structure (12)), the other with the impersonal transitive (sub-section 5.2.2, structure (58)). In both cases, it is the 
internal argument that moves to the [Spec-VoiceP]. It is more likely that the BI complex predicate ter- $\sqrt{ }$-kan in examples (66)-(68) above is that of impersonal transitive (i.e., transitive-causative) structure, rather than that of "unaccusative causative" one. This is the case where the structure does not have an AGENT - i.e., [Spec-vP], the position for AGENT is empty - as is apparent also in the English translation ("unwakeable", "undescribeable", "undefeatable").

\subsubsection{Frighten versus fear verbs}

I have argued that to derive a PASSIVE in BI an AGENT must be present at [Spec-vP]. Our analysis is on the right track. We shall demonstrate that if a $v \mathrm{P}$-aspect does not alternate with another, then we only have the PASSIVE form of this particular $v \mathrm{P}$-aspect and not the other. From the following examples (70) we strike two phenomena. One is where in BI to derive a PASSIVE form an AGENT must be present at the [Spec- $\nu \mathrm{P}]$ and the other is where there is no ACTIVE form with $-i$ there is no PASSIVE form with $-i$ (And where there is no ACTIVE form with -kan, there is no PASSIVE form with $-k a n)$. The examples (70) are taken from Sub-section 4.2.2.1, psych-predicates, examples (41).

(70) Change of state
a. Berita itu meN-sedih-kan ibu newS DEM ACT-Sad-KAN mother 'The news saddened mother' (made mother sad)
b. Suara-nya meN-takut-kan anak-anak voice-3sg ACT-afraid-KAN child-PL 'His voice scared the children' (made the children afraid)
c. Cerita-nya meN-bosan-kan saya
Story-3sg ACT-bored-KAN 1sg 'His story bored me' (made me bored)

Each form in (70) involves a CAUSER but not an AGENT, and does not have the $i$-aspect counterpart, (71).

(71) Change of state
a. *Berita itu
meN-sedih-i ibu
news DEM
ACT-sad-I mother
'The news saddened mother' (made mother sad) 


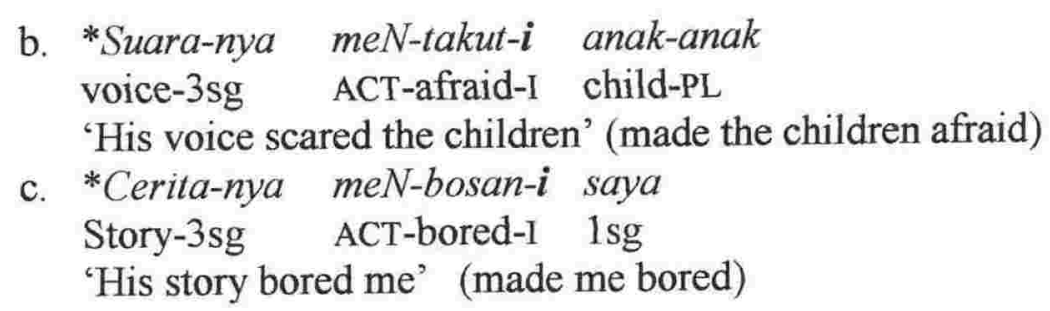

In addition, each form in (70) does not have the PASSIVE counterpart, (72).

(72)a. *Ibu di-sedih-kan (oleh) berita itu
mother PASS-sad-KAN by news DEM
'Mother was saddened by the news' (mother was made sad)
b. *Anak-anak di-takut-kan (oleh) suara-nya
child-PL PASS-afraid-KAN by voice-3sg
'The children were scared by his voice' (the children were made afraid)
c. *Saya di-bosan-kan (oleh) cerita-nya
1sg PASS-bored-KAN by story-3sg
'I was bored by his story' (I was made bored)

In (72) the CAUSERS berita itu 'the news', suara-nya 'his voice', and cerita-nya 'his story' cannot be the argument of the PP oleh by-phrase. Like the CAUSERs in (72), suara Maria 'Maria's voice' in (73a) below cannot be the argument of the PP by-phrase, because meN-senang-kan is derived from that of senangl (i.e., that of frighten verbs) 'BE glad, BE pleased', (73b).

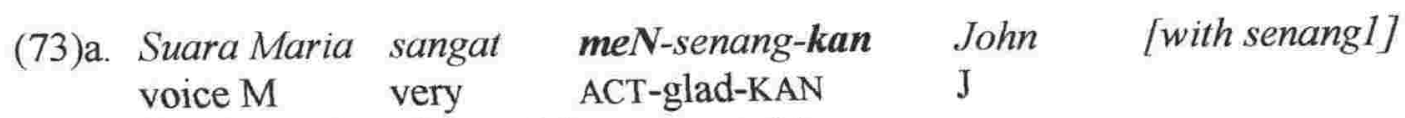 'Maria's voice pleases John very much'
b. *John sangat di-senang-kan (oleh) suaraMaria [with senangl] $\mathrm{J}$ very PASS-glad-KAN by voice $\mathrm{M}$ 'John was pleased by Maria's voice very much'

Recall that the form in (73a) does not have the $i$-aspect counterpart, (74).

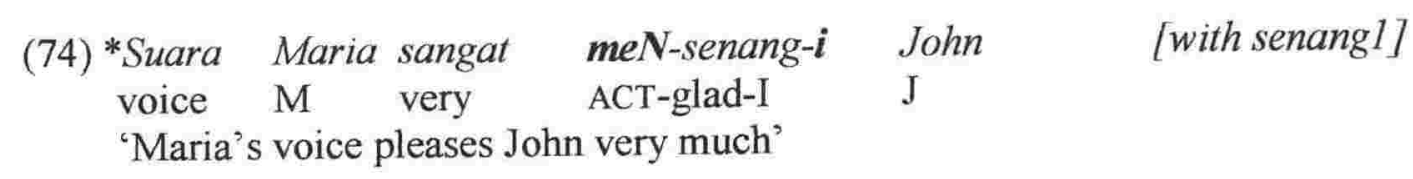

There is no PASSIVE form of (74); the form simply does not derive, because a CAUSER cannot be involved in an event with the $i$-aspect. It is thus pointless to try to derive a 
PASSIVE with $-i$ when the ACTIVE form counterpart is unacceptable, (74). With senang2 (i.e., that of fear verbs) 'to like, BE fond of', however, we have the ACTIVE/PASSIVE forms, (75).

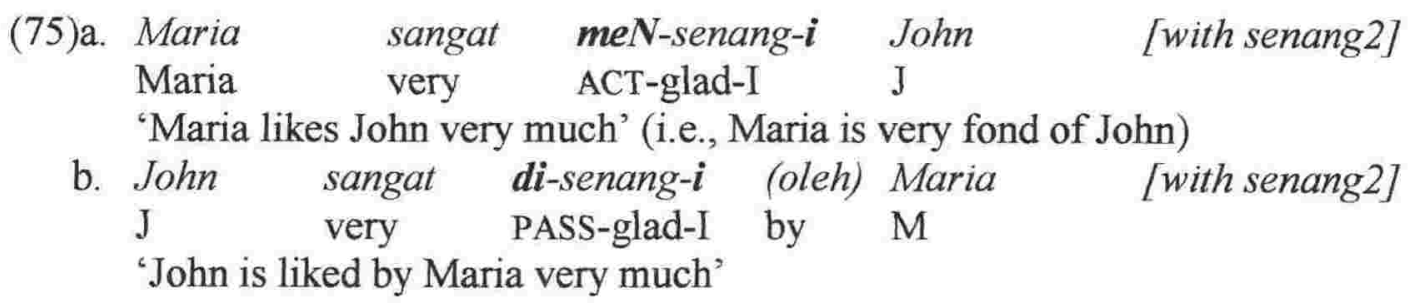

But Maria in both examples (75a,b) is an AGENT(-Experiencer), thus different from (73a) and (74) where a CAUSER is involved in the derivation. To conclude, the predicate disenangi 'to be liked' shown in the example (75b) is not the PASSIVE alternant of menyenangkan 'to please, pleasing' of (73a), it is a separate beast entirely.

As another example, consider (76). The explanation is the same as above.

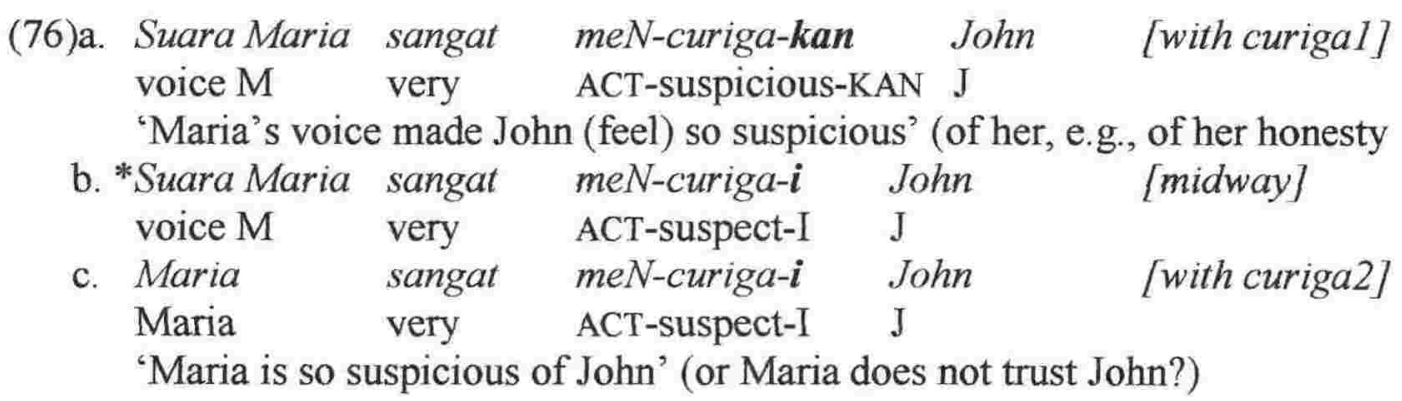

The form (76c) has a PASSIVE form but not (76a): in (76a) we have a CAUSER, but in (76c) we have an AGENT. The lack of PASSIVE derivation is shown in $(77 \mathrm{a}, \mathrm{b})$ below.
(77)a. Suara Maria sangat meN-curiga-kan John [withcurigal] voice $M$ very ACT-suspicious-KAN J 'Maria's voice made John (feel) so suspicious' (of her, e.g., of her honesty)
b. *John sangat di-curiga-kan (oleh) suara Maria [with curigal] $J$ very PASS-suspicious-KAN by voice $M$ 'John was suspected by Maria's voice very much'

And again, (77a) is a separate beast entirely, from (78a,b). 


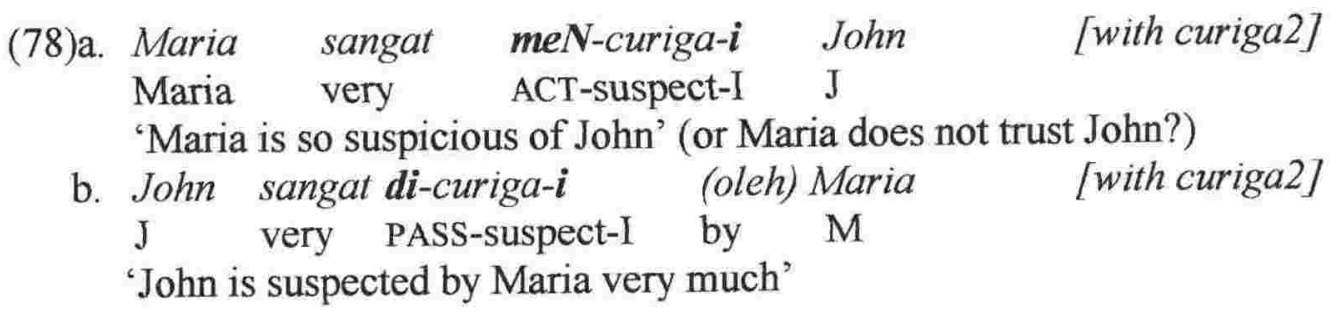

Different from (77a), where a CAUSER is involved, in the following example (79a) it is an AGENT $i b u$ 'mother' that is involved in the event of thickening the gravy, and we have a PASSIVE form, (79b) (Recall that a CAUSER cannot be involved in the event such as (79), i.e., mengentalkan 'to thicken something' is not a psych-predicate).

$\begin{array}{lll}\text { (79)a. Ibu sedang meN-kental-kan kuah-nya } & \text { kavy-3sg } \\ \text { mother PROG ACT-thick-KAN } & \text { grav } \\ \text { 'Mother is thickening the gravy' } & \\ \text { b. Kuah-nya sedang di-kental-kan } & \text { (oleh Ibu) } \\ \text { gravy-3sg PROG PASS-thick-KAN mother } & \text { 'The gravy is being thickened (by mother)' }\end{array}$

Since (79a) does not alternate with the $i$-aspect, as discussed in Sub-section 4.2.2.2, then there is no PASSIVE form with $-i$. We do not have the form *dikentali because there is no such a form *mengentali, whatever these two forms may mean. The predicate kental 'thick' is an end-state, and the kan-predicate with kental takes a THEME as complement (Sub-section 3.2.6). 


\subsubsection{Summary}

To conclude the discussion of BI VOICE I will sum up the main points I made:

1. From our observation, we gain an important insight that in BI all sentences display VOICE, whereas not all sentences display transitivity (not all structures have the $v$ P). I propose following Bowers (2002) and Pylkkänen (2002) that the Voice head is separate from the transitivity head.

2. Bowers (2002) argues that the Voice head "relates" the surface subject to the predicate. Pylkkänen (2002) spells out what the subject is, in terms of external versus internal arguments. In Pylkkänen's terms, the Voice head "introduces" the surface subject. Our analysis supports Bowers (2002) and Pylkkänen (2002). I have shown that the surface subject "introduced" by the Voice head has an origin, either from [Spec-vP] or from [Spec-VP] (See Table (84) below), i.e., consistent with their roles in constructions which have an AGENT/CAUSER argument in [Spec- $\nu \mathrm{P}]$.

3. The BI vOICE system is not just about ACTIVE versus PASSIVE VOICES, or, meNversus $d i$ - The Voice head correlates with the structure it occurs in, that is, it is dependent on the available argument, because it checks an argument as a surface subject. Some ACTIVE sentences in BI do not have PASSIVE counterparts, and vice versa. For instance, an ACTIVE sentence with $m e N$ - lacking an AGENT (Psychpredicate of the frighten / "THEME-experiencer" verbs) does not have the diPASSIVE counterpart, and conversely, an impersonal PASSIVE with ter- does not have the ACTIVE counterpart.

4. BI has two different unergatives, $m e N$-unergatives and ber-unergatives, although both are denominals. The former are true light verbs, whereas the latter are vague action verbs. In $\mathrm{BI}$ we also have the contrast between the personal and the impersonal transitives, namely, the personal transitive with the ACTIVE $m e N$ - and the PASSIVE di-, against the impersonal (PASSIVE) with ter- (but no ACTIVE counterpart).

5. As a general picture, the morphological realisations of the BI Voice head and the related structures are tabularised as follows, (83). 
(80) BI Voice heads and the related structures:

\begin{tabular}{|l|c|c|c|c|c|}
\hline Voice & kan-transitive & i-transitive & $\varrho$-transitive & unergative & unaccusative \\
\hline$m e N-$ & + & + & + & + & - \\
\hline$d i-$ & + & + & + & - & - \\
\hline ber- & + & - & - & + & - \\
\hline ter- & + & - & - & - & $($ i $)+$ \\
\hline \multicolumn{7}{r}{} & & & & $\begin{array}{c}\text { (ii) impersonal } \\
\text { transitive }\end{array}$ \\
\hline
\end{tabular}

Note: '+' occurs; '-' doesn't occur; I ø-transitive has a root that can be categorised as transitive.

From (80) we see that:

$m e N$ - occurs in/with both transitives and intransitives;

$d i$ - occurs only in/with transitives;

ber- occurs in unergatives and in kan-transitive, ter- occurs in unaccusatives and in kantransitive.

6. The argument roles checked by the Voice head as the subject are tabularised as follows, (81a). The BI transitivity (i.e., predicate valency) is shown in (82b).

(81)a.

\begin{tabular}{|c|c|c|c|}
\hline Voice & subject & origin & structure \\
\hline \multirow[t]{3}{*}{$m e N-$} & AGENT & {$[\mathrm{Spec}-v \mathrm{P}]$} & all transitives, unergative \\
\hline & CAUSER & {$[\mathrm{Spec}-v \mathrm{P}]$} & kan-transitive, Psych-predicates \\
\hline & THEME & [V-DP complement] & $i$-transitive \\
\hline \multirow[t]{2}{*}{ ber- } & AGENT & {$[$ Spec- $v \mathrm{P}]$} & unergative \\
\hline & AGENT & {$[$ Spec- $v \mathrm{P}]$} & unergative with kan-transitive \\
\hline \multirow[t]{2}{*}{$d i$} & THEME & [Spec-VP] & kan-transitive, $\varnothing$-transitive \\
\hline & PATIENT & [Spec-VP] & $i$-transitive, $₫$-transitive \\
\hline \multirow[t]{3}{*}{ ter- } & "EXPERIENCER" & {$[$ Spec-VP] } & unaccusative \\
\hline & & & unaccusative with kan-transitive \\
\hline & & & impersonal transitive \\
\hline
\end{tabular}


(81)b. BI transitivity:

1. transitives: kan-transitive $i$-transitive o-transitive

2. unergatives: meN-unergative ber-unergative o-unergative

3. unaccusatives: ter-unaccusative $\emptyset$-unaccusative

I $\sigma$-transitive, $\sigma$-unergative, and $\sigma$-unaccusative each has a root that can be categorised as a transitive, unergative or an unaccusative verb. The rest are derived by means of affixes.

\subsection{Derivations above VoiceP: Aspect merge and edges}

Finally, we come to the end of a complete derivation: (Temporal, vP-external) Aspect merge and edges. The subject-predicate relation of the VoiceP discussed in the previous sections (5.1 and 5.2) continues to be crucial for a further derivation, be that of the Aspect merge, or of 'Wh-extractions'. The first sub-section (5.3.1) discusses the final stage of the complete derivation of BI declarative sentences involving Aspect merge. The second sub-section (5.3.2) discusses derivations as required in sentences with other types of force, such as imperatives and interrogative sentences.

\subsubsection{Aspect merge}

In the previous sections we saw that VOICE is distinct from transitivity. We saw that VOICE is related to the argument structure of the predicate $(v \mathrm{P} / \mathrm{VP})$ but, up till now, timerelated interpretation has not entered the discussion. I have shown that the surface subject 'introduced' by the Voice head has an origin, either from [Spec- $v \mathrm{P}$ ] or from [Spec-VP], i.e., consistent with their roles in constructions which have an AGENT/CAUSER argument in [Spec- $v \mathrm{P}]$. The Voice head correlates with the structure it occurs in, that is, it is dependent on the available argument, because it checks an argument as a surface subject.

Following Chomsky's (1999:9-11) notion of "edge", $\left.{ }^{8}\right)$ in the present section I propose that argument role is relevant only as far as the Voice Phrase. Once the Spec- 
head relation is established at the VoiceP layer, which I assume to be the lowest edge, derivations that follow only involve the move of either the edge or the head, or elements adjoined to the edge.

I will discuss the BI Aspect as far as it shows the sentence's morpheme order. It is not my aim to discuss in detail the semantics of Aspect in relation to the event structure. There is already a large body in literature on temporal Aspect (for instance, Reichenbach 1947, Comrie 1976, Stowell 1995, Giorgi and Pianesi 1997, Smith 1997, Cinque 1999, Kearns 2000, to name a few). In general, in BI sentences, Aspect occurs freely, realised as a MODAL or MODALs, to merge with the VoiceP. However, there are instances when some MODALs cannot occur. It is not my aim to show all occurences of BI Aspect, but rather, it is of interest here to discuss why some MODALs cannot occur.

Before we go on further, I must clarify that BI does not have tenses such as "past tense", "present tense", "future tense", or "present/past continous tense". What we have in BI is what Comrie (1976) and Tobin (1993) call "tense aspect" - and I have adopted, and abbreviated the term as "Aspect". Following Comrie (1976), I assume that Aspect falls into two categories, the unmarked [-perfective] and the marked [+perfective]. These [ \pm perfective] features code whether the event has or has not been completed.

In Chapter 2 (2.3.2.1) I gave a list of the BI MODALs representing the [ \pm perfective] Aspect. I have also demonstrated with examples in sub-section 2.3.2.1 that some BI MODALs carry a particular feature that I notated as [ \pm expected]. For instance, the [+perfective] sudah 'HAVE' carries [+expected] feature, as in the English "I HAVE eaten

8) Chomsky's (1999:9-11) notion of "edge" is extracted as follows: For strong phase HP with head $\mathrm{H}$,

(i) The domain of $\mathrm{H}$ is not accessible to operations outside HP, but only $\mathrm{H}$ and its edge, the edge being the residue outside of $\mathrm{H}$-bar, either SPECs or elements adjoined to HP.

Accessibility of $\mathrm{H}$ and its edge is only up to the next strong phase, under the Phase Impenetrability Condition (PIC), in (ii), elements of HP are accessible to operations within the smallest strong ZP phase but not beyond.

(ii) $[\mathrm{ZP} Z \ldots[\mathrm{HP} \quad \alpha[\mathrm{H} \mathrm{YP}]]]$ 
the apple", as against the [+perfective] baru that carries [-expected] feature (in English, the sentence "I ate the apple" may be used to contrast the [+expected] "I HAVE eaten the apple"). I argued in Chapter 3 (3.3.1.1 and 3.3.1.2) that the notion that some MODALs carry [ \pm expected] feature is separate from the notion of intention belonging to the event structure (e.g., agentive versus eventive), although the two notions interact with each other.

Because BI Aspect is realised as a MODAL, it easily carries certain meanings, comparable to the English modals HAVE, WILL, CAN, HAVE NOT, OUGHT, MUST, MAY, HAVE TO, DARE and so on. We shall find out what it is about both Aspect and VOICE that prevents some realisation of Aspect. We start with a [-perfective] Aspect, the progressive. Sub-sections 5.3.1.1 discusses progressive with canonical state predicates, 5.3.1.2 progressive with agentive event, 5.3.1.3 shows progressive in state versus process predicates. Sub-section 5.3.1.4 discusses future with the psych-predicates, sub-section 5.3.1.5 shows that the sub-feature [ \pm expected] pertaining to [-perfective] applies also to the $[+$ perfective]. Examples of sentences with combination of two MODALs will be given in 5.3.1.6. The derivation involving the Aspect merge is proposed in 5.3.1.6.

\subsubsection{The progressive with canonical state predicates}

The progressive interacts with aspectual event classes (Tenny 1987, Arad 1998, Kearns 2000), and I have acknowledged this premise, as outlined in Chapter 2. However, I will demonstrate that $\mathrm{BI}$ has a distinction between the progressive sedang, which is [+expected] and masih, [-expected]. State predicates like those in (82) resist the progressive sedang ([-perfective], [+expected]).

(82)a. Saya tahu (tentang) jawaban-nya

1 sg know about answer-3sg

'I know the answer'

a' *Saya sedang tahu (tentang) jawaban-nya

$1 \mathrm{sg}$ PROG know about answer-3sg

'I am knowing the answer' 


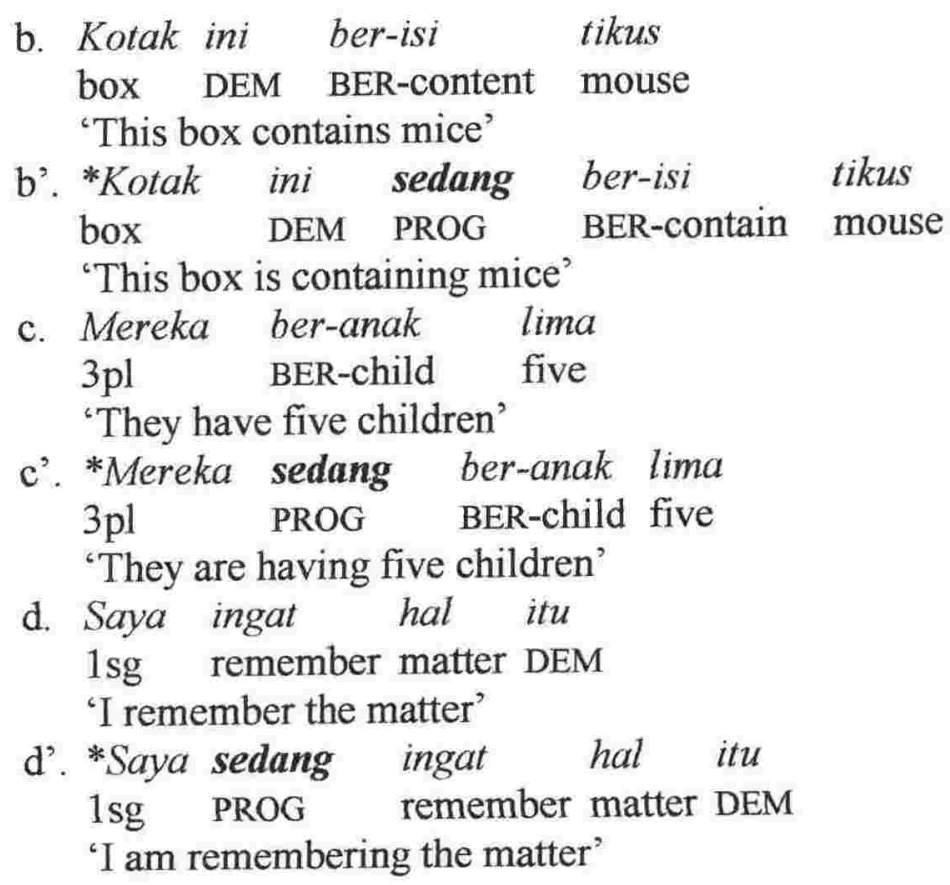

However, all the examples in (82) above are grammatical if the progressive masih, ([-perfective] [-expected]) is used instead, (83).

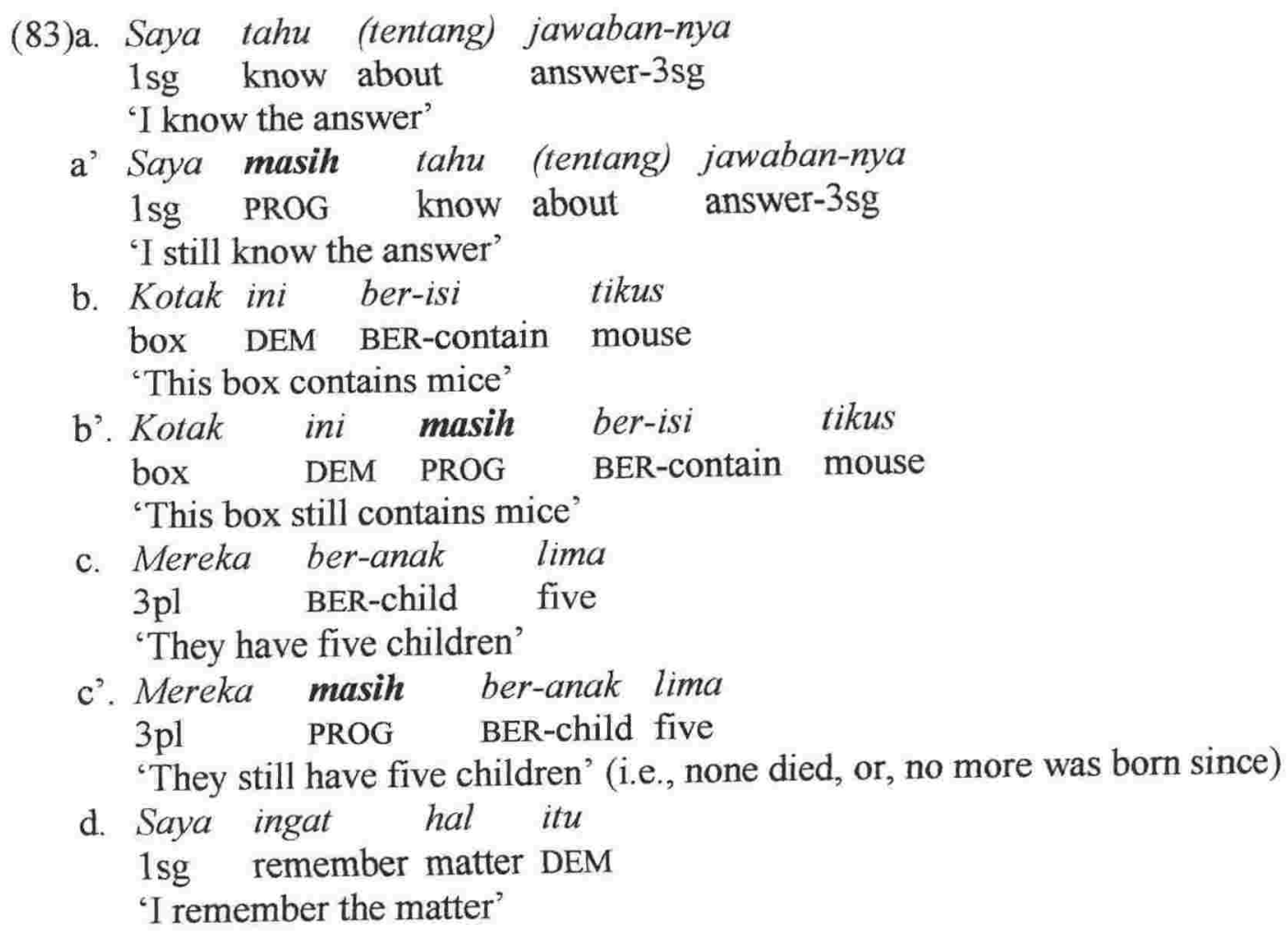


d'. Saya masih ingat hal itu

1sg PROG remember matter DEM

'I still remember the matter'

The difference in features [ \pm expected] seems to matter, because both sedang and masih are both [-perfective] (and both are progressive). The meaning given by the [-expected] masih for all the sentences in (83) is that it is not expected that the state still 'remains as before'. The 'sub-features' [ \pm expected] of [-perfective] seem to hold on to other occurences, such as with agentive versus causative events, (5.3.1.2) below.

\subsubsection{The progressive with agentive and causative events}

Agentivity of VoiceP and Aspect do not seem to be entirely independent. A structure with an AGENT at [Spec-VoiceP] takes sedang, but a structure with a CAUSER resists sedang. In the following examples, (84) is causative agentive, (85) is causative nonagentive. Both (84) and (85) are transitive. Recall that with the kan-aspect the state predicate (such as kental 'thick' (84) and sedih 'sad' (85)) is transitivised, and the kanaspect encodes change of state.

$$
\begin{array}{lrr}
\text { Ibu sedang meN-kental-kan } & \text { kuah-nya } \\
\text { mother PROG ACT-thick-KAN } & \text { gravy-3sg } \\
\text { 'Mother is thickening the gravy' } & (\text { ibu = AGENT })
\end{array}
$$

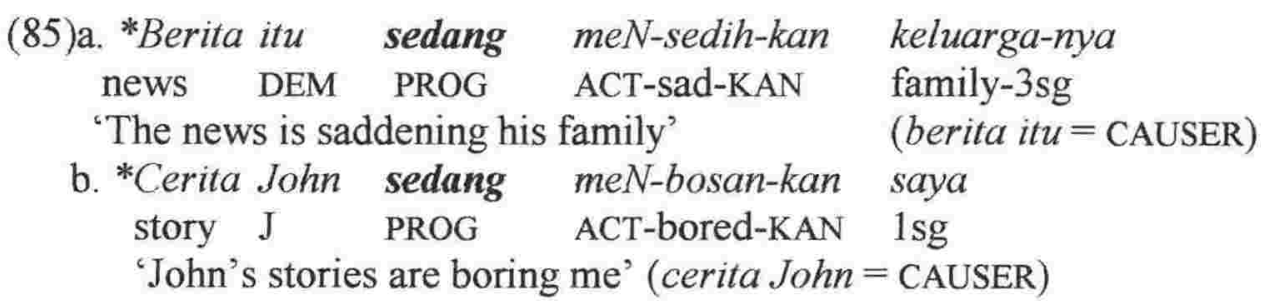

In (84) there is an AGENT ( $i b u$ intends to ACT, to bring about the event), but there is no AGENT in (85): berita itu 'the news' and cerita John 'John's stories' are CAUSERs. We cannot have "intention" for a subject such as the news or the stories. The CAUSER berita itu 'the news' or cerita John 'John's stories' only happens to trigger the event. Thus, there is a feature [-intentional] in the event $(85 \mathrm{a}, \mathrm{b})$ - or, to be precise, '[øintention]'. This feature '[øintention]' does not match the [+expected] in $(85 \mathrm{a}, \mathrm{b})$, but it matches with [-expected] in (86) below. 
(86)a. Berita itu masih meN-sedih-kan
news Deluarga-nya
'The news still saddens his family'
b. Cerita John masih meN-bosan-kan saya story J PROG ACT-bored-KAN 1sg
'John's stories are boring me'

\subsubsection{State versus process predicates}

The canonical state predicates cannot take the progressive sedang (5.3.1.1) above, and (87) below. All the process predicates, however, which in BI bear $m e N$ - but without the kan-aspect, take sedang (88). Thus, here state versus process also plays a role in the constraints in addition to the features [ \pm expected].

(87)a. Padi-nya kuning rice-3sg yellow 'The rice is yellow'

b. Sup-nya kental soup-3sg thick 'The soup is thick'

(88)a. Padi-nya meN-kuning rice-3sg ACT-yellow 'The rice turns yellow'

b. Sup-nya meN-kental soup-3sg ACT-thick 'The soup thickens'

$$
\begin{aligned}
& \text { *Padi-nya sedang kuning } \\
& \text { rice-3sg PROG yellow } \\
& \text { 'The rice is being yellow' } \\
& \text { *Sup-nya sedang kental } \\
& \text { soup-3sg PROG thick } \\
& \text { 'The soup is being thick' }
\end{aligned}
$$

Padi-nya sedang meN-kuning
rice-3sg PROG ACT-yellow
'The rice is becoming yellow'
Sup-nya sedang meN-kental
soup-3sg PROG ACT-thick
'The soup is becoming thick'

Padi-nya sedang meN-kuning rice-3sg PROG ACT-yellow 'The rice is becoming yellow' Sup-nya sedang meN-kental 'The soup is becoming thick'

The examples (87) and (88) contrast with (89) and (90) below, with the [-expected] masih.
(89)a. Padi-nya masih kuning rice-3sg PROG yellow 'The rice is still yellow'
b. Sup-nya masih kental soup-3sg PROG thick
'The soup is still thick'

\author{
*Padi-nya sedang kuning \\ rice-3sg PROG yellow \\ 'The rice is being yellow' \\ *Sup-nya sedang kental \\ soup-3sg PROG thick \\ 'The soup is being thick'
}


(90)a. Padi-nya masih meN-kuning rice-3sg PROG ACT-yellow 'The rice is still becoming yellow'

b. Sup-nya masih meN-kental soup-3sg PROG ACT-thick 'The soup is still thickening'
Padi-nya sedang meN-kuning

rice-3sg PROG ACT-yellow

'The rice is becoming yellow'

Sup-nya sedang meN-kental

soup-3sg PROG ACT-thick

'The soup is becoming thick'

Those that can take sedang can also take masih $(90 \mathrm{a}, \mathrm{b})$, but not vice versa. Thus, process predicates take [ \pm expected] progressive and state predicates resist [+expected] progressive.

\subsubsection{The future Aspect with the psych-predicates}

The canonical state predicates cannot take the progressive [+expected] sedang (5.3.1.1 and 5.3.1.3) above. Those presented in (87) also resist the future akan/mau 'will/going to', (91).

(91) Padi-nya kuning rice-3sg yellow 'The rice is yellow'

\author{
*Padi-nya akan/mau kuning \\ rice-3sg FUT yellow \\ 'The rice is going to be yellow'
}

With the psychological state predicates, (92) below, it is quite the opposite: they take [+expected] progressive sedang and the [-expected] progressive masih, (92b), but not the [+expected] future akan/mau, (92c) (Here I assume that the future Aspect is always [+expected]).

(92)a. Ibu sedih

mother sad

'Mother is/was sad'
b. Ibu sedang/masih sedih
mother PROG sad
'Mother is/was being sad'
c. *Ibu akan sedih
mother FUT sad
'Mother will be sad' 
However, when the cause of the state of being sad is included, the future akan 'will' can occur, (93).

(93)a. Ibu*(tentunya) akan sedih kalau meN-dengar berita itu
mother certainly FUT sad if ACT-hear news DEM
'Mother will certainly be sad if she hears the news'

The state of being sad in $(92 a, b)$ is only temporary. In (93) the future akan can appear only if preceded by the adverbial tentunya 'certainly', making the Aspect subjunctive (or perhaps also because we never know exactly how a person would react to a news) and is grammatical only if combined with kalau 'if'. The statement (93) is thus hypothetical only, and is ungrammatical with ketika 'when/the time', (94).

(94) *Ibu (tentunya) akan sedih ketika meN-dengar berita itu
mother certainly FUT sad when ACT-hear news DEM
'Mother will certainly be sad when she heard the news'

In BI the time adverbial ketika 'when/the time' (94) is used only if the event - in this case of hearing the news - has happened, thus, there is a mismatch between the future akan 'will' and the use of ketika 'when/the time' to indicate that the event has happened.

\subsubsection{The [+perfective] sudah and baru}

We now come to the [+perfective] Aspect, which in BI is realised by sudah ' [+expected] HAVE' and baru '[-expected] HAVE. Thus, like with the [-perfective] in the previous subsections, here with the [+perfective], we also have the features [+expected] sudah and [-expected] baru. Contrast the unaccusative (95) with the unergative (96).

(95) Unaccusative with jatuh 'to fall':
a. John jatuh
$\mathrm{J}$ fall
*John sudah jatuh
'John fell'

\section{John baru jatuh}




\section{b. John ter-jatuh *John sudah ter-jatuh J TER-fall John baru ter-jatuh 'John fell'}

(96) Unergative with jatuh 'to [DO] a fall':
a. John meN-jatuh J ACT-fell
John sudah meN-jatuh
'John did a fall'
John baru meN-jatuh
b. Ira meN-tari 'John has done a fall'
I ACT-dance
'Ira did a dance'
Ira sudah meN-tari
Ira baru meN-tari
'Ira has done a dance'

Thus, the unaccusatives in $(95 \mathrm{a}, \mathrm{b})$ take only the [-expected] [+perfective], whereas unergatives in $(96 \mathrm{a}, \mathrm{b})$ take both [ \pm expected]. This [ \pm expected] distinction, however, falls into the distinction between the non-agentive (unaccusative) and the agentive (unergative), on a par with the causative transitive and the agentive transitive (5.3.1.2) above. We have also two different readings, namely, between an event that is a result of an accident, i.e., [-intentional], (95), and an event as a result of a deliberate action, i.e., [+intentional], (96). In the event in $(95 \mathrm{a}, \mathrm{b})$, the fall is not expected and is unintentional. This is not to say that an unaccusative cannot co-occur with the [+expected] [+perfective] sudah. If the fall is expected, even though the subject is not an AGENT, sudah can cooccur with the unaccusative, $(97)$, because the feature $[ \pm$ intentional] does not apply (notated as '[øintention]' in the examples).
(97)a. Nangka yang matang sudah jatuh [+expected][øintention] jack fruit COMP ripe PERF fall 'The ripe jack fruit has fallen'
b. Nangka yang matang baru jatuh [-expected][øintention] jack fruit COMP ripe PERF fall 'The ripe jack fruit has fallen'

From the examples given above, (82)-(97), we conclude that those that take Aspect with the features [+expected][ \pm perfective] can also take the [-expected] Aspect. But those that take $[$-expected] $[ \pm$ perfective $]$ do not take $[+$ expected $][ \pm$ perfective $]$. The implication is if an event can be expected to happen, it can also be unexpected to happen. 
But the inverse is false, in that, an unexpected event does not always have an expected counterpart.

In sum, [ \pm expected] as sub-features of [ \pm perfective] play a part in Aspect selection for merge. The sub-features are lexical, in that, they are readable in each entry, as in the following table (98).

(98) BI Aspect with sub-feature [ \pm expected]:

\begin{tabular}{|l|l|l|}
\hline Aspect & {$[$ +expected $]$} & {$[$ - expected $]$} \\
\hline$[-$ perfective]: & & \\
\hline \multicolumn{1}{|c|}{ progressive: } & sedang/lagi & masih \\
\hline future: & akan/mau & N/A \\
\hline [+perfective]: & sudah & baru \\
\hline
\end{tabular}

\subsubsection{Combination of two Aspect MODALS}

I mentioned earlier on in Chapter 2 (2.3.2.1) that like in English, in BI combinations of two Aspect MODALs are possible. And like that of English, the BI MODAL combination creates complexities within the temporal Aspect. The present work is not concerned with Aspect complexities. But rather, we must keep in mind what we have concluded in the previous sub-section, that those that take Aspect with the features [+expected][ \pm perfective] can also take the [-expected] Aspect. But those that take [-expected] $[ \pm$ perfective $]$ do not take $[+$ expected $][ \pm$ perfective]. In the following examples (99) the ordering of the combination is the inverse of that of English.

$$
\begin{aligned}
& \text { (99)a. Padi-nya sedang akan meN-kuning (f English: WILL BE+ing) } \\
& \text { rice-3sg PROG FUT ACT-yellow } \\
& \text { 'The rice is beginning the process of becoming yellow' (the 'yellowing' has } \\
& \text { not started yet) }
\end{aligned}
$$


In both examples, the two MODALs carry the same [+expected] feature. If we reverse the order, we gain different meaning, (100).
(100)a. Padi-nya akan sedang meN-kuning (=English: WILL BE+ing) rice-3sg FUT PROG ACT-yellow
'The rice will be in the process of becoming yellow'
b. Padi-nya akan sudah meN-kuning (=English: WILL HAVE) rice-3sg FUT PERF ACT-yellow
'The rice will have been in the process of becoming yellow'

The main difference between (99) and (100) is that in (99) the Aspect refers to the event that is happening at present ('Right now, what we see is the rice that is beginning the process, or, has started the process'), whereas in (100) the event of becoming yellow will happen in the future.

We can substitute the [+expected][-perfective] sedang and the [+expected] [+perfective] sudah of (99) with the [-expected] counterparts, masih instead of sedang and baru instead of sudah, (101).

(101)a. Padi-nya masih akan meN-kuning rice-3sg PROG FUT ACT-yellow

'The rice is still in the process of becoming yellow'

b. Padi-nya baru akan meN-kuning rice-3sg PERF FUT ACT-yellow

'The rice has just started the process of becoming yellow'

The order of the combined features such as in $(101 \mathrm{a}, \mathrm{b})$ is [-expected] [+expected], which can be reversed, $(102 \mathrm{a}, \mathrm{b})$, with the future Aspect now determining when the event will happen, as in examples (100) above. 


\section{(102)a. Padi-nya akan masih meN-kuning (minggudepan) rice-3sg FUT PROG ACT-yellow week next 'The rice will still in the process of becoming yellow (next week)'}

b. Padi-nya akan baru meN-kuning (minggudepan) rice-3sg FUT PERF ACT-yellow week next 'The rice will have started the process of becoming yellow (next week)'

In sum, the sub-features [+expected] and [-expected] of different Aspect (refer back the table (98)) can co-occur, for instance, the [-expected] of progressive masih can co-occur with the [+expected] future akan, (101a) or (102a); the [-expected] of [+perfective] baru can co-occur with the [+expected][-perfective] akan, (101b) or (102b). Different orders give different temporal Aspect interpretations. However, the sub-feature [+expected] and [-expected] of the same Aspect cannot co-occur, (103), regardless of the order, (104).

\section{(103)a. *Padi-nya sedang masih meN-kuning rice-3sg PROG PROG ACT-yellow \\ 'The rice is still in the process of becoming yellow' \\ b. *Padi-nya sudah baru meN-kuning rice-3sg PERF PERF ACT-yellow 'The rice has started the process of becoming yellow'}

(104)a. *Padi-nya masih sedang meN-kuning
rice-3sg PROG PROG ACT-yellow
'The rice is still in the process of becoming yellow'
b. *Padi-nya baru sudah meN-kuning
rice-3sg PERF PERF ACT-yellow
'The rice has started the process of becoming yellow'

Examples (103) and (104) show redundant realisation of Aspect MODAL.

\subsubsection{The derivation of BI Aspect Phrase}

Aspect merge involves a fresh selection from the lexicon, with features [ \pm perfective] [ \pm expected] considered as discussed in the previous sub-sections $(5.3 .1 .1-5.3 .1 .6)$. The simple restrictions as outlined in the previous sub-sections do not seem to be encoded in the structure, but rather, as a matter of selection of MODAL. 
In the present sub-section I propose that we view [Spec-VoiceP] as an "edge" (see Chomsky 1999: 9-10 for discussion on edge). The argument occupying the [SpecVoiceP] edge is made ready for a further syntactic operation. I shall also propose that the role of this argument is relevant only as far as the Voice Phrase. Once the Spec-head relation is established at the VoiceP layer, which I assume to be the lowest edge, syntactic operations that follow only involve the move of either the edge or the head, or both. Elements adjoined to the edge or the head can also be involved in the derivation. The BI VoiceP from (17) above is repeated as (105).

(105) The BI VoiceP

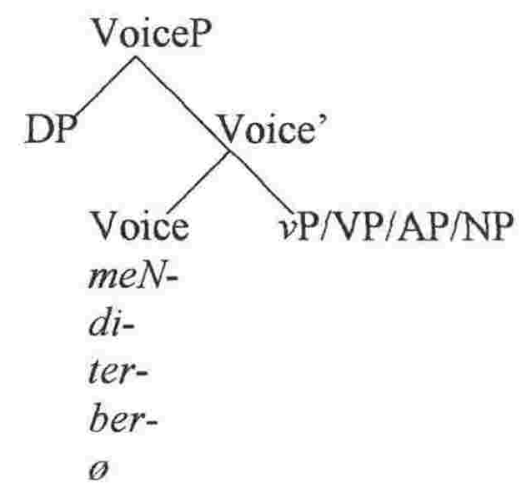

The [Spec-VoiceP] is an edge, because only the argument that occupies this position can undergo further movement. It will become massively clear as we go that $W h$-movement in $\mathrm{BI}$ is a movement from the inner-edge to the outer-edge: any element left below the VoiceP that does not undergo further syntactic operation is spelled out in its base position. What the VoiceP does is provide an argument originating from the lower phrase an edge to ease the derivation. The origin of each argument is listed in (81a) above, repeated here as (106). In (106) the possible occupants of the edge are listed under the "subject" heading, and the morphological realisations of the Voice head are listed under "Voice". For derivations that follow, however, the origin of the subject is no longer relevant. But it is worth remembering why the Voice head is realised as, for instance, diwhen the subject is a THEME or a PATIENT. 
(106)

\begin{tabular}{|c|c|c|c|}
\hline Voice & subject & origin & structure \\
\hline \multirow[t]{3}{*}{$m e N-$} & AGENT & {$[\mathrm{Spec}-v \mathrm{P}]$} & transitive, unergative \\
\hline & CAUSER & {$[\mathrm{Spec}-v \mathrm{P}]$} & kan-transitive, Psych-predicates \\
\hline & THEME & [DP complement] & $i$-transitive \\
\hline \multirow[t]{2}{*}{ ber- } & AGENT & {$[\mathrm{Spec}-v \mathrm{P}]$} & unergative \\
\hline & AGENT & {$[\mathrm{Spec}-v \mathrm{P}]$} & unergative with kan-transitive \\
\hline \multirow[t]{2}{*}{$d i$} & THEME & {$[$ Spec-VP] } & kan-transitive \\
\hline & PATIENT & [Spec-VP] & $i$-transitive \\
\hline \multirow[t]{3}{*}{ ter- } & "EXPERIENCER" & [Spec-VP] & unaccusative \\
\hline & & & unaccusative with kan-transitive \\
\hline & & & impersonal transitive \\
\hline
\end{tabular}

Considering the VoiceP (105) and the potential subjects (106), I propose the edge with its head, (107) and (108). The diagram (107) shows the VoiceP with the edge that has the origin from the $v \mathrm{P}$ (with light verbs and unergatives included), and (108) shows the edge with the VP origin (unaccusative). For (107), either DP1 or DP2 (but not DP3) moves to the edge.

(107) The edge and its head at VoiceP, with $v \mathrm{P}$ as the head's complement:

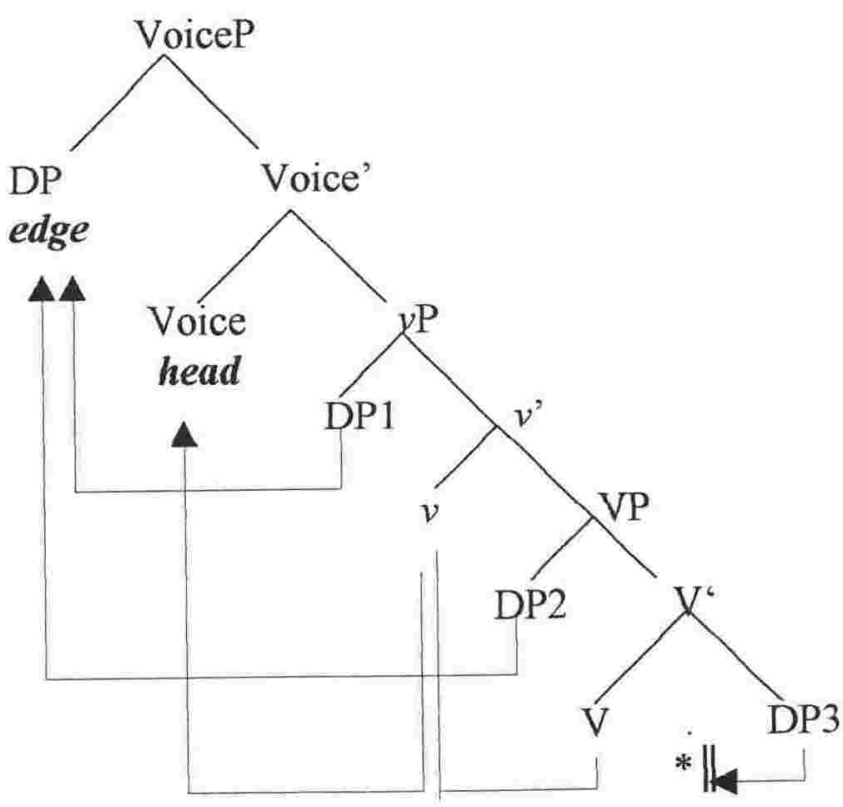


(108) The edge and its head at VoiceP, with VP as the head's complement:

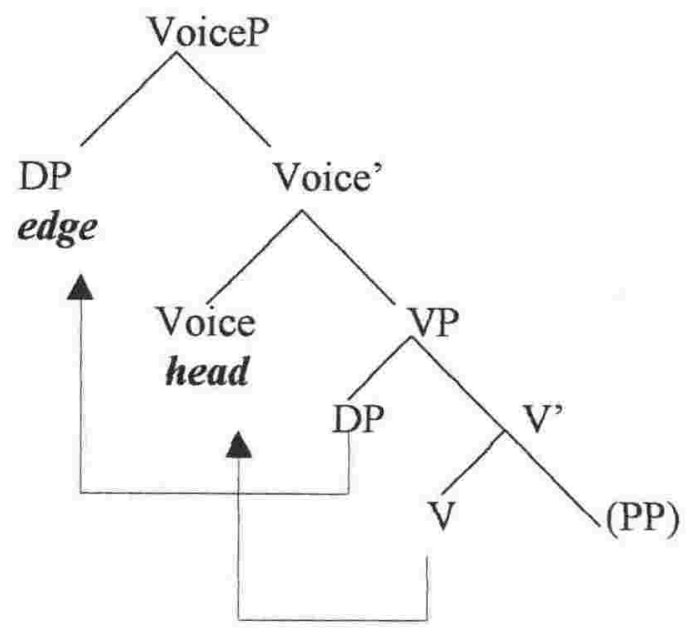

After the displacement of the argument (from $v \mathrm{P}$ or from $\mathrm{VP}$ ) to the edge and the verb to the head, only the edge and its head (i.e., [Spec-VoiceP] and Voice ${ }^{\circ}$ ) in $(107) /(108)$ can be involved in further syntactic operations. Elements left behind at the $v \mathrm{P}$ domain (107) are spelled out at their base positions. As proposed by Chomsky (1999:9), we can "forget earlier stages of derivation" - i.e., the weak phase $v \mathrm{P}$ - since the $v \mathrm{P}$ as a phase is "impenetrable": derivations above the VoiceP cannot involve displacement from the $v \mathrm{P}$, which follows from the assumption that at the level VoiceP the $v \mathrm{P}$ is spelled out.

The first derivation involving the edge is the Aspect Phrase (Asp-P henceforth), where the Aspect ${ }^{\circ}$ merges with VoiceP, (109) below, with sentence examples John baru jatuh 'John has fallen', (110), and John sudah/baru menjatuh 'John has done a fall', (111). For simplicity of presentation, I assume an amalgam of features discussed in the previous sub-sections at the $\mathrm{Asp}^{\circ}$. 
(109) The Aspect and VoiceP merge:

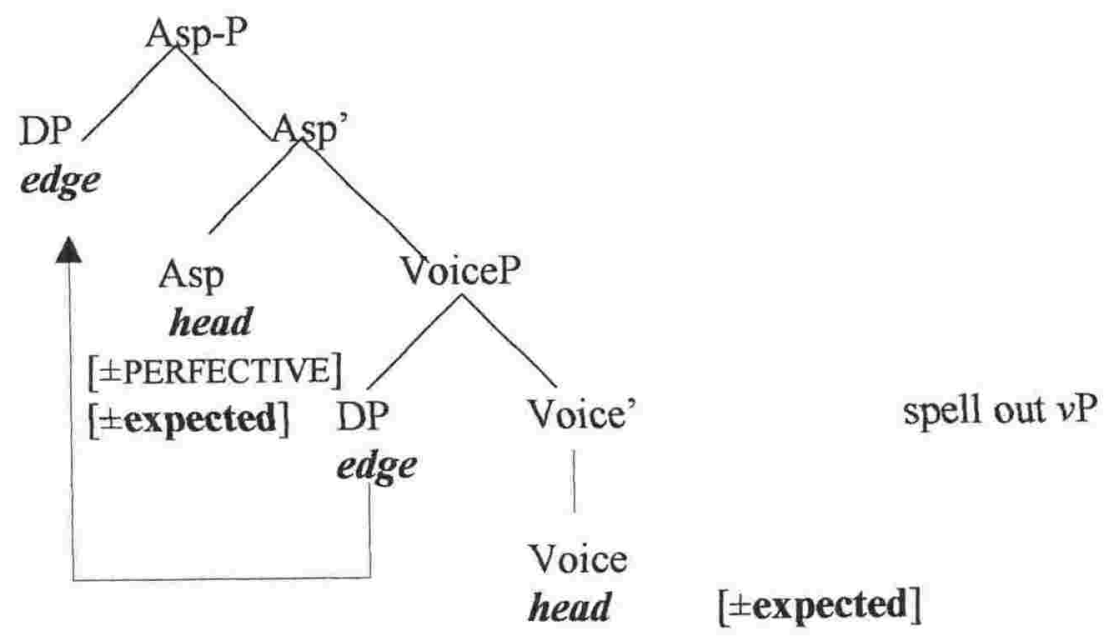

The interpretation/evaluation of [ \pm expected] of VoiceP is done at the level Asp-P.

(110)

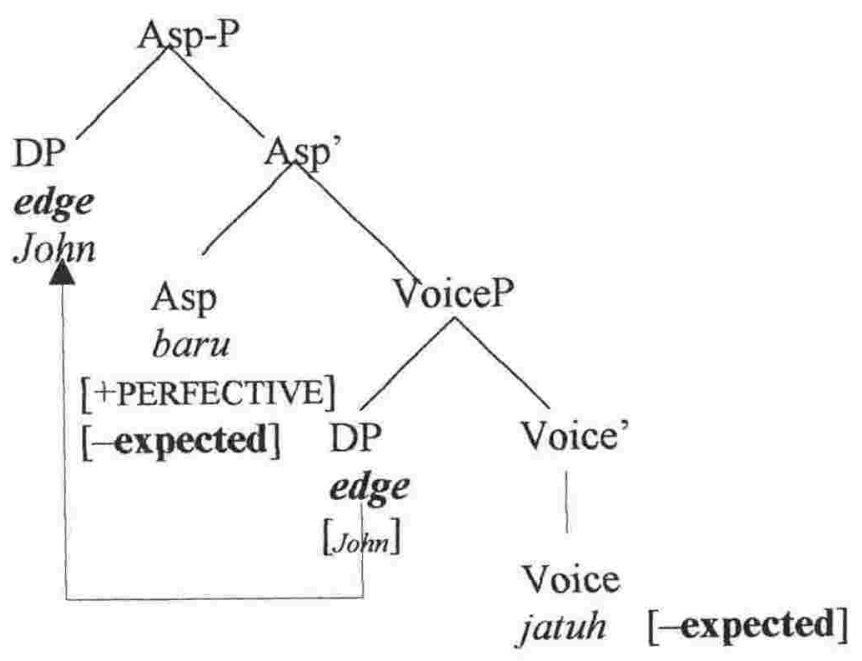

John baru jatuh

J PERF fall 'John has fallen' 
(111)

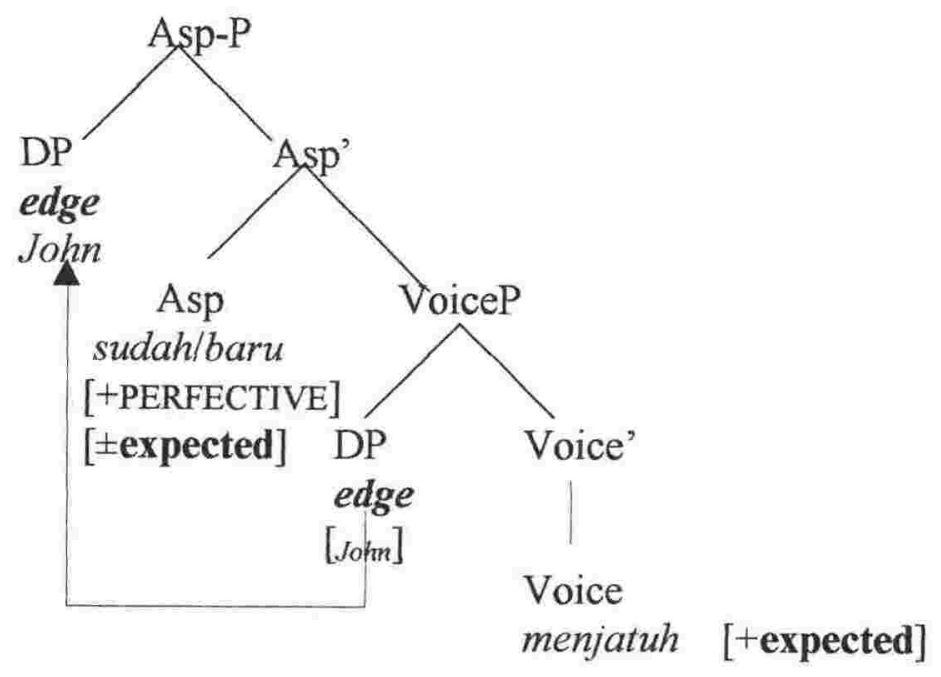

John sudah/baru meN-jatuh

J PERF ACT-fall 'John has (just) done a fall'

In summary, the basic morpheme order of a simple BI declarative sentence, for example the unaccusative-based (110) or the unergative-based (111), is as shown in (112).

(112) The BI morpheme order of a one-place predicate:

\section{Subject Aspect Verb}

I leave open the question whether the head Voice ${ }^{\circ}$ (menjatuh 'to deliberately fall') moves to adjoin with the lexical head Asp ${ }^{\circ}$ (sudah/baru 'HAVE') in (111). ${ }^{9)}$ If adjoined, this

9) As a note, BI Aspects are not adverbials. BI adverbials will not be discussed for they are beyond the scope of the present work. However, we can assume the relatively free possible positions, for instance, of dengan sengaja 'deliberately', to modify (111) 'John has done a fall'.

(i) Dengan sengaja John sudah/baru meN-jatuh

Deliberately J PERF ACT-fall

'Deliberately John has done a fall'

(ii) John dengan sengaja sudah/baru meN-jatuh

J deliberately PERF ACT-fall

'John deliberately has done a fall'

(iii) John sudahbaru dengan sengaja meN-jatuh

J PERF deliberately ACT-fall

'John has done deliberately a fall'

(iv) John sudah/baru meN-jatuh dengan sengaja J PERF ACT-fall deliberately

'John has done a fall deliberately' 
head-to-head movement is allowed because both Asp $^{\circ}$ and Voice ${ }^{\circ}$ in (111) belong to the outer edge (Chomsky 1999:10). The one thing we must keep in mind is that the head Voice $^{\circ}$ bears a prefix and the head $\mathrm{Asp}^{\circ}$ is a MODAL. But see the sub-section that immediately follows, 5.3.2 below, where it will be shown that both Asp-P and VoiceP in (111) are intermediary between the "weak phase" $v \mathrm{P}$ and the "strong phase" CP. If the head menjatuh 'to fall' remains in situ as in (111) - and not adjoined to Asp head - then it is spelled out and no longer accessible for a further derivation.

The BI basic morpheme order of a simple transitive declarative sentence is (114), based on the structure with a transitive head menjatuhkan 'to MAKE-fall something', (113). In (113) the THEME object is spelled out because it is left in situ, and cannot be 'extracted' from its position below the edge. I will discuss 'extractions' in the section that immediately follows, 5.3.2.

(113) BI transitive:

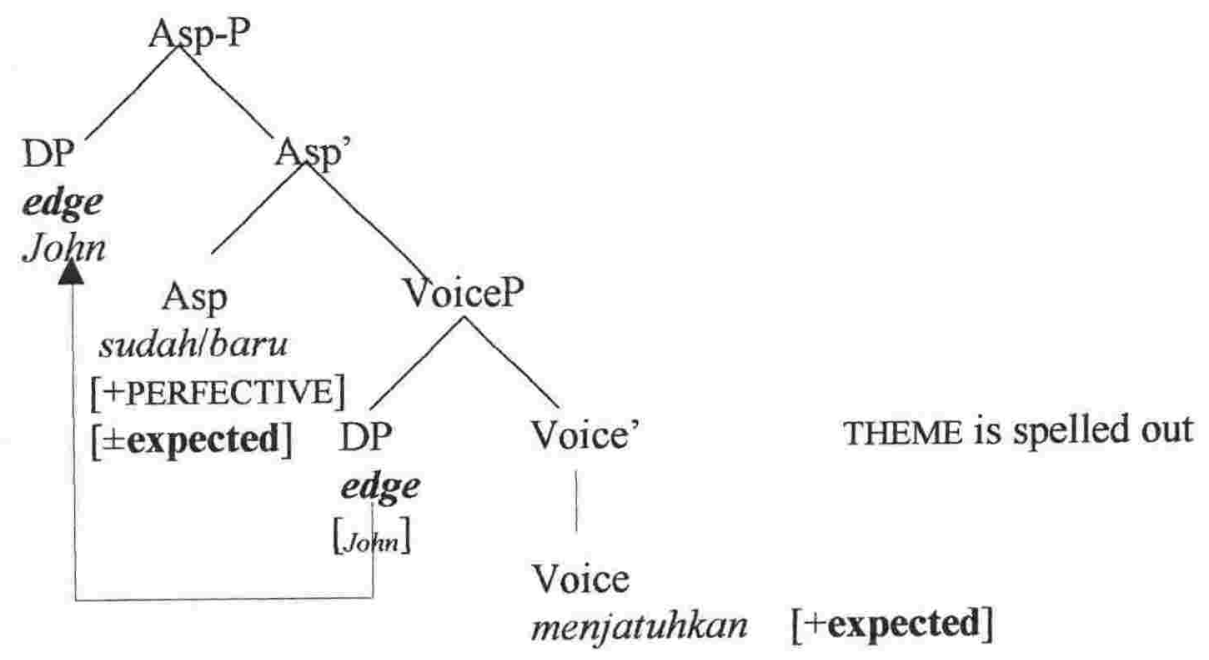

$\begin{array}{lll}\text { John sudah/baru } & \text { meN-jatuh-kan } & \text { bola itu } \\ \text { J PERF } & \text { ACT-fall-KAN } & \text { ball DEM } \\ \text { 'John has dropped the ball' } & \end{array}$

(114) The basic BI morpheme order of a two-place predicate:

Subject Asp Verb Object 


\subsubsection{Wh-extractions: The move of edge to edge continues}

I have demonstrated in the previous sub-section the complete derivation of the BI simple declarative sentence. In the present sub-section I will discuss derivations as required in sentences with other types of force, such as imperative and interrogative sentences. The derivations that will be shown in this sub-section may or may not involve a 'Whextraction'. Extraction is done from the Asp-P, with the edge-to-edge movement (firstly from VoiceP to Asp-P then to $\mathrm{CP}$ ) as a successive-cyclic movement, which may also involve a local head-to-head movement.

Before we go on to extractions, I shall show that the derivation of a direct imperative sentence does not involve an edge, 5.3.2.1, whereas invitations involve an intermediary phase, with an edge, 5.3.2.2. The derivation of expectations involves a higher-level edge, the Asp-P, 5.3.2.3. Finally, in sub-section 5.3.2.4 I will demonstrate that $\mathrm{BI} W$-extraction to $\mathrm{CP}$ follows the characteristic of the edge-to-edge movement as discussed in 5.3.1.5.

\subsubsection{Direct imperatives}

The derivation of a direct imperative sentence does not involve an edge. I will demonstrate that in essence the derivation of a direct imperative sentence cannot involve a Voice head. To start with, consider the imperatives (115) that make the strongest demands.

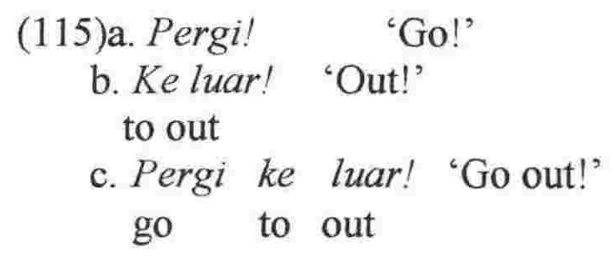

In (115) it is not obvious whether or not the Voice head is involved. But it is, in (116) below, in that, the Voice head cannot be used in strong demands, (116a') and (116b'). 


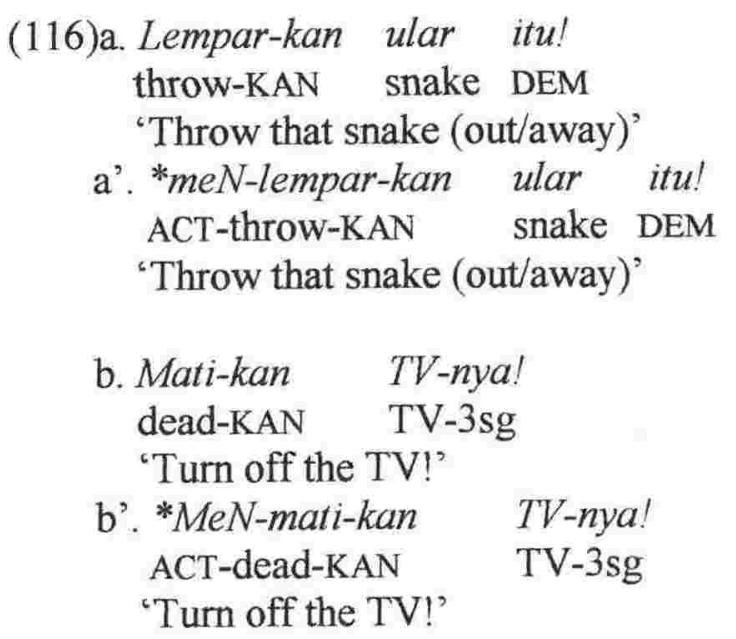

For a weaker demand, tolong/mohon 'help, please' can be added as well as the second singular/plural pronoun, (117). The English word please has two corresponding BI words: one is tolong 'please1 (help me)' the other is silakan 'please2 (yourself)'. In BI the imperative with tolong/mohon 'help' is midway between the demand and the invitation. The sentences (116a,b) above can be modified with tolong, (117). The VoiceP edge cannot be used, (117a', b'), except in the PASSIVE form, (118). In all examples of direct imperatives the second person is optional, which is obligatory in the declarative form. Note that sentences $\left(117 \mathrm{a}^{\prime}, \mathrm{b}^{\prime}\right)$ are acceptable without tolong, which make the forms declarative.

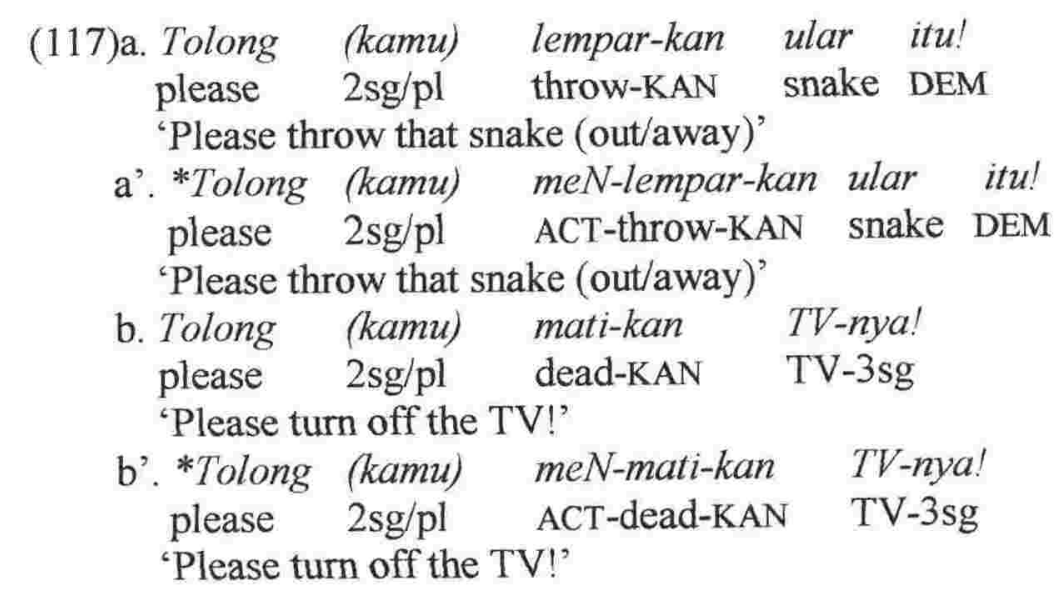


I assume that the sentences $(117 \mathrm{a}, \mathrm{b})$ are acceptable because the external argument kamu '2sg' does not move to the VoiceP edge. This assumption is strongly supported by the analysis of Spec-head relations in BI VOICE (Section 5.1). Recall that the displacement of [Spec- $v \mathrm{P}]$ argument to [Spec-VoiceP] requires the Voice head $m e N-$ in transitive structures. The Spec-head relation is satisfied in $\left(117 \mathrm{a}^{\prime}, \mathrm{b}^{\prime}\right)$, but the sentences are ungrammatical. Thus, the grammatical forms $(117 \mathrm{a}, \mathrm{b})$ are of the base structure, i.e., of the $v \mathrm{P}$, see tree diagram (129). However, tolong takes the PASSIVE Voice head di-, (118) below. Contrast the example (118a) with (117a') above, and (118b) with (117b').

(118)a. Tolong ular itu di-lempar-kan! please snake DEM PASS-throw-KAN

'Please throw that snake (out/away)!' (Please the snake be thrown away)

b. Tolong TV-nya di-mati-kan!

please TV-3sg PASS-dead-KAN

'Please turn off the TV!' (Please the TV be turned off)

In $(118 \mathrm{a}, \mathrm{b})$ the subjects ular itu 'that snake' and TV-nya 'the TV' occupy the VoiceP edge. Thus, imperative with tolong is midway between the demand and the invitation. It does not mean, however, that a PASSIVE of (118a,b) type can always be used, (119c) and (120c). The (b) examples of (119)-(121) show that tolong is incompatible with the ACTIVE VOICE $m e N$-.

(119)a.Tolong (kamu) beli-kan rokok (untuksaya/mereka) please $2 \mathrm{sg} / \mathrm{pl}$ buy-KAN cigarette for $1 \mathrm{sg} / 3 \mathrm{pl}$ 'Please (you) buy cigarette (for me/them)!'
b. Tolong (kamu) meN-beli-kan rokok please $2 \mathrm{sg} / \mathrm{pl} \quad$ ACT-buy-KAN cigarette 'Please (you) buy cigarette (for me/them)!'

(120)a. Tolong (kamu) tutup-kan pintu itu (untuk saya) please $2 \mathrm{sg} / \mathrm{pl}$ close-KAN door DEM for $1 \mathrm{sg}$ 'Please close the door (for me)!' 
b. *Tolong (kamu) meN-tutup-kan pintuitu (untuksaya) please 2sg/pl ACT-close-KAN door DEM for $1 \mathrm{sg}$ 'Please close the door (for me)!'

Examples (119c) and (120c) contrast with the acceptable (121c).

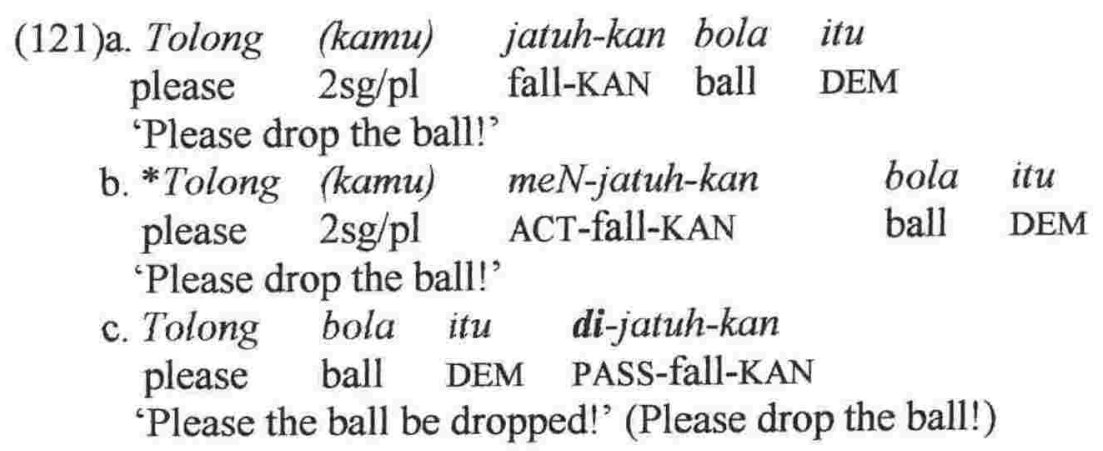

We see that the PASSIVE in (119c) and (120c) cannot be used, but it can in (121c) and $(118 \mathrm{a}, \mathrm{b})$ above. The difference is that in (119a) and (120a), the $v$ P-aspect encodes a transit path of change, but a direct path of change in $(121 \mathrm{c})$ and $(118 \mathrm{a}, \mathrm{b})$. If the $v \mathrm{P}$-aspect encodes a transit path of change, only the 'beneficiary' can occupy the VoiceP edge of PASSIVE (see also Vamarasi 1999 on the BI PASSIVE with 'benefactive -kan'). Thus, instead of (119c) and (120c), we can have the following sentences, (122a,b), as the acceptable imperative tolong with PASSIVE VOICE. Contrast $(122 \mathrm{a}, \mathrm{c})$ with the unacceptable ones, $(122 b, d)$.

$\begin{array}{clll}\text { (122)a. Tolong } & \text { saya/mereka } & \text { di-beli-kan } & \text { rokok } \\ \text { please } & 1 \mathrm{sg} / 3 \mathrm{pl} & \text { PASS-buy-KAN } & \text { cigarette }\end{array}$ 'Please (help me/them), may some cigarette be bought!' ( $\neq$ Please help me buy...)
b. *Tolong rokok di-beli-kan please cigarette PASS-buy-KAN
(untuk saya/mereka)
'Please cigarette be bought for me/them!' for $1 \mathrm{sg} / 3 \mathrm{pl}$ 
c. Tolong saya di-tutup-kan pintu itu please 1sg PASS-close-KAN door DEM 'Please (help me), may that door be closed!' ( $\neq$ Please help me close that door)
d. *Tolong pintu itu di-tutup-kan (untuk saya) please door DEM PASS-close-KAN for $1 \mathrm{sg}$ 'Please that door be closed (for me)!

In $(122 \mathrm{a}, \mathrm{c})$ the path of change encoded by the $v \mathrm{P}$-aspect contains a transit point, and the VoiceP edge as the subject position is controlled by the object of the higher phrase tolong saya/mereka 'help me/them' in (122a) and tolong saya 'help me' in (122c). Both objects - or subjects - saya/mereka (122a) and saya (122c) are 'beneficiaries'. Because the edge is controlled by the higher object, the $v \mathrm{P}$-objects rokok 'cigarette' (122a) and pintu itu 'that door' (122c) thus cannot move up to occupy the VoiceP edge - i.e., *Tolong saya/mereka rokok di-beli-kan is ungrammatical. The inverse is also true, that is, if the path of change is direct, $(118 \mathrm{a}, \mathrm{b})$ and $(121 \mathrm{c})$, we cannot have PASSIVE the type of (122a,c), as shown in the (b) examples of (123), (124) and (125) below, because the VoiceP edge is not controlled by the object 'beneficiary' of the higher phrase. The acceptable examples. (123c). (124cl and (125c) show that the $y$ P-obiects move to the 


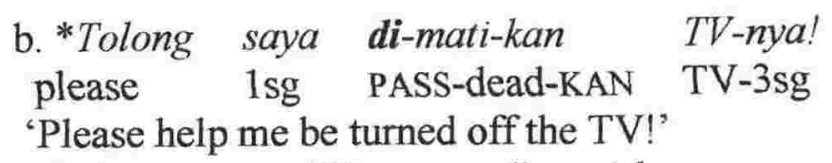
c. Tolong saya TV-nya di-mati-kan please 1sg TV-3sg PASS-dead-KAN TV
'Please help me, may the TV be turned off?'

(125)a. Tolong bola itu di-jatuh-kan!
please ball DEM PASS-fall-KAN
'Please, may the ball be dropped'
b.*Tolong saya di-jatuh-kan bola itu!
please 1sg PASS-fall-KAN ball DEM
'Please help me be dropped the ball!'
c. Tolong saya bola itu di-jatuh-kan!
please 1sg ball DEM PASS-fall-KAN
'Please help me, may the ball be dropped!'

To summarise, what we see in (116)-(125) above are examples of combination of [tolong $+v \mathrm{P}]$ and $[$ tolong $+\mathrm{PASSIVE}$ VoiceP]. In the latter the $v \mathrm{P}$-object cannot raise to the [SpecVoiceP] if the $v \mathrm{P}$-aspect encodes a transit path of change, in which the VoiceP edge is controlled by the 'beneficiary' of tolong 'help', (122b,d). In either case, the external argument $2 \mathrm{sg} / \mathrm{pl}$ at $[\mathrm{Spec}-\mathrm{vP}]$ argument is optional.

\subsubsection{Invitations}

The derivation of a direct imperative sentence in the previous sub-section (5.3.2.1) does not involve an edge. With tolong 'help, please' the derivation may involve an edge only if the $v$ P-aspect does not encode a transit path of change, and only in PASSIVE. In the present sub-section I will show that the derivation of invitations with the second 'please', silakan, involves an intermediary phase, with an edge (126) and (127). The (a) examples show invitations with an ACTIVE VOICE, and the (b) examples show invitations with a PASSIVE VOICE.

(126)a. Silakan (Bapak) meN-tonton TV-nya
please Sir ACT-watch TV-3sg
'Please (Sir) watch the TV'




\section{b. Silakan (TV-nya) di-tonton please TV-3sg PASS-watch \\ 'Please watch the TV' (Please the TV be watched)}

\begin{tabular}{|c|c|c|c|}
\hline $\begin{array}{c}\text { (127)a. Silakan } \\
\text { please }\end{array}$ & $\begin{array}{l}\text { (Bapak) } \\
\text { Sir }\end{array}$ & $\begin{array}{l}\text { (meN-) minum } \\
\text { ACT-drink }\end{array}$ & $\begin{array}{l}\text { kopi-nya } \\
\text { coffee-3sg }\end{array}$ \\
\hline \multicolumn{4}{|c|}{ 'Please (Sir) drink the coffee' } \\
\hline $\begin{array}{l}\text { b. Silakan } \\
\text { please }\end{array}$ & $\begin{array}{l}\text { (kopi-nya } \\
\text { coffee-3s }\end{array}$ & $\begin{array}{l}\text { di-minum } \\
\text { PASS-drink }\end{array}$ & \\
\hline
\end{tabular}

In sum, direct imperatives involve only the $v \mathrm{P}$, whereas invitations involve the edge VoiceP. Midway between the two is direct imperatives with tolong 'please (help me, do me a favour)'. The invitation silakan 'please (yourself)' modifies sentences with VoiceP.

\subsubsection{Expectations}

What follows are examples of sentence modification of even a higher layer edge, namely the Asp-P, with harap or ber-harap 'to expect' (and sometimes 'to hope'). This unergative harap/ber-harap takes a CP (but not an infinitival like the English counterpart) with the complementiser bahwa 'that', (128).

(128)a. Saya harap (bahwa) kamuakan datang ke pesta nanti malam 1 sg expect that 2sg FUT come to party coming night

'I expect (that) you will come to the party tonight'

b. Saya harap (bahwa) kamu sudah pergi waktu saya sampai di rumah $1 \mathrm{sg}$ expect that $2 \mathrm{sg}[+\mathrm{PERF}]$ go when $1 \mathrm{sg}$ arrive at/in house 'I expect (that) you have gone when I arrive home'

c. Saya harap saudara semua sudah meN-baca buku itu 1sg expect brother all [+PERF] ACT-read book DEM 'I expect (that) you all have read the book'

To capture the main points of sub-sections 5.3.2.1 - 5.3.2.3, the following diagram, (129), shows the possible locations of direct imperatives, invitations, and of expectations. This diagram is not to be seen as having co-occurrences. 


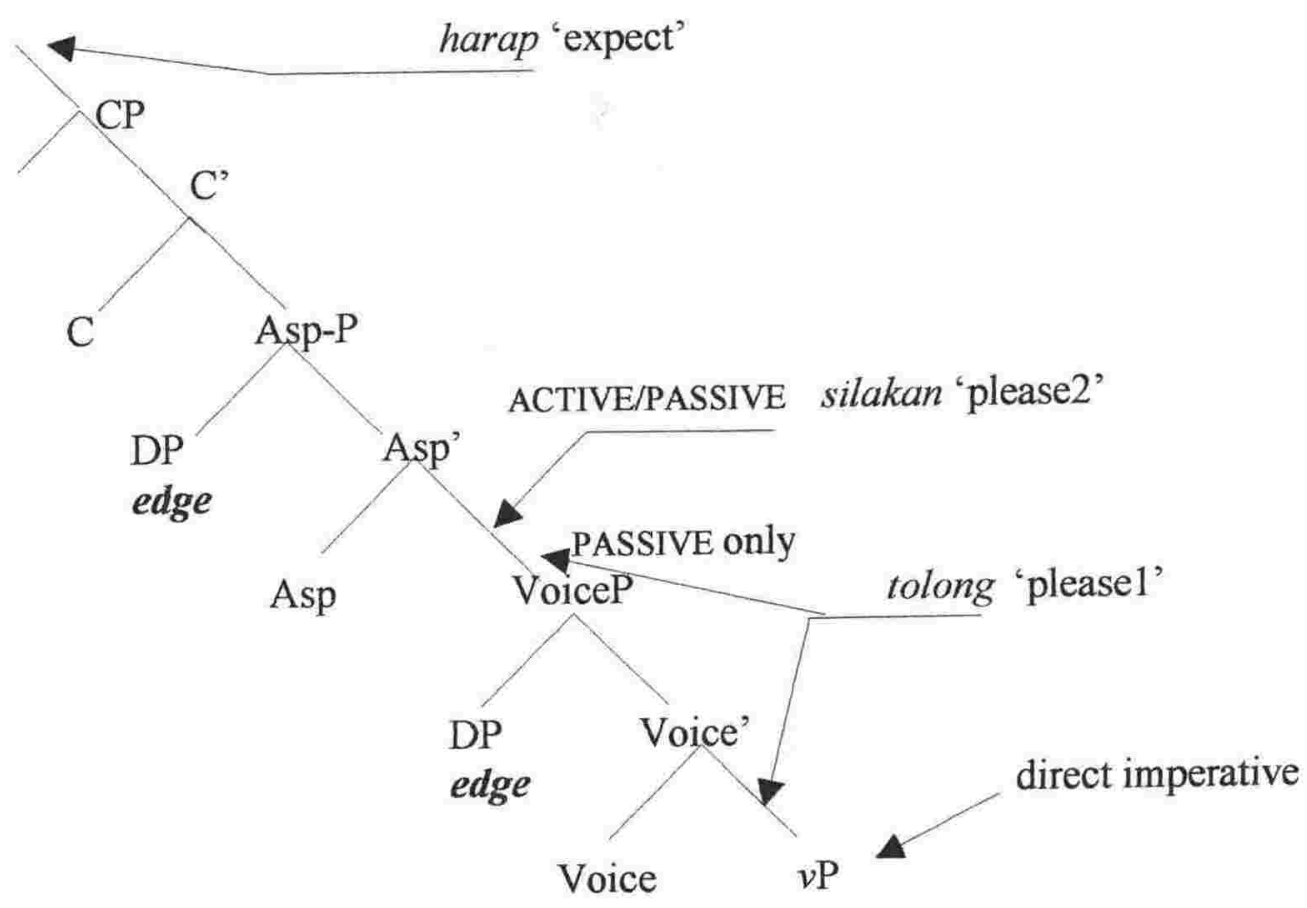

\subsubsection{Wh-extraction in interrogative sentences}

Extractions are done after the derivation of Asp-P is completed, involving only the displacement of the Asp-P edge to the outermost edge, of the CP. The BI CP is a clefted structure (which is also argued for by Cole et al 2002). For clarity, in this sub-section I make a distinction between a CP with the head -kah (in Question CP, "Q-CP" henceforth) and a CP with the head yang (in Relative Clause CP, "RC-CP" henceforth). Three types of questions will be discussed. Sub-section 5.3.2.4.1 discusses echo questions, sub-section 5.3.2.4.2 Yes/No questions, and sub-section 5.3.2.4.3 discusses constituent questions.

\subsection{Echo questions}

Echo questions are the simplest of interrogative sentences. They merely echo the PF structure, where the item in question is replaced with the "Wh-elements" APA "what', SIAPA 'Who', (130), MANA 'place', (131). 
(130)a. Si Siti sedang meN-baca buku porno PERS S PROG ACT-read book porn

'Siti is reading a porn book'

b. Si Sitisedang meN-baca buku APA? PERS S PROG ACT-read book Wh'Siti is reading a what book?'

c. Si Sitisedang meN-baca APA? PERS S PROG ACT-read Wh-

'Siti is reading what?'

d. Si Siti sedang (meN-)APA?

PERS S PROG ACT-Wh-

'What is Siti doing?'

e. $\mathrm{Si}$ APA sedang meN-baca APA?

PERS Wh- PROG ACT-read Wh-

'Who is reading what?'

(131)a. Ibu mau ke pasar mother will to market 'Mother will go to the market'

b. Ibu mau ke MANA? mother will to Wh-

'Mother will go to where?'

(132)a. Ibu sedang meN-kental-kan kuah-nya mother PROG ACT-thick-KAN gravy-3sg 'Mother is thickening the gravy'

b. Ibu sedang meN-APA-kan kuah-nya? mother PROG ACT-Wh-KAN gravy-3sg

'What is mother doing to the gravy?'

(133)a. Kuah-nya sedang di-kental-kan gravy-3sg PROG PASS-thick-KAN

'The gravy is being thickened'

b. Kuah-nya sedang di-APA-kan? gravy-3sg PROG PASS- $W h$-KAN

'What is being done to the gravy?'

I assume that in (130)-(133) there is no Wh-extraction from the Asp-P, although I will not use the term "in situ" (for instance, Cole et al 2002), the term that I shall reserve for items left in the $\nu \mathrm{P}$. Of interest is when the derivation involves an extraction, 5.3.2.4.2. 


\subsubsection{2. 'Yes/No' questions (Q-CP with the functional head - kah)}

In BI the Q-CP head - kah 'marks' a question, which may be left out in spoken utterances (in which case a distinctive intonation must be used to indicate that the sentence is interrogative). There are three ways to elicit Yes or No answers, (134), (135), (136). All the following question sentences (134)-(136) require a Yes or No answer, but only in (134) is the 'APA support' that corresponds to the English 'DO/BE support' used.

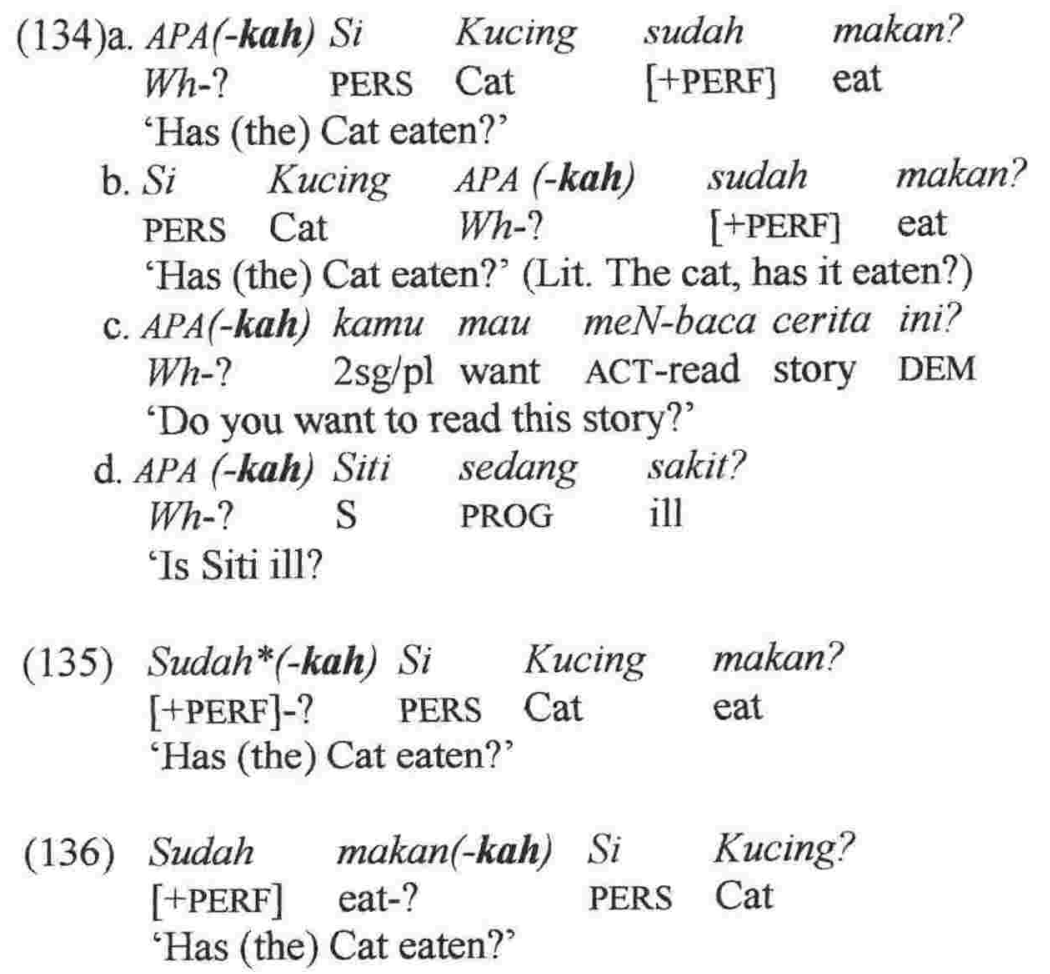

In $(134 \mathrm{a}, \mathrm{c}, \mathrm{d})$ there is no extraction, but there is in (134b). The proposed structures are as (137a) and (137b) below. In (135) above only the Asp head is extracted, as shown in the (138) below, whereas in (136) it is the whole adjoined $\mathrm{Asp}^{\circ},(139)$. I assume that for (134) and (135) the head Asp may or may not adjoin with the head Voice, but they must in (136). The structures of the three questions above are as (137a,b), (138) and (139) respectively. 
(137)a.

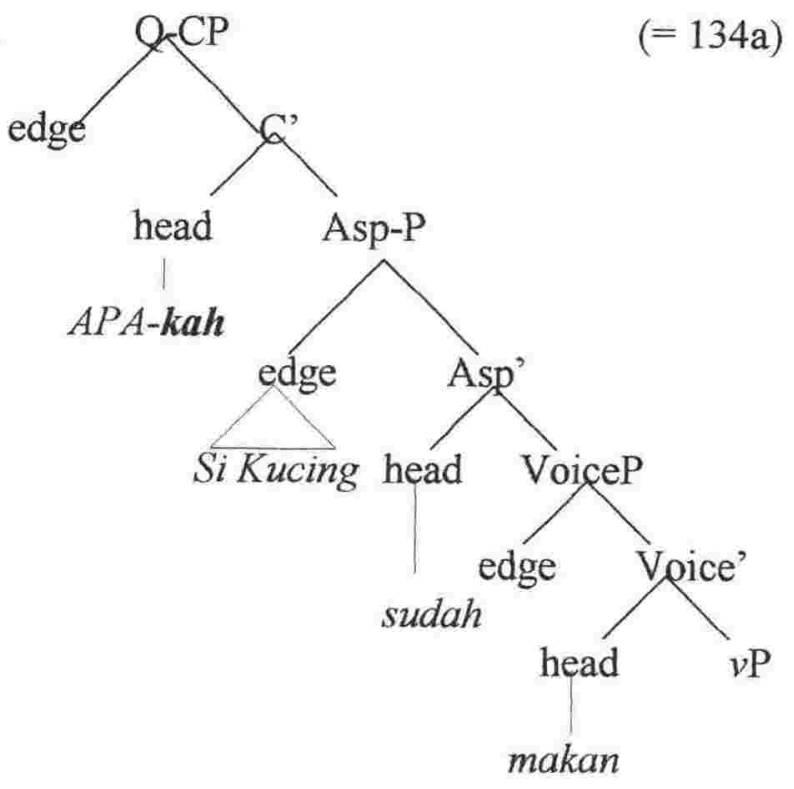

Apakah Si Kucing sudah makan? 'Has (the) Cat eaten?

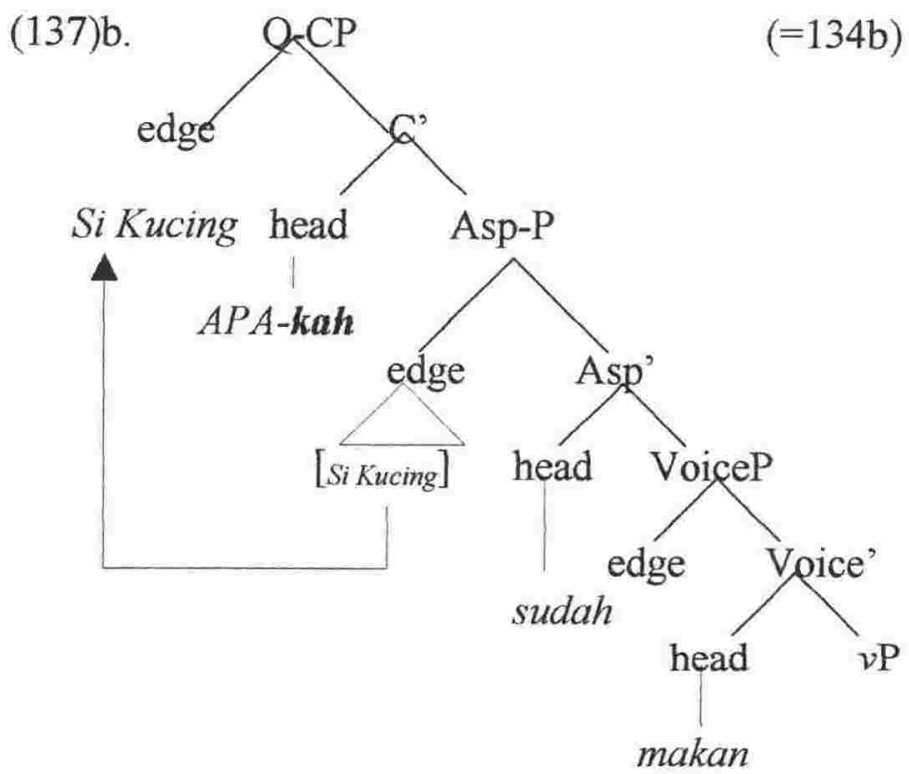

Si Kucing apakah sudah makan? '(The) Cat, has it eaten?' 
(138)

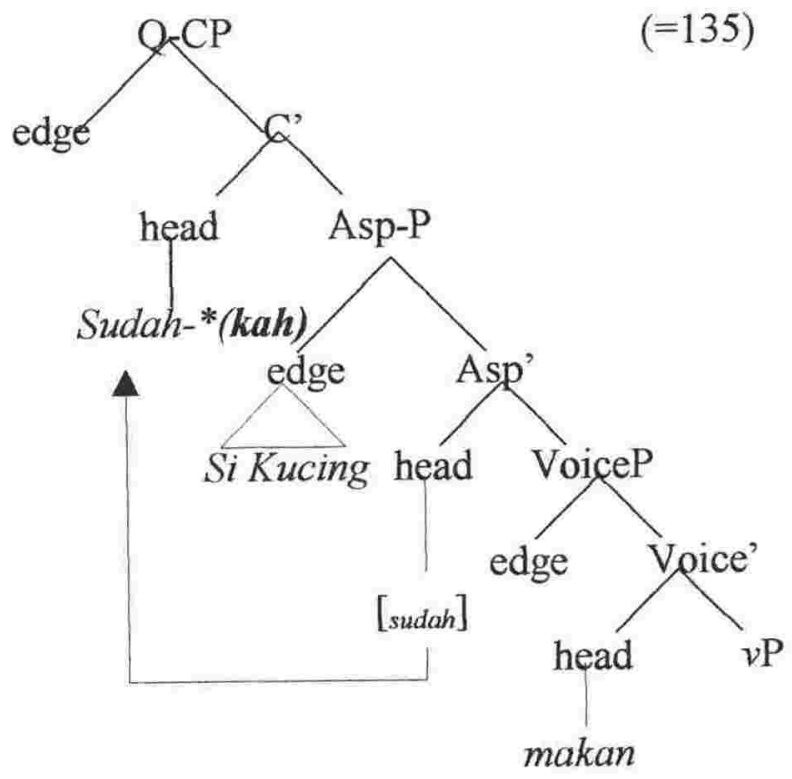

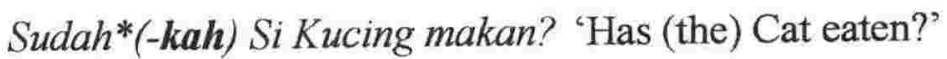

(139)

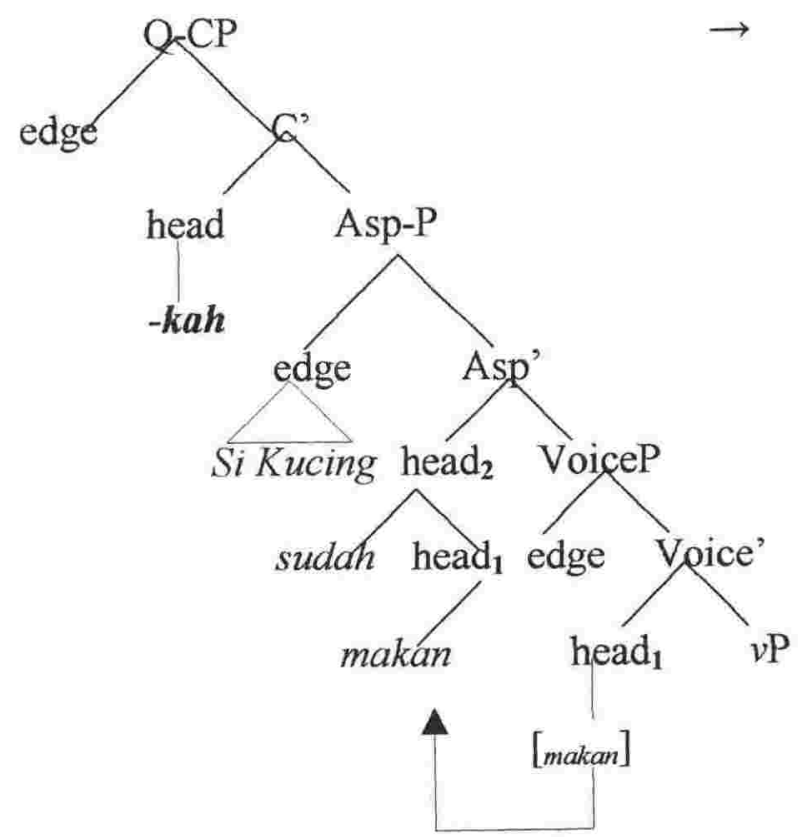

Si Kucing [sudah makan]

'(The) Cat has eaten' 


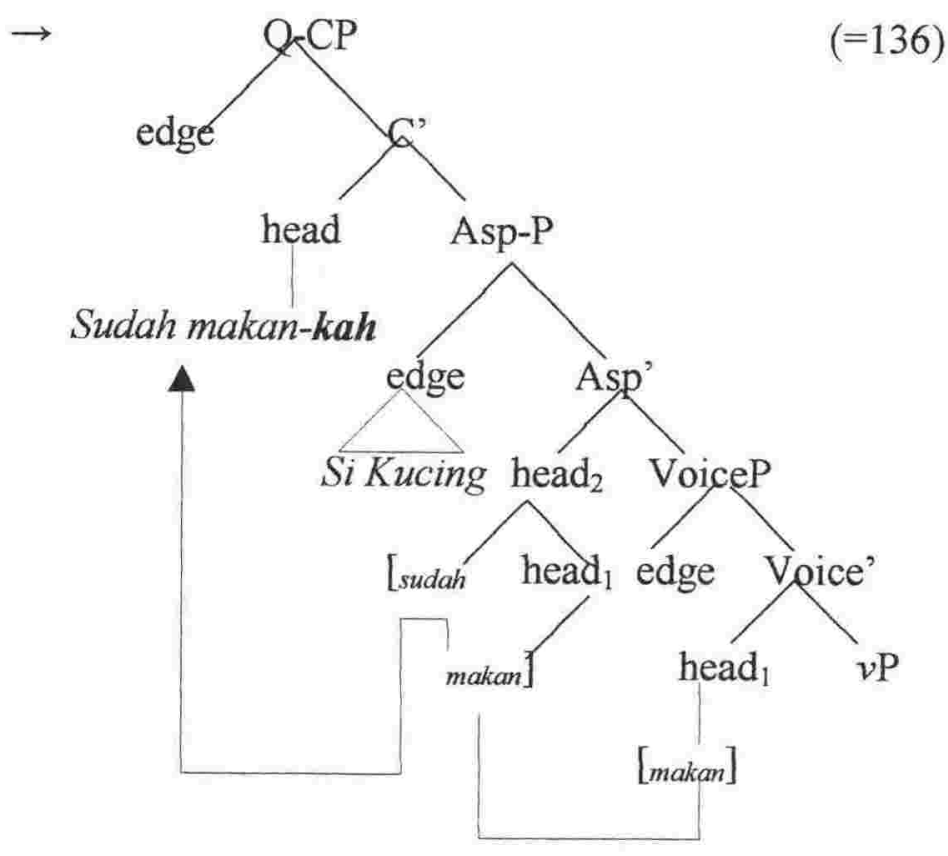

Sudah makankah Si Kucing? 'Has (the) Cat eaten?'

\subsection{Constituent questions with the complementiser yang}

Unlike the head - kah of Q-CP shown in 5.3.2.4.2, the complementiser head yang of the $\mathrm{RC}-\mathrm{CP}$ does not elicit an answer. I propose that the BI interrogative sentence is made not with the head yang 'that/who/which', but rather, with the head -kah, which I assume to be the outermost head. I will demonstrate that the cyclic movement of edge-to-edge continues, with extracted Asp-P edge. The combination of the outer phrase Q-CP and its adjacent phrase RC-CP makes a structure corresponding to the English - more or less 'Who is it that...? or 'What is it that...?'.

The following example, (140b), shows that the head yang clefts the subject Tina, the subject of the Asp-P (140a).

$\begin{array}{cl}\text { (140)a. Tina sedang } & \text { sakit } \\ \text { T PROG } & \text { ill } \\ \text { 'Tina is ill' } & \end{array}$




\section{b. Tina yang sedang sakit \\ $T$ COMP PROG ill \\ 'It is Tina who is ill'}

In the RC-CP (140b) Tina moves from the Asp-P edge to the outer edge, the RC-CP with the head yang, (141).

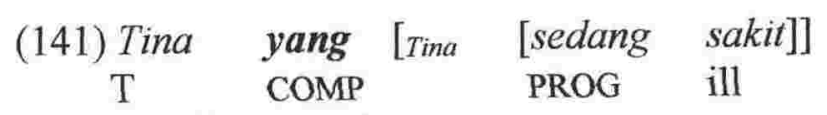

'It is Tina who is ill'

The RC-CP can be embedded (just like any other nominal expression), as the 'subject' of the following sentences, (142) and (143). The combination of a Wh- element and the complementiser yang does not make an interrogative sentence.

$\begin{array}{clllll}\text { (142) [Siapa } & \text { yang sedang } & \text { sakit] tidak boleh ke sekolah } \\ \text { Wh- } & \text { COMP PROG } & \text { ill } & \text { NEG allow to school }\end{array}$ 'Those who are ill are not allowed to go to school'

(143) [Siapa yang sudah makan] boleh pergi sekarang Wh- yang [+PERF] eat allow go now 'Those who have eaten may go now'

Thus, the combination of the Wh- element and the complementiser yang itself does not necessarily make an interrogative sentence (142) and (143). In (142) and (143) above the (non-sentence) RC Siapa yang sedang sakit... 'Those who are ill...' Siapa yang sudah makan... 'Those who have eaten...' are embedded at the [Spec-Asp-P], (144).

$\left[\begin{array}{llllll}\text { [Asp-P [Spec Siapa yang } & \text { sudah } & \text { makan] [Asp } & \text { boleh [pergi] } & \text { sekarang] } \\ \text { Wh- } & \text { yang } & \text { [+PERF] } & \text { eat } & \text { may go now }\end{array}\right.$ 'Those who have eaten may go now' 
I shall claim that to derive a $W h$ - question in $\mathrm{BI}$ the Q-CP is combined with the RC-CP. In (145) and (146) below the $W h$ - element moves further up to the outermost edge with $-k a h$ as the head, (147) and (148).

$\begin{array}{clll}\text { (145) Siapa-kah } & \text { yang sedang } & \text { sakit? } \\ \text { Wh-? } & \text { COMP PROG } & \text { ill }\end{array}$

'Who is it being ill?'

(146) Siapa-kah yang sudah makan?

Wh-? COMP [+PERF] eat

'Whom (of you) have eaten?'

(147) Siapa-kah [Siapa] yang sedang sakit?

Wh-? Wh- COMP [PROG] eat

'Who is it being ill?'

(148) Siapa-kah [Siapal yang sudah makan?

Wh-? Wh- yang [+PERF] eat

'Whom (of you) have eaten?/Who is it that have eaten?'

The Q-CP cannot be embedded the way the RC-CP can as shown in (144) above, (149) and (150). Alternatively, we can view the ungrammaticality of (149) and (150) below as pertaining to the sentential subject constraint, that is, extraction from an embedded subject clause is not allowed. I shall not go further into details on this matter. However, I must emphasise that the sentential subject in (149) and (150) below is a Q-CP. The point to note is that $-k a h$ should be positioned in the main clause only (in the main trunk of the tree).

(149) *Siapa-kah yang sedang sakit tidak boleh ke sekolah? Wh-? COMP PROG ill NEG allow to school

'Who is it being ill are not allowed to go to school?'

(150) *Siapa-kah yang sudah makan boleh pergi? Wh- ? COMP [+PERF] eat allow go

'Who is it who have eaten may go?'

The above analysis leads us to assume the structure of the BI RC-CP, shown as (151), and of the BI Q-CP with RC-CP, (152). 
(151) The BI RC-CP:

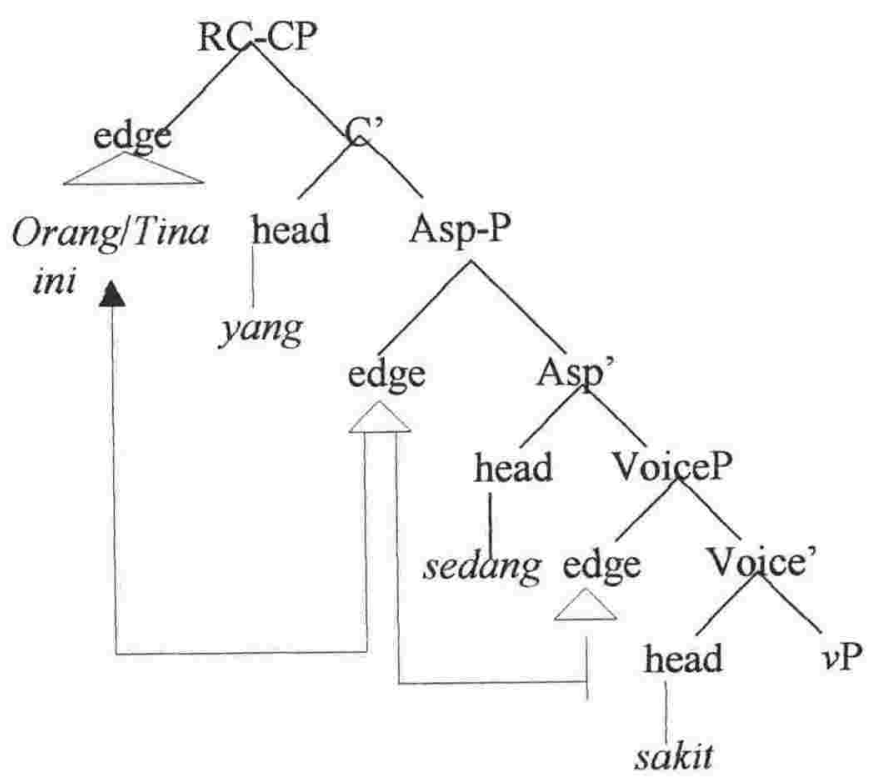

Orang ini/Tina yang sedang sakit 'It is this person/It is Tina who is ill'

(152) The structure of $B I Q-C P$ with $R C-C P$ :

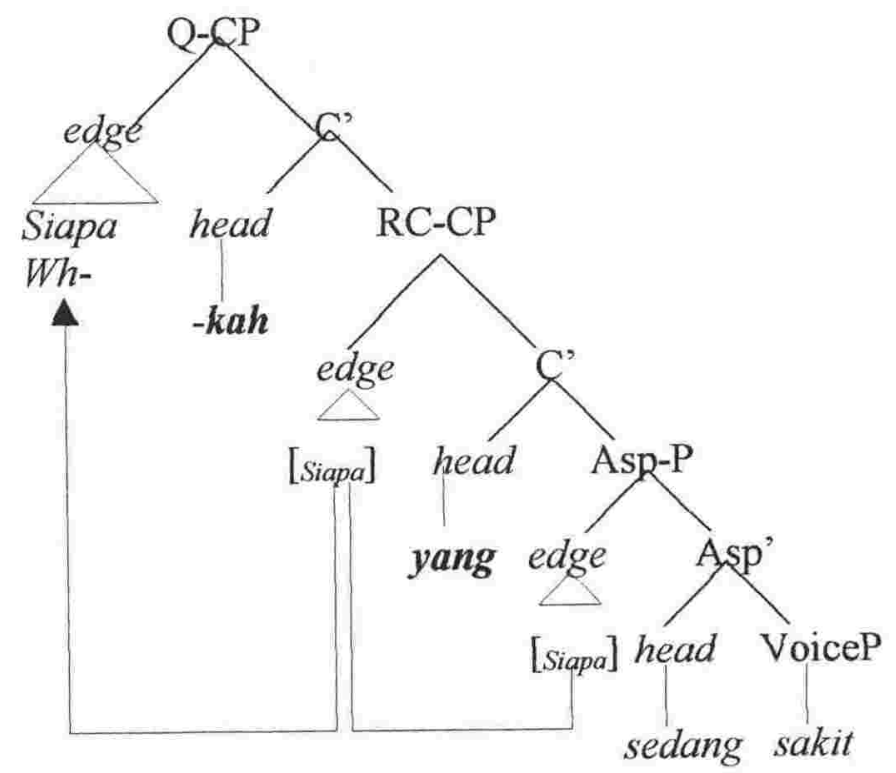

For (152) Siapa-kah yang sedang sakit? Wh-? COMP PROG ill

'Who is it being ill?' 
By 're-substituting back' the Wh- element siapa 'who' with Tina, we have the 'Yes/No question' of a different type of that shown in 5.3.2.4.2 ('Yes/No questions' with the functional head $-k a h$ but without the head yang), (153).

(153) Structure of BI Q-CP with RC-CP for a 'Yes/No question':

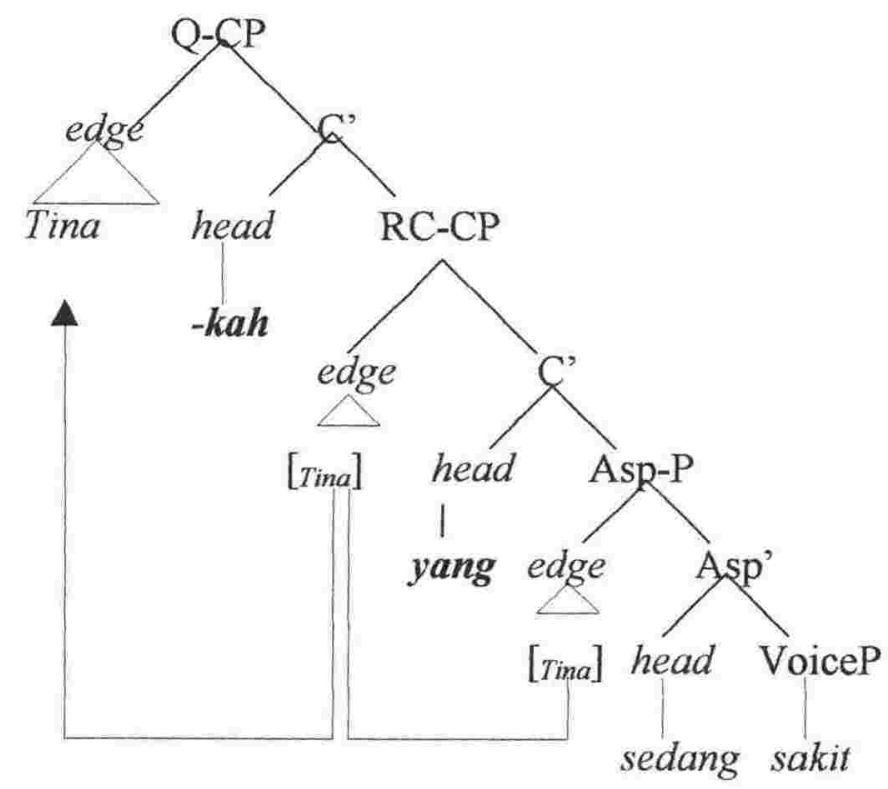

Tina-kah yang sedang sakit? 'Is it Tina who is ill?'

Lastly, the embedded RC-CP of example (144) can be represented as the following structure, (154). 
(154) The embedded RC-CP:

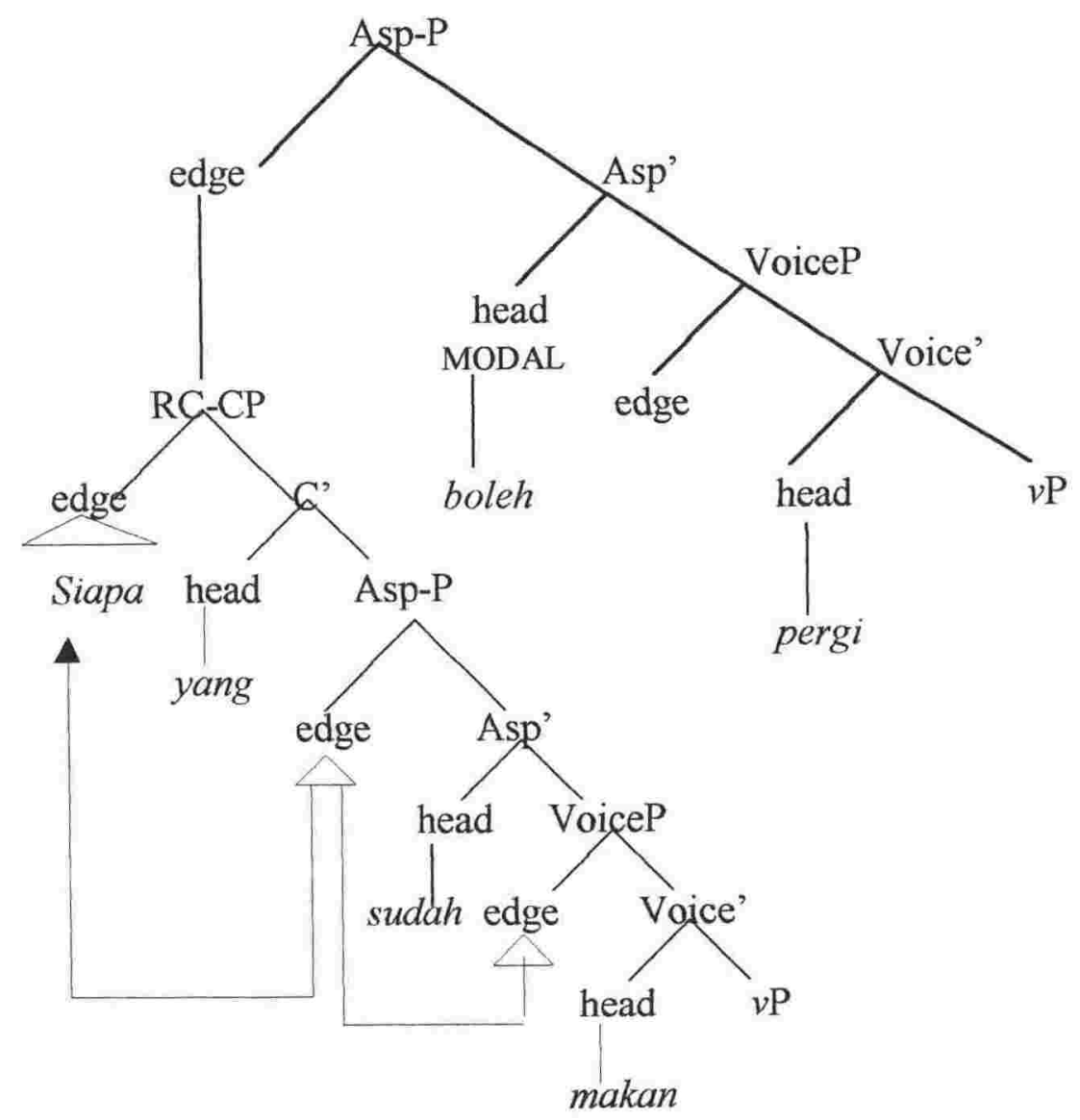

(154) $(=(144))$

[Asp-P [Spec Siapa yang sudah makan] [Asp boleh [pergi]] Wh- yang [+PERF] eat may go

'Those who have eaten may go'

\subsubsection{Summary and implication}

To conclude the discussion of derivations above VoiceP I will sum up the main points I made:

1. Once the Spec-head relation is established, namely, the relation between the argument at [Spec-VoiceP] and the related Voice head (meN-, di-, ber-, ter-, or $\varnothing$ ), the argument structure of the predicate is no longer relevant in the higher layers of 
derivations above VoiceP. I have adopted Chomsky's (1995) notion of edge, to demonstrate that further derivations that follow the VoiceP only involve local head movement and successive-cyclic edge-to-edge movement. Any element left behind within the domain of $v \mathrm{P}$ that does not undergo further movement is spelled out in its position. I have demonstrated that in $\mathrm{BI}$ derivations involving the $v \mathrm{P}$ external aspect (Asp-P), RC-CP and the Q-CP all strictly follow the local head movement and successive-cyclic edge-to-edge movement.

2. While some interrogative sentences in BI require the complementiser yang, it is the head $-k a h$ that makes a sentence interrogative: yang only relativises the subject of the phrase below it. The ' $W$ h-extractions' - a conventional term - in BI follow the strict rule of edge-to-edge movement.

3. The implication is that the BI structures that correspond to the English RC 'The book John is reading' and to the Q-RC 'What is John reading?' are barred (156) and (157) below, respectively. The corresponding BI structures start from the PASSIVE VOICE, (155a,b), the English structures start from the ACTIVE VOICE, (157). 
(155)a. The $B I R C-C P$ :

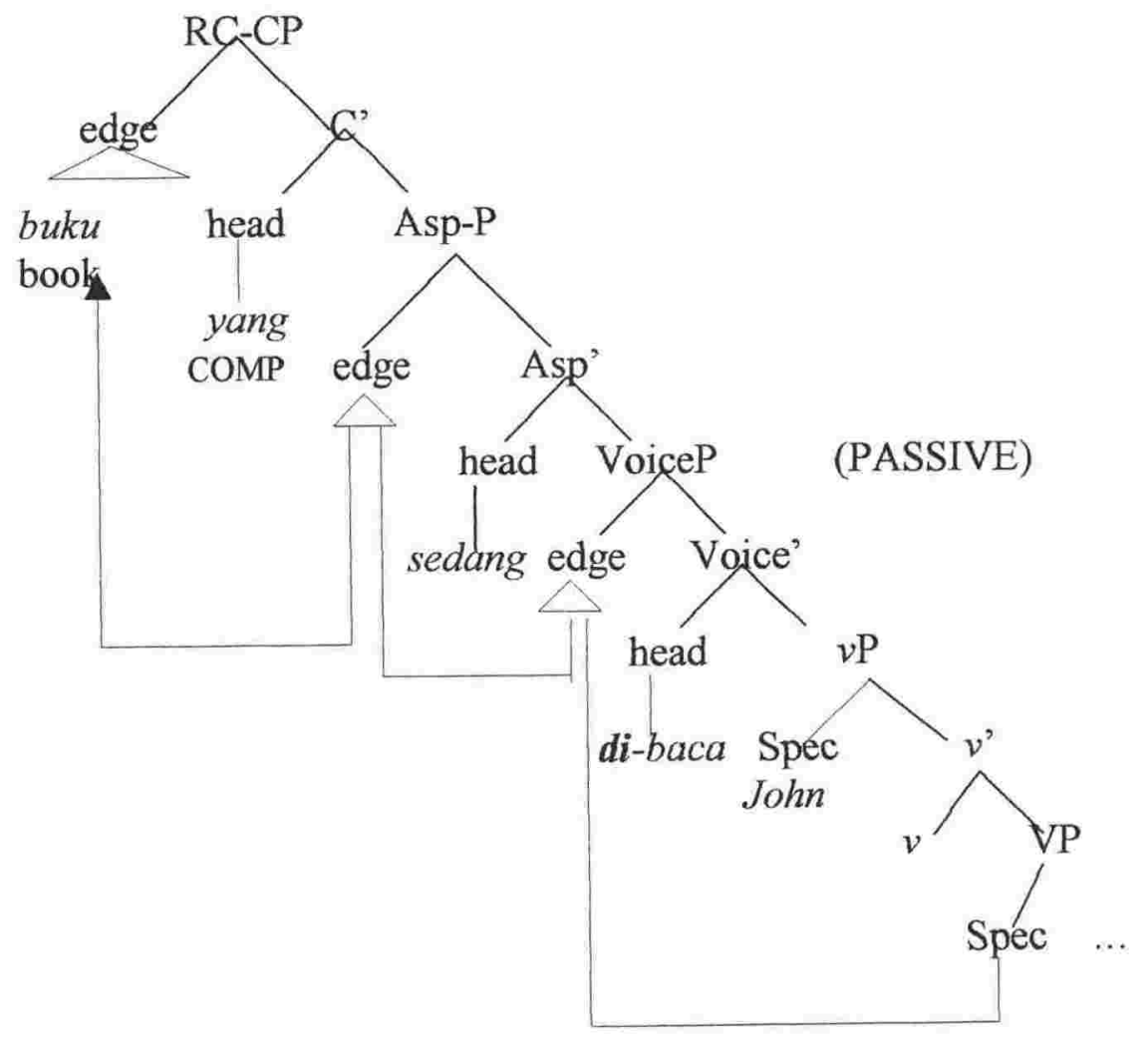

Buku yang sedang di-baca ((oleh) John)

book COMP PROG PASS-read by J

'The book (that is) being read (by John)' 
(155)b. The BI Q-CP with RC-CP:

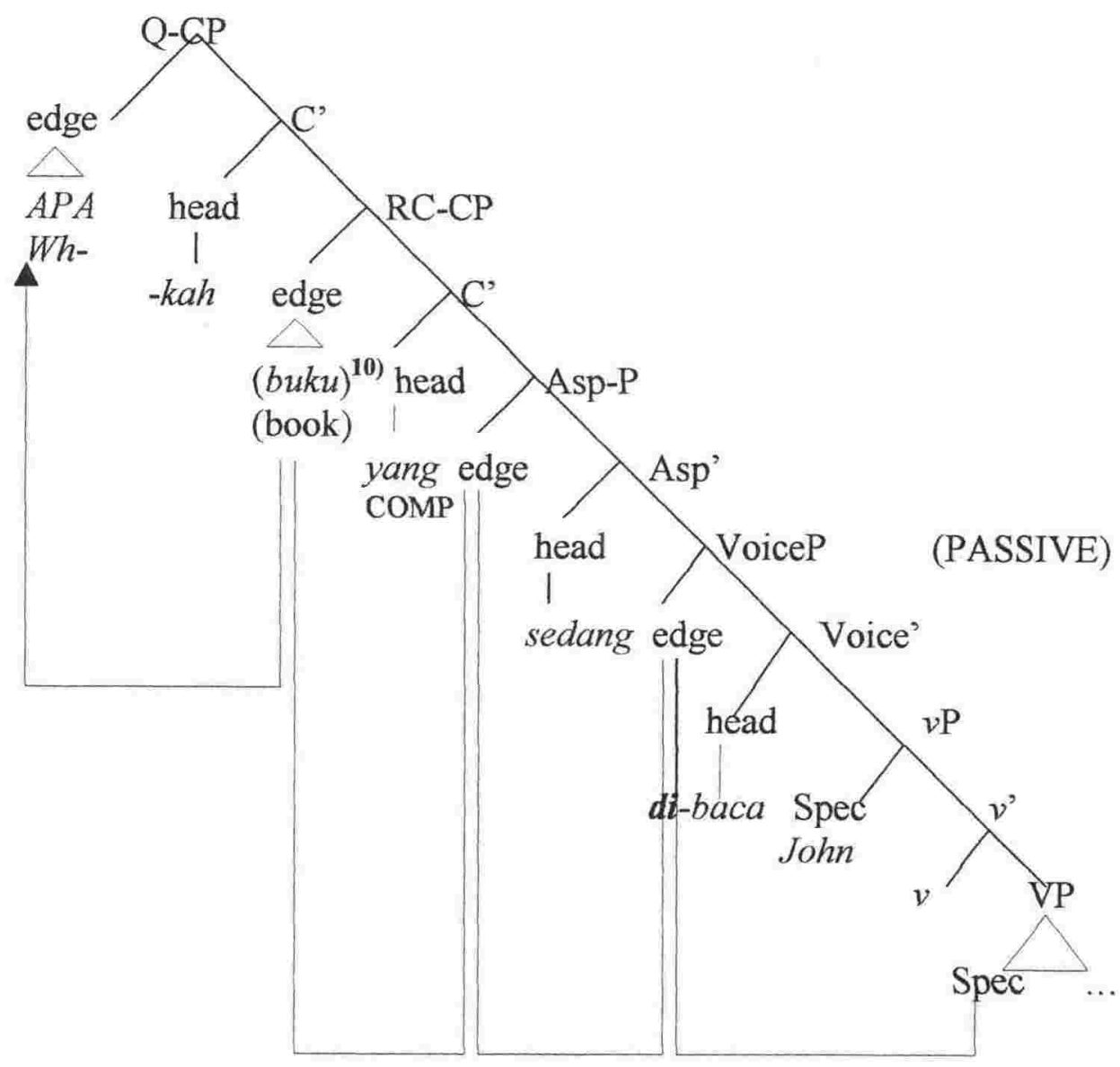

Apa(-kah) yang sedang di-baca ((oleh) John)?

Wh-? COMP PROG PASS-read by J

'What is being read (by John)?'

In $\mathrm{BI}, \mathrm{RC}-\mathrm{CP}$ extraction from below the VoiceP (i.e., $v \mathrm{P}$ ) is not allowed, (156).

${ }^{10)}$ Note that I have left intact (bracketed in the diagram) the questioned subject buku itu 'that book' at the RC-CP edge. This subject can further move to the uppermost edge to make a Yes/No question:

Buku itu(-kah) yang sedang di-baca ((oleh) John)?

Book DEM-? COMP PROG PASS-read by J

'Is it that book that is being read (by John)?' 
(156) BI: *Buku yang John sedang meN-baca [buku] book COMP J PROG ACT-read

English: 'The book John is reading'

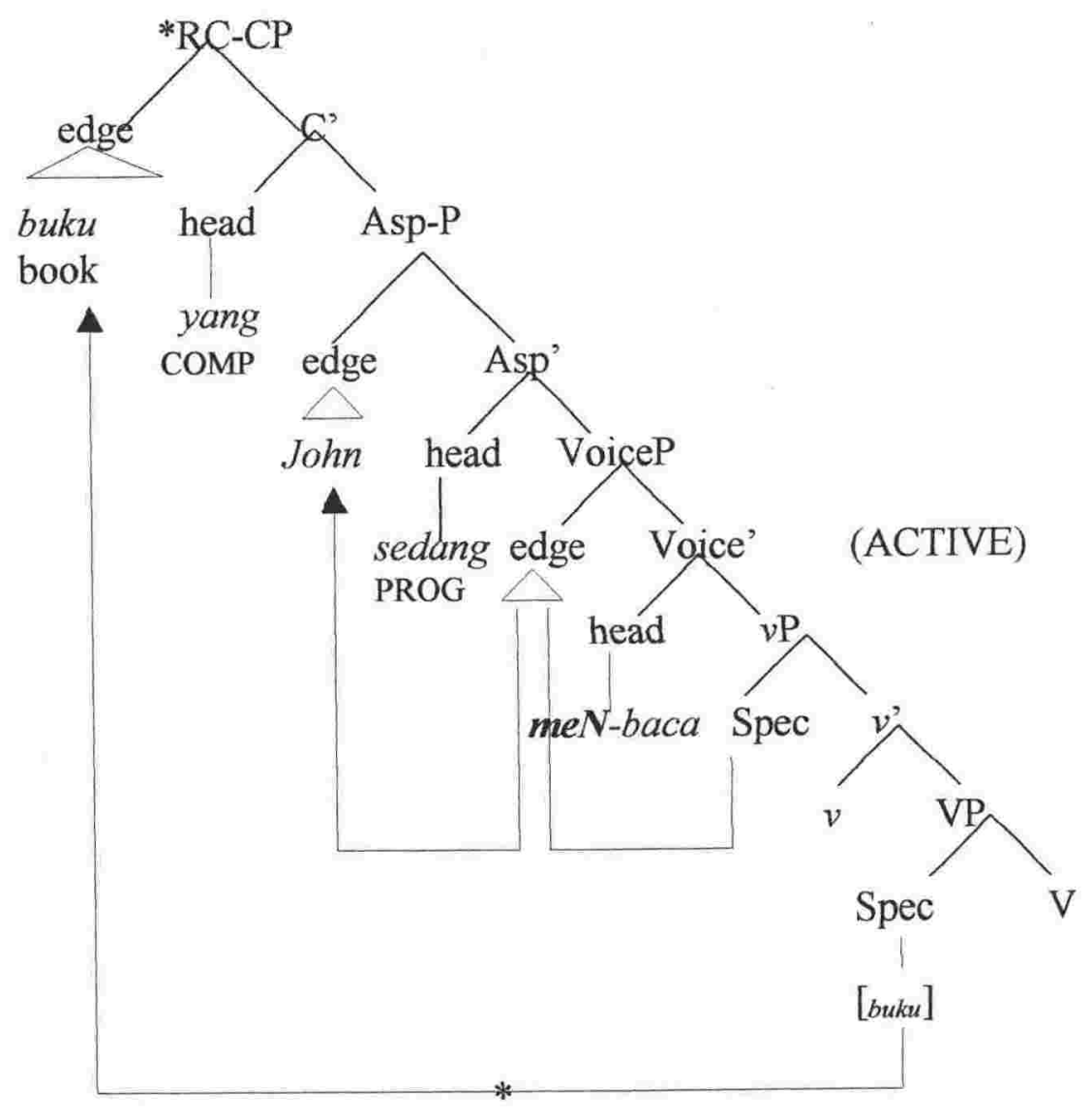

And thus, the Wh- 'extraction' from the ungrammatical RC-CP merely continues what is barred in BI, namely from the structure (156) above, shown as (157) below. 
(156) BI: $\begin{array}{cllll}\text { *Apa-kah } & \text { yang } & \text { John } & \text { sedang } & \text { meN-baca [Wh-]? } \\ \text { Wh-? } & \text { COMP J } & \text { PROG } & \text { ACT-read }\end{array}$

English: 'What is John reading?'

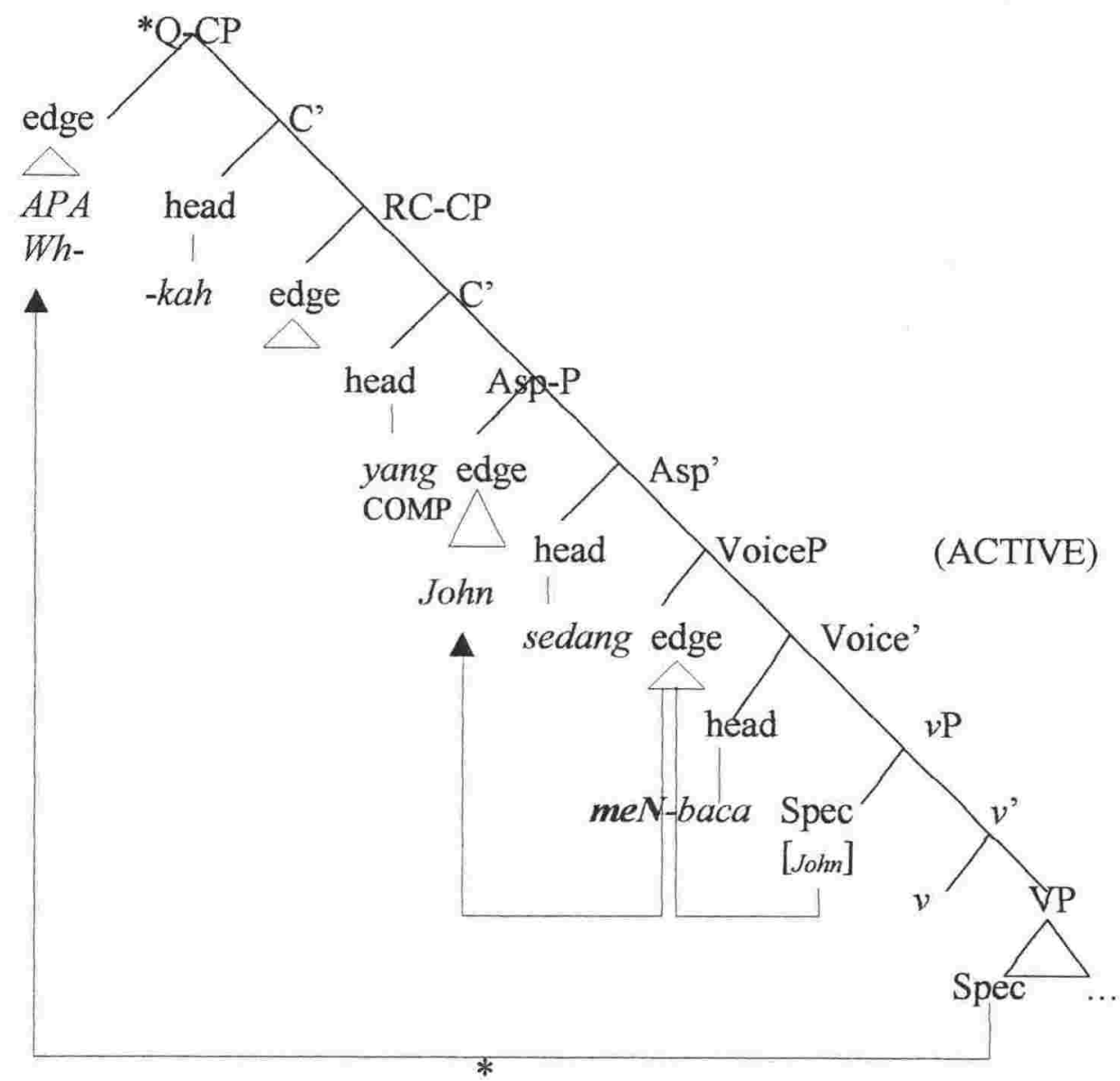

*Apa(-kah) yang John sedang meN-baca?

Wh-? COMP J PROG ACT-read

'What is John reading?'

The question is, why are the structures 'The book John is reading' and 'What is John reading?' allowed in English but barred in BI? To answer the question, we must look back to what is argued for by Ouhalla (1991), that in English the ACTIVE VOICE has a default value, and as we have seen, in BI ACTIVE and PASSIVE VOICES are equally strong. It all thus boils down to the difference between the Voice Phrases of the two 
languages. In English, the displacement of a [Spec-VP] argument to the edge is allowed in the ACTIVE VOICE, (158).

(158) English VoiceP (After Bowers 2002):

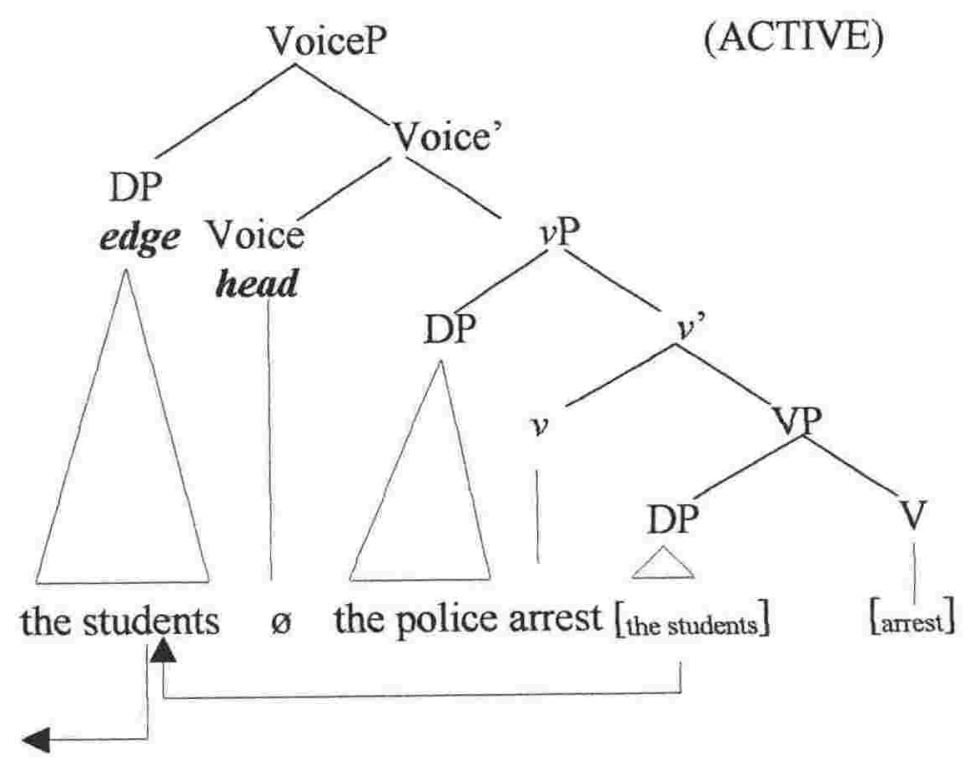

The two DPs in (158) will eventually move up to the outer edges (not shown in the diagram) to check off their features in a "multiple checking" operation (Ura 2000), and the verb raises to get inflected at $T^{\circ}$. For the English PASSIVE VoiceP, refer back to diagram (2) above.

The mechanism that works for the structure (158) above does not apply to BI ACTIVE: in BI, if the DP the students moves to the edge, then we have two options. The first option is, the head must be realised as di- (as the canonical PASSIVE of the personal transitive), and at the same time the verb arrest must raise to adjoin with the head, as I have shown in the previous sections. The second option is, if the external argument at $[\mathrm{Spec}-v \mathrm{P}]$ is a pronoun, this argument and the verb may remain in situ, and thus spelled out. This is the case with the other type of PASSIVE, where the verb is not, 
and cannot be, affixed with the Voice head, $(159 \mathrm{a}, \mathrm{b})$ below, in the same manner with the direct imperatives discussed above.

(159)a. Buku itu sudah saya (*di-/*meN-) baca book DEM PERF 1sg PASS/ACT read 'That book has been read by me' (That book has been I-read)

b. *Buku itu saya sudah (*di-/*meN-) baca book DEM 1sg PERF PASS/ACT read 'That book has been read by me' (That book I have read)

c. Main-an itu harus kamu letak-kan di meja play-NOUN DEM must 2 sg location-KAN on table 'That toy must be put down on the table' (must you-put down)

d. *Main-an itu kamu harus letak-kan di meja play-NOUN DEM 2sg must location-KAN on table 'That toy you must put down on the table'

Notice that the pronouns saya '1sg' and kamu '2sg' in both examples do not raise above the MODALs sudah [+perfective], (159a), harus 'must', (159b), and the verbs do not raise to adjoin with the Voice head $d i$ - or meN-. Since the edge is occupied by the [Spec-VP] argument, the [Spec- $v \mathrm{P}]$ argument cannot move up. Multiple checking is not allowed in $\mathrm{BI},(159 \mathrm{~b}, \mathrm{~d})$. This is also basically the difference between the English RC-CP and the BI RC-CP above.

In Sukarno (1996) I analyse the occurrence of the second type of PASSIVE such as as $(159 \mathrm{a}, \mathrm{c})$ above as an "AGENT-Incorporation", or "D-Incorporation", to be precise. Sukarno's (1996) analysis is based on Pesetsky's (1995) theory of "zero-morpheme". The zero preposition of the oleh by-phrase because it is zero, it must be affixed. The AGENT, based at the bottom of the tree is raised together with the zero preposition to pick up the verb. Considering the theory envisaged in the present work - that elements left behind that do not undergo further derivation are spelled out at their base positions - then the following syntactic analysis, (160a,b), of the second type of PASSIVE are more tenable than that of Sukarno (1996). In both $(160 \mathrm{a}, \mathrm{b})$ only the edge moves up to check off the Aspect head, and so on. 
(160)a. Second type of PASSIVE, without $d i$-, with the kan-aspect:

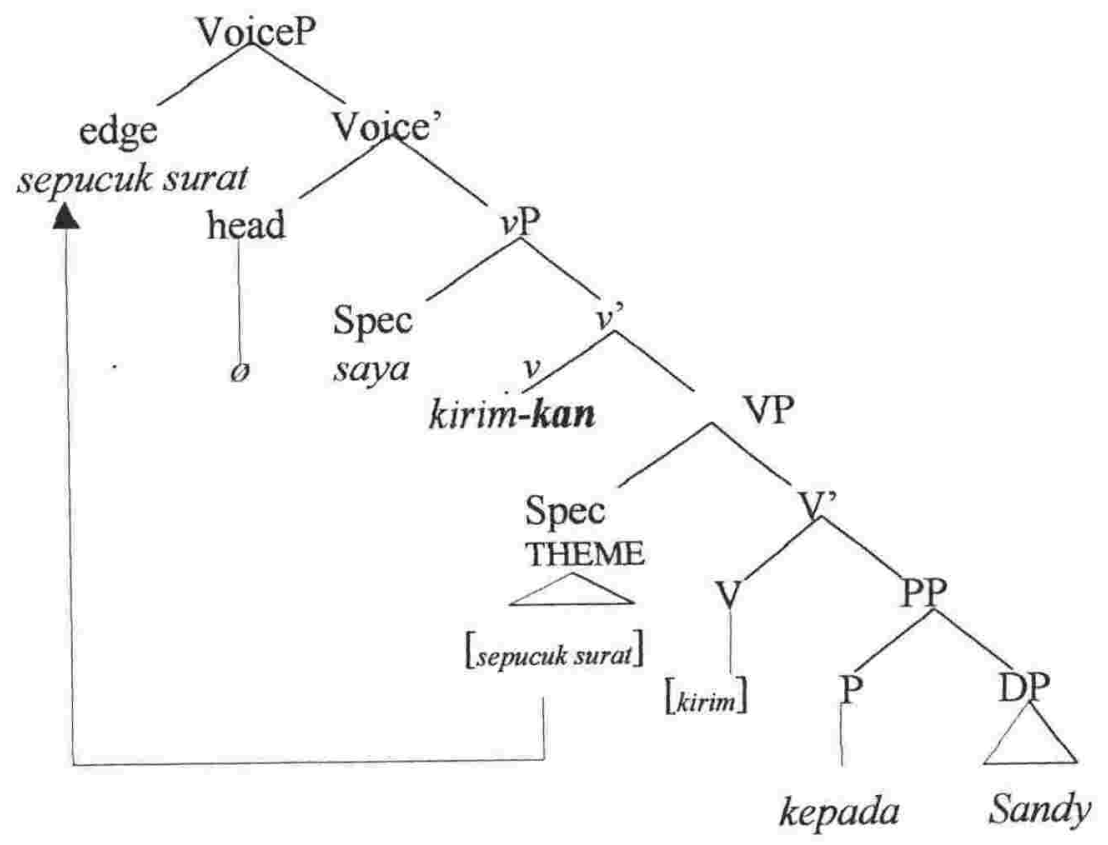

Se-pucuk surat saya kirim-kan $\quad$ ke-pada Sandy
a-CLASS letter $1 \mathrm{sg}$ send-KAN to-DATIVE S
'A letter was sent to Sandy by me' (A letter was I-sent to Sandy)

(160)b. Second type of PASSIVE, without $d i$ - with the $i$-aspect:

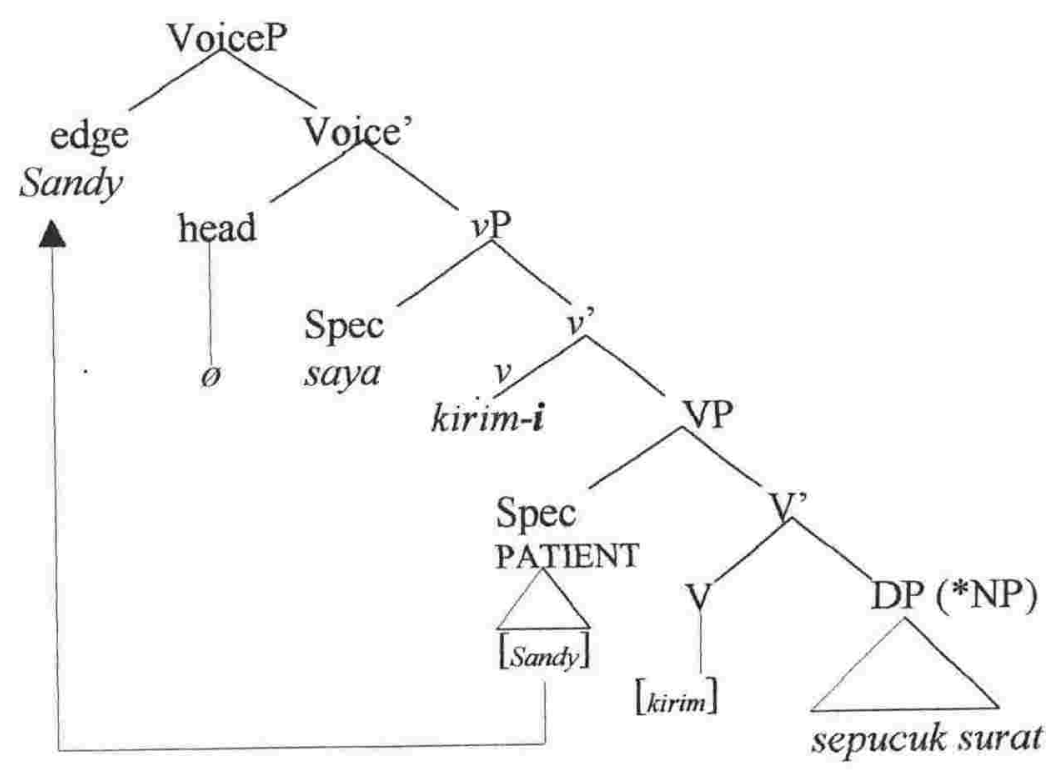

Sandy saya kirim-i se-pucuk surat $\mathrm{S} \quad 1 \mathrm{sg}$ send-I a-CLASS letter 'Sandy was sent a letter by me' (Sandy was I-sent a letter) 


\section{Chapter 6}

\section{Conclusions}

The main conclusions that can be drawn from this study are as follows:

\section{(i) - kan versus $-i$}

Unlike the previous studies on the BI suffixes $-k a n$ and $-i$, which state that the suffixes have several different functions, this thesis proposes that a simple notion of change answers the question as to why in BI sentences the predicate sometimes bears the suffix $-k a n$, sometimes $-i$ or $-\varnothing$.

(i)a. I have shown that kan-predicates and $i$-predicates are in opposition with each other, and each has its own argument structure;

(i)b. I have discussed the opposition in terms of two opposing $v \mathrm{P}$-aspects: with the kanaspect the direct internal argument undergoes change, and conversely, with the $i$-aspect the direct internal argument is stationary and/or unchanged;

(i)c. The syntactic effects of the $v \mathrm{P}$-aspect can be seen also through the opposing interpretation of the direct internal argument: with the kan-aspect the [Spec-VP] bears a THEME interpretation, whereas with the $i$-aspect it has a PATIENT interpretation.

(i)d. I have argued throughout this study that a BI sentence with the kan-aspect is independently derived from that with the $i$-aspect.

(i)e. From the discussion in the present work in general, the dichotomy of the related terminologies used in the literature can also be included in the change versus non-change distinctions encoded by the $\nu \mathrm{P}$-aspect, all in respective order:

Larson's (1988) “dative-double object constructions", Hale and Keyser's (1993, 1998) "LOCATION" verbs (e.g., "to jail the criminals") versus "LOCATUM" verbs (e.g., 
'to salt the stew'), Pesetsky's (1995) “Object-Experiencer" versus "SubjectExperiencer" psych-predicates, and Arad's (1998) THEME at [Spec-VP] versus PATIENT at [Spec-VP].

\section{(ii) VOICE and transitivity}

I have proposed following Ouhalla (1991), Bowers (2002) and Pylkkänen (2002) that the Voice head is separate from the transitivity head, and that VOICE is distinct from transitivity. From our observation, we gain an important insight that in BI all sentences display VOICE, whereas not all sentences display transitivity (not all structures have the $v \mathrm{P})$. We saw that VOICE is related to the argument structure of the predicate $(v \mathrm{P} / \mathrm{VP})$. The Voice head correlates with the structure it occurs in, that is, it is dependent on the available argument, because it checks an argument as a surface subject.

Bowers (2002) argues that the Voice head "relates" the surface subject to the predicate. Pylkkänen (2002) spells out what the subject is, in terms of external versus internal arguments. In Pylkkänen's terms, the Voice head "introduces" the surface subject. Our analysis supports Bowers (2000) and Pylkkänen (2002). I have shown that the surface subject "introduced" by the Voice head has an origin, either from [Spec- $v \mathrm{P}]$ or from [Spec-VP], i.e., consistent with their roles in constructions which have an AGENT/CAUSER argument in [Spec- $v$ P].

Following Chomsky's (1999:9-11) notion of "edge", in the present work I propose that argument role is relevant only as far as the Voice Phrase. Once the Spec-head relation is established at the VoiceP layer, which I assume to be the lowest edge, derivations that follow only involve the move of either the edge or the head, or elements adjoined to the edge. The predicate argument structure is thus relevant only to establish the innermost edge.

The central notion of the present study is that a structure with a $v \mathrm{P}$-aspect is always transitive (including also di-transitive). In BI we have a transitive structure with the kanaspect (kan-transitive) and a transitive structure with the $i$-aspect ( $i$-transitive). The so- 
called "DAC-DOC alternation" in BI constitutes only a minor part of the $v$ P-aspect alternation. The BI DAC belongs to the kan-aspect and the DOC to the $i$-aspect.

As a part of the $v \mathrm{P}$-aspect alternation, I have also included in the discussion the $\mathrm{BI}$ psychpredicates, which, predictably, can be classified into two groups: psych-predicates with the kan-aspect are what in the literature are called "Object-experiencer" predicates, and those with the $i$-aspect are the "Subject-experiencer" predicates. The former group bears an eventive interpretation, the latter an agentive interpretation. The unaffixed psychpredicates in BI correspond to the stative interpretation. It all boils down to points (ib) and (ic) above.

For derivations that are transformationally un-related, (id) above, I have included in the discussion the derivation of the BI ACTIVE and PASSIVE structures involving the $v \mathrm{P}-$ aspect: each $v$ P-aspect has its own ACTIVE and PASSIVE paths of derivation.

\section{(iii) Derivations above VoiceP}

In $\mathrm{BI}$ the derivations of Asp-P, RC-CP and Q-CP follow the strict successive-cyclic edgeto-edge movement and the local head movement. Once the innermost edge is established, the domain of the $v \mathrm{P}$ is not available for a further syntactic operation and any element left behind within $v \mathrm{P}$ that does not undergo further movement is spelled out in its position. In effect, 'Wh-extraction' in the conventional sense does not apply in BI: by comparing English and BI expressions (such as 'What are you reading?', 'That's the book I have been reading', and the RC 'The book John read...') I assume that the structure of Voice Phrase in BI is different from that of English. In English the [Spec-VP] argument of the transitive structure may move to the edge even in the ACTIVE VOICE, whereas in BI this type of movement only occurs in the PASSIVE VOICE. 


\section{Reference:}

Abas, Lutfi 1985. Linguistik Deskriptif dan Nahu Bahasa Melayu. Kuala Lumpur: Dewan Bahasa dan Pustaka, Kementerian Pelajaran Malaysia.

Abraham, Werner, Samuel D. Epstein, Höskuldur Tráinson, C. Jan-Wouter Zwart (eds.) 1996. Minimal Ideas: Syntactic Studies in the Minimalist Framework. Amsterdam: John Benjamins.

Adams, Catherine M. 2001. The Conative Alternation: An exploration of semelfactives and the elusive non-Theme Patient. MA Thesis, University of Canterbury.

Arad, Maya 1998. VP-Structure and The Syntax-lexicon Interface. Cambridge, Mass.: MIT Occasional Papers in Linguistics.

Baker, Mark 1988. Incorporation: A Theory of Grammatical Function Changing. Chicago: The University of Chicago Press.

, 1997. Thematic Roles and Syntactic Structure. In: Haegeman (ed.), Elements of Grammar, pp. 73-137.

Belletti, A. and L. Rizzi 1988. Psych Verbs and Theta Theory. Natural Language and Linguistic Theory 6: 291-352.

Bowers, John 1993. The Syntax of Predication. Linguistic Inquiry 24: 591-655. , 2002. Transitivity. Linguistic Inquiry 33: 183-224.

Blust, Robert 2002. Notes on the history of 'focus' in Austronesian languages. In: Wouk and Ross (eds.), pp. 63-78.

Burzio, L. 1986. Italian Syntax. Dordrecht: Reidel

Butt, Miriam and Wilhelm Geuder (eds.) 1998. The Projection of Arguments, Lexical and Compositional Factors. Stanford: CSLI Publications.

Chametzky, Robert A. 2000. Phrase Structure: from GB to Minimalism. Malden, Mass.: Blackwell Publishers Inc. 
Chomsky, Noam 1995. The Minimalist Program. Cambridge, Mass.: The MIT Press. , 1999. Derivation by Phase. (MIT Occasional Papers in Linguistics 18) Cambridge, Mass: MTTWPL.

Chung, Sandra 1976. An Object-Creating Rule in Bahasa Indonesia. Linguistic Inquiry 7: 41-87.

Cinque, Guglielmo 1999. Adverbs and Functional Heads: A Cross-Linguistic Perspective. New York: Oxford University Press.

Cole, Peter, Gabriella Hermon, Kozue Inoha, and Yassir Tjung 2002. A Constraint on $W h$ in Situ in Javanese. In: Andrea Rackowski and Norvin Richards (eds.), Proceedings of AFLA 8, MITWPL 44: 91-106.

Comrie, Bernard 1976. Aspect: An Introduction to The Study of Verbal Aspect and Related Problems. Cambridge: Cambridge University Press.

Croft, William 1998. Event Structure in Argument Linking. In: Butt and Geuder (eds.), pp. 21-63.

Dikken, Marcel den 1995. Particles: On the Syntax of Verb-Particle, Triadic, and Causative Constructions. New York: Oxford University Press.

Dowty, David 1991. Thematic Proto-Roles and Argument Selection. Language 67: 547619.

Farrell, Patrick 1998. Comments on the Paper by Lieber. In: Lapointe et al (eds.), pp. 34 53.

Fokker, A. A. 1972. Pengantar Sintaksis Indonesia. A translation by Djonhar, from 'Inleiding tot de studie van de Indonesische Syntaxis', 1950. Jakarta: Pradnja Paramita.

Gil, David 2002. Riau Indonesian -kan: A Synchronic Analysis, ms. presented at the $9^{\text {th }}$ ical, ANU Canberra.

Giorgi, Alessandra and Fabio Pianesi 1997. Tense and Aspect: From Semantics to Morphosyntax. New York: Oxford University Press.

Grimshaw, Jane 1990. Argument Structure. Cambridge, Mass.: The MIT Press.

Gruber, Jeffrey S 1970. Studies in Lexical Relations. A PhD dissertation, MIT (1965), reproduced and distributed by the Indiana University Linguistics Club. 
Guilfoyle, Eithne, Henrietta Hung and Lisa Travis 1992. SPEC of IP and SPEC of VP:

Two Subjects in Austronesian Languages. Natural Language and Linguistic Theory 10: 375-414.

Haegeman, Liliane (ed.) 1997. Elements of Grammar. Dordrecht: Kluwer Academic Publishers.

Hale Ken and Samuel Jay Keyser (eds.) 1993. The View from Building 20, Essays in Linguistics in Honor of Sylvain Bromberger, Cambridge, Mass.: The MIT Press. , 1993. On Argument Structure and the Lexical Expression of Syntactic Relations. In: Hale and Keyser (eds.), pp. 53-109.

, 1998. The Basic Elements of Argument Structure. In: Harley (ed.), pp. 73-118. ,2002. Prolegomenon to a Theory of Argument Structure. Cambridge, Mass.: The MIT Press.

Harley, Heidi (ed.) 1998. Papers from the Upenn/MIT Roundtable on Argument Structure and Aspect. Cambridge Mass.: MTWPL 32.

Himmelmann, Nikolaus P. 2002. Voice in western Austronesian: an update. In: Wouk and Ross (eds.), pp. 7-16.

Jackendoff, Ray 1987. The Status of Thematic Relations in Linguistic Theory. Linguistic Inquiry 18: 369-411.

1990. On Larson's Account of the Double-Object Construction. Linguistic Inquiry 21: 427-454.

Johns, Yohanni 1977. Bahasa Indonesia Book One. Canberra: Australian National University Press. ,1985. Bahasa Indonesia Book Two. Canberra: Australian National University Press.

Kaswanti Purwa, Bambang 2002. Bitransitive Constructions in some Austronesian Languages, ms. presented at the $9^{\text {th }}$ ical, ANU Canberra.

Kayne, Richard S. 1984. Connectedness and Binary Branching. Dordrecht: Foris. ,2001. Preposition as Probes, ms. New York University.

Kearns, Kate 1988. Light Verbs in English, ms. MIT. ,2000. Semantics. Hampshire/New York: Palgrave. 
Kratzer, Angelika 1993. On external arguments. In: E. Benedicto and J. Runner Functional projections. University of Massachusetts Occasional Papers 17. Amherst: University of Massachusetts, GLSA, pp. 103-129.

Lasnik, Howard 1999. Minimalist Analysis. Malden, Mass.: Blackwell Publishers Inc.

Larson, Richard K. 1988. On the Double Object Construction. Linguistic Inquiry 19: 335-391.

Lapointe, Steven G., Diane K. Brentari and Patrick M. Farrell (eds.) 1998. Morphology and Its Relation to Phonology and Syntax. Stanford: CSLI Publications.

Levin, Beth 1993. English Verb Classes and Alternations, A Preliminary Investigation. Chicago: The University of Chicago Press.

Levin, Beth, and Malka Rappaport Hovav 1995. Unaccusativity At the Syntax-Lexical Semantic Interface. Cambridge, Mass.: The MIT Press.

Lieber, Rochelle 1998. The Suffix -ize in English: Implications for Morphology. In: Lapointe et al, pp. 12-33.

Marantz, Alec 1995. The Minimalist Program. In: Webelhuth (ed.), pp. 351-382.

Margetts, Anna 2002. Grammaticalization from possession to benefaction in Oceanic languages, ms. presented at the $9^{\text {th }}$ ical, ANU Canberra.

McGinnis, Martha 2001. Phases and the syntax of applicatives. In: Kim Minjoo and Uri Strauss (eds.), Proceedings of the NELS 31, Georgetown University, pp. 333-349.

McKoon, Gail and Talke MacFarland 2000. Externally and Internally caused change of sate verbs. Language 76: 833-858.

Musgrave, Simon 2000. Emotion Predicates and Grammatical Functions in Indonesian. In: Klamer, Marian (ed.), Proceedings of AFLA 7, Vrije Universiteit Amsterdam.

Mylne, Tom 2000. Argument Structure and the Status of the Complement. A PhD Thesis, Department of English, The University of Queensland.

Ouhalla, Jamal 1991. Functional Categories and Parametric Variation, London: Routledge. , 1999. Introducing Transformational Grammar: From P\&P to Minimalism. London: Arnold. 
Paul, Eleana, Vivivanne Phillips and Lisa Travis (eds.) 2000. Formal Issues in Austronesian Linguistics, NLLT. Dordrecht: Kluwer.

Perlmutter, David M and Paul M. and Postal 1984. The 1-Advancement Exclusiveness Law. In: Perlmutter and Carol G. Rosen (eds.), Studies in Relational Grammar, pp. 81-125. The University of Chicago Press: Chicago.

Pesetsky, David 1995. Zero Syntax: Experiencers and Cascades. Cambridge, Mass.: The MIT Press.

Poser, William J. 1983. Lexical rules may exchange internal arguments. TLR 2: 97-100.

Postman, Whitney Anne 2001. Agrammatic Aphasic Comprehension of Thematic Role Assignment in Indonesian. In: Kim Minjoo and Uri Strauss (eds.), Proceedings of the NELS 31, Georgetown University, pp. 407-418. 2002. When the Sum of the Parts Doesn't Equal the Whole: Agrammatic Comprehension of Complex Sentence in Indonesian. In: Andrea Rackowski and Norvin Richards (eds.), Proceedings of AFLA 8, MITWPL 44: 273-292.

Pylkkänen, Liina 2002. Introducing Arguments. A PhD dissertation, MIT. Reproduced and distributed by MIT Working Papers in Linguistics.

Radford, Andrew 1997. Syntax: A minimalist introduction. Cambridge: University Press.

Rappaport Hovav, Malka and Beth Levin 1998. Building Verb Meanings. In: Butt and Geuder (eds.), pp. 97-134.

Reichenbach, Hans 1947. Elements of Symbolic Logic. New York: MacMillan.

Richards, Norvin 2001. An Idiomatic Argument for Lexical Decomposition. Linguistic Inquiry 32: 183-192.

Ritter, Elizabeth and Sara Thomas Rosen 1998. Delimiting events in syntax. In: Butt and Geuder (eds.), pp.135-163.

Rizzi, Luigi 1997. The Fine Structure Of The Left Periphery' In: Haegeman (ed.), pp. 281-337.

Safire, William 1991. Izationization. 'On Language' column in The New York Times Magazine, April 21, 1991: 18-20.

Selkirk, Elisabeth O. 1982. The Syntax of Words. Cambridge, Mass.: The MIT Press.

Sie, Ing Diiang (Sidharta) 1988. The Syntactic Passive In Bahasa Indonesia: A Study in Government-Binding Theory. A PhD dissertation, University of Amsterdam. 
Smith, Carlota S. 1997. The Parameter of Aspect (second edition). Dordrecht: Kluwer Academic Publishers.

Sneddon, James Neil 1996. Indonesian Reference Grammar. St Leonard, NSW.: Allen \& Unwin.

Stowell, Tim 1995. The Phrase Structure of Tense, ms. UCLA.

Sukarno, Wahyono E. 1996. The Morpho-syntax of Agent Incorporation in Bahasa Indonesia. MA Thesis, Victoria University of Wellington.

Tampubolon, D. P. 1983. Verbal Affixation in Indonesian: A Semantic Exploration. Series D-48. The Australian National University, Canberra: Pacific Linguistics.

Tarigan, Henry Guntur 1985. Pengajaran Morfology. Bandung: Angkasa.

Tenny, Carol L. 1987. Grammaticalizing Aspect and Affectedness. A PhD dissertation, MIT. , 1994. Aspectual Roles and The Syntax-Semantics Interface. Dordrecht: Kluwer Academic Publishers. , and James Pustejovsky (eds.) 2000. Events as Grammatical Objects. Stanford, California: CSLI.

Tobin, Yishai 1993. Aspect in the English Verb: Process and Result in Language. London: Longman.

Travis, Lisa [1994] 2000. Event Structure in Syntax. In: Tenny and Pustejovsky (eds.), pp. 145-185.

2002. Agent and Causers in Malagasy and Tagalog. In: Andrea Rackowski and Norvin Richards (eds.), Proceedings of AFLA 8, MITWPL 44: 273-292.

Tyler, Andrea and Vyvyan Evans 2001. Reconsidering Prepositional Polysemy Networks: The Case of over. Language 77: 724-765.

Ura, Hiroyuki 2000. Checking Theory and Grammatical Functions in Universal Grammar. New York/Oxford: Oxford University Press.

Vamarasi, Marit Kana 1999. Grammatical relations in Bahasa Indonesia. Series D-93. The Australian National University, Canberra: Pacific Linguistics.

Vendler, Zeno 1967. Verbs and Times. In: Vendler, Linguistics in Philosophy, pp. 97121, Ithaca, New York: Cornell University Press. 
Voskuil, Jan 1996. Comparative Morphology: Verb Taxonomy in Indonesian, Tagalog and Dutch. Holland Institute of Generative Linguistics.

Webelhuth, Gert (ed.) 1995. Government and Binding Theory and the Minimalist Program. Cambridge, Mass.: Blackwell.

Williams, Edwin 1981. On the Notions "Lexically Related" and "Head of a Word", Linguistic Inquiry 12: 245-274.

Wouk, Fay and Malcom Ross (eds.) 2002. The history and typology of western Austronesian voice systems. Pacific Linguistics 518. The Australian National University, Canberra: Pacific Linguistics.

Wunderlich, Dieter 1997. Cause and the Structure of Verbs. Linguistic Inquiry 28: 25-68.

Wyngaerd, Guido Vanden 1996. Participles and Bare Argument Structure. In: Abraham et al (eds.), pp. 283-304.

\section{Dictionaries:}

Asher, R.E. (ed.) 1994, The Encyclopedia of Language and Linguistics Vol. 10 , Pergamon Press: Oxford.

Bussmann, Hadumod (1996), Routledge Dictionary of Language and Linguistics, translated and edited by Gregory Trauth and Kerstin Kazzazi, Routledge: London and New York.

Crystal, David (1991), A Dictionary of Linguistics and Phonetics ( $3^{\text {rd }}$ edn.), Basil Blackwell: Cambridge, Mass.

Matthews, P.H. (1997), The Concise Oxford Dictionary of Linguistics, Oxford University Press: Oxford.

Trask, 1993, A Dictionary of Grammatical Terms in Linguistics, Routledge: London.

Trask (1997), A Student's Dictionary of Language and Linguistics, Arnold: London.

Kamus Lengkap 'A Complete Dictionary'. Bandung: Hasta (1980).

Kamus Besar Bahasa Indonesia 'A Large Dictionary of Bahasa Indonesia'. Jakarta:

Balai Pustaka (1988).

Kamus Ungkapan 'A Dictionary of Expression'. Jakarta: Gramedia (1985). 